\title{
Preliminary Technical Data Summary No. 3 for the DEFENSE WASTE PROCESSING FACILITY
}

\author{
Compiled by L. F. Landon \\ Engineering Technology Division \\ Savannah River Laboratory
}

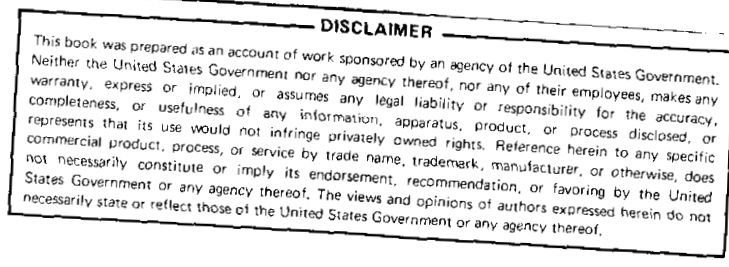

May 1980

\section{Issued by E. I. du Pont de Nemours \& Co. (Inc.) \\ Savannah River Laboratory \\ Aiken, SC 29801}

PREPARED FOR THE U. S. DEPARTMENT OF ENERGY UNDER CONTRACT DE-ACO9-76SR00001 


\section{DISCLAIMER}

This report was prepared as an account of work sponsored by an agency of the United States Government. Neither the United States Government nor any agency Thereof, nor any of their employees, makes any warranty, express or implied, or assumes any legal liability or responsibility for the accuracy, completeness, or usefulness of any information, apparatus, product, or process disclosed, or represents that its use would not infringe privately owned rights. Reference herein to any specific commercial product, process, or service by trade name, trademark, manufacturer, or otherwise does not necessarily constitute or imply its endorsement, recommendation, or favoring by the United States Government or any agency thereof. The views and opinions of authors expressed herein do not necessarily state or reflect those of the United States Government or any agency thereof. 


\section{DISCLAIMER}

Portions of this document may be illegible in electronic image products. Images are produced from the best available original document. 


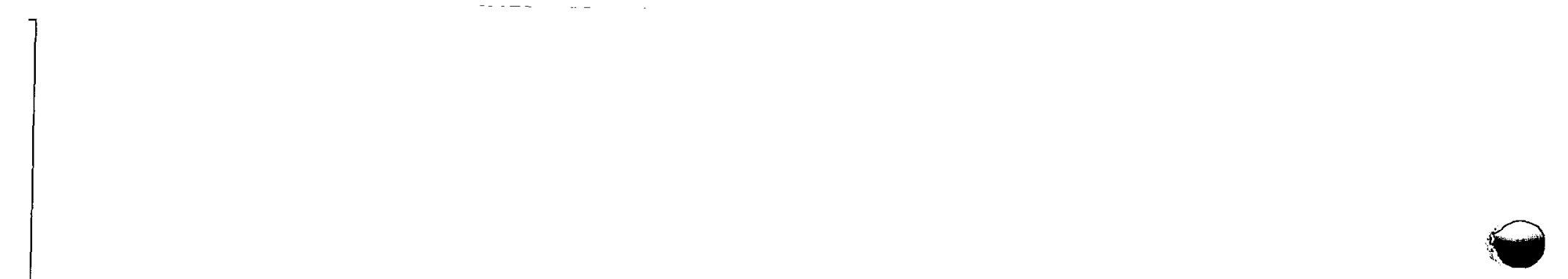

.

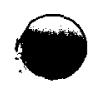

$\theta$

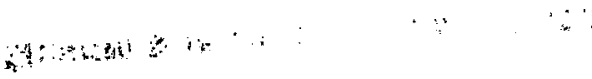


1. Introduction 1.1

2. Feed Description 2.1

3. Product Description 3.1

4. Process Description 4.1

5. Process Equipment Requirements 5.1

6. Process Control 6.1

7. Radionuclide Content, Activities and Heat Generation 7.1

8. Effluent Control and Estimated Releases to the Environment 8.1

9. Safety Analysis 9.1

10. Materials of Construction 10.1

11. Regulatory Requirements 11.1

12. Solid Waste Handing 12.1

13. Appendices 13.1 
2.1 Chemical Composition of Soluble and Insoluble Fraction of DWPF Feed (Dry Basis) 2.5

2.2 Deleted 2.6

2.3 Isotopic Content (g/gal) of Supernate Feed Stream - 5 Years 2.7

2.4 Isotopic Content (g/gal) of Supernate Feed Stream - 15 Years 2.8

2.5 Isotopic Content ( $\mathrm{Ci} / \mathrm{gal}$ ) of Supernate Feed Stream - 5 Years 2.9

2.6 Isotopic Content ( $\mathrm{Ci} / \mathrm{gal}$ ) of supernate Feed Stream 15 Years 2.10

2.7 Isotopic Content ( $g / g a 1)$ of Sludge-Slurry Feed Stream 5 Years 2.11

2.8 Isotopic Content ( $\mathrm{g} / \mathrm{gal}$ ) of Sludge-Slurry Feed Stream 15 Years 2.12

2.9 Isotopic Content ( $\mathrm{Ci} / \mathrm{gal}$ ) of Sludge-Slurry Feed Stream 5 Years 2.13

2.10 Isotopic Content ( $\mathrm{Ci} / \mathrm{gal}$ ) of Sludge-Slurry Feed Stream 15 Years 2.14

2.11 Percent of Radionuclides in Gravity-Settled In-Tank Sludge 2.15

2.12 Representative Elemental Composition of SRP Reference Sludge 2.15

2.13 Viscosity of SRP Sludge 2.16

2.14 Concentration of Major Chemical Components in Reference SRP Supernate 2.16 
3.1 Chemical Composition of Reference Glass Waste Form 3.13

3.2 Chemical Composition of Glass Frit $131 \quad 3.13$

3.3 Isotopic Content $(\mathrm{Ci} / \mathrm{lb})$ of Waste Glass - 5 Years 3.14

3.4 Isotopic Content ( $\mathrm{Ci} / \mathrm{Ib}$ ) of Waste Glass - 15 Years 3.15

3.5 Physical Properties of Glass Waste Forms 3.16

3.6 Calculated Effective Thermal Conductivity of the Reference Glass Waste Form 3.17

3.7 Calculated True and Mean Heat Capacity of the Reference Glass Waste Form 3.17

3.8 Calculated Density of the Reference Glass Waste Form 3.18

3.9 Calculated Viscosity of the Reference Glass Waste Form 3.18

3.10 Effect of Sludge Components on Devitrification of Waste Glass [14] 3.19

3.11 Glass Leach Rates Based on Cs-137 3.20

3.12 Glass Leach Rates Based on Pu 3.21

3.13 Glass Leach Rates Based on $S_{r}-90$

3.14 Major Chemical Constituents of Saltcrete 3.23

3.15 Isotopic Content $(\mathrm{nCi} / \mathrm{g})$ of Saltcrete ${ }^{\mathrm{a}}-5$ Years 3.24

3.16 Isotopic Content $(\mathrm{nCi} / \mathrm{g})$ of Saltcrete ${ }^{a}-15$ Years 3.25

4.1 Defense Waste Processing Facility, Material Balance and Flowsheet Identification 4.101

4.2 Sludge and Supernate Preparation (MB-2) 4.102

4.3 Aluminum Dissolution $(M B-3) \quad 4.103$

4.4 Sludge Washing (MB-4) 4.104

4.5 Calcination and vitrification (MB-5) 4.107

4.6 Off-Gas Treatment $(M B-6) \quad 4.109$

4.7 Recycle Evaporation (MB-7) 4.113 


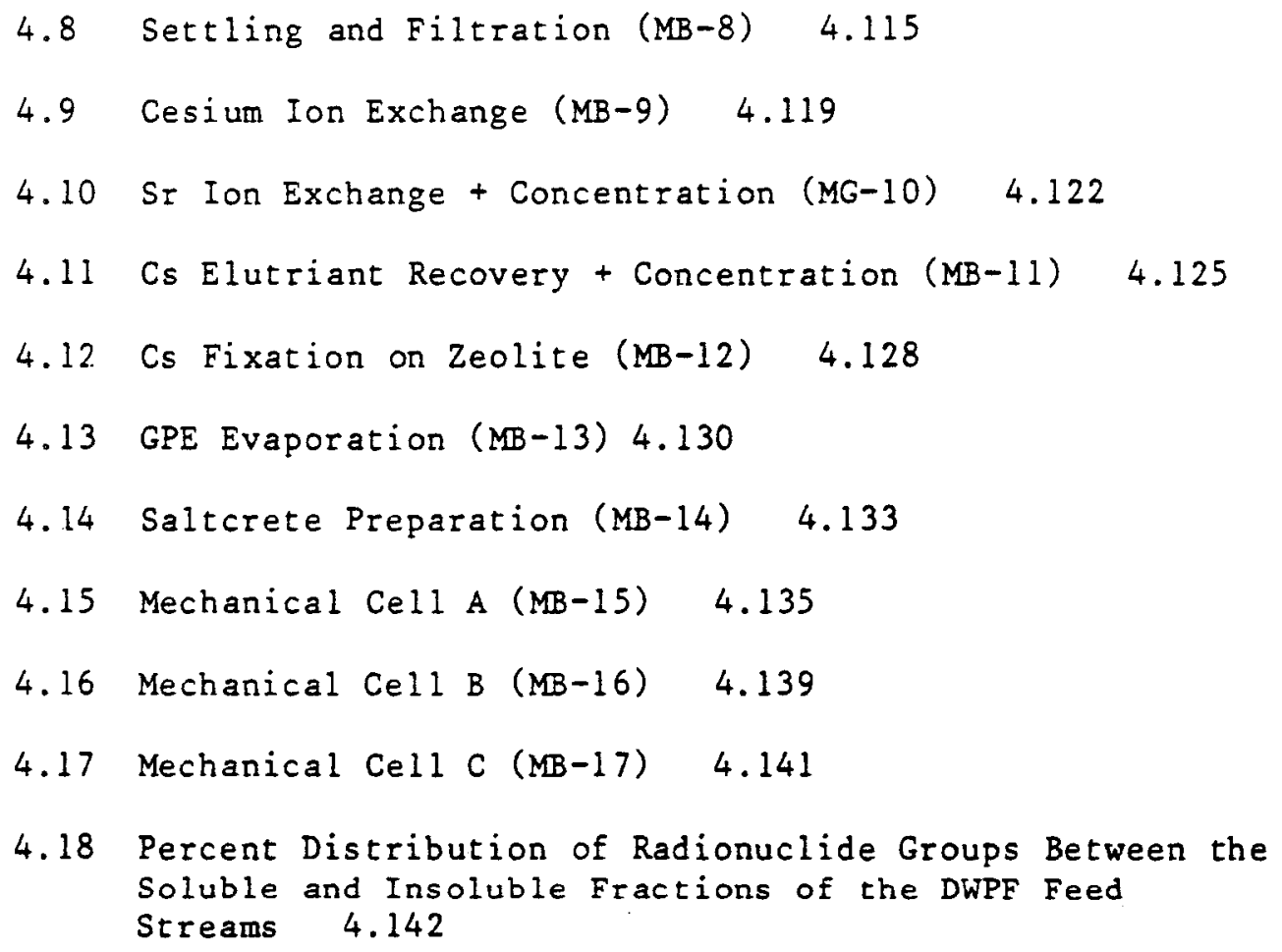

4.19 Summary of Aluminum Dissolving Tests 4.143

4.20 Effect of Aluminum Dissolving on Sludge Composition 4.144

4.21 Batch Washing Cycle 4.145

4.22 Centrifuge Cycle 4.145

4.23 Description of Synthetic Sludge Waste 4.146

4.24 Small Scale TNX Centrifuge Performance with Undiluted Slurry Feed 4.147

4.25 Centrifuge Scaleup 4.147

$4.26 \mathrm{Na}^{+}, \mathrm{NO}_{3}^{-}$, and $\mathrm{SO}_{4}{ }^{2-}$ Concentrations in washed Sludge 4.148

4.27 Spray Dryer Product Bulk Density 4.148

4.28 Particle Size Distribution of Powder Produced with Simulated SRP Feed in the PNL 36-inch Spray Dryer 4.149

4.29 Median Particle Diameter of Spray Dryer Product 4.150

4.30 Spray Dryer Product Composition, wt \% 4.150 
4.31 Elemental and Ionic Analyses of Spray Dryer Product 4.151

4.32 TGA Analysis and DTA Analyses of Spray Dryer Product 4.151

4.33 Sumary of PNL Spray Dryer Tests Using Simulated SRP Waste Feed $\quad 4.152$

4.34 Rheology of Non-Newtonian Melts 4.153

4.35 Composition Dependence of Coefficients 4.153

4.36 Effect of Mixing Frit and Waste on Dissolution Rate 4.154

4.37 Mixing and Homogenization of Glass Melts 4.154

4.38 Effect of Frit Particle Size on Melting Behavior of Sludge Feed 4.155

4.39 Total Particle and Mass Loading in Spray Dryer Off-Gas Stream 4.156

4.40 Composition of Supernate Used in 700-Gallon GS Tests 4.156

4.41 700-Gallon GS Results (PTDS No. I Flowsheet) 4.157

4.42 700-Gallon GS Results - (PTDS No. 2 Flowsheet) 4.158

4.43 Large-Scale GS Results 4.159

4.44 4-In.-Diameter Sand Filter Performance 4.160

4.45 Large-Scale Sand Filter Feed Results 4.161

4.46 Large-Scale Sand Filter Backwash Results 4.162

4.47 Viscosities of Stock Solutions for Settling/Filtration 4.163

4.48 Proposed Cesium Ion Exchange Cycle Schedule 4.163

4.49 Requirements for Optimum Results in Countercurrent Ion Exchange [32] 4.164

4.50 Physical Properties of "Duolite" ARC-359 Ion Exchange Resin 4.165

4.51 "Duolite" ARC-359 Density and Swelling Data [70] 4.166

4.52 Ion Exchange Capacity of "Duolite" ARC-359 Resin (Sulfonic acid exchange capacity - $2.49 \mathrm{~g}$ eq $/ \mathrm{kg}$ air-dry resin) 4.167 
4.53 Effects of Feed $\mathrm{Na}^{+}$and $\mathrm{OH}^{-}$on $\mathrm{Cs}^{+}$Sorption by

"Duolite" ARC-359 Resin 4.167

4.54 Effect of $\mathrm{Cs}^{+}$Concentration on the Sorption of $\mathrm{Cs}^{+}$by

"Duolite" ARC-359 Resin from 4.75M NaNO $3-1.0 \mathrm{M} \mathrm{NaOH} 4.168$

4.55 Removal of ${ }^{137} \mathrm{Cs}$ and Plutonium by "Duolite" ARC-359

Resin (Feed ${ }^{137} \mathrm{Cs}=2.0$ to $2.2 \mathrm{Ci} / \mathrm{gal}$ ) 4.168

4.56 Strontium Ion Exchange Cycle Schedule 4.169

4.57 Sr Distribution Coefficient for Various Ion Exchange Resins 4.169

4.58 Selectivity Series for "Amberlite" IRC-718 Distribution Coefficients $k_{d}$ for Metal Ions in $1.0 \mathrm{M} \mathrm{NaOH}-4.75 \mathrm{M} \mathrm{NaNO}$ 4.170

4.59 Bulk Density of "Ionsiv" IE-95 4.171

4.60 Fixation of $\mathrm{Cs}-137$ on Zeolites 4.171

5.1 DWPF Services and Equipment 5.60

5.2 Cold Feed Services 5.68

5.3 Technical Specifications for Wash Centrifuge 5.69

5.4 PNL Spray Dryer Basic Data 5.70

6.1 DWPF On-Line Process Control Measurements 6.2

6.2 DWPF Off-Line Analyses (Unless otherwise specified, the desired uncertainty is $\pm 10 \%$ ) 6.9

7.1 Calculational Bases (Beyond FY-1988) 7.4

7.2 Fraction of Radioactivity in Spent SRP Fuel Lost to High-Level Waste During Fuel Reprocessing 7.5

7.3 Volume Proportion of Wastes 7.6

7.4 Isotopic Content ( $g / g a l$ ) of The Reference DWPF Waste Blend - 5 Years 7.7

7.5 Isotopic Content ( $\mathrm{C} / \mathrm{gal}$ ) of The Reference DWPF Waste Blend - 5 Years 7.8 
7.6 Isotopic Content ( $g / g a l)$ of The Reference DWPF Waste Blend - 15 Years 7.9

7.7 Isotopic Content ( $\mathrm{Ci} / \mathrm{gal}$ ) of The Reference DWPF Waste Blend - 15 Years 7.10

7.8 Isotopic Content ( $\mathrm{g} /$ assembly) of a Mark 16B Fuel As sembly - 5 Years 7.11

7.9 Isotopic Content ( $\mathrm{Ci} /$ assembly) of a Mark 16B Fuel As sembly - 5 Years 7.12

7.10 Isotopic Content ( $\mathrm{g} / \mathrm{assembly}$ ) of a Mark 16B Fuel Assembly - 15 Years 7.13

7.11 Isotopic Content ( Ci/assembly) of a Mark 16B Fuel Assembly - 15 Years 7.14

7.12 Isotopic Content (g/assembly) of a Mark 22 Assembly 5 Years 7.15

7.13 Isotopic Content ( $\mathrm{Ci} /$ assembly) of a Mark 22 Assembly 5 Years 7.16

7.14 Isotopic Content (g/assembly) of a Mark 22 Assembly 15 Years 7.17

7.15 Isotopic Content ( $\mathrm{Ci} /$ assembly) of a Mark 22 Assembly 15 Years 7.18

7.16 Isotopic Content (g/assembly) of a Mark 31A Assembly 5 Years 7.19

7.17 Isotopic Content ( $\mathrm{C}$ //assembly) of a Mark 31A Assembly - 5 Years 7.20

7.18 Isotopic Content ( $g /$ assembly) of a Mark 31A Assembly 15 Years 7.21

7.19 Isotopic Content ( $\mathrm{Ci} /$ assembly) of a Mark $31 \mathrm{~A}$ Assembly - 15 Years 7.22

7.20 Isotopic Content ( $\mathrm{g} /$ assembly) of a Mark 31B Assembly 5 Years 7.23

7.21 Isotopic Content ( Ci/assembly). of a Mark 31 B Assembly - 5 Years 7.24 .

7.22 Isotopic Content ( $g /$ assembly) of a Mark 31B Assembly 15 Years 7.25 


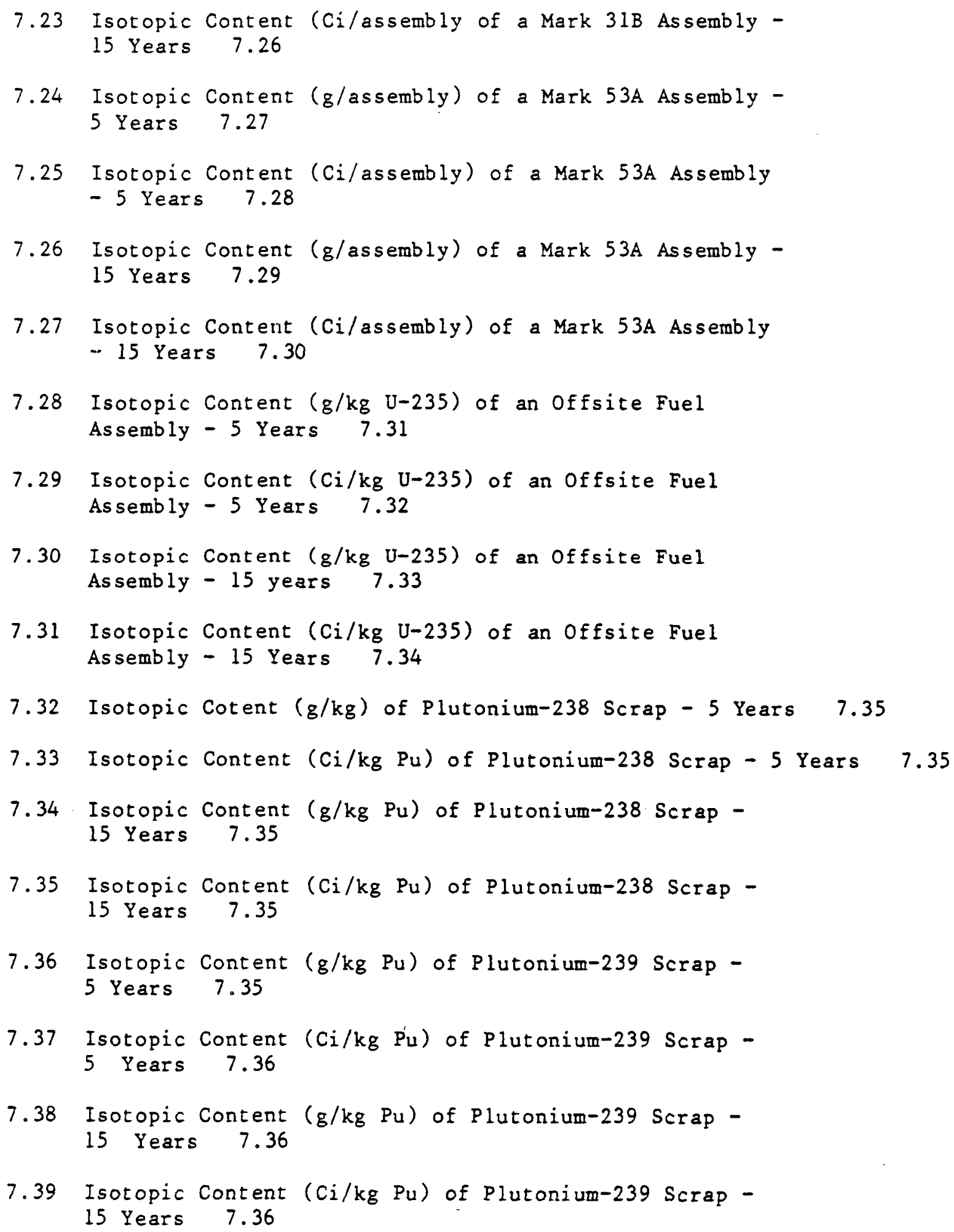


8.1 Savannah River Plant Annual Exposure Operating Guides 8.3

8.2 Estimated Annual Aqueous Release to the Environment - 5 Years 8.4

8.3 Estimated Annual Aqueous Releases to the Environment - 15 Years 8.5

8.4 Estimated Annual Atomspheric Releases to the Environment 5 Years Source - Sand Filter Stack 8.6

8.5 Estimated Annual Atmospheric Releases to the Environment 15 Years Source - Sand Filter Stack 8.7

8.6 Estimated Annual Atmospheric Releases to the Environment 5 Years Source - Regulated Facility Vessel Vent 8.8

8.7 Estimated Annual Atmospheric Releases to the Environment 15 Years Source - Regulated Facility Vessel Vent 8.9

8.8 Estimated Annual Atmospheric Releases to the Environment 5 Years Source - Product Salt Concentration/Solidification Vessel Vent 8.10

8.9 Estimated Annual Atmospheric Releases to the Environment 15 Years Source - Product Salt Concentration/Solidification Vessel Vent 8.11

8.10 Estimated Total Annual Releases ( $\mathrm{Ci}$ ) to the Environment 8.12

8.11 Comparison of Annual Radioactive Releases (Ci) SRP vs. DWPF 8.12

9.1 Operational Areas in the DWPF 9.10

9.2 Potential Incidents 9.11

9.3 Engineered Safety Features 9.19

9.4 SRP Whole Body Occupational Dose 9.31

9.5 SRP Reprocessing Area Whole Body Occupational Dose 9.31

9.6 Occupational Radiation Exposure 9.32

9.7 Manpower and Time Requirements 9.32

9.8 Non-Nuclear Occupational Casualties During Construction of New Facilities 9.33 

9.9 Non-Nuclear Occupational Casualties During the Operational Campaign 9.33
9.10 DOE Radiation Exposure Limits to Offsite Individuals, mrem 9.33
9.Il Typical State and Federal Air and Water Quality Standards 9.34
9.12 Summary of Risks for Processing Waste to Glass (glass stored in offsite geologic storage) 9.35
9.13 Radionuclide Deposition Limits for Evacuation and Restrictions on Farming, $\mathrm{Ci} / \mathrm{m}^{2} 9.36$
9.14 Radiation Dose Criteria 9.36
9.15 Contamination Effects from Sabotage During Removal of Waste from Tanks 9.37
9.16 Contamination Effects from Sabotage During Waste Processing 9.37
9.17 Consequences of Runoff from Abandoned Salt Tanks Reaching the Savannah River 9.37
12.1 DWPF Solid Waste Generation 12.3

13.1-1 High-Heat Waste Flowsheet 13.1.5

13.1-2 Low-Heat Waste Flowsheet 13.1 .6

13.1-3 Purex Waste vs. Total Waste 13.1.7

13.1-4 Waste Volumes 13.1 .7

13.1-5 HM High-Heat Waste 13.1.8

13.1-6 HM Low-Heat Waste 13.1 .9

13.1-7 Frame Waste Flowsheet 13.1.10

13.1.8 Frame Waste Composition (Low-Heat Waste) 13.1 .11

13.3-1 Chemical Composition of Washed, Dried Tank 5 Sludge 13.3 .3

13.3-2 Chemical Composition of Washed, Dried Tank 7 Sludge 13.3 .4 
13.3-3 Chemical Composition of Washed, Dried Tank 13 Sludge 13.3 .5

13.3-4 Chemical Composition of Washed, Dried Tank 19 Sludge 13.3.6́

13.3-5 Residual Leachable Components 13.3.7

13.3-6 Specific Activity of Radionuclides 13.3.7

13.3-7 Principal Components of Washed, Dried Sludge 13.3 .8

13.3-8 Principal Radionuclides in Washed, Dried Sludge, mCi/g 13.3 .8

13.3-9 Calculated Principal Consituents of Washed and Dried Tank 16 Sludge 13.3 .9

13.3-10 Major Radionuclides in Tank 16H Sludge 13.3.10

13.4-1 F-Area Waste Tank Supernate Analyses 13.4.2

13.4-2 F-Area Waste Tank Supernate Radionuclide Analyses 13.4 .2

13.4-3 H-Area Waste Tank Supernate Analyses 13.4.3

13.4-4 H-Area Waste Supernate Radionuclide Analyses 13.4 .4 


\section{LIST OF FIGURES}

1.1 SRP Defense Waste Processing Reference Flowsheet 1.7

2.1 Effect of Sludge Concentration on Viscosity of Sludge Suspensions 2.17

2.2 SRP Sludge Settling Rates 2.18

2.3 Sludge Settling in Waste Tank No. 132.19

3.1 Activity in DWPF Glass 3.26

3.2 Decay Heat in DWPF Glass 3.27

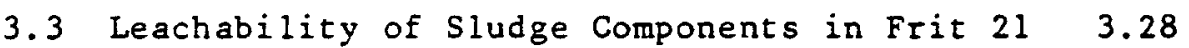

3.4 Cumulative Leaching of Frit 21-Simulated SRP Sludge Glasses in Brine Based on $137 \mathrm{Cs}$ (Duplicate Sample Data Included) $\quad 3.29$

3.5 Cumulative Leaching of Frit 21-SRP Waste Tank No. 13 Glasses Based on $90 \mathrm{SI} 3.30$

3.6 Cumulative Leaching of Frit 21-SRP Waste Tank No. 16 Glasses Based on ${ }^{90} \mathrm{Sr} 3.31$

3.7 Reference Canister Design 3.32

3.8 Isotherms at End of Canister Fill 3.33

3.9 Temperature History for Canister 3.34

3.10 Short-Term Temperature Effects of Subsequent Canister/Container Processing (Process Duration $=4$ hours) 3.35

3.11 Canister Isotherms at Steady State 3.36

3.12 Deleted 3.37 
4.1 DWPF Overall Reference Flowsheet 4.172

4.2 Sludge and Supernate Feed Preparation

Flowsheet (FS-2) 4.173

4.3 Aluminum Dissolution Flowsheet (FS-3) 4.174

4.4 Sludge Washing Flowsheet (FS-4) 4.175

4.5 Spray Calcination/Vitrification

Flowsheet $(F S-5) \quad 4.176$

4.6 Off-Gas Treatment Flowsheet (FS-6) 4.177

4.6A Mercury Recovery Flowsheet (FS-6A) 4.178

4.7 Recycle Evaporation Flowsheet (FS-7) 4.179

4.8 Settling and Filtration Flowsheet (FS-8) 4.180

4.9 Cesium Ion Exchange Flowsheet (FS-9) 4.181

4.10 Strontium Ion Exchange and Concentrator

Flowsheet (FS-10) 4.182

4.11 Cesium Elutriant Recovery and Cesium

Concentration (FS-11) 4.183

4.12 Cesium Fixation on Zeolite Flowsheet (FS-12) 4.184

4.13 General-Purpose Evaporation Flowsheet (FS-13) 4.185

4.14 Product Salt Solution Concentration and Solidification in Concrete (FS-14) 4.186

4.15 Mechanical Cell A Flowsheet (FS-15) 4.187

4.16 Mechanical Cell B Flowsheet (FS-16) 4.188

4.17 Mechanical Cell C Flowsheet (FS-17) 4.189

4.18 Solubility of Gibbsite in Caustic. Total $\mathrm{OH}^{-}=\mathrm{OH}^{-}+\mathrm{Al}^{3+}$ in solution 4.190

4.19 Solubility of Boehmite in Caustic. Total $\mathrm{OH}^{-}=\mathrm{OH}^{-}+\mathrm{Al}^{3+}$ in solution 4.191

4.20 Deleted 4.192

4.21 Deleted 4.193 


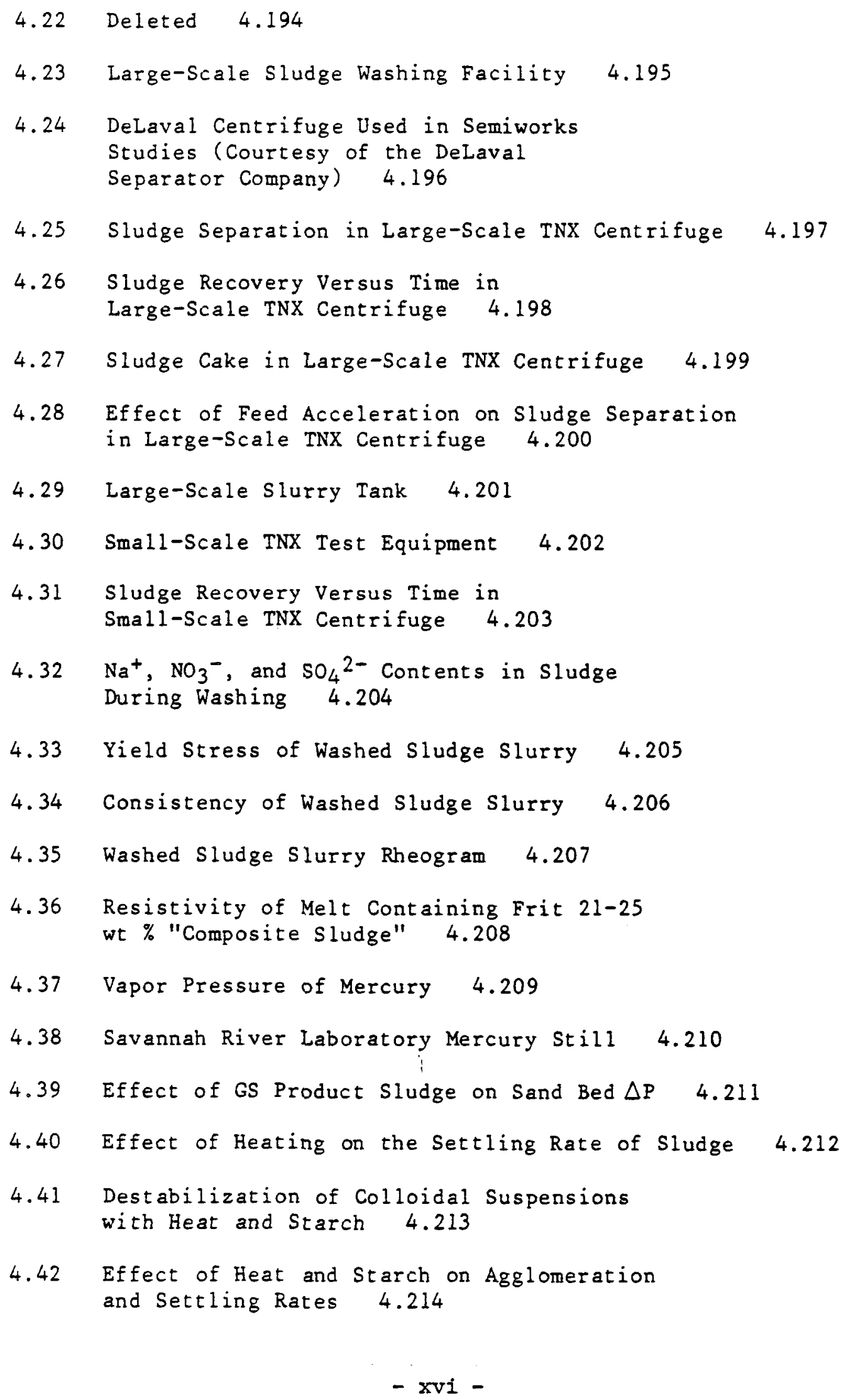




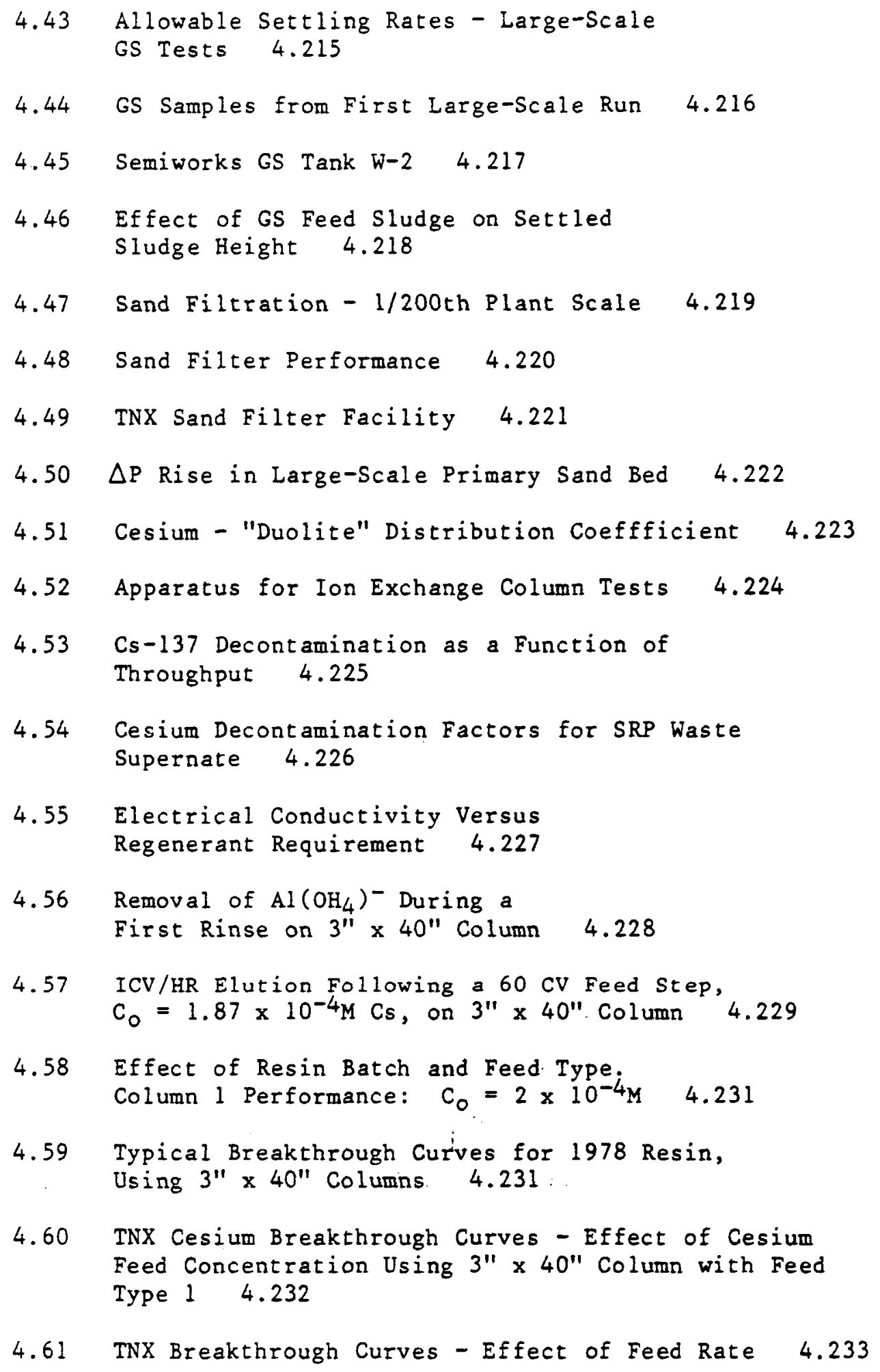




4.62 Downflow Pressure Drop of "Amberlite" IRC-718 4.234
4.63 Column Test of "Amberlite" XE-318 (Presently
Manufactured as Amberlite IRC-718) 4.235

5.1 High-Capacity Atomizing Nozzle 5.71

5.2 Conceptual Developmental Spray Dryer 5.72

5.3 Spray-Dryer Filter Assembly 5.73

5.4 Joule-Heated Continuous Glass Melter 5.74

5.5 Continuous Evaporator 5.75

5.6 Bent-Tube Evaporator 5.76

5.7 Disposal of Decontaminated Salt 5.77

13.1-1 Purex High-Heat Waste 13.1.12

13.1-2 Miscellaneous High-Heat Waste 13.1 .12

13.1-3 Purex Low-Heat Waste 13.1.12

13.1-4 Miscellaneous Low-Heat Waste 13.1 .13

13.1-5 Frame Waste Flowsheet 13.1.14 


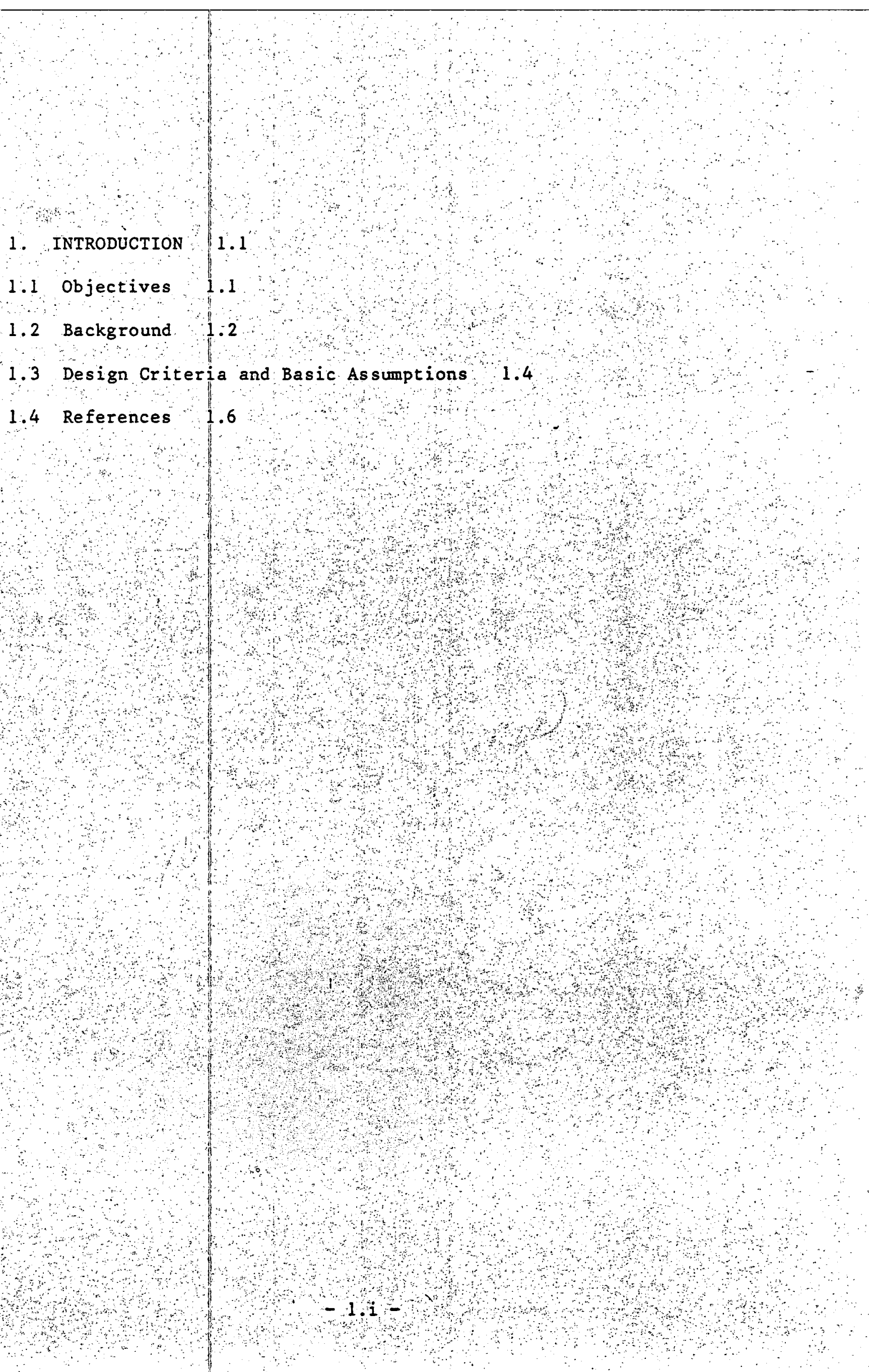





\section{INTRODUCTION}

\subsection{Objectives (L. F. Landon)*}

This Preliminary Technical Data Summary (PTDS No. 3) presents an update on the best information presently available for the purpose of establishing the basis for the design of a Defense Waste Processing Facility (DWPF). The objective of this project is to provide a facility to fix the radionuclides present in Savannah River Plant (SRP) high-level liquid waste in a high-integrity form (glass). The issue of this document is to be considered preliminary since the research and development effort will be an ongoing activity during the early stages of plant design. The document will continue to be updated as new information is obtained.

Additional basic data evolved from the continuing research and development programs and flowsheet optimization studies will supersede the data presently contained in this document. As individual data packages are formalized, the Technical Information Service of the Savannah River Laboratory will issue revisions to each individual assigned a copy of Preliminary Technical Data Summary No. 3. Additional Technical Data Summaries will be issued when deemed appropriate.

The major changes in this issue relative to PTDS No. 2 (DPSTD-77-13-2, June 1979) are as follows:

1. Material balance flowsheets have been updated based on the following revised process data:

- The three-wash sludge washing scheme has been changed to a dewatering step followed by two washes.

- The water content of the centrifuge sludge cake has been reduced from 6.2 to $3.01 \mathrm{~b} \mathrm{H} \mathrm{H}_{2} \mathrm{O} / 1 \mathrm{~b}$ of solids.

- Solids recovery for each centrifuge pass has been increased from 97 to $98 \%$.

- Solids recovery for the gravity settling operation has been increased from 98 to $99 \%$.

* Contributor. Questions concerning material in this Preliminary Technical Data Summary should be addressed to contributor whose name appears after a heading. 
- Total solids content of spray-dryer feed has been increased from about $6 \%$ to 17 wt \%.

2. Volumetric underflow recycle for the gravity settling operation has been decreased from 10 to $7 \%$.

3. The parallel-train concept of ion exchange columns for cesium and strontium recovery has been reduced to a single-train concept consisting of two cesium ion exchange columns and one strontium ion exchange column, all in series.

4. The clarified supernate fraction of the waste following treatment by ion exchange will be incorporated into concrete and stored onsite as large monoliths in an intermediate-depth land burial site.

5. The canister overpack and associated equipment and offsite shipping facilities are eliminated from the scope of this document.

6. The capacity of the glass-waste interim-storage facility has been increased to 6500 canisters.

7. The canisters will undergo a two-step decontamination procedure in Mechanical Cells $A$ and B. A nitric acid-sodium fluoride solution will be used in the first step followed by an oxalic acid cleaning step.

8. Sludge settling rate in Gravity Settler increased from 10 to 20 inches/hour.

Additional alternatives to the technical bases presented here will continue to be evaluated as potentially valuable contributions toward improved operability and/or reduced cost of the facility. These alternatives will be handled on an individual basis if and when a clear-cut advantage becomes apparent.

\subsection{Background (L. F. Landon)}

Since 1953, the Savannah River Plant (SRP), near Aiken, South Carolina, has been producing special nuclear materials, primarily plutonium and tritium, for defense purposes. The SRP facilities were constructed and operated by the Du Pont Company initially for the Atomic Energy Commission (AEC), now the Department of Energy (DOE). The SRP site occupies an area of about 300 square miles along the Savannah River, about 25 miles downstream from Augusta, Georgia. SRP includes a nuclear fuel fabrication plant, three production reactors, two fuel reprocessing plants, and a facility for producing heavy water. 
The SRP operations produce high-level radioactive waste in the chemical processing of fuel and target elements after irradiation in the SRP nuclear reactors. This waste is stored in large underground tanks as an alkaline liquid with a precipitated sludge until the decay heating has abated appreciably. Then the supernatant liquid is evaporated and returned to the tanks to form a salt cake to reduce volume and mobility.

In 1971, the Division of Waste Management and Transportation was formed in the AEC and published initial plans for the longterm management of defense waste. For $\mathrm{SRP}$, the plan was storage of liquid waste in a deep-mined cavern under the SRP site. In November 1972, the AEC deferred further study of that storage option in favor of an investigation of the conversion of SRP waste to a high-integrity solid. The status of the technology, technical data base, proposed design criteria, and estimated risks for the deep-mined cavern were summarized in a Technical Assessment [1].

As a first step in evaluating waste forms for Savannah River waste, a survey was made of all pertinent forms and processes, and the applicability of these waste forms and processes to $S R$ waste was evaluated [2]. One of the principal conclusions of this evaluation was that the presence of the soluble salts $\left(\mathrm{NaNO}_{3}, \mathrm{Na}_{2} \mathrm{CO}_{3}\right.$, etc.) presented significant difficulties if these salts had to be incorporated into a high-integrity form such as glass or concrete. A process for segregating the soluble salts from the radionuclides was suggested based on physical separation of the insoluble sludge and supernate via centrifugation and filtration and separation of soluble radionuclides in the supernate (principally Cs-137) by ion exchange.

Subsequent laboratory studies showed that the separation of nuclides from soluble salts was feasible [3], that concrete was an acceptable waste form [4], but that glass had the highest integrity (principally greater leach resistance in water and absence of off-gassing when heated [5].

Concurrent with initial small-scale research in the Savannah River Laboratory ( $S R L$ ), conceptual studies were carried out as a joint effort between $S R L, S R P$, and the Du Pont Engineering Department to evaluate the feasibility and cost of selected options. These studies included evaluation of basic parameters such as waste form, disposal mode for the solid radioactive waste form and the decontaminated salts, processing rates, etc.

During this same period, SRL also made an overall evaluation of the costs and risks of all options for long-term management of Savannah River waste. This overall evaluation included options such as onsite bedrock storage and continued tank storage as well as solidification [6]. 
In 1977, the following reference process was chosen:

- Incorporation of radionuclides in glass and offsite shipment to a Federal repository.

- Return of the decontaminated supernate as damp salt cake to onsite bulk storage.

- Processing al1 >5-year-old waste.

In August 1978, a Preliminary Technical Data Summary (PTDS No. 1) was issued which presented the best information that was currently available for the purpose of establishing the basis for design of a Defense Waste Processing Facility [7]. This document was updated and reissued in June 1979 (DPSTD-77-13-2). The current reference process flowsheet is shown schematically in Figure 1.1 .

\subsection{Design Criteria and Basic Assumptions (L. F. Landon)}

1. The waste processing facility will be located at a new site (200-S Area) on the $S R P$ site in reasonable proximity to the $F$ and H-Area Interim Waste Storage Facilities.

2. The waste processing facility is designed for an average attained rate of $9 \mathrm{gpm}$ equivalent feed on a reconstituted basis.

3. The aged waste will be separated into two fractions, a supernate fraction and a sludge-slurry fraction, for feed to the DWPF. The supernate fraction is composed of decanted supernate and redissolved salt cake. The sludge-slurry fraction is prepared by slurrying the in-tank, settled-sludge.

4. The waste will be processed to obtain a borosilicate glass (containing essentially all the radioactivity) and a concretesalt matrix (containing very low concentrations of radioactivity).

5. The chemical composition of the waste feed to the DWPF is based on past analyses of supernate and sludge samples obtained from existing waste storage tanks. For planning purposes perfect blending of the two waste fractions at the time of plant startup is assumed in calculating material balances. 
6. Clarified supernate following ion exchange, will be incorporated into concrete and stored as a concrete matrix in a new intermediate-depth land burial facility. The clarified supernate fraction of the waste feed will be sufficiently decontaminated such that the radionuclide content of the saltcrete will conform to the projected NRC waste classification $\mathrm{C}$.

7. The radionuclide composition of the waste is based on the following:

- Reactor operation for the late 1980's.

- Irradiated fuel is cooled for 180 days before processing.

- The high-heat and low-heat waste streams generated during fuel reprocessing are blended in the proportion they are generated.

8. The only current regulatory requirement for the glass waste form is that it be a solid. Possible future criteria and regulations regarding the uniformity of the glass, maximum beat output, leachability limits, chemical composition, etc., may alter the scope of the project.

9. The glassform will be stored onsite in an air-cooled vault.

10. The radioactive borosilicate glass will be contained in a 2-ft-diameter, 10-ft-long steel canister. Approximately 3260 lbs of glass will be loaded into each canister filling it to approximately $80 \%$.

11. Selection of materials of construction, particularly for items that would be very difficult to replace (such as embedded piping) should assume the DWPF will eventually be decontaminated with nitric acid.

12. This document does not address the technical bases for preparation of the feed to the DWPF (sludge slurrying, salt cake dissolution, waste tank cleaning, and excess oxalic acid digestion). 


\subsection{References}

1. R. F. Bradley and J. C. Corey. Technical Assessment of Bedrock Waste Storage at the Savannah River Plant. USERDA Report DP-1438, E. I. du Pont de Nemours \& Company (Inc.), Savannah River Laboratory, Aiken, SC (November 1976).

2. R. M. Wallace, H. L. Hul1, and R. B. Bradley. Solid Forms for Savannah River Plant High-Level Waste. USERDA Report DP-1335, E. I. du Pont de Nemours \& Company (Inc.), Savannah River Laboratory, Aiken, SC (December 1973).

3. A. S. Jennings. Plan for Solidification of Savannah River Plant High-Level Waste. Report CONF-771102-4, American Institute of Chemical Engineers, New York (1978).

4. J. A. Stone. Evaluation of Concrete as a Matrix for Solidification of Savannah River Plant Waste. USERDA Report DP-1448, E. I. du Pont de Nemours \& Company (Inc.), Savannah River Laboratory, Aiken, SC (June 1977).

5. J. A. Kelley. Evaluation of Glass as a Matrix for Solidification of Savannah River Plant Waste. USERDA Report DP-1382, E. I. du Pont de Nemours \& Company (Inc.), Savannah River Laboratory, Aiken, SC (May 1975).

6. Alternatives for Long-Term Management of Defense High-Level Radioactive Waste - Savannah River Plant. Report ERDA-77-42 (Two volumes), U.S. Energy Research and Development Administration, Washington, DC (May 1977).

7. Preliminary Technical Data Summary for the Defense-Waste Processing Facility. USDOE Report DPSTD-77-13, E. I. du Pont de Nemours \& Company (Inc.), Savannah River Laboratory, Aiken, SC (August 1978). 


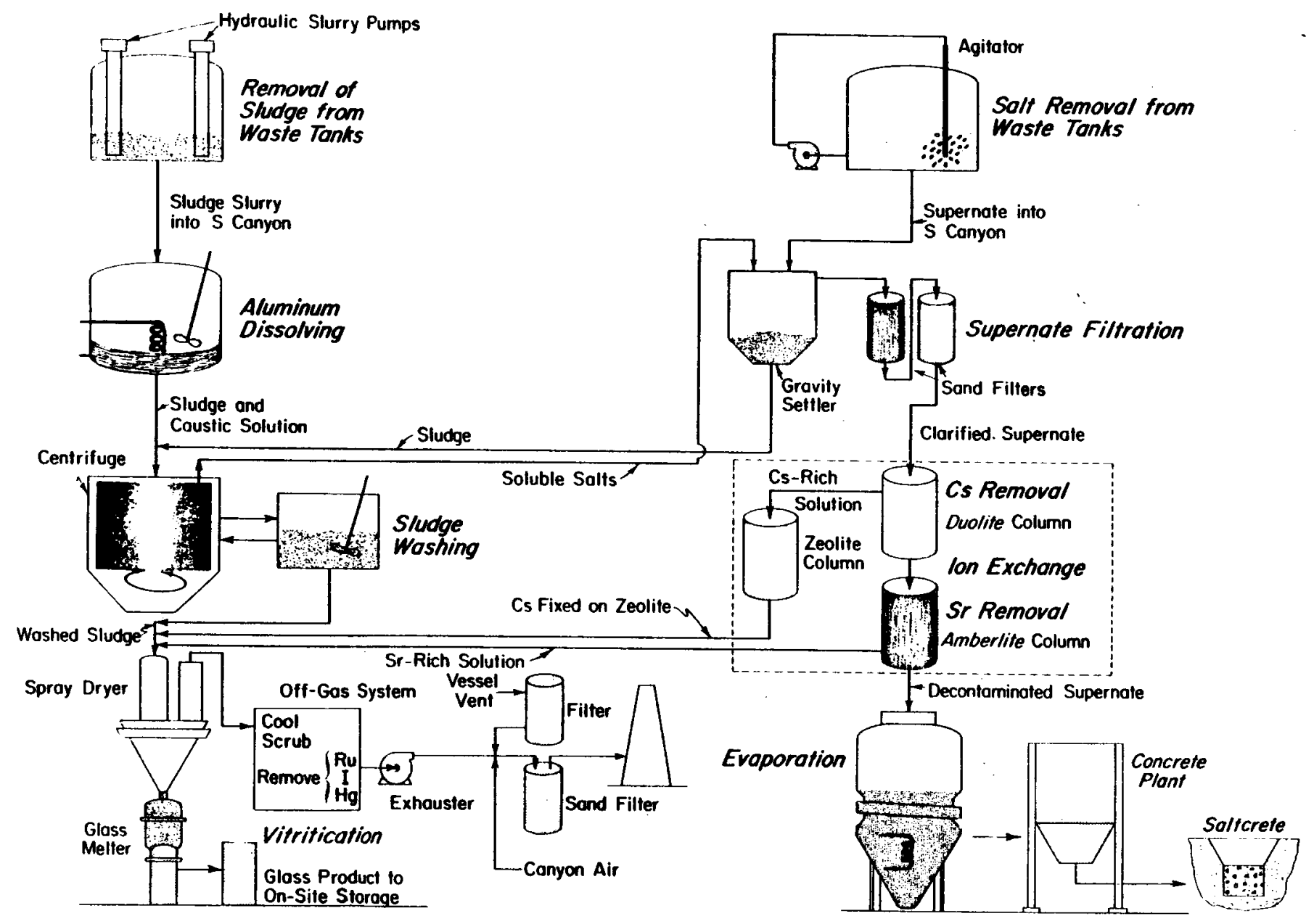

FIGURE 1.1 SRP Defense Waste Processing Reference Flowsheet 


\section{FEED DESCRIPTION}

\subsection{Genera1}

The high- and low-heat acidic waste generated from the separations processes (Appendix 13.1) are neutralized with sodium hydroxide prior to transfer to interim storage. Neutralization of the wastes causes precipitation of insoluble compounds (sludge) of stable and radioactive fission products, actinide elements, and elements added in the processes, primarily $\mathrm{Fe}, \mathrm{Mn}, \mathrm{Al}$, and $\mathrm{Hg}$. The neutralized wastes are transferred to selected underground waste tanks, according to their heat contents. After the wastes have aged (during which the insoluble fraction of the waste settles out) $[1,2]$, the supernates are transferred to an evaporator for dewatering. The concentrate from the evaporator is transferred to cooled waste tanks where the cooling causes the salt to crysta11ize. Fresh neutralized waste has been added to the sludge heel in some tanks, and there has been some mixing of high- and low-heat waste sludges. In other cases sludge has been removed from several tanks and transferred to others. Tanks from which sludge has been removed have been used to retain salt from the concentration of supernate. Thus, sludge composition and characteristics are variable and are not only a function of sludge source and age, but are affected by waste management practices. Variations can occur not only from tank to tank but also within a tank as a function of location and depth.

\subsection{Feed Composition}

\subsubsection{Chemical Composition (A. J. Hill, J. R. Wiley)}

Table 2.1 summarizes the chemical composition of the soluble and insoluble fractions of the two waste streams that comprise the feed to the processing facility. The detailed bases for calculating these compositions are presented in Chapter 4 and Appendix 13.2.

\subsubsection{Radionuclide Composition (J. R. Chandler)}

The concentration of radionuclides in the supernate and sludge-slurry feed streams for 5 and 15-year-old waste are tabulated in Tables 2.3 through 2.10. The distribution of radionuclides between gravity-settled, in-tank sludge and supernate are tabulated in Table 2.11. The bases for radionuclide composition calculations are outlined in detail in Chapter 7. 


\subsection{Sludge Description (A. J. Hill, J. A. Stone)}

\subsubsection{General $^{1}$}

Insoluble solids represent 7.3 volume percent of the neutralized wastes transferred from the Separation Facilities to the waste tank farm. During aging, the sludge settles to the bottom of the waste tank. About three-fourths of the settled sludge is compacted into a sticky, dark brown, gelatinous mass. The remainder is loosely settled, finely divided material of essentially the same composition. Sludge, as sampled, is a mixture of water soluble salts, insoluble solids, and interstitial liquid. Following centrifugation and drying, approximately $70-80 \%$ of the sludge is a complex mixture of oxides and hydroxides of manganese, iron, and aluminum, plus uranium, mixed fission products, and actinides.

\subsubsection{Characteristic Types of Sludge}

The plant feed represents a weighted average or composite composition based on individual tank analyses. It is important to recognize that this composition assumes perfect blending of the sludge in storage in both areas and that reported sludge analyses from a given tank approximate the composition of the entire tank.

\subsubsection{Chemical Components of Sludge}

The representative elemental composition of SRP sludge is 1isted in Table 2.12. More detalled analyses for sludges from several SRP tanks are shown in Appendix 13.3 and Reference 3.

\subsubsection{Physical Properties}

\subsubsection{Density}

A density of $1.369 \mathrm{~g} / \mathrm{cc}$ for in-tank settled sludge was used in calculating the reference feed.

\subsubsection{Viscosity}

The viscosity of sludge suspensions in supernate have been measured as a function of the volume ratio of sludge to supernate. For these tests synthetic supernate and synthetic sludge were used to represent the characteristics of early samples of sludge from Tanks 12 and 14. The results are shown in Figure 2.1. 
Viscosity data on actual sludge are summarized in Table 2.13. Apparently, viscosities of 1:1 mixtures of centrifuged sludge and supernate may vary from 10 to $100 \mathrm{cp}$ depending on the sludge type.

\subsubsection{Settling Velocity}

In early studies of the properties of sludge [5], a sample from Tank $12 \mathrm{H}$ was slurried with supernate (specific gravity $=1.25$ ) and allowed to settle. The observed settling rate for the major portion of the sludge was $6 \mathrm{in} . / \mathrm{hr}$ while that of the finer material was $1 \mathrm{in.} / \mathrm{hr}$. The settled volume of sludge was $25 \%$ of the total mixture and the volume of sludge after centrifugation was about half the settled volume [5]. Settling rates in dilute sodium hydroxide for early samples of sludge from Tanks 2 and 9 are shown in Figure 2.2. The as-received sludge was stirred vigorously in a graduated cylinder and allowed to settle. The sludges settled with a very sharp interface between sludge and supernate, with no tail of fines extending into the interface [4]. However, this sharp interface was not observed following sludge transfer from Tank $11 \mathrm{H}$ to 13H (Figure 2.3). The settling behavior will be dependent on the specific gravity of the supernate. The data in Figure 2.2 should be applied only to settling behavior in wash water or in dilute tank rinses.

In recent settling tests with washed Tank $16 \mathrm{H}$ sludge, repetitive tests showed good reproducibility of sludge settling rates. The sludge settled fairly rapidly at first, but the settling rate diminished with time. The initial volume ratio of water/sludge was 9:1. Average settling rates were about $15 \mathrm{in./hr}$ for the first 10 minutes, about 4 in./hr for the first hour, and about $0.3 \mathrm{in./hr}$ for 16 hours. No significant change in the volume of settled sludge was observed after 16 hours.

\subsection{Supernate Description (R. S. Ondrejcin)}

\subsubsection{General}

Supernate solution from about half of the waste tanks at SRP has been sampled and characterized [6,7]. Table 2.14 1ists the concentration of major components of the supernate. Detailed analyses for major chemical components in supernate samples taken since 1972 are shown in Appendix 13.4 Minor ions which have also been identified in the supernate are $\mathrm{PO}_{4}^{3-}, \mathrm{Cl}^{-}, \mathrm{CrO}_{4}{ }^{2-}$, and $\mathrm{NH}_{4}{ }^{+}$. Trace metals in the supernate are $\mathrm{Fe}, \mathrm{Hg}, \mathrm{Ag}, \mathrm{Pb}$, and $\mathrm{U}$. Analyses of trace elements are available in Reference 6. 


\subsubsection{Density}

A density of $1.242 \mathrm{~g} / \mathrm{cc}$ for in-tank supernate was used for calculating reference feed. See Appendix 13.1 for a detailed description for calculating the density of supernate.

\section{4 .3 Viscosity}

The viscosity of the reference waste tank supernate is about $2 \mathrm{cp}$. 
TABLE 2.1

Chemical Composition of Soluble and Insoluble Fraction of DWPF Feed (Dry Basis)

\begin{tabular}{|c|c|c|c|c|}
\hline & & & $\mathrm{Ib} / \mathrm{hr}$ & \\
\hline & & Solubles & Insolubles & \\
\hline $\begin{array}{l}\text { Sludge-SIur } \\
\text { Supernate F }\end{array}$ & $e^{a}$ & $\begin{array}{l}144.2 \\
1975\end{array}$ & $\begin{array}{l}103.1 \\
1.302\end{array}$ & \\
\hline Soluble Sol: & wt $\%$ & & Insoluble So & ids, wt \% \\
\hline $\mathrm{NaNO}_{3}$ & 4.65 & & $\mathrm{Fe}(\mathrm{OH})_{3}$ & $3.85+01$ \\
\hline $\mathrm{NaNO}_{2}$ & 1.8 & & $\mathrm{UO}_{2}(\mathrm{OH})_{2}$ & 2.91 \\
\hline $\mathrm{NaAlO}_{2}$ & 9.7 & & $\mathrm{CaCO}_{3}$ & 3.82 \\
\hline $\mathrm{NaOH}$ & 7.2 & & $\mathrm{Ni}(\mathrm{OH})_{2}$ & 4.42 \\
\hline $\mathrm{Na}_{2} \mathrm{CO}_{3}$ & 7.5 & & $\mathrm{Na}_{2} \mathrm{O}$ & 1.93 \\
\hline $\mathrm{Na}_{2} \mathrm{SO}_{4}$ & 1.01 & & $\mathrm{NaNO}_{3}$ & 1.14 \\
\hline $\mathrm{Na}_{2} \mathrm{C}_{2} \mathrm{O}_{4}^{\mathrm{d}}$ & 1.23 & & $\mathrm{Na}_{2} \mathrm{SO}_{4}$ & $6.15-01$ \\
\hline $\mathrm{NaC1}$ & 3.0 & & $\mathrm{MnO}_{2}$ & 7.58 \\
\hline $\mathrm{NaF}$ & 1.95 & & $\mathrm{Hg}(\mathrm{OH})_{2}$ & 1.16 \\
\hline $\mathrm{Na}[\mathrm{HgO}(\mathrm{OH})]$ & 6.08 & & $\mathrm{NaCl}$ & 1.23 \\
\hline & & & $\mathrm{NaF}$ & $1.29-01$ \\
\hline & & & $\mathrm{C}$ & 1.31 \\
\hline & & & $\mathrm{Al}(\mathrm{OH})_{3}$ & $3.44+01$ \\
\hline & & & $\mathrm{SiO}_{2}$ & $5.62-01$ \\
\hline & & & $\mathrm{HgI}_{2}$ & $3.13-01$ \\
\hline
\end{tabular}

a. Actual sludge contains $1.95 \mathrm{lb}$ suspended solids per gallon with a specific gravity of 1.37. Dissolved salts are present at $\sim 29 \%$ by weight, exclusive of suspended solids. Sludge-slurry feed is prepared by slurrying with water such that the resulting volume is twice the sludge volume.

b. Supernate feed is constituted to $\sim 29$ wt \% salt solution by dissolving the salt cake in the tank with recycle water.

c. Modified scientific notation used throughout this report. For example, $4.69+01$ is equivalent to $4.69 \times 10^{1}$; i.e., 46.9 .

d. Not accounted for in supernate fraction of sludge-slurry feed. 
Table 2.2 (Deleted) 
TABLE 2.3 ISOTOPIC CONTENT (g/gal) OF SUPERNATE

\begin{tabular}{|c|c|c|c|c|}
\hline ISO' & $T_{C P} P_{0}$ & CINC =NTRATIIJN & ISS TOPE & CNCENTRA TI CA \\
\hline & 3 & $5.80525-i y$ & PnI 34 & $5.4525 Z E-J E$ \\
\hline CF 5 & 51 & $7.20031=-27$ & POI 05 & $4.255825-04$ \\
\hline & & $2.45861=-7$ & PJIJ6 & $2.7427 P E-14$ \\
\hline$s=7$ & 77 & $2.34317=-j 0$ & P01C7 & $1.22501 E-04$ \\
\hline sL 7 & 76 & $5.010207=-06$ & onlue & $7.74233 t-.35$ \\
\hline SF 7 & 79 & $1.455 d 6=-35$ & p)lle: & $2.639635-.15$ \\
\hline s. & Bu & $3.46955 E-J E$ & Arics & $4.22 Z 21 E-J 5$ \\
\hline SF $\varepsilon$ & $8 z$ & $7.03294 .5-5$ & AGI $1^{r}$ & $2.60 .4015-n 8$ \\
\hline$R P A$ & P5 & $7.31481 E-155$ & DOllo & $3.7366 \in-16$ \\
\hline RE $:$ & 97 & $1.79578 \equiv-v_{4}$ & C.0111 & $1.7 t<175-05$ \\
\hline Sk: & 86 & $2.6 .386 i-54$ & CNI 12 & $1.21651 t-75$ \\
\hline SP. & AC & $3.13389-15$ & $=0112$ & $8.32857 F-C 7$ \\
\hline SR 9 & 90 & $\equiv .74776=-04$ & 00114 & $1.58455 \mathrm{~F}-15$ \\
\hline & BC & $3.48578=-44$ & $50115 M$ & $2.686415-19$ \\
\hline ra & נפ & $c .75206=-j 8$ & Cग116 & $C .17 C A A E-0 E$ \\
\hline & 01 & t. $t \in 434=-i 4$ & jNil 16 & $6.516,7 E-17$ \\
\hline IR & 90 & $5.1514 i j=-.5$ & 3N1 17 & $\because 37478 E-36$ \\
\hline ZF & 91 & $4.09134:-04$ & SHI18 & $2.6(t)<F-0 t$ \\
\hline IF & 02 & $4.19038 z-1.4$ & SNI 19 & $3.5216<E-76$ \\
\hline$L P$ & 03 & $7.249325-.04$ & $3 N 120$ & $\Xi E \leq \geq \leq 3 F-0 t$ \\
\hline Ik & 94 & $4.66272=-04$ & $5 N 121 M$ & $1.46551 t-09$ \\
\hline & 05 & $7.68847 \div-13$ & 5N1 22 & 4.6829 SF -16 \\
\hline If & $q_{c}$ & $4.68026 c-04$ & $j N 1<3$ & $8.57(4) E-11$ \\
\hline & $\$ 5$ & R. $89325:-13$ & SN1 24 & $6.111712 \bar{r}-6$ \\
\hline & $95 M$ & $5.28151=-1 \epsilon$ & SN1 25 & $4.94 \equiv 2 \leq \varepsilon-64$ \\
\hline जe. & 95 & $5.09145=-04$ & jN1 26 & $1.41136 E-J 5$ \\
\hline me & 96. & $2.16006=-6$ & 58121 & $3.75571 \mathrm{E}-16$ \\
\hline & 97 & $4.86753:=-14$ & 59122 & 4.EO28 IE-Ut \\
\hline & 98 & $4.91314:-04$ & $591<4$ & $1.085775-17$ \\
\hline мत1. & & $5.748\} 8=-814$ & 59125 & $2.142735-36$ \\
\hline & & $1.66231:-02$ & $j B 126$ & c. $712915-14$ \\
\hline KLI & & $1.5 .895:-.4$ & $3 B 126 \mathrm{M}$ & $5.18 \cdot 195[-16$ \\
\hline+111 & & $1.44) 92=-12$ & T:122 & $1.55474 E-27$ \\
\hline aU10 & & $1.26205 c-52$ & $T \leqq 124$ & 7. $\angle 478 \leqq F-0 E$ \\
\hline DU1: & & $4.172 \cup 5 i-17$ & $T \equiv 125$ & $1.655126-35$ \\
\hline RU1 & & $0.23417 \vdots-03$ & 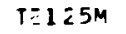 & $F .20 \geq t E:-J F$ \\
\hline$P(1)$ & & $5.11101:-45$ & 79126 & 7.1957 EE- $) 7$ \\
\hline $\mathrm{AHI}$ & & $1.33393:-04$ & $I=127$ & $2.443955-13$ \\
\hline$=+1$ & J3M & $9.036895-23$ & $T E 127^{M}$ & $6.5809<\varepsilon-11$ \\
\hline PHI & 26 & $4.78394 \vdots-11$ & $T 5128$ & $1.966345-14$ \\
\hline
\end{tabular}

\begin{tabular}{|c|c|}
\hline 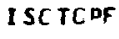 & \\
\hline $\begin{array}{l}\text { TE1 } 29 \\
\text { TF1 } 29 M\end{array}$ & $\begin{array}{l}7.82654 E-25 \\
8.46959 \div-22\end{array}$ \\
\hline 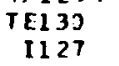 & $\begin{array}{l}7.119315-J 4 \\
8.15234 F-J 5\end{array}$ \\
\hline $\begin{array}{l}11<9 \\
1131\end{array}$ & $\begin{array}{l}3.41,422=-14 \\
4.874670-73\end{array}$ \\
\hline $\operatorname{cs133}$ & 4. $71463 i-32$ \\
\hline CS 134 & $2 . .22156=-$ \\
\hline$C 5135$ & $5.86465 t-3$ \\
\hline$c 51 \geq t$ & $1.56331<-4$ \\
\hline $\operatorname{css} 137$ & $4.16426 \%=$ \\
\hline PAI $\geq 4$ & $1.44997 L-J$ \\
\hline 90136 & 1. $51 \in 52=-8$ \\
\hline BAL $36 \mathrm{M}$ & \\
\hline BA137 & $7.7257 . J-3$ \\
\hline PA1 ?7M & $6.3452 x-$ \\
\hline BAl 38 & $5.09198 \div-J$ \\
\hline PA1 40 & 5. $87559--4$ \\
\hline LA130 & $1.137670-3$ \\
\hline$|A| 40$ & $2.06285 e-4$ \\
\hline CF.24 $4:$ & $1.12136=-?$ \\
\hline CF141 & $3-346 j \geqslant=-2$ \\
\hline$C=142$ & $1.05489<-3$ \\
\hline CEI44 & $8.2 \cdot 636=-i$ \\
\hline PP1 41 & $1.05132=-3$ \\
\hline$P R 143$ & $4.72394^{-}-4$ \\
\hline D\&l 44 & $3.462725-1$ \\
\hline PFI 44M & $1.73133 t-1$ \\
\hline$N \Gamma 142$ & 3.734055 \\
\hline 10143 & $1.2549 \times 6-$ \\
\hline ND $! 44$ & $1.07845=-1)$ \\
\hline NCl 45 & $E . C 37 R 7 E-:$ \\
\hline AD1 46 & $5.633 \geqslant 6 F-3$ \\
\hline$N 0147$ & $4.10571 E-5$ \\
\hline NO2 48 & $2.25682 \div$ \\
\hline ND 150 & $1.30493+-5$ \\
\hline $9 M 147$ & $6.9156 ? c-$ \\
\hline DM1 48 & $1.12282 E-$ \\
\hline PMI $48 N$ & $1.25211 \%$ \\
\hline $5 M 147$ & $2.22793^{c}-$ \\
\hline
\end{tabular}

\begin{tabular}{|c|c|}
\hline ISCTCPE & CNCENT \\
\hline $\begin{array}{l}S N 148 \\
S N 140\end{array}$ & $\begin{array}{l}4.53794 t-05 \\
1.92622 E-6.5\end{array}$ \\
\hline SMI Su & 2.7217 VE-C.4 \\
\hline SMI $5 i$ & $2.45551 E-U 5$ \\
\hline $\begin{array}{l}\operatorname{sm} 152 \\
\operatorname{sm} 1 a_{4}\end{array}$ & $\begin{array}{l}9.85978=-75 \\
1.75028 \bar{c}-05\end{array}$ \\
\hline $\begin{array}{l}\operatorname{sm} 154 \\
\operatorname{cts} 51\end{array}$ & $\begin{array}{l}1.75028 \bar{c}-05 \\
6.35689 \bar{s}-37\end{array}$ \\
\hline $\begin{array}{l}\text { EL151 } \\
\text { FL15? }\end{array}$ & $3.41649=-68$ \\
\hline FU153 & $3.36439 E-05$ \\
\hline FU154 & $3.761445+6$ \\
\hline FC155 & $1.6726 \pi-16$ \\
\hline FU1 56 & $1.55721 E-42$ \\
\hline 18159 & $5.42166=-J 7$ \\
\hline TAI GC & $2.63 .071 E-16$ \\
\hline$T L 208$ & $2.6824775-17$ \\
\hline 1232 & 3. $50 \leqslant 74 E-10$ \\
\hline U234 & $1.2044 \mathrm{BE}-\mathrm{CC}$ \\
\hline L.235 & $4.253 .26 .5-0$ \\
\hline U236 & 2. $\leqslant 2 \in 22 E-35$ \\
\hline U238 & $1.41040 \mathrm{t}-\mathrm{J}$ \\
\hline NP230 & $2.14331 \mathrm{~F}-12$ \\
\hline NP237 & $2.04587 E-05$ \\
\hline FU230 & $1.93578 E-1 J$ \\
\hline PL2 27 & $t .15545 \bar{E}-22$ \\
\hline FU238 & $7.15515 E-05$ \\
\hline FU239 & $1.966 .558-.4$ \\
\hline PU24:J & $\because 23 E 52 E-35$ \\
\hline PU2 41 & $1.35769 E-u$ \\
\hline$P L 242$ & $2.541965-r$ \\
\hline $\operatorname{AM} 241$ & $5.13625 E-66$ \\
\hline $\operatorname{An} 242$ & $2.87562 f-14$ \\
\hline$A M 242 M$ & $2.47 \leq 17 E-C$ \\
\hline $\operatorname{An} 243$ & $4.70564 E-08$ \\
\hline$C+242$ & $\begin{array}{l}1.72361 \subseteq-1 \\
1.75277:-1\end{array}$ \\
\hline & 1. $75277 E$ \\
\hline ( $\$ 244$ & $3.27954 F$ \\
\hline CM245 & $6.28>14 F-11$ \\
\hline CM246 & Z.R123zE-12 \\
\hline 1247 & $1.144685-14$ \\
\hline & \\
\hline
\end{tabular}


TABLE 2.4

ISOTOPIC CONTENT (g/gal) OF SUPERNATE FEED STREAM - 15 YEARS

\begin{tabular}{|c|c|c|c|c|}
\hline \multicolumn{2}{|c|}{ ISOTCFE } & CONCENTRATIOV & ISOTOFE & CONCEN TRA II CA \\
\hline & & $3.349715-58$ & QHIC3M & $1.3741 \leq E-47$ \\
\hline Ca & 51 & $2.02500 \varepsilon-66$ & RHIUG & $5.0128=-14$ \\
\hline $\mathrm{co}$ & su & $6.57651=-13$ & PD104 & $5.45252 \mathrm{~F}=05$ \\
\hline SE & 77 & $2.34317=-06$ & 00105 & $4.25 \leq 82 F-04$ \\
\hline SE & 78 & $5.902 \cup 7 i-06$ & PDIOE & $2.8058 F E-04$ \\
\hline $5 \varepsilon$ & 79 & $1.455700-65$ & PDIC7 & $1.32501 \mathrm{~F}-04$ \\
\hline SE & Bo & $3.46955:-0 j$ & PDLCE & 7.7423 EE- 0 S \\
\hline SF & 82 & $7 . C 1294 \div-.5$ & PחI 10 & $2.639635-75$ \\
\hline & A5 & 7. $31431=-65$ & +616 & $4.32231 \mathrm{~F}-? 5$ \\
\hline$R \mathbf{B}$ & 87 & $1.79578 \div-04$ & $4 G 110$ & $E .6854 \leq E-12$ \\
\hline SR & 88 & $2.6 .1386 E-14$ & CDI1 & $3.75665 E-56$ \\
\hline$S R$ & 95 & $2.74720 \tilde{E}-36$ & CDI11 & 1. $76417 \mathrm{~F}-05$ \\
\hline SR & 90 & $2.92849 \vec{*}-144$ & $\operatorname{Co1} 12$ & $1.21 \in 51 t-05$ \\
\hline & 89 & $3.485788-134$ & CD113 & $0.328575-07$ \\
\hline$r$ & 90 & $7.02023=-09$ & $\operatorname{col} 14$ & 1. CE 45 SE- 05 \\
\hline $\mathbf{Y}$ & 91 & $1.15019 \vdots-32$ & CO1 15N & $5.97 \equiv 11 F-44$ \\
\hline $2 \mathrm{k}$ & of & 1. $282,5 i-104$ & CD116 & $5.1708=E-j 6$ \\
\hline $2 \mathrm{~F}$ & 01 & $4.09184 \equiv-04$ & SN1 16 & t. $\leq 1 \in 0 \mathrm{IE}-0\}$ \\
\hline 20 & 92 & $4.19938:-64$ & SN117 & $3.37478 E-06$ \\
\hline $2 k$ & 93 & $7.29927 F-J 4$ & SN118 & $\equiv-E 2 \in C 4 E-0 E$ \\
\hline $2 R$ & 94 & $4.66272=-04$ & SN119 & $2.5216 \in E-06$ \\
\hline $2 \mathrm{k}$ & 05 & $1.25723 i-29$ & SNI $2 C$ & $3.65353 E-06$ \\
\hline $2 R$ & 96 & $4.6 B D 20 E-04$ & SN121M & $1.27516 \mathrm{E}-09$ \\
\hline NB & 95 & $1.45 ? 60=-29$ & SN1 22 & $4.508299 E-16$ \\
\hline NR & $95 \mathrm{M}$ & $8.79994 \bar{c}-3 ?$ & SNI 23 & $2.57020 E-19$ \\
\hline & 95 & $5.09149:-04$ & $5 N 124$ & $t .1171 \mathrm{aE}-0 \mathrm{t}$ \\
\hline MO & 96 & 2. $066665-16$ & $5 N 126$ & $1.41135 E-35$ \\
\hline$M C$ & 97 & 4.8673 3E-04 & 58121 & $3.7559(\bar{c}-06$ \\
\hline & & $4.91314 \equiv-04$ & SBI2Z & $4.80395 \bar{E}-06$ \\
\hline Mก 1 & & E. $348 \cup 8=-1,4$ & 38124 & $5.90894 E-36$ \\
\hline$T C$ & & $1.66226 i-32$ & SRIZS & $1 . t c 15$ CF -07 \\
\hline F L L 1 & & 1. $51895:-4$ & 58126 & $0.7128 \in E-14$ \\
\hline$R \| 1$ & & $1.44092 \div-. J 2$ & $3 A 126 \%$ & 5. $10192 F-16$ \\
\hline RUI & & $1.262 \times 5 \equiv-J 2$ & $T=122$ & 1. $5 E 47<E-07$ \\
\hline FUI & & t. $C 8953 \equiv-45$ & $T S 124$ & $7.24783 E-18$ \\
\hline RUI & & $6.23417 \vdots-03$ & $T \leqslant 125$ & $2.1546 \mathrm{CF}-05$ \\
\hline$R(1$ & & $5.345 J 4 \div-38$ & $T \equiv 125 \mathrm{M}$ & $6.4764 C F-09$ \\
\hline RHI & & $1.23353:-044$ & $T: 126$ & $7.198355-U 7$ \\
\hline
\end{tabular}

\begin{tabular}{|c|c|c|c|}
\hline I SOTOPE & COACEATRATICN & ISOTOPF & CCNCENT RATION \\
\hline IFI 27 & $1.99912 E-23$ & $S N 150$ & $2.72170 E-04$ \\
\hline TE127M & $5.71033 E-21$ & shis & $.27904 E-05$ \\
\hline$T E 1<8$ & $1.96634 \mathrm{~F}-044$ & SN $1 \leq 2$ & S. B5578E-05 \\
\hline TF 129 & $9.42 .354 F-58$ & SN154 & $1.75028 E-05$ \\
\hline TE129M & 1. $11945-54$ & $E(1 \leq 1$ & $1.72727 E-U 6$ \\
\hline TE1 30 & $7.11931 \mathrm{E}-04$ & EU152 & $2.003838-C 8$ \\
\hline 1127 & $0.15235 E-05$ & EU153 & $3.36439 E-05$ \\
\hline 1129 & $3.43421=-.34$ & El154 & $1.67 \subseteq 11 E-06$ \\
\hline $\operatorname{csi} 33$ & $4.71463 E-02$ & Eu155 & $3.94298 E-07$ \\
\hline$C S 1 \geq 4$ & $1.04453 E-05$ & TA1 59 & $5.42166 E-017$ \\
\hline $\operatorname{CS1} 35$ & $5.86463 z-03$ & $T B 160$ & $1.63081 \mathrm{LE}-31$ \\
\hline C 5137 & 3. $30772 E-J 2$ & TL208 & $5.73507 E-17$ \\
\hline$B A 1 \geq 4$ & $1.74157 E-13$ & $\lfloor 232$ & $5.16646 E-10$ \\
\hline EA1 36 & $1.51652 \mathrm{~F}-J 4$ & U234 & $1.2044 \&-06$ \\
\hline$B A 1 \equiv 7$ & 1.6291 OF -02 & U235 & 4.0530 OE- 05 \\
\hline$B A 1 \geq 7 M$ & $5.340) 7 E-09$ & 1236 & $2.92622 E-05$ \\
\hline BAI 38 & 5.0918 QE -02 & U238 & $1.4104 D E-03$ \\
\hline LA1 39 & $1.137675-03$ & PF236 & $2.14318 E-12$ \\
\hline CEL 40 & $1.121365-43$ & NP2 37 & $2.04586 E-C 5$ \\
\hline CE1 41 & $5.30388 E-55$ & FU236 & $1.69760 \mathrm{E}-11$ \\
\hline CE 142 & $1.05488 E-U 3$ & PU237 & $4.93512 E-46$ \\
\hline CE1 44 & 1.117.J8f-J9 & PU238 & 6.E1E39E-05 \\
\hline PR141 & 1. $05132 \mathrm{E}-\mathrm{J} 3$ & FU2 39 & $1.86551 E-04$ \\
\hline PR 144 & $4.71356=-14$ & PL240 & $3.20513 E-05$ \\
\hline$P R 144 M$ & $2.35073 \mathrm{~F}-16$ & PU241 & $8.47257 E-0 E$ \\
\hline ND 142 & 3. $73495 E-06$ & FU242 & $2.54194 E-06$ \\
\hline$N: 0143$ & $1.25493 c-J 3$ & $\triangle M 241$ & $1.01151 E-05$ \\
\hline NDI 44 & $1.08665 \mathrm{f}-33$ & $\operatorname{An} 242$ & $2.74742 E-14$ \\
\hline ND 145 & t. $\subset 3789=-v 4$ & AM242M & $2.29796 E+19$ \\
\hline ND1 46 & $5.63026 \mathrm{E}-34$ & AM243 & $4.7012 z E-C 8$ \\
\hline Nก 148 & $3.256825-04$ & $\cos 242$ & $5.5647 \mathrm{BE}-12$ \\
\hline NC1 50 & $1.30493 E-34$ & C 1243 & $1.37435 E-10$ \\
\hline FMI 47 & $4.92240 E-D 6$ & CN2.44 & $2.236598-C 9$ \\
\hline PMI 48 & $2.67771=-48$ & C.245 & $6.28201 E-11$ \\
\hline PMI $48 M$ & $2.986) 3 E-46$ & CM24t & 2. EC E2 OE-12 \\
\hline SM1 47 & $2.87026 \mathrm{~F}-04$ & C1247 & $1.14488 E-14$ \\
\hline $\operatorname{SM148}$ & $4.937945-15$ & $\cos 248$ & $2.61396 F-16$ \\
\hline $\operatorname{Sin} 40$ & $1.92622 F-35$ & & \\
\hline
\end{tabular}


TABLE 2.5

ISOTOPIC CONTENT (Ci/gal) OF SUPERNATE

5 YEARS

\begin{tabular}{|c|c|c|}
\hline & u & CONCENTF ITICN \\
\hline & 3 & $5.6 S P 75:-24$ \\
\hline$c^{\circ}$ & 51 & $6.62605=-22$ \\
\hline ro & 6:, & $2.78994:-14$ \\
\hline & 75 & $1.01533 E-36$ \\
\hline$\dot{F}$ & 87 & $1.57274 \div-11$ \\
\hline$S P$ & 95 & $8.85125-11$ \\
\hline$S R$ & $a_{J}$ & $5.33323=-32$ \\
\hline & 9 & $5.3 \times 461=-22$ \\
\hline & 91 & $1.633525-25$ \\
\hline 20 & 93 & $2.9586 \mathrm{~J}=-\mathrm{JS}_{0}$ \\
\hline & 55 & 1. $t 1495-8$ \\
\hline & 95 & $3.482 J 1 c-J 3$ \\
\hline & $95 \mathrm{~m}$ & $2.05058=-10$ \\
\hline & & $2.81817 \bar{c}-04$ \\
\hline FU1 & 33 & $1.334 .98 \div-12$ \\
\hline & $1: 6$ & $1.74437=-11$ \\
\hline $\begin{array}{l}\mathrm{r} H 1 \\
\mathrm{RH}\end{array}$ & & $\begin{array}{l}\overline{c . c} 12 j 3 i-12 \\
1.70457--111\end{array}$ \\
\hline$D D 1$ & & 6. $82159=-18$ \\
\hline$A C_{1}$ & & $4.45210 \vdots-105$ \\
\hline $\operatorname{CDI}$ & & $c .84483 \vdots-15$ \\
\hline & & $8, t 96 i 4 E-i, d$ \\
\hline
\end{tabular}

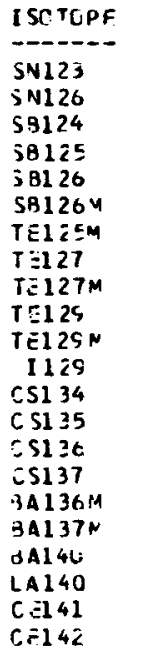

$7.0,5 E C E F-07$

CEI 44

ISCTEPE

CLNCENT RATION .01010F-0

1.9UNGSE-13

$1.24 E 4 E F-J 3$
$5.61413 E-29$

4.VIUICE-J 8

$1.47 E 64$ 드) 3

$6.45470 E-) 7$

$.5 F C 7 C E-J 7$

. $63 C B C E-17$

$.56464 F-17$
$541 \varepsilon \in F-0 \varepsilon$

?.9159 1E-11

$6.761645-06$

1. $15527 F-42$

3.61259610

3. $41751 F=0$

$4.47378-4$

$4.28737 E-41$

1236

3.17835F-40

PR144M $\quad 3.14175 \mathrm{E}-34$

ND144 $1.27666^{\prime \prime}=-15$

N0147 3.3688R=-50

PM147 $\quad 6.41564 \mathrm{E}-\mathrm{J2}$

1.84578:-16

PMI $48 M \quad 2.6763 .=-15$

$5.070 \cup 9 E-12$

$1.49283=-17$

$4.62734 \mathrm{~F}-18$

t. 2586$) 5-14$

$6.19836=-06$

1. $01653 i-03$

E. $546966^{\circ}-: 4$

$8.57935 ?-38$
$2.97083=-12$

$2.970 R 3=-12$

$7.89875=-J 4$

1.14E53E-42 U232 2324

$\begin{array}{lll}2.53263^{\circ}-11 & 0235 & 8.75922 t-11\end{array}$

U? 38

1.89 $277 F-C 9$

2. $823325-14$

$1.44182 \mathrm{E}-\mathrm{JB}$

. $43564 E-18$

$1.22526 \mathrm{E}-03$

$1.15564 E-05$

$7.29517 E-C 6$

$1.36979 E-03$

5. $70113 E-69$

$1.76289 \varepsilon-05$

$2.32537 E-38$

$2.33703 E-C E$

$9.39112 F-09$

. 7.3770E-CB

$9.0457 \mathrm{BF}-\mathrm{C} 9$

$2.65262 E-47$

.08222E-11

$.63840 E-13$

1. $10294 E-18$

TOTAL ACTIVITY $8.0000 \mathrm{ci} / g a l$ TOTAL HEAT GENERATION, watts/gal Primary 6.22-03 
TABLE 2.6

ISOTOPIC CONTENT (Ci/gal) OF SUPERNATE

FEED STREAM - 15 YEARS

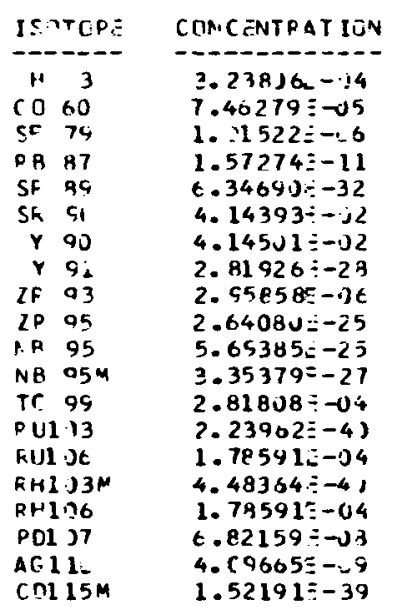

\begin{tabular}{|c|c|}
\hline DTUPE & CCNCENTFATIONI \\
\hline SN1 21N & $7.56572 E-7 E$ \\
\hline $\begin{array}{l}\text { SN123 } \\
\text { SN126 }\end{array}$ & $\begin{array}{l}2-11667 E-15 \\
2\end{array}$ \\
\hline $5 B 124$ & $1 . C=43 \mathrm{EE}-31$ \\
\hline 53125 & 1.7734 EE-04 \\
\hline 39126 & $5.614 / S E-09$ \\
\hline $581 \approx 6 \mathrm{M}$ & $4.01 \subset C 7 E-38$ \\
\hline TFI 25N & $1.16732 \varepsilon-J 4$ \\
\hline$T \equiv 127$ & 5. $2758 T E-17$ \\
\hline$T \equiv 1<7 M$ & $5.390 \geq E 5-17$ \\
\hline$T E 129$ & $1.963 \%$ EE - $5 r$ \\
\hline$i \equiv 129 \mathrm{M}$ & $\Xi . C \subseteq 17$ is $-5 C$ \\
\hline 1129 & $5.94186 E-08$ \\
\hline $\cos 34$ & $1.35371 F-U 2$ \\
\hline CS13E & $t .7 \in 1 \in 1 E-J E$ \\
\hline $\begin{array}{l}\text { CS137 } \\
34137 N\end{array}$ & $2.86552 E$ (i) \\
\hline & $2.71456 \mathrm{JU}$ \\
\hline $\begin{array}{l}C=141 \\
C \equiv 142\end{array}$ & $\begin{array}{l}1.51695-50 \\
2.53263 E-11\end{array}$ \\
\hline & $=$ EE $281 E-O E$ \\
\hline
\end{tabular}

PP144 $3.56394 F-36$

$\begin{array}{ll}\text { PR } 144 M & 4 . ? 7665=-J 8 \\ \text { NDI 44 } & 1.28632=-15\end{array}$

FM147 $4.56652 E-J 3$

PM148 4. 4CE18? $=-43$

FP1 48M $\quad 0.382435-42$

SML $47 \quad 0.53185 F-12$

SM148 $\quad 1.492835-17$

SMI $49 \quad 4.627345-18$

SMISI 5. 1088 J J -34

E1152 $\quad 3.62958 E-36$

U154 4.53783E-J4

EU155 1.89E91C-14

$1.84166 \%-27$

$T L 208 \quad 1.68874 E-08$

1.11721 $12-18$

U2 255

U236

$\begin{array}{ll}\text { U236 } & 1.89277 F-. J 9 \\ \text { U238 } & 4.74) 15 F-10\end{array}$ .74 $15 F-10$

ISCTCPE

NF236

A. 237

PU236

PU237

PU235

Pl241

PU242

AM 24

AM242M

AM243

CM24

Cस243

Cr 244

C.246

Cथ246

c) 248

TOTAL ACTIVITY 5.69 DO Ci/gal TOTAL HEAT GENERATION, watts/gal Primary $3.30-03$
CCACENT RAT ION $2.82 \equiv 15 E-14$ S. 0182 E -19 $5.95764 E-42$ 1.1322 JF -03 1. $15931<-05$ . $23746 E-06$ Q. 5 COO TE-04 . $70102 E-C S$ $3.47174 E-05$ (.22171E-Ca 2.2328 9.38229549 $7.09283 E-09$ 1. $9754 E-C 7$ $1.09133 E-11$ $8.62574 \bar{E}-13$

$8.62574 \bar{c}-13$ $1.761925-18$
$1.10894 E-18$ 
TABLE 2.7

ISOTOPIC CONTENT (g/gal) OF SLUDGE-SLURRY

FEED STREAM - 5 YEARS

\begin{tabular}{|c|c|c|c|c|c|c|c|}
\hline ISCTUPE & ECNCSNTHATIVN & ISC.TCPE & CCNCE NTPATICN & I SLTDFE & CONC ENTRATI UN & ISCTOPE & CCACEAT RATICN \\
\hline H 3 & $1.7 .346 t=-17$ & PDIC4 & 4. $\varepsilon \equiv 29 \leq 5-) 3$. & TF120 & $6.93722 F-23$ & $\sin 148$ & $1.22578 E-02$ \\
\hline CR 51 & $0.38187=-25$ & PD1J5 & $3.8112<(5-1) 2$ & TE129M & $7.50723-20$ & SMI 49 & $4.78161 \mathrm{~F}-\mathrm{W}$ \\
\hline $\cot \theta_{i}$ & S. $556355-25$ & pnijo & $2.43112 \varepsilon-32$ & TFI 30 & $6.31034 t-12$ & $5 N 1 \leq 0$ & $6.78112 E-n 2$ \\
\hline SE 77 & $2.07692=-04$ & PD107 & $1.1744 E E-32$ & 1127 & $7.225005-J 3$ & $\operatorname{sen} 51$ & $6.09551 E-03$ \\
\hline SF. $7 H$ & $5.23142=-04$ & PDI OP & $6.86257 \mathrm{E}-33$ & 1129 & $3.6174 \mathrm{JF}-12$ & $S N 1 \leq 2$ & $2.44757 \equiv-32$ \\
\hline SF 79 & $1.29 .543=-6.3$ & DDll & $2.33965 E-13$ & 1131 & $4.320775-71$ & $\sin 154$ & $4.2448 x-C 3$ \\
\hline SE Bu. & $2.07531=-03$ & $A G I C C$ & $\Xi .8 \supseteq 117 \mathrm{E}-03$ & C 5133 & $1.89362 \bar{c}-02$ & EUISI & $2.57273 F-04$ \\
\hline$S \bar{c} \quad 8 \bar{c}$ & 6. $2,919 \div-3$ & AGIIS & $1.777: 95-06$ & C5 134 & $1.21367 \bar{V}-14$ & $E L 1 \leq 2$ & 1.3827 UE - 05 \\
\hline RP 85 & C.76799:-J2 & Coldo & $? .3126 \in E-34$ & C 5135 & $2.355535-03$ & EU153 & $1.36162 E-02$ \\
\hline KR 87 & $6.79539 \bar{E}-\mathrm{J} 2$ & $=2111$ & $1.5 E \geq 71 \mathrm{E}-J \geq$ & $\operatorname{cs} 5136$ & $6.279025-48$ & FLI 54 & $1.52231 \varepsilon-03$ \\
\hline$S R \quad 86$ & 5.85327 & CDIiz & $1.07828 \mathrm{E}-03$ & CS137 & $1.67257 t-1) 2$ & EU155 & $t .7 E 556 E-04$ \\
\hline SR AS & $1.18589-12$ & $\operatorname{co113}$ & $7.38226-35$ & AAl 34 & $5.82338 \mathrm{~F}-\mathrm{J}_{4}$ & EथI 56 & $6.30229 E-40$ \\
\hline SR 9u & $1.418+9 \equiv-01$ & COL14 & $1.7590 .4 E-13$ & BA1 36 & t. r,s11 QE- - S & TB159 & $1.34586 E-74$ \\
\hline$Y 89$ & $1.210,5=-11$ & CD115M & $2.38115 E-17$ & BA1 36M & $5.50966 \bar{c}-55$ & TB160 & $6.5304 x-14$ \\
\hline Y 90 & $3 . t 9028 \equiv-05$ & CDIle & $8.12 E 7<E-04$ & BAL137 & $3.10302 \div-03$ & $T L 208$ & $2.37766 E-15$ \\
\hline$\forall q_{i}$ & $2.52135 \equiv-11$ & SNI 16 & $1.61754 E-14$ & BAI 274 & $2.54855-29$ & 1232 & $1.56071 \mathrm{E}-07$ \\
\hline 2090 & $2 .(14485=-.22$ & SNL17 & E. 3774 CE-04 & eAl 38 & $2.04515 r-32$ & 0234 & $4.87471 \mathrm{E}-04$ \\
\hline 2R 91 & $1.656 v j \equiv-31$ & SNL 18 & $9.00120 \mathrm{~F}-04$ & PAL 40 & $2.35092 E-46$ & U2 35 & $1.64031 E-02$ \\
\hline $2 R \quad 92$ & $1.69955-11$ & SNI $10^{\circ}$ & $8.7421 \cup E-J 4$ & LAL 39 & $2.82413 \bar{e}-11$ & U2 $3 t$ & $1.1842 \%-32$ \\
\hline $2 R 93$ & $2.95415:-01$ & $\sin 1<0$ & c. $c \in c 4 \leq[-34$ & $L A 140$ & $5.12079=-46$ & U238 & $5.70811 E-01$ \\
\hline $2 R \quad 94$ & 1. $.887 J 8=-3 i$ & SNI $21 \mathrm{M}$ & $3.64787 E-37$ & (E14) & $2.78364 E-11$ & NP236 & $8.67431 F-15$ \\
\hline $2 \mathrm{k} 95$ & $3.111645-1.3$ & SN1 22 & $1.01355 f-.33$ & CEI41 & 8. 3) $610 \div-19$ & NP 237 & P. $27994 E-03$ \\
\hline $209 t$ & $1.89417 t-01$ & SN125 & Z.12750E-JE & $C E 142$ & $2.61861 \mathrm{~F}-01$ & fu236 & $7.81415 E-08$ \\
\hline NB $\$ 5$ & $3.50518=-15$ & IN 24. & $1.5185 C E-13$ & CE144 & $2.03713 E-13$ & PL237 & $2.492825-19$ \\
\hline A. B $95 \mathrm{M}$ & $2.17798 \dot{c}-13$ & SN125 & $1.2271 \mathrm{CE}-61$ & PR1 41 & $2.639778-01$ & PU2 38 & 2.8974 IE -02 \\
\hline MO 95 & $1.52667=-01$ & 5N1 26 & $3.502536-03$ & PR 143 & $1.172660-42$ & FU2 39 & $7.55218 E-02$ \\
\hline mo ob & $7.82046 z-4$ & SAL 21 & 0.4223 SE -J 4 & PR144 & A. $59578 \bar{c}-1) 8$ & PU240 & $1.298545-02$ \\
\hline MO 97 & $1.84184=-01$ & SALE? & $1.1925 \mathrm{CE}-03$ & PRI 44M & $4.297815-10$ & FU241 & $5.49478 E-03$ \\
\hline & $1.85918=-31$ & SBl 24 & $2.69530 \mathrm{~F}-15$ & NO142 & S. $2715 \mathrm{rE}-14$ & PL242 & $1.02877 E-03$ \\
\hline Mnlos & c. $0 \geq 3775-41$ & SA125 & $5.319 J 8 F-34$ & $\mathrm{NO1} 43$ & $3.125235-111$ & $A M 241$ & $2.07872 x-03$ \\
\hline TC 96 & $1.02264 e-31$ & $5 B 1<6$ & $1 . t \in \in 40 F-11$ & NC 144 & $2.677125-31$ & A 1242 & $1.16381 E-11$ \\
\hline PU1U. & C. $28294 \Xi-14$ & $S B 126 \mathrm{~N}$ & $1.2665 C E-13$ & ND1 45 & $1.72225 \mathrm{~F}-t .1$ & AF $242 M$ & 9.7341 UE -67 \\
\hline F(II)i & P. $\varepsilon 6437=-62$ & $T=122$ & $1.378 C 7 E-05$ & NOI 46 & $1.39764=-31$ & AN 243 & $1.93445 E-05$ \\
\hline RUI JE & $7.76770 \equiv-02$ & $T \equiv 124$ & $t .4<4 ? t \mathrm{t}-0 t$ & NO1 47 & $1.034 J 9=-52$ & C.242 & $6.97572 E-1.9$ \\
\hline FUI 3 & $=5,546 \div-16$ & $T=125$ & $1.46734 \mathrm{~F}-13$ & $N C 148$ & $8.08465=-12$ & CM24三 & $7.093715-08$ \\
\hline fill 34 & $3-83520=-02$ & $T E 125 \mathrm{M}$ & $7.2714 \mathrm{EE}-06$ & No1 50 & $3.23934 r-32$ & $C+244$ & $1.32728 E-06$ \\
\hline$R \cup J$ & $3.13939=-14$ & $T \leq 126$ & $6.37 R U 7 E-J 5$ & PM147 & $1.716725-12$ & CM245 & $2.54450 \equiv-08$ \\
\hline PH123 & $8.23622=-4$ & $T \equiv 127$ & $2.16624 \mathrm{~F}-11$ & PMI 48 & $2.797275-19$ & CM246 & $1.13816-09$ \\
\hline FH1 O3M & $4.02577 \div-19$ & $T \equiv 127 \mathrm{M}$ & C.1876CE-0S & PMI 48M & $3.10821 E-17$ & $C \times 247$ & $4.63352 E-12$ \\
\hline RH1 16 & $2.04315 \vdots-1$, & $T \leq 128$ & $1.7429(E-12$ & $5 M 147$ & $5.5335 \pi-12$ & $C M=48$ & $1.05791 \equiv-13$ \\
\hline
\end{tabular}


TABLE 2.8

ISOTOPIC CONTENT (g/gal) OF SLUDGE-SLURRY

FEED STREAM - 15 YEARS

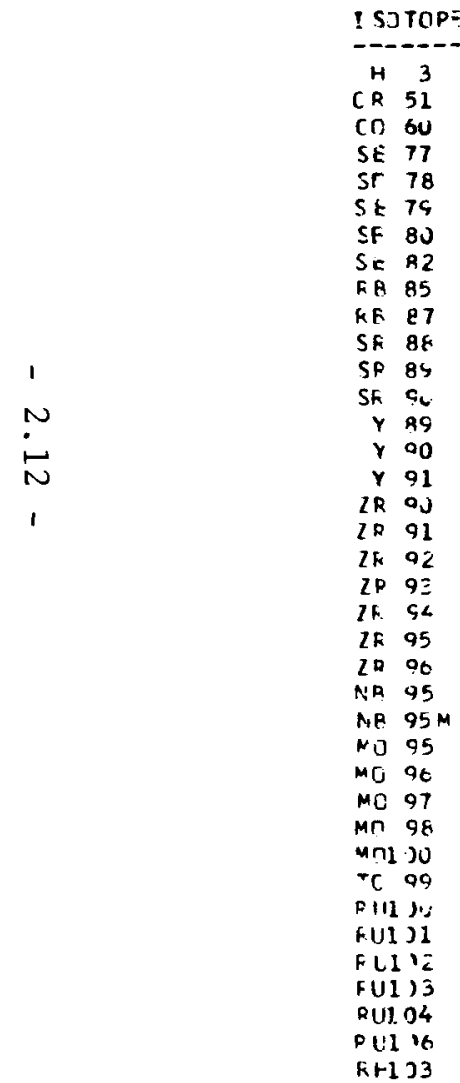

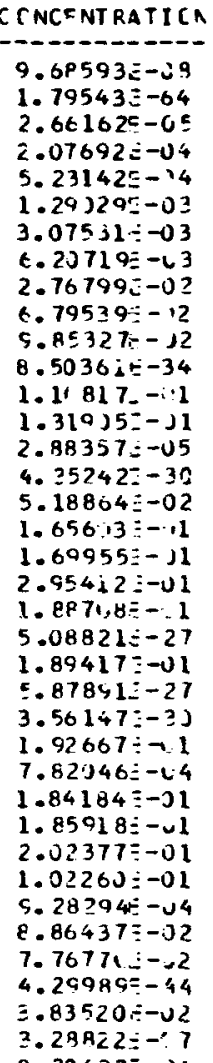

CCNCENTPATION RHIO3N PD104

PDI05

P0106

$P 0107$

PDI 0

D 011

$\triangle G I C S$

AGI li

Colli

Col1

$\mathrm{COI12}$

col13

CD115M

CO116

SNi17

SNI18

SNIIS

IN 120

SN1 $21 \mathrm{~N}$

SN122

SNI 23

SN126

5 SA12

5 S1 23

SB124

$5 R_{i} 25$

38126

SA126M

$T=122$

TE124

TH. $125 \mathrm{~N}$

TC126

.1744 EE-02

$6.8(257 E-J 3$

2.3396 (5-) 3

¿.8 $3117 F-03$

$7.70 .2 J 7 E-11$

2. 3257 fF-04

1.se $271 E-9$

$1.07828 E-J 3$

1.759.

5.

. $12 E 74 E-04$

$101754 E-34$

E. 3774 SE-04

C.00120E- 4

C. 7421 UE UU

c. $0 \in C 4 \mathrm{kF}-04$

3.1753EF-17

$1.01355 E-93$

T. $3802=E-17$

1.5185 UE-i

2. $5035 \mathrm{CE}-J 3$

- 4228 E $=04$

$1.19252 \mathrm{E}-03$

1. 4 ERR ZE- 33

$4.19 \div 17 E-35$

1.6663 CF-1

$1.3781178-145$

t. $4242(E-1) t$

$1.94=2=E-0 ?$

t. 3 BC4 1F-OS
ISOTOPF

TE 127

TE128

TE 129

TF.1 29M

TE 130

CONCENTRATION

$5.36147 E-19$

9. $3615=-53$

6. $31034 E-02$

1129

csi33

CS 134

CS1 35

BAI 36

BAL7

BA1 38

CE1 4 J

CE1 4.

CEI 42

CE144

PR 141

PF1 144

PR $144 \mathrm{M}$

ND142

$\mathrm{NOI}_{4}$

ND 144

NO1 45

ND146

ND 148

AD150

PM147

FM148

PMI 4R

SMI 147

SMI 49

0173 QE- $) 2$

1. $89362 \varepsilon-J 2$

$4.19536 \div-36$

$.35552 E-33$

1. $32854=-02$

$6.99501 E-J 4$

6. J91JAL-J5

2. $J 2434 F-J 9$

$04515 i-02$

$2.82413 E-J 1$

$2.78364=-J 1$
$1.316625-52$

$1.316625-52$
$2.61861 \mathrm{~F}-01$

2. $773 \cdot 1=-07$

$2.63977=-01$

$1.17 n 08=-11$

5. $85031=-14$

S. $27157 \bar{c}-14$

$3.11523 \varepsilon-J 1$

2. $55749=-J 1$

$1.72225 F-J 1$

1. $39764 E-J 1$

c. $38465 \mathrm{C}-J 2$

?. $239345,-1) 2$

1. $22193 E-J 3$

C. $647995-46$

$7.41247 E-44$

$7.125092-02$

1.225785-12
I SO TOPE

$\sin 150$

S1:

EUI

FL153

CM247
CNCE NT RA TI CA

$6.78112 E-02$

.EST43E-O3

. $34485 F-03$

$6.59 C 52 E-94$

$.109825-06$

$1.36162 \varepsilon-32$

t.79564E-04

$1.595785-04$

$1.34586 E-64$

4.0483 JF -29

$5.0834 J E-15$

2.CकC

$4.87457 E-04$

$1.64731=-32$

$1.1842 t-02$

$673785-10$

Q. $27592 E-03$

Q. $27592 E-J 3$

1. $\subseteq \backslash 732 \varepsilon-43$

$2.67735 \mathrm{E}-02$

7. 55 ju jé -02

$1.25717 E-32$

$3.42898 E-03$

1.C2876E-03

$4.09371 E-03$

.111925-11

9. $30018 E-67$

$1.90265 E-05$

$2.25215 E-09$

$5.56221=-08$

$9.05181 \mathrm{c}-\mathrm{J} 7$

$2.54242 E-C 8$

1.63552E-12

4.63 
TABLE 2.9

ISOTOPIC CONTENT (Ci/gal) OF SLUDGE-SLURRY

\begin{tabular}{|c|c|c|c|c|c|c|}
\hline & ZCNCENTRATICN & ISUTDFE & CCNCENTRATION & ISUTNDE & CCNCENTRE TION \\
\hline \multicolumn{2}{|c|}{$H^{3}$} & $1.64784 \bar{\varepsilon}-03$ & SN1:Z & 1. IE $\angle(E E-) 4$ & CEE144 & E.49907E JO \\
\hline \multirow{4}{*}{\multicolumn{2}{|c|}{$\begin{array}{ll}C R & 51 \\
C N & B U \\
\text { SE } & 7 C \\
R P & 87\end{array}$}} & $5.87312 \equiv-21$ & SN] 26 & $9.954585-16$ & PEI 43 & $7.88989 F-38$ \\
\hline & & $1.12913=-11$ & 38124 & $4.7182 \equiv E-11$ & PRI 44 & $6.4993)=00$ \\
\hline & & $8.09955 E-05$ & \$B125 & $5.57657 E-J 1$ & PRI 44M & 7. $79902 E-02$ \\
\hline & & 5. $551398-9$ & SB126 & $1.39364 F-16$ & $\mathrm{NrI} 44$ & $3.169) 2=-13$ \\
\hline \multirow{4}{*}{$\begin{array}{l}S F \\
S F \\
Y \\
Y\end{array}$} & ค9 & $3.34940 E-J 8$ & $59126 M$ & C. SE 45 SE-JE & NDI 47 & $8.36285=-48$ \\
\hline & su & $2.00679: 01$ & $T=125 \mathrm{~N}$ & $1.31062 E-01$ & PMI 47 & 1. 592005 11 \\
\hline & at & $2.04732=j 1$ & $T E 127$ & $5.72125 \mathrm{E}-\cup 5$ & DMi 48 & $4.58192 \mathrm{~F}-14$ \\
\hline & 91 & $6.18139 \div-07$ & TE127M & E.EACSCF-J) & PMI $48 M$ & $6.64359 \mathrm{E}-13$ \\
\hline & 93 & $1.10739=-13$ & $T=129$ & $1.44557 E-15$ & $\operatorname{Sin} 147$ & $1.25859 F-05$ \\
\hline & 95 & $6.53594:-6 t$ & $T=129 M$ & 2.2767 GE -15 & $\operatorname{SMI} 48$ & $3.735775-15$ \\
\hline & 95 & $1.40922 E-155$ & 1129 & $5.26 E 6$ SE-JE & SMI 49 & $1.1486 B E-15$ \\
\hline \multirow{2}{*}{\multicolumn{2}{|c|}{$\begin{array}{l}\text { NA } 95 \\
\text { TC OG }\end{array}$}} & P. 3$) 062=-88$ & $5 \$ 134$ & $1.57282 \varepsilon-11$ & SM151 & $1.55362 \mathrm{~F}-01$ \\
\hline & & $1.73371 \equiv-03$ & $C S I \equiv S$ & $2.71 \leq 8 C 5-0 t$ & EUI5? & $2.50452 \varepsilon-33$ \\
\hline \multirow{4}{*}{\multicolumn{2}{|c|}{$\begin{array}{l}R(1103 \\
Q \cup 1) 6 \\
\text { PHI J3M }\end{array}$}} & $8.02813=-12$ & $C \$ 136$ & $4 . t 4052 F-43$ & EU154 & $4.114075-11$ \\
\hline & & $1,048515 \mathrm{JJ}$ & $C 5237$ & 1.4509 SFDD & Ell155 & $3.25673 \mathrm{~F}-.11$ \\
\hline & & $1.60720 c-11$ & $B A 1 \equiv 6 M$ & $1.4 E 4 C E F-43$ & $E \cup 156$ & $3.472 \geq 0=-35$ \\
\hline & & $1 .(4851 \equiv 0)$ & Q A1 $37 \mathrm{M}$ & $1.37264 E$ tU & TB1E & $7.37473 F-10$ \\
\hline \multicolumn{2}{|c|}{$\begin{array}{l}\text { RHI bo } \\
\text { Print }\end{array}$} & t. $14646=-36$ & tA1 4C & $1.72201 E-41$ & $T L 2 J 8$ & $7.00123 r-07$ \\
\hline \multirow{2}{*}{\multicolumn{2}{|c|}{$\begin{array}{l}A G 110 \\
C 01113 M\end{array}$}} & $8.37811 \bar{E}-03$ & $L 1140$ & $z .8511 \mathrm{CE}-40$ & U2 32 & 3. $396785-06$ \\
\hline & & $6.167+5 \equiv-13$ & $C E 141$ & $2.36012 F-14$ & U2 34 & $\begin{array}{l}3.04427 E-\cup 6 \\
3.54499 E-38\end{array}$ \\
\hline \multirow[t]{4}{*}{ SNI } & $121 M$ & $2.15871 \Xi-05$ & ZE & t. $2 E \in S 4 E-3 C$ & U235 & $3.54499 E-38$ \\
\hline & & & & ITY $7.70 \quad 01 \mathrm{ci} /$ & & ENERATION, watts/gal \\
\hline & & & & & Primary & $2.21-01$ \\
\hline & & & & & Gamma & $1.62-02$ \\
\hline
\end{tabular}

\begin{tabular}{|c|c|}
\hline TOPE & COACEATRATIOA \\
\hline 236 & $7.66034 E-37$ \\
\hline 238 & $1.51841 \equiv-C 7$ \\
\hline 236 & $1.14264 E-11$ \\
\hline A 9237 & $5.83525 \mathrm{E}-\mathrm{j} 6$ \\
\hline$P \cup Z \geq 6$ & $4.1511 \pi-0 S$ \\
\hline FU237 & $3.00922 E-15$ \\
\hline PU238 & $4.95881 E-01$ \\
\hline pu239 & $4.69 \geq 24=-03$ \\
\hline FU240 & $2-95247 F-03$ \\
\hline$(241$ & $5,54374 \mathrm{E}-01$ \\
\hline P11242 & $3.92620 E-06$ \\
\hline 10241 & $7.13468 E-03$ \\
\hline $\operatorname{AM} 242$ & $5.411114 E-C 6$ \\
\hline $\operatorname{AM2} 42 M$ & $9.45832 E-06$ \\
\hline$\triangle M 243$ & 3.80073E-06 \\
\hline cm 242 & $2.30999 E-05$ \\
\hline$C+243$ & $3.66097 \mathrm{E}-06$ \\
\hline$=244$ & $1.07355 E-64$ \\
\hline$=245$ & $4.3759 \mathrm{JE}-\mathrm{C} 9$ \\
\hline & $3.49609 E-10$ \\
\hline $\operatorname{cm} 247$ & $4.2977 \pi-16$ \\
\hline$C * 248$ & $4.48806 E-16$ \\
\hline
\end{tabular}


TABLE 2.10 ISOTOPIC CONTENT (Ci/gal) OF SLUDGE-SLURAY

\begin{tabular}{|c|c|c|c|c|c|}
\hline ISOTCPE: & CONCENTRATIJN & I SO TUFE & RCNCENTKA II CN & I SC:TCPF & CCACENTRATION \\
\hline H 3 & 5. $363 \cup 5=-14$ & SN1 21N & 1.ETSJSE-UE & PR1 44 & $8.84705=-04$ \\
\hline $\cos 60^{\circ}$ & $3.02031 \equiv-J 2$ & 5N123 & $5.25437 E-1 \geq$ & PR1 44M & $1.06163 E-05$ \\
\hline SE TS & e. $\$ \$ 859 \mathrm{~g}-.5$ & $5 N 126$ & $9.95450 E-16$ & NO1 44 & $3.19313 E-13$ \\
\hline R B 87 & $5.95139=-09$ & $5 B 124$ & 2. $5 E T 7 \geq E-2 S$ & FM1 47 & $1.13358 \mathrm{~F} \mathrm{JO}$ \\
\hline SP 89 & $2.40173 \therefore-29$ & 58125 & $4.402445-02$ & PM148 & 1. บ927าE-4n \\
\hline SR Si & $1.5681 \mathrm{j}=31$ & SA1 26 & $1.39363 E-06$ & PMI 48 N & $1.584368-39$ \\
\hline$Y 90$ & $1.56851 \mathrm{J1}$ & SB1ÉW & C. SE $45 Z E-0 t$ & $\operatorname{SM1} 14$ & $1.62146 E-09$ \\
\hline$\times 91$ & $1.9 .6684 \because-25$ & $T=25 \mathrm{~N}$ & $1.03468 F-J 2$ & $\sin 148$ & $3.7657 \pi-15$ \\
\hline 2003 & $1.19738=-1,3$ & $T=127$ & $4.67993 E-15$ & SMI 49 & $1.1486 A C-15$ \\
\hline 2995 & $1.06377 \div-22$ & $T E 127 M$ & $4.777 E$ TE- 15 & SM1 $\leqslant 1$ & $1.44196=-01$ \\
\hline NR 95 & $2.36439 E-2 ?$ & Tr129 & $1.73998 E-48$ & EU152 & $1.46895 \varepsilon-J 3$ \\
\hline NR OE,M & $1.35733=-24$ & $T \leq 129 M$ & 2. $74 C 4 C E-48$ & E.U1 54 & $1.83653 F-J 1$ \\
\hline TC 95 & $1.73306=-03$ & $I 1<9$ & $5.2 t \in E$ SF -06 & EUI55 & $7.67706 E-32$ \\
\hline RU1 & 1. $2778 v E-35$ & C 5134 & $5.43714 E-03$ & TAleJ & $4.57169 E-25$ \\
\hline FUI Jo & 1. $M 9867 E-01$ & $\operatorname{cs} 135$ & $2.71 \leq 755-0 t$ & TL208 & $1.49685^{2}-36$ \\
\hline FH $103 \mathrm{M}$ & $2.7583 u=-37$ & $\operatorname{css} 37$ & $1.15254 E 00$ & $42 \geq 2$ & $4.45323 F-.16$ \\
\hline RHIIO6 & 1. $09807 E-4]$ & SA137M & $1.0503 C F$ OD & U2 34 & $3.34418=-06$ \\
\hline Dח107 & $6.04645 \mathrm{E}-06$ & $c \equiv 141$ & $2.75061 F-48$ & U255 & $3.544998-J 8$ \\
\hline AGIl L & $3.631166-17$ & $C E 14 \overline{2}$ & $6.28694 F-j 9$ & U236 & $7.660342-07$ \\
\hline $\operatorname{co1} 154$ & $1.348+8 \equiv-37$ & $c \equiv 144$ & E. EAETAE-04 & 4238 & $1.919415-37$ \\
\hline & & & Tr $3.6101 \mathrm{ci} /$ & & IATION, watts/gal \\
\hline & & & & & $\begin{array}{l}1.23-01 \\
5.88-03\end{array}$ \\
\hline
\end{tabular}

\begin{tabular}{|c|c|}
\hline ISCTOPF & CCACEAT RATION \\
\hline AF236 & $1.14257 E-11$ \\
\hline AF237 & $5.83523 F-06$ \\
\hline PUEZE & $3 .+4 C 84 E-C 6$ \\
\hline FU237 & $2.41115 E-39$ \\
\hline PU238 & $4.58217^{5}-01$ \\
\hline PU239 & 4.t5189E-03 \\
\hline FU240 & $2.94935 E-03$ \\
\hline$P(24)$ & $3.45953 \mathrm{E}-\mathrm{Cl}$ \\
\hline FU242 & $3.92615 E-06$ \\
\hline A.241 & $1.475) 75-02$ \\
\hline $\operatorname{AM} 242$ & $8.55159-06$ \\
\hline $0 \times 242 m$ & $9.03668 \varepsilon-06$ \\
\hline $\cos 243$ & $3.79716 \equiv-06$ \\
\hline CM242 & $7.45794 E-0 E$ \\
\hline$C+243$ & $2.87058 E-06$ \\
\hline CM244 & $7 . \equiv 2145 E-05$ \\
\hline CY245 & $4.37632 E-C 9$ \\
\hline$C+246$ & $3.49097 E-10$ \\
\hline CM247 & $4.2577 \pi-16$ \\
\hline & \\
\hline
\end{tabular}


TABLE 2.11

Percent of Radionuclides in Gravity-Settled In-Tank S1udge ${ }^{a}$

\begin{tabular}{lll} 
Group Ident. & Radionuclides & $\%$ \\
\hline I & Cs-Ba & 6.8 \\
II & Tc, Ru-Rh & 52.8 \\
III & $\begin{array}{l}\mathrm{Ag}, \mathrm{Cd}, \mathrm{I}, \mathrm{Cr}, \mathrm{Se}, \\
\text { Pd, Te, TI }\end{array}$ & 94.2 \\
IV & $\begin{array}{l}\mathrm{La}, \mathrm{Ce}-\mathrm{Pr}, \mathrm{Pm}, \mathrm{Nd} ; \\
\text { Sm, } \mathrm{Sn}-\mathrm{Sb}, \mathrm{Tb}\end{array}$ & 97.8 \\
V & $\mathrm{Sr}-\mathrm{Y}, \mathrm{Rb}, \mathrm{Mo}$ & 98.6 \\
VI & $\begin{array}{l}\mathrm{U}, \mathrm{Pu}, \mathrm{Am}, \mathrm{Cm}, \mathrm{Np}, \\
\mathrm{Co}, \mathrm{Zr}-\mathrm{Nb}, \mathrm{Eu}\end{array}$
\end{tabular}

a. See Appendix 13.9.

TABLE 2.12

Representative Elemental Composition of SRP Reference Sludge

\begin{tabular}{|c|c|c|c|}
\hline Element & Wt \% & Element & Wt \% \\
\hline $\mathrm{Fe}$ & 20.1 & $\mathrm{Na}$ & 2.50 \\
\hline $\mathrm{A} 1$ & 11.9 & Si & 0.26 \\
\hline Mn & $4.79^{a}$ & $\mathrm{NO}_{3}^{-}$ & 0.83 \\
\hline $\mathrm{U}$ & 2.28 & $\mathrm{SO}_{4}{ }^{2-}$ & 0.42 \\
\hline $\mathrm{Ca}$ & 1.53 & $\mathrm{Cl}$ & 0.75 \\
\hline $\mathrm{Ni}$ & 2.80 & F & 0.058 \\
\hline $\mathrm{Hg}$ & 1.13 & C & 1.31 \\
\hline
\end{tabular}

a. Includes the manganese used during digestion of the sodium oxalate generated during tank cleaning. 
TABLE 2.13

Viscosity of SRP Sludge

Condition

Sample from Tank 12H Settling Tests

Sample from Tank 12H, Centrifuged and Mixed with Equal Volume Supernate 4

Sample from Bottom of Tank 14H, Centrifuged and Mixed with Equal Volume Supernate 5 n, cp Temp, ${ }^{\circ} \mathrm{C}$

$10 \quad 25$

$70 \quad 25$

15

TABLE 2.14

Concentration of Major Chemical Components in Reference SRP Supernate

Component Molarity

$\mathrm{NaOH} \quad 0.75$

$\mathrm{NaNO}_{3} \quad 2.2$

$\mathrm{NaNO}_{2} \quad 1.1$

$\mathrm{NaAlO}_{2} \quad 0.5$

$\mathrm{Na}_{2} \mathrm{CO}_{3} \quad 0.3$

$\mathrm{NaSO}_{4} \quad 0.3$ 


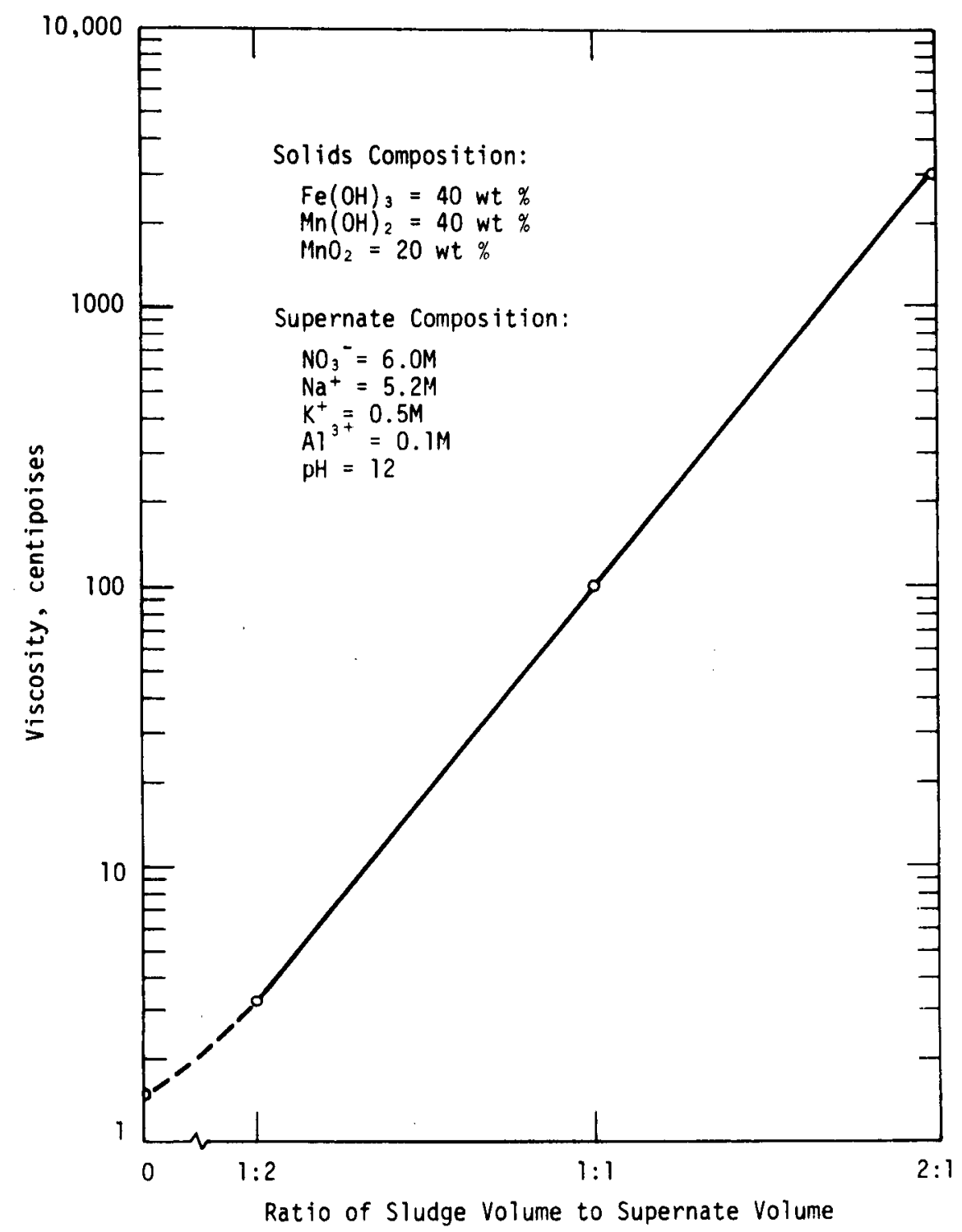

FIGURE 2.1. Effect of Sludge Concentration on Viscosity of Sludge Suspensions 


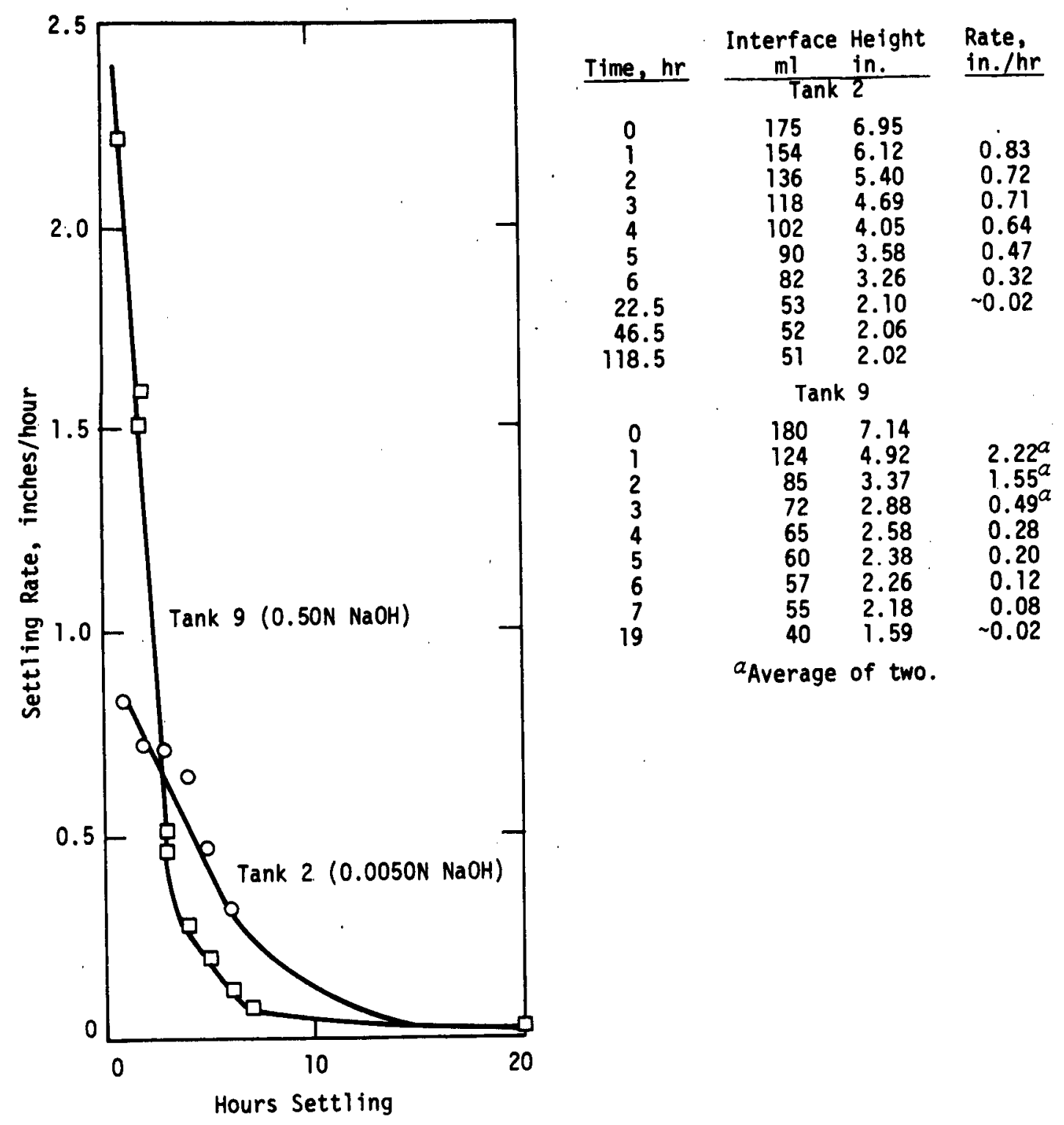

FIGURE 2.2. SRP Sludge Settling Rates 


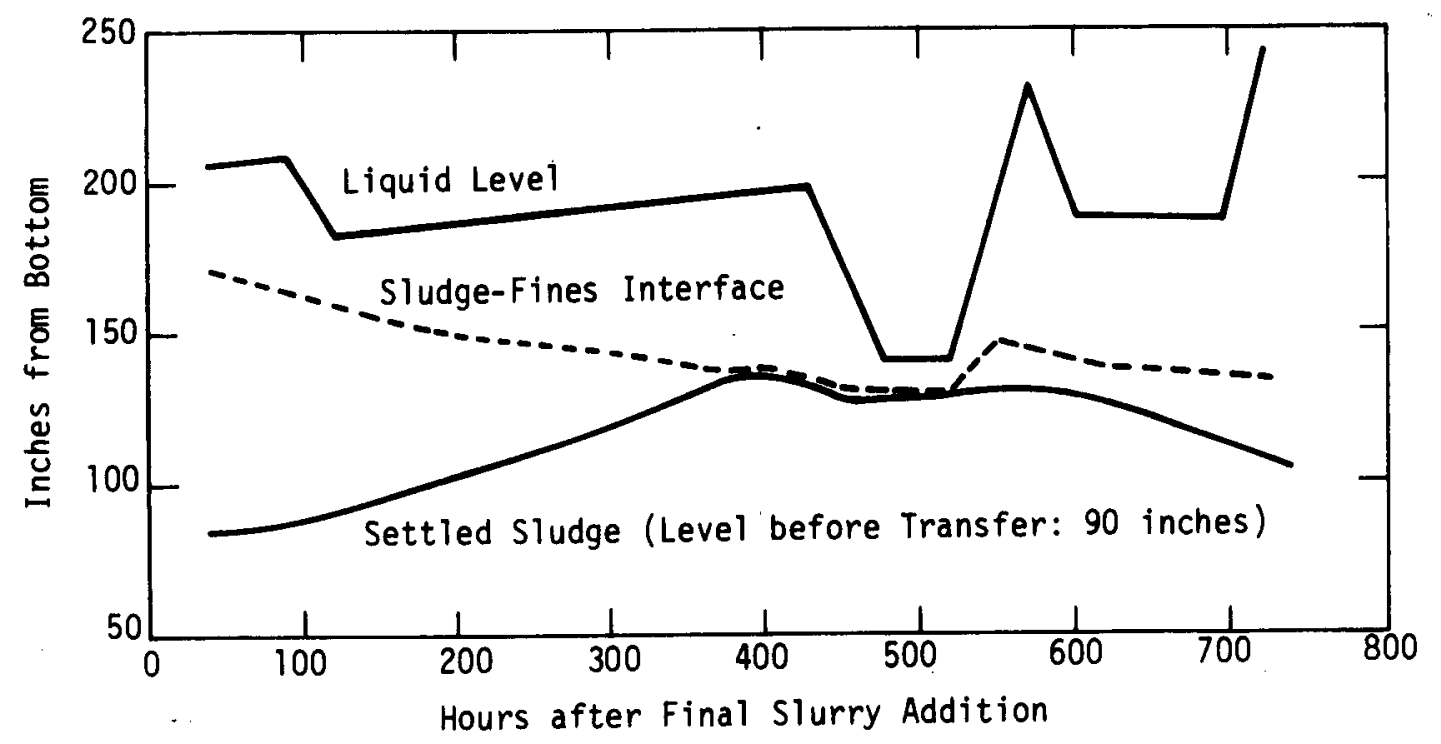

FIGURE 2.3. Sludge Settling in Waste Tank No. 13 


\subsection{References}

1. SRP Radioactive Waste Sludge. Memorandum, H. M. Kelley to J. A. Porter. Internal Report DPST-73-222, E. I. du Pont de Nemours \& Co. (Inc.), Savannah River Laboratory, Aiken, SC (January 1973).

2. R. M. Wallace, H. L. Hull, and R. F. Bradley. Solid Forms for Savannah River High-Level Wastes. USERDA Report DP-1335, E. I. du Pont de Nemours \& Co. (Inc.), Savannah River Laboratory, Aiken, SC (December 1973).

3. J. A. Stone. Detailed Analyses of SRP High-Level Waste Sludges. Internal Report DPST-76-425, E. I. du Pont de Nemours \& Co. (Inc.), Savannah River Laboratory, Aiken, SC (February 1961).

4. Examination of Solids from Tank 12H. Memorandum M. D. Snyder to V. P. Thayer. Internal Report DPST-61-186, E. I. du Pont de Nemours \& Co. (Inc.), Savannah River Laboratory, Aiken, SC (February 1961).

5. M. D. Snyder. Examination of Solids from Waste. Internal

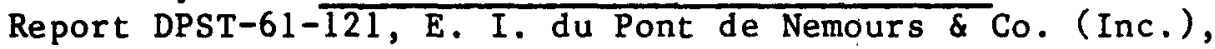
Savannah River Laboratory, Aiken, SC (January 1961).

6. R. S. Ondrejcin. Chemical Compositions of Supernate Stored in SRP High Level Waste Tanks. USERDA Report DP-1347, E. I. du Pont de Nemours \& Co. (Inc.), Savannah River Laboratory, Aiken, SC (August 1974).

7. J. R. Wiley and R. M. Wallace. Removal of Cesium from Savannah River Plant Waste Supernate. USERDA Report DP-1388, E. I. du Pont de Nemours \& Co. (Inc.), Savannah River Laboratory, Aiken, SC (July 1975). 
3. PRODUCT DESCRIPTION

3.1 Glass 3.1

3.1.1 Composit ion and General Properties 3.1

3.1.1.1 Chemical Composition 3.1

3.1.1.2 Radionuclide Composition 3.1

3.1.1.3 Physical Properties 3.1

3.1.1.3.1 solidified Glass 3.1

3.1.1.3.2 Models of Physical Properties of SRP Waste Glass 3.2

3.1 .1 .4 Microstructure 3.3

3.1.2 Thermal stability 3.4

$3.1 .2,1$ Devitrification 3.4

3.1.2.2 Thermal Shock 3.5

3.1.3 Leachability 3.5 3.1.3.1 Leachability of Glas Containing Simulated

3.1.3.2 Leachability of Glass Containing Actual siudge 3.7

3.1.4 Sulfate Phase Separation 3.7

3.1 .5 Radiation Stability 3.7

3.1.6 Canister Specifications 3.8

3.1.6.1 Reference Requirements 3.8

3.16 .2 Canister 3.9

3.1.6.3 Materials of Construction Compatibility 3.10 
3.1.7 Heat Generation Rate and Temperature Profile 3.10 3.1.7.1 Heat Generation Rate 3.10 3.1.7.2 Temperature Profile 3.10 3.1.8 Regulatory Aspects of Solidified Glass, 3.11

3.2 Saltcrete 3.12

3.2.1 Composition and General Properties of Saltcrete 3.12 3.2.1.1 General 3.12

3.2.1.2 Chemical Properties 3.12

3.2.1.3 Residual Radioactivity 3.12

3.2.2 Radiation Stability 3.12

3.3 References 3.38 


\section{PRODUCT DESCRIPTION}

\subsection{Glass}

The purpose of this section is to describe the composition and properties of SRP high level waste glass. As currently planned, the waste glass product will be produced by melting composite dried sludge and glass frit in a Joule-heated ceramic melter. The molten glass will be poured into a $2 \times 10 \mathrm{ft}$ canister. This section addresses only the properties of the vitrified product and not those of the entire package. The subjects discussed herein are glass composition and general properties, sulfate phase separation, thermal stability, leachability, and radiation stability.

\subsubsection{Composition and General Properties}

\subsubsection{Chemical Composition (M. J. Plodinec)}

Table 3.1 lists the major components in the glass waste form based on a composite feed. The composition of the reference glass frit, Frit 131, is listed in Table 3.2.

\subsubsection{Radionuclide Composition (J. R. Chandler)}

The isotopic content and total heat generation rate for the reference waste glass are tabulated in Tables 3.3 and 3.4 . The effect of storage period is shown in Figures 3.1 and 3.2 . Based on 3260 lbs of waste glass per reference canister, the total activity and heat generation per canister are $1.84 \times 10^{5} \mathrm{Ci}$ and 541 watts for 5-year aged waste and $1.04 \times 10^{5} \mathrm{Ci}$ and 310 watts for 15-year aged waste.

\subsubsection{Physical Properties (M. J. Plodinec)}

\subsection{Solidified Glass}

Several important physical properties of the solid glass waste form are compiled in Table 3.5. For most of these, no experimental value has been determined for glasses containing SRP waste. Thus, reasonable values for similar systems reported in the literature have been included. Mechanical properties of glass have been reviewed in Reference 2 . 


\subsection{Models of Physical Properties of SRP waste Glassa}

Models were developed to enable prediction of the thermal conductivity, specific heat, density, coefficient of expansion, refractive index, and viscosity of SRP waste glass as functions temperature. Physical properties for the reference glass product of containing composite sludge are summarized in this section. Details of the development of these models are summarized in Appendix 13.5 .

\section{Thermal Conductivity}

The calculated effective thermal conductivity, as a function of temperature, is shown in Table 3.6 .

\section{Heat Capacity}

Table 3.7 summarizes the calculated mean and true heat capacity of glass containing calcined composite sludge as a function of temperature.

\section{Density}

The calculated density of glass containing calcined composite sludge as a function of temperature is summarized in Table 3.8. The strain point temperature is defined as the temperature at which the viscosity of glass is about $3.2 \times 10^{8}$ poises.

\section{Coefficient of Expansion}

The coefficient of expansion $\left(\beta_{\mathfrak{m}}\right)$ calculated for composite glass containing $27.5 \mathrm{wt} \%$ sludge at $20^{\circ} \mathrm{C}$ to $90^{\circ} \mathrm{C}$ is $2.54 \times 10^{-5} 1 /{ }^{\circ} \mathrm{C}$. The coefficient of expansion increases slowly and is nearly constant from $25^{\circ} \mathrm{C}$ to just below the strain point temperature $\left(596^{\circ} \mathrm{C}\right)$. A rapid and large increase in the coefficient occurs, starting just below the strain point temperature. The calculated mean cubic expansion coefficient from above the strain point temperature to the melting temperature is $7.62 \times 10^{-5} 11^{\circ} \mathrm{C}$.

a. Data reported in this section and in Tables $3.6,3.7,3.8$, and 3.9 were calculated based on Frit 21 . Physical properties will be recalculated using the revised waste glass composition containing Frit 131 . 


\section{Refractive Index}

The refractive index ( $n_{D}$ ) calculated for composite glass containing 27.5 wt \% sludge with Frit No. 21 is 1.585 at $25^{\circ} \mathrm{C}$. Changes in the refractive index of glass caused by temperature, are small up to the annealing point (temperature at which the viscosity is about $10^{13}$ poises) of the glass.

\section{Viscosity}

The viscosity $(n)$ calculated for composite glass containing 25 wt \% sludge in Frit No. 21 is tabulated in Table 3.9 over a temperature range of $850^{\circ} \mathrm{C}$ to $1225^{\circ} \mathrm{C}$.

\subsubsection{Microstructure (M. J. Plodinec)}

The vitrified product will contain several phases. The amount of each phase will vary with sludge type, but all will probably be present to some extent.

- The glassy phase is the most important and present by far in the largest amount. This phase acts as the host matrix for the other phases and will determine most of the properties of the final waste form.

- Often nepheline ( $\mathrm{NaAlSiO}_{4}$ ) or other alkali aluminosilicate phases will be present, especially for sludges high in aluminum. These phases result from devitrification of glasses and are easily formed. This may reduce the impact strength of the glass and make it more leachable.

- Also present will be insoluble metal oxides of the formula $\mathrm{MN}_{2} \mathrm{O}_{4}$ where $\mathrm{M}$ is a bivalent cation (such as $\mathrm{Fe}^{2+}, \mathrm{Mn}^{2+}, \mathrm{Ni}^{2+}$ ) and $\mathrm{N}$ is a trivalent one (such as $\mathrm{Fe}^{3+}, \mathrm{Mn}^{3+}$ ). These materials, called spinels, are of limited solubility in the glassy phase and will probably concentrate toward the bottom of the canister $[5,6]$. Spinels are usually less leachable than the glassy phase, but can cause the glass to crack if subjected to severe thermal gradients. As the aluminum content of the sludge increases the amount of spinel crystals decreases.

- One other phase may be present as well. $\mathrm{RuO}_{2}$ has limited solubility in borosilicate glasses and may form microcrystals in the product [5]. The presence or absence of this phase will be determined mainly by the homogeneity of the feed to the glass melter [7]. 


\subsubsection{Thermal Stability (M. J. Flodinec)}

In this section, the thermal stability of the glass waste form is described. Varied thermal treatments can cause devitrification and/or thermal shock. The influence of both on the integrity of the reference glass waste form are considered. In addition, the affects of varied waste composition in the glass form on devitrification are described. It is important to recognize that there has been no waste glass form quality criteria established by the NRC at this time. Consequently, the significance of devitrification and thermal shock cannot be properly evaluated.

\subsubsection{Devitrification}

During cooling of glass melts below the liquidus, * crystals may form depending on the composition of sludge mixed with the glass frit and the rate of cooldown. This process of crystal formation is called devitrification. The presence of these crystals can alter the glass waste form's chemical [8] and mechanical behavior and consequently have an impact on the integrity of the glass waste form. The crystalline phase will likely have a higher leachability than the original glass [9-11]. Also, the residual glass phase, through removal of a network former by crystallization, will result in a glass waste form that is mechanically weaker and consequently subject to more extensive fracture in the event of a mechanical accident $[11,12]$.

The rate of devitrification will depend on the composition of the sludge mixed with glass frit. Previous studies have shown that sludges high in aluminum devitrify more quickly but the presence of uranium and nickel inhibits devitrification [13,14]. Table 3.10 summarizes the temperature at which maximum devitrification occurs in glass samples containing a variety of single major sludge components [14].

Nepheline ( $\mathrm{NaAlSiO}_{4}$ ) and other alkali aluminosilicates are always expected to be present [14]. For sludges high in iron, the spinel phase (insoluble metal oxides of the formula $\mathrm{MN}_{2} \mathrm{O}_{4}$, where $M$ is a bivalent cation and $N$ is a trivalent cation) will always form in the melt [15]. To minimize the formation of either phase, blending the "high aluminum" sludges (the basis for calculating the composite feed) is advantageous in that the aluminum apparently hinders formation of the spinel phase and the iron reduces the rate of nepheline formation.

* The lowest temperature at which no crystals exist. 
Minimizing the length of time that the waste glass form is in the temperature range of $500^{\circ} \mathrm{C}$ to $900^{\circ} \mathrm{C}$ will minimize devitrification. At temperatures near the melting temperature the viscosity of the glass is so low and the solubility of most crystalline material is so high that no crystal formation or growth occurs (spinels formed during melting, however, will still be present). At about $900^{\circ} \mathrm{C}$ however, the rate of solution of crystals has decreased so much that devitrification may begin [15]. As the glass is cooled below $900^{\circ} \mathrm{C}$, the rate of devitrification increases to a maximum between 550 and $900^{\circ} \mathrm{C}$. Further cooling results in viscosities too high for effective material transport and consequently a decrease in the rate of devitrification results. During interim and terminal storage, the rate of devitrification will be extremely low and can be ignored.

\subsubsection{Thermal Shock}

The maximum temperature gradient the waste glass form can withstand without fracturing from thermal shock is about $100^{\circ} \mathrm{C}$. This estimate is based on a formula derived by Everett [16].

$$
\Delta \operatorname{Tmax}=\frac{P(1-S)}{\alpha E}
$$

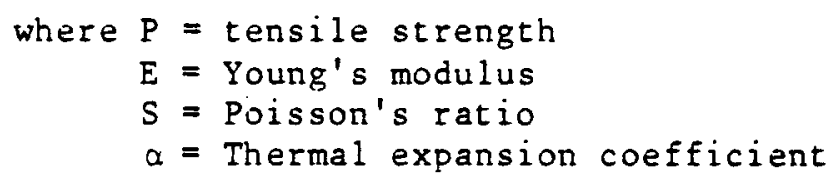

During the presently expected cooldown rate, thermal shock will effect a tenfold increase in surface area of the glass. Stresses may occur during cooling at the glass-filled canister interface; however, this is not expected to be a problem. Even if the stress in the canister reaches the yield point, the canister would compensate by yielding since it is a malleable material.

\subsubsection{Leachability (M. J. Plodinec)}

Leachability is one of the parameters that is used to evaluate the integrity of a particular waste form. It is usually expressed as the quantity of waste form that dissolves per unit area into a surrounding medium per unit time $\left(\mathrm{g} / \mathrm{cm}^{2}-\mathrm{day}\right)$. By assuming that radionuclides are uniformly distributed throughout the waste form, leachability data allow calculation of the quantity of radionuclides that could be released into the surrounding 
medium over a period of time. To date, no criteria for leachability of waste glass has been established by any governmental agency. However, leachabilities of most vitreous products are $10^{-5}$ to $10^{-7} \mathrm{~g} / \mathrm{cm}^{2}-d a y$ and these values are used as a guideline to determine acceptable leach resistance of a waste form [17].

The glass used in the leachability tests described in the following two sections utilized either Frit 18 or 21 , neither at which is the current reference frit.

\subsubsection{Leachability of Glass Containing Simulated Sludge}

Extensive laboratory investigations have been conducted at SRL to evaluate the effect of simulated SRP sludge components on the distilled water leachability of borosilicate glass $[17,18]$. The majority of these tests utilized glass frit 18.

Figure 3.3 summarizes that portion of data where Frit 21 was used [18]. Glass samples containing $\mathrm{U}_{3} \mathrm{O}_{8}$, $\mathrm{NiO}, \mathrm{MnO}_{2}$, or $\mathrm{CaO}$ all had higher leachabilities than glass without these components. At low concentrations, $\mathrm{Fe}_{2} \mathrm{O}_{3}$ and $\mathrm{Al}_{2} \mathrm{O}_{3}$ increased leachability but at higher concentrations (about 12 wt \%), the leachability of glasses containing $\mathrm{Fe}_{2} \mathrm{O}_{3}$ and $\mathrm{Al}_{2} \mathrm{O}_{3}$ was comparable to that of Frit 21 alone. The substitution of $4 \mathrm{wt} \% \mathrm{LiO}_{2}$ (to 1 the lower viscosity) for $\mathrm{Na}_{2} \mathrm{O}$ had no effect on leachability of the glass.

Brine leaching of glass containing simulated waste is also being studied to evaluate the durability of the glasses under possible salt bed storage conditions. Leaching at $20-25^{\circ} \mathrm{C}$ and $90^{\circ} \mathrm{C}$ has been studied thus far.

Glass containing Cs-137 tracer was leached for 67 days in brine at ambient temperatures. The cumulative leachabilities clearly differ with glass composition as shown in Figure 3.4. The glasses made with high $\mathrm{Fe}$ sludge leached more rapidly than those made with high Al sludge. Glasses containing composite sludge with an intermediate composition have intermediate leachabilities.

Glass leach rates in $90^{\circ} \mathrm{C}$ brine decrease with time as do those for room temperature tests. The leachabilities are, however, a factor of approximately 5 greater at $90^{\circ} \mathrm{C}$. Testing at $90^{\circ} \mathrm{C}$ also revealed that distilled water is a more severe leachant than brine. 


\subsubsection{Leachability of Glass Containing Actual Sludge}

Leach rate data are shown in Tables $3.11,3.12$, and 3.13 . Tests of the effect of $\mathrm{pH}$ on leaching were begun and have continued $>200$ days. Cumulative fractions leached based on $\mathrm{Sr}-90$ analysis are shown in Figures 3.5 and 3.6 of this report. In $\mathrm{pH}=4$ buffer, the leach rate increased after about 50 days, the whereas in the other solutions the leach rate remained nearly constant. The increased leaching may be caused by the acetate ion in the $\mathrm{pH}=4$ buffer rather than an actual $\mathrm{pH}$ effect [1]. Cs-137 and $\mathrm{Pu}$ activity in the buffered solutions are being measured to determine glass leaching based on these isotopes.

\subsubsection{Sulfate Phase Separation (J. R. Wiley)}

Sulfate is the only constituent of SRP waste which is present in significant amounts that is not compatible with borosilicate glass. If the sulfate solubility limit (about 1 wt $\%$ ) is exceeded, alkali metal sulfates segregate into a separate phase on the surface of the glass during melting. This is undesirable because the sulfate phase is water-soluble and rich in radioactive cesium.

Laboratory tests included measurement of the solubility of sulfates in glass made with simulated sludge in Frit $21[17,20]$. Solubilities ranged to 1.25 wt \% for $\mathrm{Na}_{2} \mathrm{SO}_{4}$ in Frit 21 . For glass loaded with 35 wt \% sludge, the sulfate level in the sludge itself could be about 2.8 wt \% before a sulfate phase would segregate. Typical, washed, SRP sludges contain only about 0.5 wt \% sulfate [19].

Washed sludges from seven SRP tanks were successfully incorporated with Frit No. 21 glass without sulfate segregation $[20,21]$.

\section{1 .5 Radiation Stability (N. E. Bibler)}

During long term storage, the glass waste form will be continuously irradiated by beta-gamma emissions from fission products and by alpha emissions from transuranic nuclides. Properties of the glass that may potentially be affected by these radiations are leachability, stored energy, density and microstructure. The accumulation of helium in the glass from neutralization of alpha particles is of additional concern in that helium accumulation in the glass network may cause stresses and/or diffused helium may result in pressure buildup in the canister freeboard. 
The estimated dose received during long-term storage $\left(2 \times 10^{5}\right.$ years) is calculated to be $4.8 \times 10^{10}$ rads from beta-gamma and $7.4 \times 10^{10}$ rads from alpha radiation. Results of radiolysis studies with Co-60 gamma, Cm-244 alpha, and Pu-238 alpha radiations on glass and simulated wastes indicate that these radiations will have minimal and insignificant effects on the leachability and stored energy of the glass.

The maximum expansion of glass during storage is expected to be less than $1.0 \%$ due to alpha irradiation. Tests have not been performed to determine if beta and ganma radiation will cause positive expansion of the glass. However, at identical doses, the effect of beta-gamma irradiation would be less than that due to alpha emissions.

After $2 \times 10^{5}$ years storage, approximately $0.09 \mathrm{~cm}^{3}$ He (STP) will have been produced for each $\mathrm{cm}^{3}$ of glass. Assuming the helium diffuses through the glass, the gas pressure in the free volume of the canister could be about 6 psi assuming a 20\% freeboard.

A more detailed summary of the specific effects of radiation on glass is in Appendix 13.6.

\subsubsection{Canister Specifications (J. P. Howell, W. N. Rankin)}

\subsubsection{Reference Requirements}

Regulatory requirements for the permanent storage of defensegenerated waste have not been established. The DW glassform will be stored on-site in an interim storage facility.

Even though provisions are being made for long-term storage on-site, the design of the canister should not preclude the possibility of its shipment to a geologic repository at a later date.

Several draft documents are being written as criteria for Commercial Nuclear Waste. Among these documents are: "Interim Waste Package Performance and Acceptance Criteria," ONWI-33(4), "Rockwell Hanford Operations Commercial Waste and Spent Fuel Packaging Program Package Design Criteria, RHO-CD-772, "Interim Report: Commercial Waste Packaging Studies," RHO-ST-10. These documents along with "The Cask Designers Guide," Federal Shipping Regulations, CFR-Title 10-Part 71.42 NRC-NUREG 0274, "Determination of Performance Criteria for High-Level Solidified Nuclear Waste," and NRC Regulatory Guide 7.6, "Stress Allowables for the Design of Shipping Cask Containment Vessels," can be used for guidelines in the design of the container but should not be construed as given regulations at this time. 
The package should be designed in accordance with the American Society of Mechanical Engineers (ASME Boiler and Pressure Vessel [BPV] Code, Division I, Section III, Class 3). Exceptions should be obtained fcr pressue testing, x-ray inspection, and other sections of this code which placed undue and unnecessary restraints on the design.

\subsubsection{Canister}

The reference design canister, shown in Figure 3.7 is made of Type $304 \mathrm{~L}$ stainless steel with a wall thickness of about $3 / 8$ inch; it weighs about 1100 pounds. Although $304 \mathrm{~L}$ stainless steel is the reference material at this time, the use of a refined grade of low carbon steel such as calcium treated, ASTM-A516 (Grade 65-70) (plate) and ASTM-A707 (flanges) should not be precluded.

The objectives of the canister are to provide:

- a form for solidifying the waste glass

- containment during Interim Storage

- a surface for decontamination

- a means for handing the glass form

The reversed dished head at the canister bottom allows the canister to be set down on flat surfaces. The double flanged nozzle atop the glass canister is intended to facilitate attachment to the continuous glass melter for containment of molten glass vapors and particulate contamination. The top flange is intended to be the electrical grounding surface for the five inch resistance plug weld which seals the throat opening and insures that the canister is leaktight from liquid entry during decontamination. The weld must also be leaktight to prevent the escape of plutonium or other radioactive particulate matter from the container into the canyon or interim storage facility.

The entire canister surface finish should be specified as a 2B finish as defined by ASTM Specification A-480, "General Requirement for Flat Roll Stainless and Heat Resisting Steel Plate, Sheet, and Strip Steel." This surface finish is necessary prior to heating to insure uniformity in decontaminating the container after processing. 


\subsubsection{Materials of Construction Compatibility (w. N. Rankin)}

Type 304I stainless steel is the recommended canister alloy for cast vitrified waste [22]. This recommendation is based on long-term heating tests for up to 20,000 hours ( 2.3 years) at temperatures that bracket the temperature expected during interim storage [25]. In these tests the lifetime of canisters of cast vitrified waste stored in air was predicted. The thickness of reactions observed between vitrified waste/canister alloy, and canister alloy/environment similar to that expected during interim storage was extrapolated to estimate the time required for penetration of the reference design (3/8-inch thick) canister.

Data from tests up to 20,000 hours ( 2.3 years) indicate that oxidation would penetrate a 3/8-inch-thick low carbon steel canister in about 200 years of storage in a surface facility, and its strength would be reduced in a much shorter period. A 3/8-inchthick canister of Type $304 \mathrm{~L}$ stainless steel would not be penetrated for more than 8000 years in a surface facility.

Differences in canister lifetime, predicted from the data fro these tests, are attributable to the difference in corrosion resistance of the candidate alloys. Both Type 304L stainless steel andlow carbon steel reacted similarly with vitrified waste. But, Type $304 \mathrm{~L}$ stainless steel is much more resistant to atmospheric corrosion in a radiation field than low carbon steel. The lifetime of canisters constructed from other compositions of austenitic stainless steels would be expected to be similar. Past experience indicates that other compositions of austenitic stainless steels have similar compatibility with molten vitrified waste, which is a much more severe condition [27].

\subsubsection{Heat Generation Rate and Temperature Profile}

\subsubsection{Heat Generation Rate (J. R. Chandler)}

Tables 3.3 and 3.4 summarize the heat generation data for the reference glass waste form. For 5 and 15 year aged waste feed, the total heat generation rate in a glass-filled canister is 541 and 310 watts, respectively.

\subsubsection{Temperature Profile (M. H. Tennant)}

Heat transfer models were developed to predict glass temperature profiles during the glass melt pour, canister cooling, helium leak testing and encapsulation [31]. Based on these models, the following overall process characteristics were determined. 


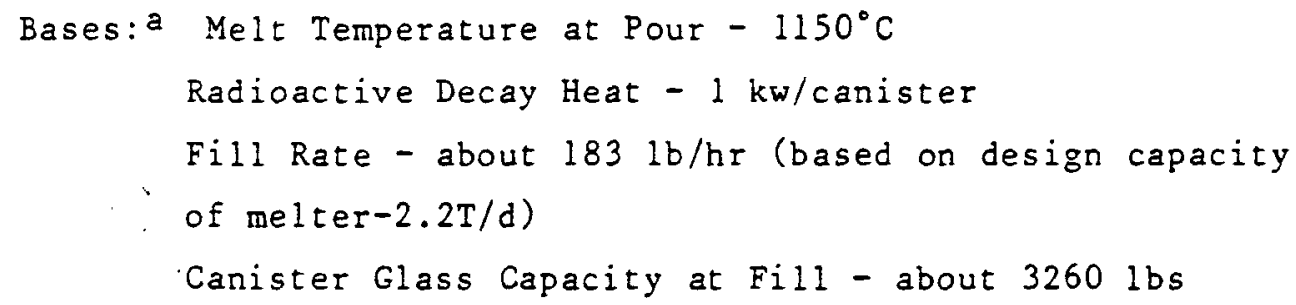

- At the end of the fill period (about 17 hours), the maximum glass temperature will remain in excess of $800^{\circ} \mathrm{C}$. Figure 3.8 describes the temperature distribution of the glass at the end of fill.

- Subsequently, 11-15 additional hours are required to reduce the glass temperature to below the devitrification temperature (about $500^{\circ} \mathrm{C}$ ). Figure 3.9 shows the maximum glass centerline temperature and the maximum canister surface temperature as a function of elapsed time after fill for three cooling modes (natural air convection, forced air convection and water cooling).

- Helium leak testing and canister encapsulation processes will raise the temperature of the glass near the canister surface but will have little effect upon the glass centerline temperature as depicted in Figure 3.10 .

- Equilibrium temperatures (radioactive decay heat controlling) will be $120^{\circ} \mathrm{C}$ glass centerline and $60^{\circ} \mathrm{C}$ at canister surface. See Figure 3.11 for the temperature profile throughout the canister at steady state.

Additional thermal analysis data for canister processing are described in Reference 31.

\subsubsection{Regulatory Aspects of Solidified Glass (E. J. Hennelly)}

Currently, there are no Federal regulations that specify the required properties of solidified high-level waste and its container. NRC has studies under way and expects to have preliminary drafts of proposed regulations available for review and comment in 1979. Section 11 provides a broader view of regulatory matters and indicates some of the items that may require measurement or control in order to meet possible regulations.

a. This analysis assumes a radionuclide heat generation rate of 1000 watts. Although this rate is no longer applicable (Section 3.1.7.1), the temperature data in Figures 3.8 and 3.9 are still valid since the sensible heat content is controlling. However, the temperature data in Figure 3.11 ("steady state") are no longer applicable, being high by approximately 1.5 . 


\subsection{Saltcrete}

\subsubsection{Composition and General Properties}

\section{2 .1 .1 General}

Following treatment by ion exchange resin to remove cesium, strontium, and plutonium, the water-soluble portion of SRP waste (supernate) will be solidified in concrete to reduce the leachability of the salt. The concrete would then be buried in soil trenches below the ground surface. The solidified product (saltcrete) can be characterized by its chemical properties and its residual radioactivity.

\subsubsection{Chemical Properties (J. R. Wiley)}

Chemical properties of saltcrete will be determined by its major components (Table 3.14) [28]. - Many other ions are present in trace concentrations [29]. Those which have been identified include $\mathrm{PO}_{4}{ }^{3-}, \mathrm{CrO}_{4}{ }^{2-}$, and $\mathrm{NH}_{4}{ }^{+}$. Trace metals include $\mathrm{Fe}, \mathrm{Hg}$, $\mathrm{Ag}, \mathrm{Pb}$, and $\mathrm{U}$. Trace components do not contribute to chemical behavior of the bulk salt. However, some are biological hazards.

\subsubsection{Residual Radioactivity (J. R. Chandler)}

The isotopic content and associated decay heat in 5 and 15 year saltcrete are tabulated in Tables 3.15 and 3.16 .

\subsubsection{Radiation Stability (N. E. Bibler)}

During long-term storage, saltcrete will be continuously irradiated from decay of the residual radionuclides. The only significant effect of this irradiation will be to produce gases. Because of the small yields of these gases and the small amounts of radioactivity present, the amount of gases produced will be insignificant. 
TABLE 3.1

Chemical Composition of Reference Glass Waste Form

\begin{tabular}{|c|c|c|}
\hline Oxide & Source* & Amount, wt \% \\
\hline $\mathrm{Ii}_{2} \mathrm{O}$ & $\mathbf{F}$ & 4.08 \\
\hline $\mathrm{B}_{2} \mathrm{O}_{3}$ & $F$ & 10.5 \\
\hline $\mathrm{IiO}_{2}$ & $\mathbf{F}$ & 0.718 \\
\hline $\mathrm{CaO}$ & $F+S$ & 0.843 \\
\hline $\mathrm{Na}_{2} \mathrm{O}$ & $F+S$ & 13.7 \\
\hline $\mathrm{SiO}_{2}$ & $F+S$ & 42.2 \\
\hline $\mathrm{Fe}_{2} \mathrm{O}_{3}$ & $s$ & 11.8 \\
\hline $\mathrm{Al}_{2} \mathrm{O}_{3}$ & $s$ & 2.38 \\
\hline $\mathrm{MnO}_{2}$ & $s$ & 3.39 \\
\hline $\mathrm{U}_{3} \mathrm{O}_{8}$ & $\mathrm{~s}$ & 1.09 \\
\hline $\mathrm{NiO}$ & $s$ & 1.45 \\
\hline Zeolite & $s$ & 2.60 \\
\hline $\mathrm{MgO}$ & $\mathbf{F}$ & 1.43 \\
\hline $\mathrm{ZrO}_{2}$ & $F$ & 0.357 \\
\hline $\mathrm{La}_{2} \mathrm{O}_{3}$ & $\mathrm{~F}$ & 0.357 \\
\hline o Solids & $F+S$ & 3.03 \\
\hline NR Salt & $s$ & 0.0984 \\
\hline Density & & $\begin{array}{l}2.37 \mathrm{~g} / \mathrm{Cc} C 1100^{\circ} \mathrm{C} \\
2.5 \mathrm{~g} / \mathrm{Cc} \mathrm{C} 120^{\circ} \mathrm{C}\end{array}$ \\
\hline
\end{tabular}

* $F=$ Frit; $S=$ composite sludge;

TABLE 3.2

Chemical Composition of Glass Frit 131

\begin{tabular}{lrr} 
Oxide & & Wt $\%$ \\
\cline { 1 - 1 } $\mathrm{SiO}_{2}$ & 57.9 \\
$\mathrm{Na}_{2} \mathrm{O}$ & 17.7 \\
$\mathrm{TiO}_{2}$ & 1.0 \\
$\mathrm{~B}_{23} \mathrm{O}$ & 14.7 \\
$\mathrm{Li}_{2} \mathrm{O}$ & 5.7 \\
$\mathrm{MgO}$ & 2.0 \\
$\mathrm{ZrO}_{2}$ & 0.5 \\
$\mathrm{La}_{2} \mathrm{O}_{3}$ & 0.5
\end{tabular}


TABLE 3.3

ISOTOPIC CONTENT (Ci/b) OF WASTE GLASS - 5 YEARS

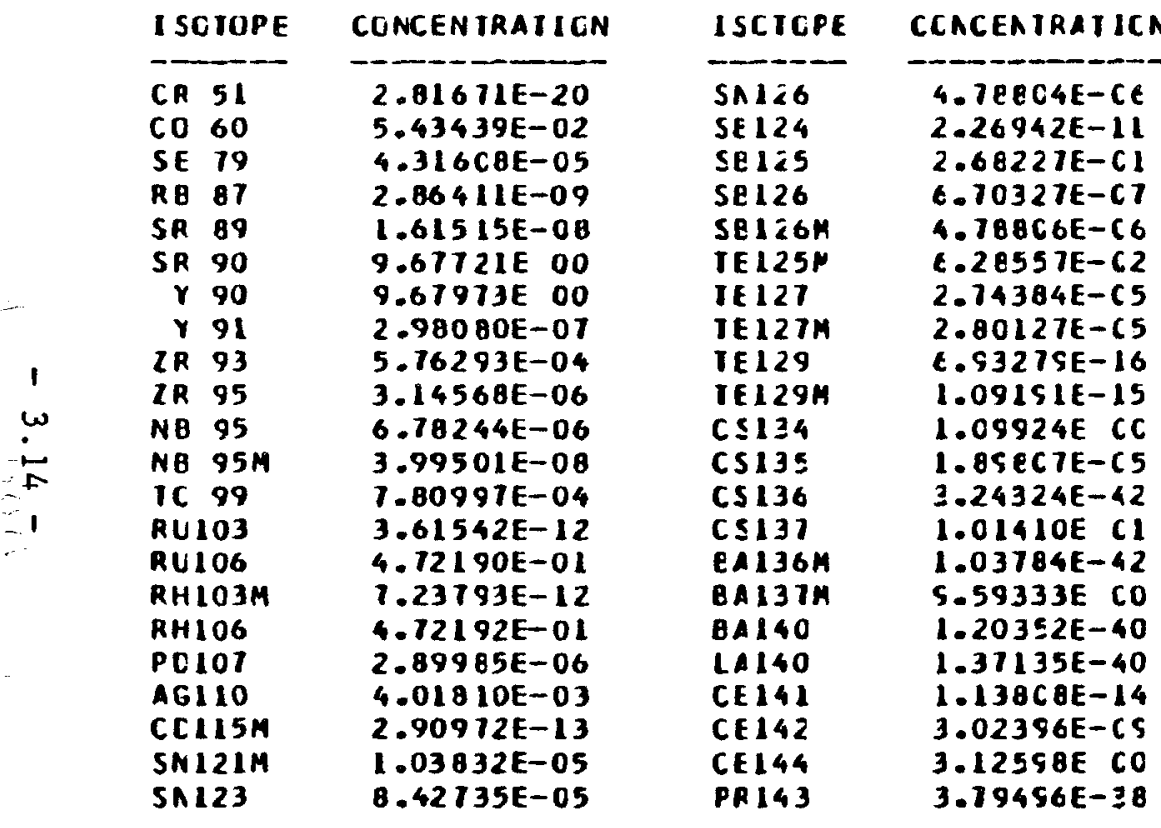

TOTAL ACTIVITY $5.64 \quad 01 \mathrm{Ci} / \mathrm{lb}$

HEAT GENERATION, watts/b

Primary 1.17-01

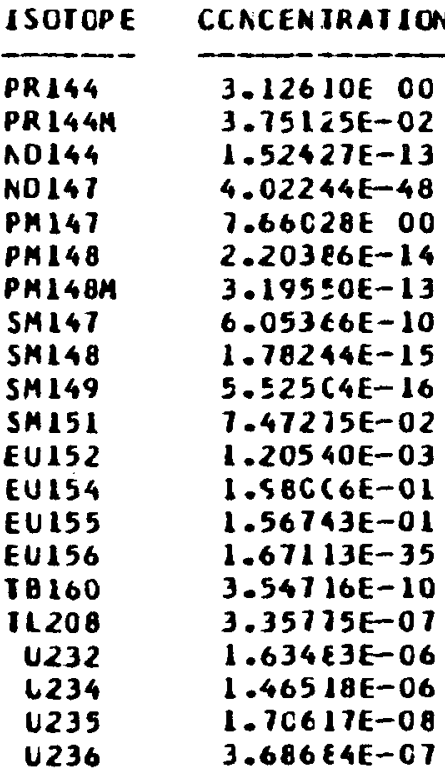

4238 NP236

NP237

PU236

PU23T

PU238

PU239

PU240

PU241

PL242

AH241

AM242

AM242K

AN243

CN242

CM243

CH244

CM245

CM246

CM247

CM248
CONCENIRATION

$9.233 \mathrm{CBE}-0 \mathrm{E}$ $5.49941 E-12$

2. $60845 E-06$

$1.99990 E-05$

$1.44979 E-15$

$2.38898 E-01$

$2.261 C 5 E-03$

$1.42241 \mathrm{E}-03$

$2.07080 E-01$

$1.89152 E-O E$

$3.43384 E-03$

4.52947 E-06

$4.55217 E-06$

$1.82925 E-06$

$1.11121 E-05$

$5.16690 E-05$

2.1075SE-CS

$1.68263 E-1 C$

$2.06847 E-16$

2. $16006 E-16$ 
TABLE 3.4

ISOTOPIC CONTENT (Ci/lb) OF WASTE GLASS - 15 YEARS

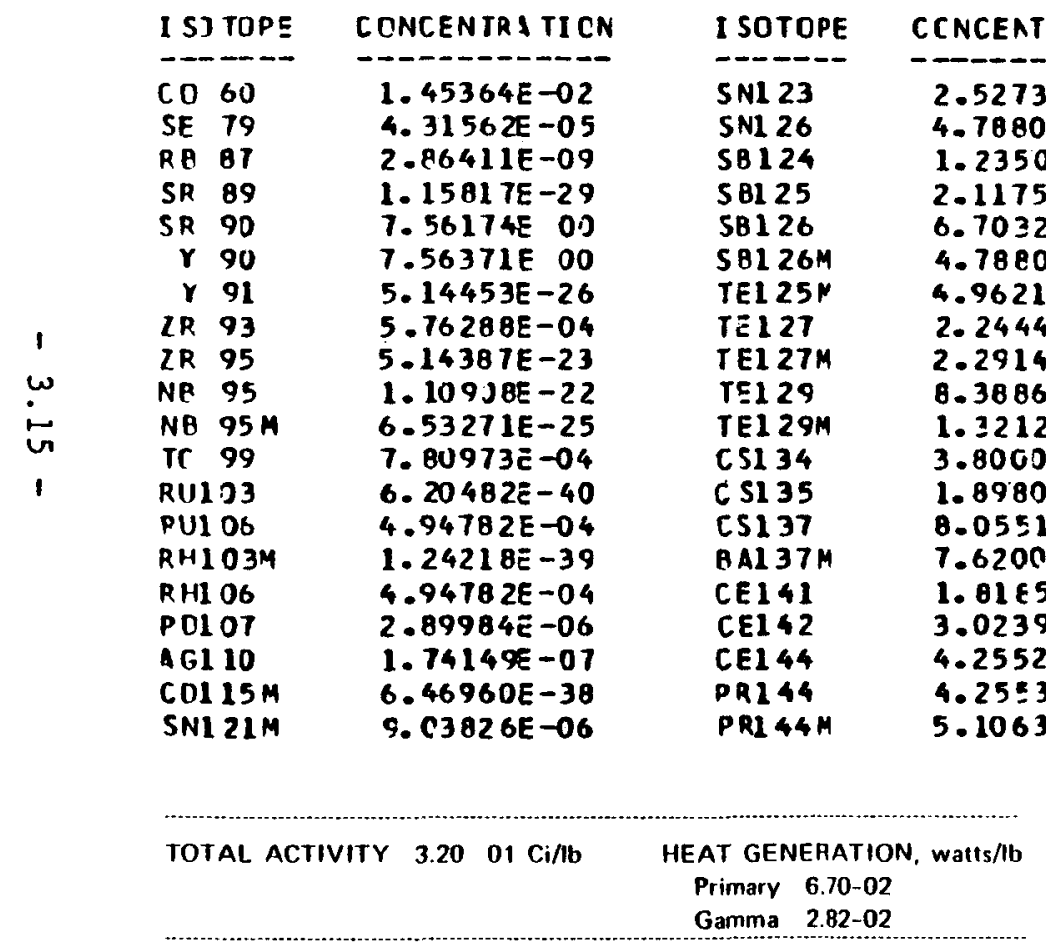


TABLE 3.5

Physical Properties of Glass Waste Forms

\begin{tabular}{llll} 
Property & Value & Reference \\
\cline { 1 - 1 } $\begin{array}{l}\text { Thermal Conductivity } \\
\text { at } 100^{\circ} \mathrm{C}\end{array}$ & $0.55 \mathrm{pcu} / \mathrm{hr}-\mathrm{ft}-{ }^{\circ} \mathrm{C}$ & Table 3.6 \\
Heat Capacity at $100^{\circ} \mathrm{C}$ & $0.22 \mathrm{pcu} / 1 \mathrm{~b}-{ }^{\circ} \mathrm{C}$ & Table 3.7 \\
$\begin{array}{l}\text { Fractional Thermal } \\
\text { Expansion }\end{array}$ & $1.1 \times 10^{-5}{ }^{\circ} \mathrm{K}$ & $\mathrm{d}$ \\
Young's Modulus & $9 \times 10^{6} \mathrm{psi}$ & 1 \\
Tensile Strength & $9 \times 10^{3}$ & 1 \\
Compressive Strength & $1 \times 10^{5} \mathrm{psi}$ & 4 \\
Poisson's Ratiob & 0.2 & 1 \\
Density at $100^{\circ} \mathrm{C}$ & $2.49 \mathrm{~g} / \mathrm{cc}$ & Table 3.8 \\
Softening Point & 500 to $550^{\circ} \mathrm{C}$ & $\mathrm{d}$
\end{tabular}

a. Young's modulus, or the modulus of elasticity, measures the stiffness of the material, e.g., carbon steel is about $30 \times 10^{6} \mathrm{psi}$.

b. Poisson's ratio can be thought of as the ratio of equatorial to axial strain, under an applied axial stress.

c. Experimentally determined. Range is 2.35 to 3.25 .

d. Experimentally determined. 


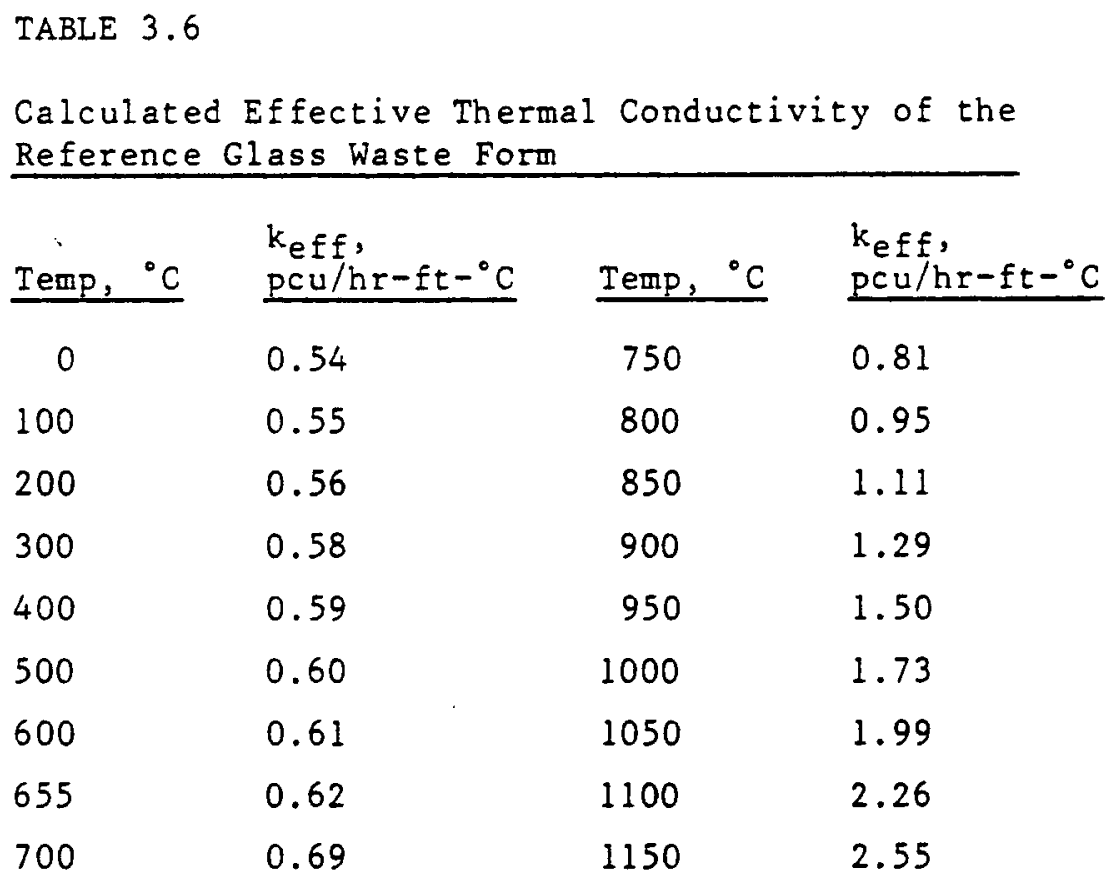

TABLE 3.7

Calculated True and Mean Heat Capacity of the Reference Glass Waste Form

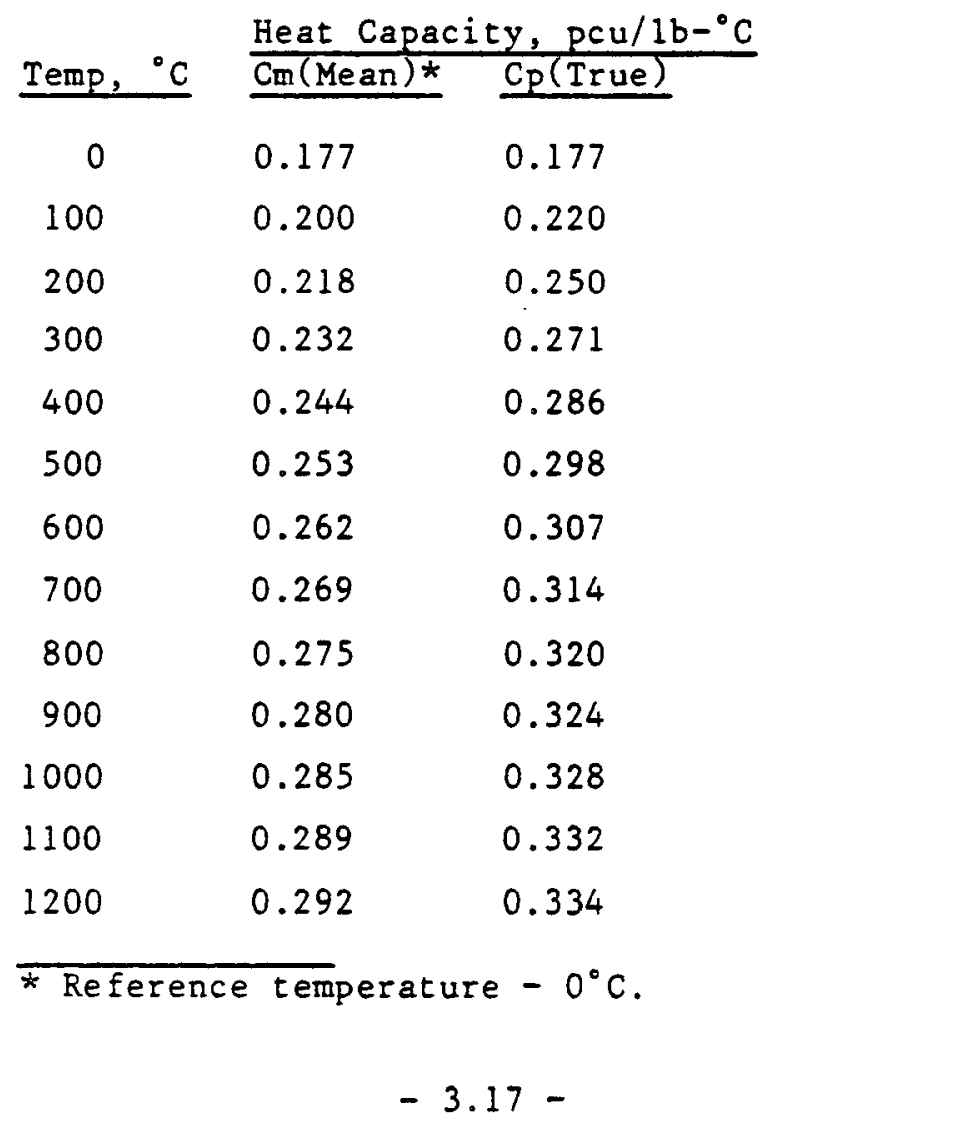


TABLE 3.8

Calculated Density of the Reference Glass Waste Form

\begin{tabular}{lllll} 
Temp., ${ }^{\circ} \mathrm{C}$ & $\begin{array}{l}\text { Density, } \\
\text { gm/cc }\end{array}$ & $\begin{array}{l}\text { Temp., }{ }^{\circ} \mathrm{C} \\
25\end{array}$ & $\begin{array}{l}\text { Density, } \\
\text { gm/cc }\end{array}$ \\
\hline 100 & 2.495 & 700 & 2.440 \\
200 & 2.490 & 800 & 2.421 \\
300 & 2.484 & 900 & 2.403 \\
400 & 2.478 & 1000 & 2.385 \\
500 & 2.465 & 1150 & 2.358 \\
596 & $2.459 *$ & 1200 & 2.349 \\
600 & 2.458 & 1300 & 2.330
\end{tabular}

* Density of glass at strain point temperature.

TABLE 3.9

Calculated Viscosity of the Reference Glass Waste Form

\begin{tabular}{|c|c|c|c|}
\hline Temp., ${ }^{\circ} \mathrm{C}$ & $\eta$, poise & Temp., ${ }^{\circ} \mathrm{C}$ & $\eta$, poise \\
\hline 850 & 1930 & 1050 & 92.6 \\
\hline 875 & 1080 & 1075 & 74.4 \\
\hline 900 & 656 & 1100 & 61.0 \\
\hline 925 & 425 & 1125 & 50.9 \\
\hline 950 & 291 & 1150 & 43.0 \\
\hline 975 & 208 & 1175 & 36.9 \\
\hline 1000 & 154 & 1200 & 32.0 \\
\hline 1025 & 118 & 1225 & 28.1 \\
\hline
\end{tabular}


TABLE 3.10

Effect of Sludge Components on Devitrification of Waste Glass [14]

Heated One Month at $600^{\circ} \mathrm{C}$

Relative

Component, Amount of

Phase

wt \%

$\mathrm{T}_{\mathrm{D}},{ }^{\circ} \mathrm{C}$

Devitrificationa

Formed

None

623

$\mathrm{S}$

b

CaO (1.2)

632

$S$

b

NiO (2.4)

645

$\mathrm{S}$

b

$\mathrm{U}_{3} \mathrm{O}_{8}(5.5)$

c

$\mathrm{S}$

b

$\mathrm{MnO}_{2}(6.6)$

608

S-M

$\mathrm{Mn}_{3} \mathrm{O}_{4} \mathrm{~d}$

$\mathrm{Al}_{2} \mathrm{O}_{3}(21.1)$

576

XI

$\mathrm{NaAlSiO}_{4}$

$\mathrm{Fe}_{2} \mathrm{O}_{3}(19.3)$

620

I

$\mathrm{Fe}_{3} \mathrm{O}_{4} \mathrm{~d}$

a. $S=$ Small; $M=$ Moderate $\quad L=$ Large; $X L=$ Essentially complete.

b. Too little to detect by x-ray diffraction.

c. None observed at $\mathrm{T}<850^{\circ} \mathrm{C}$.

d. Though listed as $\mathrm{C}_{3} \mathrm{O}_{4}(\mathrm{C}=\mathrm{Fe}$ or $\mathrm{Mn}$ ) they probably contain $\mathrm{Ti}, \mathrm{Na}$, and $\mathrm{Li}$, in a spinel structure. 
TABLE 3. 1

G1ass Leach Rates Based on Cs-137

\begin{tabular}{|c|c|c|c|c|c|c|c|c|c|c|}
\hline \multirow[b]{2}{*}{ Glass Type } & \multicolumn{10}{|c|}{ Leach Rate $\left(g / \mathrm{cm}^{2}-\mathrm{day}\right)^{b}$} \\
\hline & 1 & 2 & 4 & 7 & 14 & 21 & 35 & 50 & 74 & 100 (days) \\
\hline $21-35-4.6$ & $3.7-07^{c}$ & $8.8-07$ & $7.5-08$ & $7.6-08$ & $3.1-08$ & $9.5-08$ & $7.7-08$ & $1.5-08$ & $1.0-07$ & $9.4-09$ \\
\hline $21-35-5 A$ & $2.2-07$ & $2.0-07$ & $3.0-07$ & $2.0-07$ & $1.3-07$ & $1.0-07$ & $5.2-08$ & $1.4-08$ & $2.2-08$ & $3.6-08$ \\
\hline $21-35-5 B$ & $3.8-07$ & $3.8-07$ & $1.1-06$ & $6.1-07$ & $2.9-06$ & - & $1.8-07$ & $4.1-08$ & $1.8-08$ & $6.5-09$ \\
\hline $21-35-13 A$ & 3.3-07 & $2.4-07$ & $6.3-07$ & $2.7-07$ & $1.5-07$ & $3.0-06$ & $1.1-07$ & - & $1.5-08$ & $3.5-08$ \\
\hline $21-35-13 B$ & $2.9-07$ & $1.4-07$ & $2.7-07$ & $4.5-07$ & $2.8-05$ & $3.6-06$ & $5.7-07$ & $2.7-07$ & $1.1-07$ & $9.4-08$ \\
\hline $21-35-13 c$ & $1.6-07$ & $1.3-08$ & $1.2-07$ & $2.2-07$ & $1.2-07$ & $2.4-04$ & $2.7-06$ & $7.2-08$ & $3.1-08$ & $3.2-08$ \\
\hline $21-35-15$ & $3.8-07$ & $2.6-07$ & $3.5-07$ & $3.9-07$ & $9.6-07$ & $1.6-06$ & $1.6-07$ & $3.9-08$ & $1.2-07$ & $6.6-08$ \\
\hline $21-35-16$ & $5.2-06$ & 8.0-07 & $1.6-06$ & $4.0-07$ & $6.2-07$ & $9.5-06$ & $4.8-07$ & $1.7-07$ & $4.2-07$ & $2.1-07$ \\
\hline
\end{tabular}

a. Glass is designated by: Frit number - wt $Z$ sludge - SRP waste storage farm sludge source (Tank).

b. Leach rate $=$ grams of waste form $/ \mathrm{cm}^{2}-$ day.

c. Leach rates are given in exponential form, i.e., 3.7-07 $=3.7 \times 10^{-7}$. 
TABLE $3: 12$

Glass Leach Rates Based on Pu

\begin{tabular}{|c|c|c|c|c|c|c|c|c|c|c|}
\hline & Leach $R$ & $\left(\mathrm{~g} / \mathrm{cm}^{2}\right.$ & y) $)^{b}$ & & & & & & & \\
\hline Glass Type ${ }^{a}$ & 1 & 2 & 4 & 7 & 14 & 21 & 35 & 50 & 74 & 100 (days) \\
\hline $21-35-4.6$ & $2.2-08^{c}$ & $2.9-07$ & $5.2-07$ & $1.5-08$ & $4.4-09$ & $1.4-08$ & $4.8-09$ & $4.8-09$ & $2.1-09$ & $1.9-09$ \\
\hline $21-35-5 A$ & $3.7-06$ & $3.4-07$ & $1.8-06$ & $4.2-07$ & $9.7-08$ & $8.2-08$ & $3.6-08$ & $2.4-08$ & $4.2-08$ & $1.6-08$ \\
\hline $21-35-5 B$ & $7.8-07$ & $2.8-07$ & $4.0-07$ & $7.7-07$ & $9.6-08$ & - & $1.9-07$ & $4.0-08$ & 1. $9-08$ & $1.5-08$ \\
\hline $21-35-13 A$ & $6.4-07$ & $1.4-06$ & $7.3-06$ & $1.2-06$ & $5.5-07$ & - & $5.4-07$ & - & $2.7-07$ & $4.8-08$ \\
\hline $21-35-13 B$ & $2.5-06$ & $2.2-06$ & $1.8-06$ & $2.8-06$ & $1.3-06$ & $8.9-07$ & $5.1-07$ & $6.1-07$ & $8.6-08$ & $9.2-08$ \\
\hline $21-35-13 c$ & $3.5-07$ & - & $3.1-07$ & $1.9-07$ & $2.0-07$ & $8.5-07$ & $1.5-07$ & $1.1-07$ & $3.2-09$ & $9.2-09$ \\
\hline $21-35-15$ & $3.6-06$ & $1.4-06$ & $6.4-07$ & $7.3-07$ & $7.8-07$ & 6.9-07 & 5.9-07 & $3.7-07$ & $2.6-07$ & $4.6-08$ \\
\hline $21-35-16$ & $1.2-06$ & $3.5-07$ & $5.0-07$ & $1.9-07$ & $1.4-07$ & $2.5-07$ & $9.0-08$ & $9.2-08$ & $7.4-08$ & $1.2-08$ \\
\hline
\end{tabular}

a. Glass is designated by: Frit number - wt $\Varangle$ sludge - SRP waste storage farm sludge source (Tank).

b. Leach rate $=$ grams of waste form $/ \mathrm{cm}^{2}-\mathrm{day}$.

c. Leach rates are given in exponential form, i.e., $2.2-08=2.2 \times 10^{-8}$. 
TABLE 3.13

Glass Leach Rates Based on $\mathrm{Sr}-90$

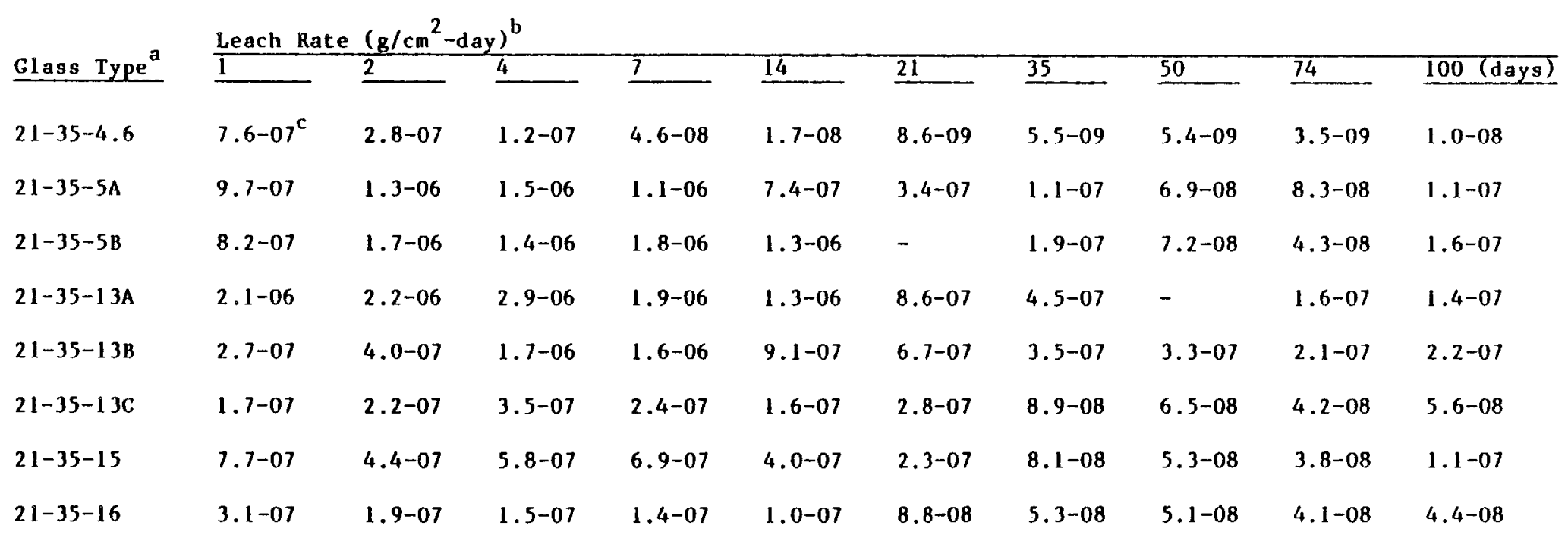

a. Glass is designated by: Frit number - wt $\%$ sludge - SRP waste storage farm sludge source (Tank).

b. Leach rate $=$ grams of waste form $/ \mathrm{cm}^{2}$-day.

c. Leach rates are given in exponential form, i.e., $7.6-07=7.6 \times 10^{-7}$. 
TABLE 3.14

Major Chemical Constituents of Saltcrete

\begin{tabular}{|c|c|}
\hline Compound & wt \% \\
\hline $\mathrm{NaNO}_{3}$ & 5.89 \\
\hline $\mathrm{NaNO}_{2}$ & 2.10 \\
\hline $\mathrm{NaOH}$ & 3.07 \\
\hline $\mathrm{NaAlO}_{2}$ & 1.29 \\
\hline $\mathrm{Na}_{2} \mathrm{CO}_{3}$ & 1.40 \\
\hline $\mathrm{Na}_{2} \mathrm{SO}_{4}$ & 1.18 \\
\hline $\mathrm{Na}_{2} \mathrm{C}_{2} \mathrm{O}_{4}$ & .0169 \\
\hline $\mathrm{NaCl}$ & .0419 \\
\hline $\mathrm{NaF}$ & .00274 \\
\hline $\mathrm{Na}\left[\mathrm{H}_{\mathrm{g}} \mathrm{O}(\mathrm{OH})\right]$ & .00837 \\
\hline $\mathrm{H}_{2} \mathrm{O}$ & 29.2 \\
\hline Cement & 55.8 \\
\hline
\end{tabular}


TABLE 3.15

ISOTOPIC CONTENT (ICI/g) OF SALTCAETE ${ }^{\theta}$ - 5 YEARS

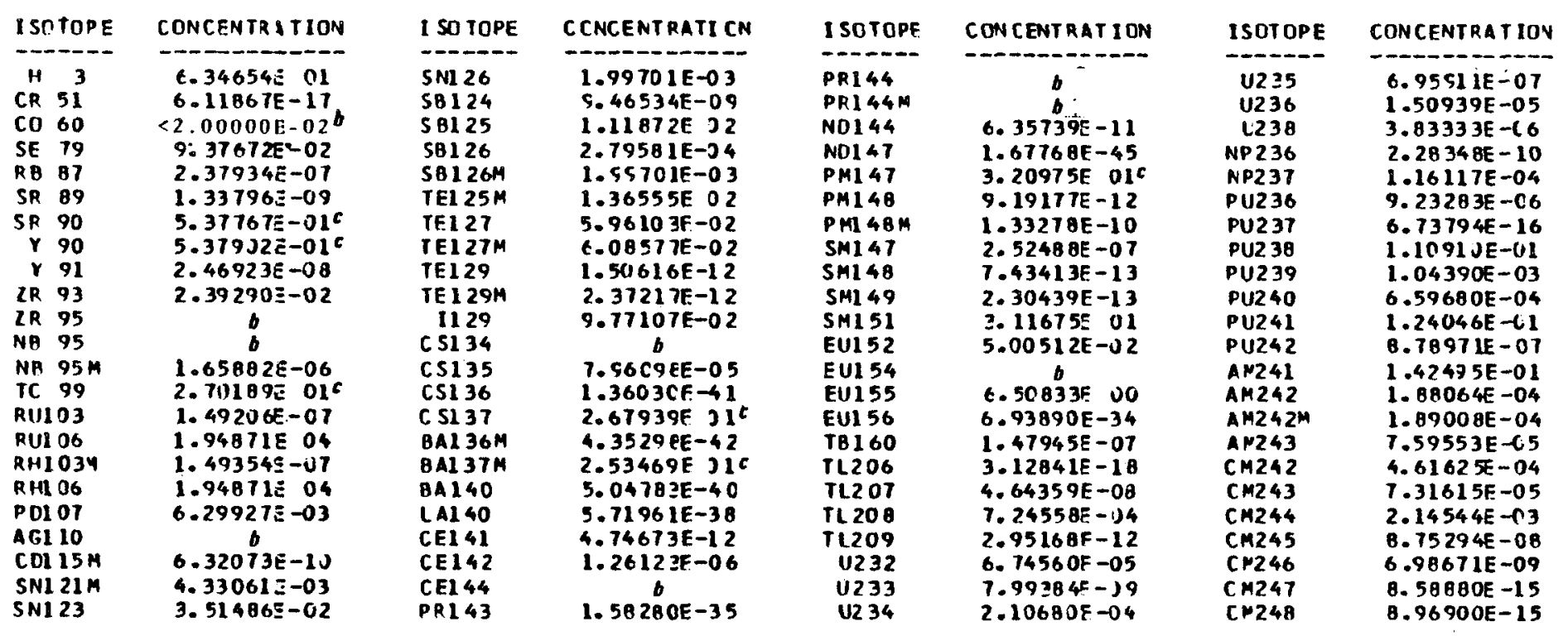

a. The isotopic concentrations were computed by a computer model which simulates the flow of isotopes through the reference process. Unless otherwise noted, no credit was taken for decontamination by the ion exchange flowsheet except for cesium, plutonium, and strontium.

b. Based on chemical analyses (see footnote c) the total contribution from these isotopes is $<0.5 n \mathrm{Ci} / \mathrm{g}$

c. These values were determined analytically after actual SRP waste supernate was clarified and treated by the refercnce ion exchange process Isee "Reference Process for Disposal of SRP Waste Salt." Intemal memorandum, B. W. Benjamin-P. L. Roggenkamp to S. Nirshak, November 16, 1979). Concentrations computed by the computer model are documented in appendix 13.7. 
TABLE 3.16

ISOTOPIC CONTENT (nCi/g) OF SALTCRETE - 15 YEARS

\begin{tabular}{|c|c|c|c|}
\hline Is & JTOPE & CONCENIRATION & I SOTOPE \\
\hline H & 3 & $3.60612 E$ Ol & $5 N 123$ \\
\hline Co & 60 & $\angle 2.00000 t-02^{6}$ & SA 126 \\
\hline SF & 19 & $9.37572 E-02$ & SB 124 \\
\hline RA & 81 & $2.37934 E-07$ & SE125 \\
\hline $\mathrm{SH}_{\mathrm{H}} \mathrm{CH}$ & 69 & $9.59357 E-31$ & 58126 \\
\hline SR & 90 & $4.20208 E-01 C$ & SO126M \\
\hline$r$ & 90 & $4.2 J 31 \mathrm{BE}-01^{c}$ & TE I25M \\
\hline $\mathbf{Y}$ & 91 & $4.26160 E-27$ & TE12T \\
\hline IR & 93 & $2.39288 \mathrm{~F}-02$ & IE127M \\
\hline IR & 35 & $b$ & IEI29 \\
\hline $\mathrm{NH}$ & 95 & & TE129M \\
\hline NA & $75 M$ & $2.11253 E-23$ & 1129 \\
\hline I C & & 7.101 TOE O1C & C5134 \\
\hline P.U & & $2.56069 t-35$ & $\operatorname{cs} 135$ \\
\hline KU & & $2.04194 \mathrm{E} \mathrm{OI}$ & $\operatorname{cs} 137$ \\
\hline RH & $103 \mathrm{M}$ & $2.56323 E-35$ & UA13IM \\
\hline RH & & $2.04144 E 01$ & CEI4I \\
\hline PC & & $6.29927 E-03$ & CE 142 \\
\hline$a G$ & & b & CEI44 \\
\hline Co & $115 \mathrm{M}$ & $1.40534 E-34$ & PRI4\% \\
\hline sn & $121 \mathrm{M}$ & $3.76966 E-03$ & PR 144M \\
\hline
\end{tabular}

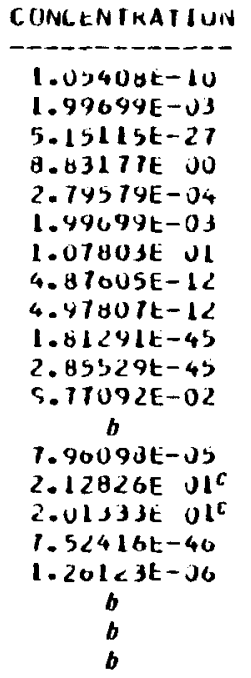

\begin{tabular}{ll} 
ISOTUPE & CLNCENTRATION \\
\hline NO144 & $0.40515 E-11$ \\
PM147 & $2.28463 E 00 C$ \\
P,4148 & $2.14205 E-38$ \\
PM148.4 & $3.17844 E-31$ \\
SM147 & $3.25283 E-07$ \\
SM148 & $1.43413 E-13$ \\
SM149 & $2.30439 E-13$ \\
SM151 & $2.89275 E 01$ \\
EU152 & $2.93561 E-02$ \\
EU154 & 86 \\
EU155 & $1.53421 E 00$ \\
IU160 & $5.17126 E-23$ \\
IL206 & $1.04528 E-16$ \\
IL207 & $1.27675 E-07$ \\
IL208 & $1.54548 E-03$ \\
TL209 & $1.34413 E-11$ \\
$U 232$ & $8.92189 E-05$ \\
$U 233$ & $1.30598 E-08$ \\
U234 & $4.00362 E-04$ \\
$U 235$ & $6.95911 E-07$ \\
U236 & $1.51114 E-05$
\end{tabular}

\begin{tabular}{|c|c|}
\hline Sotor & CONCENIKAIID \\
\hline 4238 & $3.83333 \mathrm{E}-06$ \\
\hline NP236 & $2.28334 E-10$ \\
\hline NP237 & $1.16648 \mathrm{E}-04$ \\
\hline PU236 & B.11771E-01 \\
\hline PU237 & $5.39863 E-40$ \\
\hline PUZ3B & $1.024 \mathrm{HGE}-01$ \\
\hline PU239 & $1.04360 \mathrm{E}-03$ \\
\hline PU240 & $6.58990 E-04$ \\
\hline PU241 & $1.74102 E-02$ \\
\hline Pu242 & $8.78966 E-07$ \\
\hline $\operatorname{AN} 241$ & $2.80618 E-01$ \\
\hline $\operatorname{AM} 242$ & $1.79681 E-04$ \\
\hline AM2 $42 M$ & $1.605 A 2 E-04$ \\
\hline $\operatorname{AM2} 43$ & $1.58838 \mathrm{BE}-05$ \\
\hline CM242 & $1.49034 E-04$ \\
\hline $\mathrm{CM} 243$ & $5.1366 \angle E-0 S$ \\
\hline CM244 & $1.46315 E-03$ \\
\hline CM245 & B. $14519 E-C E$ \\
\hline CM246 & $6.97646 E-09$ \\
\hline $\operatorname{CM} 247$ & B. 5 AB BOE-IS \\
\hline CM248 & $8.969 \mathrm{COE}-15$ \\
\hline
\end{tabular}

a. The isotopic concentrations were computed by a computer model which simulates the flow of isotopes through the reference process. Unless otherwise noted, no credit was taken for decontamination by the ion exchange flowsheet except for cesium, plutonium, and strantium.

b. Based on chemical analyses (see footnote $c$ ) the total contribution from these isotopes is $<0.5 n \mathrm{Ci} / \mathrm{g}$.

c. These values were determined analytically after actual SRP waste supernate was clarified and treated by the reference ion exchange process (see "Reference Process for Disposal of SRP Waste Salt." Internal memorandum, B. W. Benjamin-P. L. Roggenkamp to S. Mirshak, November 16, 1979). Concentrations computed by the computer model are documented in appendix 13.7. 


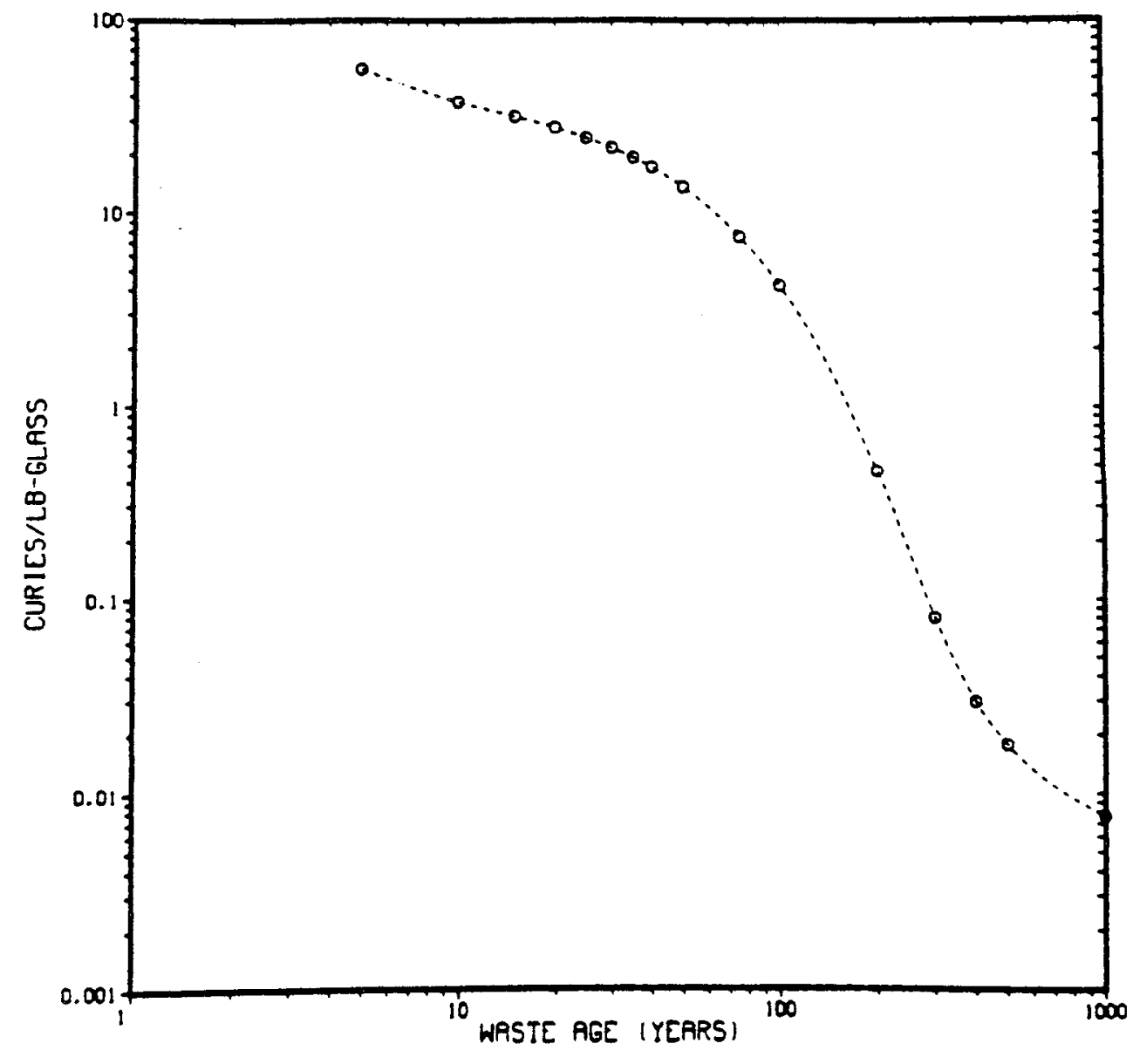

FIGURE 3.1 Activity in DWPF Glass 


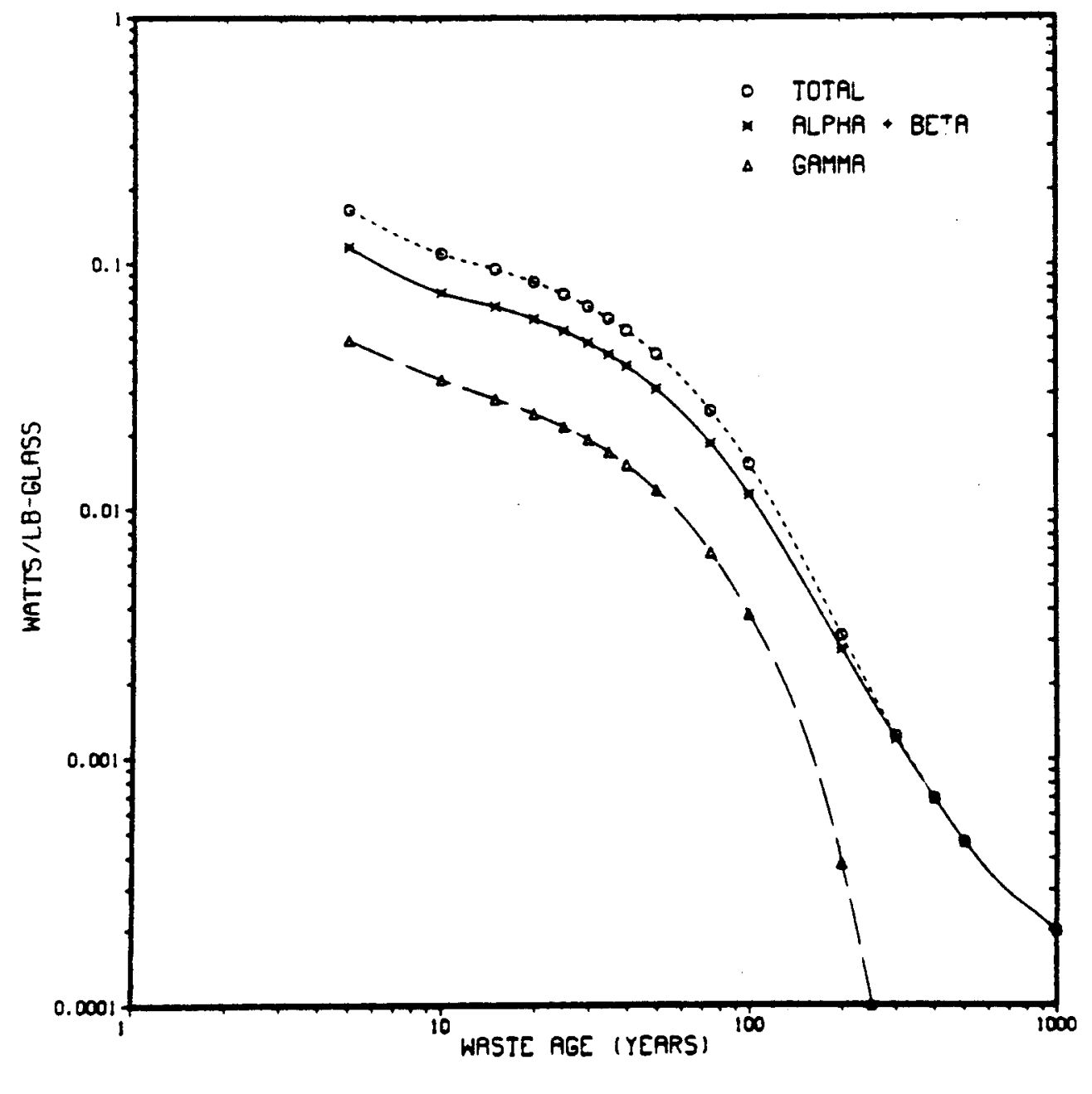

FIGURE 3.2 Decay Heat in DWPF Glass 


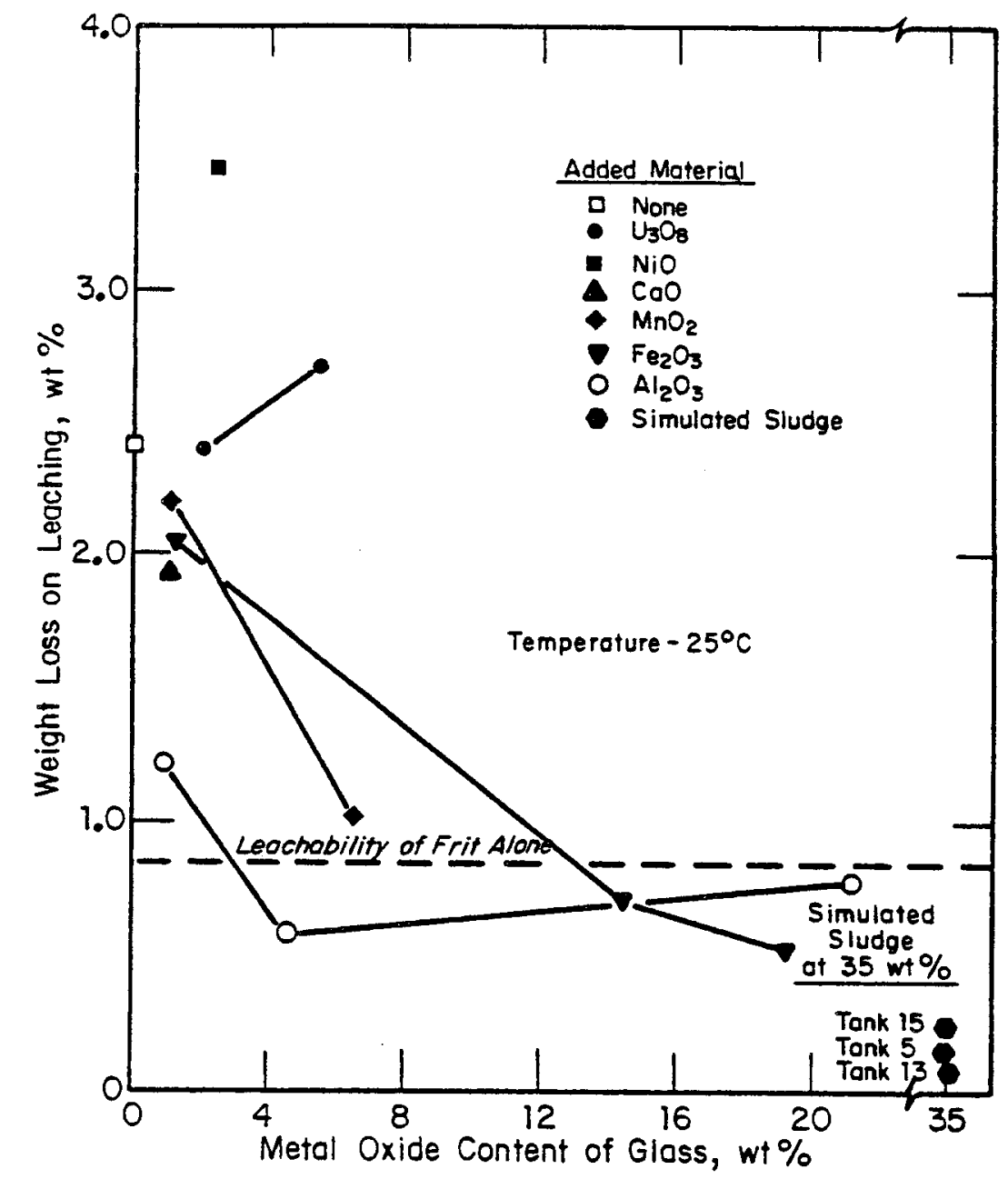

FIGURE 3.3. Leachability of Sludge Components in Frit 21 


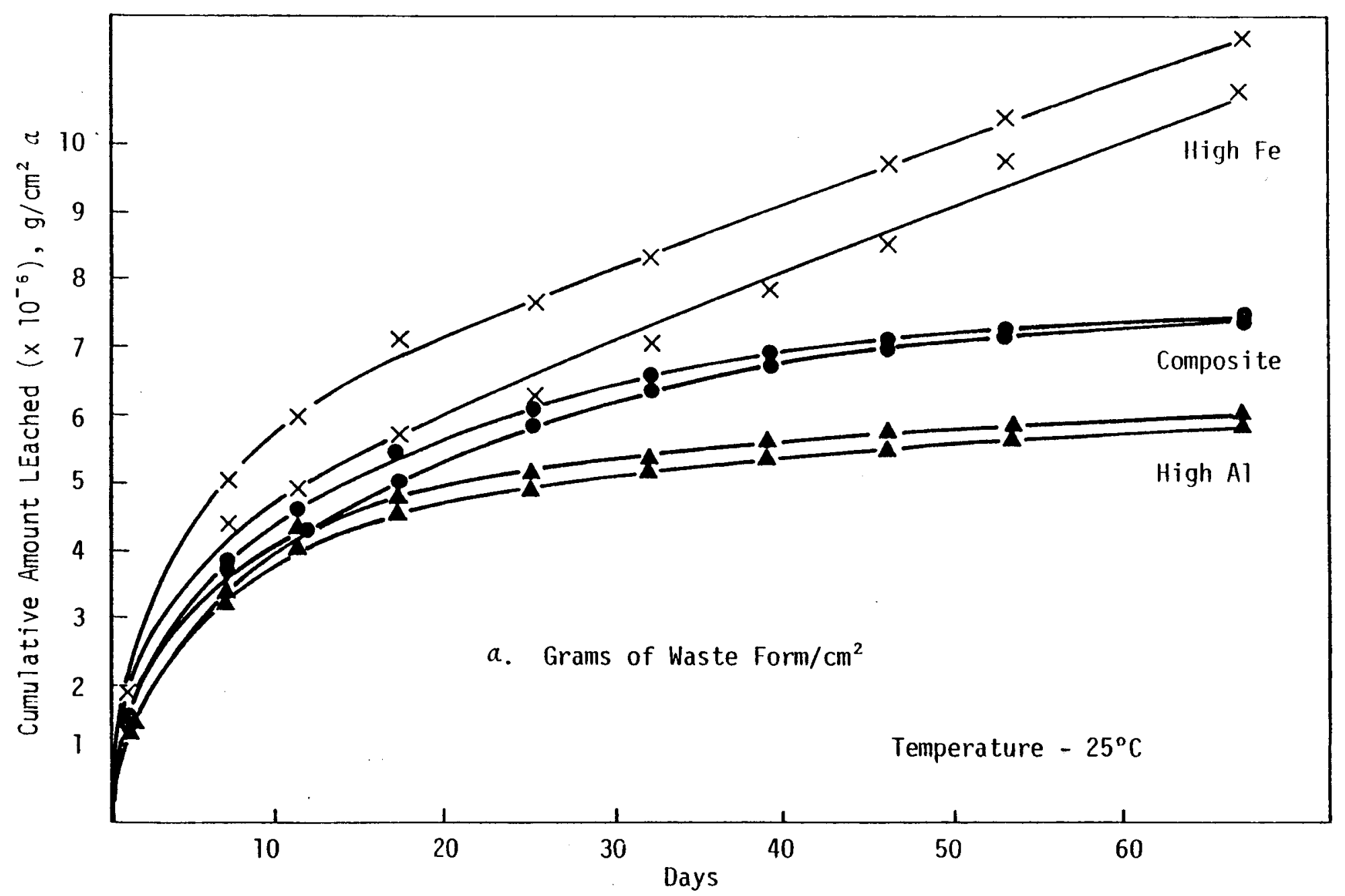

FIGURE 3.4. Cumulative Leaching of Frit 21-Simulated SRP Sludge Glasses in Brine Based on ${ }^{137} \mathrm{Cs}$ (Duplicate Sample Data Included) 


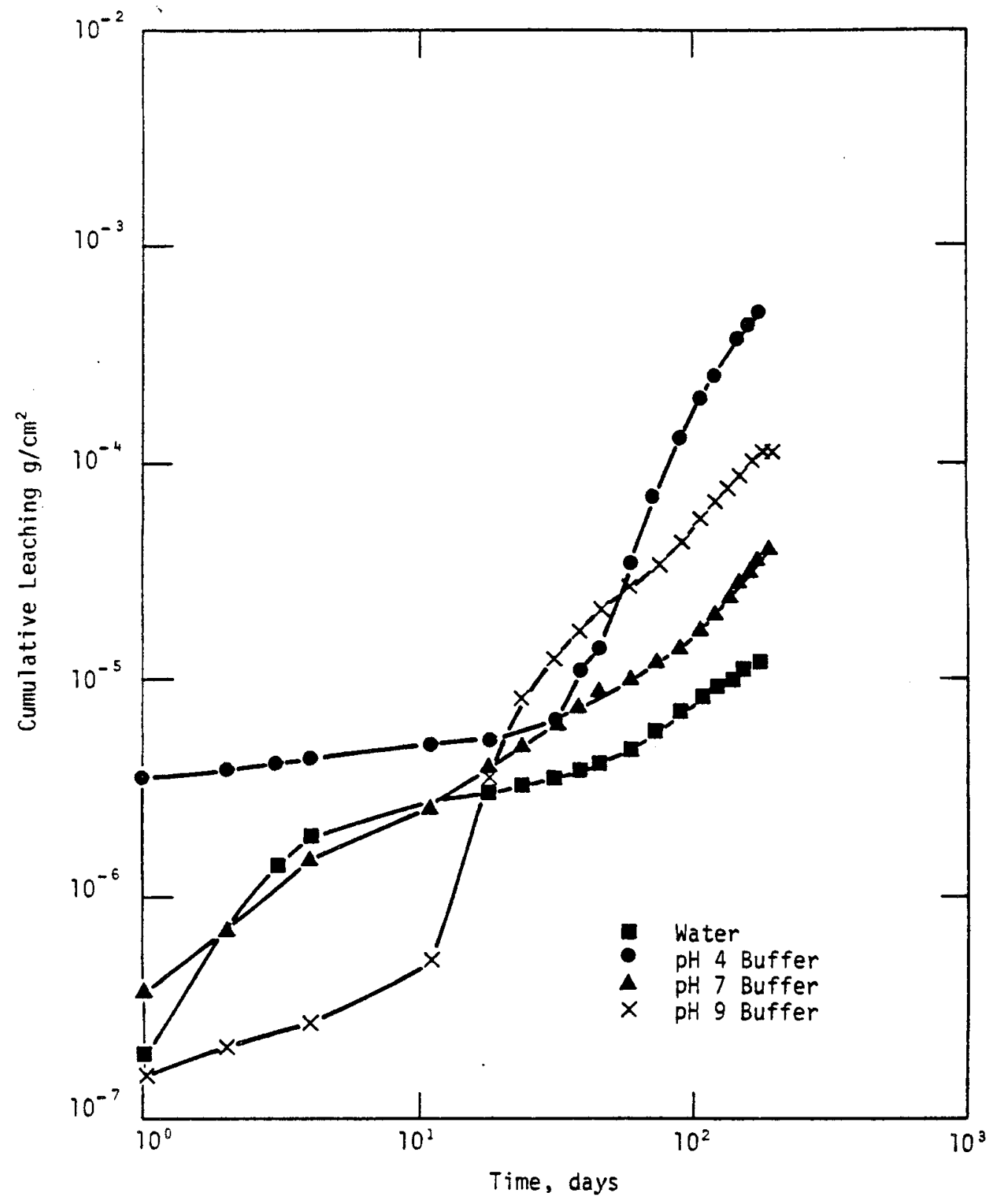

FIGURE 3.5. Cumulative Leaching of Frit 21-SRP Waste Tank No. 13 Glasses Based on ${ }^{9} \mathrm{Sr}$ 


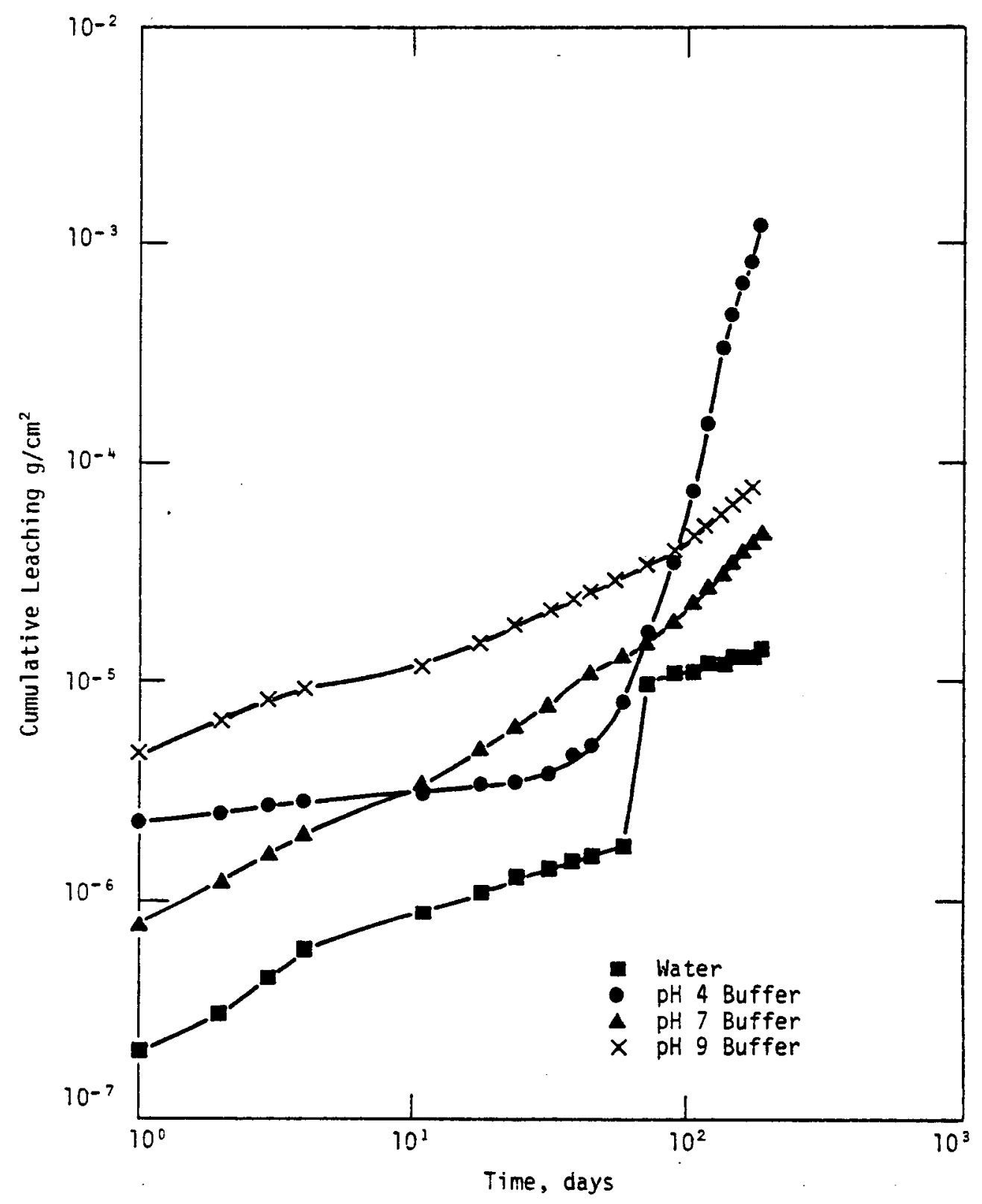

FISURE 3.6. Cumulative Leaching of Frit 21-SRP Waste Tank No. 16 Glasses Based on ${ }^{98} \mathrm{Sr}$ 


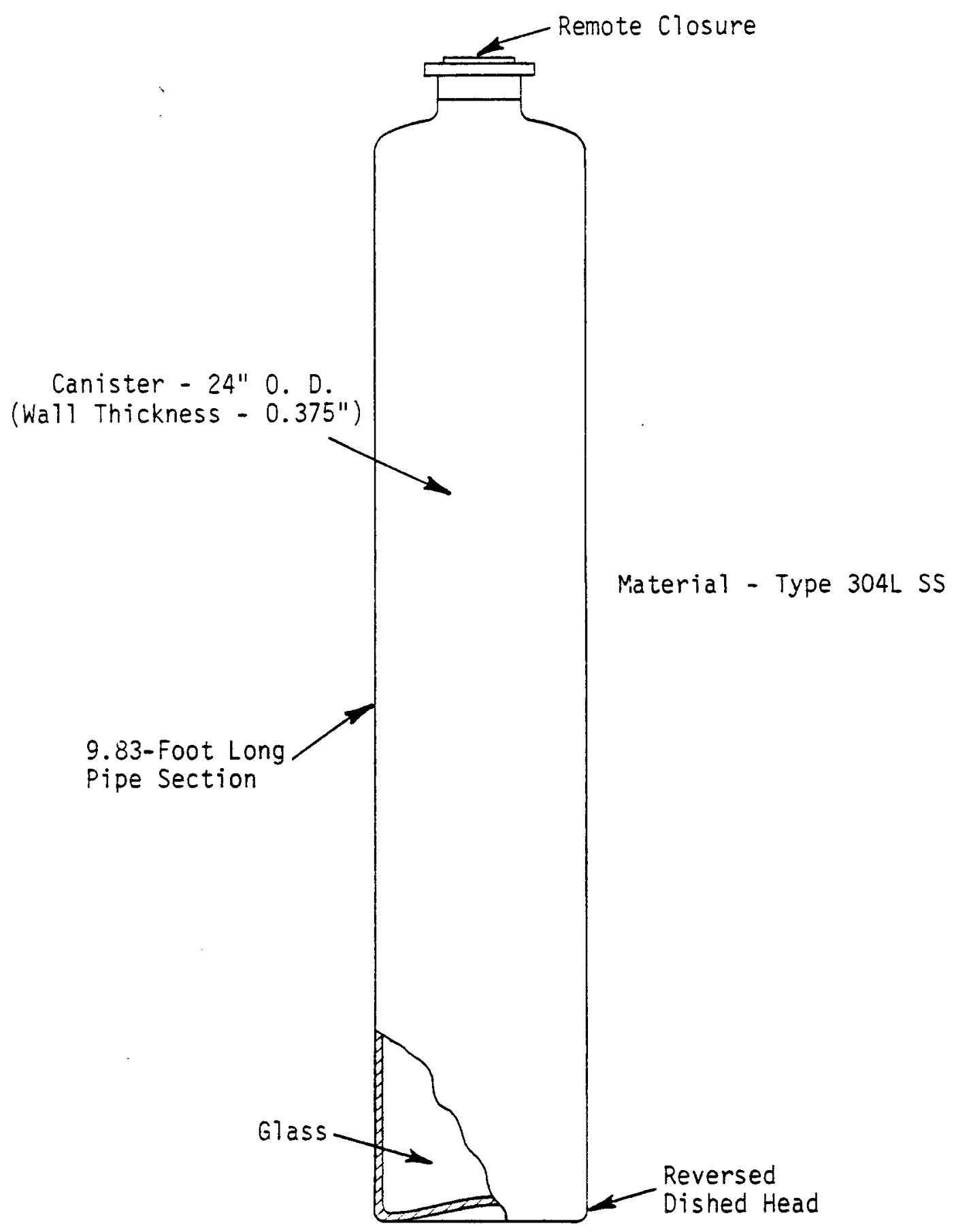

FIGURE 3.7. Reference Canister Design 


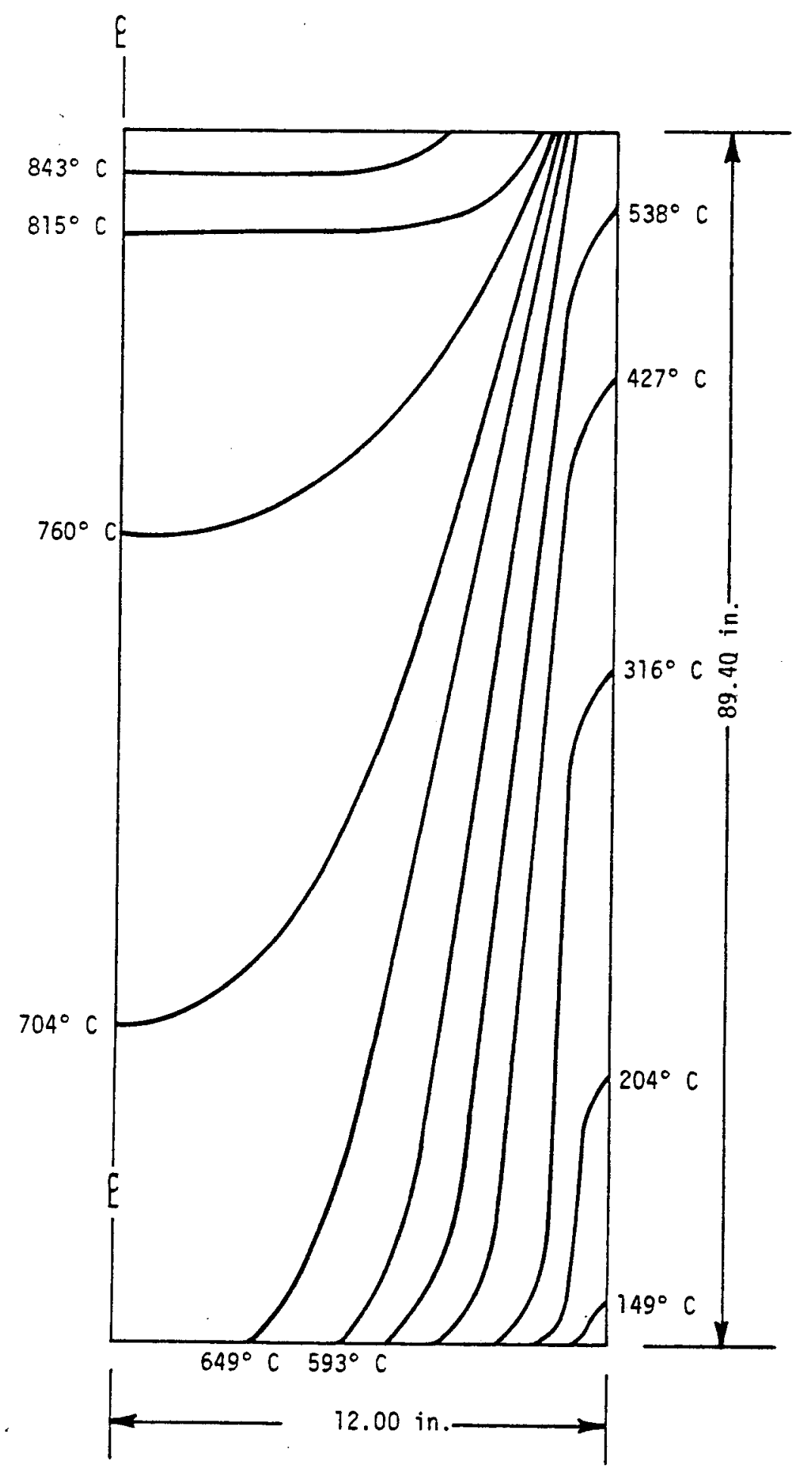

FIGURE 3.8. Isotherms at End of Canister Fill 


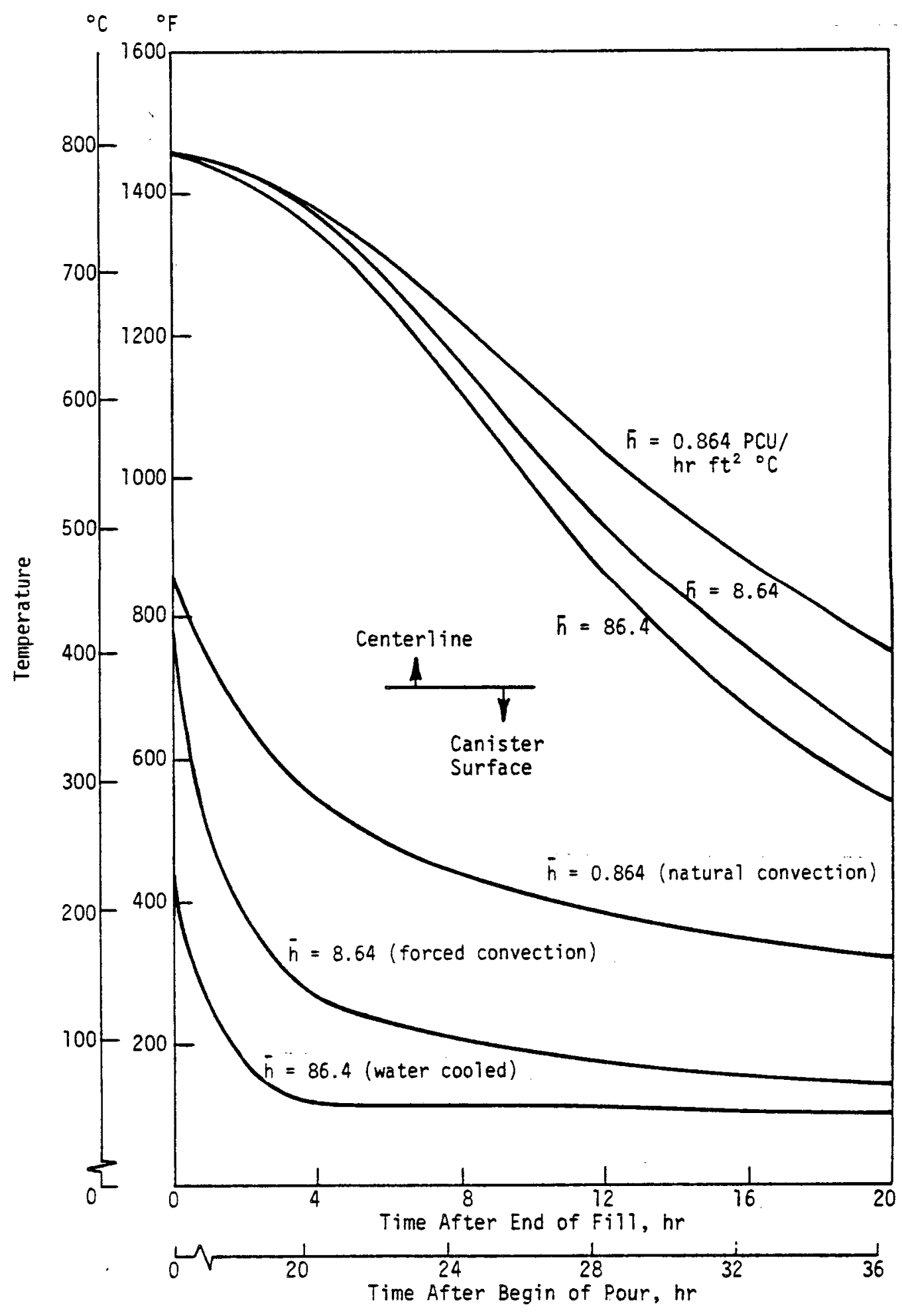

FIGURE 3.9 Temperature History for Canister 


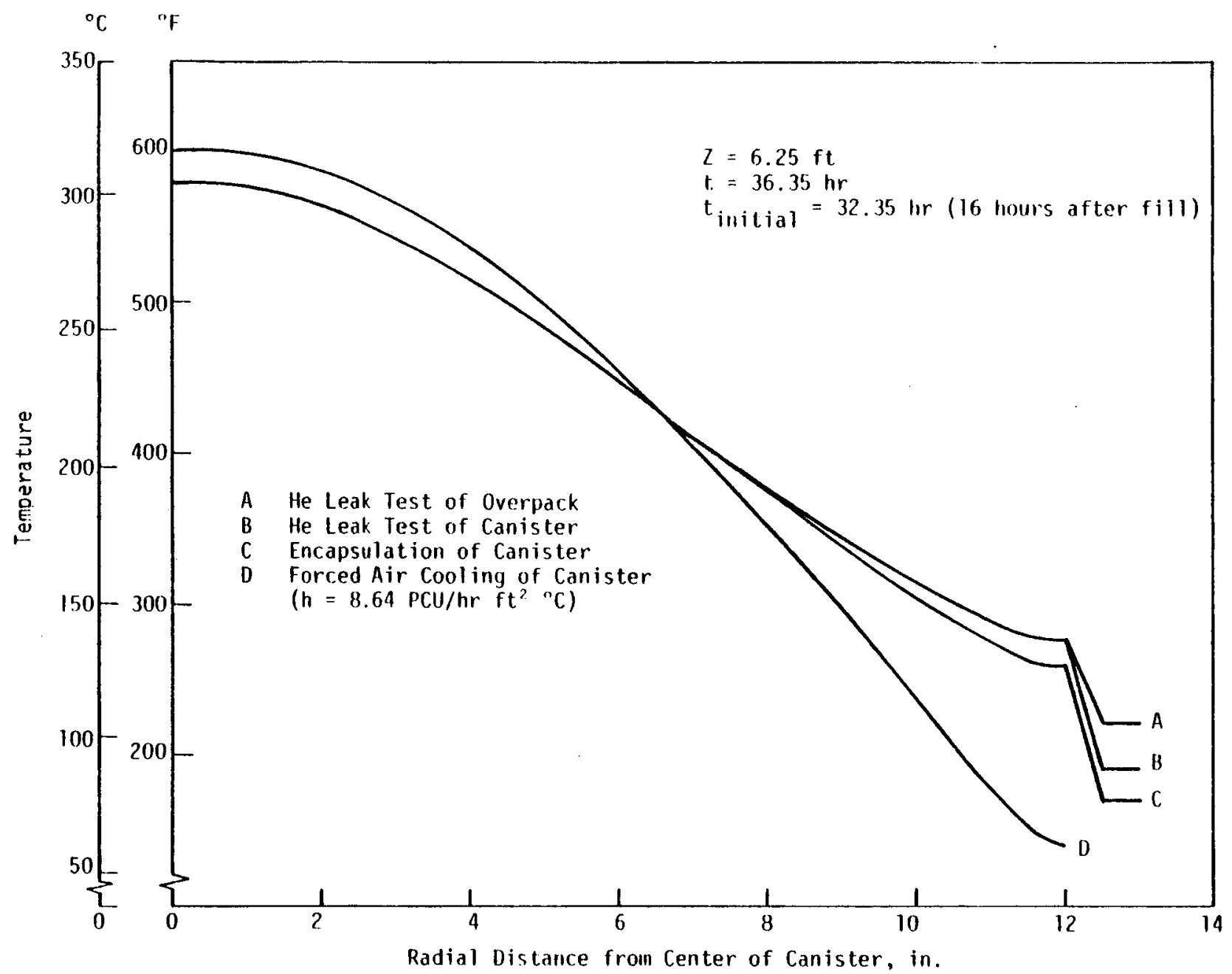

FIGURE 3.10. Short-Term Temperature Effects of Subsequent Canister/Container Processing (Process Duration $=4$ hours) 


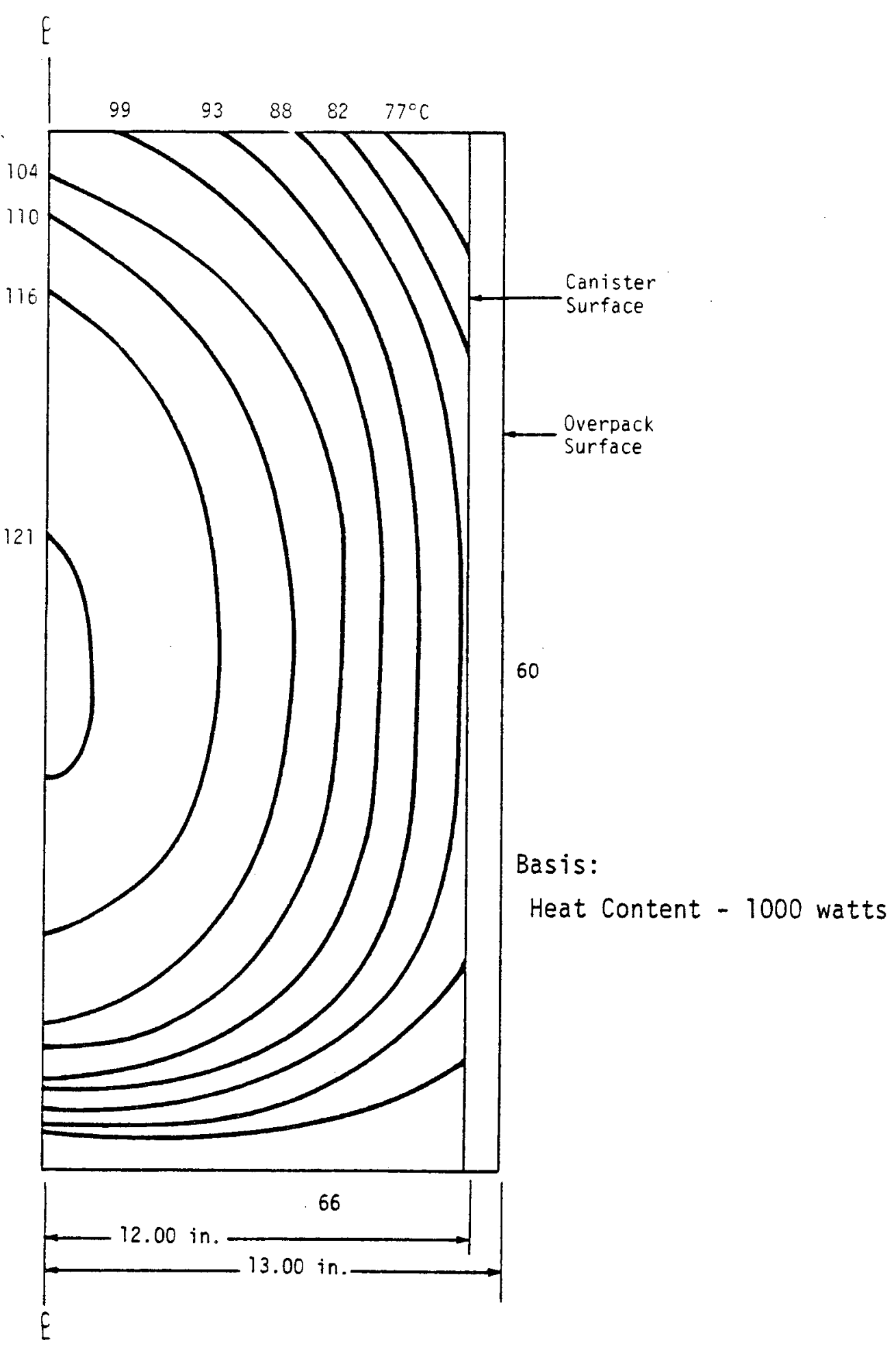

FIGURE 3.11. Canister Isotherms at Steady State $\bar{h}=0.864 \mathrm{PCU}\left(\mathrm{hr}-\mathrm{ft}^{2}-{ }^{\circ} \mathrm{C}\right)$ 
FIGURE 3.12 (Deleted)

$\Theta$ 


\subsection{References}

1. G. W. Morey. The Properties of Glass, Second Edition, Reinnold, New York (1952).

2. G. G. Wicks. Phenomena and Processes of Interest in Making SRP Waste-Glass Forms. Internal Report DPST-77-307, E. I. du Pont de Nemours \& Co. (Inc.), Savannah River Laboratory, Aiken, SC (May 1977).

3. F. P. Hall, J. Amer. Ceram. Soc. 13, 182 (1930).

4. J. A. Kelley. Evaluation of Glass as a Matrix for Solidification of Savannah River Plant Waste - Nonradioactive and Tracer Studies. USERDA Report DP-1382, E. I. du Pont de Nemours \& Co. (Inc.), Savannah River Laboratory, Aiken, SC (1975).

5. R. P. Turcotte and F. P. Roberts. "Phase Behavior and Radiation Effects in High Level Waste Glass." In Ceramic and Glass Radioactive Waste Forms. CONF-770102 (1977).

6. J. A. Kelley and W. N. Rankin. Correlation of Radionuclide Leachabilities with Microstructures of Glass Containing SRP Waste. USERDA Report DP-1411, E. I. du Pont de Nemours \& Co. (Inc.), Savannah River Laboratory, Aiken, SC (1975).

7. A. R. Hall, J. T. Dalton, B. Hudson, and J. A. C. Marples. "Development and Radiation Stability of Glasses for Highly Radioactive Wastes." In International Symposium on the Management of Radioactive Wastes from the Nuclear Fuel Cycle. IAEA-SM-207/24, International Atomic Energy Agency, Vienna, Austria (1976).

8. D. R. Uhlman. "The Stability of Glasses." In Ceramic and Glass Radioactivce Waste Forms. CONF-770102, p 121(1977).

9. G. G. Wicks. Phenomena and Processes of Interest in Making SRP Glass Waste Forms. Internal Report DPST-77-307, E. I. du Pont de Nemours \& Co. (Inc.), Savannah River Laboratory, Aiken, SC (1977).

10. J. A. Kelley. Evaluation of Glass as a Matrix for Solidification of SRP waste. USERDA Reports DP-1382 and DP-1397, E. I. du Pont de Nemours \& Co. (Inc.), Savannah River Laboratory, Aiken, SC (1975).

11. W. Heimer1, H. Heine, L. Kahl, H. W. Levi, W. Letze, G. Malow, E. Schiewer, and P. Schubert. "Studies on the Behavior of Radioactive Glass." In Management of Radioactive Wastes from Fuel Reprocessing, Paris, France (1972). 
12. I. H. Smith and W. A. Ross. Impact Testing of Vitreous Simulated High-Level Waste in Canisters. USERDA Report BNWL-1903, Battelle Northwest Laboratories, Richland, WA (1975).

13. "Thermal Effects." Report of a Comittee. In Ceramic and Glass Radioactive Waste Forms. CONF-770102, pp 249-255 (1977).

14. Savannah River Laboratory Monthly Report, May 1977. USERDA Report DP-77-1-5, E. I. du Pont de Nemours \& Co. (Inc.), Savannah River Laboratory, Aiken, SC (1977) (Confidential).

15. J. E. Mende1, W. A. Ross, F. P. Roberts, R. P. Turcotte, Y. B. Katayama, and J. H. Westsik, Jr. "Thermal and Radiation Effects on Borosilicate Waste Glasses." In Management of Radioactive Wastes from the Nuclear Fuel Cycle. IAEA-SM207/100, V. II, International Atomic Energy Agency, Vienna, Austria (1976).

16. W. M. Hampton. J. Soc. Glass Tech. 20, 461 (1936).

17. J. A. Kelley. Evaluation of Glass as a Matrix for Solidification of Savannah River Plant Waste: Nonradioactive and Tracer Studies. USERDA Report DP-1382, E. I. du Pont de Nemours \& Co. (Inc.), Savannah River Laboratory, Aiken, SC (1975).

18. Savannah River Laboratory Quarterly Report: Waste Management January-March 1977. ISERDA Report DPST-77-125-1, E. I. du Pont de Nemours \& Co. (Inc.), Savannah River Laboratory, Aiken, SC (1977).

19. J. A. Stone. Separation of SRP Waste Sludge and Supernate. USERDA Report DP-1441, E. I. du Pont de Nemours $\&$ Co. (Inc.), Savannah River Laboratory, Aiken, SC (1976).

20. Savannah River Laboratory Quarterly Report: Waste Management July-September 1976. USERDA Report DPST-76-125-3, E. I. du Pont de Nemours \& Co. (Inc.), Savannah River Laboratory, Aiken, SC (1976).

21. J. A. Kelley. Evaluation of Glass as a Matrix for Solidification of Savannah River Plant Waste: Radioactive Studies. USERDA Report DP-1397, E. I. du Pont de Nemours \& Co. (Inc.), Savannah River Laboratory, Aiken, SC (1975).

22. W. N. Rankin. Prediction of Canister Lifetime. Internal Report DPST-79-584, E. I. du Pont de Nemours \& Co. (Inc.), Savannah River Laboratory, Aiken, SC (December 1979). 
23. Deleted

24. Deleted

25. W. N. Rankin. "Compatibility Testing of Vitrified Waste Forms." Presented at Corrosion/78 NACE Meeting, Houston, Texas, March 6-10, $197 \overline{8 .}$

26. Deleted

27. W. N. Rankin. Attack of High-Strength, Oxidation-Resistant Alloys During In-Can Melting of Simulated Waste Glasses. SRL Manuscript DP-MS-79-39 (Rev.), proposed for presentation at Corrosion/80 NACE Meeting, Chicago, Illinois, March 6-10, 1980 .

28. R. M. Wallace, H. L. Hull, and R. F. Bradley. Solid Forms for Savannah River Plant High-Level Waste. USAEC Report DP-1335, E. I. du Pont de Nemours \& Co. (Inc.), Savannah River Laboratory, Aiken, SC (1974).

29. R. S. Ondrejcin. Chemical Compositions of Supernate Stored in SRP High Level Waste Tanks. USAEC Report DP-1347, E. I. du Pont de Nemours \& Co. (Inc.), Savannah River Laboratory, Aiken, SC (1974).

30. M. H. Tennant to G. F. Merz. Thermal Analysis of DWPF Canister Processing. Internal Report DPST-78-380, E. I. Du Pont de Nemours \& Co. (Inc.), Savannah River Laboratory, Aiken, SC (June 20, 1978). 


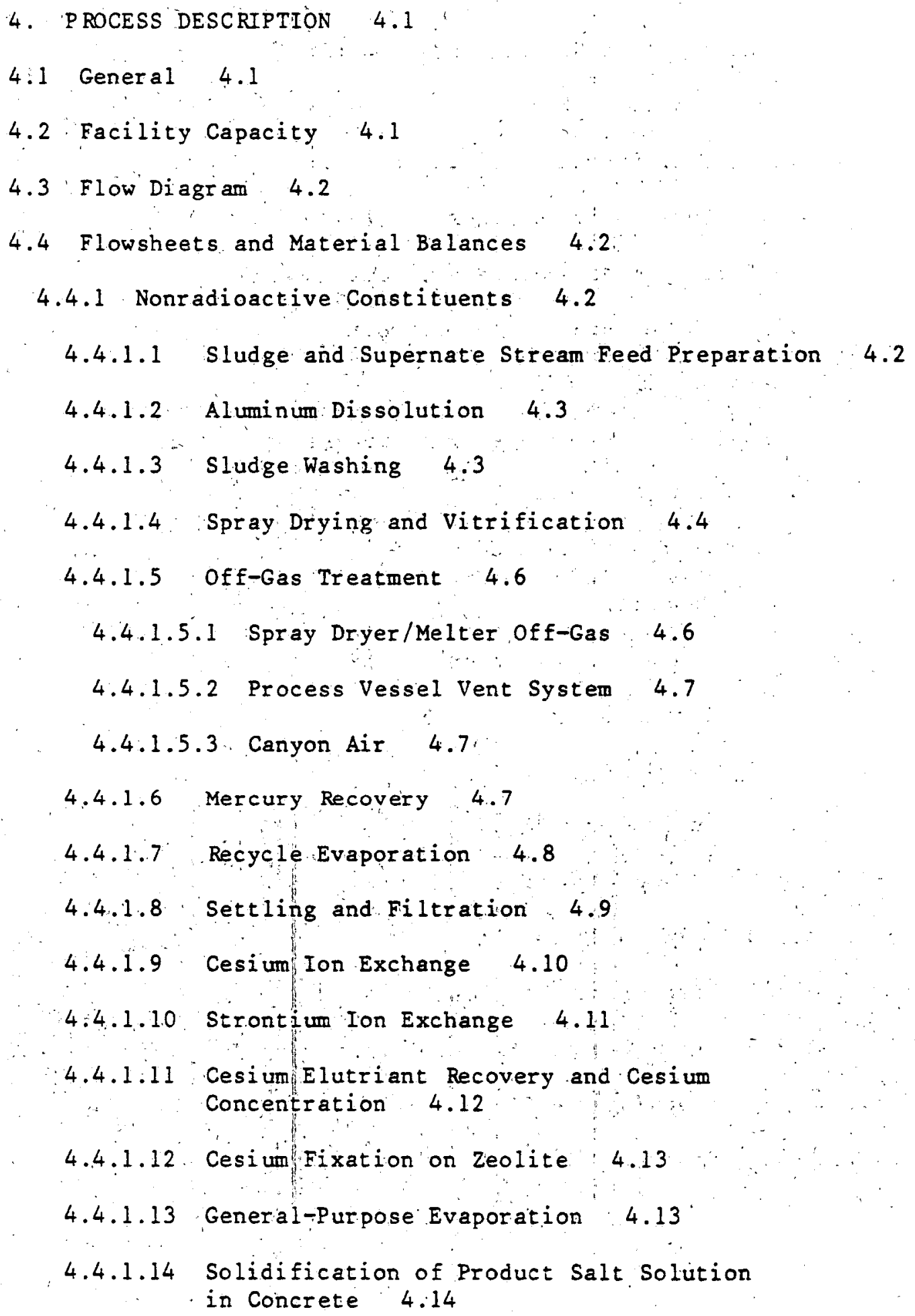




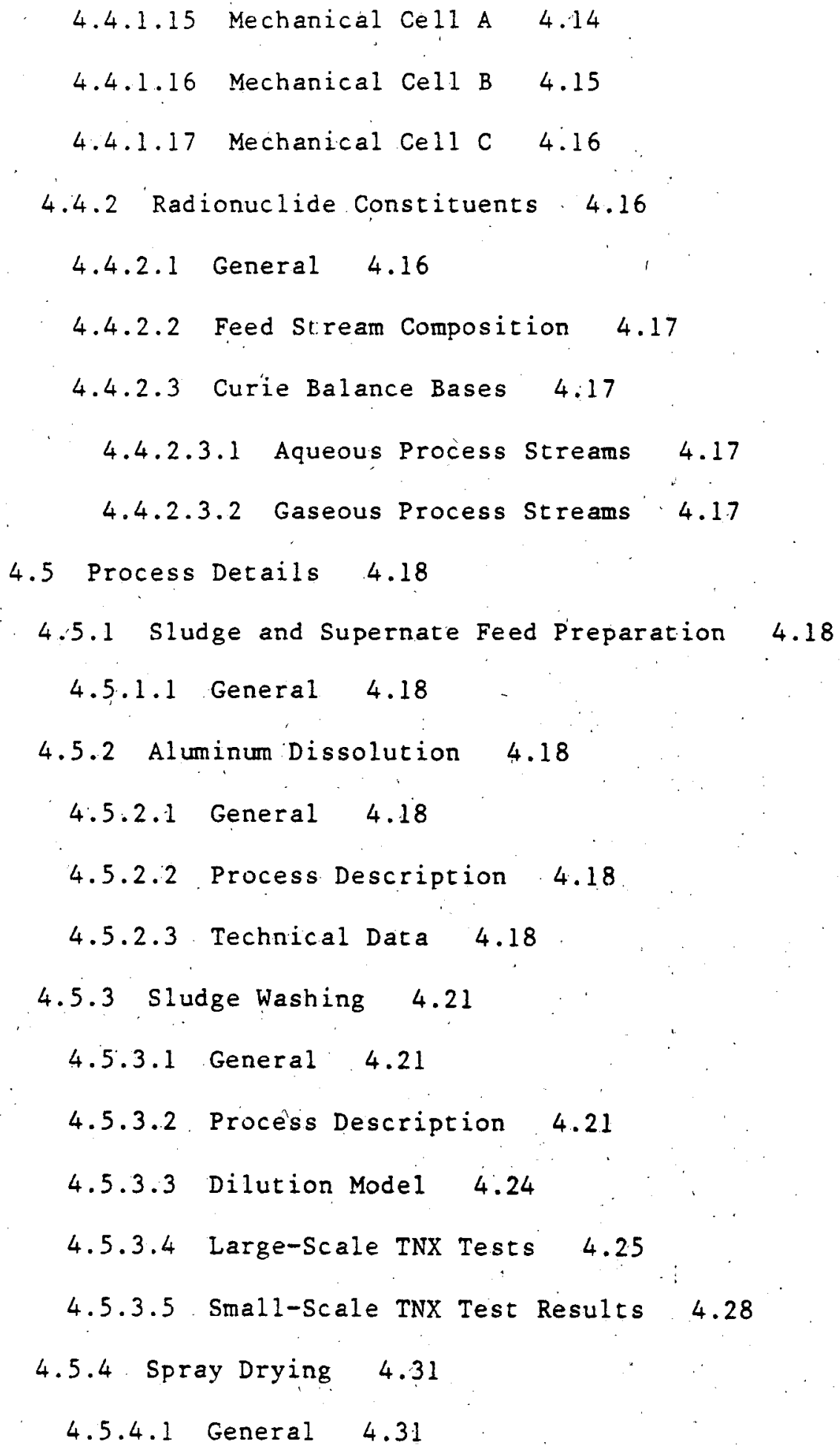




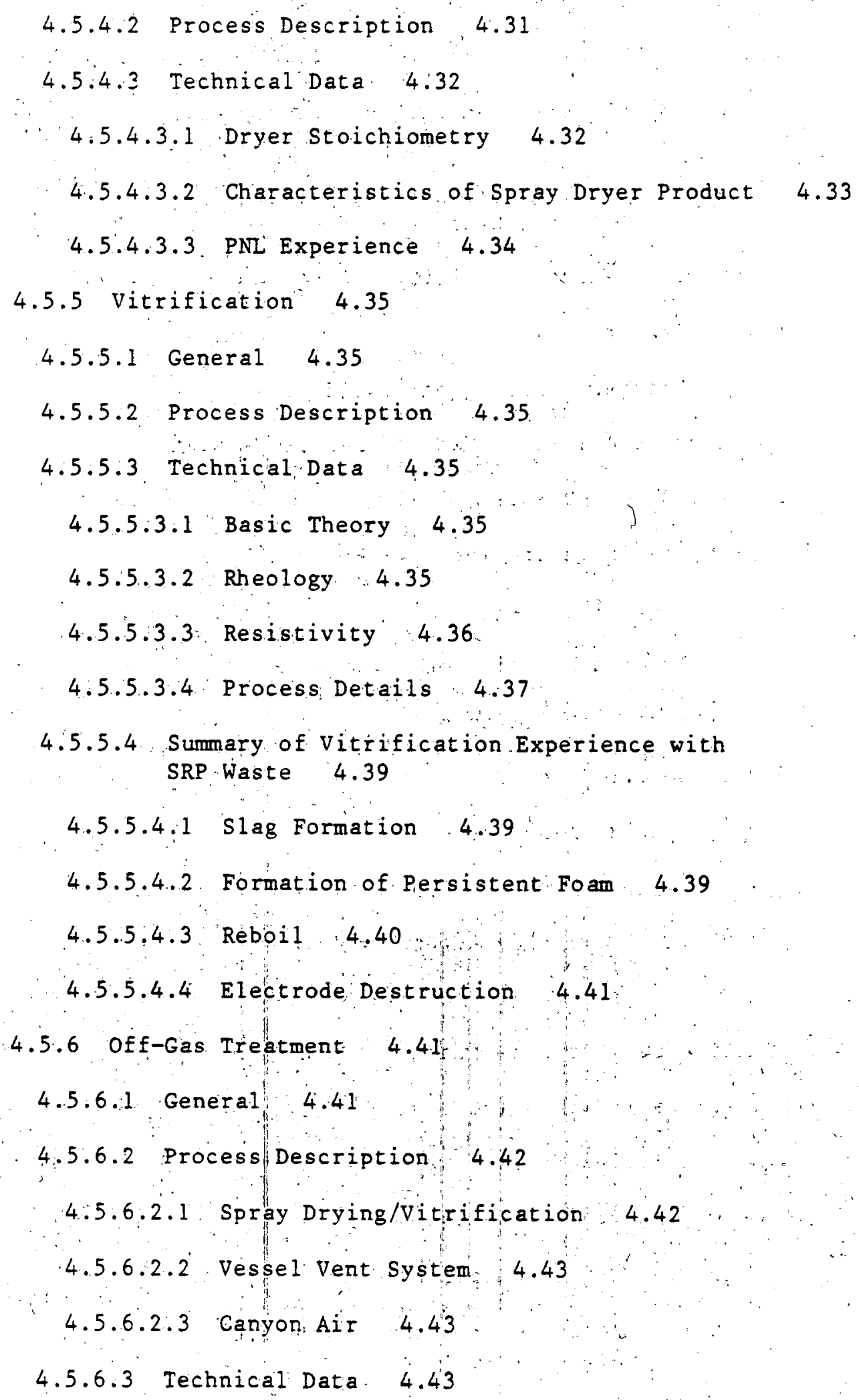


4.5.6.3.1 Spray Dryer/Melter $\quad 4.43$

4.5.6.3.2 Process Vesse1 Vent 4.44

4.5.6.3.3 Volatile Components in Spray Dryer Off-Gas 4.45

4.5.6.3.4 Particulate Characteristics of Off-Gas Stream 4.47

4.5.7 Mercury Recovery Facility 4.48

4.5.7.1 General 4.48

4.5.7.2 Process Description 4.48

4.5.7.3 Physical Properties of Mercury 4:48

4.5.7.4 SRL Experience 4.49

4.5.8 Recycle Concentration $\quad 4.49$

4.5.8.1 General 4.49.

4.5.8.2 Process Description 4.49

4.5.9 Settling and Filtration 4.50

4.5.9.1 General 4.50

4.5.9.2 Process Description 4.51

4.5.9.3 Technical Data 4.52

4.5.9.3.1 Gravity Settling 4.52

4.5.9.3.2 Sand Filtration 4.57

4.5.10 Supernate Decontamination 4.62

4.5.10.1 Cesium and Plutonium 4.62

4.5.10.1.1 General $\quad 4.62$

4.5.10.1.2 Process Description 4.62

4.5.10.1.3 Cycle Schedule 4.62

4.5.10.1.4 Resin Description and Physical

Properties. 4.63 


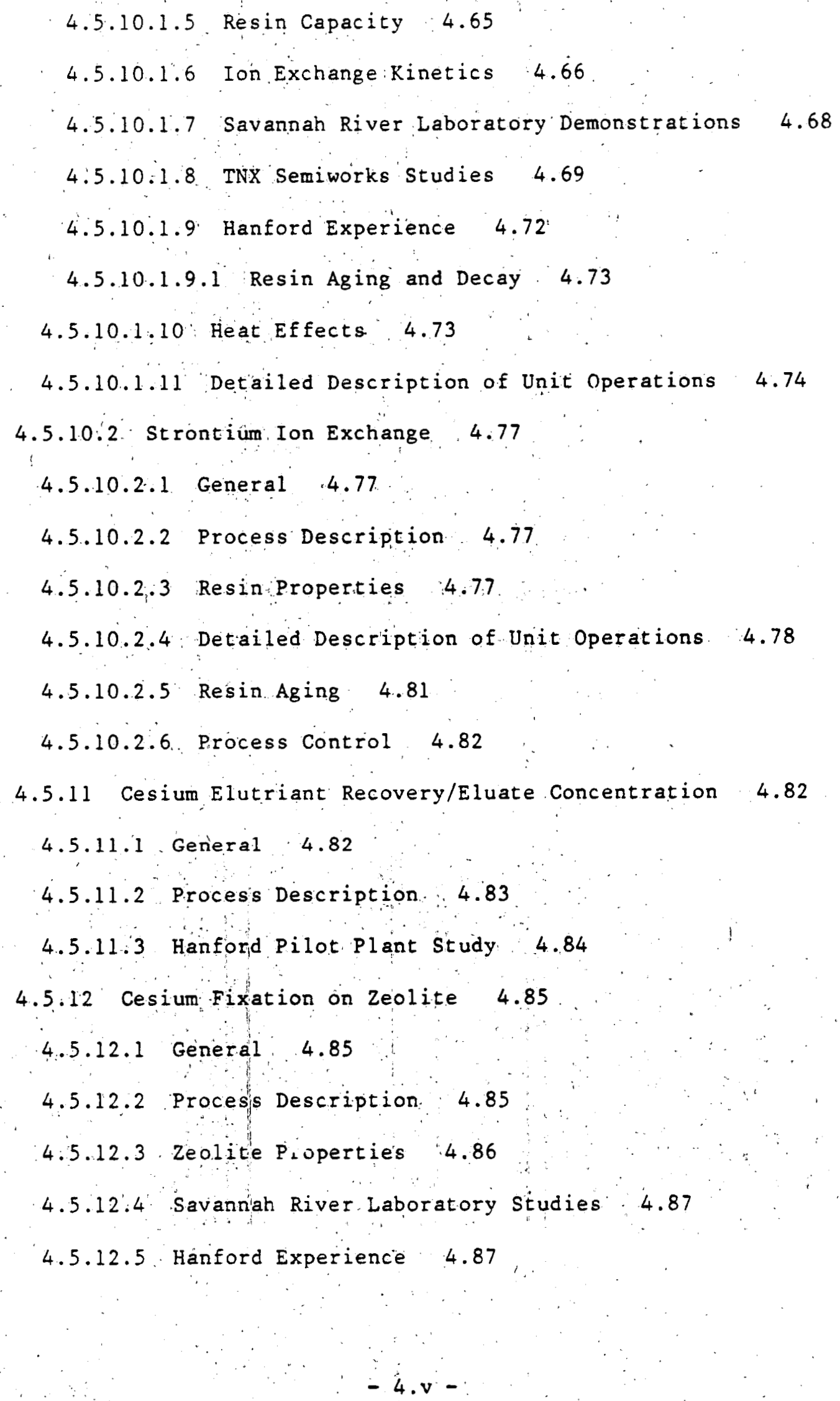




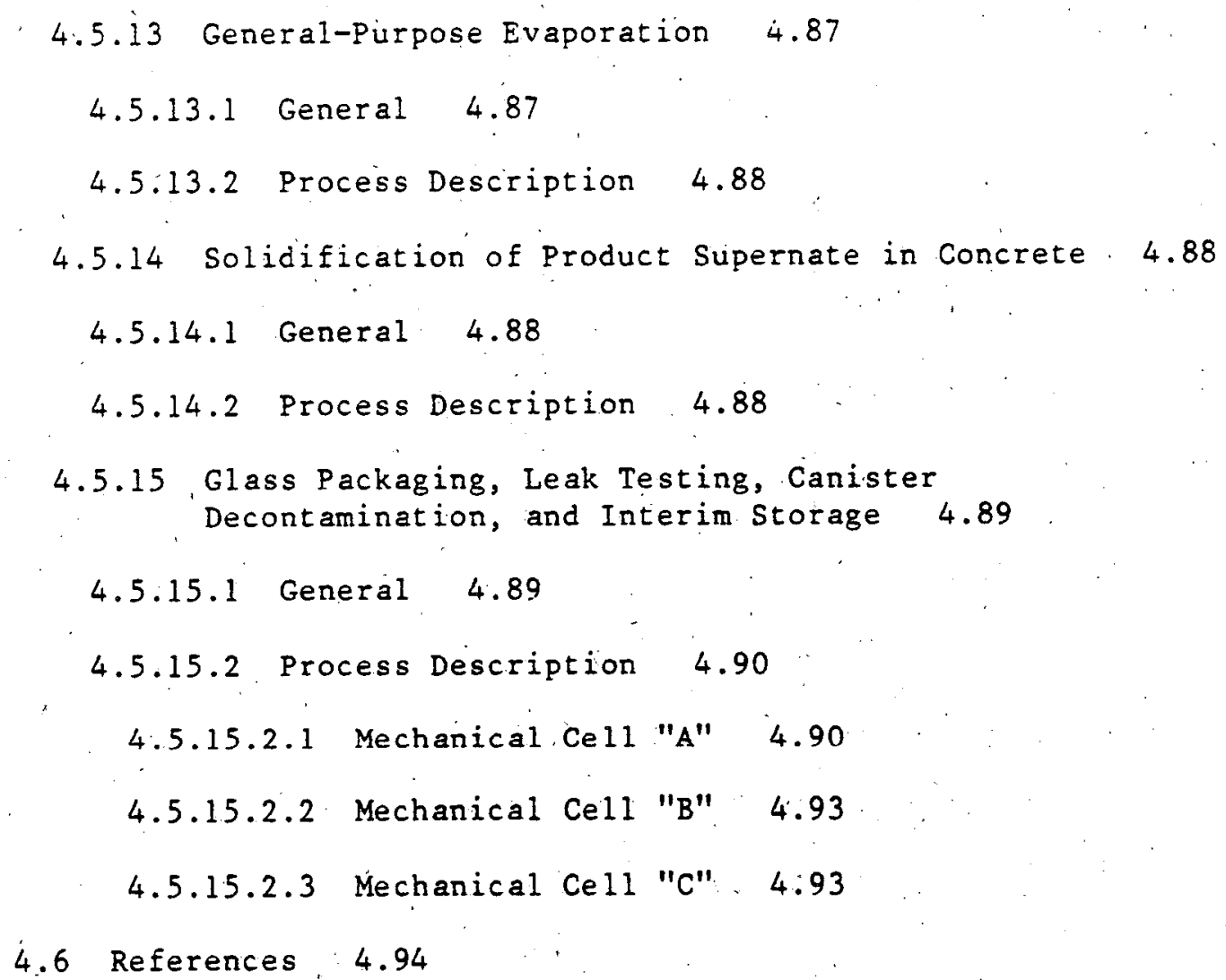




\section{PROCESS DESCRIPTION}

\subsection{General (I. F. Landon)}

High-level liquid wastes are separated into two fractions in the 241-F and the 241-H waste tank storage facilities prior to transfer to the DWPF. The first fraction, designated the supernate feed stream, is a blend of appropriately aged supernate and redissolved salt cake. The other fraction, designated as the sludge-slurry feed stream, is a blend of the in-tank settled insolubles.

The aluminum content of the sludge-slurry is reduced by caustic dissolution. Soluble salts are then separated from the sludge by washing and centrifugation.

The insoluble solids fraction of the supernate feed stream is separated by gravity settling and filtration. Cesium, plutonium, and strontium are removed from the clarified supernate using ion exchange resins. The clarified supernate is solidified in concrete and buried in soil trenches.

Cesium and plutonium eluted from the ion exchange resin are separated from the elutriant by fixation on zeolite. The zeolite slurry, concentrated strontium eluate, and washed sludge are dried and melted with additives to form a borosilicate glass. The glass is poured into stainless steel canisters where it hardens upon cooling. Lids are welded on the canisters. Each canister is inspected, leak checked, decontaminated and shipped to an on-site interim storage facility.

\subsection{Facility Capacity (L. F. Landon)}

The facility is to be capable of processing waste at an average attained rate of $9 \mathrm{gpm}$ equivalent feed on a reconstituted basis. This rate is a good compromise between low cost and rapid waste inventory reduction. Smaller, slightly lower-cost plants would require excessively long processing periods and would be unresponsive to the need for prompt action on waste disposal. Larger plants, although processing waste faster, would be more expensive and would "catch up" with SRP waste generation after a few years of operation, thereafter requiring inefficient operation at a reduced rate and imposing an additional cost penalty. Additional information concerning the selection of the reference capacity is detailed in DPST-78-582. 
4.3 Flow Diagram (L. F. Landon)

Figure 4.1 is a block flow diagram for the defense waste processing facility.

4.4 Flowsheets and Material Balances (G. W. Becker, J. R. Chandler,
L. F. Landon)

This section describes in detail the bases used to develop flowsheets and material balances for each process module. Only main process lines are illustrated and parallel operations are combined into a single representative operation. Streams that are inconsistent in terms of chemical makeup and solids content (such as lab waste, stack condensate and sand filter condensate) were considered in terms of total flow only. The material balances were prepared using the Du Pont Engineering Department's Chemical Process Evaluation System (CPES) computer program. Unless otherwise specified, process streams are assumed to be at $38^{\circ} \mathrm{C}$ for material balance purposes.

Table 4.1 was prepared to assist in locating flowsheet/ material balance information quickly. Listed are (1) the various process modules which comprise the defense waste processing facility; (2) the flowsheet identification numbers, (3) the flowsheet figure number, (4) the material balance identification numbers, and (5) the material balance table number. The basis used to develop each module's material balance is presented below. More comprehensive discussions of each module are in Section 4.5.

\subsubsection{Nonradioactive Constituents}

\subsubsection{Sludge and Supernate Feed Stream Preparation}

The purpose of these operations is to feed the DWPF two feed streams - a supernate stream and a sludge-slurry stream. The flowsheet (FS-2) is shown in Figure 4.2. The material balance $(M B-2)$ is tabulated in Table 4.2. The material balance bases assumed are:

- F- and H-Area sludges and supernates are blended.

- Sludge is slurried and removed from storage tanks with recycle water. The original compacted sludge volume is slurried with a volume of water such that the resultant volume is twice the original sludge volume. The sludge-slurry is then transferred to aluminum dissolving.

- Redissolved salt cake and aged decanted supernate are removed from storage tanks and sent to gravity settling. One gallon of salt cake makes four gallons of supernate. 
- The detailed bases for the compositions and quantities used in preparing these feed streams are detailed in Appendix 13.2.

- The equivalent of $130 \mathrm{lb} / \mathrm{hr}$ recycle water is used to flush the sludge-slurry transfer line. This is equivalent to a $9360 \mathrm{lb}$ water flush following a transfer made every three days.

\subsubsection{Aluminum Dissolution}

The purpose of these facilities is to remove aluminum from the sludge by boiling the sludge in a caustic solution. The flowsheet (FS-3) is shown in Figure 4.3. The material balance $(\mathrm{MB}-3)$ is tabulated in Table 4.3. The material balance bases are:

- Sludge is in a water-sludge slurry produced by slurrying the original settled volume of the sludge with a volume of water such that the resultant volume is twice that of the original sludge volume.

- Sodium hydroxide is added to the sludge as a 50 wt \% solution so that there are 16 moles of added $\mathrm{NaOH}$ per mole of undissolved aluminum.

- The solution is adjusted to $5 \mathrm{M} \mathrm{NaOH}$ at the beginning of the batch.

- Forty-five percent of the water fed is boiled at total reflux for at least $30 \mathrm{~min}$. For material balance purposes, $75 \%$ of the aluminum is assumed to be dissolved according to the reaction:

$$
\begin{aligned}
& \mathrm{Al}_{2} \mathrm{O}_{3} \cdot 3 \mathrm{H}_{2} \mathrm{O}(\mathrm{s})+2 \mathrm{NaOH} \\
& (\mathrm{aq}) \\
& x=75 \%
\end{aligned}
$$

- Gravity settler bottoms and waste sand/coal are blended in the dissolver after aluminum dissolution is complete.

\subsubsection{Sludge Washing}

The purpose of this operation is to wash salts from the sludge in order to maintain spray dryer feed (Figure 4.5 ) with $\leq 5 \% \mathrm{Na}^{+}$, $\leq 10 \% \mathrm{NO}_{3}{ }^{-}$, and $\leq 3 \% \mathrm{SO}_{4}{ }^{2-}$ on a dry weight bases. The flowsheet (FS-4) is shown in Figure 4.4 . The material balance $(M B-4)$ is tabulated in Table 4.4. The material balance bases are: 
- Washed sludge contains 2.0 wt $\%$ soluble salts on a dry weight basis.

- Sludge is batch washed by dilution with water.

- Three centrifuge passes per batch of feed. The first pass is a sludge dewatering step followed by two wash passes.

- Solids recovery - $98 \%$ in each centrifuge pass.

- Fill basket to $90 \%$ volume in first centrifuge pass.

- Skim to cake surface in each pass.

- Three (3.0) lbs $\mathrm{H}_{2} \mathrm{O} / \mathrm{lb}$ solids in cake.

- Addition of spray water following the third centrifuge pass to provide a washed sludge slurry containing 17 wt \% total solids.

- Use an equal volume of spray water in each centrifuge pass.

- Use an equal volume of wash water plus spray water in each centrifuge pass.

- Centrifuge bowl volume - 120 gallons.

\subsubsection{Spray Drying and Vitrification}

The purpose of spray drying is to convert the sludge slurry feed into a powder for feed to the melter. The purpose of the continuous joule-heated melter is to melt borosilicate glass frit and dryer product into a homogeneous molten glass to be poured into canisters. The flowsheet (FS-5) is shown in Figure 4.5. The material balance (MB-5) is tabulated in Table 4.5. Bases used in developing the material balance are:

- The spray nozzles are operated with four pounds of atomizing air per gallon of dryer feed slurry.

- Total average filter blowback air is $85 \mathrm{SCFH}$.

- $65 \mathrm{lb}$ of frit added/35 lb of solids and salt in spray dryer feed (dry basis).

- Air inleakage rate assumed at $20 \mathrm{lb} / \mathrm{hr}$. 
- Entrained frit air has the same volume as frit.

- $2 \%$ Eree $\mathrm{H}_{2} \mathrm{O}$ in spray dryer product.

- Glass melt temperature $-1150^{\circ} \mathrm{C}$.

- Off-gas temperature - $350^{\circ} \mathrm{C}$ (at sintered metal filters).

- For material balance purposes, the spray dryer/melter stoichiometry is as follows:

$$
\begin{aligned}
& \mathrm{Hg}(\mathrm{s}) \rightarrow \mathrm{Hg}(\mathrm{v}) \\
& \mathrm{HgO}(\mathrm{s}) \rightarrow \mathrm{Hg}(\mathrm{v})+1 / 2 \mathrm{O}_{2}(\mathrm{v}) \\
& \mathrm{Hg}(\mathrm{OH})_{2}(\mathrm{~s}) \rightarrow \mathrm{HgO}_{(\mathrm{s})}+\mathrm{H}_{2} \mathrm{O}(\mathrm{v}) \\
& \mathrm{Cl}^{-}+\mathrm{Na}^{+} \rightarrow \mathrm{NaCl}(\mathrm{s}) \\
& \mathrm{F}^{-}+\mathrm{Na}^{+} \rightarrow \mathrm{NaF}(\mathrm{s}) \\
& 2 \mathrm{NaF}(\mathrm{s})+\mathrm{H}_{2} \mathrm{O}(\mathrm{v}) \stackrel{\mathrm{x}}{\longrightarrow} 2 \mathrm{HF}(\mathrm{v})+\mathrm{Na}_{2} \mathrm{O}(\mathrm{s}) \quad \mathrm{x}=3.8 \% \\
& 2 \mathrm{I}^{-}+\mathrm{Hg}(\mathrm{v}) \rightarrow \mathrm{HgI}_{2}(\mathrm{v}) \\
& \mathrm{HgI}_{2}(\mathrm{v}) \stackrel{\mathrm{x}}{\longrightarrow} \mathrm{Hg}(\mathrm{v})+\mathrm{I}_{2}(\mathrm{v}) \quad \mathrm{x}=1 \% \text { (a } 350^{\circ} \mathrm{C} \text { ) } \\
& 2 \mathrm{Al}(\mathrm{OH})_{3} \rightarrow \mathrm{Al}_{2} \mathrm{O}_{3}(\mathrm{~s})+3 \mathrm{H}_{2} \mathrm{O} \\
& 2 \mathrm{Fe}(\mathrm{OH})_{3} \rightarrow \mathrm{Fe}_{2} \mathrm{O}_{3}(\mathrm{~s})+3 \mathrm{H}_{2} \mathrm{O} \\
& \mathrm{Na}_{2} \mathrm{CO}_{3} \rightarrow \mathrm{Na}_{2} \mathrm{O}(\mathrm{s})+\mathrm{CO}_{2}(\mathrm{v}) \\
& \mathrm{CaCO}_{3} \rightarrow \mathrm{CaO}(\mathrm{s})+\mathrm{CO}_{2}(\mathrm{v}) \\
& 2 \mathrm{Na}_{4} \mathrm{C}_{10} \mathrm{H}_{12} \mathrm{O}_{8} \mathrm{~N}_{2}+22 \mathrm{O}_{2} \rightarrow 20 \mathrm{CO}_{2}(\mathrm{v})+4 \mathrm{NO}(\mathrm{v})+12 \mathrm{H}_{2} \mathrm{O}(\mathrm{v})+4 \mathrm{Na}_{2} \mathrm{O}(\mathrm{s}) \\
& 2 \mathrm{Na}^{+}+\mathrm{SO}_{4}{ }^{2-} \rightarrow \mathrm{Na}_{2} \mathrm{SO}_{4}(\mathrm{~s}) \\
& 2 \mathrm{NaNO}_{3}(\mathrm{~s}) \rightarrow \mathrm{Na}_{2} \mathrm{O}(\mathrm{s})+2 \mathrm{NO}(\mathrm{v})+3 / 2 \mathrm{O}_{2}(\mathrm{v}) \\
& 2 \mathrm{NaOH}_{(\mathrm{v})} \rightarrow \mathrm{Na}_{2} \mathrm{O}(\mathrm{s})+\mathrm{H}_{2} \mathrm{O}(\mathrm{v}) \\
& 2 \mathrm{NaNO}_{2}(\mathrm{~s}) \rightarrow \mathrm{Na}_{2} \mathrm{O}(\mathrm{s})+2 \mathrm{NO}(\mathrm{v})+1 / 2 \mathrm{O}_{2}(\mathrm{v}) \\
& \mathrm{Ni}(\mathrm{OH})_{2} \rightarrow \mathrm{NiO}(\mathrm{s})+\mathrm{H}_{2} \mathrm{O}(\mathrm{v}) \\
& 2 \mathrm{NaAlO}_{2}(\mathrm{~s}) \rightarrow \mathrm{Na}_{2} \mathrm{O}(\mathrm{s})+\mathrm{Al}_{2} \mathrm{O}_{3}(\mathrm{~s}) \\
& 3 \mathrm{UO}_{2}(\mathrm{OH})_{2}(\mathrm{~s})-\mathrm{U}_{3} \mathrm{O}_{8}+3 \mathrm{H}_{2} \mathrm{O}(\mathrm{v})+1 / 2 \mathrm{O}_{2}(\mathrm{v}) \\
& \mathrm{C}_{6} \mathrm{H}_{10} \mathrm{O}_{5}(\mathrm{~s})+6 \mathrm{O}_{2}(\mathrm{v}) \rightarrow 5 \mathrm{H}_{2} \mathrm{O}(\mathrm{v})+6 \mathrm{CO}_{2}(\mathrm{v}) \\
& -4.5 \text { - }
\end{aligned}
$$




\subsubsection{Off-Gas Treatment}

The purpose of these facilities is to decontaminate gaseous effluents such that they meet state and federal regulations.

The flowsheet (FS-6) is shown in Figure 4.6. The material balance $(M B-6)$ is shown in Table 4.6. Material balance bases are as follows:

\subsection{Spray Dryer/Melter Off-Gas}

- Temperature of vapor leaving spray dryer filters $-350^{\circ} \mathrm{C}$.

- The ejector/venturi scrubber liquid cooled to $40^{\circ} \mathrm{C}$ vapor temperature.

- Off-gas temperature reduced to $50^{\circ} \mathrm{C}$ in ejector/venturi.

- Water and mercury vapor concentrations in the vapor effluent from the off-gas condensate tank and the secondary deep bed filter are the saturation concentrations at the vapor temperature.

- Mercury is separated as $100 \%$ mercury liquid.

- HF is totally soluble in the off-gas condensate.

- $\mathrm{HgI}_{2}$ vapor and the volatile species of cesium, technetium, selenium, tellurium, rubidium, and molybdenum condense and coalesce in the ejector/venturi to form submicron particulates with a nominal diameter of $0.3 \mu \mathrm{m}$.

- Washed deep bed filter lower spray - 2 gpm; upper spray - 40 gpm.

- Atomizing air to deep bed filter lower spray nozzle - $5 \mathrm{scfm} / \mathrm{gpm}$.

- Secondary deep bed scrubber liquid cooled to a temperature such that the vapor temperature is reduced to $10^{\circ} \mathrm{C}$.

- Temperature of vapor feed to Ra adsorber $-10^{\circ} \mathrm{C}$ above its dew point.

- Temperature of vapor feed to $I_{2}$ guard bed $-150^{\circ} \mathrm{C}$.

- Temperature of vapor feed to exhauster $-50^{\circ} \mathrm{C}$.

- Assumed DF's are as follows: 


\begin{tabular}{|c|c|c|}
\hline & Vapors & $\begin{array}{l}\text { Solids } \\
\text { (particulates) }\end{array}$ \\
\hline Spray Dryer Filters & 1 & $10^{3}$ \\
\hline E/V Scrubber & 1 & 2.5 \\
\hline Deep Bed Filter (each) & $\begin{array}{l}20 \text { on } \mathrm{Ru} \\
1 \text { on others }\end{array}$ & 50 \\
\hline Ru Adsorber (each) & $\begin{array}{l}100 \text { on } \mathrm{Ru} \\
1 \text { on others }\end{array}$ & 2 \\
\hline$I_{2}$ Guard Bed & $\begin{array}{l}100 \text { on } I_{2} \\
1 \text { on others }\end{array}$ & 2 \\
\hline
\end{tabular}

\subsection{Process Vessel Vent Systems}

- Purge Rate - 50 scfm (inlet)/vessel

- Inlet Conditions $-35^{\circ} \mathrm{C} \mathrm{DB}, 25.6^{\circ} \mathrm{C}$ WB

- Outlet Conditions $-35^{\circ} \mathrm{C} \mathrm{DB}, 29.4^{\circ} \mathrm{C}$ WB

- Process Vessel Vent Filter DF - Particulates - $10^{3}$ Volatiles - 1

- HEPA Filter DF - Particulates - $10^{3}$ Volatiles - 1

- Preheater Capacity - raise temperature $10^{\circ} \mathrm{C}$ above dew point.

\subsection{Canyon Air}

- $\mathrm{DB}-35^{\circ} \mathrm{C}$

WB $-25.6^{\circ} \mathrm{C}$

- Flow - 356,400 acfin

\subsubsection{Mercury Recovery}

Approximately 1.2 Ib of metallic mercury will be condensed each hour from the off-gas vapor stream and accumulate in the off-gas condensate tank. The mercury will most likely be as a sludge and will require further cleaning before it is of a purity suitable for reuse in the separations process and/or storage. The flowsheet (FS-6A) is shown in Figure 4.6A. 
The mercury that accumulates will be intermittently pumped to a mercury receipt tank and subsequently pumped through a backwashable filter to remove the majority of solids occluded to the mercury. Periodically, the filter cake will be dislodged from the filter and pumped to the off-gas condensate tank for recycle into the process.

The filtered mercury, on a batch basis, will be pumped to the top of a column containing $10 \% \mathrm{HNO}_{3}$. The formed droplets will fall by gravity through the acid and overflow a barometric leg to an oxidizing tank. Particulates, not removed by the initial filtration step, that are soluble will be removed from the mercury. Periodically, the nitric acid will be pumped to the backwash hold tank and replaced with fresh acid.

To remove contaminants such as iron and aluminum, the acidwashed mercury will be air sparged at room temperature to oxidize the contaminants. After sparging is complete, the mercury is filtered through another backwashable filter to remove the formed oxides. Final cleanup of the mercury is achieved by vacuum distilling the mercury and bottling the condensed overheads.

\subsubsection{Recycle Evaporation}

The purpose of this operation is to (1) remove excess water from dilute recycle streams to maintain the salt concentration in the gravity settler feed at $30 \mathrm{wt} \%$, (2) to reduce supernate processing equipment size, and (3) provide the first stage of decontamination for process water. The flowsheet (FS-7) is shown in Figure 4.7. The material balance $(M B-7)$ is tabulated in

Table 4.7. Material balance bases are:

- Recycle concentrator bottoms are concentrated (to about 35 wt \% salt) so that the gravity settler feed contains $30 \mathrm{wt} \%$ salt supernate.

- Recycle evaporator condensate is sent to the general purpose evaporator for another stage of evaporation.

- HF in off-gas condensate reacts with excess $\mathrm{NaOH}$ in the recycle evaporator feed tank to form soluble $\mathrm{NaF}$.

- The ratio of the concentration of salt in the concentrate to the concentration of salt in the condensate is $10^{6}$. 
- A fraction of the $\mathrm{HgI} 2$ collected in $\mathrm{E} / \mathrm{V}$ and deep bed filter scrubber liquid reacts in the Recycle Evaporator Feed Tank as follows:

$\mathrm{HgI}_{2}(\mathrm{~s})+\mathrm{NaOH}(\mathrm{DS}) \quad \mathrm{x} \quad 2 \mathrm{NaI}(\mathrm{DS})+\mathrm{Hg}(\mathrm{OH})_{2}(\mathrm{~s}) \quad \mathrm{x}=8 \%$

\subsubsection{Setting and Filtration}

The purpose of this operation is to clarify the supernate feed to ion exchange. The flowsheet (FS-8) is shown in Figure 4.8. The material balance $(M B-8)$ is tabulated by Table 4.8. Material balance bases are:

- Feed concentration - 30 wt \% salt. Feed temperature $-40^{\circ} \mathrm{C}$.

- $99 \%$ of the solids fed to the gravity settler (GS) are recovered for recycle to sludge washing. 93 vol \% of the GS feed is sent to sand filtration and 7 vol \% is recycled to sludge washing via the aluminum dissolver.

- 0.0005 gal of 8 wt \% starch dispersion/gal GS feed. Starch follows the insoluble fraction.

- Decanted supernate is cooled to $\leq 25^{\circ} \mathrm{C}$ before feeding to sand filters.

- Sand filter No. 1 removes $90 \%$ of its feed solids. Sand filter feed consists of $1.15 \mathrm{gpm} / \mathrm{ft}^{2}$ supernate and $0.05 \mathrm{gpm} / \mathrm{ft}^{2}$ polyelectrolyte solution (IN NaOH and trace polyelectrolyte).

- Sand filter No. 2 removes $80 \%$ of its feed solids. This unit's feed also consists of $1.15 \mathrm{gpm} / \mathrm{ft}^{2}$ of filtrate and $0.05 \mathrm{gpm} / \mathrm{ft}^{2}$ of polyelectrolyte solution.

- Each filter is backwashed with clarified supernate at a rate of $15 \mathrm{gpm} / \mathrm{ft}^{2}$ for $5 \mathrm{~min}$ each day.

- Used sand and coal are recycled via the aluminum dissolver. Beds are assumed to be dumped every three months. Beds are fluidized with $15 \mathrm{gpm} / \mathrm{ft}^{2}$ of $\mathrm{IN} \mathrm{NaOH}$ for $10 \mathrm{~min}$ and are jetted out.

- For purposes of preparing a material balance, the following filter bed details are assumed.

$\begin{array}{lcccl} & \begin{array}{l}\text { Density, } \\ \text { lb/ft3 }\end{array} & \begin{array}{l}\text { No. 1. Filter } \\ \text { Height, in. }\end{array} & \begin{array}{l}\text { No. } 2 \text { Filter } \\ \text { Height, in; }\end{array} & \begin{array}{l}\text { Bed } \\ \text { Diameter, } \\ \text { ft }\end{array} \\ \text { Soal } & 85 & 8 & 3 & 4 \\ \text { Sand } & 100 & 24 & 18 & 4\end{array}$




\subsubsection{Cesium Ion Exchange}

The purpose of this operation is to remove cesium and plutonium from clarified supernate. There are two ion exchange columns, in series, each containing 1525 gallons ( $50 \%$ voidage) of Duolite (Diamond Shamrock) ARC-359 resin. Each column will have at least $75 \%$ freeboard above the resin for expansion during backwashing. The flowsheet $(F S-9)$ is shown in Figure 4.9. The material balance is tabulated in Table 4.9. Material balance bases are:

- Assumed resin stoichiometry is:

$$
\begin{aligned}
& \text { Ib moles } \\
& \mathrm{Na}+/ \mathrm{gal} \\
& \text { of Resin } \\
& \hline
\end{aligned}
$$

Load:

lst Rinse:

Elution:

\section{Elution:}

Regeneration:

$$
\begin{aligned}
& \mathrm{RNa}+\mathrm{Cs}^{+} \longrightarrow \mathrm{RCs}+\mathrm{Na}^{+} \\
& \mathrm{NaOH}\left(\text { bound } \longrightarrow \mathrm{NaOH}_{(\mathrm{aq})} \longrightarrow \mathrm{NaOH}_{(\mathrm{aq})}\right. \\
& \mathrm{NaOH}(\text { bound }) \longrightarrow \mathrm{RNH}_{4}+\mathrm{NaOH} \\
& \mathrm{RNa}+\mathrm{NH}_{4} \mathrm{OH} \longrightarrow \mathrm{RNH}_{4}+\mathrm{CsOH} \\
& \mathrm{RCs}+\mathrm{NH}_{4} \mathrm{OH} \longrightarrow \mathrm{NaOH}_{(\text {bound })} \\
& \mathrm{NaOH}(\mathrm{aq}) \longrightarrow \mathrm{RNa}+\mathrm{NH}_{4} \mathrm{OH} \\
& \mathrm{RNH}_{4}+\mathrm{NaOH} \longrightarrow \mathrm{RH}^{\longrightarrow} \longrightarrow
\end{aligned}
$$

0.002

0.008

0.01

0.01

0.01

- Note that bound sodium is different from sodium in the interstitial liquid. Displacement of interstitial liquids is assumed to be by plug flow.

- Cesium and plutonium decontamination factors assumed for preparing the material balance are $10^{4}$ and 165 , respectively.

- Resin capacity - 20 gal liquid feed/gal resin.

- The steps for a complete cycle are:

$$
\text { Time, } \mathrm{hr} / \mathrm{hr} * \mathrm{CV} \text { Direction Stream }
$$

Load

$$
12
$$

$$
1.67
$$

20

Down

Supernate

$$
\text { lst Rinse }
$$

$3 \quad 1.67$

5

Down

Water

Elution

8.33

1.2

10

Up

$2 \mathrm{M} \mathrm{NH} 4 \mathrm{OH}$, $2 \mathrm{M}\left(\mathrm{NH}_{4}\right)_{2} \mathrm{CO}_{3}$

2nd Rinse

Regeneration

$2.5 \quad 1.2$

3 Up

Water

St and by

Total

$$
4.17
$$

1.2

5 Up

$2 \mathrm{M} \mathrm{NaOH}$

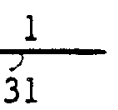

$\overline{\hbar C V}=$ column volume. 
- Resin is replaced annually.

- Material balance rates are average rates based on the 31-hour cycle.

- Maximum temperature of feed streams to columns $-30^{\circ} \mathrm{C}$.

\subsubsection{Strontium Ion Exchange}

The purpose of this operation is to remove strontium from clarified supernate. The $\mathrm{Sr}$ ion exchange column contains 762 gallons (with $50 \%$ voidage) of Amberlite ${ }^{\otimes}$ (Rohm and Haas) IRC-718 resin. This colum is provided with a freeboard allowing at least a $75 \%$ expansion of the resin. The flowsheet (FS-10) is shown in Figure 4.10. The material balance $(M B-10)$ is tabulated in Table 4.10. Material balance bases are:

- Elution and regeneration take place simultaneously. Simplified resin exchange reactions are,

Load: $\quad \mathrm{R}_{2} \mathrm{Na}_{2}+\mathrm{Sr}^{2+} \longrightarrow \mathrm{R}_{2} \mathrm{Sr}+2 \mathrm{Na}^{+}$

\section{Elution/Regeneration:}

$$
\mathrm{R}_{2} \mathrm{Sr}+\mathrm{C}_{2} \mathrm{H}_{4} \mathrm{~N}_{2}\left(\mathrm{CH}_{2} \mathrm{COO}\right)_{4} \mathrm{Na}_{4} \longrightarrow \mathrm{R}_{2} \mathrm{Na}_{2}+\mathrm{C}_{2} \mathrm{H}_{4} \mathrm{~N}_{2}\left(\mathrm{CH}_{2} \mathrm{COO}\right)_{4} \mathrm{Na} 2 \mathrm{Sr}
$$

- The decontamination factor for both soluble and insoluble strontium is $10^{3}$.

- Resin capacity: 40 gal liquid feed/gal resin.

- The steps for a complete cycle are:

Time,

hr CV/hr* CV Direction Stream

Cs Colum Effluent

$\begin{array}{lrrrll}\text { Supernate } & 12 & 3.33 & 40 & \text { Down } & \text { Supernate } \\ \text { lst Rinse } & 3 & 3.33 & 10 & \text { Down } & \text { Water }\end{array}$

lst Rinse $0.45 \quad 3.33 \quad 1.5$ Down Water

Elution/Regeneration $\quad \begin{array}{llllll}6 & 1 & 6 & \text { UP } & 0.01 M \text { Alk. EDTA }\end{array}$

$\begin{array}{llllll}\text { 2nd Rinse } & 3 & 1 & 3 & \text { Up } & \text { Water } \\ \text { St andby } & 6.55 & & & & \end{array}$

Total 31

$\overline{\star C V}=$ colum volume. $\quad-4.11-$ 
- The maximum temperature of feed streams to the column $-30^{\circ} \mathrm{C}$.

- The eluate/regenerate effluent goes to the strontium concentrator. The strontium concentrator produces a l.OM alkaline EDTA concentrate.

- Resin is replaced annually.

- The ratio of the concentration of salt in concentrate to the concentration of salt in condensate is $10^{6}$.

\subsubsection{Cesium Elutriant Recovery and Cesium Concentration}

The purpose of these facilities is to remove ammonia and carbon dioxide from the eluate and to concentrate the cesium eluate to a $2.0 \mathrm{M} \mathrm{Na} \mathrm{CO}_{3}+\mathrm{Cs}_{2} \mathrm{CO}_{3}$ solution. The flowsheet (FS-11) is shown in Figure 4.11. The material balance $(M B-11)$ is tabulated in Table 4.11. Material balance bases are:

- $\mathrm{NH}_{4} \mathrm{OH}$ and $\left(\mathrm{NH}_{4}\right)_{2} \mathrm{CO}_{3}$ are decomposed and the $\mathrm{NaOH} / \mathrm{CsOH}$ in the eluate is converted to $\mathrm{Na}_{2} \mathrm{CO}_{3} / \mathrm{Cs}_{2} \mathrm{CO}_{3}$ in the steam stripper.

- Cooled $\left(38^{\circ} \mathrm{C}\right)$ concentrate is $2 \mathrm{M}\left(\mathrm{Na}_{2} \mathrm{CO}_{3}+\mathrm{Cs}_{2} \mathrm{CO}_{3}\right)$. Purge condensate is sent to the recycle evaporator.

- Stripper condensate is at $6 \mathrm{M} \mathrm{NH}_{3}$.

- All the $\mathrm{NH}_{3}$ in the spent regenerant along with some water $\left(0.2 \mathrm{lb} \mathrm{H}_{2} \mathrm{O} / \mathrm{lb}\right.$ of $\left.\mathrm{NH}_{3}\right)$ is evolved to the cesium vent scrubber. Other vent scrubber feeds are based on:

\begin{tabular}{|c|c|c|}
\hline & $\mathrm{NH}_{3}{ }^{\mathrm{a}}$ & $\mathrm{CO}_{2}{ }^{\mathrm{a}}$ \\
\hline Tank vents & 1 & 2 \\
\hline Stripper vent & 1 & 7 \\
\hline Vent Scrubber Off-gas & 0.1 & Net of $\left(\mathrm{NH}_{4}\right)_{2} \mathrm{CO}_{3}$ \\
\hline
\end{tabular}

a. As percent of feed.

- The vent scrubber bottoms contain $2 \mathrm{M}\left(\mathrm{NH}_{4}\right)_{2} \mathrm{CO}_{3}$ and is recycled to the $C s$ concentration feed.

- Make-up $\mathrm{CO}_{2}$ is introduced into the cesium elutriant makeup tank as a gas and ammonia as an $8 \mathrm{M} \mathrm{NH} 4 \mathrm{OH}$ solution.

- DF for entrainment across the stripping section - $10^{6}$.

- The ratio of the concentration of salt in concentrate to the concentration of salt in purge condenser condensate is $\geq 10^{4}$.

- $99.95 \%$ of the $\mathrm{NH}_{3}$ entering in the feed to the cesium concentrator is stripped as overhead products. 
- $0.05 \%$ of the $\mathrm{NH}_{3}$ entering in the feed to the cesium concentrator is removed with the purge condensate. The purge condenser will be run hot to ensure that $\mathrm{NH}_{3}$ flashes to the vent scrubber.

- Stripper is assumed to operate at $100 \%$ efficiency.

\subsubsection{Cesium Fixation on Zeolite}

The purpose of these facilities is to remove the $\mathrm{Na}_{2} \mathrm{CO}_{3}$ from the feed to spray drying and melting by fixation of $\mathrm{Cs}_{s}$ and $\mathrm{Pu}$ on zeolite (Iinde AW-500 or Ionsiv IE-95). The flowsheet (FS-12) is shown in Figure 4.12. The material balance (MB-12) is tabulated on Table 4.12. Material balance bases are:

- There is one zeolite bed which is changed out every 60 days. Other column size variables are zeolite bulk density ( 45.4 $\mathrm{lb} / \mathrm{ft}^{3}$ ) and design loading ( $50 \mathrm{gallons}$ of $\mathrm{Cs}$ concentrate to one gallon of zeolite). The colum is $20 \mathrm{ft}$ high and contains a 1494-gallon zeolite bed ( $11 \mathrm{ft}$ high). Column liquid holdup (1969 gallons) is made up of freeboard and $50 \%$ bed voidage.

- Column operation consists of accumulating concentrate for three days and processing downflow at $1.5 \mathrm{gpm} / \mathrm{ft}^{2}$. The column is flushed (downflow at $1.5 \mathrm{gpm} / \mathrm{ft}^{2}$ ) with 2 bed volumes of water (2988 gallons) of which 2648 gallons are retained and circulated for cooling purposes. The effluent from the column depleted in cesium by a factor averaging at least 100, is recycled to the sand filter feed tank.

- Loaded beds are removed in a water slurry with a total volume 6 times the bed volume. Four bed volumes of water are decanted and sent to recycle evaporation. The remaining 2-bed-volume zeolite-water slurry is sent to spray drying/melting.

- Fresh zeolite is introduced from cold feed in a 4-bed-volume slurry. Water in excess of 2648 gallons is sent to recycle evaporation.

- Between loading cycles, water is circulated through the bed to maintain the zeolite at $50^{\circ} \mathrm{C}$ or less.

\subsubsection{General-Purpose Evaporation}

The purpose of this operation is to provide a final stage of evaporation (decontamination) on miscellaneous evaporator condensate prior to purging to the environment. The flowsheet (FS-13) is shown in Figure 4.13. The material balance (MB-13) is tabulated in Table 4.13. Material balance base is:

- The weight ratio of cooled bottoms to feed is 1 to 10 .

- The ratio of the concentration of salt in the concentrate to the concentration of salt in the condensate is $10^{6}$.

$$
-4.13 \text { - }
$$




\subsubsection{Solidification of Product Salt Solution in Concrete}

The purpose of these facilities is to solidify clarified supernate from ion exchange in concrete and bury the concrete in soil trenches. The flowsheet (FS-14) is shown in Figure 4.14. The material balance $(M B-14)$ is tabulated in Table 4.14. Bases for developing the material balance are as follows:

- Descaling flow - $20 \%$ of evaporator vapor rate.

- Evaporator concentrate - 35 wt \% salt.

- Rework return and flush constant at $240 \mathrm{lb} / \mathrm{hr}$ water and 40 $\mathrm{lb} / \mathrm{hr}$ concrete.

- Concrete plant water flush constant at $14.8 \mathrm{lb} / \mathrm{hr}$.

- Saltcrete composition - 29.2 wt $\% \mathrm{H}_{2} \mathrm{O}, 15.0$ wt $\%$ salt, 55.8 wt \% cement.

- Source of flush water is the Product Salt Evaporator condensate. The balance sent to the Recycle Water Tank.

\subsubsection{Mechanical Cell A}

Following sealing and leak checking of the canister, the canister undergoes the first of two, two-step surface decontamination processes (the second is carried out in Mechanical Cell B). The canister is initially etched in a $3.5 \mathrm{M} \mathrm{HNO}_{3}-0.4 \mathrm{M} \mathrm{NaF}$ solution. Following rinsing, the canister is cleaned in an oxalic acid solution $\left(100 \mathrm{~g} \mathrm{C}_{2} \mathrm{H}_{2} \mathrm{O}_{4} / \mathrm{L}\right)$. These solutions are initially used in Mechanical Cell B. Spent oxalic acid is digested prior to blending with the spent etching solution. The flowsheet (FS-15) is shown in Figure 4.15. The material balance is tabulated in Table 4.15. Bases used to develop the material balance are as follows:

- Decontamination solutions are introduced as cold feeds in Mechanical Cell B and reused in Mechanical Cell A.

- Etching agent - 3.5M $\mathrm{HNO}_{3}-0.4 \mathrm{M} \mathrm{NaF}$ at $350 \mathrm{gal} / \mathrm{canister}$.

- Cleaning agent - $100 \mathrm{~g} / \mathrm{I} \mathrm{C}_{2} \mathrm{H}_{2} \mathrm{O}_{4}$ at $350 \mathrm{gal} / \mathrm{canister.}$

- Rinsing agent $-\mathrm{H}_{2} \mathrm{O}$ at 100 gal/canister.

- Etch cycle - 1 hour. 
- Cleaning cycle - 1 hour.

- Etching rate $-0.3 \mathrm{mil} \mathrm{SS} / \mathrm{hour}$ (assumed to be $\mathrm{Fe}$ ).

$\mathrm{Fe}(\mathrm{s})+4 \mathrm{HNO}_{3} \rightarrow \mathrm{Fe}\left(\mathrm{NO}_{3}\right)_{3}(\mathrm{DS})+\mathrm{NO}(\mathrm{v})+2 \mathrm{H}_{2} \mathrm{O}$

- Canister surface area - $69 \mathrm{ft}^{2}$.

- Etching solutions maintained at $<50^{\circ} \mathrm{C}$.

- Spent cleaning solution is digested in $1.0 \mathrm{M} \mathrm{HNO} \mathrm{HN}_{3}-0.01 \mathrm{M} \mathrm{Mn}\left(\mathrm{NO}_{3}\right)_{2}$ at $295^{\circ} \mathrm{C}$ for 2 hours. Digestion reaction:

$3 \mathrm{C}_{2} \mathrm{H}_{2} \mathrm{O}_{4}+2 \mathrm{HNO}_{3} \stackrel{\mathrm{x}}{\longrightarrow} 6 \mathrm{CO}_{2}(\mathrm{v})+2 \mathrm{NO}_{(\mathrm{v})}+4 \mathrm{H}_{2} \mathrm{O} \quad \mathrm{x}=95 \%$

- Spent etching solution is blended with the digested cleaning solution and neutralized with $10 \%$ excess $50 \% \mathrm{NaOH}$. The following reactions are assumed for material balance purposes.

$\mathrm{C}_{2} \mathrm{H}_{2} \mathrm{O}_{4}+2 \mathrm{NaOH} \rightarrow \mathrm{Na}_{2} \mathrm{C}_{2} \mathrm{O}_{4}$ (DS) $+2 \mathrm{H}_{2} \mathrm{O}$

$\mathrm{HNO}_{3}+\mathrm{NaOH} \rightarrow \mathrm{NaNO}_{3}$ (DS) $+\mathrm{H}_{2} \mathrm{O}$

$\mathrm{Mn}\left(\mathrm{NO}_{3}\right)_{2}+2 \mathrm{NaOH}+1 / 4 \mathrm{O}_{2} \rightarrow \mathrm{MnO} \cdot \mathrm{OH}_{(\mathrm{s})}+1 / 2 \mathrm{H}_{2} \mathrm{O}+2 \mathrm{NaNO}_{3}(\mathrm{DS})$

$\mathrm{Fe}\left(\mathrm{NO}_{3}\right)_{3}+3 \mathrm{NaOH} \rightarrow \mathrm{Fe}(\mathrm{OH})_{3}(\mathrm{~s})+3 \mathrm{NaNO}_{3}(\mathrm{DS})$

- $98 \%$ of the fluoride upon neutralization forms the soluble salt of sodium and upon recycle to the Recycle Evaporator Feed Tank remains soluble, ultimately being carried through ion exchange. The remaining fluoride is associated with the insoluble fraction of the neutralized spent decontamination solutions and ultimately will be part of the feed to the spray dryer.

\subsubsection{Mechanical Cell B}

The function of this facility is to carry out the second of the two-step canister decontamination processes (See Section 4.4.1.15). The etching solution (3.5M $\left.\mathrm{HNO}_{3}-0.4 \mathrm{M} \mathrm{NaF}\right)$ and the cleaning solution ( $100 \mathrm{~g} / \mathrm{L} \quad \mathrm{C}_{2} \mathrm{H}_{2} \mathrm{O}_{4}$ ) are introduced into this cell as cold feeds. The canister surface is to be decontaminated to $<220$ $\mathrm{d} / \mathrm{min} / \mathrm{dm}^{2}$ alpha and $<2200 \mathrm{~d} / \mathrm{min} / \mathrm{dm}^{2}$ beta-gamma before transfer to Mechanical Cell C. The flowsheet (FS-16) is shown in Figure 4.16. The material balance $(M B-16)$ is tabulated in Table 4.16. Bases used to develop the material balance are as follows: 
- Etching agent $-3.5 \mathrm{M} \mathrm{HWO}_{3}-0.4 \mathrm{M} \mathrm{NaF}$ at $350 \mathrm{gal} / \mathrm{canister}$

- Cleaning agent - $100 \mathrm{~g} / \mathrm{L} \mathrm{C}_{2} \mathrm{H}_{2} \mathrm{O}_{4}$ at $350 \mathrm{gal} / \mathrm{canister.}$

- Rinsing agent $-\mathrm{H}_{2} \mathrm{O}$ at $100 \mathrm{gal} /$ canister.

- Etch cycle - 1 hour.

- Cleaning cycle - 1 hour.

- Etching rate $-0.3 \mathrm{mil} \mathrm{SS} / \mathrm{hr}$ (assumed to be Fe).

$$
\mathrm{Fe}(\mathrm{s})+4 \mathrm{HNO}_{3} \rightarrow \mathrm{Fe}\left(\mathrm{NO}_{3}\right)_{3}(\mathrm{DS})+\mathrm{NO}_{(\mathrm{v})}+2 \mathrm{H}_{2} \mathrm{O}
$$

- Canister surface area - $69 \mathrm{ft}^{2}$.

- Etching solution maintained $<50^{\circ} \mathrm{C}$.

\subsubsection{7' Mechanical Cel1 C}

The function of this facility is to ( 1 ) perform a contamination survey of the exterior surface of the canister, (2) make temperature and radiation profile on the canister, and (3) perform spot electropolishing if the contamination survey dictates. The flowsheet (FS-17) is shown in Figure 4.17 and the material balance $(M B-17)$ is tabulated in Table 4.17.

\subsubsection{Radionuclide Constituents (J. R. Chandler)}

\subsubsection{General}

A model has been written and placed on SRL's IBM-360 computer which calculates the concentration (and corresponding heat generation rates) in every process stream for $>160$ specific radionuclides. Isotopic content of the two reference feed streams, glass product, saltcrete product, and gaseous/aqueous effluents are tabulated in Tables $2.3-2.10,3.3-3.4,3.15-3.16$, and $8.2-8.10$, respectively. The concentration of a specific radionuclide in any process stream may be obtained from the microfiches in Appendix 13.7.

\subsubsection{Feed Stream Composition}

The radionuclide composition of the two reference feed streams to the DWPF (see Tables 2.3-2.10) were calculated from the 200 Area waste blend (see Section 7). This waste blend is computed from a knowledge of reactor operating parameters, 200 Area processing rates and waste generating factors (Section 7). Using the radionuclide composition of the waste blend, the radionuclide inventory

$$
-4.16-
$$


is distributed between the supernate and sludge-slurry feed streams based on the insoluble fraction of each stream and the distribution of each radionuclide between the supernate fraction of the reference waste blend and the in-tank settled in-soluble fraction. The resulting percent distribution of these radionuclides between the reference feed streams, as well as between the soluble and insoluble fractions of each stream, are tabulated in Table 4.18.

\subsubsection{Curie Balance Bases}

\subsection{Aqueous Process Streams}

- Soluble fraction of each isotope (exclusive of tritiun) follows the salt.

- Insoluble fraction of each isotope follows the insoluble solids.

- Tritium follows the water throughout the process.

- Behavior of isotopes during vitrification and off-gas treatment is detailed in Section 4.5.6.3.

- Eight (8) percent of the iodine recycled from the off-gas condensate tank as unsoluble $\mathrm{HgI}_{2}$ is converted to soluble $\mathrm{NaI}$.

- The radionuclides associated with the insoluble fraction in the sludge-slurry feed stream remain with the solid fraction across aluminum dissolving.

\subsection{Gaseous Process Streams}

- Calciner Off-Gas Treatment

See Section 4.5.6.3.

- Process Vessel Vapor Space Purge

Inlet Flow - $50 \mathrm{scfm}$ (dry air) at $95^{\circ} \mathrm{F}$ dry bulb and $78^{\circ} \mathrm{F}$ wet bulb

Outlet Flow $-95^{\circ} \mathrm{F}$ dry bulb, $85^{\circ} \mathrm{F}$ wet bulb

Entrainment $-10^{-9} \mathrm{gal}_{\mathrm{ft}} \mathrm{ft}^{3}$

- Canyon Air

Flow $-356,400$ acfm (dry bulb $-95^{\circ} \mathrm{F}$, wet bulb $-78^{\circ} \mathrm{F}$ )

Radionuclide Content - 2.25 times that calculated in the filtered Process Vessel Vent System. This is based on measured contribution of the filtered process vessel vent system and canyon air (unfiltered) system non-volatile beta radioactivity in the 221-F and $-\mathrm{H}$ Area facilities over the period of $1 / 78$ through $12 / 79$. 


\subsection{Process Details}

\subsubsection{Sludge and Supernate Feed Preparation}

\subsubsection{Gevieral}

The purpose of these operations is to prepare two feed streams - a supernate stream and a sludge-water slurry stream for transfer to the DWPF. The generalized flowsheet, material balance, and calculational bases were described in Section 4.4.1.1 and Appendix 13.2. The technical bases upon which waste removal equipment and blending procedures were developed are outside the scope of this document and will be presented in a separate basic data report.

\subsubsection{Aluminum Dissolution (C. T. Randal1)}

\subsubsection{General}

The purpose of this section is to present the process details and technical data bases for reducing the aluminum content of the sludge. Advantages of this process step are:

- The amount of glass required to contain SRP waste is reduced by $20 \%$.

- Glass melt viscosities are reduced for improved glass quality.

- Requirements for blending high-aluminum sludges with other sludges are relaxed.

\subsubsection{Process Description}

Batches of $1: 1$ sludge slurry are adjusted to an $\mathrm{OH}^{-} / \mathrm{Al}^{3+}$ molar ratio* of 16 and an initial $\mathrm{NaOH}$ concentration of $5 \mathrm{M}$. The slurry is boiled at total reflux for a minimum of 30 minutes. The aluminumrich liquid phase and the aluminum depleted solid phase are subsequently transferred to the sludge washing module (FS-4) where solid phase separation and washing is performed. A flowsheet (FS-3) is shown in Figure 4.3 and the material balance $(\mathrm{MB}-3)$ in Table 4.3 .

\subsubsection{Techrical Data}

This section sumarizes experience and technology in dissolving aluminum from SRP sludges. Initial investigation concluded that boiling $5 \mathrm{M} \mathrm{NaOH}$ removed $>75 \%$ of the aluminum

* Moles of $\mathrm{NaOH}$ added per mole of undissolved aluminum. 
in washed, dried sludge from Tank 16. Subsequent studies that used as-received (raw) sludge from Tanks 11,15 , and 21 showed that $70-78 \%$ of the solid phase aluminum is removed from the highalumina sludges from Tanks 11 and 15 , and $45-50 \%$ from the lowalumine sludge from Tank 21 .

The two crystalline forms of hydrated aluminum likely to be found in SRP sludges are the trihydrate, gibbsite ( $\left.\mathrm{Al}(\mathrm{OH})_{3}\right)$, and the monohydrate, boehmite (AlOOH). Freshly precipitated aluminum in SRP sludges is an amorphous material that crystallizes to gibbsite. Dissolution of the amorphous or gibbsite form is rapid. The aluminum industry typically obtains $99 \%$ solubility of gibbsite in 20-30 minutes using $\sim 3 \mathrm{M}$ caustic at $150^{\circ} \mathrm{C}$.

In caustic mixtures, gibbsite begins converting to boehmite at significant rates at about $140^{\circ} \mathrm{C}$, a temperature that has probably been reached in several SRP sludges. Boehmite is harder to dissolve than gibbsite - dissolution temperatures around $230^{\circ} \mathrm{C}$ are used industrially. Solubilities of gibbsite and boehmite in caustic solutions are shown in Flgures 4.18 and 4.19 [3].

Also plotted in Figure 4.18 are the compositions of six aluminum-bearing supernate solutions that have been stable at $20^{\circ} \mathrm{C}$ for over 2 months. Synthetic gravity settler feed solutions were spiked with $\mathrm{Al}\left(\mathrm{NO}_{3}\right)_{3}$, seeded with $\mathrm{Al}(\mathrm{OH})_{3}$ crystals, and observed over a period of 2 months. No precipitation of gibbsite occurred. Apparently, other ions in solution $\left(\mathrm{Na}^{+}, \mathrm{NO}_{3}{ }^{-}, \mathrm{NO}_{2}^{-}\right.$, $\mathrm{CO}_{3}{ }^{2-}, \mathrm{SO}_{4}{ }^{2-}$ ) increase the solubility of aluminum in caustic solution and, in addition, dramatically reduce the effect of temperature on solubility. This conclusion is supported by the data of Barney.

SRI experience dissolving aluminum in actual SRP waste sludges is summarized in Table 4.19. These results show that a large fraction of the aluminum in SRP sludges can be removed by boiling $\mathrm{NaOH}$ solution in 30 minutes to 1 hour.

For dissolution in $5 \mathrm{M} \mathrm{NaOH}$ the final Al/OH molar ratio in the supernate was typically $0.04(\mathrm{OH} / \mathrm{Al}$ ratio $=25)$. This is well below the solubility line at $T=100^{\circ} \mathrm{C}$ in Figure 4.18 and also below the $\mathrm{T}=100^{\circ} \mathrm{C}$ line in Figure 4.19 . Therefore, it may be possible to decrease the initial OH/AI ratio significantly and still allow good aluminum removal.

Table 4.20 shows how Al dissolution changes the composition of Tank 15 sludge. The percent of each metal ion in the sludge after Al dissolution is still well within the overall variation of SRP sludges. Aluminum removal will therefore not create any new problems associated with sludge composition. Tank 15 sludge, before Al removal, has a relatively high $\mathrm{Al} / \mathrm{Fe}$ ratio, but is otherwise typical of most SRP sludges. 
For convenience of operation the laboratory tests used $5 \mathrm{~g}$ of dry sludge (or $5 \mathrm{~mL}$ of as-received sludge) and $100 \mathrm{mI}$ of caustic, although data in Figures 4.18 and 4.19 show that lower caustic concentrations should be acceptable. Because they have been demonstrated to give good aluminum dissolution, reaction conditions chosen for preliminary process design are those that yielded $76 \%$ dissolution of Tank 16 sludge (see Table 4.19):

$$
\begin{aligned}
\mathrm{OH} / \mathrm{A} I \text { molar ratio } & =16 \text { to } 1 \\
{\left[\mathrm{OH}^{-}\right] } & =5 \mathrm{M} \\
\text { Temperature } & =\text { boiling }\left(\sim 105^{\circ} \mathrm{C}\right) \\
\text { Time } & =30 \text { minutes to an hour }
\end{aligned}
$$

No major incompatibilities with other parts of the solidification process have been identified as resulting from the additional $\mathrm{NaOH}$.

Boiling caustic should be used for best aluminum recovery. Higher temperatures would ensure removing essentially all aluminum from SRP sludge. Lower temperatures would greatly slow the dissolution rate and increase the chance that aluminum in the boehmite form would not be adequately removed. Residence times of 30 minutes to 1 hour in boiling caustic should be used.

Sludge bottoms from the gravity settlers and spent filter media (sand and coal) from the sand filters are blended with the dissolver bottoms (after aluminum dissolution is completed). The volumes of sludge recycle and spent filter media added are controlled to maintain a relatively uniform process feed composition for sludge washing. 


\subsubsection{Sludge Washing (D. W. Jones)}

\subsubsection{General}

The objective of the sludge washing step is to remove most of the soluble salt from the sludge waste prior to vitrification. This is necessary in order to meet sulfate, sodium, and nitrate salt concentration criteria for waste vitrification and to reduce the volume of vitrified product. Without washing, the glass volume and therefore the cost of product handling and storage would be increased severalfold. Washing also removes caustic and dissolved aluminum added to the sludge during aluminum dissolution.

The sludge waste is received from the aluminum dissolver and batch washed with water in two parallel processing units. Each unit contains an agitated wash tank to mix the gelatinous sludge solids and wash water, a solid-wall basket centrifuge to separate the sludge and liquid phases after contacting, and a centrate tank to hold the centrifuge liquid effluent. The centrifuge has 48-inch-diameter by 30-inch-high bowl with a 120-gallon fill capacity and generates $1300 \mathrm{~g}$ 's maximum separating force at 1400 rpm.

A simple three-step dilution washing process is employed consisting of an initial sludge dewatering step followed by two wash steps. These operations reduce sludge salt content from $88 \%$ to $2 \%$ on a dry weight basis. The $2 \%$ concentration is nearly optimum for the process and is more than sufficient to meet individual product specifications for sulfate, sodium, and nitrate salts in the washed sludge. These specifications are $\leq 3 \%, \mathrm{SO}_{4}{ }^{2-}, \leq 5 \% \mathrm{Na}^{+}$, and $\leq 10 \%$ $\mathrm{NO}_{3}^{-}$dry weight basis.a The final washed sludge is slurried with water to produce a slurry containing 17 wt \% total solids. The design processing rate for the two sludge washing units is $851 \mathrm{~b} / \mathrm{hr}$ of insoluble solids, and about 40 pounds of wash water are used per pound of solids washed.

\subsubsection{Process Description}

A process flow diagram is shown in Figure 4.4, material balance data are listed in Table 4.4, and an estimated operating cycle for the process is described below and in Table 4.21.

a. Bases for these limits are as follows:

$$
\begin{aligned}
& \mathrm{SO}_{4}^{2-} \text { - See Section } 3.1 .4 \\
& \mathrm{Na}^{+} \text {- Glass leachability } \\
& \mathrm{NO}_{3}^{-} \text {- Ruthenium volatility. }
\end{aligned}
$$


Sludge feed for the washing process is received batchwise in the sludge feed tank from the aluminum dissolver at the end of each dissolving cycle. This feed includes sludge bottoms from the supernate gravity settlers and spent sand and coal from the sand filters which are combined with the digested sludge in the dissolver in fixed proportions in order to maintain a uniform feed composition for the washing process. This composition is monitored by periodic sampling and analysis of sludge feed tank contents for volume \% solids and weight \% solids, salt, and water.

Fixed volume batches of feed are pumped from the sludge feed tank to the two wash tanks at the start of each batch washing cycle. Batch volume is controlled so that the centrifuge bowl is filled to $90 \%$ of crpacity with sludge (108 gallons) during the dewatering step. If this volume is exceeded, heavy overflow of solids in the centrifuge effluent will result. Both the batch volume and wash water addition are adjusted to compensate for changes in feed composition.

The undiluted sludge feed is initially centrifuged in the dewatering step to remove as much of the salt-rich liquid as possible before washing. Use of the dewatering step before washing minimizes water usage and is the most efficient processing scheme. The centrifuge bowl is accelerated to full speed and the bowl filled at a $30 \mathrm{gpm}$ rate. A centrifuge feed rate of $5.0 \mathrm{gpm}$ is used during dewatering to meet the design basis of $98 \%$ solids recovery for each centrifuge pass. The feed rate for the wash steps is $12.0 \mathrm{gpm}$. A lower centrifuge throughput is necessary in the dewatering step to compensate for lower solids separation due to the smaller density difference between the sludge and liquid phases.

The centrifuge effluent containing salt removed from the sludge and the unrecovered sludge fines drains by gravity into the centrate tank. At the end of each centrifuge cycle the centrate is pumped to the centrate hold tank where centrate from both washing units is combined. The centrate is then transferred to the recycle evaporation system for concentration by evaporation. The evaporator bottoms containing the concentrated salt and sludge fines are added to the plant supernate feed stream and fed to the gravity settlers where the fines are agglomerated and removed from the salt solution by gravity settling. The bottoms from the settling units are then recycled to the aluminum dissolver. 
A constant centrifuge feed rate is maintained during dewatering until the wash tank is empty. The centrifuge is then operated at full speed ( $1400 \mathrm{Imm}$ ) for five minutes to further compact the sludge cake. This step reduces cake volume by about $10 \%$. A 1 -gpm water feed must be maintained during the compaction spin to prevent standing waves from forming on the pool surface in the bowl which can cause bowl imbalance. The excess liquid left on the cake surface after compaction is skimmed off, and the bowl is braked by the drive motor to a speed of $50 \mathrm{rpm}$ for sludge unloading. A vertical knife-edged plow is then activated to scrape the sludge from the bowl wall. The cake falls through the open bottom of the centrifuge and through a chute into the wash tank below. Discharge is assisted by high pressure water sprays which are directed on the cake to help disperse the cake and clean the bowl. An estimated operating cycle for the centrifuge is given in Table 4.22.

During sludge compaction and discharge, wash water for the first wash is added to the wash tank, and the sludge and water are well mixed. During mixing, the salt ions diffuse rapidly from the interstitial liquid in the sludge particles to the bulk liquid phase. Concentration equilibrium is achieved within a matter of minutes. After discharge is completed, the centrifuge bowl is accelerated to full speed and the bowl is filled with the diluted sludge from the wash tank at a $30 \mathrm{gpm}$ rate. This rate is controlled so that the bowl is filled to capacity ( 120 gallons) between a speed of $400 \mathrm{rpm}$, the minimum speed needed to support liquid in the bowl, and $1400 \mathrm{rpm}$. At full speed, the feed is reduced to a $12 \mathrm{gpm}$ rate, and this rate is maintained throughout the feed step. When the wash tank is emptied, feed is stopped and centrifuge spin, skim, deceleration, and discharge operations are repeated to complete the first wash cycle.

Operating steps and timing for the second wash are very similar to those in the first wash. However, an on-line measurement of centrate conductivity is made during the second wash to determine whether the washed sludge batch meets the product specification of $<2$ dry wt \%.salt. If the conductivity reading indicates less than 0.68 wt \% salt in the centrate liquid on a solids free basis; product specifications have been met and sludge washing is complete. Otherwise, additional washing will be necessary. The washed sludge is discharged from the centrifuge into the wash tank and slurried using only the discharge spray water. The amount of spray water is controlled to obtain 17 wt \% total solids (insoluble 
plus dissolved solids) which is the maximum solids content for satisfactory slurry transfer and storage. The same amount of spray water is used in the dewatering and first wash steps. The washed sludge is then transferred from the wash tank to the washed sludge run tank where it is combined with slurry from the other washing unit. The washed sludge in the run tank is sampled and analyzed for wt \% total solids, dry wt \% salt, and dry wt \% $\mathrm{SO}_{4}{ }^{2-}$, $\mathrm{Na}^{+}$, and $\mathrm{NO}_{3}^{-}$, and then transferred batchwise to the slurry mix tank prior to spray drying and vitrification.

\subsubsection{Dilution Model}

Sludge washing studies show that washing follows a simple dilution model described by the equation:

$$
S_{n}=\frac{S_{f}}{\left(\frac{W_{f}+R I}{R I}\right)_{d}\left(\frac{W+R I}{R I}\right)_{1}\left(\frac{W+R I}{R I}\right)_{2} \cdots\left(\frac{W+R I}{R I}\right)_{n}}
$$

where

$\mathrm{d}=$ dewatering step

$I=$ mass of insoluble solids in centrifuged sludge

$\mathrm{n}$ = number of washes

$R=$ mass ratio of water to insoluble solids in centrifuged s ludge

$S_{f}=$ mass of salt in unwashed sludge feed

$S_{n}=$ mass of salt in washed sludge

$W=$ mass of wash water and spray water added to centrifuged sludge

$\mathrm{W}_{f}=$ mass of water in unwashed sludge feed. 
The values of $I$ and $R$ are essentially constant for each step of the DWPF washing process, and an equal amount of wash water is added in each wash. Thus, Equation 1 can be simplified to give

$$
S_{n}=\frac{S_{f}}{\left(\frac{W_{f}+R I}{R I}\right)\left(\frac{W+R I}{R I}\right)^{n}}
$$

where average values of $I$ and $R$ are used. These equations describe the relationship between salt removal and major process parameters of solids throughput, wash water addition, sludge cake water content, and number of wash steps.

\subsubsection{Large-Scale TNX Test Results}

Large scale tests of the washing process and equipment are being conducted at TNX using a nonradioactive, synthetic sludge waste. The test equipment is shown in Figure 4.23 and includes a 1200-gallon agitated wash tank, 48-inch batch basket centrifuge, a 250-gallon sludge slurrying tank, and a large centrate tank (not shown).

The sludge washing centrifuge is one of the more complex pieces of mechanical equipment to be operated in the DWPF canyon, and therefore considerable attention is being given to its development and design. Figure 4.24 is a cutaway drawing of the large scale centrifuge now being tested at TNX. This unit was procured from Delaval Separator Company of Poughkeepsie, New York, and is a vertical, solid-wall, batch basket centrifuge which generates 1300 $\mathrm{g}^{\prime} \mathrm{s}$ force at the basket wall and $900 \mathrm{~g}$ 's at the liquid pool surface when operating at maximum operating speed of $1380 \mathrm{rpm}$. The bowl is unbaffled. The centrifuge is made of $304 \mathrm{~L}$ stainless steel and weighs 7300 pounds with the bowl empty. The static load on the spindle bearings with an empty bowl is $3400 \mathrm{lb}$, and the machine is rated for a maximum sludge loading of $1500 \mathrm{lb}$ based on a sludge bulk density of $94 \mathrm{lb} / \mathrm{ft}^{3}$. Bowl dimensions are 48 inches in diameter by 30 inches high by $7-1 / 4$ inches deep and fill capacity is 120 gallons. Bowl wall thickness is 1.04 inches.

The motor and drive, bowl, and curb housing are all rigidly connected and the entire assembly is suspended by three stands on steel rods or links. The links have ball and socket end joints, and any load imbalance in the machine is acconmodated for by displacement of the entire assembly on these links. The bowl is 
supported from the curb cover and is driven by a top-mounted, variable-speed, 75-hp hydraulic motor. The drive delivers $300-\mathrm{ft}-1 \mathrm{~b}$ torque and can provide full drive torque during plowing. The hydraulic drive also provides regenerative braking for bowl decleration. The centrifuge is fed through a bottom rotating feed accelerator which brings the feed up to the angular velocity of the bowl before it enters the liquid pool or settling zone. This minimizes turbulence due to feed entry and thereby substantially improves solids separation. The separated sludge is discharged from the basket at approximately $50 \mathrm{rpm}$ by single, air-driven, scraper-type plow which advances to the bowl wall during discharge and then is retracted from the wall during the remainder of the centrifuge operating cycle. A single, air-driven, linear skimming device is also provided to remove excess liquid from the cake surface prior to discharge. The centrifuge can be operated in either a fully automatic or manual mode.

The synthetic sludge waste used in the large scale test program simulates the slurry feed entering the washing process as characterized in Table 4.23. The sludge waste contains only the $\mathrm{Fe}, \mathrm{Al}, \mathrm{Mr}, \mathrm{Ca}$, and $\mathrm{Ni}$ cations; other major metal constituents, $\mathrm{Hg}$ and $U$, were omitted for health and environmental control reasons. Based on a comparison of the sludge properties and small scale test results obtained so far, the synthetic sludge waste appears to be less dense, more gelatinous, and have a higher water content than actual wastes. Consequently, test results with synthetic waste should provide a conservative basis for plant design.

Figure 4.25 shows sludge recovery in the 48-inch centrifuge as a function of feed rate and liquid density, the two major parameters affecting sludge separation. As expected from sedimentation theory, recovery declines with increasing throughput and liquid density. Sludge separation is directly proportional to the density difference between the sludge and liquid phases and therefore varies inversely with liquid density at constant throughput. Feed rate affects separation by altering the residence time for sludge settling in the centrifuge bowl. Based on preliminary recovery data in Figure 4.25 , the design basis of $98 \%$ sludge recovery can be achieved with a throughput of up to $5 \mathrm{gpm}$ in the dewatering step and at least $12 \mathrm{gpm}$ in the first and second wash steps where the estimated liquid densities are $1.21,1.00$, and $0.993 \mathrm{~g} / \mathrm{mL}$, respectively. 
A typical plot of sludge recovery versus time is shown in Figure 4.26. Recovery remains nearly constant until the bowl is filled with sludge and then drops abruptly as solids overflow in the effluent begins. Figure 4.27 shows the bowl fully loaded with a uniform, standup cake. The photograph was taken after the machine was shut down after solids overflow had started but without the normal five minute cake compaction spin. Other tests have shown that cake volume is reduced by about $10 \%$ in the compaction step. Analysis of the cake reveals that the dense, dry solids settle at the bowl bottom and outer wall while the light, more gelatinous solids collect in the inner, upper portion of the bowl. Cake density in the dewatering step ranges from 1.3 to $1.7 \mathrm{~g} / \mathrm{mL}$.

The effect of feed acceleration on separating performance was also studied in the large TNX centrifuge. Complete acceleration of the feed before entry into the liquid pool is normally provided by the rotating feed pump and distributor located at the bottom of the centrifuge (see Figure 4.24). The centrifuge is also fitted with a 1-inch-diameter, top-entering, stationary feed pipe which discharges the feed directly onto the pool surface near the bowl floor and provides essentially no acceleration. Figure $4.28 \mathrm{com}$ pares centrifuge separation with and without feed acceleration and indicates that complete or nearly complete feed acceleration is necessary to achieve $98 \%$ sludge recovery at the desired feed rates. Based on this data, the simpler stationary feed pipe does not appear suitable for the DWPF centrifuge.

An alternate means of skim liquid removal has been successfully tested in the small and large TNX centrifuges in which the liquid on the cake surface is allowed to drain into the wash or slurry tank below as the centrifuge bowl is decelerated for sludge discharge. The liquid is then pumped from the tank before plowing. This method of liquid removal would simplify centrifuge design by eliminating the skimming device but would require an additional pump or transfer jet in the wash tank.

The TNX small-scale washing tests indicated that slurrying of the centrifuge cake with water in the wash tank might be difficult. Lumps of sludge tended to adhere to the tank wall and floor and often plugged the centrifuge feed line. However, tests with the large-scale INX slurry tank have shown that satisfactory cake dispersion can be obtained with a cylindrical tank using a conventional turbine agitator, and that a specialized, high-shear mixing device is not required. The slurry tank is shown in Figure 4.29 and is equipped with a dual-impeller, $45^{\circ}$ pitchedturbine agitator driven by a 5-hp, SCR-controlled, variable-speed DC motor. The impeller to tank diameter ratio is 0.6 and maximum 
impeller speed is $125 \mathrm{rpm}$. The lower portion of the tank is unbaffled and usually only the bottom impeller is submerged during operation. In a typical slurring test, 50 gallons of sludge cake are discharged from the centrifuge into 30 gallons of water in the slurry tank with the agitator operating at maximum speed. Under these conditons, the sludge is fully dispersed within eight minutes of the start of discharge which takes five minutes. Agitation conditions can best be described as strong with surface splashing, a deep center vortex, and good batch circulation. No problem has been experienced with sludge holdup or buildup in the discharge chute which enters the slurry tank at a $60^{\circ}$ angle and converges in area by about $60 \%$. Undiluted sludge cake has been mixed in the slurry tank, although the batch circulation rate is low and a stagnant zone 4 to 5 inches wide exists along the tank wall. To avoid the possibility of agitator stallout which has occurred with undiluted sludge, the agitator should be operated during discharge and some water present in the tank prior to discharge.

\subsubsection{Small-Scale TNX Test Results}

Washing tests at roughly $1 / 100$ of plant scale have been performed at TNX using synthetic sludge waste. The test equipment is shown in Figure 4.30 and consists of an agitated wash tank, bench model basket centrifuge, and a centrate collector. The centrifuge contains a 12-inch-diameter by 5.5 -inch-high imperforate bowl and was procured from Delaval Separator Company of Poughkeepsie, New York. Bowl cap height is 2 inches and fill capacity 1.5 gallons. Unless otherwise noted, all tests were conducted at $1300 \mathrm{~g}$ 's force $(2775 \mathrm{rpm}$ ) measured at the bowl wall ( $900 \mathrm{~g}^{\prime} \mathrm{s}$ at the pool surface). Feed is introduced near the center of the solid bottom of the baffled bowl and is accelerated to bowl speed before it enters the liquid pool.

Table 4.24 sumarizes centrifuge separating performance, sludge capacity, and cake water content as a function of feed throughput for undiluted sludge slurry. This data shows that throughput has a substantial effect on sludge recovery and capacity but appears to have little effect on cake water content. The process design criteria of a $90 \%$ basket fill and 3.0 lb cake water/lb solids were selected primarily on the basis of this data. Additional results not included in this report demonstrate that the cake water to solids ratio remains essentially constant throughout the washing process. Figure 4.31 is a typical plot of centrifuge sludge recovery versus time showing that recovery is nearly constant up to basket capacity and then drops abruptly as in for the large TNX centrifuge. 
Centrifuge scaleup was also investigated. The $\Sigma$ method described by Amblerl was found to be an effective means of scale up of centrifuge throughput from small scale test results. Using this method, a feed flow scaleup factor of 23 was estimated for the TNX small and large scale centrifuges, where

$$
\text { Feed Flow Factor }=\frac{g p m \text { Feed in Large Centrifuge }}{\text { gpm Feed in Small Centrifuge }}
$$

As shown in Table 4.25, the measured factor for the TNX centrifuges is in close agreement with the predicted value. The scaleup factor for sludge loading capacity is simply the ratio of basket fill volume in the large centrifuge to that of the small centrifuge. This factor equals 80 for the TNX centrifuges. After being tested at TNX with synthetic waste, the sigma technique will be used to scale up results of HLC small scale centrifuge tests with actual wastes.

Numerous small scale tests have been performed with synthetic waste which demonstrate the basic feasibility of the dilution washing process. Figure 4.32 shows salt removal in a typical test in which 8 liters of sludge slurry were washed three times with 29 liters of water using the test equipment shown in Figure 4.30. This data shows that removal of the soluble $\mathrm{SO}_{4}{ }^{2-}, \mathrm{Na}^{+}$, and $\mathrm{NO}_{3}{ }^{-}$ salts closely follows the dilution model. Most of the salt remaining in the washed sludge appears to be effectively insoluble. However, even with this residual insoluble material, product quality criteria for the washed sludge were easily met as shown in Table 4.26.

The rheology of washed sludge slurry was evaluated to determine the maximum solids content for satisfactory slurry handing and transport. Washed sludge cake from the small centrifuge was mixed with different amounts of water and slurry rheology analyzed using a Haake Model RV-3 rotational viscometer (Haake, Inc., Saddlebrook, New Jersey). Figure 4.33 is a typical slurry theogram or shear stress-shear rate diagram obtained with the Haake instrument. The slurries were found to be Bingham plastic fluids displaying definite yield stress and consistency properties. The rheology of a Bingham plastic is described by the equation

$$
T=T_{y}+n \dot{\gamma}
$$

where $T$ and $T_{y}$ are the fluid shear stress and yield stress, respectively, in dynes/ $\mathrm{cm}^{2}$, $n$ is the fluid consistency in centipoise, and $\dot{\gamma}$ is the shear rate in reciprocal seconds. Slurry yield stress and consistency properties were calculated from the rheograms and are plotted as a function of slurry total solids 
content (insoluble plus dissolved solids) in Figures 4.34 and 4.35 . A qualitative description of slurry fluidity is also given on these plots. Based on this data, a conservative design basis of 17 wt \% total solids was selected for the washed sludge slurry. Large-scale slurry transport tests are now being performed and may show that a higher solids loading is feasible. The rheology of the washed sludge slurry did not show any significant timedependency. 


\subsubsection{Spray Drying (M. H. Tennant)}

\subsubsection{General}

The purpose of this section is to present a description and available technical data bases of the process to convert the feed slurry from the sludge washing and ion-exchange modules into a dry powder suitable for feed to a melter.

Spray drying of simulated $S R P$ waste has been demonstrated at Battelle-Pacific Northwest Laboratories (PNL). Simulated SRP waste was initially dryed in a 21-inch-ID developmental spray dryer at PNL. Feed rates ranged from 15 to $55 \mathrm{~L} / \mathrm{hr}$ and no problems were encountered [6].

More-recent runs were made in PNL's 36-inch-ID spray dryer to determine dryer capacity and to evaluate off-gas sintered metal filter performance. The dryer was successfully operated at feed rates up to $300 \mathrm{~L} / \mathrm{hr}$.

\subsubsection{Process Description}

The flowsheet (FS-5) and material balance (MB-5) for the spray drying system is shown in Figure 4.5 and Table 4.5, respectively. In the reference process, the washed sludge cake from the washed sludge run tank is slurried with the cesium-zeolite slurry and the $\mathrm{Sr}$ concentrate to produce a feed containing 17 to 18 wt \% total solids. The slurry is sampled for sludge content, conveyed to a hold tank, and subsequently transferred to the spray dryer feed tank. This slurry is then fed at a controlled rate to the dryer at a pressure of 1 to 4 atm. The slurry is pneumatically atomized in an internal mix nozzle and sprayed into top center of a cylindrical spray dryer chamber. The ratio of atomizing air and slurry feed is controlled at approximately $4.00 \mathrm{lb} / \mathrm{gal}$. The atomized slurry in the form of fine droplets is sequentially evaporated, dried, and partially calcined as it falls through the spray dryer chamber.

The dryer walls are heated to a temperature between 800 and $950^{\circ} \mathrm{C}$. Inside the chamber heat is transferred to the droplets by a combination of radiation and convection to produce a powder containing less than 2 wt moisture. Fouling of the drying chamber heat transfer surface is minimized by the periodic operation of wall-mounted vibrators. The dryer off-gases, which consist primarily of superheated steam and air, may entrain as much as $50 \%$ of the particles. The entrained particles are removed by passing the off-gas through sintered metal filters. Less than $0.1 \%$ of the 
particulates are expected to penetrate the filters. The off-gas exits the filters and is routed to an off-gas system for radionuclide abatement and mercury recovery. For the purpose of designing the sintered metal filters and off-gas treatment system, the off-gases are assumed to be at $350^{\circ} \mathrm{C}$. The powder collected on the filters is periodically removed by a pulse of blowback air. The total average quantity of blowback air is estimated to be $85 \mathrm{acfm}$. The dry sludge powder from the filters drops into the cone below the dryer along with that which falls directly from the chamber and is combined with glass-forming frit. Frit is fed into the cone to provide a 35:65 ratio by weight of centrifuged sludge (on a dry basis) and glass frit. The frit addition rate is set based on a determination of the sludge content of the waste slurry and the dryer feed rate. No special care is provided to mechanically ensure good mixing of the calcine and frit. However, the size of the frit particles should be as near to that of the dryer product, consistent with reliable transport to the dryer cone. The dried sludge and frit mixture are then discharged to the continuous ceramic melter by gravity flow.

\subsubsection{Technical Data}

\subsection{Spray Dryer Stoichiometry}

The primary reaction that occurs in the spray dryer is the loss of water. Additional reactions assumed for material balance purposes were detailed in Section 4.4.1.4.

A thermodynamics study of the spray dryer/melter off-gas has raised several unresolved questions. These are briefly highlighted below.

- Chlorine and fluorine which vaporize from the melt surface may reflux between the melter and spray dryer filters as sodium, cesium, and lithium halides. These elements form gaseous products at melter temperatures and form solids at the filter.

- Sodium hydroxide, which melts at $318^{\circ} \mathrm{C}$, will form if $\mathrm{Na}_{2} \mathrm{CO}_{3}$ is left on the filters when sludge feed to the spray dryer is stopped.

- LiCl and CsCl may accumulate on the sintered metal filters. A $\mathrm{LiCl}-\mathrm{CsCl}$ eutectic $(60 \% \mathrm{LiCl})$ melts at $306^{\circ} \mathrm{C}$ and could possibly blind the filters if allowed to accumulate. 
Until appropriate experimental programs are carried out to resolve the previously outlined questions, the bases in Section 4.4.1.4 should serve as a design bases.

\subsection{Characteristics of Spray Dryer Product}

Physical

Tables 4.27 through 4.29 summarize measured physical characteristics of the powder produced in the PNL 36-inch spray dryer with simulated SRP waste feed for constant chamber wall temperature. Experience with the powder shows that it dusts readily and is hydroscopic. Bin storing, conveying, or transporting of the powder is therefore not recommended.

Chemical

Table 4.30 summarizes the concentration of the major components in the powder produced during the 3rd run in the 36-inch PNL spray dryer as a function of feed rate. Also included is weight loss data at $200^{\circ} \mathrm{C}$ and $800^{\circ} \mathrm{C}$. These data were provided by PNL.

Additional chemical characterization of the powder is under way at the Savannah River Laboratory. The following paragraphs summarize the observations and findings to date. The powder in these analyses was produced during operation of the PNL 21-inch spray dryer.

- Scanning electron microprobe analyses indicate (1) higher concentrations of sodium than anticipated, (2) sodium exists primarily on the surface of the particle and (3) iron, manganese, nickel, calcium, and residual sodium and aluminum were generally uniformly distributed throughout the powder (some areas indicated less abundant manganese - these areas were more abundant in iron and nickel).

- X-Ray Diffraction Analysis (XRD) showed both amporphous and crystalline material. The crystalline phase was identified as a spinel-type oxide with a cubic structure similar to $\mathrm{NiFe}_{2} \mathrm{O}_{4}$. XRD analysis of the water soluble fraction of the powder (after crystallization by evaporation) showed $\mathrm{Al}(\mathrm{OH})_{3}$ and $\mathrm{Na}_{3} \mathrm{H}\left(\mathrm{CO}_{3}\right)_{2}$. 
- Elemental and ionic analyses of the powder following dissolution in $\mathrm{HCl}$ are summarized in Table 4.31. These data indicate that approximately $95 \%$ of the sodium, $90 \%$ of the nitrate, and $60 \%$ of the aluminum are present as a water-soluble form. Solubility data for sodium and aluminum indicate $\mathrm{NaAlO}_{2}$. The remainder of the aluminum and essentially all the iron, manganese, nickel, and calcium are present in water-insoluble forms. The insoluble aluminum species is probably aluminum oxide, possibly hydrated carbonate and nitrate exist primarily in a water-soluble form.

- Thermogravimetric Analysis (TGA) and Differential Thermal Analysis (DTA) data are summarized in Table 4.32. These data indicate that the powder may contain as much as $13 \%$ water, probably in hydrous oxides. Transitions above $500^{\circ} \mathrm{C}$ are likely thermal decompositions yielding $\mathrm{CO}_{2}$ or oxygen.

- Mossbauer spectrometry of the powder leads to the following initial observations:

1. All iron is in the ferric state ( $\mathrm{FeOOH}$ or as $\mathrm{Fe}_{2} \mathrm{O}_{3}$ with particle size (10 $\mu \mathrm{m})$.

2. None of the following iron species are present (in detectable quantities) - $\mathrm{Fe}_{2} \mathrm{O}_{3}$ (particle size $>10 \mu \mathrm{m}$ ), $\mathrm{Fe}_{2} \mathrm{O}_{4}$, $\mathrm{FeOOH}, \mathrm{FeOOH}$, or FeOOH.

\subsection{PNL Experience}

As noted earlier in this section, several spray dryer runs have been performed at PNL using simulated SRP waste. Table 4.33 summarizes the first four runs. The first two runs were made in PNL's 21-inch I.D. spray dryer and the latter two in their 36-inch I.D. spray dryer. 
4.5.5 Vitrification (T. A. Willis, M. J. Plodinec)

\subsubsection{General}

Vitrification in a Joule-heated continuous melter is the current reference process for incorporating SRP high-level liquid waste into a solid matrix. Experience has been limited to largescale tests at Battelle-Pacific Northwest Laboratories and smal1scale tests at the Savannah River Laboratory using simulated SRP waste.

\subsubsection{Process Description}

The reference process is comprised of four basic steps. First, the product from the spray dryer is combined with glassforming additives (frit) and delivered onto the melt surface. Secondly, the spray dryer product and frit are incorporated into the molten glass at $1150^{\circ} \mathrm{C}$. Thirdly, the melt undergoes homogenization and finally, the glass melt is poured into steel canisters. The reference flowsheet (FS-5) and material balance (MB-5) are found on Figure 4.5 and Table 4.5 , respectively.

\subsubsection{Technical Data}

\subsection{Basic Theory}

Molten glass is an electrolytic conductor at high temperatures due to its low resistivity (about $10 \mathrm{ohm}-\mathrm{cm}$ ). Thus, an electric current can pass through the glass and heat it by the Joule effect. The heat generated, $q$, as the current passes through a glass will be

$$
q=I^{2} \mathbf{r k}
$$

where $I$ is the current, $r$ is the resistivity, and $k$ is a constant which depends on the geometry of the melter.

\subsection{Rheology}

The rheological (fluid) behavior of molten glass is the most important single property in the pouring phase [7]. The maximum viscosity of the molten glass in the melter and tank riser should be limited to 50 poise or less. This assures an acceptable rate of dissolution of calcine and frit. However, to minimize refractory corrosion and assure sufficient power is dissipated in the glass, the viscosity should not be less than 10 poise. For smooth pouring from the pour spout and adequate flow of melt in the canister, the viscosity of the glass leaving the pour spout should not exceed about 200 poise. 
The reference glass melt is considered a Newtonian fluid. Viscosities of simulated SRP waste glassforms have been measured as functions of temperature, composition, and shear rate. The viscosities of Newtonian melts were modeled as a function of temperature by least-squares fit of the data to Fulcher's equation [8]. Results for the reference glass waste form are tabulated in Table 3.9, Section 3 .

If the glass melt contains $\geq 35$ wt $\%$ sludge, the melt will contain an increasing percentage of crystals. Consequently, the melt behaves as a non-Newtonian fluid and does not have a constant viscosity. However, a reasonably good agreement with experimental results was obtained by fitting the data to [9]:

$$
\mathrm{T}=\mathrm{m} \mathrm{S}^{\mathrm{n}}
$$

( $T=$ shear stress in dyne $\mathrm{cm}, \mathrm{S}=$ rate of shear in $\mathrm{sec}^{-1}$ ). Values of $\mathrm{m}$ and $\mathrm{n}$ were determined at several temperatures for the nonNewtonian melts by the method of least squares. The values listed in Table 4.34 are probably accurate to $20 \%$.

\subsection{Resistivity}

In the melter, the amount of energy produced for melting is controlled by the resistivity of the melt, which is dependent on the composition, the viscosity, and the temperature [10].

The resistivity of the molten glass has been discussed in detail elsewhere [11]. The resistivity of composite sludge with Frit 21 is shown in Figure 4.36. As the percent of sludge in glass increases, the resistivity increases. This can be thought of as simply a dilution of the alkali content, which should increase the resistivity. The resistivities have been fitted to the empirical equation:

$$
\log \rho=a_{0}+a_{1} / T+a_{2} / T^{2}
$$

where $\rho=$ resistivity, ohm $\mathrm{cm} ; a_{i}$ are regression coefficients; and $T$ is the temperature, ${ }^{\circ} \mathrm{K}$. Each of the regression coefficients $\left(a_{i}\right)$ was assumed to be a linear function of the wt $\%$ of each principal sludge and frit component in a melt.

$$
a_{i}=b_{0}(S i)+b_{2}(\mathrm{Na})+b_{3}(\mathrm{Ii})+b_{4}(\mathrm{Fe})+b_{5}(\mathrm{Al})
$$

where the terms in parentheses are the concentrations of the element in the glass, as wt \%. The values of the $b_{i}^{\prime} s$ are listed in Table 4.35 . 
For stable melter operation, the temperature dependence of the resistivity, $\mathrm{d} \rho / \mathrm{dT}$, is just as important as the resistivity itself. In an actual melter, there will not be perfect thermal equilibrium. Hot areas will have lower resistivities, hence pass more current, than cooler regions. Thus, the hotter areas will tend to become even hotter, and the cooler ones even cooler. This "self-deregulating" effect is governed by do/dT at whatever melting temperature is chosen $[10,12,13]$.

Borel [13] and others have pointed out that the ideal condition for controlling electric melting is $\mathrm{d} p / \mathrm{dT} \leq 7 \times 10^{-3} \mathrm{ohm} \mathrm{cm} / \mathrm{K}$, but that control was still possible up to about twice this value. Using the calculated regression coefficients (see Table 4.35) and implicitly solving the empirical resistivity equation for $d p / T$, one can calculate the approximate minimum operating temperatures.

\subsection{Process Details}

\section{Feed Blending}

Glassforming additives (frit) are introduced into the bottom of the spray dryer and combined with the calcine. Care must be taken not to exceed the softening temperature of the frit (about $400^{\circ} \mathrm{C}$ ) before the frit enters the melter to preclude plugging the dryer/melter transition piece. Frit feed rate is proportional to the sludge feed rate to the spray dryer.

The present dryer/melter concept assumes the natural mixing that will take place in the bottom of the dryer is adequate. Laboratory studies with a small-scale melter indicate that the degree of mixing has a significant effect on the waste dissolution rate, foam persistence, and slag formation. Results of these tests are summarized in Tables 4.36 and 4.37 .

The data demonstrates that waste can be vitrified up to 60 times faster if the frit and waste are well mixed (this assumes that no segregation of frit and waste occurs during processing see subsequent section). - In addition, premixing virtually eliminates formation of persistent foam and slags.

\section{Spray Dryer Product/Frit Particle Size}

Laboratory studies indicate that if the particle size of the frit and the dried waste differ markedly, the benefits attained by premixing are somewhat negated due to frit and waste segregation in the melter. Table 4.38 sumarizes these data. 
Feeds containing the largest frit size $(1.7 \mathrm{~mm})$ separated on the melt surface, forming islands of calcine nearly free of glassformer. Analysis of these islands showed that they contained ferrite-spinel crystals. As the frit particle size decreased, the number and size of the islands decreased until none was observed in tests that used the smallest frit size $(0.15 \mathrm{~mm})$. This trend was reversed when frit particles of less than $0.15 \mathrm{~mm}$ diameter were used. This is attributed to the greater amount of water absorbed by the finer particle during handling. These data suggest that the waste dissolution rate, the depression of slag formation, and foam persistence can be optimized by feeding a dry frit the same size as the median particle diameter of the spray dryer product.

Melting

The melter is assumed to operate at $1150^{\circ} \mathrm{C}$. The composition of the melt corresponds to 65 wt \% Frit 131 and 35 wt \% dried waste solids. After the waste is dried, the melt composition is 71.1 wt $\%$ frit, 28.9 waste oxides, for composite sludge. The resistivity is about 2 ohm-cm, the viscosity is about 12 poise, and $1150^{\circ} \mathrm{C}$ is well above the minimum operating temperature. Thus, on the basis of the physical criteria, good-quality glass can be produced as long as concentration fluctuations are not too severe.

\section{Homogenization}

After the melting process, the glass is homogenized [14]. In the glass industry, a glass is considered homogeneous when no difference in the properties of the glass can be measured. The degree of homogeneity will be determined by the thermal history of the glass, its composition, the degree of mixing of the glass components, and the presence of convection current in the melt. At a given temperature, the glass will increase its homogeneity quickly in the first few hours, then more slowing thereafter $[15,16]$.

The single most important way to ensure homogeneity is to mix the batch well. This means that the particles should be as small as possible and their distribution of sizes as narrow as possible [17]. The time required for mixing will then be short, separation of the batch constituents minimal, and homogeneity ensured $[18,19]$.

Material flow through the melter is to be balanced so that a constant level is maintained in the melter (amount added from the calciner equals the amount poured into the canister). A mean 
residence time for the melt of about 25 hours will assure the molten glass will be as homogeneous as possible. The minimum residence time required to homogenize the glass depends on the composition and degree of uniformity of the feed (size and composition) and the temperature of the melt.

Pouring

After melting and homogenization, the molten glass flows through the throat and is allowed to cool slightly. A heater in the pouring section maintains the glass at about $1000^{\circ} \mathrm{C}$. The glass overflows into steel canisters. Based on a heat transfer model developed to predict glass temperatures during canister fill and subsequent cooling (see Section 3.1.7.3), approximately 11 to 15 hours will be required for the glass to cool below $500^{\circ} \mathrm{C}$. Consequently, some devitrification may be expected to occur.

\subsubsection{Summary of Vitrification Experience with SRP Waste}

Based on large-scale tests at Battelle-Pacific Northwest Laboratories (PNL) and small-scale tests at SRL, using simulated SRP waste, four potential problems have been identified.

- Formation of a slag at the bottom of the melter.

- Formation of a persistent foam at the melt/batch interface.

- Formation of a foam when the melter is heated after extended low-temperature idling (Reboil).

- Electrode destruction by molten glass.

\subsection{Slag Formation}

Slag formation has been discussed in detail elsewhere [20]. The slag observed in both the smali-scale and the PNL melter has been identified as ferrite-spinel crystals in a glassy matrix. The data indicate that slag forms as a result of exceeding the solubility of this crystalline phase in molten glass. Slag formation is enhanced by sludges high in iron, low melter temperature, and lack of uniformity (particle size and composition) of the feed. For a given composition there is a residence time which minimizes slag accumulation on the melter bottom. This residence time is determined by throughput, settling of the slag through the melt, and dissolution of the slag. 


\subsection{Formation of Persistent Foam}

Tests in both the PNL and SRL melters have demonstrated that the batch may prodice a persistent foam as it melts [21]. This results in a reduced melting rate. The foam persistence is apparently determined by the effective viscosity of the molten material. Thus, sludges high in aluminum or which form large amounts of ferrite-spinels will produce persistent foam. In both cases, good mixing of frit and calcine, higher melt temperatures, and decreased $\mathrm{TiO}_{2}$ content of the frit, will reduce foam persistence.

\subsection{Reboil}

When the melter is cooled from $1150^{\circ} \mathrm{C}$ to a lower temperature (such as $900^{\circ} \mathrm{C}$ ) for extended periods, the glass in the melter reaches a new equilibrium state, where gases (especially $\mathrm{O}_{2}$ ) are absorbed. Transition metal ions, such as iron or manganese, shift to higher oxidation states (i.e., $\mathrm{Fe}^{2+}$ to $\mathrm{Fe}^{3+}, \mathrm{Mn}^{2+}$ to $\mathrm{Mn}^{3+}$, etc.). Ferrite-spinels collect on the relatively cool floor of the melter. When the glass is reheated, oxygen solubility decreases. The slag on the melter bottom starts to dissolve. In the region of the dissolving slag, the iron equilibrium shifts more toward the lower oxidation state, reducing the amount of oxygen required to maintain electroneutrality, and thus further increasing the supersaturation of oxygen in the glass. The dissolving slag rapidly nucleates bubbles which can form a stable foam. If there is insufficient distance between the molten surface and the top of the melter, this foam can clog feed lines and stop melter operation.

There are three ways to prevent this from occurring.

(1) Design the melter so that any reboil foam will not cause melter failure.

(2) Operate the melter in such a manner that slag cannot form, either by reducing the proportion of waste in the glass, or by flushing the melter with pure frit before reducing the temperature.

(3) Never reduce the melter temperature. ${ }^{a}$

Items (1) and (2) will not prevent reboil, but they will prevent it from being a significant operational problem.

a. The melt temperature may be raised $75^{\circ} \mathrm{C}(\max )$ without experiencing a serious foaming problem when not: feeding. If raised $>100^{\circ} \mathrm{C}$, foaming is a problem whether the melter is being fed or not. 


\subsection{Electrode Destruction}

During small-scale tests at SRL, three electrodes have been destroyed during the glass melting process. In all three cases, the current density on the electrode destroyed was greater than $7 \mathrm{~A} / \mathrm{in.}{ }^{2}$, and the electrode was hotter than its partner. In each case, gas evolution was observed from the electrode that was eventually lost. In each case, the electrode was partially recovered as spheres of metal, indicating that at least part of the electrode had melted.

The mechanism for this destruction is not understood, but the cause is probably excessive current density on the electrode. The gas evolved ( $p r o b a b l y \mathrm{O}_{2}$ ) could be due to electrolysis of the glass at the electrode, which is symptomatic of excessive current density [22]. Obviously, this points out the need to design the electrodes so that high current densities are unnecessary to generate sufficient power to melt glass.

\subsubsection{Off-Gas Treatment (E. L. Wilhite, G. B. Woolsey)}

\subsubsection{General}

There are three primary sources of airborne radioactive releases to the environment from the DWPF: 1) off-gas generated during spray drying and vitrification, 2) vapor space purge of process vessels, and 3 ) the canyon atmosphere.

During spray drying and vitrification, a vapor stream is evolved that contains both nonradioactive and radioactive pollutants. The vapor stream is composed mostly of steam and the inerts used to atomize the feed slurry into the spray dryer chamber. Several radioactive volatile species will be generated during melting such as ruthenium and cesium. To a lesser degree, varying amounts of iodine, technetium, selenium, tellurium, rubidium, and molybdenum will be evolved. Corrosive species such as the alkali borates and halides will also be present. The principal nonradioactive constituents will be mercury vapor and mercury iodide. Various abatement systems are employed to reduce the radioactive emissions to within existing SRP guidelines.

Each canyon process vessel will be purged with $50 \mathrm{scfm}$ of canyon air to maintain the vapor space slightly-negative with respect to the canyon atmosphere pressure. These purges are combined and drawn through a process vessel vent filter prior to release to the sand filter. The vents from the product salt hold tanks, cesium vent scrubber and the general purpose evaporation module vessels are combined, super heated and vented to the atmosphere through HEPA filters. The vents from the saltcrete facility are handled similarly.

$$
-4.41-
$$


The canyon air atmosphere is combined with the treated spray dryer off-gas and the filtered vessel vent air and filtered through a deep-bed sand filter before being discharged to the atmosphere via a stack. Appropriate online instrumentation and stack air sampling facilities must be provided to monitor and audit the airborne radionuclide discharges to the environment.

\subsubsection{Process Description}

The off-gas treatment flowsheet (FS-6) and the material balance $(M B-6)$ are shown in Figure 4.6 and Table 4.6, respectively.

\subsection{Spray Drying/Vitrification}

The temperature of the vapor stream leaving the spray dryer sintered metal filters is expected to be in the range of $300-350^{\circ} \mathrm{C}$. The material balance flowsheet is based on $350^{\circ} \mathrm{C}$. A DF of 1000 for particulates is assumed to be attained across the sintered metal filters (recent tests with the type of sintered metal filter element to be used on the spray dryer that will be installed at TNX indicates that a coated filter may provide DF's as high as 5000).

The off-gas stream, composed principally of steam and inerts, enters an ejector/venturi where it is cooled to $50^{\circ} \mathrm{C}$ by contacting cooled, circulating off-gas condensate $\left(40^{\circ} \mathrm{C}\right)$. The vapor and condensate discharge into a collecting tank.

Exiting the collection tank, the vapor stream is drawn successively through two, washable, deep-bed filters to reduce the particulate loading by at least $99.96 \%$. An overall DF for volatile ruthenium of 400 is assumed for material balance purposes. No $D F$ is taken for $I_{2}$. The first deep-bed filter is operated at $50^{\circ} \mathrm{C}$. The latter is operated at $10^{\circ} \mathrm{C}$ to reduce mercury vapor emissions to about $50 \mathrm{~g} /$ day. Mercury that is condensed at the ejector/venturi and the second deep-bed filter is accumulated and periodically drawn off for purification and recovery (see Section 4.5.7). Contents of the off-gas condensate tank are purged at a rate equal to the rate at which steam is condensed from the offgas stream leaving the spray dryer. This purge is accumulated in a hold tank (recycle collection tank) and periodically transferred for subsequent evaporation in the recycle evaporator and recovery of insolubles in the settling and filtration module. 
Exiting the latter deep-bed filter, the vapor stream is heated to $10^{\circ} \mathrm{C}$ above its dew point and then drawn through two silica gel beds in series to adsorb the volatile species of ruthenium. A DF of $100 /$ bed is assumed for material balance purposes.

The vapor effluent from the second silica gel bed is heated to $150^{\circ} \mathrm{C}$ and drawn through a silver mordenite $\left(\mathrm{Ag}^{\circ} \mathrm{Z}\right)$ bed to reduce the iodine concentration in the vapor stream. A DF of 100 is assumed for material balance purposes.

The vapor effluent from the iodine adsorber bed is cooled to $<50^{\circ} \mathrm{C}$ prior to being combined with canyon air and filtered vessel vent air. Effluent from the sand filter is discharged to the atmosphere via a 200-ft stack.

\subsection{Vessel Vent System}

The vapor space in each canyon process vessel is maintained slightly negative with respect to the canyon atmosphere by drawing approximately $50 \mathrm{scfm}$ (dry basis) of canyon air through the vessel overflow pipe. The purge from each vessel is combined and drawn through a deep-bed canyon filter. A DF of 1000 is assumed for entrained activity across the process vessel vent filter.

\subsection{Canyon Air}

The atmosphere in the process building canyon is maintained negative with respect to less-contaminated areas of the building by continuously purging the canyon air to the sand filter. Canyon air is combined with filtered vessel vent air and off-gas from the spray dryer/vitrification module prior to the sand filter. After being drawn through the sand filter, the filtered air is discharged to the atmosphere through a $200 \mathrm{ft}$ stack. A DF for particulates of 1000 is assumed across the sand filter.

\subsubsection{Technical Data}

\subsection{Spray Dryer/Melter}

The composition of the vapor stream leaving the sintered metal filters has not been fully defined. Thermodynamic studies performed by the Engineering Services Division demonstrate that the composition of the off-gas is very sensitive to spray dryer feed composition and the temperature of the off-gas at the point of equilibria (currently assumed to be at the sintered metal

filters). Results of these studies are summarized below [23]. 
- Iodine is present mostly as I or $I_{2}$ at equilibria temperatures $>627^{\circ} \mathrm{C}$ and as an increasing percentage of $\mathrm{HgI}_{2}(\mathrm{v})$ as the equilibria temperature falls below $627^{\circ} \mathrm{C}$ (at $327^{\circ} \mathrm{C}$, the iodine exists essentially all as $\mathrm{HgI}_{2}$ ). Since the fate of iodine is so temperature sensitive and dependent upon the presence of mercury, the off-gas system must be able to handle all predictable species of iodine. High temperature excursions and/or the absence of mercury will greatly increase the rate of silver mordenite depletion. Material balance calculations are based on $1.0 \% \mathrm{HgI}_{2}$ disassociation $\left(350^{\circ} \mathrm{C}\right)$.

- Mercury in excess of the iodine will be present as $\mathrm{Hg}(\mathrm{v})$ and trace amounts of $\mathrm{HgO}$.

- Boron is present as $\mathrm{H}_{3} \mathrm{BO}_{3}(\mathrm{v})$ at $627^{\circ} \mathrm{C}$ and cooler. At about $175^{\circ} \mathrm{C}$, it will condense.

The following DF's are assumed for preparation of the material balance and the curie balance across the spray dryer off-gas treatment systems.

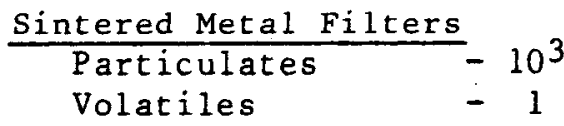

Ejector/Venturi

$\begin{array}{ll}\text { Particulates } & - \\ \text { Iodine } & -1 \\ \text { Volatile Ruthenium }- & 1\end{array}$

Deep-Bed Filter

$\begin{array}{ll}\text { Particulates } & -50 \\ \text { Volatile Ruthenium } & -20 \\ \text { Iodine } & -\quad 1\end{array}$

With the exception of $\mathrm{HF}, \mathrm{I}_{2}$, and the volatile specie of ruthenium $\left(\mathrm{RuO}_{4}\right)$, all volatiles condense as particulates across the wet scrubbing portion of the off-gas system. Consequently the stated DF's for particulates are applicable.

\subsection{Process Vessel Vent}

For purposes of material balance calculations, the vapor space of each canyon process vessel is purged with $50 \mathrm{scfm}$ of canyon air. The canyon air enters the vessel at a dry bulb temperature of $35^{\circ} \mathrm{C}$ and a wet bulb temperature of $25.6^{\circ} \mathrm{C}$. The exit purge is assumed to have a dry bulb temperature of $35^{\circ} \mathrm{C}$ and a wet bulb temperature of $29.4^{\circ} \mathrm{C}$.

$$
\begin{array}{ll}
\text { Silica Gel Bed } & \\
\hline \text { Particulate } & -2 \\
\text { Volatile Ruthenium } & -10^{2} \\
\text { Iodine } & -1
\end{array}
$$

Silver Mordenite Bed

$\begin{array}{ll}\text { Particulates } & -2 \\ \text { Volatile Ruthenium } & -1 \\ \text { Iodine } & -10^{2}\end{array}$ 
To compute the degree of entrainment in a vessel vent, an entrainment of $10^{-9} \mathrm{gal} / \mathrm{ft}^{3}$ was used. This factor was based on observed entrainment in the vapor sweep exiting a fresh alkaline waste receiver (Waste Tank No. 35) in the 241-H tank farm. Observed entrainment was increased 200 fold to account for agitated vessels. Where the amount of entrainment is known to be significantly higher, as with the centrifuges, it is assumed that adequate de-entrainment systems will be provided to reduce entrainment to design bases or less.

The combined vessel vents are to be heated to assure the vapor temperature is at least $10^{\circ} \mathrm{C}$ above the dew point to prevent condensation in the process vessel vent filter. A DF of $10^{3}$ is assumed for particulates across the filter.

\subsection{Volatile Components in Spray Dryer Off-Gas}

\section{Ruthenium}

Volatilization of ruthenium is not expected to be a problem in the spray dryer. However, it is anticipated that ruthenium volatility will be significant at the expected temperature (about $1150^{\circ} \mathrm{C}$ ) in the melter. Based on experiments completed at SRL, it is assumed that $10 \%$ of the ruthenium in the waste feed will volatilize.

\section{Cesium}

The cesium entering the melter is expected to volatilize as $\mathrm{Cs}_{2} \mathrm{O}$ and $\mathrm{CsCl}$ (the degree of volatilization is based on the reference surface area of the glass melt). Although a thermodynamics study indicates the $\mathrm{Cs}_{2} \mathrm{O}$ and $\mathrm{CsCl}$ will exist as

particulates at the sintered metal filter temperature $\left(350^{\circ} \mathrm{C}\right)$ and experience $a \mathrm{DF}$ of $10^{3}$ across the filters, the curie balance assumes no DF. Design volatilization - .05\% of the cesium entering the melter.

Mercury

Mercury occurs in SRP waste from the use of $\mathrm{Hg}^{2+}$ catalyst during dissolution of aluminum-clad fuel in $H$ Area. It is assumed that the mercury exists as $\mathrm{H}_{\mathrm{g}} \mathrm{O}$ in the neutralized wastes. Some mercury is soluble and exists as $\mathrm{Na}[\mathrm{HgO}(\mathrm{OH})]$. All the mercury that enters the spray dryer/melter is volatilized as Hg. A fraction of the mercury will react with iodine depending upon the equilibria temperature (Design bases - $99.0 \%$ of the iodine reacts with $\mathrm{Hg}$ to form $\left.\mathrm{HgI}_{2}(\mathrm{v})\right)$. 
Mercury halides condense as particulates in the ejector/ venturi and are recycled back to the recycle evaporator.

\section{Fluorides and Chlorides}

Chloride and fluoride volatilize from glass melts as HCl and $\mathrm{HF}$ in the presence of water vapor. Laboratory studies (with the melter decoupled from the spray dryer) indicate that $50 \%$ of the fluoride and less than $10 \%$ of the chloride volatilize. However, as indicated by thermodynamic studies, no $\mathrm{HCl}$ and only $3.8 \%$ of the fluoride (as HF) will leave in the spray dryer off-gas. The chloride and majority of the fluoride react preferentially with sodium and are solids at the sintered metal filter temperature $\left(350^{\circ} \mathrm{C}\right)$.

Sodium and Boron

Sodium and boron volatilize from sodium borosilicate glass melts as sodium metaborate. The sodium metaborate subsequently hydolyzes to form $\mathrm{H}_{3} \mathrm{BO}_{3}(\mathrm{v})$ and $\mathrm{Na}_{2} \mathrm{O}(\mathrm{s})$ at the reference sintered metal filter temperature $\left(350^{\circ} \mathrm{C}\right)$. The reference process assumes a $\mathrm{NaBO}_{2}$ vaporization rate of $2.4 \times 10^{-2} \mathrm{lb} / \mathrm{hr}$.

Iodine

The reference flowsheet shows an insoluble iodine feed rate to the DWPF of about $0.23 \mathrm{lb} / \mathrm{hr}$. Of this amount, only about $10 \%$ is attributed to fission product iodine (I-127, I-129). Greater than $90 \%$ of the iodine inventory is attributed to the I-127 used by plutonium reduction processes from 1953 to 1963 . Once the process works off the current waste inventory, the iodine content in the feed will be that of fission product iodine only.

Iodine may exist in the spray dryer/melter off-gas as a mixture of $\mathrm{HgI}_{2}, \mathrm{I}_{2}$, or $\mathrm{I}$ depending upon the spray dryer temperature and the amount of mercury. At the reference waste composition to the spray dryer and an equilibria temperature of $350^{\circ} \mathrm{C}, 1 \%$ of the iodine will exist as $\mathrm{I}_{2}$ or $\mathrm{I}$. 


\section{Other Radionuclides}

other radionuclides that may volatilize include rubidium, molybdenum, tellurium, technetium, and selenium. Of these, Tc-99 and $\mathrm{Se}-79$ are of particular interest because of their long halflives $\left(2.1 \times 10^{5} \mathrm{yr}\right.$ and $6.5 \times 10^{4} \mathrm{yr}$, respectively). Essentially no data exists on the volatility of these radionuclides during the vitrification of SRP defense waste. It is assumed for material and curie balance purposes that $5 \%$ of each volatilize from the glass melter and enter the off-gas system. It is further assumed that these volatile species will condense as submicron particulates in the ejector/venturi.

\subsection{Particulate Characterization of Off-Gas Stream}

Preliminary results from efficiency tests of the sintered metal filter to be used in the SRP spray dryer indicate a removal efficiency (based on 0.7 -micrometer-diameter particles) of $99.98 \%$. This collection efficiency is based on the filter element being loaded as would be the case immediately prior to filter blowback. Based on PNL observations, a significant increase in total particle loading downstream of the filters occurs immediately following blowback of the filter elements. For material balance purposes, the filters are assumed to remove $99.9 \%$ of the particulates generated during spray drying of the reference waste.

During the first run of simulated SRP waste at PNL, particle size analyses were completed on the spray dryer off-gas. The analysis was done on the vapor stream immediately downsteam of the sintered stainless steel filters. Table 4.39 summarizes the total particle and mass loading per actual cubic foot of off-gas vapor for four particle size ranges. The PNL spray dryer filters have a nominal ( $98 \%$ ) particle removal rating of 65 micrometers.

The tests indicate that a large portion of the particles passed the filter immediately following the blowback and vibrator operation. A sample taken during no blowback or vibrator operation indicated that only one-third of the particles observed during normal operation passed the filters. In addition, it was found that essentially no particles greater than 0.5 micrometer in diameter passed the filters when there were no filter blowback vibrator operations. 


\subsubsection{Mercury Recovery Facility (L. F. Landon)}

\subsubsection{General}

Approximately 1.2 lb of metallic mercury will be condensed each hour from the off-gas vapor stream and accumulate in the offgas condensate collection tank. The mercury will most likely be as a sludge and will require further cleaning before it is of a purity suitable for reuse in the separations process and/or storage.

\subsubsection{Process Description}

Figure $4.6 \mathrm{~A}$ is a schematic drawing of a conceptual mercury recovery process. The mercury that accumulates in the off-gas condensate tank will be intermittently pumped to a mercury hold tank through a backwashable filter to remove the majority of solids occluded to the mercury. Periodically, the filter cake will be dislodged from the filter and pumped back to the recycle evaporator via the off-gas condensate tank for recycle to the process.

The filtered mercury, on a batch basis, will be pumped to the top of a column containing $10 \% \mathrm{HNO}_{3}$. The formed droplets will fall by gravity through the acid and overflow a barometric leg to a sparge tank. Particulates, not removed by the initial filtration step, that are soluble will be removed from the mercury. Periodically, the nitric acid will be pumped from the column, neutralized, and recycled back to the off-gas condensate collection tank.

In order to remove contaminants such as iron and aluminum, the acid-washed mercury will be sparged gently at room temperature to oxidize the contaminants. After sparging is complete, the mercury is filtered through another backwashable filter to remove the formed oxides. Final cleanup of the mercury is achieved by vacuum distilling the mercury and bottling the condensed overheads.

\subsubsection{Physical Properties of Mercury}

$$
\begin{array}{ll}
\text { Density } & -13.59 \mathrm{~g} / \mathrm{cm}^{3} \\
\text { Boiling Point } & -356.66^{\circ} \mathrm{C} \text { at } 760 \text { torr } \\
\text { Viscosity } & -1.407 \mathrm{cp} \text { at } 50^{\circ} \mathrm{C} \\
\text { Vapor Pressure } & - \text { See Figure } 4.37
\end{array}
$$




\subsubsection{SRL Experience}

Mercury that is used in laboratories throughout the SRP that is no longer of suitable purity is sent to the Apparatus and Glassblowing Shop in 773-A for reclaiming. The mercury reclaiming facility is housed in a ventilated glass hood approximately $2 \mathrm{ft}$ deep $\times 4 \mathrm{ft}$ wide $\times 5 \mathrm{ft}$ high. Recovery rate averages about $6 \mathrm{lb}$ $\mathrm{Hg} / \mathrm{hr}$.

The mercury is first filtered through filter paper shaped into a cone with several $0.5-\mathrm{mm}$ holes punched in the bottom. The filtered mercury is then poured into a separatory funnel which disperses the mercury into an acid wash column containing $10 \%$ $\mathrm{HNO}_{3}$.

After acid washing, the mercury is transferred to an oxifier in which air is bubbled through the mercury for 1 hour. After oxification, the filtration step is repeated. The solids removed during this filtration step are subsequently treated with $\mathrm{HNO}_{3}$ for mercury recovery.

The filtered mercury is then introduced into a vacuum disti1lation apparatus (see Figure 4.38). The still operates at a pressure of about $5 \times 10^{-2}$ torr $\left(\mathrm{Hg} \mathrm{b} . \mathrm{p} .-192^{\circ}+2^{\circ} \mathrm{C}\right)$. The recovered mercury is stored in 1-liter bottles (about $\mathrm{TO}$ lb of $\mathrm{Hg} /$ bottle).

\subsubsection{Recycle Concentration}

\subsubsection{General}

An evaporation step is included in the reference flowsheet to (1) remove excess water from dilute recycle streams to maintain the salt concentration in the gravity settler feed at about 30 wt $\%$, (2) to reduce the size of supernate processing equipment, and (3) provide the first stage of decontamination of process water. The flowsheet (FS-7) and material balance (MB-7) are shown in Figure 4.7 and Table 4.7 , respectively.

\subsubsection{Process Description}

Process streams that are presently candidates for evaporation are combined in the evaporator feed tank. These streams include:

- Condensate purge from the cesium concentrator

- Centrate from the sludge-washing centrifuges

- Off-gas condensate 
- Aluminum dissolver condensate

- Ion exchange transfer water

- Canyon sump contents

- Sand filter and stack condensate

- Laboratory waste

- Contents of the cesium regenerant catch tank (spent cesium ion exchange regenerant after $\mathrm{NH}_{3}$ removal)

- Excess water from the cesium fixation module

- Bottoms from the general-purpose evaporator

- Deionizer purge

- Spent canister decontamination solutions and water rinses from Mechanical Cell A

The feed will be concentrated to about 35 wt \% salt. Evaporator concentrate is transferred to the gravity settler feed tank for recovery of the solids. Overheads are transferred to the general-purpose evaporator feed tank for additional decontamination. A DF of $10^{6}$ is assumed across the evaporator/de-entrainer (concentration in the evaporator concentrate/the concentration in the evaporator condensate).

\subsubsection{Settling and Filtration (E. J. Weber)}

\subsubsection{General.}

The purpose of this section is to present the process details and technical data bases for reducing the suspended matter in feed to ion exchange to $1 \mathrm{ppm}$ or less. It is estimated that feed to this module will nominally contain 6000 to $7000 \mathrm{ppm}$ of sludge. Essentially complete sludge removal is desired to provide:

- Operation of the ion exchange columns for cesium, plutonium, and strontium removal without pluggage or fouling.

- Removal of the highly insoluble Sr-90 to produce an acceptable clarified supernate for subsequent incorporation into concrete. 


\subsubsection{Process Description}

The supernate stream from the waste tanks is blended with recycled evaporator concentrate and sand-filter backwash to form the feed to gravity settlers. The decanted supernate is blended with zeolite raffinate and fed successively through a primary, No. 1 , sand filter, and (3) a polish, or No. 2, sand filter to reduce the concentration of sludge to $1 \mathrm{ppm}$ or less. A flow diagram (FS-8) is shown in Figure 4.8 , and a material balance (MB-8) is shown in Table 4.8.

Blended feed is heated, then transferred to one of two gravity settler (GS) tanks. A small quantity of coagulant is added to agglomerate the colloidal particles into larger, fastersetting masses. After periods of high speed, moderate, then gentle mixing, agitation is stopped and the agglomerates allowed to settle. The clear top layer, representing most of the feed volume, is then decanted. The bottom sludge layer is left for resettling with the next feed batch. After several batches of feed slurry are received, settled, and decanted, the accumulated sludge is agitated and transferred to the gravity settler bottoms tank.

Decanted supernate from the GS is cooled to less than $25^{\circ} \mathrm{C}$. Zeolite raffinate is blended with the decanted supernate. Polyelectrolyte solution at $0.05 \mathrm{gpm} / \mathrm{ft}^{2}$ is added to the cooled supernate via a mixing tee just before the supernate reaches the No. 1 sand filter. Total flow to the filter is $1.2 \mathrm{gpm} / \mathrm{ft}^{2}$. Filtrate is collected in the first filtrate tank.

When the No. 1 sand filter loads up with suspended matter ( 3 psi $\triangle P$ max), the sand filter is backflushed with filtrate from the filtrate hold tank. The backwash is transferred to the gravity settler feed tank via the filter backwash tank for treatment in the gravity settler.

Polyelectrolyte is added to the No. 1 sand filter filtrate as above, just before it reaches the No.: 2 sand filter. Filtrate from sand filter No. 2 is collected in the second filtrate tank and sampled for vol \% suspended matter. If it is 1 ppr or less, the filtrate is transferred to the filtrate hold tank for ionexchange feed. Out-of-spec filtrate is recycled to the sand filter feed tank. When required, the No. $2^{\prime}$ filter is backflushed the same as No. 1 filter. 


\subsubsection{Technical Data}

\subsection{Gravity Settling}

The objective of gravity settling is to serve as a pretreatment for sand filtration to reduce the load of sludge that must be removed in the sand filters. Without gravity settling, the filters would be abruptly clogged, terminating the filter run. In addition, prohibitive quantities of backwash requiring recycle would be produced. The gravity settling treatment must remove suspended matter in supernate to $50 \mathrm{ppm}$ or less to obtain an acceptable sand filter operating cycle $(>24 \mathrm{hrs})$ without prohibitive backwashing requirements and thus produce acceptable recycle quantities in the sand filter backwashes. This is seen in the 4-inch diameter sand filter results of Figure 4.39 . With $40 \mathrm{ppm}$ of sludge in the gravity settler product, the filter can produce acceptable filtrate product for almost $48 \mathrm{hr}$ before a rapid rise in filter pressure drop concludes the run. With $150 \mathrm{ppm}$ of sludge in the GS product, only about $12 \mathrm{hrs}$ of filtrate production is obtained before excessive pressure drop dictates backwashing. The same quantity of filter backwash is required in both cases, so that the better quality GS product results in about one-fourth the recycle volume. $50 \mathrm{ppm}$ of sludge has therefore been selected as the desired upper limit in GS product.

\section{Glassware Studies}

Destabilization of the colloidal hydrous oxides suspended in settled or centrifuged supernate is essential to accomplish the settling in reasonably-sized vessels. According to Kolthoff and Sandel1 [26], coagulation of suspensions of colloidal hydrous ferric oxide and especially the agglomeration of primary particles, is greatly accelerated by raising the temperature of the solution. This was confirmed in glassware studies. Agglomeration is accomplished by heating the centrate to temperatures of 60 to $100^{\circ} \mathrm{C}$ using very gentle agitation. When the centrate reaches 60 to $65^{\circ} \mathrm{C}$, particles large enough to observe with the unaided eye ( 80 to 100 micrometers) become visible. Agglomeration reaches its maximum after 20 to 30 minutes without mechanical agitation, but with the required gentle agitation supplied by thermal convection generated at the higher temperatures. At this point, cooling to temperatures below $45^{\circ} \mathrm{C}$ reduces thermal currents and allows more rapid settling of the agglomerates.

Figure 4.40 shows that heat alone agglomerates suspended matter to produce a faster settling rate. Bnth Samples "A" and " $B$ " were taken from the same centrate batch which contained 0.70 vol \%, or $7000 \mathrm{ppm}$, of suspended matter. The agglomerates that 
mostly settled out, and relatively clear supernate is seen in the heated sample after 16 to 25 minutes. It took the unheated control 12 times as long to settle to the same quantity of suspended matter in supernate [27].

Using Floje1 ${ }^{\circledR} 60$ (National Starch and Chemical Corp.) cornstarch derivative as a coagulant proved to be a second method of destabilizing the colloidal suspension. Starch was tested after SRL learned of its use in the chemically similar Bayer process for destabilizing colloidal red mud, with subsequent removal of these impurities from caustic sodium aluminate solution. The red mud consists of hydrous oxides of iron, silicon, and titanium which must be separated for recovery of pure alumina from bauxite. Similar to defense waste supernate, the impurities are suspended in a highly conductive solution containing several percent free sodium hydroxide and several molar sodium ion. A number of polyelectrolytes, normally effective in agglomerating impurities from raw water, were tried without success on the supernate.

With both heat and the starch coagulant, larger and tougher agglomerates are produced than with heat alone. Figure 4.41 illustrates the destabilization of suspended matter in composite centrate using heat and coagulant. The two samples shown were from the same centrate batch which contained 2000 ppm $(0.20$ vol \%) suspended matter. $50 \mathrm{ppm}$ of Flojel ${ }^{\circledR} 60$ was added to the treated sample prior to heating it for $1 \mathrm{hr}$ to $80^{\circ} \mathrm{C}$ with gentle agitation. It was removed from the heat and allowed to settle for about one minute when the photo was made. The unheated control sample was agitated and had been settling for $1 \mathrm{hr}$ at the time.

Figure 4.42 shows quantitative effects of heat and coagulant addition on supernate quality. Using composite centrate containing $2000 \mathrm{ppm}$ suspended matter in 4-1iter containers, samples were taken $4 \mathrm{in}$. beneath the $\mathrm{liquid}$ surface at designated times and treatment conditions. With neither heat nor starch, there is little settling in $1 \mathrm{hr}$, as the samples show no change from the feed concentration. With heat alone, visual agglomeration is confirmed by the decrease to less than $300 \mathrm{ppm}$ suspended matter in 1 hr. With addition of as little as $5 \mathrm{ppm}$ of starch, suspended matter in the samples was reduced to about $100 \mathrm{ppm}$ in 10 minutes. Concentrations of starch up to $200 \mathrm{ppm}$ did not change the settling rate significantly.

Mini-scale glassware tests showed that the GS operations are best performed batchwise in a single vessel to minimize pumping and flows that fracture the agglomerates. Continuous gravity settling produces smaller and slower settling agglomerates, results in poorer quality supernate; and introduces a sludge layer control 
problem in the continuous settler. Detection and control of the sludge layer would be very difficult in the remotely operated canyon. On the other hand, all batch tank operations of agglomeration, settling, decanting, and sludge removal have been performed for years in routine $F$ and $H$ canyon operations.

\section{0-Gallon Semiworks Studies}

Following these glassware studies, seven 700-gallon test runs were made using salt compositions specified in the PTDS No. 1 flowsheet. This earlier flowsheet did not include aluminum dissolution and consequently contained less free caustic (see Tabie 4.40 for salt concentrations). Semiworks Tank A-6, 5-ft diameter $\times 6-\mathrm{ft}$ high was used in this study of GS variables. The A-6 tank is about $1 / 15$ the size of the anticipated GS plant vessel.

Feed batch volumes were 715 to 740 gallons of "average" or "composite" centrate containing 4000 to 8500 ppm of suspended matter. Test procedure was to add the starch in a pre-mixed $8 \%$ aqueous dispersion to the agitated tank contents. The slurry was heated with steam to the tank coils during the mixing period. After mixing periods of up to one hour, the agglomerating particles were allowed to settle over the next 3 to 8 hours with cooling water to the tank coils. The clear supernate was then decanted via a 3/4-inch suction pipe and exterior pump to stainless drums. Decanting was completed when the 1 iquid level was reduced to the height of the upturned weir of the suction pipe. At this time, the settled sludge on the tank bottom was covered with an undecanted layer of clear supernate some 4 to 8 inches high. The agitation was turned on and the resulting slurry, with 10 to $15 \%$ of the starting feed volume and $98 \%$ of its sludge, was pumped to waste. The decanted supernate product was subsequently treated in the 4-inch diamter sand filter studies as described later.

The test data are shown in Table 4.41. Runs 1 to 3 were made by first adding starch to the cold centrate, then heating. Because of the desire to avoid heating in a cooled and jacketed plant settler (whereby heat would be added in an upstream tank), Runs 4,5 , and 7 were made by first heating with agitation, then shutting off steam and adding starch with $1 \mathrm{hr}$ of agitation. The agglomerating particles were then settled and the run continued in normal fashion. Run 6 was made as above, except without any heat addition.

Further 700-gallon test Runs, 8 and 9 , were made using a high-caustic flowsheet as a consequence of changing the reference process to include aluminum dissolution of waste tank sludge. Glassware studies indicated higher temperatures were essential 
for acceptable settling in the high-caustic supernate. Consequently, the large-scale followup tests made in Tank A-6 were conducted at maximum temperatures between 90 and $100^{\circ} \mathrm{C}$, as shown in Table 4.42 .

Figure 4.43 relates supernate quality and settling time for all the 700-gallon runs. Results indicate the desired maximum of $50 \mathrm{ppm}$ or less of sludge in supernate feed to sand filters is attained at a settling time equivalent to a $10 \mathrm{in./hr}$ rate. The latter appears to be optimum because allowing longer settling times, or shorter equivalent settling rates, produces smaller quality improvement. No difference is noted in product quality attained in the higher caustic supernate.

Figure 4.44 is a photograph of samples obtained from the initial 700-gallon GS run. The sample at the left is the decanted supernate which contains about $150 \mathrm{ppm}$, or 0.015 vol \% suspended matter. The middle sample is the feed centrate containing 4000 ppm suspended matter. The sludge sample at the right contains 2.5 vol \% suspended matter. Al1 suspended matter determinations were made by centrifuging at $10,000 \mathrm{~g}$ for 3 minutes.

\section{Large-Scale Studies}

Large-scale GS studies were continued in Semiworks Tank W-2, a. nominal 6000-gallon capacity $\mathrm{flat}$-bottomed unit, $10-\mathrm{ft}$ OD by 11-ft high flat bottom. The tank is equipped with a variablespeed agitator, baffles, and coils. A 2-in.-diameter standpipe, 10 in. high is mounted on the tank bottom for decanting the clear supernatant 1 iquid with the $\mathrm{W}-2$ pump to the filter feed tank. The semiworks $W-2$ vessel is approximately one-half the size of the anticipated plant GS tank. Length-to-diameter ratios of the filled test and plant units are both about equal to unity. Figure 4.45 is a scaled drawing of the $\mathrm{W}-2$ GS tank.

Ten large scale GS runs were made. The procedure was similar to the 700 gallon study except:

- Product decant rate with the W-2 pump was $125-130 \mathrm{gpm}$ or some 12 times greater than the 700-gallon scale.

- High caustic (see Table 4.40) and intermediate caustic flowsheets were used. Intermediate flowsheet concentrations of caustic $(0.99 \mathrm{M})$, sodium aluminate, $(0.48 \mathrm{M})$ and total sodium ion $(5.3 \mathrm{M})$ represent minimal addition of caustic in the Al-dissolving process. 
- Variable mixing speeds using flat paddles were employed, as compared with single-speed, high shear agitation using a propeller-type mixer in the 700-gallon work. An effective combination of mixing speeds in the baffled $W-2$ tank was 20 minutes of high-intensity agitation ( $50 \mathrm{rpm}$ ), during which $8 \%$ starch was added to the preheated slurry, followed by 10 minutes at $30 \mathrm{rpm}$, and 60 minutes at $6 \mathrm{rpm}$. The agitator was then turned off to allow agglomerates to settle.

- Several of the runs were made using the technique of leaving the undecanted sludge for reslurrying and resettling with the next feed batch. In the 700-gallon runs, the sludge layer was removed before the next feed batch was introduced. When reslurring, starch was added for the new sludge only, since the reslurried sludge had already received starch.

Objective of the latter tests was to demonstrate a decrease in GS bottoms volume recycled to sludge washing. By thickening the undecanted layer with sludge from additional feed batches, volume recycled to the washers should be reduced below the nominal $10 \%$ obtainable when recycling a single sludge batch. It is assumed that the height of clear supernate in the undecanted layer is the same as for a single sludge batch and that the decant pump orifice is raised to accommodate multiple sludge batches. A second feature is that salt is displaced by sludge in the thickened recycle. Both features improve feed characteristics to sludge washing where salt removal is the objective.

Results of these large-scale tests, Table 4.43, show cleaner decanted product is obtained at faster settling and with less bottoms recycle than earlier small-scale results. Use of reduced temperatures evidently reduces sludge in decanted product, probably because of water evaporation, supersaturation, then post precipitation occurring at higher temperatures. At $35-45^{\circ} \mathrm{C}$, less than $25 \mathrm{ppm}$ sludge is found in decanted supernate. Corresponding settling times are equivalent to $20-25 \mathrm{in}$./ hr settling rates. Demonstrated recycle volume with the sludge reslurrying and resettling technique (Runs 1-3) is $7.9 \%$. Use of this technique has no apparent ill effects on product quality or settling rate. In fact, results indicate the increased sludge quantity present may produce a scavenging effect on the particles most difficult to settle. 


\subsection{Sand Filtration}

The objective of sand filtration is to remove the small quantity of suspended matter ( $50 \mathrm{ppm}$ or less) remaining in supernate after GS treatment via deep-bed filtering. Sand filtration is a part of the conceptual process because of the successful results obtained in small-scale studies performed at the semiworks and in the high-level caves. In the latter tests already referred to, actual plant waste supernates and sludges were blended, then separated in a series of two centrifuge runs, followed by sand filter clarification. Centrate feeds containing 500 to $2000 \mathrm{ppm}$ of suspended matter were clarified to less than $100 \mathrm{ppm}$ of suspended matter [24]. The sand-filtered supernate was subsequently processed in ion exchange columns, producing a final clarified supernate with about two nanocuries or less of $\mathrm{Sr}-90$ per gram of damp salt cake [25].

\section{4-Inch-Diameter Filter Studies}

The sand filters are fed downflow and backwashed upflow in a dual-media (anthracite/sand) bed. In depth filtration, larger particles are arrested first, followed by removal of the smaller particles in the deeper portions of the filter media. As the filter loads with suspended matter, filtration resistance increases, and the filter must eventually be backwashed to remove the particulates and recycle them for treatment in GS. Figure 4.47 shows photographs taken during the various operations. At left, the GS supernate product ( $50 \mathrm{ppm}$ suspended matter) can be seen flowing downward through the layers of anthracite/sand at a rate of 1.2 $\mathrm{gpm} / \mathrm{ft} \mathrm{t}^{2}$, equivalent to a superficial velocity of $2 \mathrm{in.} / \mathrm{min}$. Fluidization of the filter media during backwash is shown in the middle picture. An air-water mix of about $2 \mathrm{cfm}-5 \mathrm{gpm}$ per $\mathrm{ft}^{2}$, respectively, is being used to free the arrested particulate from the filter media and float it out the top of the column. The picture at right in Figure 4.47 was taken about 5 minutes after backwashing was completed. The sharpness of the anthracite/sand interface that occurs on resettling can be observed in this picture.

The reference process is to filter GS supernate product through a primary (or No. 1) bed of anthracite ( 700 micrometer average diameter) and $25-10 \% 40$-mesh sand (490 micrometer average diameter), and then refilter the primary filtrate through a polishing bed of anthracite (400-micrometer average diameter) and 40to 60-mesh sand (270-micrometer average diameter). By comparison, high-level cave sand filtration was performed directly on secondary centrate (no GS treatment) in a series of two 4-in.-diameter columns, each containing 24 in. of 25- to 40-mesh sand and 8 in. of 20- to 30-mesh, 700 micrometer average diameter, anthracite [24]. 
Table 4.44 summarizes performance at the semiworks with the 4-in.-diameter (roughly 1/200-plant scale) filter, using composite GS product from the initial low-caustic flowsheet. The data presented in Table 4.44 is an average for the feed cycle over several backwash cycles. Conditions for feeding and backwashing include addition of (1) high-molecular weight anionic polyelectrolyte in feed to the filters and, (2) air in the backwash cycle used to clean the filters. The GS supernate was reduced from 50 to $5 \mathrm{ppm}$ of suspended matter across $24 \mathrm{in}$. of sand and $8 \mathrm{in}$. of anthracite in the primary filter. In the polishing unit, refiltration across 18 in. and 3 in., respectively, of the finer sand and anthracite produced filtrate containing 1 ppm of suspended matter. Thus, design basis for filtrate quality is met in the polish sand filter product when processing the synthetic supernate from "composite" slurry.

The GS composite supernate from the high caustic flowsheet runs were also tested in the 4-in.-diameter primary sand filter. No filtration problems were indicated. Performance was essentially the same as that obtained with the lower caustic flowsheet. Figure 4.48 shows (1) the increase in $\Delta P$, and (2) color migration down the $24 \mathrm{in}$. of sand, both with increasing volumes of feed slurry containing $40 \mathrm{ppm}$ of sludge. The brownish-red color front, caused by the arrested sludge particles, was visually observed through the glass column walls, and this movement was plotted in Figure 4.48. In all cases, volume \% sludge in filtrate was less than $3 \mathrm{ppm}$. Presumably, sludge breakthrough would occur when the color had migrated the entire 24-in. sand depth. It appears under the conditions tested that excessive $\Delta P$ would conclude the filter run before such a depth of color migration was reached.

Based on results shown in Table 4.44 and Figure $4.48, \triangle P$ increase across the primary sand filter will approximate 1 psi for 24 hours of filtrate production with feed of 50 ppm sludge or less for GS. An upper limit for the $\triangle P$ rise of 1 to 3 psi is consistent with industrial water purification practice where a maximum $\Delta P$ rise of $3.5 \mathrm{psi}$ is used to avoid penetration of arrested matter through the filter media and into the effluent [28].

Filtrate production of 24 hours through the primary bed results in a backwash volume of about $5 \%$ of the feed volume. This recycle rate has been arbitrarily selected as a satisfactory goal that is within indicated capabilities of GS processing. Because the polishing filter removes a fraction of the sludge removed by the primary unit, the $\Delta P$ rise, backwash frequency, and recycle volume should be even smaller through the polishing unit. For flowsheet calculations, the $5 \%$ recycle rate was used for each of the two filters. 
Large-Scale Sand Filter Studies

A one-eighth-scale sand filtration facility, Figure 4.49, featuring 17.25-in. I.D. columns was built to process large-scale GS products. Filtration through coarse, then fine media (same bed depths and particle sizes as before) was started after receipt of the initially decanted $G S$ batch in the sand filter feed tank. Filtration was continued until all GS product was depleted.

Four GS-sand filter runs were made. Sand filter feed cycle results, presented in Table 4.45, confirm earlier small-scale work in that acceptable filtrate quality and pressure drops were demonstrated. Solids in final filtrate averaged about $1 \mathrm{ppm}$ or less according to analysis of hourly samples from the four runs by the Coulter Counter. Spot checks for centrifugable sludge $(10,000 \mathrm{~g} / \mathrm{s}$ for $3 \mathrm{~min}$ ) revealed $1 \mathrm{ppm}$ when the two filters were operated in series and each received the Versa TL 700 polymer (Runs 3 and 4). Under these conditions, turbidities of $0.07 \mathrm{JTU}$ also showed good duplication of small-scale work.

In Run 4, filtrate quality was maintained during an interruption that will routinely occur in plant operation. After 31.7 hours of continuous feed, the primary column was backwashed. Following this backwash, feed addition was resumed and polishing column product continued well below $1 \mathrm{ppm}$, despite upset of the primary column caused by the backwashing. An important design function of the second bed is to maintain product quality during such temporary upsets of the first bed.

Pressure drop in the primary bed while feeding during Run 4 is shown in Figure 4.50. The filtration of an average $35 \mathrm{ppm}$ sludge required about $32 \mathrm{hr}$ at $1.38 \mathrm{gpm} / \mathrm{ft}^{2}$ to reach a $\Delta P$ rise of 1.2 psi (vs 3.0 psi plant max). At a design feedrate of 1.2 $\mathrm{gpm} / \mathrm{ft}^{2}$, a feed cycle of 36.4 hours is calculated, a satisfactory margin over design basis feed cycle of 24 hours. $\Delta P$ rise across the polishing bed was less than 0.5 psi during the 32 -hour feed period.

Three sand filter backwash runs were made following the corresponding GS-sand filter feed runs. In this initial largescale test work, objective of backwashing was to determine relative quantities of sludge arrested in the two beds. The results from Table 4.46, Run 1 (which was made with parallel feeds to the two columns), show a $74 / 26 \mathrm{split}$ in primary/polishing filters. This is about as expected because the respective ratio of clean bed $\Delta P^{\prime} ' s$ is $0.8 / 2.2$, and most flow should go through the primary bed with smaller $\Delta P$. Average for Runs 2 and 3 , fed in series to primary then polish filters, shows $90 \%$ of the sludge was arrested in the primary column. This is also about as expected from small-scale experience. 
To demonstrate efficient large-scale backwashing and minimize recycle, three full-sized Roto-Scour (Grover Water Conditioning Co., Union, N. J.) air distributors have been installed on each of the two columns. Testing is under way. The reference backwashing cycle consists of these steps:

1. Drain excess supernate

2. Air sparge at $4 \mathrm{scfm} / \mathrm{ft}^{2}$

3. Resettle filter bed

4. Backwash with polishing bed filtrate at $15 \mathrm{gpm} / \mathrm{ft}^{2}$

5. Resettle filter bed

6. Restart filter feed
5 minutes

10 minutes

5 minutes

5 minutes

5 minutes

Filter Media Service Life

The eventual disposal of the filter media will be required because of (a) the gradual dissolution of the media and resultant loss of particulate removal efficiency, (b) irreversible radionuclide or other particulate adsorption, or (c) failure for any reason to backwash to initial clean $\Delta P$ or adsorption efficiency. Facilities will be provided for jetting the media to sludge washing after a final backwash to $G S$, then $1 M \mathrm{NaOH}$ fluidization to enable the jet transfer to take place. Facilities to acid wash the media will also be provided for decontamination of excessive radioactivity, mudball dissolution, or clean $\Delta P$ restoration as necessary.

At temperatures below $25^{\circ} \mathrm{C}$, use of the same primary sand filter media in the 4-in.-diameter column over a period of 6 months' submergence (about $15 \%$ operating time) has shown no detectable loss in particulate removal efficiency. Recovery of the initial clean-bed $\Delta \mathrm{P}$ has been complete after each backwash (this assumes that air is used for backwashing and polyelectrolyte has been added with the feed). In studies to determine solubility of sand in both the low-caustic and high-caustic supernates, no detectable $S i$ ( $<1 \mathrm{ppm}$ ) was found in the filtrate at operating temperatures below $30^{\circ} \mathrm{C}$. In low-caustic supernate at $60^{\circ} \mathrm{C}, 26$ parts $\mathrm{SiO}_{2}$ per million parts supernate dissolved in 15 minutes, the average bed contact time. Tests with high-caustic supernate showed no detectable $\mathrm{SiO}_{2}$ dissolution at temperatures below 30 to $40^{\circ} \mathrm{C}$. Facilities should therefore be provided to maintain sand filter feed temperatures below $25^{\circ} \mathrm{C}$. 


\section{Stock Solution Viscosities}

Viscosities of the polymer stock solutions for GS as well as sand filter treatment are included in Table 4.47. Viscosities were measured at several spindle speeds with a Brookfield Model RVT viscometer at temperatures of the stock solutions as indicated. The $8 \%$ starch solution was dispersed in $1 \mathrm{M} \mathrm{NaOH}$, and the $0.1 \%$ Versa TL 700 was made up in distilled water. 


\subsubsection{Supernate Decontamination}

4.5.10.1 Cesium and Plutonioum (P. K. Baumgarten, R. M. Wallace, J. R. Wiley, D. A. Whit tehurst)

\subsection{General}

Cesium and plutonium will be removed from clarified supernate by ion exchange by Duolite (Trademark of Diamond Shamrock Corporation, Redwood City, CA) ARC-359 resin, using countercurrent elution and regeneration. The resin is a strong-acid cation exchanger, of the phenol-formaldehyde type with sulfonic and phenolic functionality. It is selective to cesium at high $\mathrm{pH}$. The Savannah River Laboratory has demonstrated cesium removal from SRP plant wastes obtaining decontamination factors up to 100,000 . Plutonium was removed at $\mathrm{DF}^{\prime} \mathrm{s}=30$ to 300 .

\subsection{Process Description}

As shown in flowsheet FS-9 (Figure 4.9) filtrate from the sand filters (FS-8-20) is pumped through two ion exchange columns in series containing Duolite ${ }^{\circledR}$ ARC-359 resin. After the loading step, the columns are rinsed with water. Both the loading and first rinse steps are downflow. The effluents continue on to strontium ion exchange (FS-10). Cesium and plutonium decontamination factors assumed for material balance purposes are $10^{4}$ and 165 , respectively.

The cesium and plutonium are eluted countercurrently from the columns using $2 \mathrm{M} \mathrm{NH} 4 \mathrm{OH}-2 \mathrm{M}\left(\mathrm{NH}_{4}\right)_{2} \mathrm{CO}_{3}$ followed by a water rinse. Eluate and water rinse effluent pass on to elutriant recovery and cesium concentration (FS-11). The columns are then countercurrently regenerated with $2 \mathrm{M} \mathrm{NaOH}$; the effluent goes to a heated catch tank to separate residual ammonia.

\subsection{Cycle Schedule} 4.48 .

The proposed ion exchange cycle schedule is shown in Table 
The ion exchange equipment will consist of two columns in series. (Note that 1 column volume as used in the table above is based on the volume of a single column.) Ge(Li) gamma detectors will continuously monitor $\mathrm{Cs}-137$ in the effluent of the first columns where DF's as low as 3 to 30 may be acceptable. The second column will remove the remaining cesium. The second column effluent will also be monitored. The usual second column effluent concentrations may be too low to be detectable against background radiation.

To compensate for varying feed composition, the feed volume and cycle length can be increased or decreased to maintain the desired overall DF. Periodically, probably every 2 months, the resin is backwashed in upflow to remove fines and accumulated miscellaneous solids, correct possible channeling, and regrade the particles. Ultimately, the resin is removed by slurrying and transferring the slurry. Fresh resin is similarly transferred into the columns. If residual radioactivity content is low enough, the resin is checked for residual activity. Spent resin can be buried. Otherwise, the resin will be dewatered, dried, and incinerated in a dedicated incinerator tied into the melter offgas system.

The proposed cycle schedule is based on countercurrent elution and regeneration. Countercurrent operation is far more efficient than cocurrent [32]. Table 4.49 is a listing of recommended operating techniques for successful countercurrent operation. Between steps the liquid in the freeboard above the resin will be lowered to a level just above the resin to permit proper displacement in the subsequent step.

To achieve maximum advantage with countercurent ion exchange, a few rules must be observed. Most of these relate to the need to maintain a piston-like zone movement of ion exchange in the resin column. To draw the analogy with a distillation column, the

"theoretical plate height" must be kept to a minimum.

\subsection{Resin Description and Physical Properties}

The ion exchange follows the following simplified equations:

Load:

$\mathrm{RNa}+\mathrm{Cs}^{+} \stackrel{\mathrm{RCs}}{\rightarrow} \mathrm{Na}^{+}$

Eluate: $\quad \mathrm{RCs}+\mathrm{NH}_{4}^{+} \leftrightarrows \mathrm{RNH}_{4}+\mathrm{Cs}^{+}$

Regenerate: $\mathrm{RNH}_{4}+\mathrm{Na}^{+} \leftrightarrows \mathrm{RNa}+\mathrm{NH}_{4}^{+}$ 
where $R$ represents the resin. A simplified structural formula of $\mathrm{Na}^{+}$form "Duolite" ARC-359 resin, with both sulfonic and phenolic groups sodium-equilibrated is:

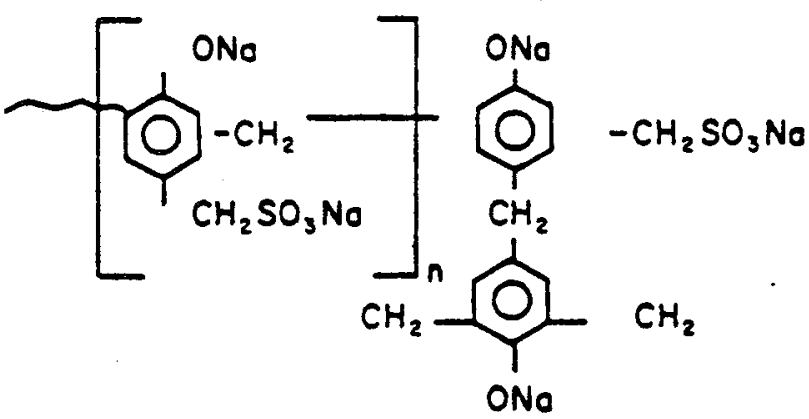

At near-neutral $\mathrm{pH}$ only the sulfonic acid groups convert to the $\mathrm{Na}$ form. As $\mathrm{pH}$ increases, more and more of the phenolic groups exchange and convert to the $\mathrm{Na}^{+}$or $\mathrm{Cs}^{+}$form.

Diamond-Shamrock produces the resin by sulfite-treating crushed, cross-linked phenol-formaldehyde polymer [33]. The standard resin is called " $\mathrm{C}-3$," and is refined and fully regenerated to make "ARC-359." The $\mathrm{NH}_{4}{ }^{+}$form is obtained by treating the $\mathrm{Na}^{+}$form with an $\left(\mathrm{NH}_{4}\right)_{2} \mathrm{CO}_{3}$ solution to which $\mathrm{NH}_{4} \mathrm{OH}$ has been added to improve solution stability. This is the elution step. The resin is regenerated with $2 \mathrm{M} \mathrm{NaOH}$.

Physical properties are tabulated in Table 4.50. Particle size of the commercial resin is mainly in the 16 to 40-mesh range, but specifications may be set in the future calling for a more closely graded, finer size distribution. The bed expansion data shows that 8 to $12 \mathrm{gpm} / \mathrm{ft}^{2}$ water flow is required for the recommended backwash expansion of $50 \%$. Table 4.51 gives swelling data, weight and volume increase when the resin is immersed in different strength $\mathrm{Na}$ and $\mathrm{NH}_{4}$ solutions [34]. The resin swells the least in $\left(\mathrm{NH}_{4}\right)_{2} \mathrm{CO}_{3}$ solution, more in $\mathrm{NaNO}_{3}$ (or another sodium salt), and most in $\mathrm{NaOH}$. Both particle and bulk density increase in the same order since in each case the weight increase is more than the volume increase, and void fraction remains approximately constant. As observed in a glass column, resin swelling is greater in the supernate than in $2 \mathrm{M} \mathrm{NaOH}$ in upflow, but less when the flow directions are those of the reference process (supernate downflow, $2 M$ $\mathrm{NaOH}$ upflow).

The pressure drop through the bed in downflow will depend on the resin size distribution. A calculated figure is 0.1 to 0.2 $\mathrm{psi} / \mathrm{ft}$ at $1.12 \mathrm{gpm} / \mathrm{ft}^{2}$. In upflow, a pressure drop of $0.54 \mathrm{psi} / \mathrm{ft}$ is calculated based on an average resin and liquid density of 1.24 This should increase only slightly as velocity increases. 


\subsection{Resin Capacity}

Ion exchange capacity for sodium was determined from static experiments and is given in Table 4.52. The capacity increases considerably with $\mathrm{NaOH}$ concentration (i.e., $\mathrm{pH}$ ) as already discussed. Since the supernate is expected to be $0.5 \mathrm{M}$ in $\mathrm{OH}^{-}$, a $\mathrm{Na}$ capacity of about $2.49+3.77=6.26 \mathrm{eq} / \mathrm{kg}$ dry resin is expected. This is approximately equal to $2.28 \mathrm{~g}$-eq/L or $0.0191 \mathrm{~b}-\mathrm{eq} / \mathrm{gal}$ wet resin.

Cesium capacity can be correlated in terms of the distribution coefficient $\mathrm{K}_{\mathrm{d}}=[\overline{\mathrm{Cs}}] /\left[\mathrm{Cs}^{+}\right]$. Here $[\overline{\mathrm{Cs}}]$ is the equilibrium concentration of cesium on the resin, with units of $\mathrm{g}-\mathrm{eq} / \mathrm{Kg}$ $\mathrm{Na}^{+}$-form resin, and $\left[\mathrm{Cs}^{+}\right]$is the equilibrium concentration of $\mathrm{Cs}^{+}$ in the liquid, with units of g-eq/L of liquid. The value of this coefficient for a range of $\mathrm{Na}^{+}$and $\mathrm{OH}^{-}$concentrations in batch equilibrium measurements is shown in Table 4.53 and Figure 4.51. These data were obtained before many of the problems associated with such measurements were fully appreciated; the results must therefore be considered only approximately. They do, however, show qualitatively the general behavior of the resin in which the $k_{d}$ increases with increasing $\mathrm{OH}^{-}$concentration and decreases with increasing $\mathrm{Na}^{+}$ concentration.

More recent data have shown that the $k_{d}$ is a very sensitive function of the cesium concentration. Table 4.54 shows the variation of $\mathrm{K}_{\mathrm{d}}$ with $\mathrm{Cs}^{+}$concentration for Duolite ${ }^{\circledR} \mathrm{ARC}-359$ in equilibrium with solutions containing $4.75 \mathrm{M} \mathrm{NaNO}_{3}-1.0 \mathrm{M} \mathrm{NaOH}$.

If only a single equilibrium were involved, the ion exchange reaction could be written:

$$
\begin{aligned}
& \overline{\mathrm{Na}}+\mathrm{Cs}^{+} \overline{\mathrm{Cs}}+\mathrm{Na}^{+} \\
& \mathrm{K}_{s}=\frac{[\overline{\mathrm{Cs}}][\mathrm{Na}]}{[\overline{\mathrm{Na}}][\overline{\mathrm{Cs}}]}=\mathrm{K}_{\mathrm{d}} \frac{\left[\mathrm{Na}^{+}\right]}{[\overline{\mathrm{Na}}]}=\mathrm{K}_{d}\left(\frac{\left[\mathrm{Na}^{+}\right]}{\overline{E x}-[\overline{\mathrm{Cs}}]}\right)
\end{aligned}
$$

where $[\overline{\mathrm{Cs}}]$ and $[\overline{\mathrm{Na}}]$ are the respective concentrations of $\mathrm{Cs}$ and $\mathrm{Na}$ in the resin, $\left[\mathrm{Cs}^{+}\right]$and $\left[\mathrm{Na}^{+}\right]$are their respective concentrations in solution, Ex is the total exchange capacity of the resin and $\mathrm{Ks}$ is the equilibrium constant for reaction (4) also known as the selectivity coefficient.

Equation (5) can be rearranged as follows: 


$$
\mathrm{K}_{\mathrm{d}}=\frac{\mathrm{Ks}}{\left[\mathrm{Na}^{+}\right]}(E \mathrm{x}-[\overline{\mathrm{Cs}}])
$$

or

$$
\mathrm{K}_{\mathrm{d}}=\frac{\mathrm{Ex}\left(\mathrm{Ks} /\left[\mathrm{Na}^{+}\right]\right)}{1+\left[\mathrm{Cs}^{+}\right]\left(\mathrm{K}_{\mathrm{s}} /\left[\mathrm{Na}^{+}\right]\right)}
$$

These equations did not give a satisfactory representation of the data in Table 4.54 or other similar data for solutions of different compositions. If, however, the resin is assumed to contain two different types of sites that act independently of each other so that the resin behaves as a mixture of two different resins each with its own capacity $\left(\mathrm{Ex}_{1}\right.$ and $\left.\mathrm{Ex}_{2}\right)$ and its own selectivity coefficient $\left(\mathrm{K}_{\mathrm{s}_{1}}\right.$ and $\mathrm{K}_{\mathrm{s}_{2}}$ ) the following equation is obtained.

$$
\mathrm{K}_{\mathrm{d}}=\frac{\mathrm{Ex}_{1}\left(\mathrm{~K}_{\mathrm{s}_{1}} /\left[\mathrm{Na}^{+}\right]\right)}{1+\left[\mathrm{Cs}^{+}\right]\left(\mathrm{K}_{\mathrm{s}} /\left[\mathrm{Na}^{+}\right]\right)}+\frac{\mathrm{Ex}_{2}\left(\mathrm{~K}_{\mathrm{s}_{2}} /\left[\mathrm{Na}^{+}\right]\right)}{1+\left[\mathrm{Cs}^{+}\right]\left(\mathrm{K}_{\mathrm{s}_{2}} /\left[\mathrm{Na}^{+}\right]\right)}
$$

Equation (8) is able to fit the data on Table 4.54 reasonably well as shown by the comparison of observed values of $\mathrm{K}_{\mathrm{d}}$ with those calculated from parameters (shown at the bottom of the table) obtained by a least squares fit of the data.

The values of $k_{d}$ shown in the table are only valid for the particular batch of resin for which the measurements were made. Preliminary studies with other batches of resin show that the $k_{d}$ curves may vary significantly from one batch of resin to the next.

\subsection{Ion Exchange Kinetics}

The ion exchange kinetics over Duolite ARC 359 are extremely complicated because the distribution coefficient $K_{d}$ varies with cesium concentration and because both resin and fluid phase resistances affect mass transfer rates. A computer code for the loading cycle has been developed (by $R$. M. Wallace) assuming diffusion through spherical particles. Liquid film resistance and preloaded (i.e., not completely eluted) resin will be included in further development. The computer program divides both particles and the column itself into discrete space elements. It has now been modified for variable $\mathrm{K}_{\mathrm{d}}$. 
Diffusion coefficients have been measured for various resin types supplied by Diamond Shamrock. A fairly strong negative correlation $(-0.804)$ was obtained between diffusion coefficients and cesium capacity.* Measured resin phase diffusivities were in the range of 0.5 to $3 \times 10^{-8} \mathrm{~cm}^{2} / \mathrm{sec}$, considerably less than for other ion exchange resins. One would therefore expect resin phase diffusion to control. On the other hand, some column data indicate that increased column height at constant volumetric throughput improves performance. This may be due to either liquid film influence or more surface area exposure at higher superficial velocity.

Two simplified approaches to predicting ion exchange performance may be used. Breakthrough $\mathrm{C} / \mathrm{C}_{0}$ may be plotted against throughput in column volumes on log-probability paper. This gives a straight line above $\mathrm{C} / \mathrm{C}_{0}>1 \%$. The steepness of the line is proportional to the kinetic rate, while the left-to-right position measures the equilibrium.

A somewhat more complicated approach is to use the J-function** chart, Figure 16-20 in the Chemical Engineer's Handbook. Here $\mathrm{C} / \mathrm{C}_{O}$ is plotted against NT with $\mathrm{N}$ as parameter where

$$
N=\text { number of mass transfer units }
$$

$$
\sim \Psi_{p} k_{d} \frac{60 D_{p}}{d_{p}^{2}} \cdot \frac{l}{(C V / h r)}
$$

\subsection{Savannah River Laboratory Demonstrations}

Removal of $\mathrm{Cs}-137$ from simulated and actual plant wastes was demonstrated in a series of laboratory tests using Duolite ${ }^{8}$ ARC-359 [35, 36, 37]. Figure 4.52 shows the general scheme used in the final tests [36]. Two 22-in.-long by 3-in.-dia stainless steel columns in series contained the Duolite. They were followed by a third similar column using "Chelex"-100t iminodiacetic

\footnotetext{
* DPST $-80-257$

** A two-argument function originally derived for recuperative heat transfer.

$\dagger$ Product of Bio-Rad Laboratories.
} 
acid resin for strontium removal. The supernate feed was prepared to simulate closely the reference salt composition and contain the expected radioactive components. Supernate at least 10 years old from $\mathrm{H}$ - and $\mathrm{F}$-Area waste tanks was adjusted to the reference composition (2.2M NaNO $3,1.1 \mathrm{M} \mathrm{NaNO}, 0.75 \mathrm{M} \mathrm{NaOH}, 0.5 \mathrm{M} \mathrm{NaAlO} 0_{2}$, $0.3 \mathrm{M} \mathrm{Na}_{2} \mathrm{SO}_{4}$ ), slurried with waste sludge to regain equilibrium in waste components, and separated from the sludge by centrifugation and filtration. In the tests, about 775 liters of waste were decontaminated in 9 trials during a 3-month campaign.

Results are shown in Figure 4.53 and Table 4.55. For 40 column volumes throughput, $\mathrm{DF}^{\prime} s$ averaged $4 \times 10^{5}$ for $\mathrm{Cs}-137$. For Test 5, first-column effluent showed Cs DF's from 60 (at $25 \mathrm{CV}$ 's) to 5 (at $40 \mathrm{CV}^{\prime} \mathrm{s}$ ). This indicated that the critical cleanup occurred in the second column. Flow rate was $0.67 \mathrm{gal} / \mathrm{min}^{-\mathrm{ft}}{ }^{2}$ in this test which is $2 / 5$ of the $\mathrm{gpm} / \mathrm{ft}^{2}$ expected in the reference process. Plutonium removal was also adequate. DF's averaged 35 for $40 \mathrm{CV}$ 's throughput and reached 60 to $20 \mathrm{CV}$ 's. In a similar test, but with the supernate saturated with $\mathrm{Pu}-238(6.8 \mathrm{Ci} / \mathrm{mL}$ vs about $0.014 \mathrm{Ci} / \mathrm{mL}$ in most other tests) the $\mathrm{DF}$ was 300 .

Preliminary tests in 25-mL, 1.3-in.-dia columns showed the effect of process variables [41]. In tracer tests at constant $\mathrm{CV} / \mathrm{hr}$ and constant diameter, DF improved with longer columns and higher linear flow rate [38] in the range of 0.077 to $0.26 \mathrm{gpm} / \mathrm{ft}^{2}$. This was probably due to reduced end effects (distributor, dead zones) and better liquid-solid mass transfer at higher linear flow rate. At constant $\mathrm{CV} / \mathrm{hr}$ and constant linear flow rate (i.e., constant bed height) limited data showed that DF improved with larger diameter [39] probably due to reduced wall effects.

Small-scale tests with actual plant waste (Fig. 4.54) showed that a $D F=10^{4}$ could be obtained at 15 column volumes or higher for $\mathrm{Na}^{+}$concentrations of 4 and $9 \mathrm{M}$. The blended DWPF liquid waste will be about $6 \mathrm{M}$ in $\mathrm{Na}^{+}$. Tank 24 supernate which had the lowest $\mathrm{Na}^{+}$ concentration gave the highest DF. This result agrees with predicted feed concentration effects.

\subsection{TNX Semiworks Studies}

An experimental study is under way at TNX semiworks to demonstrate the proposed process and investigate process variables. Two 3-in.-diameter by 40-in.-tall glass ion exchange columns, each with its own 3-in.-diameter backwash column, are installed in a temperature-controlled cabinet. Separate metering pumps feed the upflow and downflow streams from appropriate tankage. The supernate feed is obtained from the centrifuging and filtration steps carried out at TNX, and is dosed with "cold" Cs-133. Product samples are obtained in a clean glovebox and

$$
-4.68-
$$


analyzed by isotope dilution mass spectrometry. This method can determine $C s$ concentrations as low as $1 \times 10^{-8} \mathrm{M}$. Two 8-ft tall columns are currently in operation at the same volumetric ( $\mathrm{CV} / \mathrm{hr}$ ) and linear feed rates as the plant columns. A $1 / 13$ scale column, $4 \mathrm{ft}$ high $\times 2 \mathrm{ft}$ diameter, is expected to become operational in 1981 .

Results from the TNX studies show:

1) Sodium capacity of the resin at the high $\mathrm{pH}$ of the feed is much larger than that indicated by the manufacturer, namely $0.020 \mathrm{vs} 0.010 \mathrm{lb} \mathrm{mol} / \mathrm{gal}$. The sodium cannot be effectively removed by water even up to $6 \mathrm{CV}$ 's of first rinse, and would overload the glass melter if not removed otherwise. A step to fix cesium on zeolite was therefore inserted in the process after eluate concentration/cesium recovery.

2) Electrical conductivity is an effective indication of the regeneration end point, as shown in Figure 4.55. It is at least as good as $\mathrm{pH}$ for this purpose. If the feed is started before the resin is fully regenerated, aluminum hydroxide will precipitate in the bed, plug it up, and ruin its performance.

3) Some $\mathrm{Al}(\mathrm{OH})_{3}$ precipitant has been observed in eluate following $3 \mathrm{CV}$ rinses indicating a longer water first rinse is required. A 5-CV first rinse has been recommended to completely remove the sodium aluminate from the column. An experiment was conducted in which equal volumes of first rinse effluent ( 3,4 , and $\left.5 \mathrm{CV}^{\prime} \mathrm{s}\right)$ and elutriant were mixed and the resulting solution analyzed for suspended solids by centrifugation. The solutions had 150,30 , and $15 \mathrm{ppm}$ of solids for the 3,4 , and 5-CV effluent-mixtures, respectively. The 3 and 4-CV samples had white and brown solids while the 5-CV sample had only brown solids. The white solids are representative of the $\mathrm{Al}(\mathrm{OH})_{3}$ precipitant while the brown solids were probably introduced by somewhat dirty glassware. A typical set of $\mathrm{Al}(\mathrm{OH})_{4}^{-}$ analyses during a rinse step are presented in Figure $4.56 \mathrm{from}$ which it can be seen that $5 \mathrm{CV}$ of first rinse removes essentially all of the $\mathrm{Al}(\mathrm{OH})_{4}^{-}$from the column.

4) The volume of a given weight of resin depends on the chemical state, the previous resin history, and on whether flow is up or down (see Section 4.5.10.1.4). The columns should therefore be loaded in the ammonia form (which has the smallest volume) to permit the most resin to be loaded. As the bed cycles it tends to shrink, and more resin should be loaded after two or three weeks of operation. Ability to gage the resin level is essential to avoid excessive dead space between the resin and upper distributor. 
5) During elution the resin shrinks and the particles tend to fluidize near the top of the column.: Some actual gaps in the bed have been noted in the $3-i n$. columns during this step. This problem may not affect overall performance, but should be kept in mind during further development efforts.

6) The eluate analyses show that the cesium peak occurs $4 \mathrm{CV}$ (Figure 4.57) with $97 \%$ of the cesium having been removed from the column after $8 \mathrm{CV}$ 's. Note that the feed cycle for this run was $60 \mathrm{CV}^{\prime} \mathrm{s}$ instead of $20 \mathrm{CV}^{\prime} \mathrm{s}$. The sodium is removed somewhat earlier than the cesium, and the Na concentration decreases more rapidly.

7) Elutriant spiked with cesium to a level corresponding to a decontamination factor of 4,000 (based on concentrator feed) in the elutriant recovery process appears to have no detectable detrimental effects on the cesium column performance. However, the TNX process is limited to a detection 1 imit of $1 \mathrm{ngCs} / \mathrm{ml}$ corresponding to a $D F=3 \times 10^{4}$ for $2.4 \times 10^{-4} \mathrm{M} \mathrm{Cs}$ feed. The effect of elutriant below this level may be significant but cannot be observed at TNX. Therefore a reduction in the decontamination factor of $10^{6}$ for the elutriant recovery equipment cannot be recommended at this time if the possible higher DF's obtained in the high level caves studies $D F=10^{5}-10^{6}$ are to be taken advantage of and less than $10 \mathrm{nCi} \mathrm{Cs} / \mathrm{mL}$ salt product produced.

8) Large variations in column performance have been observed with different resin batches. Three resin batches have been used at TNX:

a. Duolite ARC-359, Lot \#512-17E, a resin manufactured in 1977.

b. Duolite ARC-359, Lot $\$ 512-43 \mathrm{~K}$, a resin manufactured in 1973 and used in the high level caves tests (BLC).

c. Duolite ARC-359N, Lot $\$$ 512-28G, Lab \#1463-113, a resin manufactured in 1978.

Figure 4.58 shows that the cesium capacity of the 1977 and 1973 resin were quite similar $(19-20 \mathrm{CV}$ to $\mathrm{C} / \mathrm{Co}=0.5)$ and considerably lower than that for the 1978 resin. It should be noted that the 1973 resin 'lost' more than $50 \%$ of its original capacity when used in the HIC tests. This suggests that for design purposes, the TNX data on 1977 and 1973 resin are to be regarded as degraded resin prior to removal. Programs at SRI are under development to ensure the delivery of a resin with a capacity equal to or greater than that of the 1978 resin Lot $512-28 \mathrm{G}$. 
9) The effect of feed composition is also presented in Figure 4.58. The capacity of the 1973 resin increased by about $70 \%$ with the increased hydroxide concentration (due to aluminum dissolution). Thus the number of $\mathrm{CV}$ to reach $50-55 \%$ breakthrough $\left(\mathrm{C} / \mathrm{C}_{0} \times 100\right)$ for the first column effluent increased from about $19.6 \mathrm{CV}$ to about $28 \mathrm{CV}$ (extrapolated) with the addition of the aluminum dissolution process. Thus the performance of ion exchange is primarily dependent on feed ( $\left[\mathrm{Na}^{+}\right]$and $\left[\mathrm{OH}^{-}\right]$) and resin batch. The effect of feed com position will be determined for a particular resin batch in order to set the acceptable limits of feed composition.

10) Figure 4.59 shows that $D F \geq 10^{4}$ were obtained from both columns for at least $60 \mathrm{cv}$. The effluent from between the two columns began to "break through" at 20-40 increasing to $50 \%$ breakthrough at $60-65 \mathrm{cV}$. It should be noted that for a feed with $\left[\mathrm{C}_{\mathrm{s}}^{+}\right]=2 \times 10^{-4} \mathrm{M}$, a $\mathrm{DF}=2.6 \times 10^{4}$ is the most that can be shown using the present method of analysis. The column may be performing considerably better than the $7.5 \times 10^{-9} \mathrm{M}$ product suggested from Figure 4.58 . The differences between 1 and $3 \mathrm{CV} / \mathrm{hr}$ feed rate should be considered only qualitative, since relatively large variations occurred with the same flow rates and because the differences observed may have been due to variation in $\left[\mathrm{OH}^{-}\right]$or an effect due to time (resin history).

11) Figure 4.60 presents the effect of feed concentration on the "degraded" 1973 resin. It may be seen that for feeds 3-4 times higher than the expected $2.4 \times 10^{-4} \mathrm{M}$ cesium concentration acceptable breakthrough from the second column is still obtained. Note that the $D F \approx 10^{5}$ for $C_{0}=7.7 \times 10^{-4} \mathrm{M}$ corresponds to the same effluent as $D F \approx 3 \times 10^{4}$ for $C_{0}=2 \times 10^{-4} \mathrm{M}$. The canyon process will probably not run the first colum to near the $50 \%$ breakthrough required to achieve $D F=10^{4}$ after $20 \mathrm{CV}$ in order to prevent the possible contamination of the product salt.

12) The relatively minor effect of flow rate is presented in Figure 4.61 for the "degraded" resin. Again both of these flow rates achieved the desired goal of DF $=10^{4}$ but only just barely. The effect of flow rate is most pronounced at low concentrations where the breakthrough curves begin to deviate from linearity (log-probability coordinates).

13) Correlation between the $C / C^{\prime}$ 's of the two columns will be depended upon to help control plant operation. The correlation may vary with feed composition and resin condition. Further data will be obtained during the course of this program. 


\subsection{Hanford Experience}

Duolite ${ }^{\circledR}$ ARC-359 resin has been used extensively in At lanticRichfield-Hanford's B Plant* to remove about $95 \%$ of radiocesium from alkaline Purex and Redox supernates. Original experience was with synthetic zeolite, "Linde" AW-500 [40], [41], which, however, was not stable when exposed to high alkalinity for a long time. It was therefore replaced by Duolite ARC-359 [42], [43].

At lantic-Richfield used the refined-grade ARC-359 instead of the standard $\mathrm{C}-3$ grade, since they wanted to be sure the resin would work and it was simpler to have the supplier rather than Atlantic-Richfield pretreat the resin.

The Hanford techniques are somewhat different from ours since their purpose is different. They use a single 6-ft-diameter $x$ 13-ft-tall column (with 10 to 12-ft-deep bed) and operate it in downflow except for the regenerate step. The column is drained between steps. The Hanford cycle includes a sodium elute step after the load, using a $0.2 \mathrm{M}\left(\mathrm{NH}_{4}\right)_{2} \mathrm{CO}_{3}-0.1 \mathrm{M} \mathrm{NH}_{4} \mathrm{OH}$ scrub solution to separate most of the sodium from the cesium prior to cesium elution. This also removes potassium and rubidium ions from the resin. This step was considered for the present DWPF process to remove excess sodium from the eluate, but did not appear as attractive as cesium fixation on zeolite. The scrub effluent is butted with caustic and returned to the column as regenerant to recover leaked cesium. Hanford practices backwashing only in the form of a biweekly upflow water "fluff" within the ion exchange column. They use an extra elute/regenerate cycle to correct poor column performance.

Periodically concentrated eluate is reworked to reduce the $\mathrm{Na} / \mathrm{Cs}$ ratio further. After $\mathrm{NH}_{3}$ and $\mathrm{CO}_{2}$ are stripped off in elutriant recovery, the eluate contains chiefly cesium and sodium carbonate and $\mathrm{Fe}$ and $\mathrm{Al}$ contaminants. It is reloaded onto the column. Subsequent steps - Na scrub, elution, rinse, and regeneration - are similar to the primary processing.

The Duolite ${ }^{\circledR e s i n}$ is used for about one year before being replaced [44]. The last batch was in use for 3 years (1975-78), but had deteriorated significantly when it was replaced. At lantic-Richland-Hanford standard operating procedures are on file, including SOP 11.28 "Cesium Ion Exchange PSS Processing," SOP 11.22 "Cesium Ion Exchange Product Rework Procedure," and Flowsheet ARH-F-106 (1977). Analytical procedures, "Cesium Absorption Cs-1," "Determination of Particle Size - Wet Sieve Method - Zy-24a," and "Determination of Moisture Retention Capacity - $0.7, "$ are also available.

* Currently operated by Rockwell International. 


\subsection{Resin Aging and Decay}

Duolite ARC-359 degradation under the influence of high pH and high radiation flux is slow. The Hanford experience has been favorable. One batch of $435 \mathrm{ft}^{3}$ processed 1.8 million gallons of Purex waste $\left(17 \mathrm{Ci} / \mathrm{gal}_{1}\right)$ between March 1973 and May 1975. When a fresh batch of $442 \mathrm{ft}^{3}$ was substituted, bed capacity increased $33 \%$. The second batch processed 1.5 million gallons between May 1975 and February 1976, at which time load sizes had decreased $10 \%$. Some of the reduced resin performance may have been due to channeling, which would have been corrected by backwashing.

Hanford monitors resin capacity by taking a sample from the bed measuring moisture retention and cesium capacity. For instance, the first batch of resin described above increased from 50 to $78 \%$ moisture retention between March 1973 and October 1974. Radioactive cesium capacity is measured by shaking $0.5 \mathrm{~g}$ resin with 5-ml cesim-spiked liquid for an hour, decanting the supernate, and measuring gama-activity of the separated resin. The liquid $\mathrm{Na}^{+}, \mathrm{OH}^{-}$, and $\mathrm{Cs}^{-}$concentrations should be at specified levels for the test.

Hanford also monitors bed height, and found a column decrease $(7.6 \%)$ in the first campaign cited and a very slight increase (4\%) in the second. The conclusion, therefore, is that fines are only occasionally produced, and that the main result of degradation is increased porosity. SRP waste did not chemically degrade Duolite ${ }^{\circ}$ ARC-359 resin by prolonged contact, and the radiation stability was also good [42].

Diamond Shamrock recommends a maximum resin service temperature of $40^{\circ} \mathrm{C}$ in caustic service. Above this temperature, the resin degrades by de-crosslinking. Hanford maintains its feed streams at $20-25^{\circ} \mathrm{C}$.

\subsection{Heat Effects}

Heat development via radioactive decay should not be a problem except in the extreme case of $20 \mathrm{CV}$ 's of supernate containing $\mathrm{Cs}-137 / \mathrm{Ba}-137$ being sorbed on the resin, and no flowthrough of liquid. Even in that case a temperature rise of only $0.087^{\circ} \mathrm{C} / \mathrm{hr}$ is calcualted for the case of liquid remaining in the column, and $0.25^{\circ} \mathrm{C} / \mathrm{hr}$ for the case of a drained column. Heat load was calculated to be $929 \mathrm{Btu} / \mathrm{hr}$ for 20 column volumes of 15 -year aged waste supernate sorbed on the resin. 


\subsection{Detailed Description of Unit Operation}

Resin Preparation and Column Loading

The Duolite ${ }^{\otimes}$ resin is prepared on the cold side of the canyon by slurrying it with water. The resin slurry is then gravity-fed or pumped into the ion exchange columns. Excess water is collected in the spent resin catch tank. The columns are then backwashed and settled 3 times to remove fines and grade the resin. According to Diamond Shamrock, $95 \%$ of resin fines can be removed in this step. Following backwashing, the resin is subjected to two elutionregeneration cycles. Each column is checked to make sure it is full. A velocity of 3 to $5 \mathrm{ft} / \mathrm{sec}$ in the connecting piping is recommended for hydraulic conveying. Compressed air may be used to assist the conveying and break plugs.

\section{Load (Feed) Cycle}

Filtered supernate will be fed downflow through each set of series columns. A flow rate of $1.67 \mathrm{cV} / \mathrm{hr}$, or $1.67 \mathrm{gpm} / \mathrm{ft}^{2}$ is planned. Temperature of the feed is not to exceed $30^{\circ} \mathrm{C}$. A feed density of $1.24 \mathrm{~g} / \mathrm{cc} \mathrm{c}$ an be used for design purposes. 20 to 30 column volumes of feed can be processed with $20 \mathrm{CV}$ 's being used as design basis.

The make-effluent is routed to intermediate tankage ("bounce tanks") for feed to the strontium ion-exchange columns.

\section{First Rinse Cycle}

Water for the first rinse cycle is obtained from recycle water. The rinse has two purposes. It will keep elutriant from mixing with feed retained in the column voids which would cause $\mathrm{Al}(\mathrm{OH})_{3}$, $\mathrm{Al}_{2} \mathrm{O}_{3}$, and/or aluminum basic carbonate to precipitate and plug the columns. After pushing the supernate out of the column voids it will also remove sodium from the resin, thereby minimizing the amount reaching the cesium concentrator. The rinse follows the feed to the strontium ion exchange column.

The bounce tanks should be kept relatively empty to take advantage of the increasing feed purity as the rinse passes through the cesium columns. Water purity is important to prevent elution of cesium. Its $\mathrm{pH}$ should be in the range 7 to 9 , and total cation concentration (including $\mathrm{NH}_{4}{ }^{+}$) should be less than $0.02 \mathrm{M}$. The flow rate is to be the same as for the feed. The design-basis first rinse volume is 5 column volumes. Temperature is not to exceed $30^{\circ} \mathrm{C}$. 


\section{Elution Cycle}

The elutriant will be $2 \mathrm{M} \mathrm{NH} 4 \mathrm{OH}-2 \mathrm{M}\left(\mathrm{NH}_{4}\right)_{2} \mathrm{CO}_{3}$ and is obtained from the elutriant recovery area. Make-up $\mathrm{CO}_{2}$ and $\mathrm{NH}_{3}$ are obtained from the cold side. Elutriant composition may be allowed to vary $+10 \%$ and radioisotope concentration should not exceed the desired load-effluent concentration (i.e., $10^{-8} \mathrm{M}$ ). Flow will be upflow at a rate of $1.2 \mathrm{cV} / \mathrm{hr}$, with a total volume of 10 column volumes. Temperature is not to exceed $30^{\circ} \mathrm{C}$. Effluent will be routed to a catch tank, for subsequent concentration and stripping in the elutriant recovery area.

Second Rinse Cycle

The second water rinse, upflow, follows the eluate into the eluate catch tank. This rinse prevents buildup in the recycle water system. Flow rate will be $1.2 \mathrm{cV} / \mathrm{hr}$, with a total volume of 3 column volumes (may be ad justed downward). Temperature and water quality are the same as for the first water rinse except for any limitation on $\mathrm{NH}_{3}$ concentration.

\section{Regeneration Cycle}

The resin, now in the $\mathrm{NH}_{4}{ }^{+}$form, will be regenerated with $2 \mathrm{M} \mathrm{NaOH}$ in upflow. Regenerant composition may be allowed to vary $+10 \%$ and radioisotope concentration should not exceed $10^{-2}$ times the desired load-effluent concentration. Flow rate will be $1 \mathrm{cV} / \mathrm{hr}$, with a total volume of 5 column volumes. The regeneration endpoint will be determined by electrical conductivity $>100,000 \mu \mathrm{mho} / \mathrm{cm}$. Temperature is not to exceed $30^{\circ} \mathrm{C}$. Effluent will be routed to a regenerant catch tank, which is heated and stirred in such a manner as to drive off eluted $\mathrm{NH}_{3}$ to the cesium vent scrubber.

Backwash

About every two months the resin may require backwashing. This is done with water in upflow to remove fines and miscellaneous deposits, correct channeling, and regrade the bed hydraulically. Need for backwashing is signaled by reduced decontamination factors and increased bed pressure drop. An expansion of 50 to $75 \%$ is desired in the backwash, so the required flow rate can vary, according to Table 4.50 , from 4 to $10 \mathrm{gpm} / \mathrm{ft}^{2}$ depending on the ionic form, water temperature and particle size. During each 4-hr backwash period, recycle water is recirculated through the ion exchange column to expand the bed into the available freeboard space. Degraded resin flushed into the fines are sent 
resin catch tank, where it remains for disposal. After backwashing, the resin settles back into the ion exchange column. Two or three separate backwash periods, with settling in between, are suggested. The introduction of air should be meticulously avoided. The ion exchange column is then level-gaged and fresh resin added, if necessary.

Since the backwash procedure mixes the resin bed, the bed is then eluted and regenerated at least twice to make sure the bottom zone is clean enough to produce low-contaminant make-effluent. Elution time could be extended to double the usual period if it is suspected that excessive $\mathrm{Cs}$ or $\mathrm{Pu}$ remains on the resin.

Spent Resin Removal

The time for resin removal is signaled by reduced $D F^{\prime} s$ even after backwash, and by increased resin moisture absorption and reduced $C s$ capacity in thieved samples. The resin is removed from the columns by slurrying it with water fed in through the bottom distributor. Additional water may be introduced from the top of the column. A water velocity of 3 to $5 \mathrm{ft} / \mathrm{sec}$ will be required in the up-legs of the transfer lines. The use of compressed air to break plugs and facilitate conveying is recommended.

\section{Resin Disposal}

Spent resin is checked for residual alpha, beta, and gamma activity, interstitual water is drained, and the resin is packaged in 10-50 $1 \mathrm{~b}$ batches. Packaging the resin puts it in a form suitable for burial or incineration. If total activity is less than $10 \mathrm{nCi} / \mathrm{g}$, burial as a low-level waste should be considered. In the high-level cave tests, residual radioactivity did not build up after 320 column volumes of actual plant waste had been processed. Hanford presently buries its spent Duolite ${ }^{\circledast}$ resin.

If activity is greater than $10 \mathrm{nCi} / \mathrm{g}$ incineration in equipment with proper smoke and fly-ash control is preferred. A small (50-100 $\mathrm{lb} / \mathrm{hr})$ incinerator could be installed in the $\mathrm{S}$ canyon ion exchange area. The incinerator off-gas would be routed to the melter off-gas system. 


\subsubsection{Strontium Ion Exchange}

\subsection{General}

Strontium is removed from clarified supernate by ion exchange on "Amberlite" IRC-718* resin. This resin contains a chelating functionality which results in a strong selectivity for transition metals. The Savannah River Laboratory has shown that strontium is selectively sorbed onto the resin from simulated waste supernates. Small-scale column tests led to the conclusion that plant scale columns should perform well with the "Amberlite" resin [45]. Decontamination factors approaching 1000 were obtained with a single column. Based on this DF, the reference flowsheet forecasts the Sr-90 activity in the saltcrete will be less than $2 \mathrm{nCi}$ $\mathrm{Sr} / \mathrm{g}[46]$.

\subsection{Process Description}

The effluent from the $C s$ columns is pumped downflow through the ion exchange column containing "Amberlite" IRC-718 resin. After the loading step, the column is first rinsed downflow with the effluent from the cesium first rinse and then rinsed downflow

with water. The strontium is eluted upflow using a $0.01 \mathrm{M}$ solution of ethylene diamine tetrasodium acetate $($ EDTNaA at $\mathrm{pH}=11$ ). The column is finally rinsed upflow with water to remove residual EDTNa. The cycle schedule is summarized in Table 4.56.

Because the cesium ion exchange process will be monitored to maintain acceptable DF's, the actual feed times may vary for the strontium cycle. The ion exchange operation will be countercurrent to ensure that high DF's are obtained.

A flow diagram (FS-10) is shown in Figure 4.10 and a material balance $(M B-10)$ in Table 4.10.

\subsection{Resin Properties}

"Amberlite" IRC-718 is a crosslinked macroreticular cation exchange resin. It has a styrene divinyl benzene matrix with a chelating functionality like ethylene diamine tetra-acetic acid (EDTA). This functionality consists of cation active sites which coordinate with the transition metal ion and therefore have a high selectivity toward them [47].

* Trademark of Rohm and Haas. 
Sorption experiments with various resins indicated that "Amberlite" IRC-718 has one of the most favorable equilibria for strontium sorption. The distribution coefficients ( $\mathrm{Sr}$ on resin)/( $\mathrm{Sr}$ in supernate) for the resins tested are presented in Table 4.57 .

"Amberlite" IRC-718, while having a favorable distribution coefficient for strontium ( $k_{d}=1040$ to 3250$)$, is also selective to other metal ions such as $\mathrm{Hg}, \mathrm{Ca}$, and the 1 anthanides. A selectivity series for IRC-718 is presented in Table 4.58 for an idealized supernate solution. The competing ions are present in concentrations much higher than that of strontium. Column tests using strontium tracers are to begin shortly to determine the effect of competing ions under dynamic conditions.

The highly crosslinked macroeticular structure of "Amberlite" IRC-718 prevents the excessive swelling and contracting which fragments and degrades gelular chelating resins [47] such as "Chelex" 100. Since IRC-718 particles are considerably larger than "Chelex" 100 particles, column pressure drop is less and the possibility of losing fines through screen distributors is reduced. "Amberlite" is a spherical resin which typically has a 20-50 mesh particle size range. The maximum swelling is $40 \%$ when converting from $\mathrm{H}^{+}$to $\mathrm{Na}^{+}$ form [48]. The swelling expected in the strontium columns is less than $10 \%$ since elution will be with alkaline EDTA instead of acid.

Pressure drop data for downflow operation is presented in Figure 4.62 [49].

\subsection{Detailed Description of Unit Operations}

Resin Preparation and Column Loading

Each new shipment of resin is washed initially to remove any fines that have accumulated during handling and shipment. After characterizing each batch as to particle size range and preliminary strontium absorption capacity, the "Amberlite" resin is slurried with dilute caustic and gravity fed into the ion exchange column. Gravity feeding is used to prevent destruction of the fragile spherical particles. The resin is then backwashed at least 3 times to remove any additional fines which may have accumulated during handling and to classify the resin according to particle diameter. Finally, the column is eluted and regenerated twice to prepare the resin for actual use. 
$\underline{\text { Feed }}$

The effluent from cesium ion exchange will be fed downflow into the column prepared for loading. The flow rate presently proposed is $1.67 \mathrm{gpm} / \mathrm{ft}^{2}$. The feed temperature is not to exceed $30^{\circ} \mathrm{C}$. Because the strontium feed comes directly from cesium ion exchange, the proposed 12-hour feed time is subject to the variations in cesium feed time which might occur because of changes in supernate composition. Thus the strontium column is to be sufficiently overdesigned so that any increased feed times for cesium ion exchange do not cause strontium DF's to fall below an acceptable level.

Although the volumetric flow rate to the strontium column will remain the same as for cesium ( $2542 \mathrm{gph}$ while being fed), the flow rate on a column volume basis will be twice as high $(3.33 \mathrm{cV} / \mathrm{hr})$, since the strontium column resin capacity is one-half that of the cesium column(s). Also since there is only one $\mathrm{Sr}$ column, but two Cs columns, the relative throughput (volume solution/volume resin) will be 4 times larger for $\mathrm{Sr}$ than $\mathrm{Cs}$. The column will be loaded for $40 \mathrm{CV}$ 's $(20 \mathrm{hrs})$ with cesium column effluent, where a column volume is based on the $S r$ resin bed volume (762 gal). The effluent from strontium ion exchange will be transferred to the product salt hold tank.

Breakthrough behavior for strontium ion exchange using "Amberlite" resin is shown in Figure 4.63 [45].

\section{Cs Rinse}

The first rinse from the cesium column will be passed downflow through the strontium column. This rinse should be kept separate from the Cs make (feed) effluent to properly rinse the Sr colums. Most of the strontium remaining in the holdup volume of the cesium column will be flushed out by this rinse step and sorbed onto the "Amberlite" resin. The flow rate is to be the same as the feed $\left(1.67 \mathrm{gpm} / \mathrm{ft}^{2}, 3.33 \mathrm{cV} / \mathrm{hr}\right.$ for $\left.3 \mathrm{hrs}\right)$, and the temperature is not to exceed $30^{\circ} \mathrm{C}$.

\section{$\underline{\text { Sr First Rinse }}$}

The Sr first rinse will be used primarily to push the remaining sodium and nitrates out of the column voids to reduce the load on the spray dryer and melter. Water purity should be such that leakage of strontium is held to an acceptable level. Experimentation will be done to determine the maximum allowable levels of EDTA in the water. The flow rate is to be the same as for the feed $\left(1.67 \mathrm{gpm} / \mathrm{ft}^{2}, 3.33 \mathrm{cV} / \mathrm{hr}\right.$ for $\left.0.45 \mathrm{hr}\right)$, and temperature is not to exceed $30^{\circ} \mathrm{C}$. 


\section{Elution}

The elutriant will be EDTA and caustic. The concentrations proposed are $0.01 \mathrm{M}$ EDTA and $0.001 \mathrm{M} \mathrm{NaOH}$. The $\mathrm{pH}$ should be 11 or greater to keep the EDTA in the tetra sodium form. Elution with $0.01 \mathrm{M}$ EDTA will keep the resin in the sodium form, which will eliminate large volume changes and reduce the osmotic shock. Laboratory tests were run using $0.01 \mathrm{M}$ EDTA as an elutriant for both "Amberlite" and "Chelex" resins. Figure 4.64 shows that elution with EDTA is very effective in removing strontium from the resin.

The elutriant will be made in the Sr elutriant make-up tank, sampled and tested for EDTA and $\mathrm{pH}$. The eluate from Sr ion exchange will be sent to an evaporator where it will be concentrated to a $1.0 \mathrm{M}$ alkaline EDTA concentration in order to reduce the water load on calcination.

The proposed flow rate for the elutriant is $0.5 \mathrm{gpm} / \mathrm{ft}^{2}$ (1 $\mathrm{CV} / \mathrm{hr}$ ) for a total volume of $6 \mathrm{cV}(4572 \mathrm{gal})$. The temperature is not to exceed $30^{\circ} \mathrm{C}$. The maximum permissible level of $\mathrm{Sr}$ in the elutriant is being studied.

\section{Sr Second Rinse}

The purpose of the second rinse is to wash the EDTA remaining in the voids out of the column. This will prevent the strontium in the next feed step from possibly being chelated by remaining EDTA. The effluent will be mixed with the eluate before entering the $\mathrm{Sr}$ concentrator.

The proposed flow rate is the same as for the elutriant $\left(0.5 \mathrm{gpm} / \mathrm{ft}^{2} \mathrm{~d}, 1 \mathrm{cV} / \mathrm{hr}\right)$. A total volume of $3.0 \mathrm{CV}(2286 \mathrm{gal})$ of rinse water shall be used. Temperature is not to exceed $30^{\circ} \mathrm{C}$.

\section{Backwash}

About every two months the resin may require backwashing. This is done with water in upflow to remove fines and deposits, correct channeling, and regrade the bed hydraulically. Need for backwashing is signaled by reduced decontamination factors or increased pressure drop. An expansion of 50 to $75 \%$ is desired in the backwash, so the required flow rate can vary, from 3 to 6 gpm/ft ${ }^{2}$ depending on the particle diameter and water temperature. Figure 4.65 presents expansion data for backwash operation [49]. During the 2-hr backwash period, recycle water is recirculated 
through the ion exchange column to expand the bed. Degraded resin fines are flushed into the spent resin tank for disposal. Two or three separate backwashes with settling in between are suggested. The ion exchange column is then level-gaged and fresh resin added if necessary. In that case, a second backwash is required to regrade the whole bed.

Since the backwash procedure mixes the resin bed, the bed is then eluted/regenerated with $0.01 \mathrm{M}$ EDTA at $\mathrm{pH}=11$ at least twice to make sure the bottom zone is clean enough to produce low-contaminant make-effluent.

\section{Spent Resin Removal and Disposal}

Spent resin is checked for residual alpha, beta, and gamma activity, interstitial water is drained, and the resin is packaged in 10-50 $\mathrm{lb}$ batches. Packaging the resin puts it in a form suitable for burial or incineration. If total activity is less than $10 \mathrm{nCi} / \mathrm{g}$, burial as a low-level waste should be considered. In the HLC tests residual radioactivity did not build up after 320 column volumes of actual plant waste had been processed. Hanford presently buries its spent Duolite resin.

If activity is greater than $10 \mathrm{nCi} / \mathrm{g}$, incineration in equipment with proper smoke and fly-ash control is preferred. A small (50-100 $\mathrm{lb} / \mathrm{hr})$ incinerator could be installed in the $\mathrm{S}$ Canyon ion exchange area. The incinerator off-gas would be routed to the melter off-gas system.

\subsection{Resin Aging}

"Amber lite" IRC-718 resin degrades mainly because of osmotic shock. The radiation level from cesium-free supernate $\left(<5 \times 10^{-3}\right.$ watt-hr/g) is not expected to significantly degrade the resin [50]. The structural properties of "Amberlite" IRC-718 are considerably better from a resin aging standpoint than the resin formerly suggest ("Chelex" 100). A service life of at least one year is to be expected for the "Amberlite" resin.

Aging effects will be noticed by a reduction in the decontamination factors obtained. Since continuous monitoring of Sr-90 is not practical, samples of the column effluent are to be taken each cycle. As the performance of the resin degrades, the amount of supernate fed to the cesium column will have to be adjusted accordingly in order to obtain a salt cake with acceptable levels of $\mathrm{Sr}-90$. 


\subsection{Process Control}

Strontium Feed Bounce Tank

Function

Feed cesium ion exchange column effluent to the strontium column at $1.67 \mathrm{gpm} / \mathrm{ft}^{2} \pm 10 \%$.

Control

(1) Monitor flow to ion exchange columns.

(2) Monitor discharge pressure of pump.

Sr Ion Exchange Column

Function

Provide a DF of greater than 1000 for strontium.

\section{Control}

(1) Hold the temperature of the feed to $<30^{\circ} \mathrm{C}$.

(2) Monitor $\Delta P$ across the columns.

(3) Resin level indicator.

(4) Monitor flow during loading, rinse, elution, and regeneration.

(5) Resin level indicator for the backwashing process.

\subsubsection{Cesium Elutriant Recovery/Eluate Concentration}

(B. E. Murphree)

\subsubsection{Genera1}

The cesium ion exchange column eluate is processed through this module to concentrate the eluate to $2.0 \mathrm{M}\left(\mathrm{Na}_{2} \mathrm{CO}_{3}+\mathrm{Cs}_{2} \mathrm{CO}_{3}\right)$ and recover $\mathrm{NH}_{3}-\mathrm{CO}_{2}$. Greater than $99.99 \%$ of the $\mathrm{NH}_{3}$ and $\mathrm{CO}_{2}$ is driven from the cesium eluate during this process. The flowsheet (FS-11) is shown in Figure 4.11 and the material balance (MB-11) in Table 4.11. 


\subsubsection{Process Description}

Cesium eluate collects in the cesium concentrator feed tank and is fed continuously to the top of the steam stripper. The steam stripper is a packed bed which contacts cesium eluate countercurrent ly with steam from the cesium concentrator.

$\left(\mathrm{NH}_{4}\right)_{2} \mathrm{CO}_{3}$ and $\mathrm{NH}_{4} \mathrm{OH}$ break down in the steam by the reactions:

$$
2 \mathrm{NH}_{4}^{+}+\mathrm{CO}_{3}^{2-} \underset{\text { heat }}{\longrightarrow} 2 \mathrm{NH}_{3}+\mathrm{CO}_{2}+\mathrm{H}_{2} \mathrm{O}
$$

and

$$
\mathrm{NH}_{4}^{+}+\mathrm{OH}^{-} \underset{\text { heat }}{\longrightarrow} \mathrm{NH}_{3} \mathrm{H}_{2} \mathrm{O}
$$

Removing $\mathrm{NH}_{3}$ and $\mathrm{CO}_{2}$ in the steam stripper prevents foaming in the cesium concentrator. The $\mathrm{NH}_{3}-\mathrm{CO}_{2}$-water vapor overheads pass through a de-entrainment section which removes entrained nonvolatile radioactivity with a DF of $\geq 10^{6}$. The vapor stream is condensed to produce an $\left(\mathrm{NH}_{4}\right)_{2} \mathrm{CO}_{3}-\mathrm{NH}_{4} \mathrm{OH}^{-}$solution by the reverse reactions of (1) and (2):

$$
2 \mathrm{NH}_{3}(\mathrm{~g})+\mathrm{CO}_{2}(\mathrm{~g}) \underset{\mathrm{cooling}}{2} 2 \mathrm{NH}_{4}^{+}+\mathrm{CO}_{3}^{2-}
$$

and

$$
\mathrm{NH}_{3}(\mathrm{~g})+\mathrm{H}_{2} \mathrm{O} \underset{\mathrm{coOling}}{\longrightarrow} \mathrm{NH}_{4}^{+}+\mathrm{OH}^{-}
$$

The solution flows to the cesium elutriant makeup tank via the stripper condensate tank. The concentration of the elutriant is adjusted to $2 \mathrm{M}\left(\mathrm{NH}_{4}\right)_{2} \mathrm{CO}_{3}-2 \mathrm{M} \mathrm{N} \mathrm{NH}_{4} \mathrm{OH} \pm 10 \%$ by sparging appropriate amounts of $\mathrm{CO}_{2}$ and by adding aqueous ammonia and process water. The elutriant is then ready for reuse in elution of cesium from the Duolite ${ }^{\otimes}$ resin.

$\mathrm{NH}_{3}$ and $\mathrm{CO}_{2}$, which escape from the various process vessels, are combined and drawn through a packed bed absorber (cesium vent scrubber). Chilled water countercurrently contacts the $\mathrm{NH}_{3}-\mathrm{CO}_{2}$ containing gas stream. $\mathrm{NH}_{3}$ and $\mathrm{CO}_{2}$ are absorbed by the 1 iquid phase and returned to the cesium concentrator feed tank. The depleted gas stream is vented to the regulated facility vessel vent system.

The concentrated $\mathrm{Na}_{2} \mathrm{CO}_{3}-\mathrm{Cs}_{2} \mathrm{CO}_{3}(2.0 \mathrm{M})$ solution is pumped from the cesium concentrator to the Cs concentrator bottoms tank for subsequent processing through a zeolite column. 
A purge condenser condenses a steam sidestream from the cesium concentrator. This removes water introduced by ion exchange rinse steps, jet dilution, and vent scrubber bottoms. The purge condensate is transferred to the recycle evaporator feed tank for subsequent decontamination.

\subsubsection{Hanford Pilot Plant Study}

Hanford runs an elutriant recovery/eluate concentration system which performs exactly the same function as that proposed for the DWPF process. Two major problems have appeared occasionally: (1) foaming in the evaporator and (2) $\left(\mathrm{NH}_{4}\right)_{2} \mathrm{CO}_{3}$ pluggage in the condenser. Reference 70 describes a pilot plant study performed to solve these problems at Battelle-Northwest Laboratories. The feed composition used (about $7 \mathrm{M} \mathrm{NH}_{4}^{+}$and about $3 \mathrm{M} \mathrm{CO}_{3}{ }^{2-}$ ) was similar to the DWPF cesium-loaded elutriant (about $6 \mathrm{M} \mathrm{NH}_{4}^{+}$and $2 \mathrm{M} \mathrm{CO}_{3}{ }^{-}$).

Steam stripping the feed in a packed bed effectively prevented foaming in the evaporator. The stripping operation removed $>99 \%$ of the $\mathrm{NH}_{3}$ and $\mathrm{CO}_{2}$ from the liquid entering the evaporator. Heats of vaporization for $\left(\mathrm{NH}_{4}\right)_{2} \mathrm{CO}_{3}$ and $\mathrm{NH}_{4} \mathrm{OH}$ at $25^{\circ} \mathrm{C}$ are 51.2 and $18.8 \mathrm{kcal} / \mathrm{mole}$, respectively. Overall heat transfer coefficient in the steam-heated tube bundle reboiler leg was about 500 $\mathrm{Btu} / \mathrm{ft}^{2}-\mathrm{hr}{ }^{\circ} \mathrm{F}$. A mist eliminator pad effectively disengaged entrained feed from the vapor stream exiting the stripper. Decontamination factors as high as $2 \times 10^{4}$ were demonstrated.

Downdraft condensation prevented pluggage in the condenser. Overall heat transfer coefficients of about $100 \mathrm{Btu} / \mathrm{ft}^{2}-\mathrm{hr}-{ }^{\circ} \mathrm{C}$ were calculated for the condenser. $98 \%$ recovery of $\mathrm{NH}_{3}$ and $\mathrm{CO}_{2}$ were demonstrated by the downdraft condenser. Significant losses of $\mathrm{NH}_{3}$ and $\mathrm{CO}_{2}$ occurred at condensate temperatures above 60 and $20^{\circ} \mathrm{C}$, respectively.

\subsubsection{Cesium Fixation on Zeolite}

\subsubsection{General}

Concentrated eluate from the cesium concentrator/steam stripper is processed through this module to separate the cesium from the $\mathrm{Na}_{2} \mathrm{CO}_{3}$ solution by adsorption of the cesium on zeolite. The cesium-loaded zeolite is hydraulically slurried and transferred to the slurry hold tank for subsequent processing through the spray dryer with washed sludge and strontium eluate concentrate. The flowsheet (FS-12) is shown in Figure 4.12 and the material balance (MB-12) in Table 4.12. 


\subsubsection{Process Description}

Feed to this step is the $2.0 \mathrm{M}\left(\mathrm{Na}_{2} \mathrm{CO}_{3}+\mathrm{Cs}_{2} \mathrm{CO}_{3}\right)$ cesium concentrator bottoms solution. The cesium content is about $0.001 \mathrm{M} \mathrm{Cs}{ }_{2} \mathrm{CO}_{3}$. Feed is pumped downflow through a $5 \mathrm{ft}$ diameter $x 11 \mathrm{ft}$ bed of sodium-form Ionsiv IE-95 (formerly Linde ${ }^{\circledR}$ AW-500)*. Effluent from the column depleted in cesium by a factor averaging at least 100 is recycled to the sand filter feed tank. The column is $r$ un intermittent ly for about 2.5 hours every 3 days during the loading step in order to maintain a superficial velocity of $0.2 \mathrm{ft} / \mathrm{min}$ in the bed. A 2-bed-volume water wash flushes the bed to remove interstitial salt each time the feed is terminated. Residual rinse water circulates through the bed for cooling while it is idle. Cesium breakthrough occurs at $>50$ bed volumes of feed and is signaled by an online gamma detector. The column is sized such that breakthrough occurs at a minimum of every 60 days.

Following breakthrough, the bed is rinsed with $7 \mathrm{CV}$ 's of water to remove sodium. The bed is then backflow-expanded to $150-175 \%$ of its settled height. A steam jet empties the expanded bed into a separate tank where it is dewatered to a $1: 1$ water slurry using a profile wire screen separator. Cesium content of the slurry is determined analytically. The slurry is sent in controlled batches to be mixed with the sludge slurry to the spray dryer/melter for incorporation in glass.

The empty column is refilled with a slurry of fresh sodiumform zeolite from cold feed.** The bed is back-flow expanded to $150-175 \%$ of its settled height and backwashed for about 1 hour. It is then allowed to settle for about 30 minutes. This step is repeated twice more and thus classifies the bed according to size and rounds the corners of the granular zeolite particles. This promotes even distribution to the bed.

\subsubsection{Zeolite Properties}

Zeolite was chosen as the ion exchanger on the basis of radiation and chemical stability and cesium capacity. Zeolites (natural and synthetic) are a class of hydrated crystalline alkali metal aluminosilicate minerals which exhibit cation exchange properties. Their crystal structure is composed of $\mathrm{AlO}_{4}^{-}$and $\mathrm{SiO}_{4}$

* The zeolite now manufactured as 'Linde AW-500 does not have the desirable cesium selectivity properties; and Linde IE-95 must be specified.

** The fresh zeolite must be pretreated in cold feed with $4 \mathrm{MNaNO}_{3}$ to prevent $\mathrm{Ca}_{2} \mathrm{CO}_{3}$ formation. 
tetrahedra sharing common oxygen atoms. The bond lengths and strengths are such that the crystal lattice is both open and rigid. This produces a structure with a fixed negative charge at each Al site. Mobile cations present within the voids of the crystal balance this charge. The fixed negative charges therefore serve as cation exchange sites [51].

"Ionsiv" IE-95 (formerly Linde $A W-500$ ) was chosen as the zeolite best suited for cesium fixation. It has been used successfully in similar service at Hanford [53]. It is a naturally occurring chabazite which is mined, sized, and refined by Union Carbide. It is mixed with clay binder, fired, and crushed prior to marketing [52], as a 20-50 mesh solid, and has a formula of $\left.\left(\mathrm{Na}^{+}, \mathrm{Ca}^{++}\right), \mathrm{M}^{++}\right)\left(\mathrm{Si}_{2} \mathrm{AlO}_{6}\right)_{2} \cdot \mathrm{H}_{2} \mathrm{O}$. Bulk densities are given in Table 4.59. Water content is $1-10 \%$ as shipped and $12-17 \%$ hydrated [54]. Figure 4.66 shows experimental pressure drop data with water. Figure 4.67 gives experimental backwash expansion data [55].

Total ion exchange capacity of "Linde Ionsiv" IE-95 is 2.2-2.5 meq/gm (anyhydrous) [54]. Figure 4.68 shows the effect of sodium ion on cesium loading for "Linde" AW-500 [57]. Reference 58 gives detailed information on the thermodynamics and kinetics of cesiumsodium ion exchange on chabazite.

\subsubsection{Savannah River Laboratory Studies}

SRL ion exchange studies with both tracer level synthetic eluate and adjusted composition plant waste demonstrated the feasibility of fixing cesium on zeolite from concentrated ion exchange eluate [59], [60].

Tracer level column tests were run as follows. To ensure conversion to $\mathrm{Na}^{+}$form, $25 \mathrm{ml}(19.5 \mathrm{~g})$ of "Linde" AW-500, 20-50 mesh zeolite was washed with $3 \mathrm{M} \mathrm{NaNO}_{3}$. The resin was rinsed with water and transferred to a 1.3-cm-ID column. $2 \mathrm{M} \mathrm{Na}{ }_{2} \mathrm{CO}_{3}-0.007 \mathrm{M} \mathrm{CsNO} 3$ (with $1.7 \times 10^{5} \mathrm{dis} / \mathrm{min}-\mathrm{ml} \mathrm{Cs}-137$ ) was pumped downflow through the column at $1 \mathrm{CV} / \mathrm{hr}$ at ambient temperature. $2 \%$ breakthrough ( $\mathrm{Cs}$ in column effluent $=2 \% \mathrm{Cs}$ in feed) occurred after $70 \mathrm{CV} ; 20 \%$ breakthrough occurred after $76 \mathrm{cV}$.

These results show that it will be possible to sorb at least $70 \mathrm{CV}$ of concentrated "Duolite" colum eluate on one zeolite column. After an initial water wash, further contact with water will not leach Cs-137 appreciably from zeolite [59]. 
The eluate of "Duolite" ion exchange from actual plant waste was concentrated by boiling to remove $\mathrm{NH}_{3}, \mathrm{CO}_{2}$, and $\mathrm{H}_{2} \mathrm{O}$. This concentrated eluate was used to test $\mathrm{Cs}-137$ sorption onto columns containing four solid sorbents. Effluents from the sorbent columns was monitored by on-line gamma counting [59]. Plutonium and Sr-90 could not be counted with the on-line system. Their sorption onto "Linde" AW-500 was shown previously [61].

As shown in Table 4.60 "Linde" AW-500 and "Zeolon" 900 (trademark of Norton Chemical Company) zeolites sorbed Cs-137 equally well. Each column held $100 \mathrm{ml}$ of zeolite. Including concentration of Cs-137 by the "Duolite" columns and by eluate evaporation, each zeolite bed sorbed Cs-137 from about 150 liters of SRP supernate. The Cs-137 concentration factor was about 1500 . (Sorption of Cs-137 from supernate directly onto zeolite gives a concentration factor of only 37 [59]. After being loaded with Cs-137, the "Linde" AW-500 and the "Zeolon" 900 columns each emitted gamma radiation. $>4000 \mathrm{rad} / \mathrm{hr}$ at $3 \mathrm{in.} \mathrm{"Zeolon"} 500$ and "Vermiculite" (trademark of Zonolite Company, Travelers Rest, SC) were not acceptable sorbents for $137-C s$ in these tests [60].

\subsubsection{Hanford Experience}

In 1967, Hanford started its fission product separation operation in B-plant. The Cs-137 separation step consisted of removing this isotope from alkaline liquid waste solution by ion exchange on "Linde" AW-500. The loaded resin was eluted with $\left(\mathrm{NH}_{4}\right)_{2} \mathrm{CO}_{3}-\mathrm{NH}_{4} \mathrm{OH}$ solution. The eluate was boiled down to a concentrated $\mathrm{Na}_{2} \mathrm{CO}_{3}$ solution containing the $\mathrm{Cs}-137$ [62]. This solution was later loaded on zeolite to reduce the $\mathrm{Na} / \mathrm{Cs}$ ratio. This rework step is very similar to the Cs fixation step proposed for the DWPF [63, 64]. Reference 62 describes intended operation prior to startup and contains a concise summary of development data.

\subsubsection{General Purpose Evaporation}

\subsubsection{General}

A second evaporation step is included to perform a final decontamination step on excess water that must be purged to the environment. The flowsheet (FS-I3) and material balance (MB-13) are shown in Figure 4.13 and Table 4.13, respectively. 


\subsubsection{Process Description}

Process streams that comprise the feed to the GPE include:

- Recycle evaporator condensate

- Strontium concentrator condensate

- Product salt solution evaporator condensate

A boildown ratio of $10: 1$ was assumed for material balance purposes. Overheads, after accounting for the radionuclide inventory, are discharged if within limits to a plant surface stream. Evaporator bottoms are sent to the recycle evaporator feed tank. Concentration of salt in concentrate/concentration of salt in condensate $=10^{6}$.

\subsubsection{Solidification of Product Supernate in Concrete (H. W. Bledsoe)}

\subsubsection{General}

Clarified supernate, following treatment through ion exchange, is evaporated to $35 \mathrm{wt} \%$ salt and subsequently incorporated into concrete. The concrete mix is pumped into excavated trenches located at least $10 \mathrm{ft}$ above the maximum recorded water table level and surrounded by $5 \mathrm{ft}$ of highly impermeable soil. The concrete monolith is backfilled with $5 \mathrm{ft}$ of highly impermeable soil followed by at least $28 \mathrm{ft}$ of backfill. The flowsheet (FS-14) and material balance $(M B-14)$ are shown in Figure 4.14 and Table 4.14, respectively.

\subsubsection{Process Description}

The effluent from the strontium ion exchange module, following storage in Product Salt Hold Tanks in $S$ Area, is transferred to a product salt solution storage tank located in an area adjacent to the to-be-selected concrete disposal site (selected to meet both NRC and EPA requirements). From this tank, the decontaminated supernate will be dewatered to a salt content of 50-55 wt \%. Concentration of salt in the concentrate/concentration of salt in the condensate $=10^{6}$.

The concentrated salt solution will be mixed with cement at a central batch plant. The concrete mixture will contain 55.8 wt \% cement, 15.0 wt $\%$ salt and 29.2 wt $\%$ water. The concrete/salt slurry is then pumped from the batch concrete plant to the disposal site 
for placement. The concrete/salt mixture will be placed in trenches approximately $20^{\prime}$ wide $\times 25^{\prime}$ deep to a depth of $\sim 20$ feet and then backfilled with a minimum of $5 \mathrm{ft}$ of $10^{-7} \mathrm{~cm} / \mathrm{s}$ permeability material. As trenches are filled, they will have a minimum of $33 \mathrm{ft}$ of soil overlying the top of the concrete monoliths.

\subsubsection{Glass Packaging, Leak Testing, Canister Decontamination,} and Interim Storage (J. P..Howell and W. N. Rankin)

\subsubsection{General}

The purpose of this section is to present the process details and technical data bases for the processes designed to prepare quality-assured packages of waste glass for shipment to the on-site interim storage facility. These processes will be performed in three cells. Overall function of each cell is outlined below:

Mechanical Cell A

(1) Weld a plug on the canister

(2) Helium leak check the canister plug

(3) Decontaminate the canister surface

(4) Perform contamination survey of canister surface

Mechanical Cell B

(1) Decontaminate the canister surface

(2) Perform contamination survey of canister surface

Mechanical Cell C

(1) Perform a contamination survey of the exterior surface of the canister

(2) Perform spot electropolishing if the contamination survey dictates

(3) Perform a temperature and radiation profile of the canister

The flowsheets (FS-15, 16, and 17) are shown in Figures 4.15, 4.16, and 4.17. Material balances (MB-15, 16, and 17) are tabulated in Tables 4.16, 4.17, and 4.18. Each canister will contain about 3260 lbs of waste glass. 
The flowsheets, described below, were developed to supply a single, quality-assured, storage container using minimum production operations, particularly in the glass melt cell [68]. Canisters are filled with molten glass, and after solidification and cooling to an equilibrium temperature, a plug is welded in place. After helium leak checking to ensure leaktight integrity, the primary canister is decontaminated, surveyed, and transferred to a cleaner cell where further decontamination can be done as necessary. After decontamination in Cell A and Cell B, the canister is transferred to the final Cell $\mathrm{C}$ where radiation and temperature profiles are recorded for the individual canister. The canister under goes a final smear test for contamination and can be further spot decontaminated as required before shipment to the interim storage facility.

The estimated probable transferable contamination levels, in $\mathrm{dis} / \mathrm{min} / \mathrm{dm}^{2}$, assumed possible to be maintained in the production facility, will be about $10^{7}$ in the spray dryer/melter area, $10^{5}$ in "A" cell, $10^{2}$ in "B" cell, and <10 in "C" cell.

The SRP Equipment Engineering Department (EED) is developing the required resistance welding methods, repair welding techniques, helium leak test techniques, and ultrasonic inspection techniques which may, but is not at this time, an absolute requirement. These requirements are all related to primary canister closure and integerity. This development program is leading toward full-scale demonstration of these processes at the TNX-Container Development Facility. This facility has been approved and construction should begin in early 1980.

\subsubsection{Process Description}

\subsection{Mechanical Cell "A"}

\section{General}

NDT examination of the glassform structure after cooling may be required on canisters to verify glass analysis and structure. As an aid to process control, canister surface temperatures will be measured before canister welding. 


\section{Canister Closure}

The reference closure process for the canister is electrical resistance-upset welding. Joint preparation is required prior to welding. These techniques, along with the resistance plug welding techniques are being developed on a laboratory scale welder capable of welding up to 5-in.-diameter plugs into the canister fill opening. A full scale demonstration welder capable of welding up to 8-in.-diameter stainless steel plugs is being designed and fabricated by Newcor, Inc. It is expected to be available in the latter part of. 1980.

Process parameter optimization continues on the laboratory welder with stainless steel, low carbon steel, and other oxidation and corrosion resistant alloys. For the 5-in. diameter plug weld, 70,000 lbs of force, at 230,000 amps for 2 seconds are required to make the weld.

\section{Leak Testing}

A technique (using helium) is being developed to leak check the remote resistance weld prior to canister decontamination. The maximum allowable leak at the weld is $10^{-7}$ atm $\mathrm{cm}^{3} / \mathrm{sec}$ helium as defined by ANSI Standard N14.5, "Proposed American National Standard Leakage Tests on Packages for Shipment of Radioactive Materials." Tasks are in progress to determine the surface condition, outgassing effect, helium concentration requirements, and helium injection techniques for remote canyon-type leak test facilities.

The $10^{-7}$ atm $-\mathrm{cm}^{3} / \mathrm{sec}$ leak rate criteria is conservative for establishing watertight integrity and for containment of solid particulate radioactive nuclides as they are immobilized by the glass matrix. This has been set as the maximum criteria but will be reduced to a level of $10^{-4}$ to $10^{-7}$ atm $-\mathrm{cm}^{3} / \mathrm{sec}$ if the higher permissible leak rate can be shown not to release radioactive contamination to the interim storage facility. The same test equipment and techniques will be required for the whole range of sensitivity levels. 
A fusible plug concept has been selected as the reference concept for helium injection into the seal canister. In this concept a pressurized helium reservoir is sealed with a low melting point alloy. The reservoir is attached to the closure plug which is subsequently welded into the canister fill opening. At the desired time a resistance heater is applied to the top of the closure plug and the heat is transferred to the reservoir fusible plug. When the fusible plug reaches its melting point, (which can range from $360^{\circ} \mathrm{F}$ to $600^{\circ} \mathrm{F}$ depending on the alloy) melting takes place and the plug is blown out by the pressurized helium. Vibration as well as acoustical monitors can be used to verify helium injection.

\section{Canister Decontamination}

The exterior surfaces of canisters will be decontaminated to minimize transfer of particulate contamination from cell " $A$ " to cell "B" by producing a DF of $>10^{3}$ of the transferable surface contamination (alpha, beta, or gamma). The contamination level in "A" cell is assumed to be maintained at about $10^{5} \mathrm{dis} / \mathrm{min} / \mathrm{dm}^{2}$ alpha and $10^{6} \mathrm{~d} / \mathrm{m} / \mathrm{dm}^{2}$ beta-gamma. During filling and cooling, canister exterior surfaces will reach a maximum temperature of approximately $600^{\circ} \mathrm{C}$. A \#2B surface finish (ASTM-A-480-75) is specified for the outside surface of the as-fabricated canister to ensure that a uniform oxide film will form when the canister is being filled with glass. This specification is necessary to ensure consistency in decontaminating the finished waste form. The oxide films pro duced will be removed, along with included particulate contamination, in a $\mathrm{HNO}_{3}-\mathrm{NaF}$ etch solution with a temperature-controlled recirculating solution system. After canisters are rinsed, they will be cleaned in an oxalic acid solution, also with a temperaturecontrolled recirculating solution system, to remove additional surface contamination. After the final rinse, canisters will airdry by self-heat and surveyed before transfer to Mechanical Cell "B." Process solutions for decontamination in Mechanical Cell "A" will come from Mechanical Cell "B," a cleaner cell, where they were used previously:

\section{Oxalic Acid Digestion}

Spent oxalic acid must be digested prior to neutralization to avoid accumulation of $\mathrm{Na}_{2} \mathrm{C}_{2} \mathrm{O}_{4}$ between the washing and the settling/ filtration modules. The spent oxalic acid is digested in IM $\mathrm{HNO}_{3}-0.01 \mathrm{M} \mathrm{Mn}^{+}$solution. Digestion liquor is combined with the spent etching solution and neutralized with $10 \%$ excess 50 wt \% $\mathrm{NaOH}$. The neutralized spent cleaning solutions are transferred to the recycle collection tank along with canister water rinses. 


\subsection{Mechanical Cell "B"}

\section{General}

The second of the two-step canister decontamination proesses are carried out in Mechanical Cell "B". The decontamination equipment in this cell will be identical to that in Cell "A," but the overall contamination level will be lower in Cell "B" which should permit a lower level of canister decontamination prior to shipment to Cell "C."

\section{Final Canister Decontamination}

The exterior surfaces of canisters will be decontaminated of transferable radioactive particulates to a level acceptable for transfer to cell " $\mathrm{C}$ " and final product qualification. The system will be similar to that described for Mechanica Cell "A" and produce a similar DF of $10^{3}$. Process solutions from final canister decontamination in Mechanical Cell " $B$ " will be transferred to Mechanical Cell "A" where they will be used again. The transferrable contamination level in " $C$ " cell is assumed to be maintained at less than $10 \mathrm{~d} / \mathrm{min} / \mathrm{dm}^{2}$ alpha and $10^{2} \mathrm{dis} / \mathrm{min} / \mathrm{dm}^{2}$ beta-gamma.

\subsection{Mechanical Cell "C"}

Smear, Radiation, and Temperature Measurements

The exterior surfaces of the canister will be dry smeared, and temperature and radiation profiles of the waste form will be measured in " $C$ " cell to qualify the product canister and contents prior to interim storage on plant. Contamination levels on equipment surfaces in " $C$ " cell should be maintained a at less than $10 \mathrm{dis} / \mathrm{min} / \mathrm{dm}^{2}$ alpha and less than $100 \mathrm{dis} / \mathrm{min} / \mathrm{dm}^{2}$ beta-gamma.

Limits for surface contamination of the canister are $<220 \mathrm{~d} / \mathrm{min} / \mathrm{dm}^{2}$ alpha and $<2200 \mathrm{~d} / \mathrm{min} / \mathrm{dm}^{2}$ beta-gamma. These maximum limits are based on U.S. Department of Transportation specifications for maximum smearable contamination for air, rails, highway, and water shipment [71]. This specification is the same that is presently required for off plant. shipment of material from $S R P$ [72]. This was established as the maximum limits for SRP interim storage criteria because if this could be met, there was an excellent chance that the contamination level of the interim storage facility would not become a problem in future years of storage. Any greater levels of surface contamination could lead to interim storage contamination with the large numbers of canisters involved and require more expensive interim storage ventilation and filtration systems. 


\section{Interim Storage}

Reference design storage canisters, filled with waste glass, will be placed in retrievable surface storage at SRP. Outside air will flow by natural convection through the building to remove decay heat. In the event surveillance systems (airborne radioactivity detectors) indicate airborne radioactivity, a forced ventilation system must come online to route the ventilation through a bank of HEPA filters.

\subsection{REFE RENCES}

1a. Letter, L. F. Landon to W. J. Mottel. Defense Waste Processing Facility - Spray Dryer/Melter/Off-Gas System - Revised Basic Data (May 8, 1979).

1b. Letter, R. W. Sylvester to A. M. Eisenberg. Defense Waste Processing Facilities - Calciner and Melter Gas Compositions (April 10, 1979).

1c. Letter, R. W. Sylvester to A. M. Eisenberg. Defense Waste Processing Facilities and Melter Gas Compositions - Supplement 1 (April 18, 1979).

1d. Deleted

2. Deleted

3. A. S. Russe11, J. D. Edwards, and C. S. Taylor. Solubility and Density of Hydrated Aluminas in NAOH Solutions. J. Metals, 1123 (1955).

4. Deleted

5. A. J. Hill, et al. Description of Aged Savannah River Plant Waste. Internal Report DPST-77-425, E. I. du Pont de Nemours \& Co. (Inc.), Savannah River Laboratory, Aiken, SC (August 1977). 
6. H. L. Hull. Trip Report - Battelle-Pacific Northwest Laboratories - Spray Calciner Feasibility Test. Internal Report DPST-77-402, E. I. du Pont de Nemours \& Co. (Inc.), Savannah River Laboratory, Aiken, SC (July 27, 1977).

7. M. J. Plodinec. Viscosity of Glass Melts. Internal Report DPST-77-409, E. I. du Pont de Nemours \& Co. (Inc.), Savannah River Laboratory, Aiken, SC (July 27, 1977).

8. G. S. Fulcher. "Analysis of Recent Measurements of Glass Viscosity - I, II." J. Am. Ceram. Soc. 8, 339, 789 (1925).

9. R. B. Bird, W. E. Stewart, and E. N. Lightfoot. Transport Phenomena. J. Wiley and Sons, New York, 1960, p. 3-15.

10. J. Stonek, J. Sasek, and H. Merssnerova. Proceedings of the 8th Conference on the Silicate Industry, 1965, 554-578.

11. J. R. Wiley. Electrical Resistivity of Glass Melts. Internal Report DPST-77-239, E. I. du Pont de Nemours \& Co. (Inc.), Savannah River Laboratory, Aiken, SC (May 23, 1977).

12. I. Peyches. "The Principles Underlying the Electric Melting of Glass." J. Soc. Glass Tech. 32, 399 (1948).

13. E. V. Borel. "Practical Aspects to the Electric Melting of Glass." J. Soc. Glass Tech. 34, 248 (1950).

14. J. Horowitz. "Electrical Glass Melting." Glass Industry 34, 65-9, 98, 132-7, 160, 203-8, 226 (1953).

15. F. V. Tooley and R. I. Tiede. "Factors Affecting the Degree of Homogeneity of Glass." J. Am. Ceram. Soc. 27, 42 (1944).

16. F. V. Tooley and R. L. Tiede. "Effect of Temperature on Homogenizing Rate of Soda-Lime-Silica Glass." J.Am. Ceram. Soc. 28,42 (1945).

17. F. V. Tooley and R. L. Tiede. "Influence of Batch-Mixing Time and Grain Size on Homogeneity of a Soda-Lime-Silica Glass." J. Am. Ceram. Soc. 29, 197 (1946).

18. R. F. Bradley, T. A. Willis, M. J. Plodinec, J. K. Brown, and H. K. Bethmann. Irip Report - Corning Glass Works, January 19, 1976. Internal Report DPST-77-228, E. I. du Pont de Nemours \& Co. (Inc.), Savannah River Laboratory, Aiken, SC (January 27,1977 ). 
19. T. A. Willis, H. L. Hull, R. F. Bradley, M. J. Plodinec, and G. G. Wicks. Trip Report - Owens Corning Technical Center, May 25, 1977. Internal Report DPST-77-362, E. I. du Pont de Nemours \& Co. (Inc.), Savannah River Laboratory, Aiken, SC (July 5, 1977).

20. M. J. Plodinec. Small-Scale Electric Melter, II-Slag Formation. Internal Report DPST-78-453, E. I. du Pont de Nemours \& Co. (Inc.), Savannah River Laboratory, Aiken, SC (August 3, 1978).

21. M. J. Plodinec. Small-Scale Electric, I-Foaming of Glass Melts. Internal Report DPST-78-384, E. I. du Pont de Nemours \& Co. (Inc.), Savannah River Laboratory, Aiken, SC (June 12, 1978).

22. P. A. M. Gell. "Electric Melting for Large Tonnage Furnaces." The Glass Industry (March-April 1973).

23. Deleted.

24. J. A. Stone. Separation of SRP Waste Sludge and Supernate.

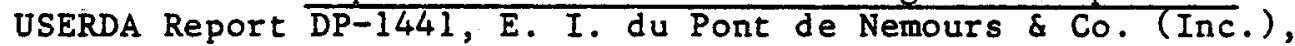
Savannah River Laboratory, Aiken, SC (1976).

25. J. R. Wiley. Decontamination of Savannah River Plant Waste Supernate. USERDA Report DP-1436, E. I. du Pont de Nemours \& Co. (Inc.), Savannah River Laboratory, Aiken, SC (1976).

26. I. M. Kolthoff and E. B. Sandell. Textbook of Quantitative Inorganic Analysis. 3rd Ed., McMillan, New York (1952).

27. Savannah River Laboratory Quarterly Report, Waste Management, April-June 1977. USERDA Report DPST-77-125-2, E. I. du Pont de Nemours \& Co. (Inc.), Savannah River Laboratory, Aiken, SC (1977).

28. Kirk-Othmer. Encyclopedia of Chemical Technology. 2nd Ed., Vol. 22, Interscience Publisher, NY (1970).

29. P. Loganathan and W. J. Maier. "Some Surface Chemical Aspects in Turbidity Removal by Sand Filtration." J. Am. Water Works Assoc. 67, 336 (1975).

30. G. D. Jones, R. E. Friedrich, and D. C. MacWilliams. Factors in Flocculation Mechanism. Paper B6683B presented at Meeting of American Institute of Chemical Engineers, New Orleans, LA (February 1961). 
31. J. W. Langhaar and H. W. Bellas. Water Purification in Feed Storage Basin. Internal Report DPSPU-70-30-2, E. I. du Pont de Nemours \& Co. (Inc.), Savannah River Laboratory, Aiken, SC (February 1971).

32. I. M. Abrams. "Countercurrent Ion Exchange with Fixed Beds." Industrial Water Engineering 10, 18-26 (1973).

33. I. M. Abrams and I. Benezra. "Ion Exchange Polymers." In Encyclopedia of Polymer Science and Technology, Vol. 7, P. 704, Wiley, 1967.

34. J. R. Wiley. Supernate Decontamination. Internal Report DPST-77-423, E. I. du Pont de Nemours \& Co. (Inc.), Savannah River Laboratory, Aiken, SC (August 19, 1977).

35. J. R. Wiley and R. M. Wallace. Removal of Cesium from Savannah River Plant Waste Supernate. USERDA Report DP-1388, E. I. du Pont de Nemours \& Co. (Inc.), Savannah River Laboratory, Aiken, SC (1975).

36. J. R. Wiley. Decontamination of Savannah River Plant Waste Supernate. USERDA Report DP-1436, E. I. du Pont de Nemours \& Co. (Inc.), Savannah River Laboratory, Aiken, SC (1975).

37. J. R. Wiley. A Study of Methods for Removing Strontium, Plutonium, and Ruthenium from Savannah River Plant Waste Supernate. USERDA Report DP-1408, E. I. du Pont de Nemours \& Co. (Inc.), Savannah River Laboratory, Aiken, SC (1976).

38. Savannah River Laboratory Quarterly Report: Waste Management, July-September 1975. USERDA Report DPST-75-125-3, E. I. du Pont de Nemours \& Co. (Inc.), Savannah River Laboratory, Aiken, SC (1975).

39. Savannah River Laboratory Quarterly Report: Waste Management, January-March 1976. USERDA Report DPST-76-125-1, E. I. du Pont de Nemours \& Co. (Inc.), Savannah River Laboratory, Aiken, SC (1976).

40. B Plant Recovery of Cesium from Purex Supernatant. USAEC Report ARH-1639, Atlantic Richfield Hanford Co., Richland, WA (1970).

41. Waste Management Technical Manual ISO-100. At lantic-Richfield Hanford Co., Richland, WA. 
42. Savannah River Laboratory Quarterly Report: Waste Management, April-June 1975. USERDA Report DPST-15-125-2, E. I. du Pont de Nemours \& Co. (Inc.), Savannah River Laboratory, Aiken, SC (1975).

43. Technical Bulletin for Dowex A-1. Dow Chemical Company, Midland, MI.

44. W. W. Schulz and J. S. Buckingham, At lantic Richfield Hanford Co. Unpublished progress reports and personal communications.

45. J. R. Wiley. Removal of ${ }^{90} \mathrm{Sr}$ from Defense Waste Supernate: Alternate Sorbent and Elution Methods. Internal Report DPST-78-318, E. I. du Pont de Nemours \& Co. (Inc.), Savannah River Laboratory, Aiken, SC (1978).

46. J. R. Wiley. A Study of Methods for Removing Strontium, Plutonium, and Ruthenium from Savannah River Plant Waste Supernate. USERDA Report DP-1408, E. I. du Pont de Nemours \& Co. (Inc.), Savannah River Laboratory, Aiken, SC (1976).

47. Amberlite Ion Exchange Resins - Amberlite XE-318. Rohm \& Haas Company Leaklet 非IE-217-76, Rohm \& Haas Company, Philadelphia, PA (1975).

48. Amberlite XE-318 - Preliminary Technical Information. Rohm \& Haas Company, Philadelphia, PA (1975).

49. G. C. Rodrigues (data to be published).

50. Savannah River Laboratory Quarterly Report: Waste Management, April-June 1975. USERDA Report DPST-75-125-2, E. I. du Pont de Nemours \& Co. (Inc.), Savannah River Laboratory, Aiken, SC (1975).

51. F. Helfferich. Ion Exchange. McGraw-Hill Boòk Company, Inc., p 11, New York (1962).

52. R. Dobson. Sales Engineer, Linde Molecular Sieve Products, Union Carbide Corporation (personal communication).

53. J. C. Buckingham. Laboratory Evaluation of Zeolite Material for Removing Radioactive Cesium from Alkaline Waste Solutions. USAEC Report ARH-SA 49, At lantic Richfield Hanford Co., Richland, WA (1970).

54. Linde Ionsiv IE-95 Ion Exchanger. Linde Molecular Sieves Ion Exchange Bulletin, Union Carbide Corporarion. 
55. G. C. Rodrigues (data to be published).

56. J. D. Sherman. Ion Exchange Separations with Molecular Sieves; Linde Molecular Sieves Ion Exchange Bulletin, Union Carbide Corporation (1977).

57. L. L. Ames and K. C. Knoll. Loading and Elution Characteristics of Some Natural and Synthetic Zeolites. USAEC Report HW-74609, p 18, Figure 4. General Electric Company, Hanford Atomic Products, Richland, WA (August 1962).

58. D. W. Breck. Ion Exchange Reactions in Zeolite, Linde Molecular Sieves Ion Exchange Bulletin, Union Carbide Corp.

59. J. R. Wiley and R. M. Wallace. Removal of Cesium from Savannah River Plant Waste Supernate. USERDA Report DP-1388, E. I. du Pont de Nemours \& Co. (Inc.), Savannah River Laboratory, Aiken, SC (1975).

60. J. R. Wiley. Decontamination of Savannah River Plant Waste Supernate. USERDA Report DP-1436, E. I. du Pont de Nemours \& Co. (Inc.), Savannah River Laboratory, Aiken, SC (1976).

61. J. R. Wiley. A Study of Methods for Removing Strontium, Plutonium, and Ruthenium from Savannah River Plant Waste Supernate. USERDA Report DP-1408, E. I. du Pont de Nemours \& Co. (Inc.), Savannah River Laboratory, Aiken, SC (1976).

62. J. S. Buckingham. Waste Management Technical Manual. USAEC Report ISO-100, Isochem, Inc., Richland, WA (1967).

63. J. S. Buckingham. Personal communication. Rockwell Hanford Operations (January 1979).

64. R. F. Carlstrom. Ion Exchange Flowsheet for Recovery of Cesium from Purex Sludge Supernate at B Plant. USERDA Report ARH-F-106, Atlantic Richfield Hanford Co., Richland, WA (April 29, 1977).

65. C. B. Goodlett, Concentration of Radioactive Wastes, USAEC Report DP-1135, E. I. du Pont de Nemours \& Co. (Inc.), Savannah River Laboratory, Aiken, SC (1968).

66. C. B. Goodlett. Transfer of Radioactive Slurries. USAEC Report DP-1136, E. I. du Pont de Nemours \& Co. (Inc.), Savannah River Laboratory, Aiken, SC (1968). 
67. Tank Farm Evaporator Experience. Internal Memorandum, B. S. Johnson to H. K. Bethmann, E. I. du Pont de Nemours \& Co. (Inc.), Savannah River Laboratory, Aiken, SC (March 8, 1977).

68. Canister Processing Flowsheet, Defense Waste Solidification Program. Internal Memorandum, J. P. Fáraci to R. T. Huntoon, Internal Report DPST-77-405, E. I. du Pont de Nemours \& Co. (Inc.), Savannah River Laboratory, Aiken, SC (August 1, 1977).

69. Defense Waste Solidification Program, Conceptual Designs of Mechanical Cell Equipment. Memor andum, SRP-EED to

R. T. Huntoon (October 24, 1977).

70. G. L. Richardson. Evaporation of Cesium Ion Exchange Eluate and Recovery of Ammonium Carbonate; Pilot Plant Studies. USAEC Report BNWL-CC-2084, Battelle-Northwest, Richland, WA (May 15, 1969).

71. R. M. Grazrano's Tariff No. 32, Supplement 2, "Hazardous Materials Regulations of the Department of Transportation." Section 173.397(a), P 203 (June 1, 1979).

72. Deleted 
TABLE 4.1

Defense Waste Processing Facility

Material Balance and Flowsheet Identification

Flowsheet
Ident. Figure No.

Sludge and Supernate

Feed Preparation

Aluminum Dissolution

FS-2 $\quad 4.2$

MB-2 $\quad 4.2$

FS-3 $\quad 4.3$

$M-3 \quad 4.3$

Sludge Washing

FS-4 $\quad 4.4$

$M B-4 \quad 4.4$

Spray Drying/Vitrification

FS $-5 \quad 4.5$

MB-5 $\quad 4.5$

Off-Gas Treatment

FS-6

4.6

$M B-6 \quad 4.6$

Mercury Recovery

FS-6A $\quad 4.6 \mathrm{~A}$

$M B-6 A^{*} \quad 4.6 A^{*}$

Recycle Evaporation

FS-7 $\quad 4.7$

$M B-7 \quad 4.7$

Settling and Filtration

FS- $8 \quad 4.8$

$\begin{array}{ll}M B-8 & 4.8\end{array}$

Cesium Ion Exchange

FS-9 $\quad 4.9$

MB-9 $\quad 4.9$

Strontium Ion Exchange

FS-10 -

4.10

MB-10 $\quad 4.10$

Cesium Elutriant Recovery and Cesium Concentration

FS-11

4.11

MB-11

4.11

Cesium Fixation on Zeolite

FS-12

4.12

MB-12

4.12

General Purpose Evaporation

FS-13

4.13

$M B-13 \quad 4.13$

Product Salt Solution

Concentration and

Solidification in Concrete

FS-14

4.14

MB-14

4.14

Mechanical Cell "A"

FS-15

4.15

MB-15

4.15

Mechanical Cell "B'"

FS-16

4.16

$M B-16 \quad 4.16$

Mechanical Cell ' $\mathrm{C}$ "

FS-17

4.17

MB-17

4.17

$\mp$ To be issued. 
TABLE 4.2

SLUDGE AND SUPERNATE PREPARATION (MB-2) PROCESS MaTEOIAL = HzO SLUDGE LINE

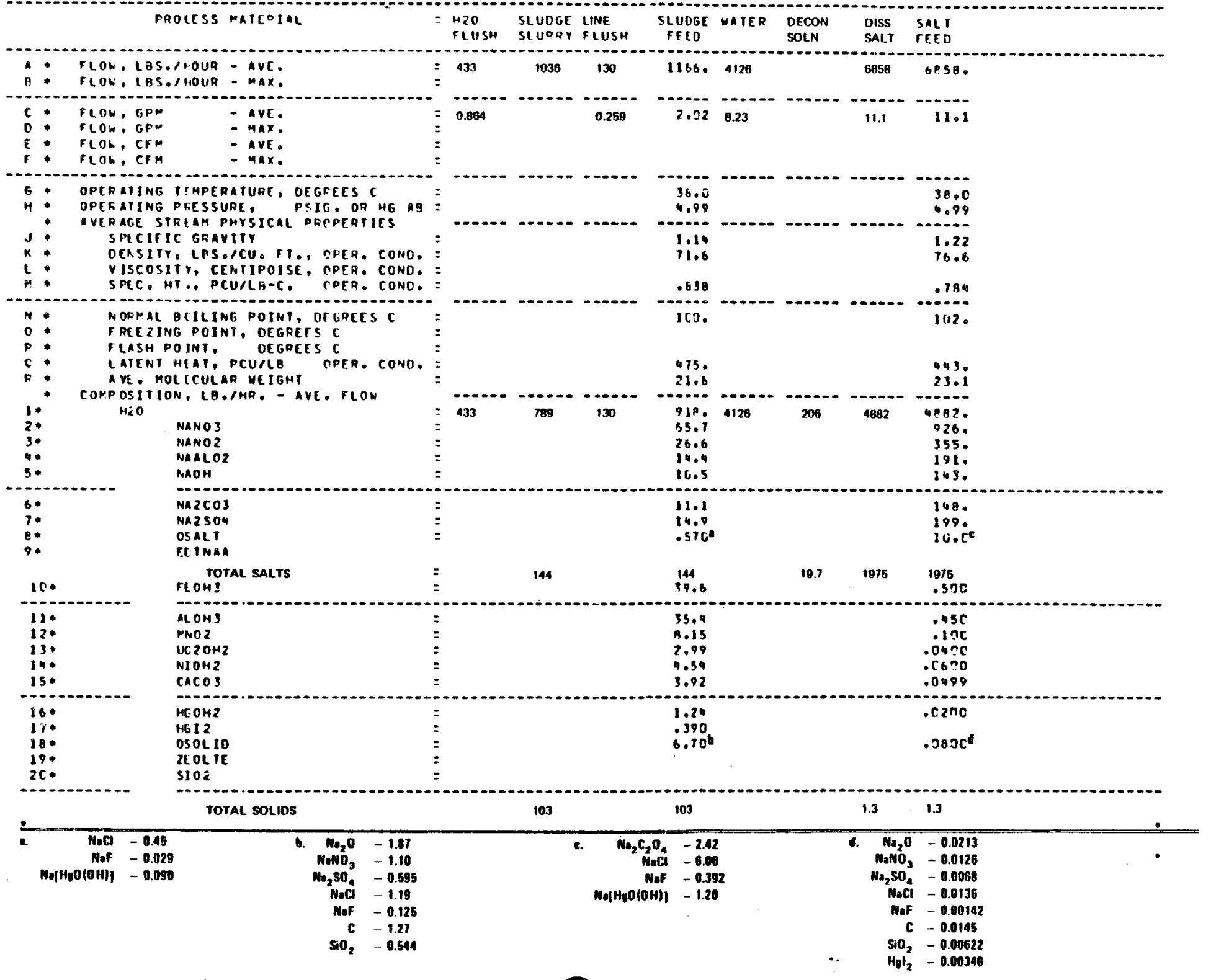


TABLE 4.3

ALUMINUM DISSOLUTION (MB-3)

$=$

6

$\sqrt{2}$

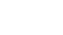

PROCESS MatePIAL

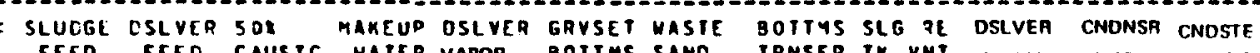
FEED FEFD CAUSTC WAIEQ VAPOR BOITAS SAMO TANSFT IK VMT CNDSTE VENT TK VNT

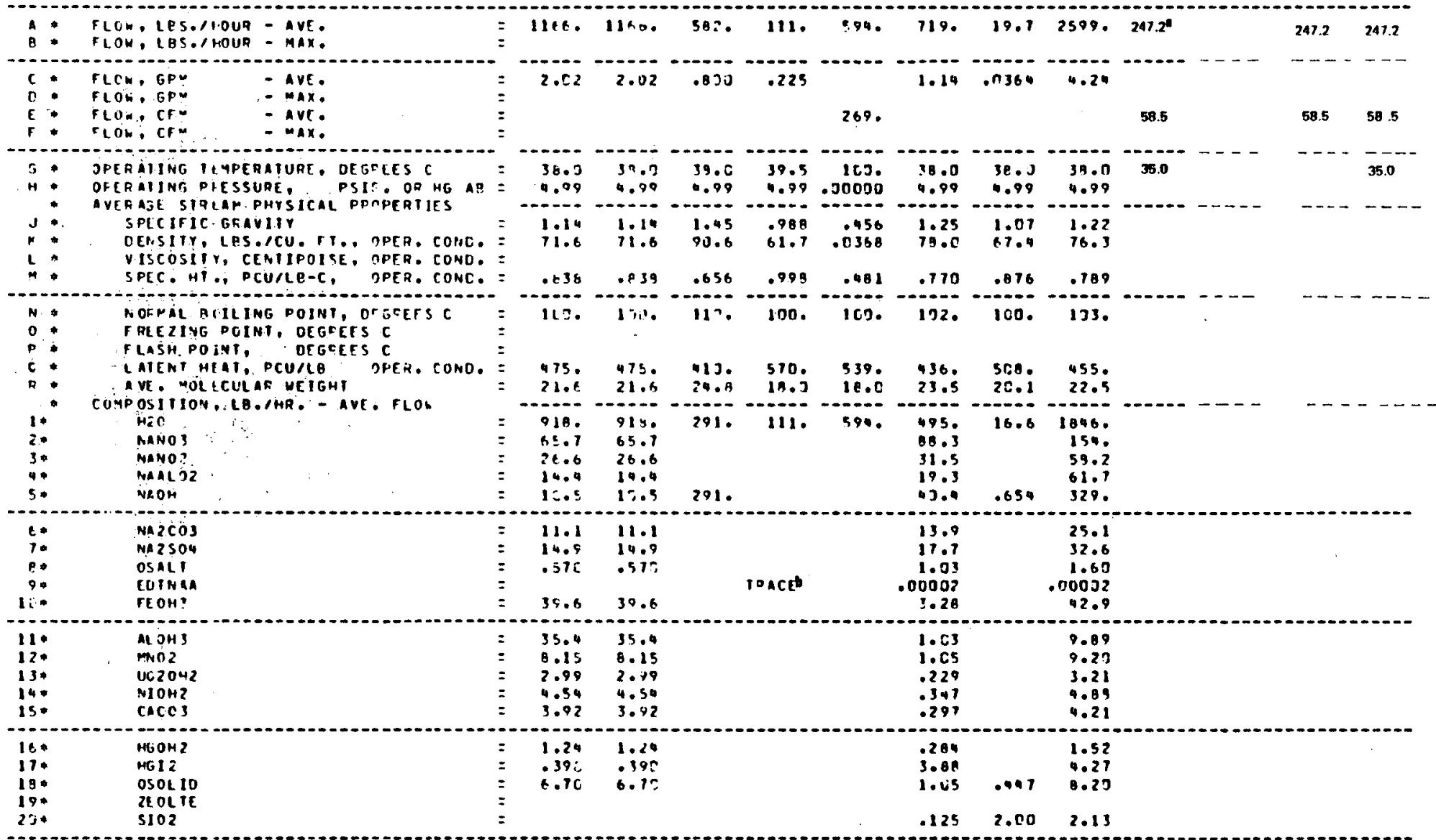

i. $13.74 \mathrm{~m} \times \mathrm{H}_{2}, 22.61 \mathrm{wt} \times \mathrm{O}_{2}, 1.26 \mathrm{mt} \times \mathrm{A}, 0.0409 \mathrm{~m} \times \mathrm{CO}_{2}, 2.34 \mathrm{mt} \times \mathrm{H}_{2} \mathrm{O}$ (This distribution holds for all

process vessol vents except those

b. $<10^{-5} \mathrm{~m} / \mathrm{mm}$. 
TABLE 4.4

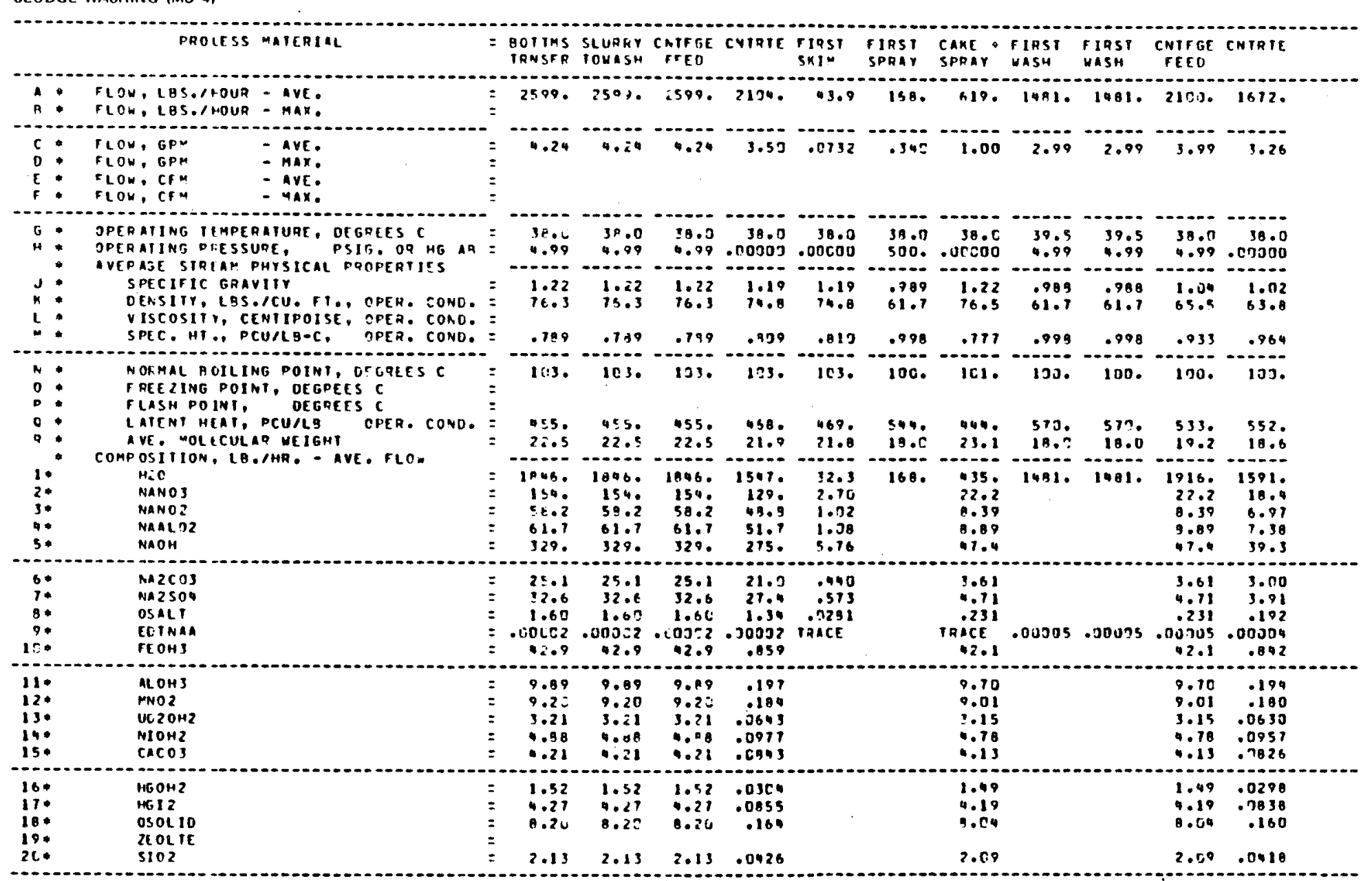


SLUDGE WASHING (MB-A)

ppocess paterial

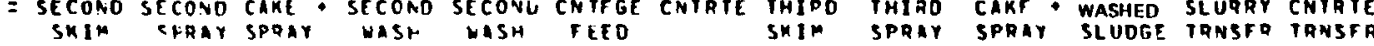

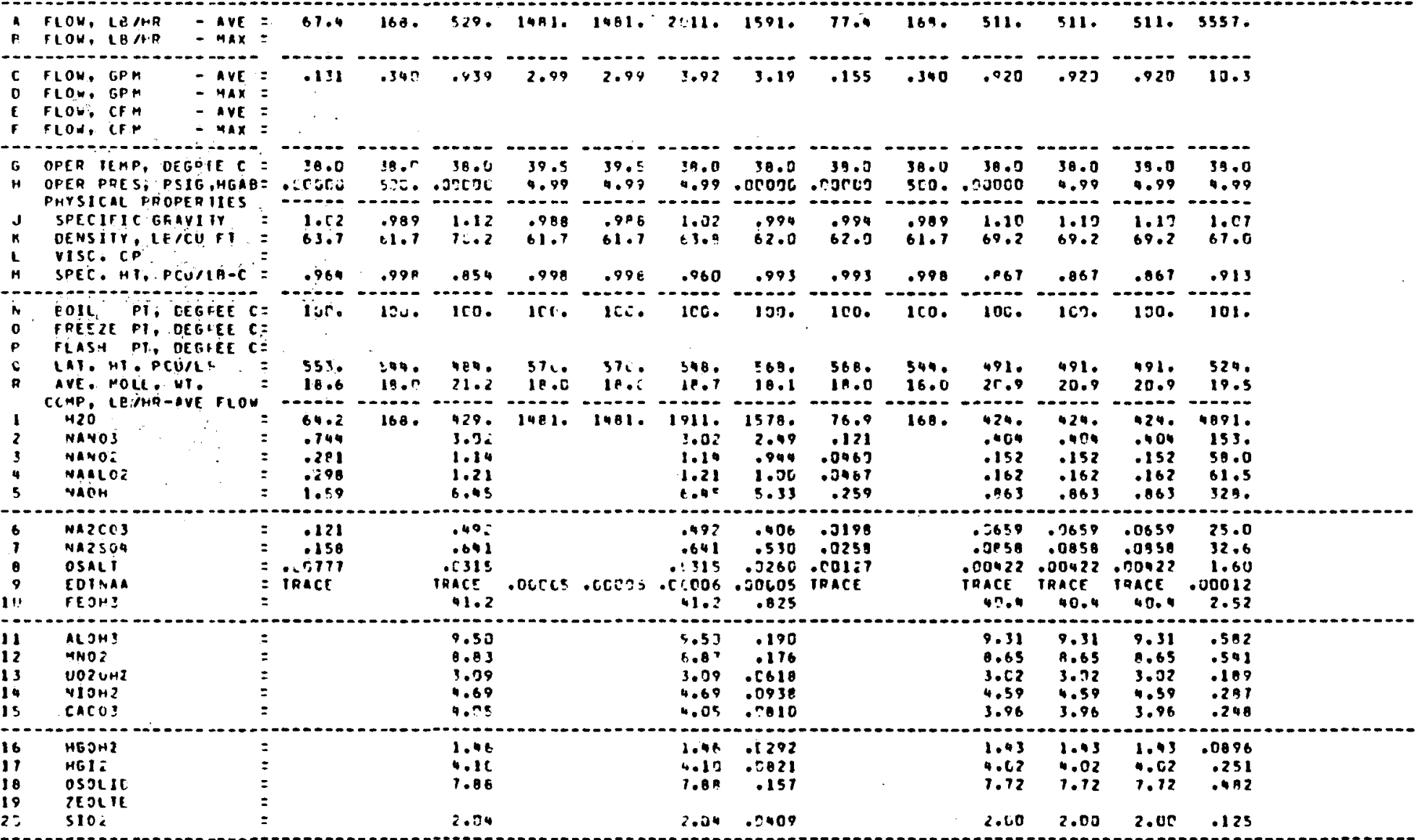




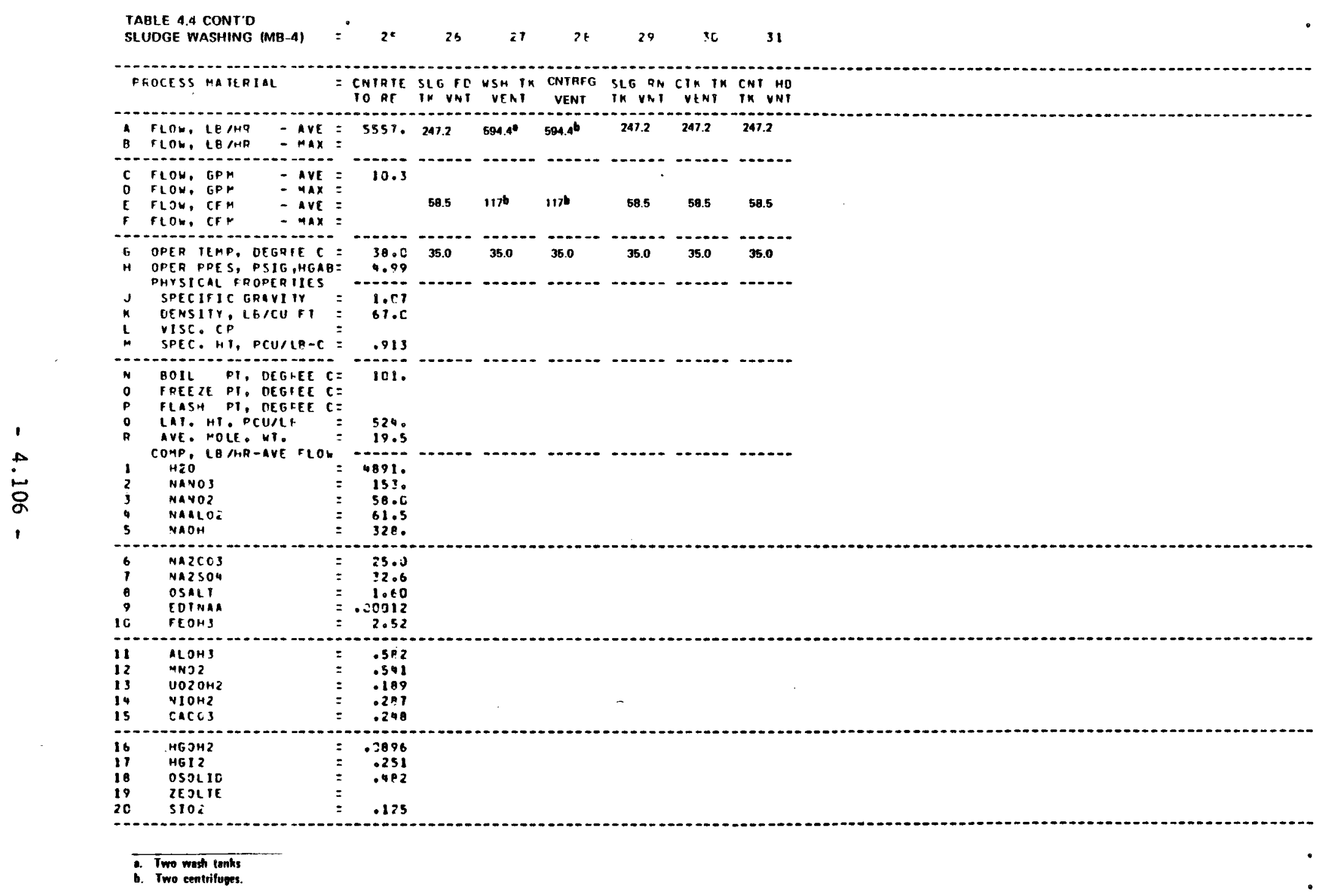


TABLE 4.5

CALCINATION AND VITRIFICATION (MB-5)

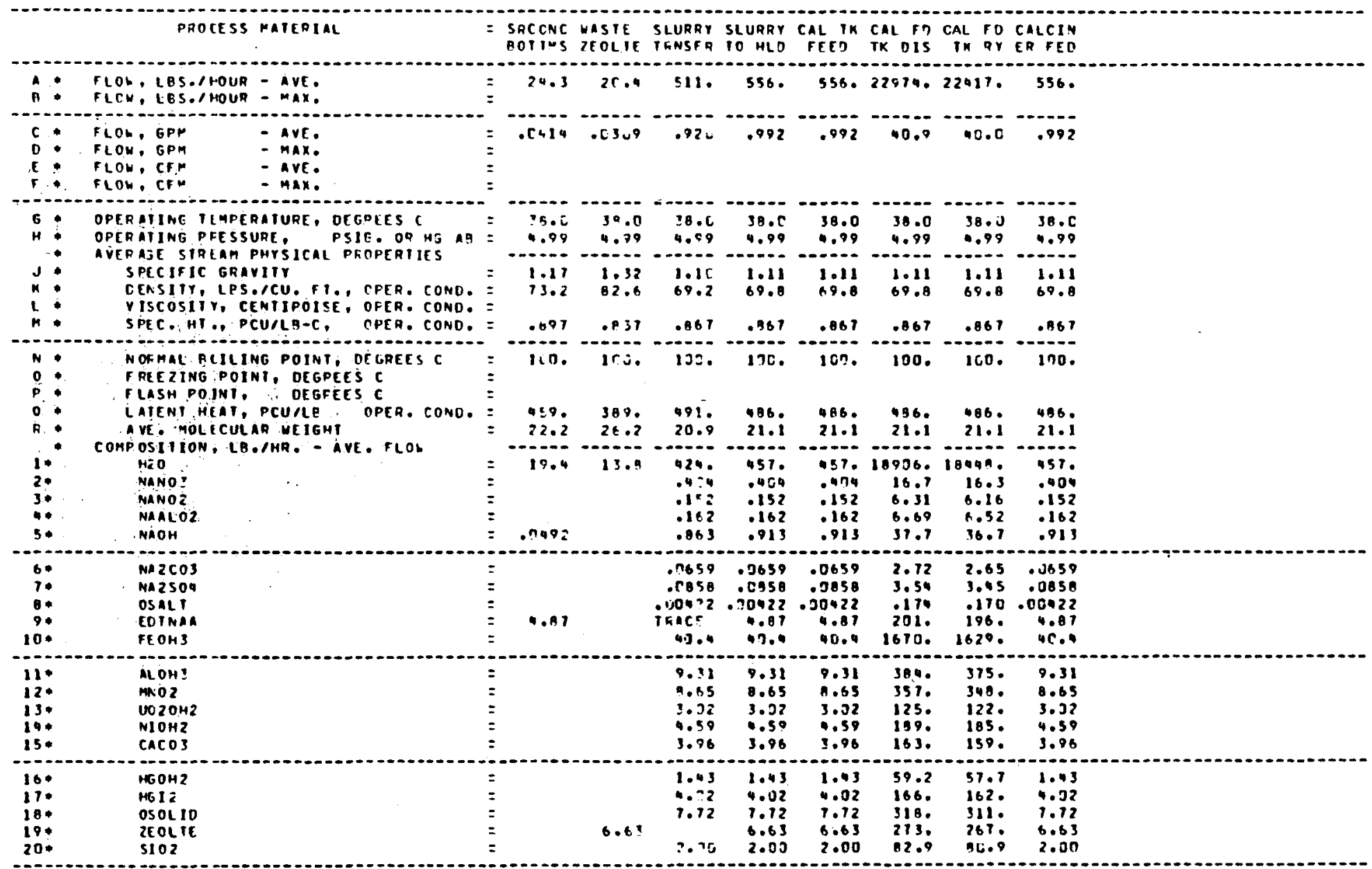


IABLE 4.5 CONTD

CALCINATION AND VITRIFICATION (MB-51

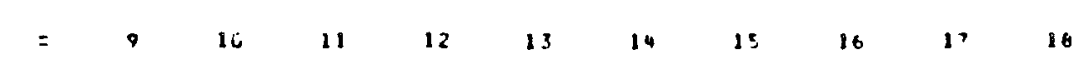

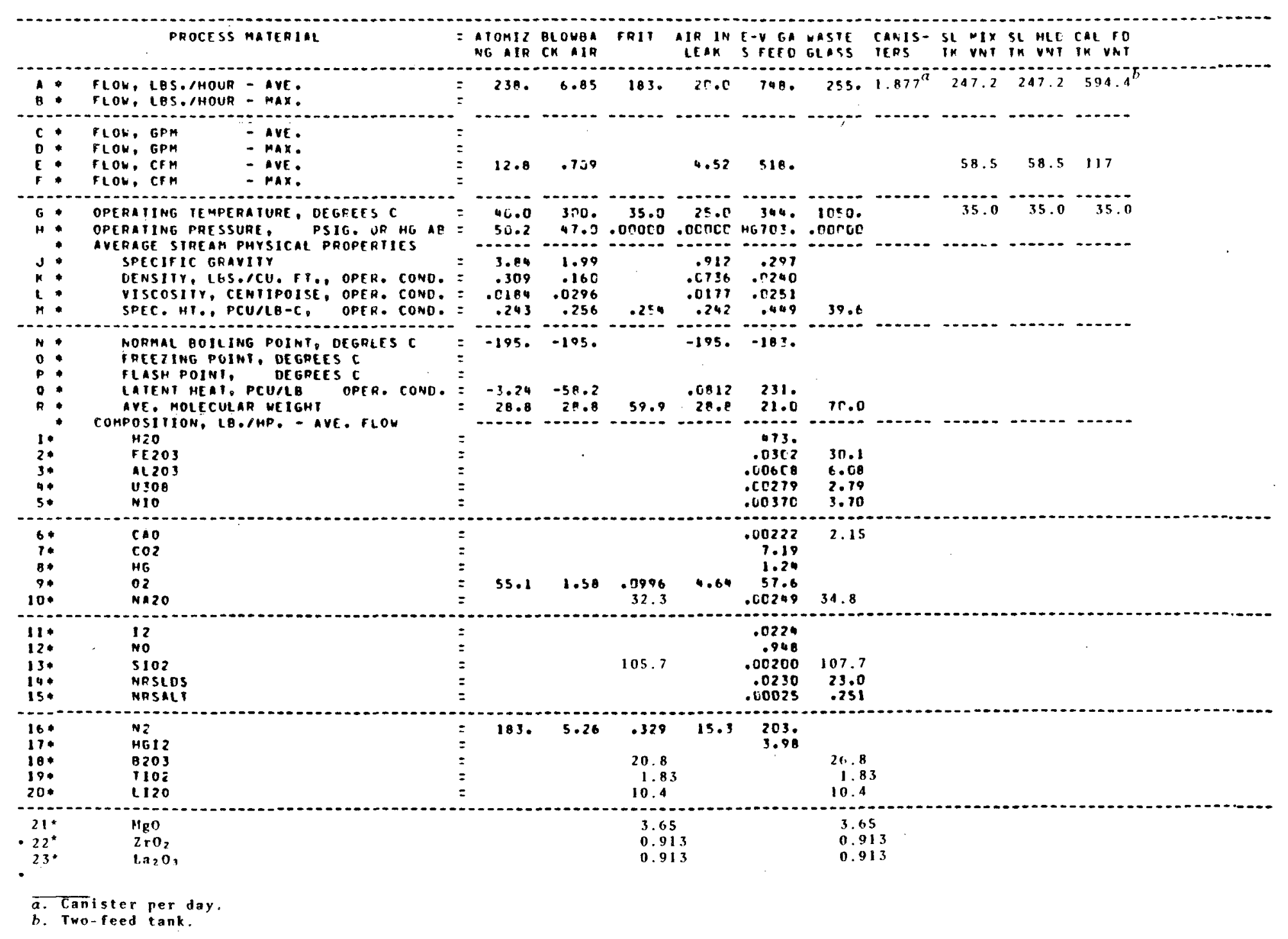


TABLE 4.6

OFF-GAS TREATMENT (MB-6)

PROCESS MATERIAL

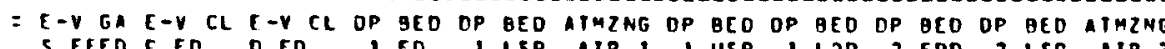

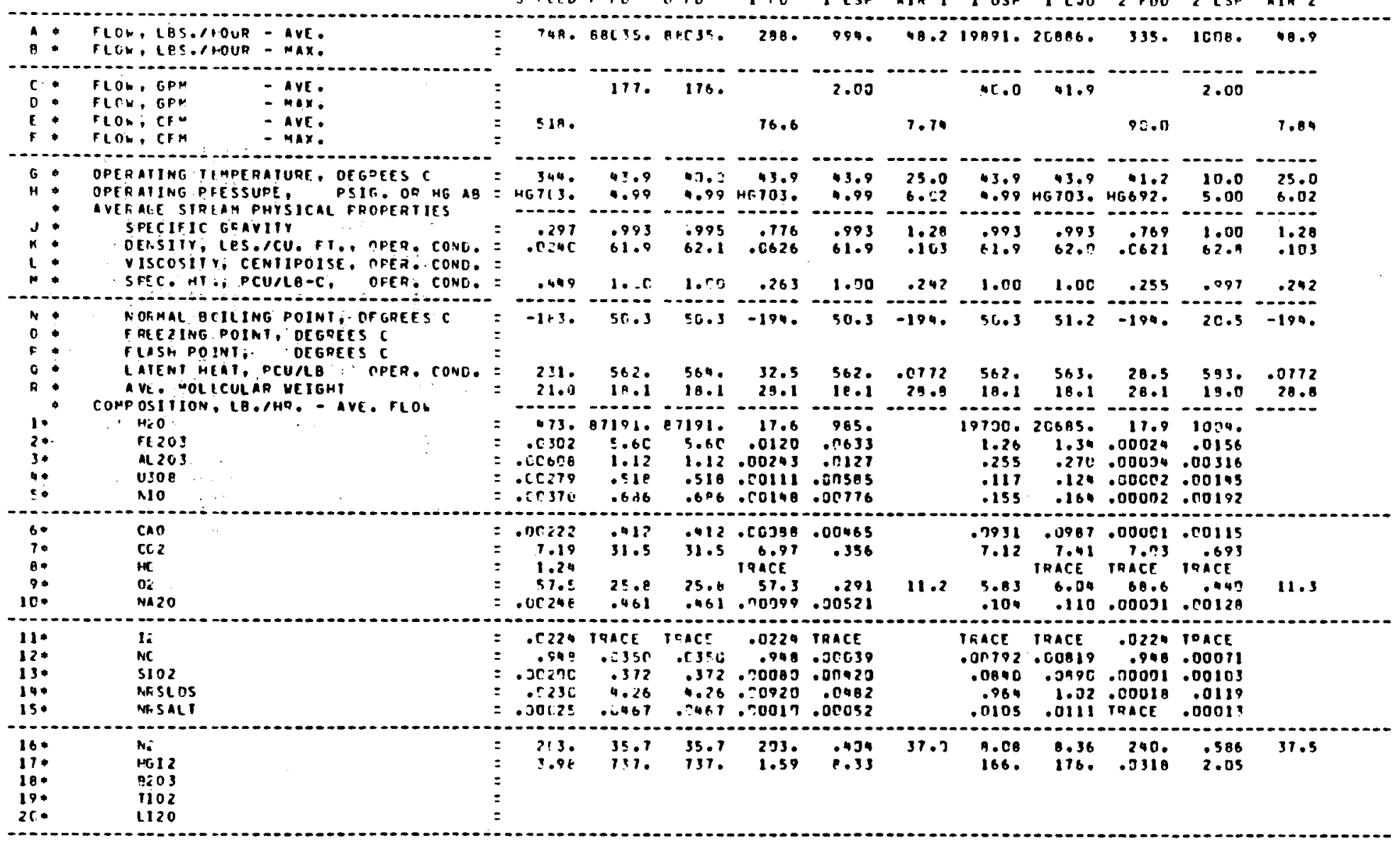


TABLE 4.6 CONT'O

OFF-GAS TREATMENT (MB-6) $=12 \quad 13 \quad 14 \quad 15 \quad 16 \quad 17 \quad 18 \quad 19 \quad 20 \quad 21 \quad 22 \quad 23 \quad 24$

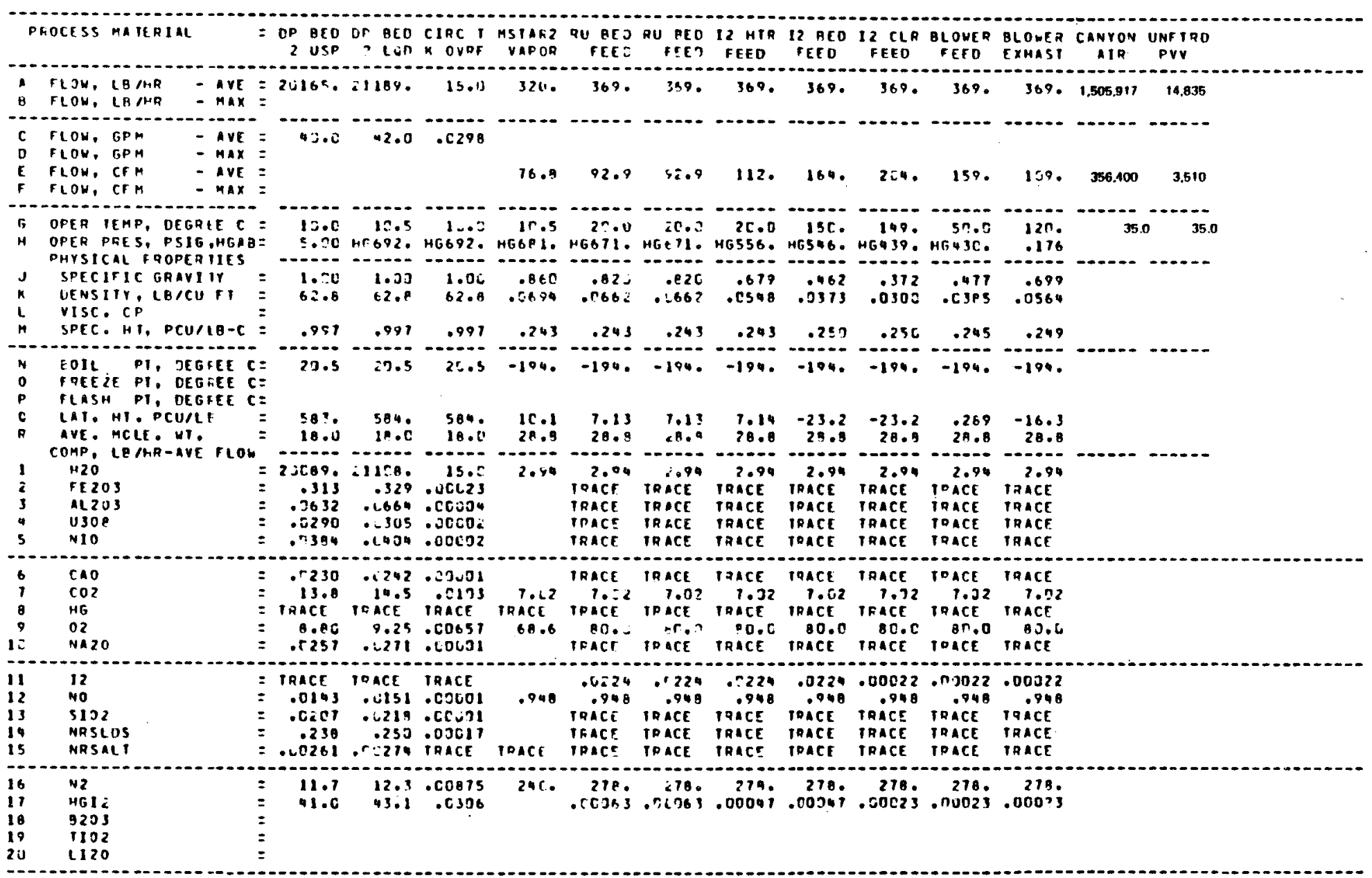


TABLE 4.6 CONT'O
OFF-GAS TREATMENT (MB-6) $=\begin{array}{llllll}25 & 26 & \text { a } & 26 & 29 & \text { 3 }\end{array}$

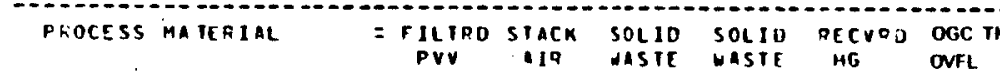

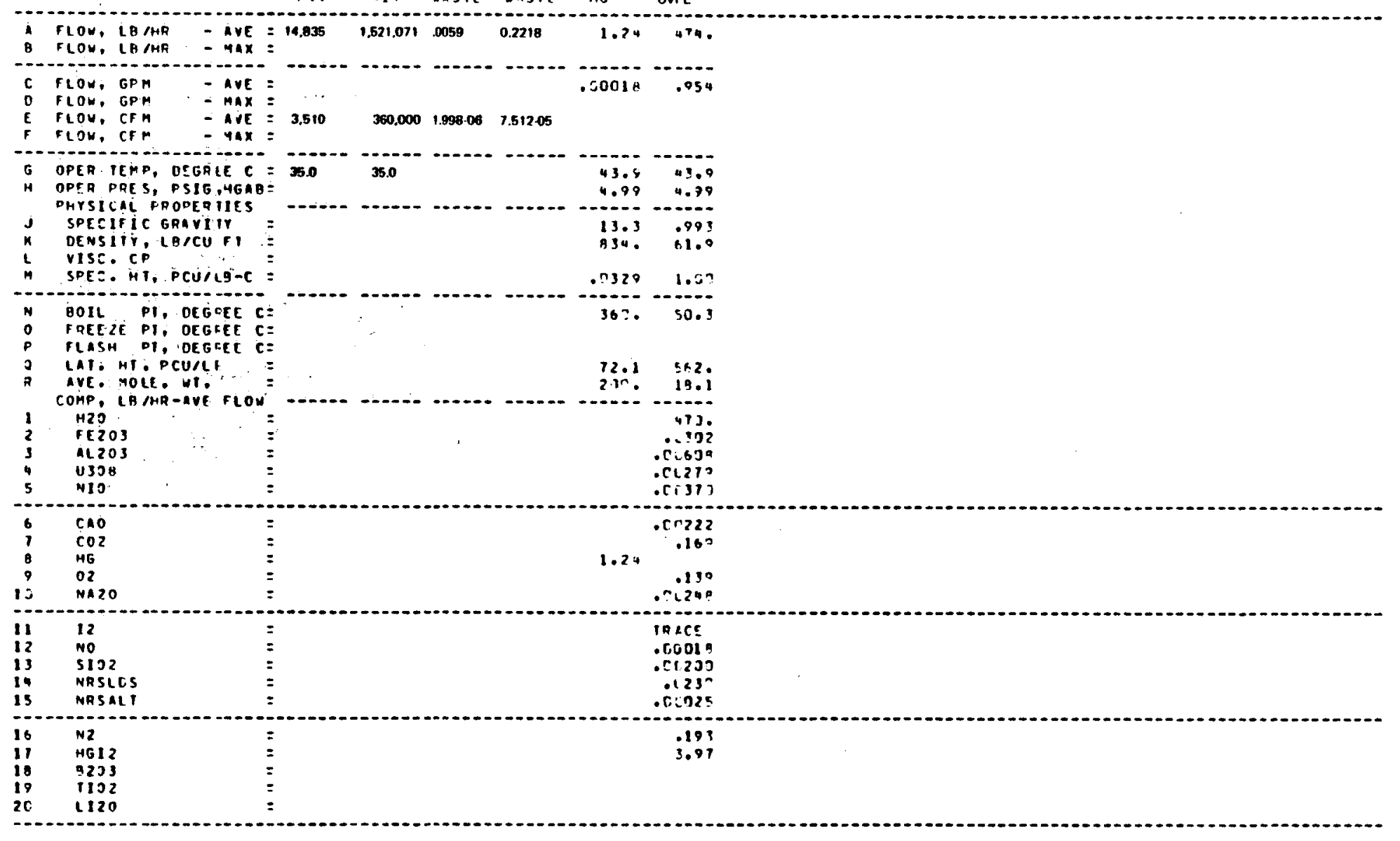


TABLE 4.6 CONT'O

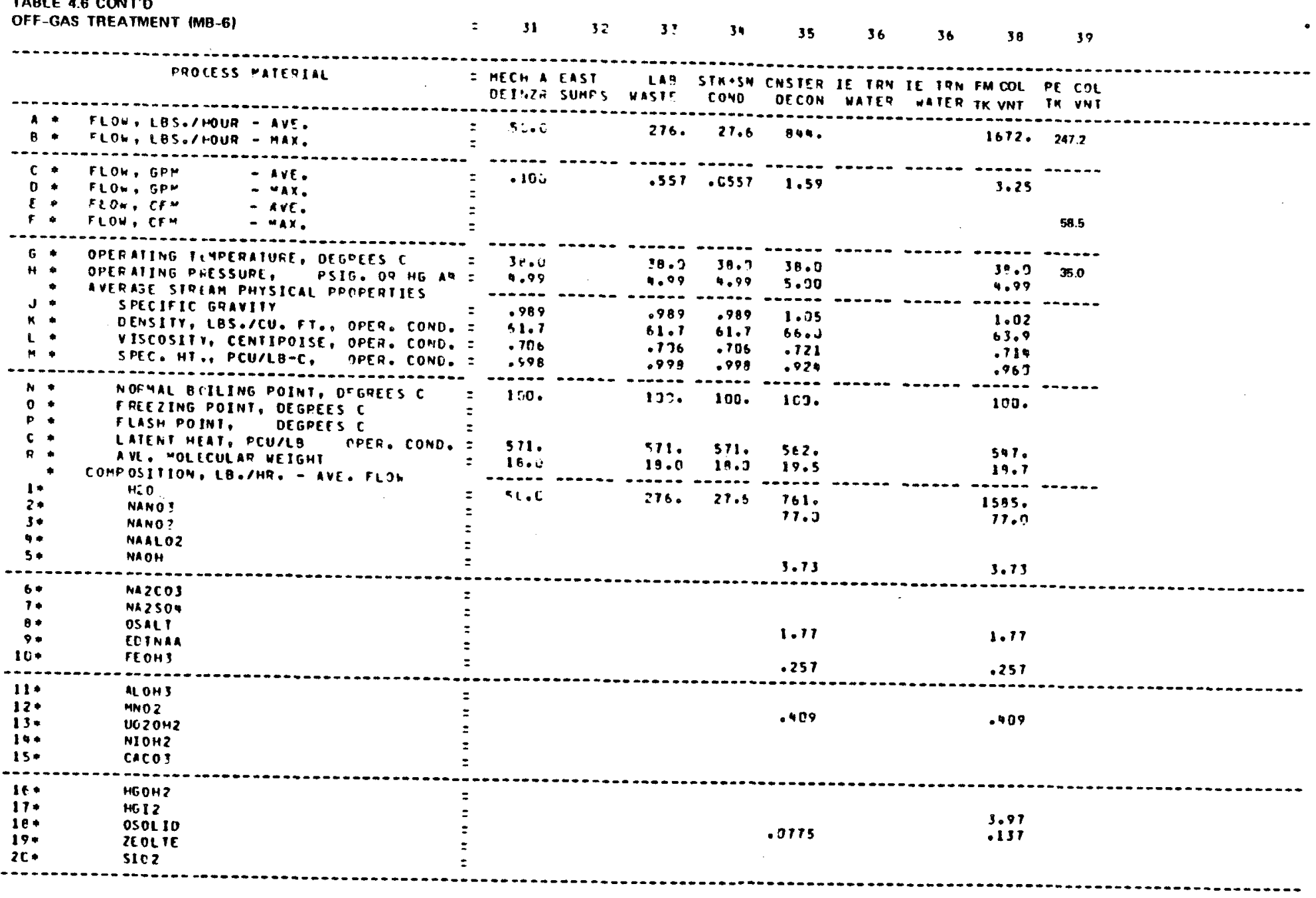


TABLE 4.7

RECYCLE EVAPORATION (MB-7)

process material

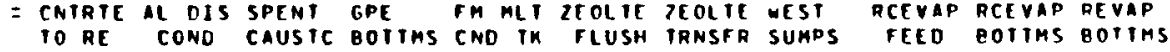

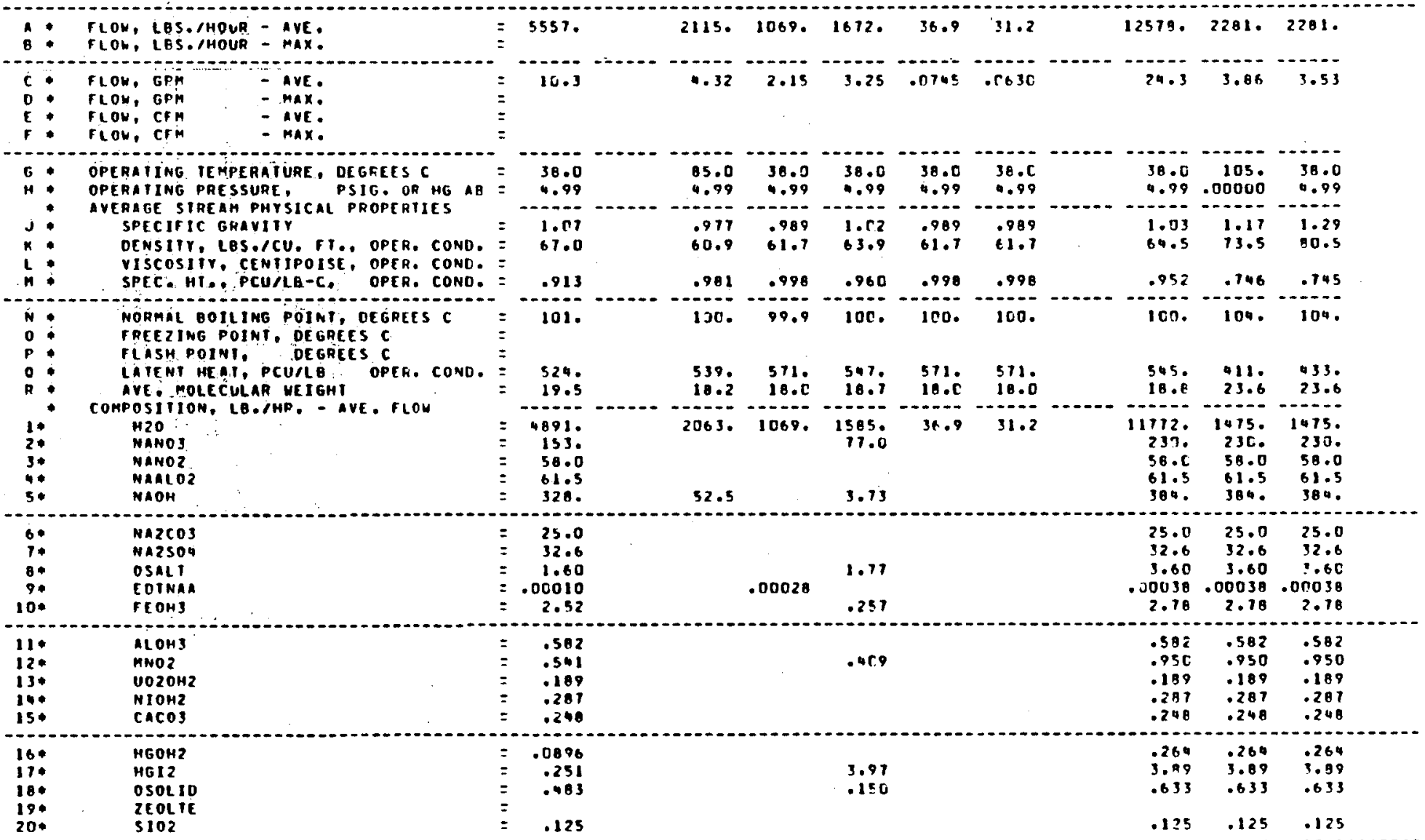


TABLE 4.7

RECYCLE EVAPORATION (MB-7) (Contd)

$\begin{array}{lllllll}17 & 13 & 14 & 15 & 14 & 17 & 18\end{array}$

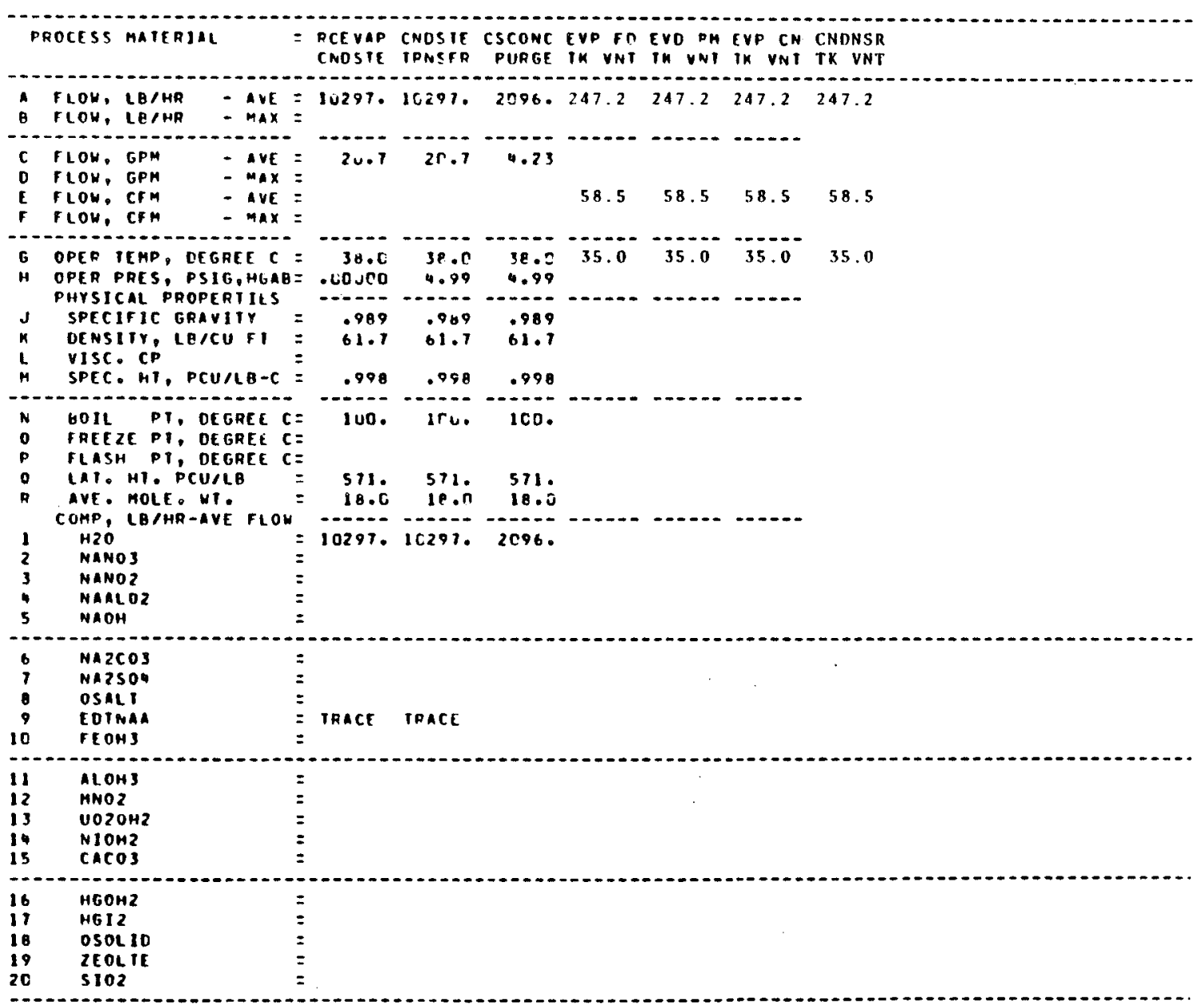


TABLE 4.8

SETTLING AND FILTRATION (MB-8)

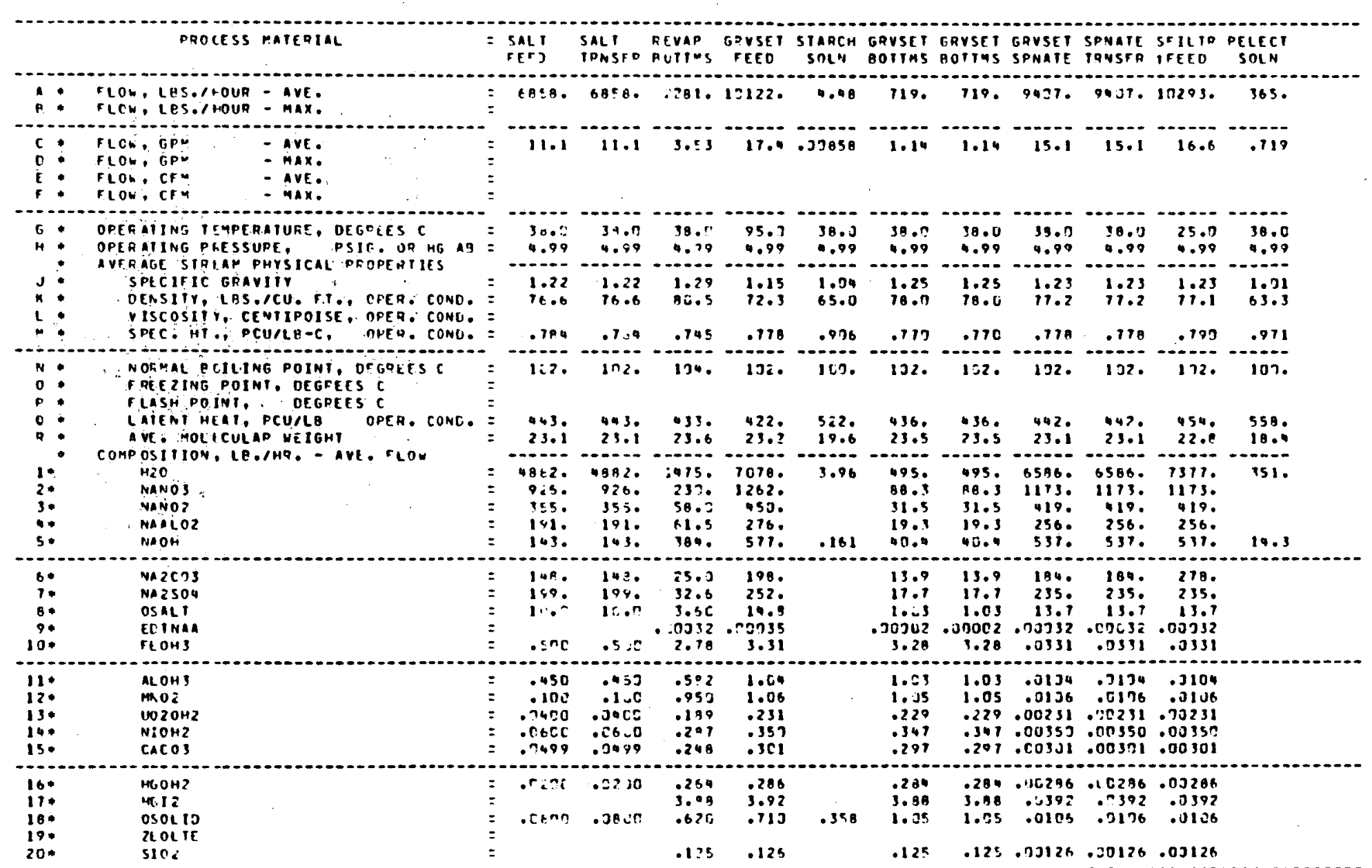




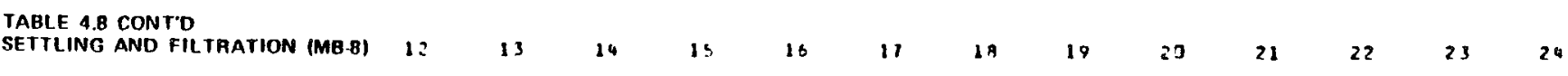

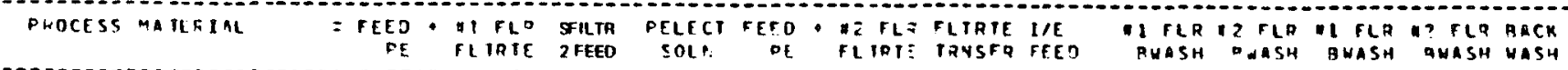

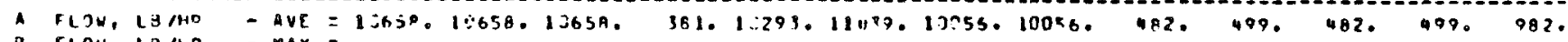
B FLON, LB/HR - AMX

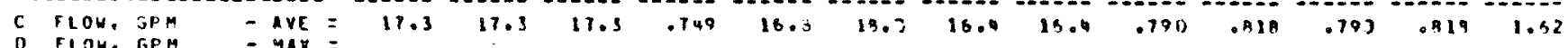

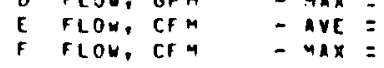

6 OPER IEMP, DEgRIE $C=25,5250$

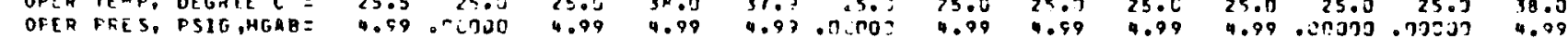
PHYSICAL FDOPERTIES

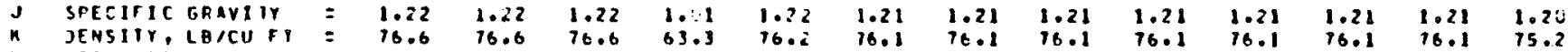

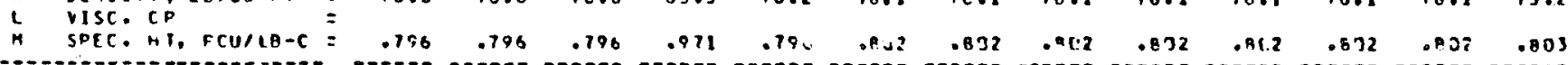

$N$ HOIL PI, OEGHEC $C=102,102,162,151,102,102.102,102,102.102 .102 .122 .102$.

P TLASH PI, OEG

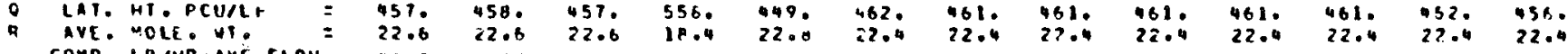

COMP, LOGHR-AVÉ FLON

HzO

Nanos

NANOZ

NAOH

$=7128.7128 .7129 .366 .737$

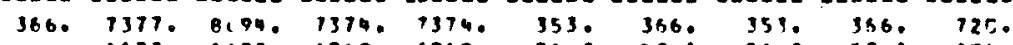

3 NAOH $=$

419.419 .419$.

$551.5510 \quad 531 . \quad 14.9$

Narcos

Nas 05

corman

256.56 .234 .214$.

278.78 .278$.

235.7235 .735 . 13.7

$\cdot \cos : 2 \cdot \cos 32 \cdot \cos 32$

278021802540254012.1212 .6

TCOH3

.0311 .0331 .00331

235. 214. 214. 15.2 $10.6 \quad 10.2 \quad 10.6 \quad 20.9$

11 ALOHS

.3164 .02154 .00134

.01c2

.00350 . run3s .00035

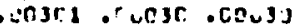

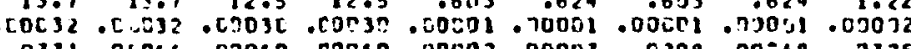

14 NIOHE

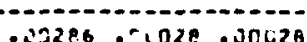

$010+0.025$

.23286 - 1028.00628

.0100 .0100 .00130

4612

OSOL10

$2 \mathrm{E} 0 \mathrm{CL}$
5102

$=.00120 .06017 .00012$

.0100 .0 rn231 O

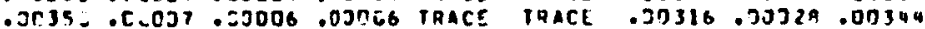

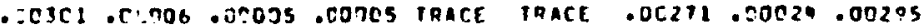

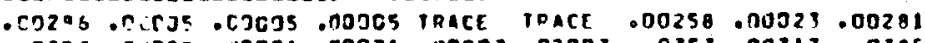

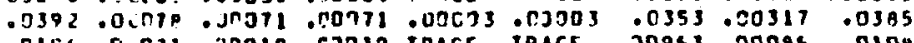

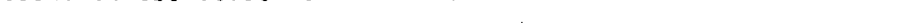

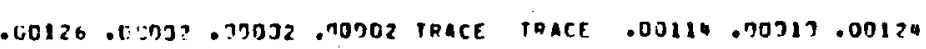


TABLE 4.8 CONT'D

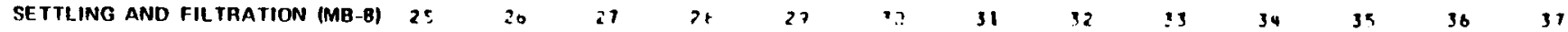

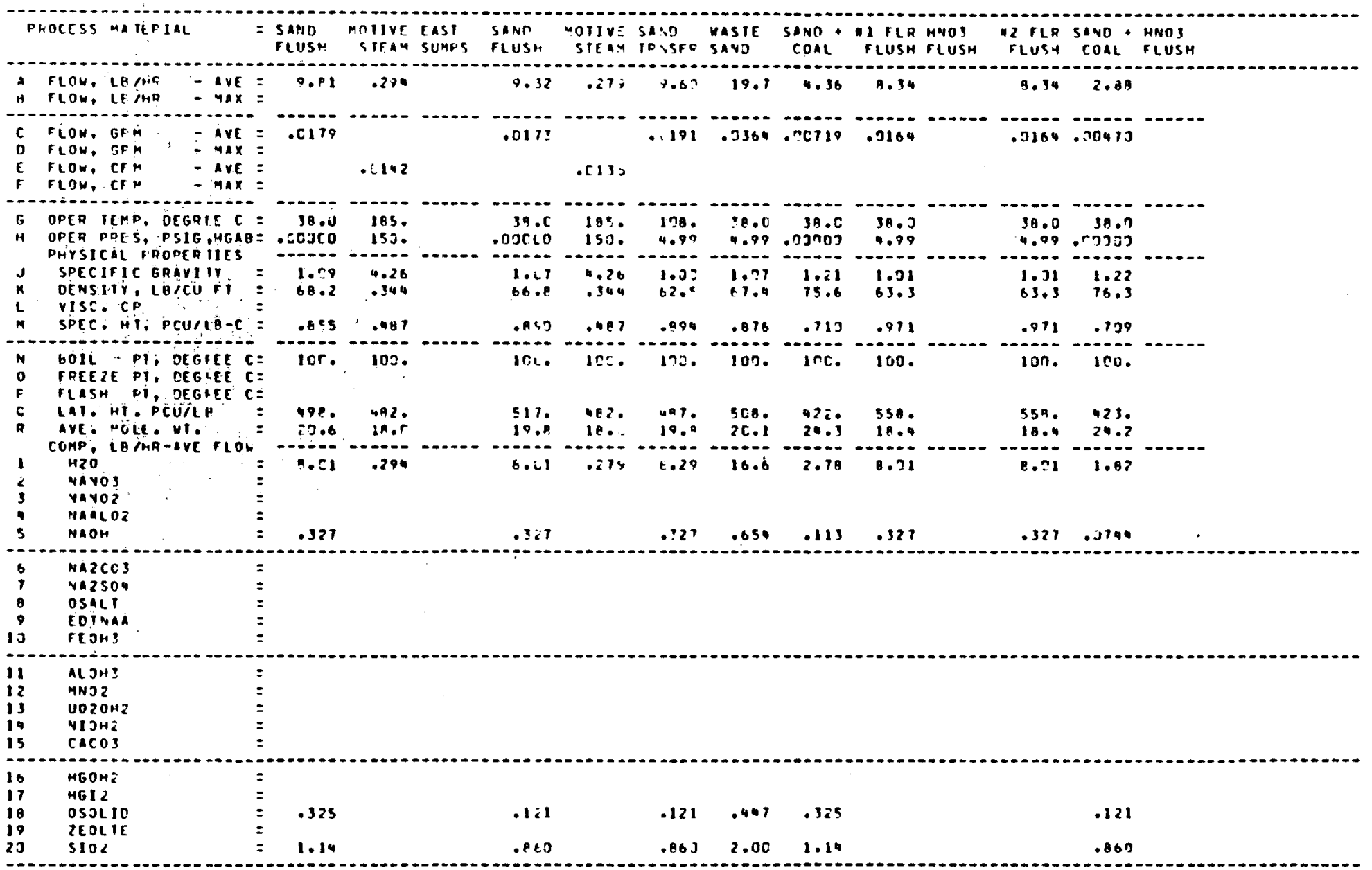


TABLE 4.8 CONT'D

SETTLING AND FILTRATION (MB-8)

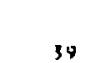

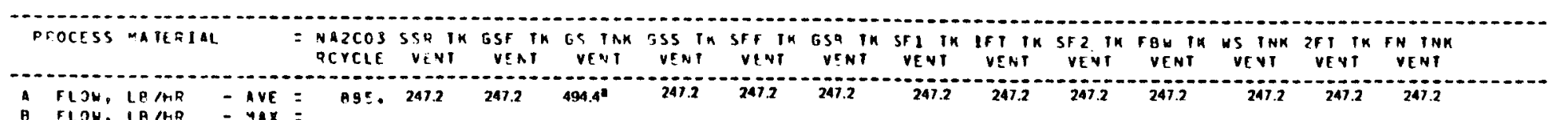

B FLOW. LAMR - YAX =

C FLOW. SFH - AVE $=1.65$

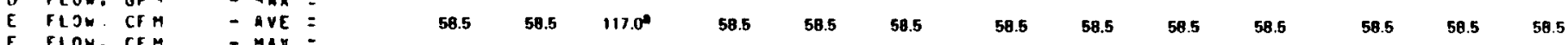

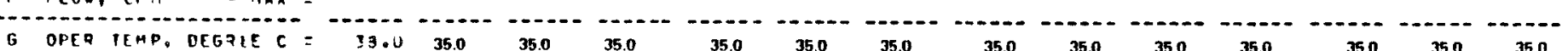

H OPEA PQE S, PSIG HGAB $=4.99$

PHYSICAL FSODE QIIES

SPECIFIC GRAVIIY $=1.7 .6$
DENSTYY, LB/CU FT $=6 B .6$

VISC. C

$N$ GOIL PI, CEGLE $C=13$.

FDEEZE PT, CESHEE C=

LAI. HI. PCUALE = 250

ave. -oik. Wi. $=19.7$

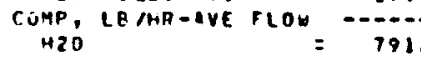

H
2

NANOS
NAYOZ

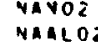

NAOH

vazcos

vas 2504

OSALI

FEOH:

11 MLOH3

12 MNO2

i. $\mathrm{NO2OH2}$

is CACOS

16 HGOHZ

$\begin{array}{ll}17 & \text { HGI2 } \\ 18 & 050 \mathrm{C}\end{array}$

18 OSOLIO

$2 \mathrm{c} 510 \mathrm{c}$

- Iwo previly senters.

791.

$$
94.0
$$

$=$


TABLE 4.9

CESIUM ION EXCHANGE (MB-9)

$=$

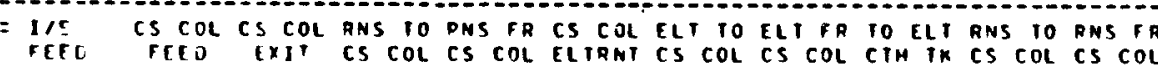

process mateaial

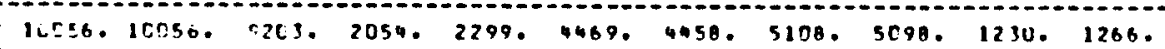

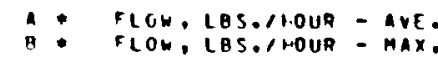

c FlCh GPM - ave.

D rLCN, GPM

E FLCH, CrF

LOW. CFr - MAX.

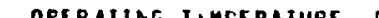

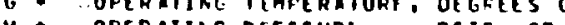

OPERATINS PRESSURE, PSIC. OD HG AB

SPECIFIC GRAVIIY

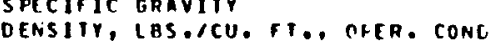

VISCOSIT, CEMTIPOISE, OFEF. CONG:

SPEC. HT., PCU/LB-C, OPEA. COND.

normal paling point, orcaees $C$

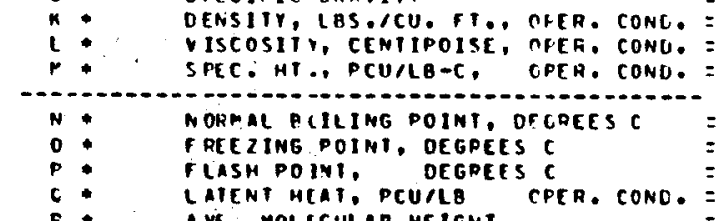

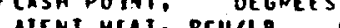

CPER. CONO.

- composition. La.hap. - ave flon

1.

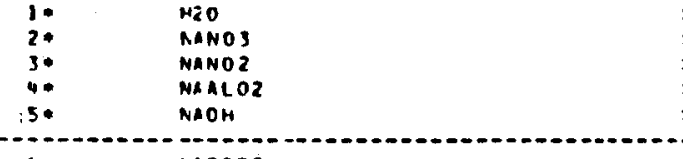

NAzCOJ
Nazson
OSALI

\begin{tabular}{|c|c|}
\hline 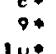 & 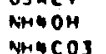 \\
\hline
\end{tabular}

\begin{tabular}{|c|c|}
\hline $\begin{array}{l}11 * \\
12 *\end{array}$ & $\mathrm{NH} 3$ \\
\hline 134 & $\begin{array}{l}\text { COZ } \\
\text { ClinaA }\end{array}$ \\
\hline
\end{tabular}

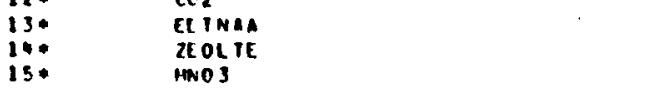

16.

17. $\quad$ N2

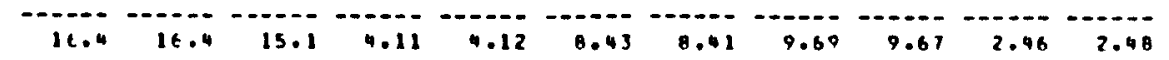
$=$

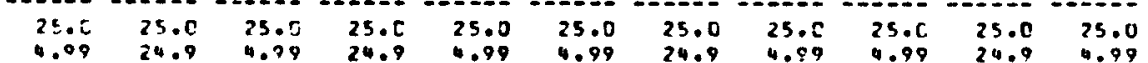

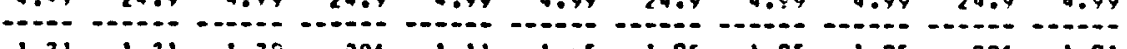

$\begin{array}{lllllllllll}1.21 & 1.21 & 1.22 & 096 & 1.11 & 1.05 & 1.05 & 1.05 & 1.05 & 0996 & 1.01 \\ 76.1 & 76.1 & 75.5 & 62.2 & 89.5 & 66.0 & 66.0 & 65.7 & 65.6 & 62.2 & 63.5\end{array}$

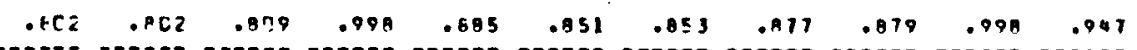

1r2. 1r2, 102, 1nc. 101, 102, 102, 101, 101. 100.100

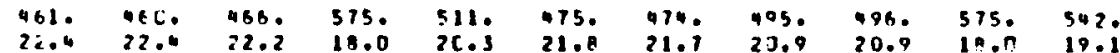

220
7170

1719. 1369. 931. 131.

$361.03510 \quad 132.0$

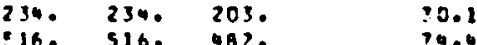

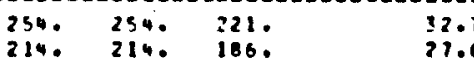

$214: 5214: 5186.9 \quad 21.6$

$\begin{array}{lllll}287 . & 296 . & 227 . & 229 . & 29.0\end{array}$

encse . ocoso . erse $20 \quad .00003$ 


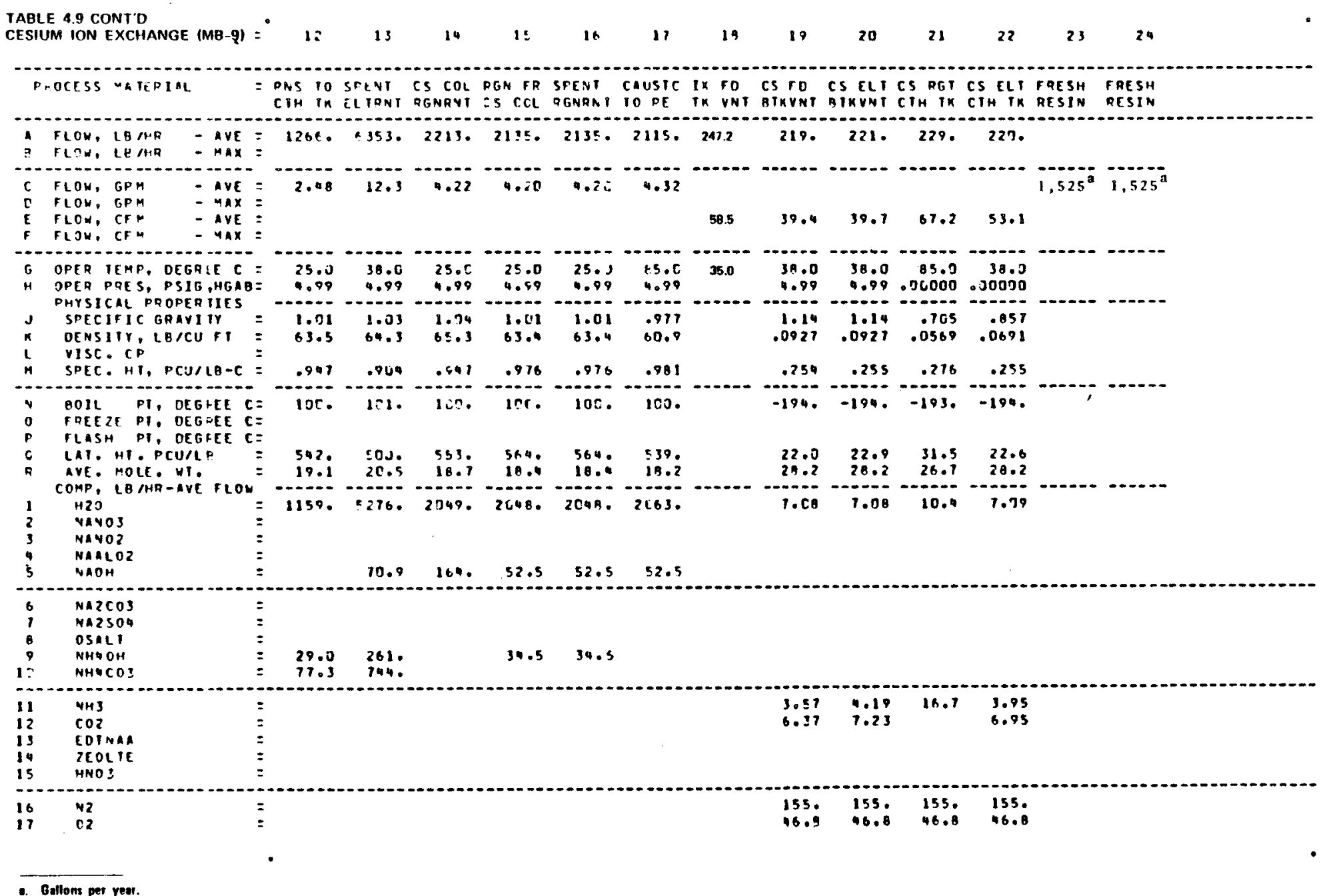


TABLE 4.9 CONT'D
CESIUM ION EXCHANGE (MB-9) : $:^{\circ} 25 \quad 26 \quad 27 \quad 28 \quad 29$

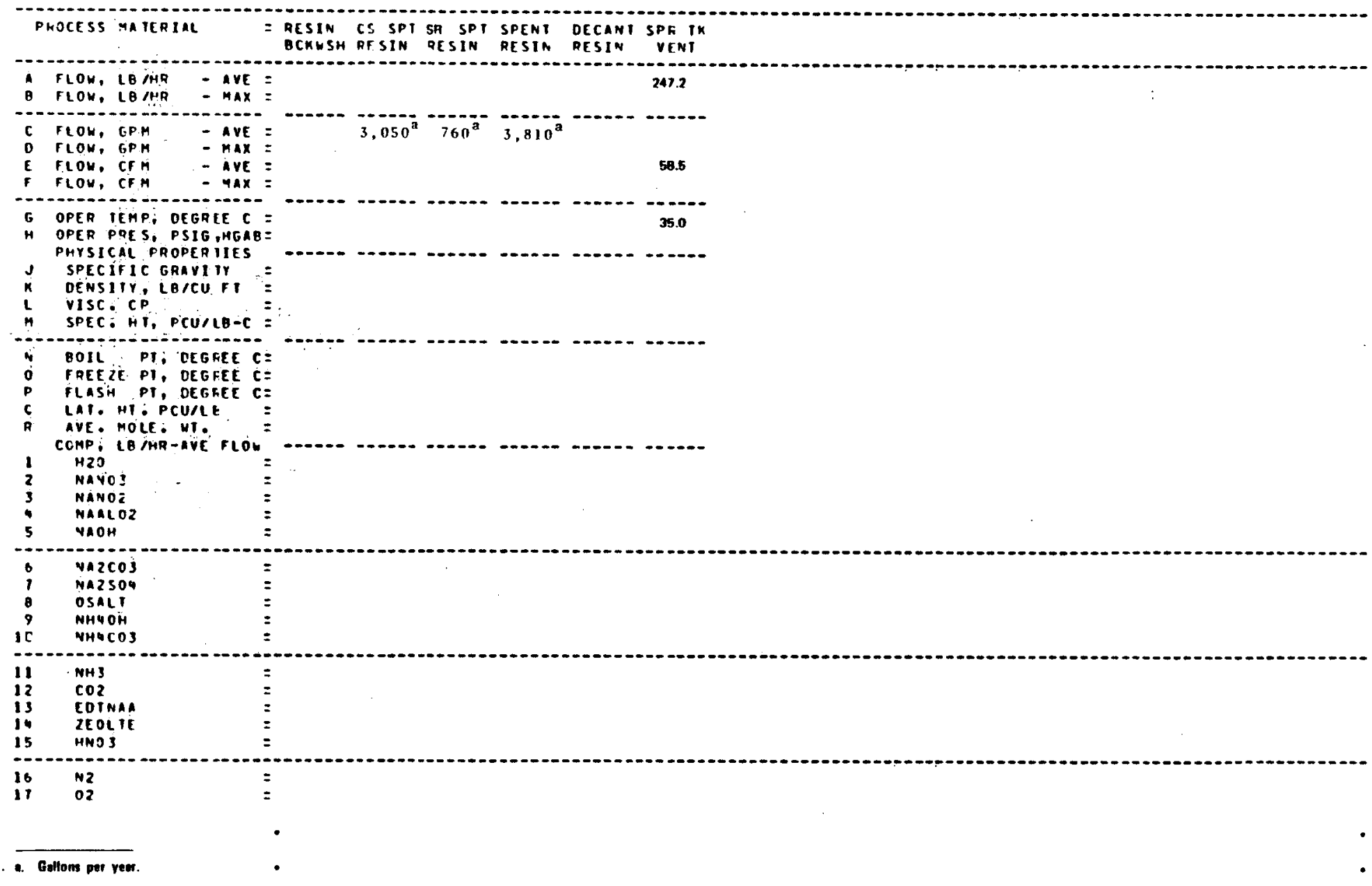




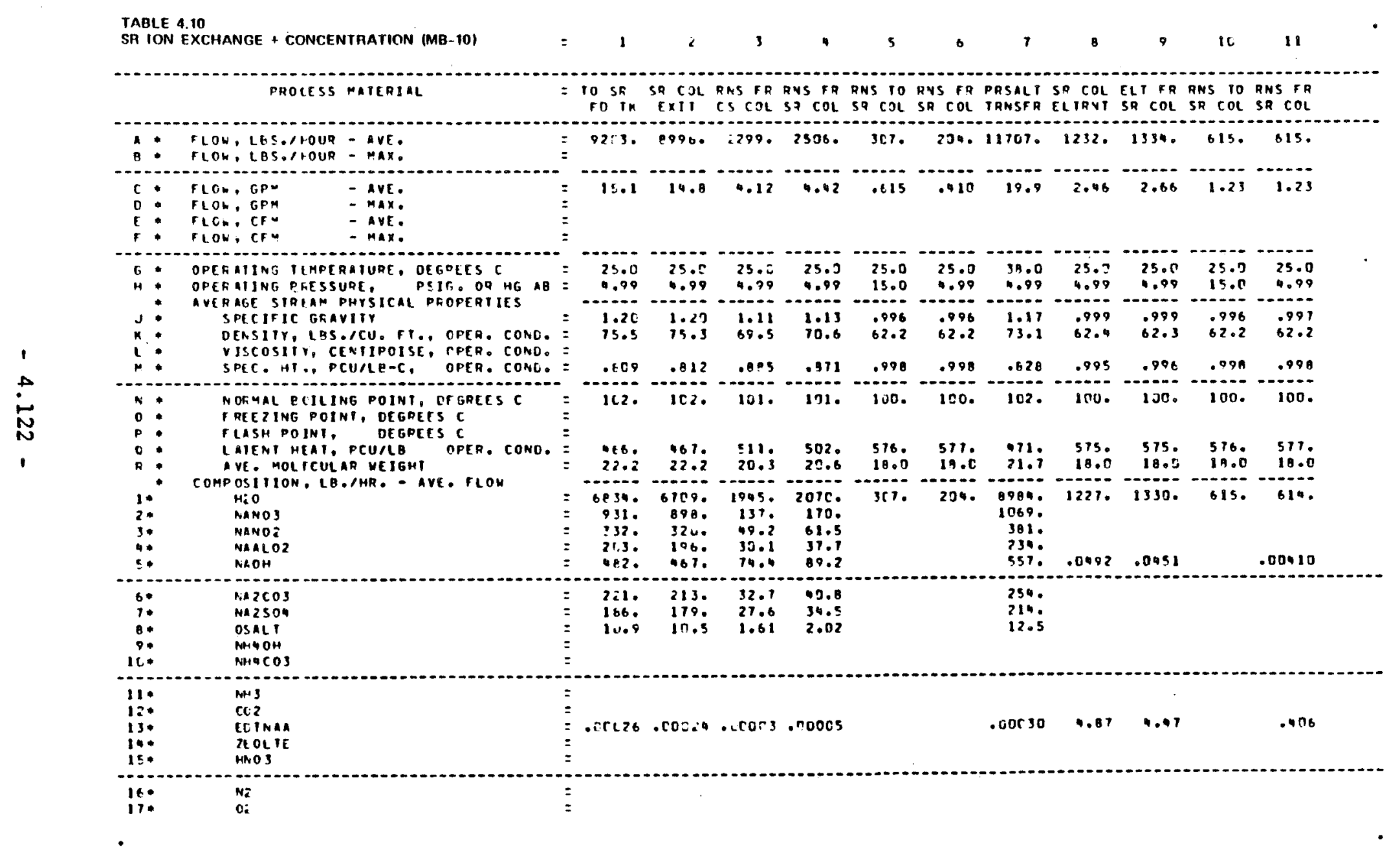


TABLE 4.10 CONT'D

TA ION EXCHANGE + CONCENTRATION (MB-10)

$$
12
$$

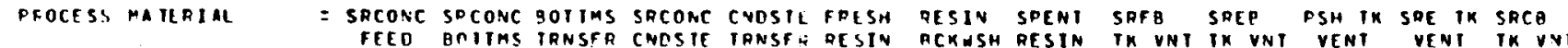

1919

20

21

22

23

24

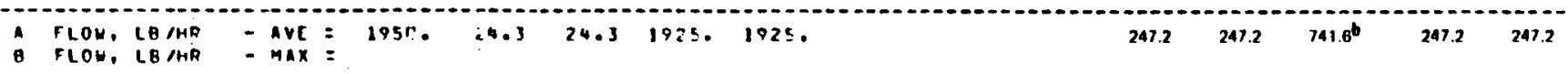

a FON, LBAHR - MAX =

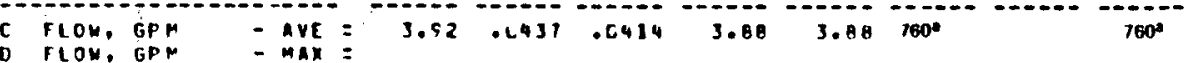

rion, $\operatorname{crs}=\max =$

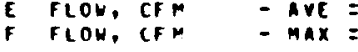

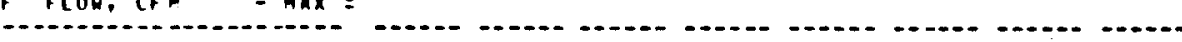

$G$ OPER IEPP, OEGRIE $C=30.0$ 102. 38.6 3P.0 36.0

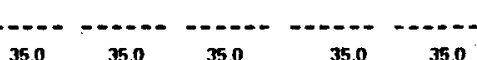

OPER PFES, PSIG pGABE

SPEC1FIC GRAVI1Y $=.901$ 1.11 1.11 .0E9 .989

OENSITY LE/CUFY = 61.869 .473 .261 .761 .1

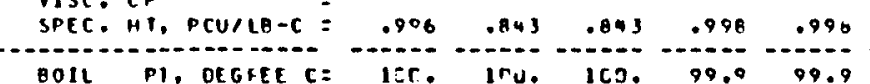

TOEE $2 E$ PI, DEGLE C:

FLASH PY, DEGLEE C

LA1. HI.PCU/LO $=58 \mathrm{C}, 436.461 .571 .571$.

AVE. MCLC UT, $=18.0$ 22.2 22.2 1e.t 18.0

COMP, LE AMR-AVE RLOH $=1944.19 .419 .41925,1925$

1 HzO

Nave:

NAYTCE

NAOH

$.0402 \quad .6452 \quad .0402$

NA2COZ
NAZSOS

OSALI

NHoOH

NHOCOS

$=$

11 NH3

12 COZ

is HNOS

it NZ

- Gellows per vers.

b. Three product sell hold temks. 
TABLE 4.10 CONT'D
SR ION EXCHANGE + CONCENTRATION IMB-10I

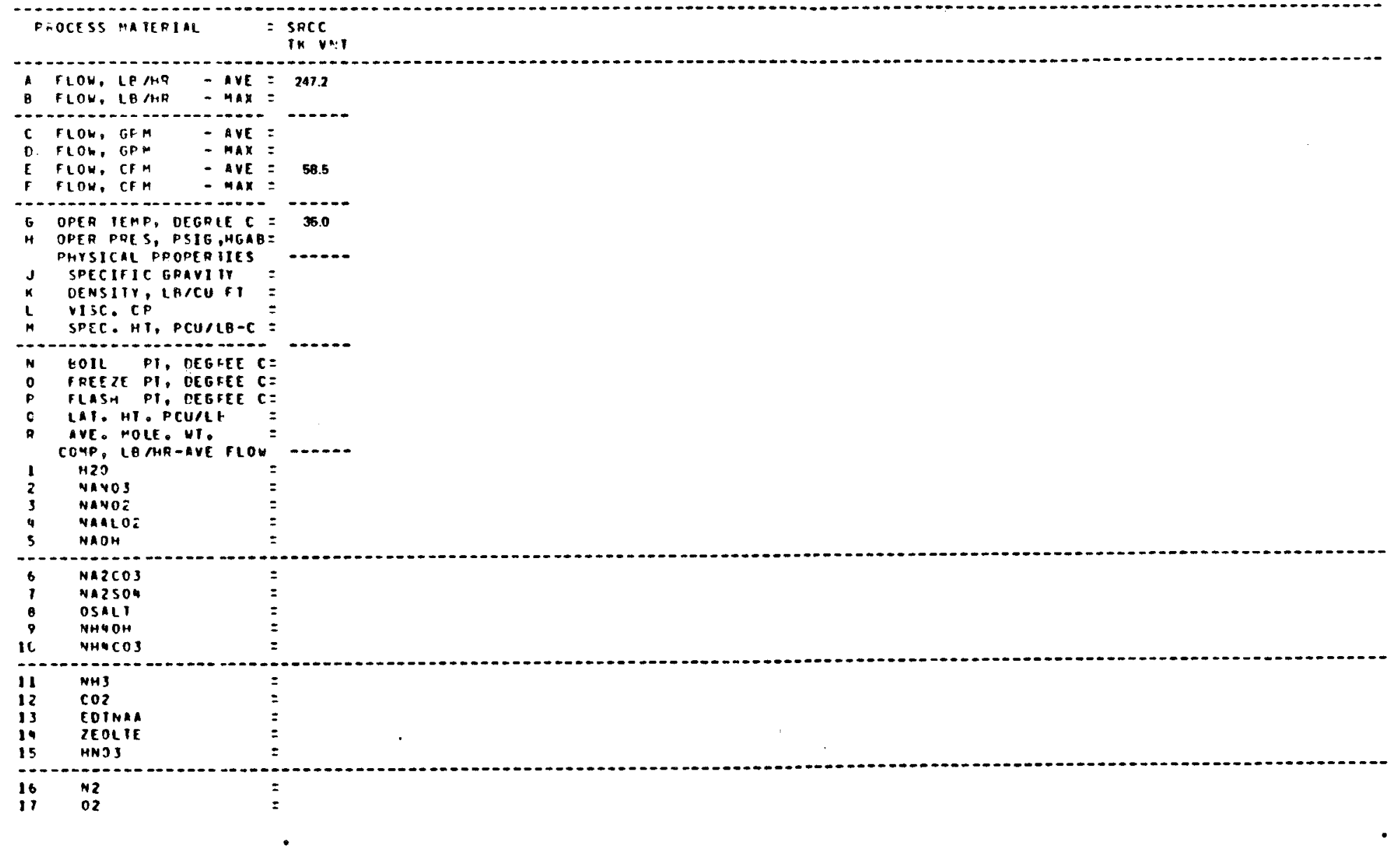




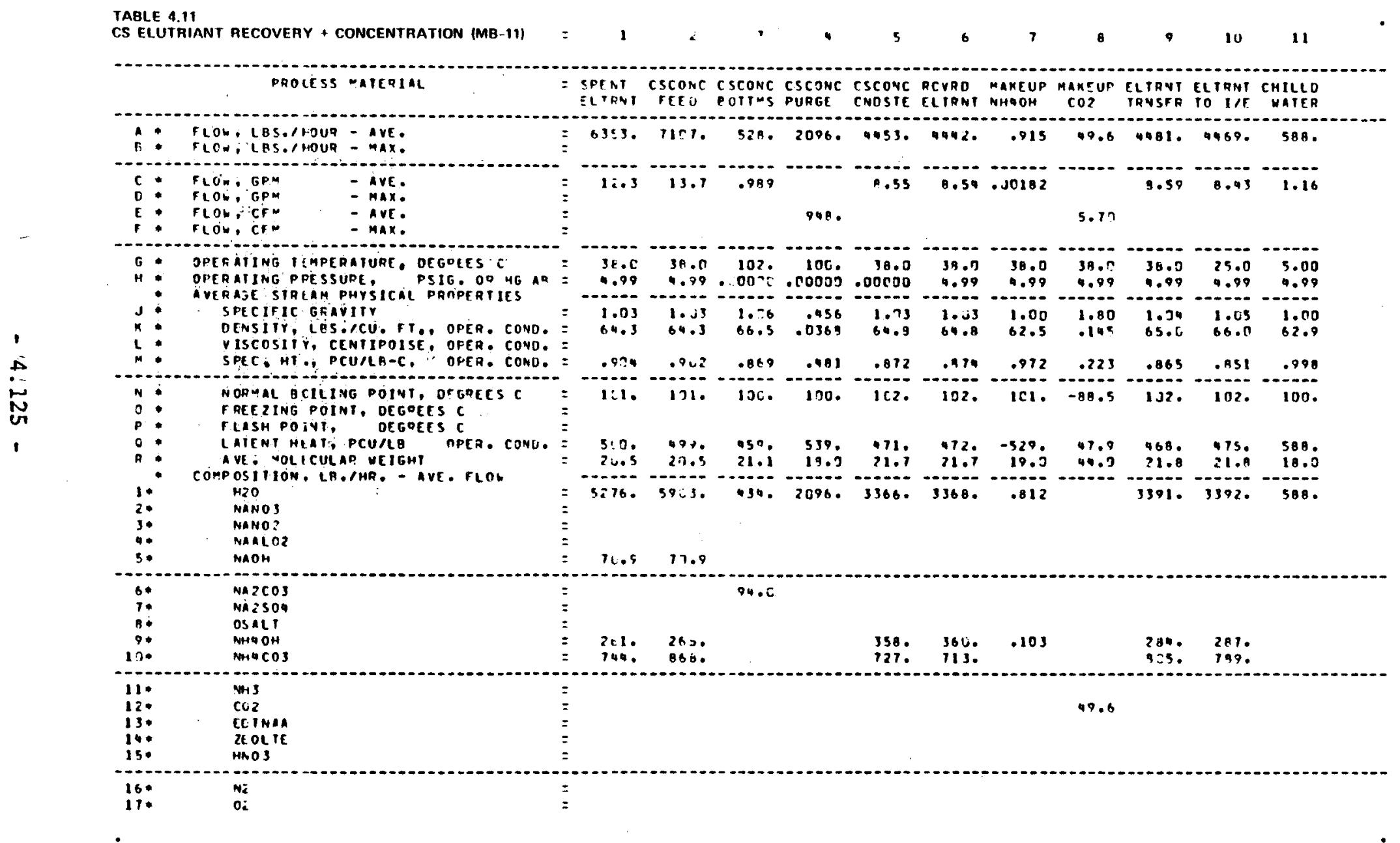


TABLE 4.11 CON T'D

CS ELUTRIANT RECOVEAY + CONCENTAATION (MB-11)

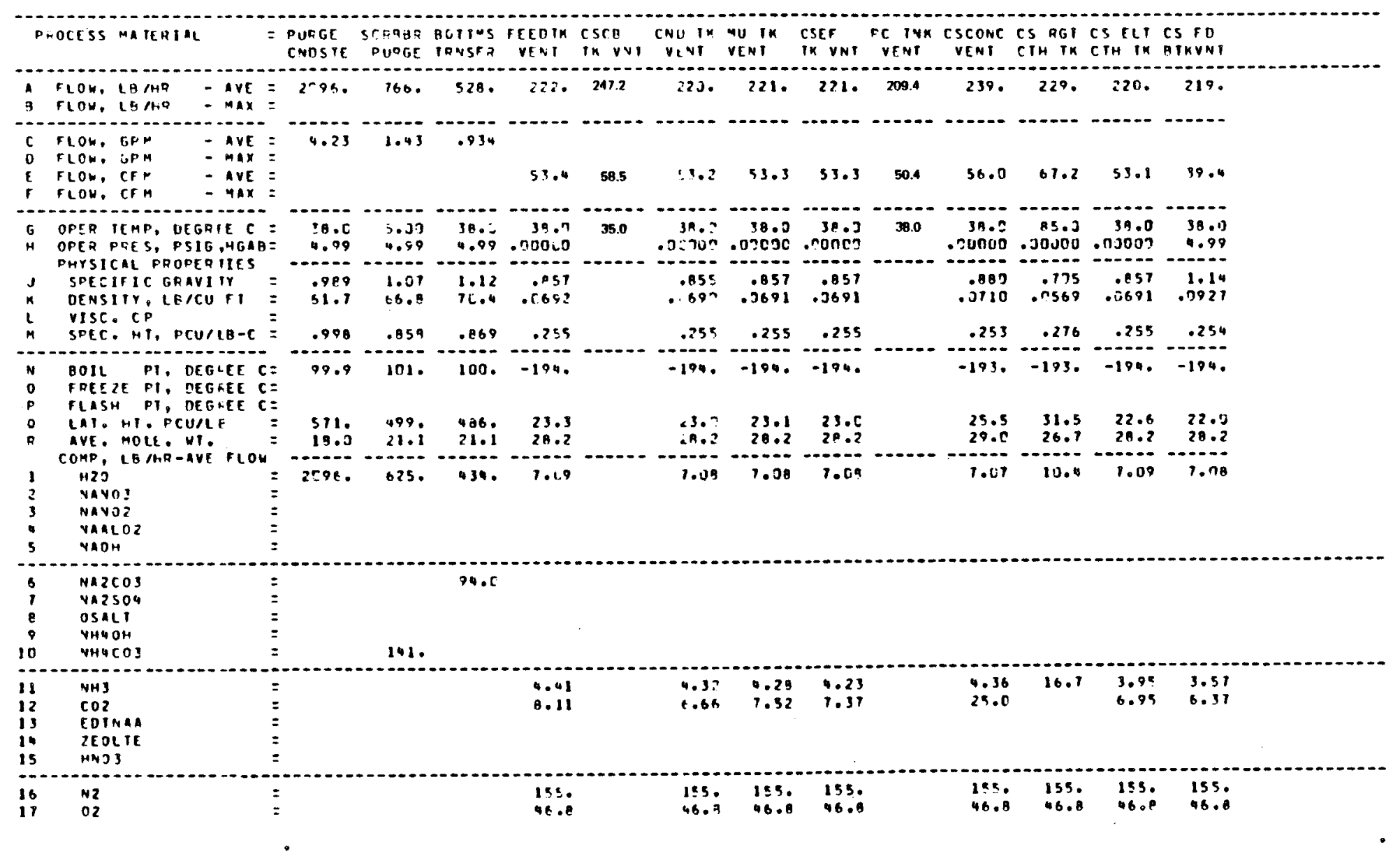




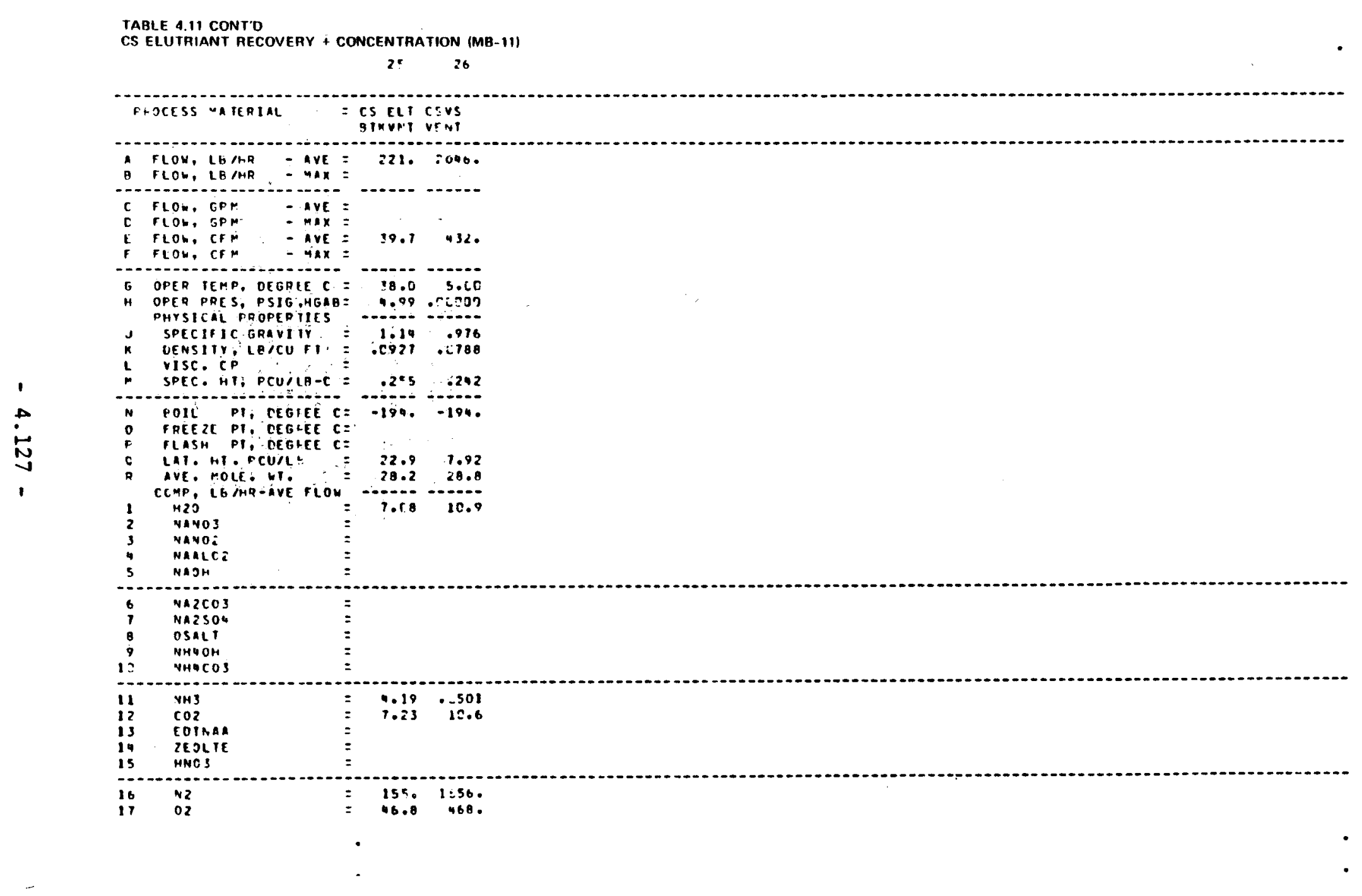




\section{TABLE 4.12}

CS FIXATION ON ZEOLITE (MB-12)

$=$

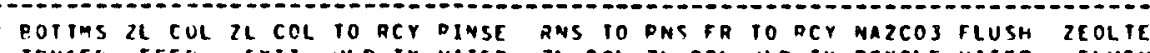
PROCESS VATEDIAL

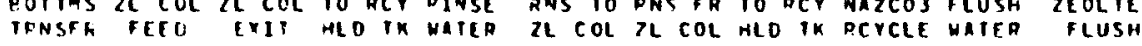

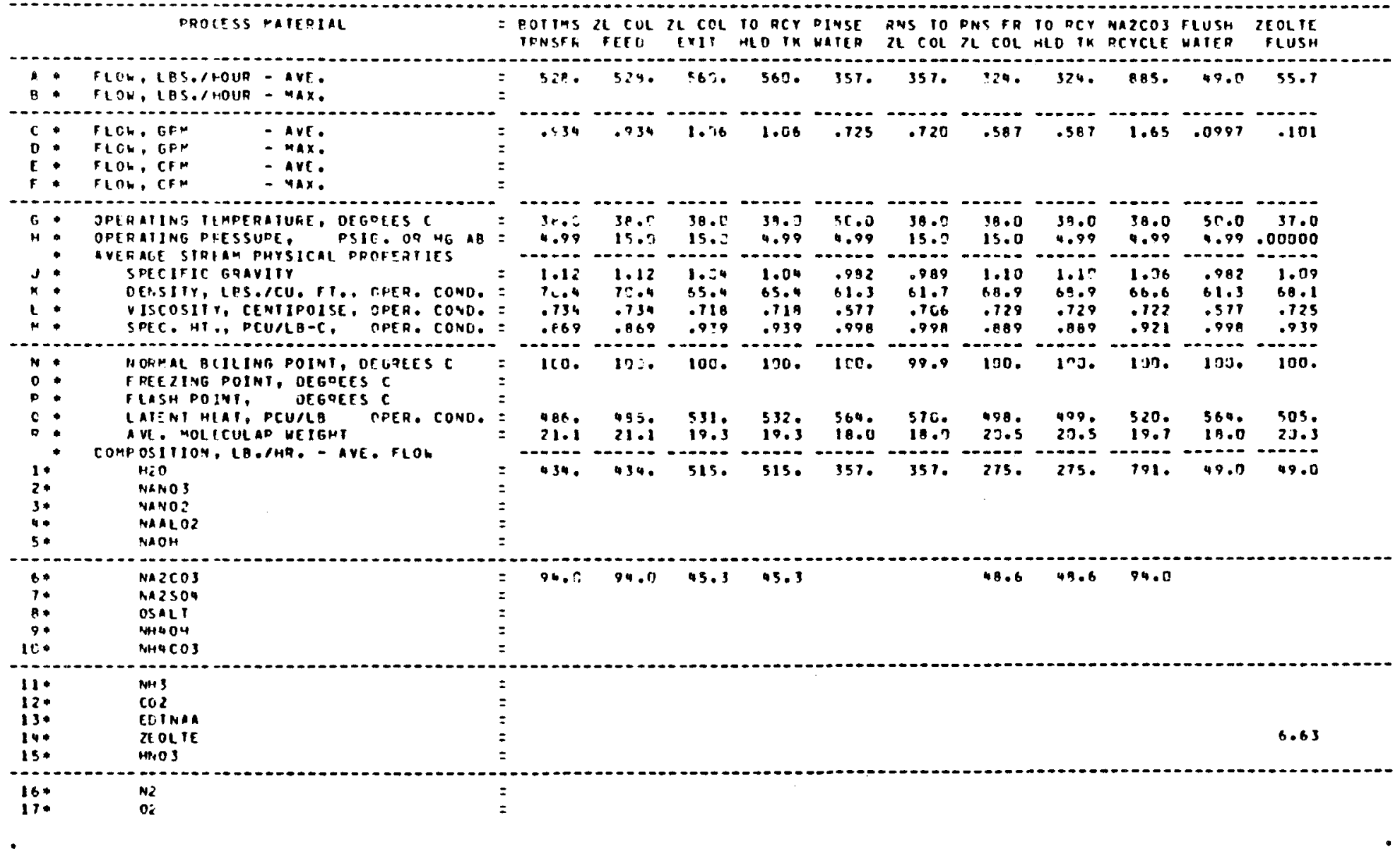


TABLE 1.12 CONT'D

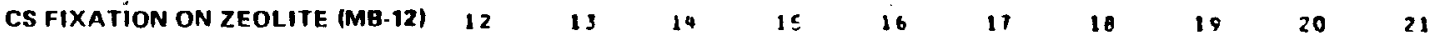

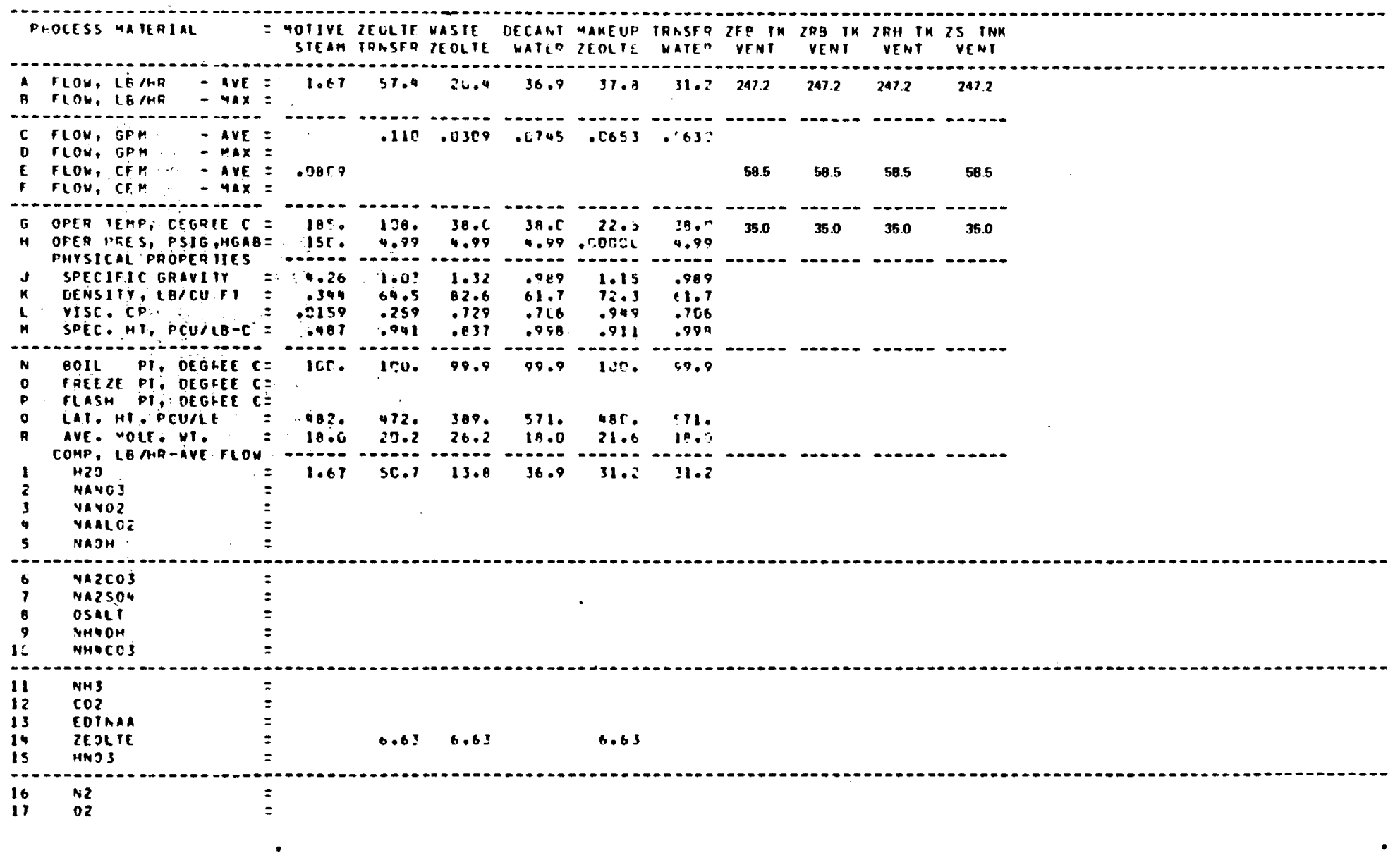


TABLE 4.13

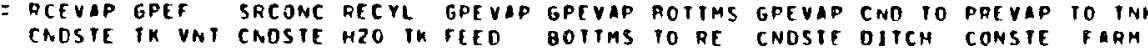

PROCESS MATERIAL

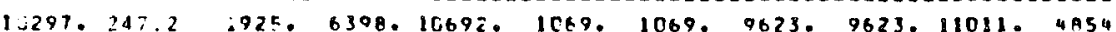

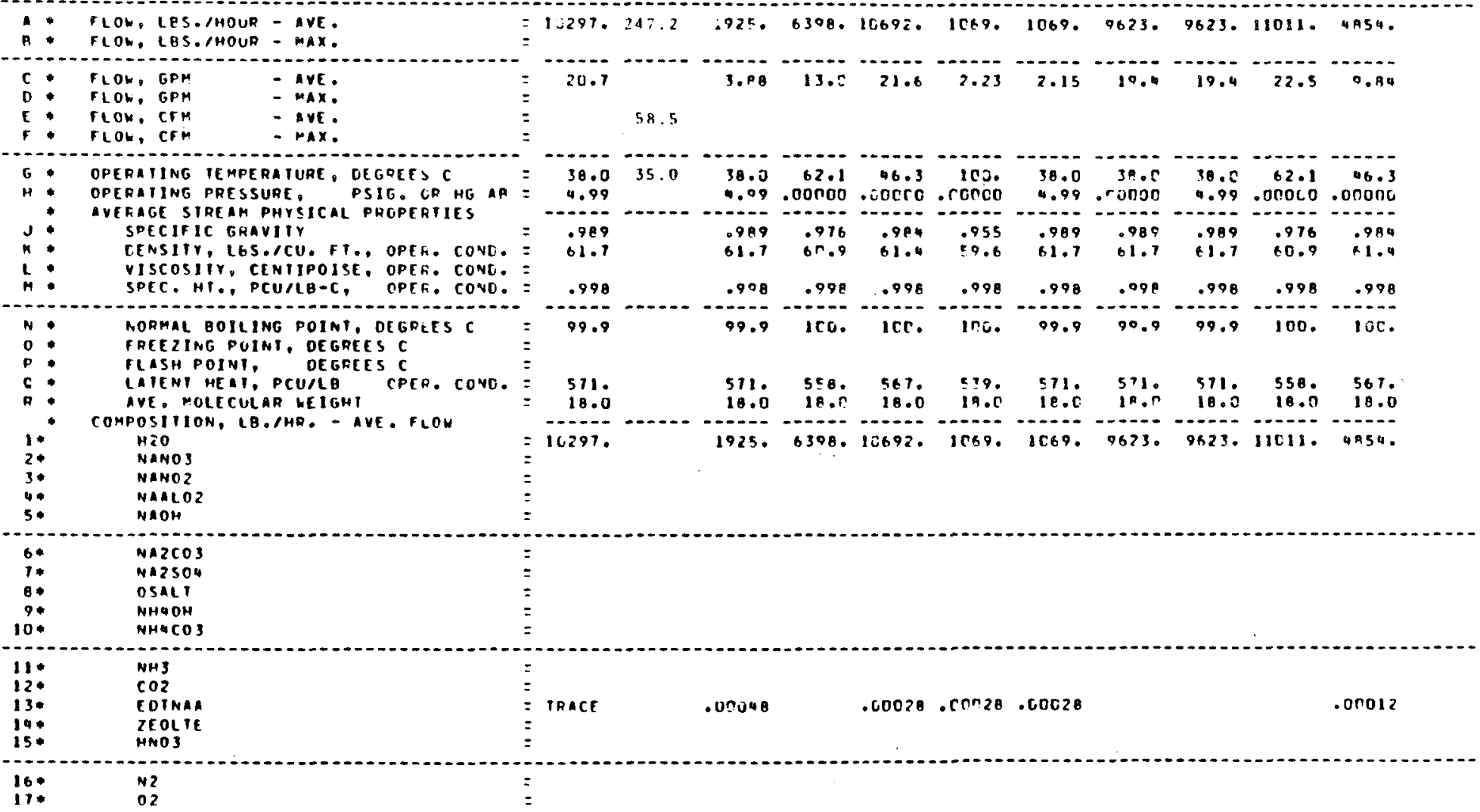




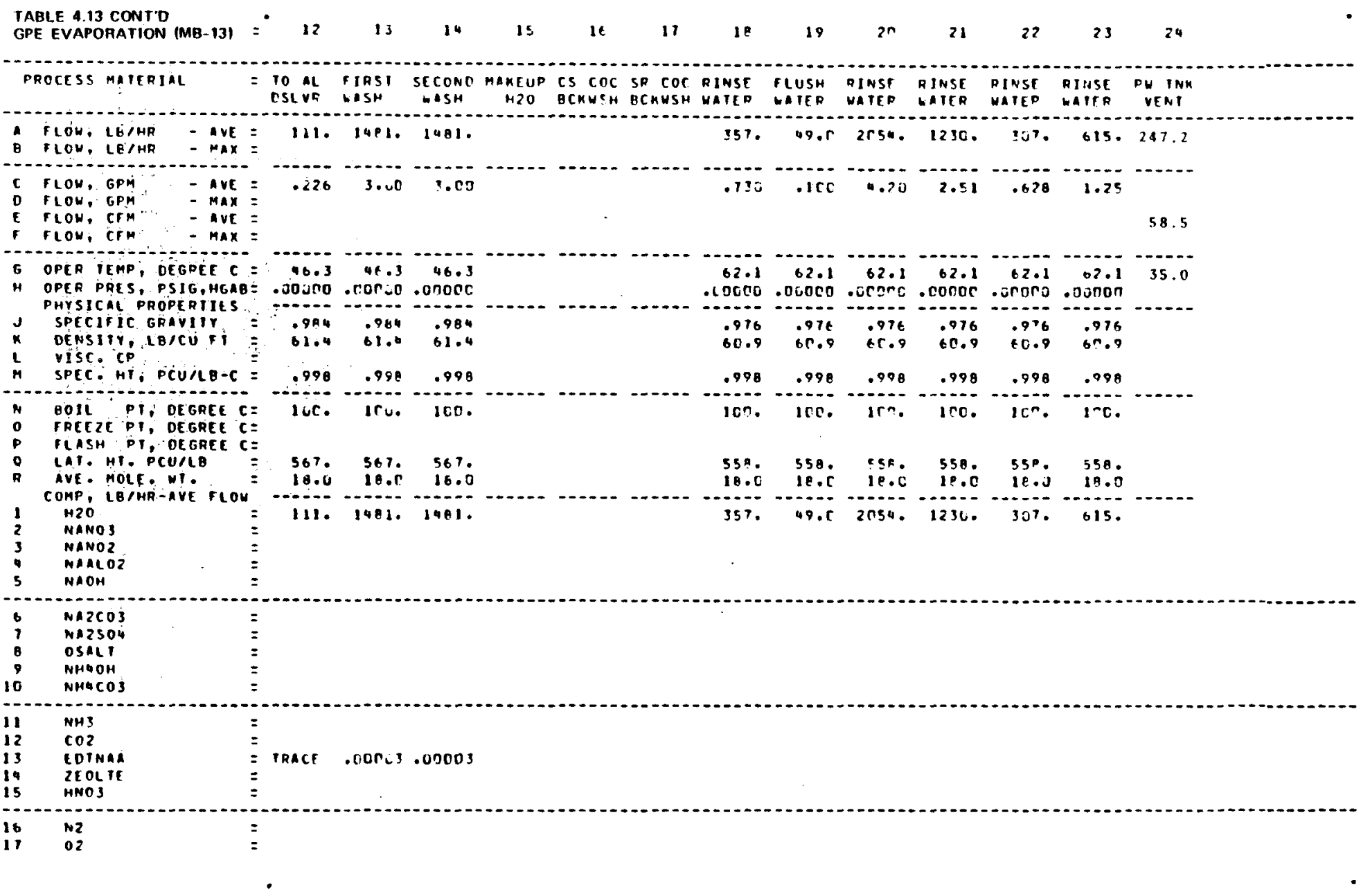




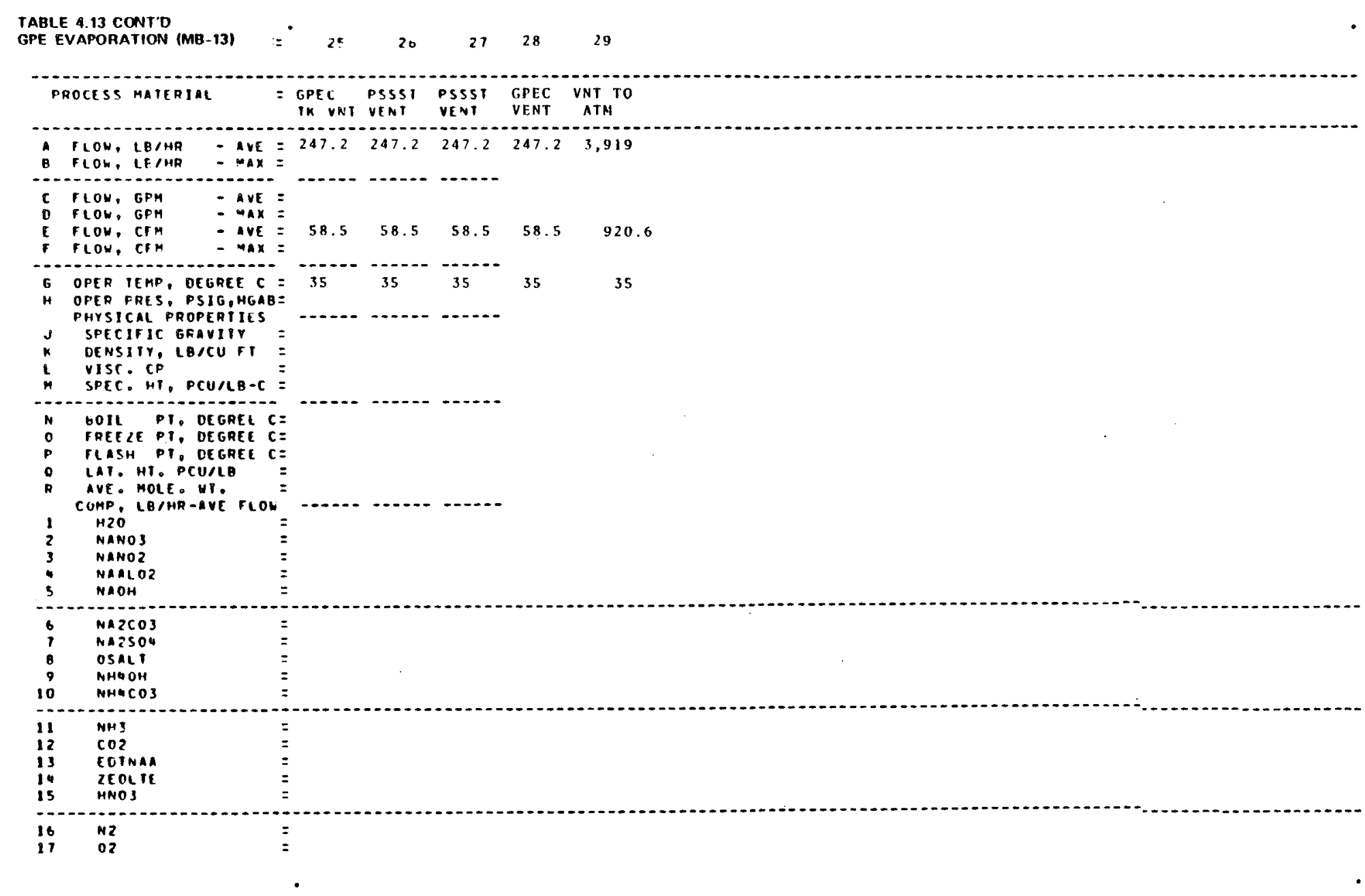




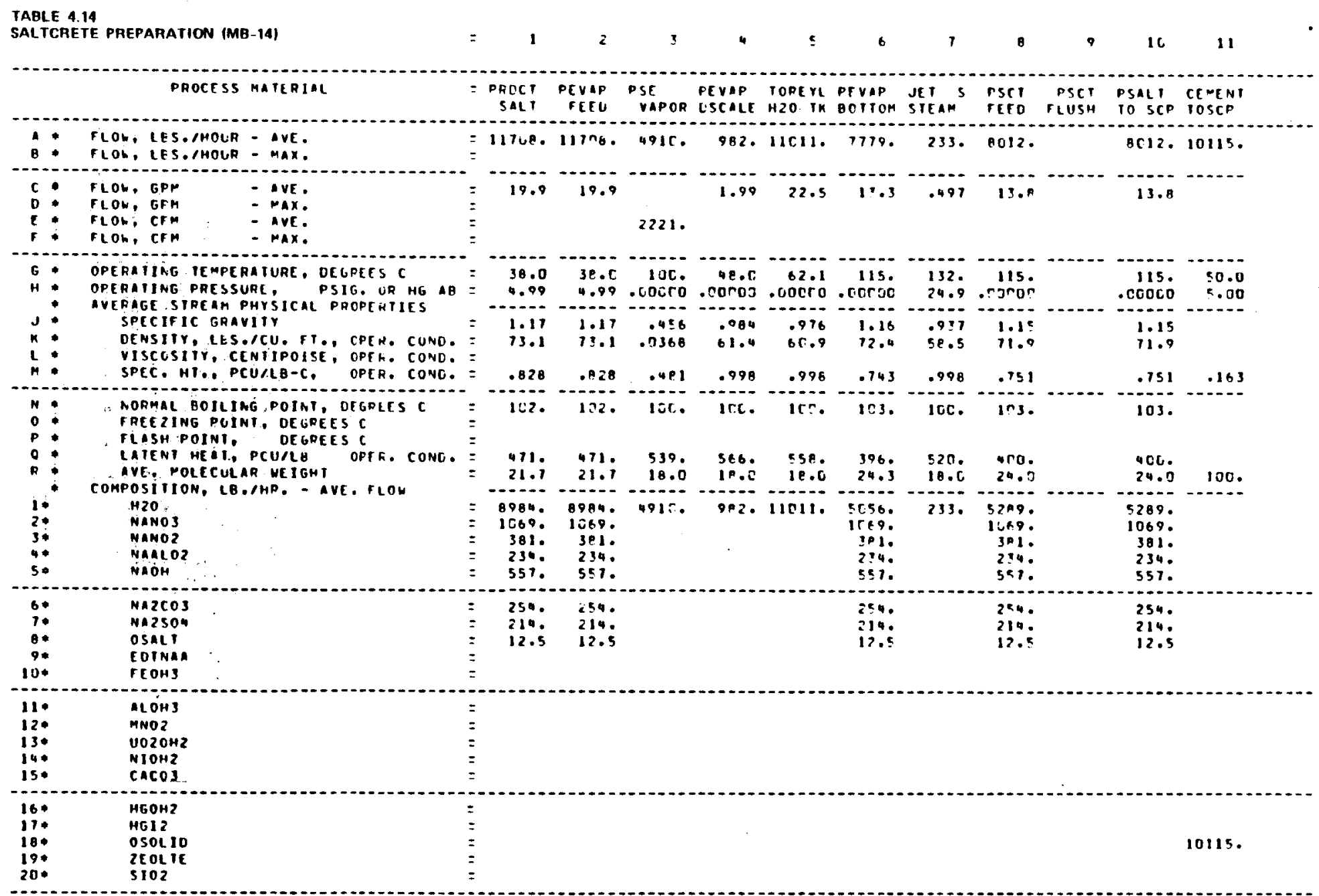


TABLE 4.14 CONT'D

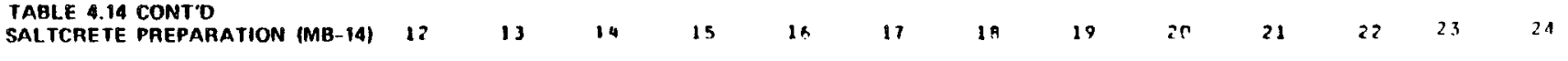

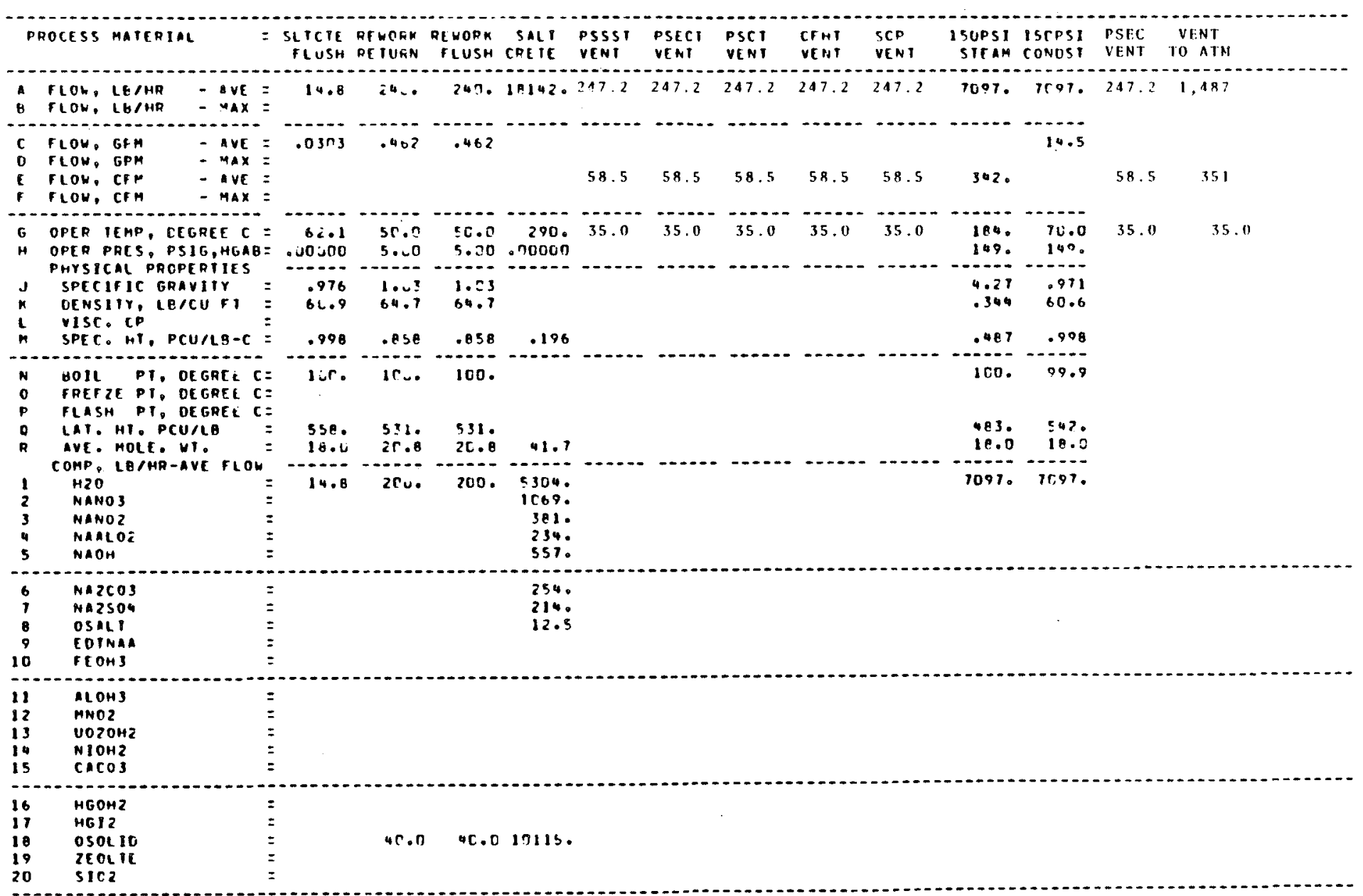


TABLE 4.15

Mechanical Cell A (MB-15)

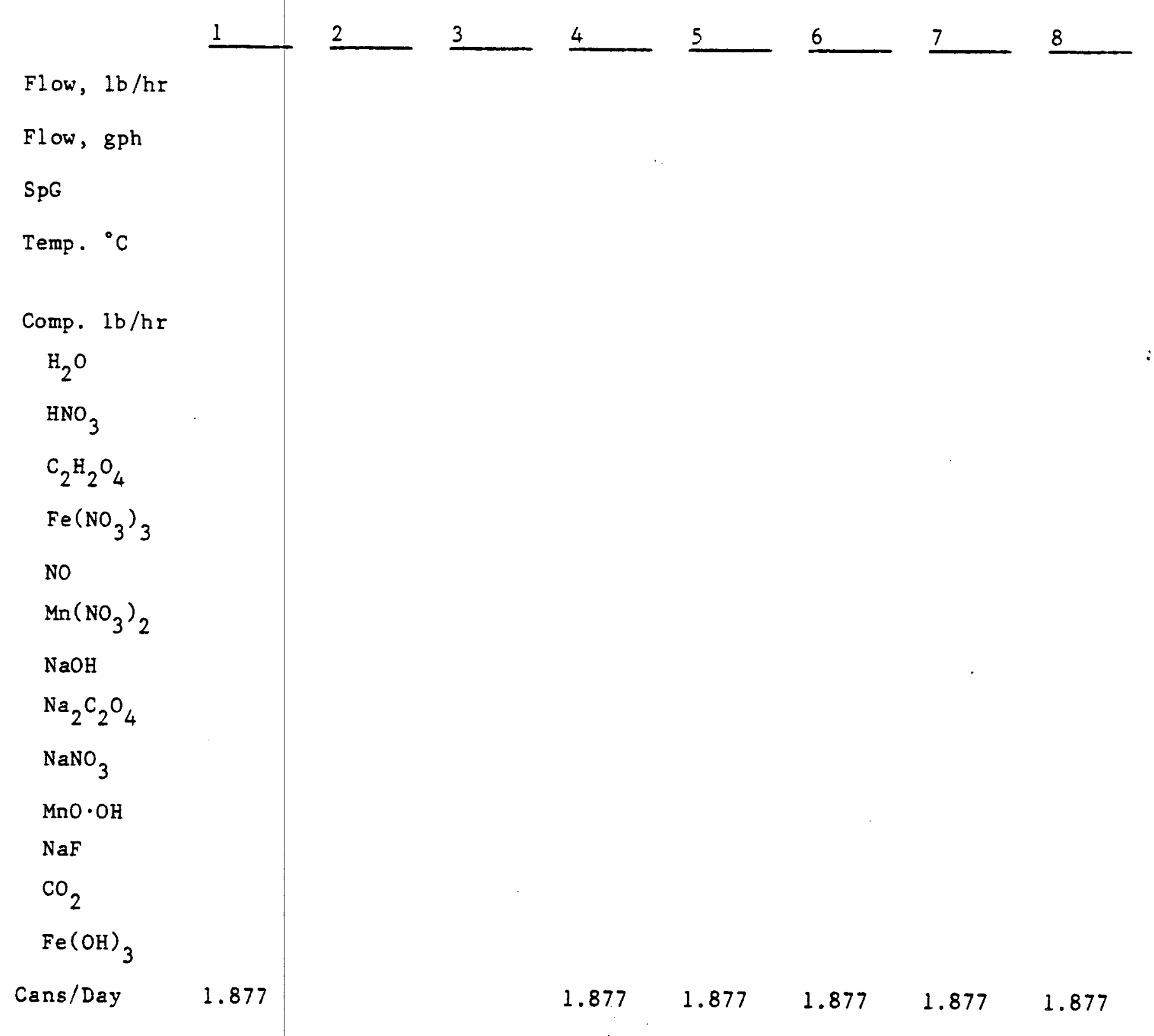


TABLE 4.15 (Contd)

\begin{tabular}{|c|c|c|c|c|c|c|c|c|}
\hline & 9 & 10 & 11 & 12 & 13 & 14 & 15 & 16 \\
\hline Flow, $1 \mathrm{~b} / \mathrm{hr}$ & & & & 256.42 & 256.35 & $0.036 *$ & 238.07 & 238.07 \\
\hline Flow, gph & & & & 27.58 & 27.58 & & 27.59 & 27.59 \\
\hline SPG & & & & 1.115 & 1.115 & & 1.035 & 1.035 \\
\hline Temp. ${ }^{\circ} \mathrm{C}$ & & & & 38 & 50 & 50 & 38 & 38 \\
\hline \multicolumn{9}{|l|}{ Comp. Ib/hr } \\
\hline $\mathrm{H}_{2} \mathrm{O}$ & & & & 201.84 & 201.79 & & 215.07 & 215.07 \\
\hline $\mathrm{HNO}_{3}$ & & & & 50.43 & 50.12 & & & \\
\hline $\mathrm{C}_{2} \mathrm{H}_{2} \mathrm{O}_{4}$ & & & & & & & 23.00 & 23.00 \\
\hline $\mathrm{Fe}\left(\mathrm{NO}_{3}\right)_{3}$ & & & & 0.291 & 0.582 & & & \\
\hline NO & & & & & & 0.036 & & \\
\hline \multicolumn{9}{|l|}{$\mathrm{Mn}\left(\mathrm{NO}_{3}\right)_{2}$} \\
\hline \multicolumn{9}{|l|}{$\mathrm{NaOH}$} \\
\hline \multicolumn{9}{|l|}{$\mathrm{Na}_{2} \mathrm{C}_{2} \mathrm{O}_{4}$} \\
\hline \multicolumn{9}{|l|}{$\mathrm{NaNO}_{3}$} \\
\hline \multicolumn{9}{|l|}{$\mathrm{MnO} \cdot \mathrm{OH}$} \\
\hline $\mathrm{NaF}$ & & & & 3.86 & 3.86 & & & \\
\hline \multicolumn{9}{|l|}{$\mathrm{CO}_{2}$} \\
\hline \multicolumn{9}{|l|}{$\mathrm{Fe}(\mathrm{OH})_{3}$} \\
\hline Cans/Day & 1.877 & 1.877 & 1.879 & & & & & \\
\hline
\end{tabular}


TABLE 4.15 (Contd)

\begin{tabular}{|c|c|c|c|c|c|c|c|c|}
\hline & 17 & 18 & 19 & 20 & 21 & 22 & 23 & 24 \\
\hline Flow, $1 \mathrm{~b} / \mathrm{hr}$ & 244.35 & 32.05 & 0.455 & $26.23 *$ & 81.86 & 583.00 & 64.76 & 64.76 \\
\hline Fl ow, gph & 27.81 & 2.94 & & & 6.44 & 64.16 & 7.82 & 7.82 \\
\hline SpG & 1.054 & 1.310 & & & 1.525 & 1.090 & 0.993 & 0.993 \\
\hline Temp. ${ }^{\circ} \mathrm{C}$ & 38 & 38 & & & 38 & 38 & 38 & 38 \\
\hline \multicolumn{9}{|l|}{ Comp. $1 \mathrm{~b} / \mathrm{hr}$} \\
\hline $\mathrm{H}_{2} \mathrm{O}$ & 236.91 & 16.03 & & & 40.93 & 496.13 & 64.76 & 64.76 \\
\hline $\mathrm{HNO}_{3}$ & 5.83 & 16.03 & & & & & & \\
\hline $\mathrm{C}_{2} \mathrm{H}_{2} \mathrm{O}_{4}$ & 1.15 & & & & & & & \\
\hline \multicolumn{9}{|l|}{$\mathrm{Fe}\left(\mathrm{NO}_{3}\right)_{3}$} \\
\hline No & & & & 4.76 & & & & \\
\hline $\mathrm{Mn}\left(\mathrm{NO}_{3}\right)_{2}$ & 0.455 & & 0.455 & & & & & \\
\hline $\mathrm{NaOH}$ & & & & & 40.93 & 3.72 & & \\
\hline $\mathrm{Na}_{2} \mathrm{C}_{2} \mathrm{O}_{4}$ & & & & & & 1.715 & & \\
\hline $\mathrm{NaNO}_{3}$ & & & & & & 76.91 & & \\
\hline $\mathrm{MnO} \cdot \mathrm{OH}$ & & & & & & 0.415 & & \\
\hline $\mathrm{NaF}$ & & & & & & 3.86 & & \\
\hline $\mathrm{CO}_{2}$ & & & & 21.37 & & & & \\
\hline $\mathrm{Fe}(\mathrm{OH})_{3}$ & & & & & & 0.256 & & \\
\hline Cans/Day & & & & & & & & \\
\hline
\end{tabular}


TABLE 4.15 (Contd)

\begin{tabular}{|c|c|c|c|c|c|c|c|c|}
\hline & 25 & 26 & 27 & 28 & 29 & 30 & 31 & 32 \\
\hline Flow, $\mathrm{lb} / \mathrm{hr}$ & 64.76 & 64.76 & 129.52 & 100.0 & 100.0 & 2.08 & 129.52 & 842.04 \\
\hline Flow, gph & 7.82 & 7.82 & 15.64 & 12.07 & 12.07 & 0.25 & 15.64 & 95.28 \\
\hline$S_{P G}$ & 0.993 & 0.993 & 0.993 & 0.993 & 0.993 & 0.993 & 0.993 & 1.060 \\
\hline Temp. ${ }^{\circ} \mathrm{C}$ & 38 & 38 & 38 & 38 & 38 & 38 & 38 & 38 \\
\hline \multicolumn{9}{|l|}{ Comp. Ib/hr } \\
\hline $\mathrm{H}_{2} \mathrm{O}$ & 64.76 & 64.76 & 129.52 & 100.0 & 100.0 & 2.08 & 129.52 & 55.17 \\
\hline \multicolumn{9}{|l|}{$\mathrm{HNO}_{3}$} \\
\hline \multicolumn{9}{|l|}{$\mathrm{C}_{2} \mathrm{H}_{2} \mathrm{O}_{4}$} \\
\hline \multicolumn{9}{|l|}{$\mathrm{Fe}\left(\mathrm{NO}_{3}\right)_{3}$} \\
\hline \multicolumn{9}{|l|}{ No } \\
\hline \multicolumn{9}{|l|}{$\mathrm{Mn}\left(\mathrm{NO}_{3}\right)_{2}$} \\
\hline $\mathrm{NaOH}$ & & & & & & & & 3.72 \\
\hline $\mathrm{Na}_{2} \mathrm{C}_{2} \mathrm{O}_{4}$ & & & & & & & & 1.715 \\
\hline $\mathrm{NaNO}_{3}$ & & & & & & & & 76.91 \\
\hline $\mathrm{MnO} \cdot \mathrm{OH}$ & & & & & & & & 0.415 \\
\hline $\mathrm{NaF}$ & & & & & & & & 3.86 \\
\hline \multicolumn{9}{|l|}{$\mathrm{CO}_{2}$} \\
\hline $\mathrm{Fe}(\mathrm{OH})_{3}$ & & & & & & & & 0.256 \\
\hline Cans/Day & & & & & & & & \\
\hline
\end{tabular}


TABLE 4.16

Mechanical Cell B $(M B-16)$

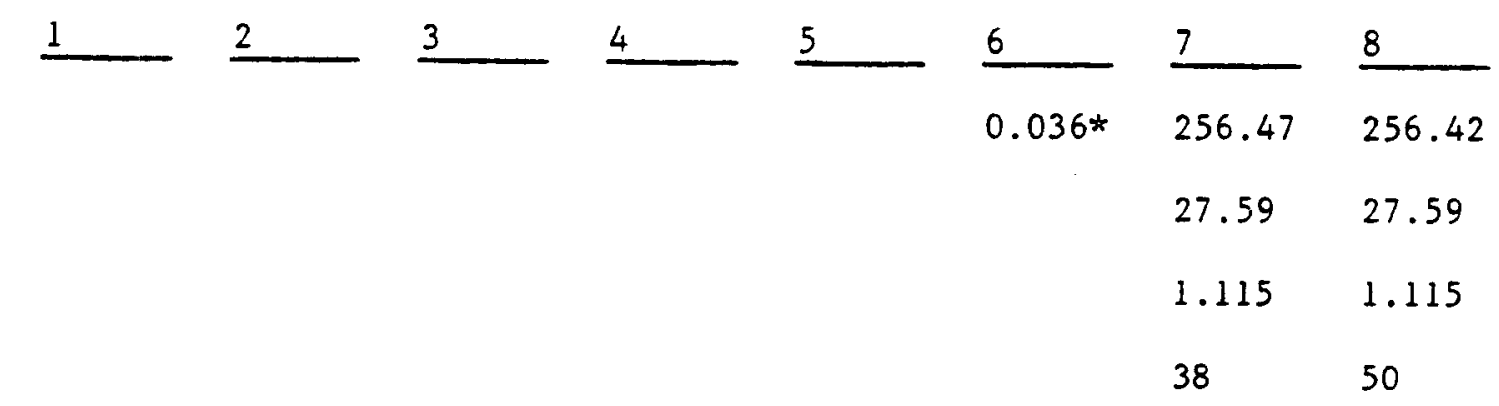

* Does not include the tank vapor space purge ( $25 \mathrm{scfm}$ air).

\section{$3.86 \quad 3.86$}

$201.88 \quad 201.84$

$50.73 \quad 50.43$

0.291 
TABLE 4.16 (Contd)

\begin{tabular}{|c|c|c|c|c|c|c|c|}
\hline & 9 & 10 & 11 & 12 & 13 & 14 & 15 \\
\hline Flow, lb/hr & 238.07 & 238.07 & 64.76 & 64.76 & 64.76 & 64.76 & 129.52 \\
\hline Flow, gph & 27.59 & 27.59 & 7.82 & 7.82 & 7.82 & 7.82 & 15.64 \\
\hline$S_{p G}$ & 1.035 & 1.035 & 0.993 & 0.993 & 0.993 & 0.993 & 0.993 \\
\hline Temp. ${ }^{\circ} \mathrm{C}$ & 38 & 38 & 38 & 38 & 38 & 38 & 38 \\
\hline \multicolumn{8}{|l|}{ Comp. Ib/hr } \\
\hline $\mathrm{H}_{2} \mathrm{O}$ & 215.07 & 215.07 & 64.76 & 64.76 & 64.76 & 64.76 & 129.52 \\
\hline \multicolumn{8}{|l|}{$\mathrm{HNO}_{3}$} \\
\hline $\mathrm{C}_{2} \mathrm{H}_{2} \mathrm{O}_{4}$ & 23.00 & 23.00 & & & & & \\
\hline \multicolumn{8}{|l|}{$\mathrm{Fe}\left(\mathrm{NO}_{3}\right)_{3}$} \\
\hline \multicolumn{8}{|l|}{ No } \\
\hline \multicolumn{8}{|l|}{$\mathrm{Mn}\left(\mathrm{NO}_{3}\right)_{2}$} \\
\hline \multicolumn{8}{|l|}{$\mathrm{NaOH}$} \\
\hline \multicolumn{8}{|l|}{$\mathrm{Na}_{2} \mathrm{C}_{2} \mathrm{O}_{4}$} \\
\hline \multicolumn{8}{|l|}{$\mathrm{NaNO}_{3}$} \\
\hline \multicolumn{8}{|l|}{$\mathrm{MnO} \cdot \mathrm{OH}$} \\
\hline \multicolumn{8}{|l|}{$\mathrm{NaF}$} \\
\hline \multicolumn{8}{|l|}{$\mathrm{CO}_{2}$} \\
\hline \multicolumn{8}{|l|}{$\mathrm{Fe}(\mathrm{OH})_{3}$} \\
\hline Cans/Day & & & & & & & \\
\hline
\end{tabular}


TABLE 4.17

Mechanical Cel1 C (MB-17)

Process

Stream

Units/Day

1

2

3

4

5

6

7

8

9

10

1.877 canisters

1.877 canisters

1.877 canisters

1.877 canisters

1.877 canisters

40 Clean Smears

40 Smears

(Individually wrapped)

11 
TABLE 4.18

Percent Distribution of Radionuclide Groups Between the Soluble and Insoluble Fractions of the DWPF Feed Streams ${ }^{a}$

\begin{tabular}{|c|c|c|c|c|c|}
\hline $\begin{array}{l}\text { Radionuclide } \\
\text { Groupb }\end{array}$ & $\begin{array}{l}\text { Percent in } \\
\text { In-Tank Gravity } \\
\text { Settled Sludge } \\
\end{array}$ & $\frac{\text { Feed to Dr }}{\text { Supernate }}$ & $\frac{\frac{\text { WPF-Percent }}{(F S-2-8)}}{\text { Insoluble }}$ & $\frac{\text { Distribut }}{\frac{\text { Sludge/s }}{\text { Soluble }}}$ & $\frac{\frac{\text { on }}{\text { Irry (FS-2-4) }}}{\text { Insoluble }}$ \\
\hline I & 6.8 & 93.20 & 0 & 6.80 & 0 \\
\hline II & 52.8 & 46.60 & 0.63 & 3.40 & 49.37 \\
\hline III & 94.2 & 4.66 & 1.19 & 0.34 & 93.81 \\
\hline IV & 97.8 & 0.93 & 1.24 & 0.07 & 97.76 \\
\hline $\mathrm{V}$ & 98.6 & 0.19 & 1.25 & 0.01 & 98.55 \\
\hline VI & 98.7 & 0.09 & 1.25 & 0.01 & 98.65 \\
\hline
\end{tabular}

The tritium composition of the feed streams to the DWPF are detailed below. Sludge-Slurry Stream (FS-2-4)

Insoluble $-0, \mathrm{Ci} / \mathrm{hr}$

Soluble -48.97 ( $\mathrm{Ci} / \mathrm{gal} \mathrm{T}$ in Ref. Waste Blend) + 67.37 ( $\mathrm{Ci} / \mathrm{gaI} \mathrm{T}$ in FS-13-11)

Supernate Stream (FS-2-8)

Insoluble $-0, \mathrm{Ci} / \mathrm{hr}$

Soluble - 75.52 ( $\mathrm{Ci} / \mathrm{gal} \mathrm{T}$ in Ref. Waste Blend) + 515.27 ( Ci/gal $\mathrm{T}$ in FS-13-11)

a. See Appendix 13.9.

b. See Table 2.11. 
TABLE 4.19

Summary of Aluminum Dissolving Tests

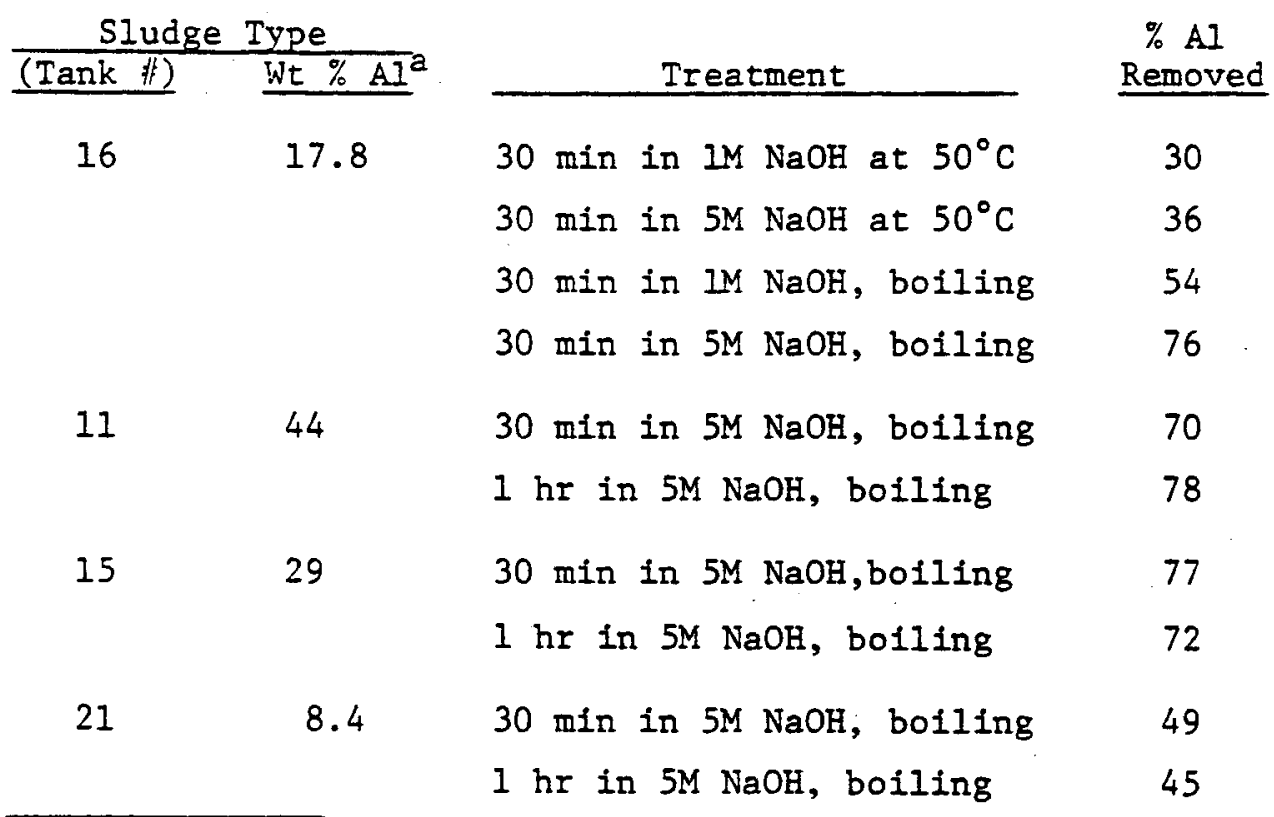

a. Based on washed, dried sludge. 
TABLE 4.20

Effect of Aluminum Dissolving on Sludge Composition

\begin{tabular}{|c|c|c|c|}
\hline $\begin{array}{c}\text { Metal } \\
\text { Ion }\end{array}$ & $\begin{array}{l}\text { Before Ala } \\
\text { Dissolving }\end{array}$ & $\begin{array}{c}\text { After AI b } \\
\text { Dissolving }\end{array}$ & $\begin{array}{l}\text { Overall Range in } \\
\text { SRP Sludges, wt \% }\end{array}$ \\
\hline $\mathrm{Al}$ & 29.0 & 7.3 & $2-44$ \\
\hline $\mathrm{Fe}$ & 3.1 & 10.5 & $3-33$ \\
\hline Mn & 2.3 & 7.8 & $2-11$ \\
\hline $\mathrm{Na}$ & 1.2 & 4.1 & - \\
\hline $\mathrm{Hg}$ & 0.9 & 3.1 & - \\
\hline $\mathrm{U}$ & 0.9 & 3.1 & $0-15$ \\
\hline $\mathrm{Ni}$ & 0.5 & 1.7 & $0-6$ \\
\hline $\mathrm{Ca}$ & 0.2 & 0.7 & $0-3$ \\
\hline
\end{tabular}

a. Measured in actual washed, dried sludge, Ref. 4.

b. Calculated assuming removal of $75 \%$ of the initial aluminum.

c. From Ref. 5. Note that Al dissolution will greatly decrease in this range of $A I$ concentrations. 
TABLE 4.21

Batch Washing Cycle

Operation

Volume, Rate, Time,

Iransfer unwashed sludge feed

to wash tank

gallons gpm minutes

$693.9 \quad 75 \quad 9.3$

Dewater sludge feed by

centrifugation

$\begin{array}{lll}693.9 & 5 & 129.5\end{array}$

Add water for first wash

$\begin{array}{lll}489.3 & 75 & 6.5\end{array}$

Centrifuge first wash slurry

$653.0 \quad 12$

59.2

Add water for second wash

$489.3 \quad 75$

6.5

Centrifuge second wash slurry

641.5

12

58.2

Slurry washed sludge cake

150.6

0

5.0

Transfer washed sludge slurry

to washed sludge run tank

150.6

75

2.0

Total cycle time

276.2

TABLE 4.22

Centrifuge Cycle

\begin{tabular}{|c|c|c|c|c|c|c|c|}
\hline Operation & $\begin{array}{l}\text { Speed, } \\
\text { Ipm }\end{array}$ & $\begin{array}{l}\text { Dewate } \\
\text { Feed } \\
\text { Rate, } \\
\text { gpm } \\
\end{array}$ & $\begin{array}{l}\text { ing Step } \\
\text { Time } \\
\text { Required, } \\
\text { minutes } \\
\end{array}$ & $\begin{array}{l}\text { First } \\
\text { Feed } \\
\text { Rate, } \\
\text { gpm } \\
\end{array}$ & $\begin{array}{l}\text { Time, } \\
\text { minutes }\end{array}$ & $\begin{array}{l}\text { Second } \\
\text { Feed } \\
\text { Rate, } \\
\text { gpm }\end{array}$ & $\begin{array}{l}\text { Wash } \\
\text { Time, } \\
\text { minutes }\end{array}$ \\
\hline Acceleration & $50-400$ & 0 & 0.8 & 0 & $\therefore 0.8$ & 0 & 0.8 \\
\hline Fill basket & $400-1400$ & 30 & 4.0 & 30 & 4.0 & 30 & 4.0 \\
\hline Feed & 1400 & 5 & 114.7 & 12 & 44.4 & 12 & 43.4 \\
\hline Cake compaction & 1400 & 1 & 5.0 & 1 & 5.0 & 1 & 5.0 \\
\hline Skim and decelerate & $1400-50$ & 0 & 3.0 & 0 & 3.0 & 0 & 3.0 \\
\hline Unload cake & 50 & 0 & 2.0 & 0 & 2.0 & 0 & 2.0 \\
\hline Total Time & & & 129.5 & & 59.2 & & 58.2 \\
\hline
\end{tabular}


TABLE 4.23

Description of Synthetic Sludge Waste*

Composition

Waste Slurry

Washed, Dried Sludge

Iiquid

3.8 wt \% solids

35.2 wt $\% \mathrm{Fe}^{3+}$

$5.9 \mathrm{M} \mathrm{Na}^{+}$

25.3 wt \% salt

1.5 wt $\% \mathrm{Al}^{3+}$

$3.7 \mathrm{M} \mathrm{OH}^{-}$

70.9 wt $\%$ water

10.6 wt $\% \mathrm{Mn}^{3+}$

$0.44 \mathrm{M} \mathrm{AlO}_{4}^{-}$

2.9 wt $\% \mathrm{Ca}^{2+}$

$1.1 \mathrm{M} \mathrm{NO}_{3}^{-}$

5.3 wt $\% \mathrm{Ni}^{2+}$

$0.46 \mathrm{M} \mathrm{NO}_{2}^{-}$

0.8 wt $\% \mathrm{Na}^{+}$

$0.13 \mathrm{M} \mathrm{SO}_{4}{ }^{2-}$

43.7 wt \% other

$0.12 \mathrm{M} \mathrm{CO}_{3} 2-$

* Suspended solids - 12 vol \% as measured by centrifugation at $5000 \mathrm{~g}$ 's for 3 minutes

Density $-1.27 \mathrm{~g} / \mathrm{mL}$ at $20^{\circ} \mathrm{C}$

Particle Size - Near logarithmically declining fractional population/particle diameter distribution; bimodal fractional volume/particle diameter distribution with mean diameters of $2.5 \mathrm{\mu m}$ and $10 \mathrm{\mu m}$ and 10 values of $1.2 \mathrm{\mu m}$ and $2.3 \mathrm{\mu m}$, respectively.

Rheology - Newtonian fluid with $6 \mathrm{cp}$ viscosity at $20^{\circ} \mathrm{C}$ 
TABLE 4.24

Small Scale TNX Centrifuge Performance

With Undiluted Slurry Feed

$\begin{array}{llll}\begin{array}{l}\text { GPM } \\ \text { Feed }\end{array} & \begin{array}{l}\text { \% Sludge } \\ \text { Recovery }\end{array} & \begin{array}{l}\text { Sludge Capacity, Basket Fill at } \\ \text { Solids Overflow* }\end{array} & \begin{array}{l}\text { Cake Water } \\ \text { Content, } \\ \text { lb water/1b } \\ \text { Solids }\end{array} \\ 0.1 & 99.6 & 104 & 2.8 \\ 0.25 & 97.1 & 93 & 2.8 \\ 0.5 & 92.1 & 88 & 2.9 \\ \text { * Based on average cake thickness as measured after the } \\ \text { five-minute cake compaction spin. }\end{array}$

TABLE 4.25

Centrifuge Scaleup

\begin{tabular}{lllll}
$\begin{array}{l}\text { \% Sludge } \\
\text { Recovery }\end{array}$ & $\begin{array}{l}\text { Feed Rate in } \\
\text { 12-Inch TNX }\end{array}$ & $\begin{array}{l}\text { Centrifuge } \\
\text { Centrifuge }\end{array}$ & $\begin{array}{l}\text { Feed Flow } \\
\text { Factor }\end{array}$ \\
\hline 88.9 & 1.1 & 23 & 21 \\
96.4 & 0.75 & 16 & 21 \\
97.2 & 0.72 & 16 & 22 \\
98.9 & 0.46 & 10 & 22 \\
99.6 & 0.46 & 11 & 24 \\
99.7 & 0.44 & 11 & 25
\end{tabular}


TABLE 4.26

$\mathrm{Na}^{+}, \mathrm{NO}_{3}^{-}$, and $\mathrm{SO}_{4}^{2-}$ Concentrations in Washed Sludge

\begin{tabular}{|c|c|}
\hline M & Specification \\
\hline
\end{tabular}

$\mathrm{Na}^{+} \quad 1.1 \leq 5$

$\mathrm{NO}_{3}{ }^{-} \quad 1.4 \leq 10$

$\mathrm{SO}_{4} 2-\quad 0.5 \quad \leq 3$

TABLE 4.27

Spray Dryer Product Bulk Densitya

Feedrate, Pour Density, Vibrated Density,

$\underline{\mathrm{L} / \mathrm{hr}} \mathrm{g} / \mathrm{mL} \mathrm{g} / \mathrm{mL}$

$\begin{array}{lll}175 & 0.52 & 0.77\end{array}$

$\begin{array}{lll}250 & 0.64 & 0.83\end{array}$

$\begin{array}{lll}300 & 0.66 & 0.79\end{array}$

a. A skeletal density of $3.18 \mathrm{~g} / \mathrm{cc}$ was determined at the Du Pont Engineering Test Center on product produced during a 21 " spray dryer run at PNL. 
TABLE 4.28

Particle Size Distribution of Powder Produced with

Simulated SRP Feed in the PNL 36-Inch Spray Dryer

\begin{tabular}{|c|c|c|c|c|}
\hline $\begin{array}{l}\text { Particle Size } \\
\text { Microns }\end{array}$ & $\frac{\text { Cumulative }}{175 \mathrm{~L} / \mathrm{hr}}$ & $\frac{\text { Amount Smaller }}{250 \mathrm{~L} / \mathrm{hr}}$ & $\frac{\text { Than Stated }}{280 \mathrm{~L} / \mathrm{hr}}$ & $\frac{\text { Size, Vol \% }}{300 \mathrm{~L} / \mathrm{hr}}$ \\
\hline 2 & 0.20 & 0.00 & 0.00 & 0.00 \\
\hline 6 & 8.20 & 0.50 & 0.00 & 0.00 \\
\hline 10 & 17.6 & 1.50 & 0.10 & 0.10 \\
\hline 20 & 48.4 & 6.50 & 1.00 & 0.80 \\
\hline 30 & 58.0 & 13.0 & 4.90 & 3.00 \\
\hline 40 & 69.4 & 41.0 & 14.4 & 6.70 \\
\hline 50 & $100^{a}$ & 67.6 & 31.1 & 15.2 \\
\hline 60 & & 80.2 & 46.3 & 28.6 \\
\hline 70 & & 100.0 & 62.0 & 48.2 \\
\hline 80 & & & 75.6 & 67.9 \\
\hline 90 & & & 91.3 & 91.7 \\
\hline 100 & & & 100.0 & 100.0 \\
\hline
\end{tabular}

a. $100 \%$ less than 44 microns. 
TABLE 4.29

Median Particle Diameter of Spray Dryer Product

Median Particle Diameter, $\mu \mathrm{m}$

$175 \mathrm{~L} / \mathrm{hr} \quad 250 \mathrm{~L} / \mathrm{hr} \quad 280 \mathrm{~L} / \mathrm{hr} \quad 300 \mathrm{~L} / \mathrm{hr}$

$\begin{array}{lrrrr}\text { Volume \% } & 25.8 & 45.7 & 63.1 & 70.1 \\ \text { Number \% } & 3.67 & 9.05 & 32.6 & 31.9\end{array}$

TABLE 4.30

Spray Dryer Product Composition, wt \%

Feedrate, L/hr

Component

$\underline{175-250}$ 300

$\mathrm{Na}$

$12.0 \quad 10.5 \quad 13.0$

$\mathrm{Fe}$

$\begin{array}{lll}16.1 & 14.5 & 17.8\end{array}$

Al

$\begin{array}{lll}17.8 & 21.6 & 14.2\end{array}$

Mn

7.1

$6.3 \quad 7.6$

$\mathrm{Ca}$

1.2

1.91 .6

$\mathrm{CO}_{3}{ }^{2-}$

2.6

3.56 .5

Wt. loss $200^{\circ} \mathrm{C}$

0.07

0.221 .0

Wt. loss $800^{\circ} \mathrm{C}$

3.8

$5.5 \quad 7.6$ 
TABLE 4.31

Elemental and Ionic Analyses of Spray Dryer Product

Ion Calcine a Insoluble

$\mathrm{Fe} \quad 23.5 \quad>95.0$

$\begin{array}{lll}\mathrm{Na} & 13.9 & 5.7\end{array}$

Al $\quad 8.4 \quad 40.0$

Mn $\quad 5.5 \quad 2_{100.0}$

$\mathrm{Ni} \quad 3.2 \quad>96.0$

$\mathrm{Ca} \quad 1.9 \quad>97.0$

Carbonate $\quad 5.2 \quad b$

Nitrate $\quad 1.2 \quad 12.5$

a. Percentages do not total $100 \%$ because oxide, water, and sulfate contents are not available.

b. Carbonate was calculated from total carbon analysis.

TABLE 4.32

TGA Analysis and DTA Analyses of Spray Dryer Product

\begin{tabular}{|c|c|c|c|c|}
\hline \multicolumn{2}{|c|}{ Region } & \multirow{2}{*}{$\begin{array}{l}\text { Type Reaction } \\
\text { Endothermic }\end{array}$} & $\begin{array}{l}\text { Weight } \\
\text { Loss; \% }\end{array}$ & Comments \\
\hline $20-$ & $90^{\circ} \mathrm{C}$ & & 7 & Loss of adsorbed species \\
\hline $90-$ & $500^{\circ} \mathrm{C}$ & Endothermic & 6 & Loss of adsorbed water \\
\hline $500-$ & $620^{\circ} \mathrm{C}$ & Exothermic & 4 & Decomposition \\
\hline 620 & $1150^{\circ} \mathrm{C}$ & $\begin{array}{l}\text { (Small exotherm } \\
\text { at } 770^{\circ} \text { ) }\end{array}$ & 1 & $\begin{array}{l}\text { Decomposition and/or } \\
\text { vaporization }\end{array}$ \\
\hline & & Total & 18 & \\
\hline
\end{tabular}


TABLE 4.33

Summary of PNI Spray Dryer Tests Using Simulated SRP Waste Feed

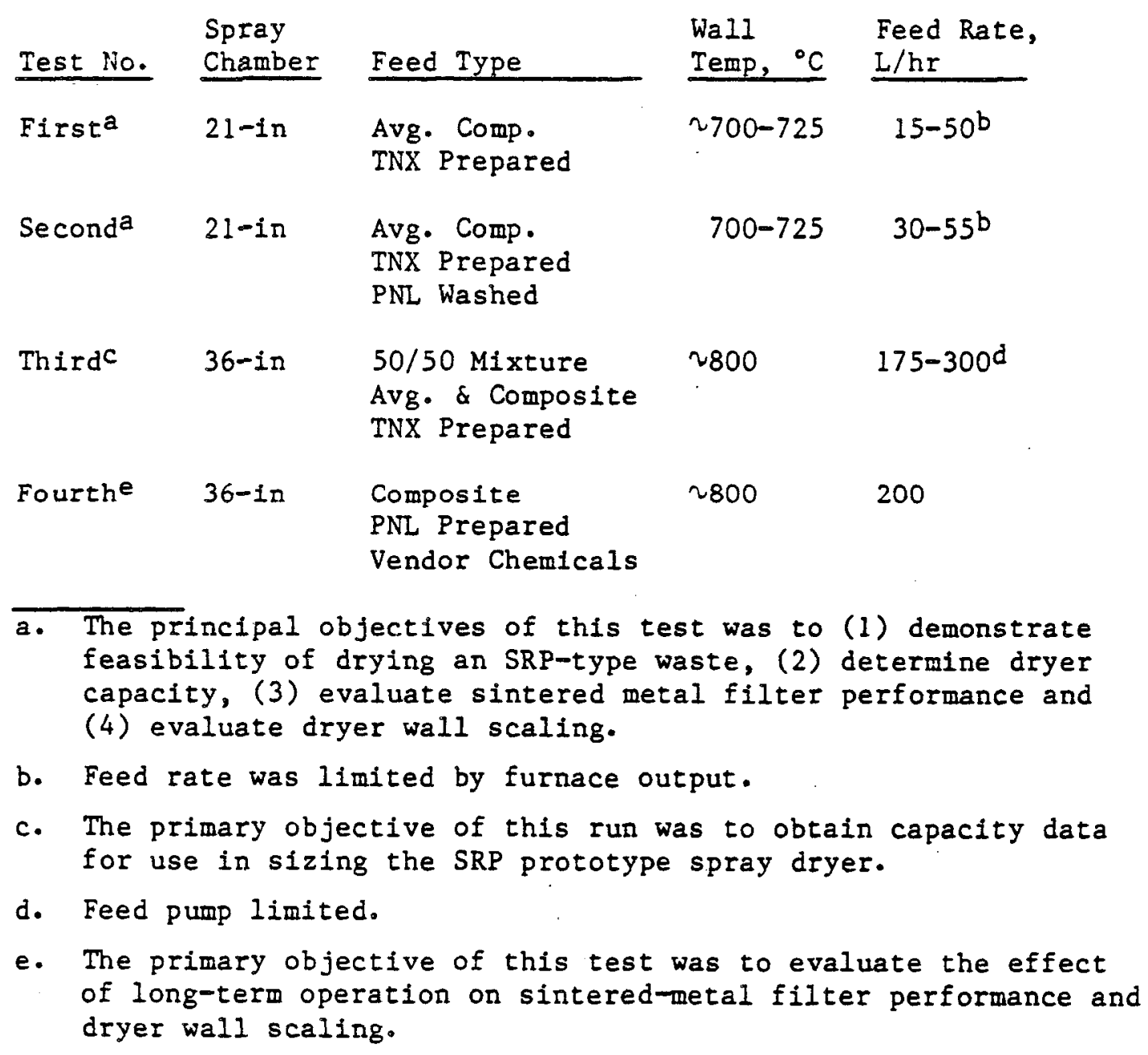


TABLE 4.34

Rheology of Non-Newtonian Melts

$\begin{array}{llllll}\text { Sludge } & \begin{array}{l}\text { Amount, } \\ \mathrm{wt}, \%\end{array} & & \mathrm{I},{ }^{\circ} \mathrm{C} & \underline{\mathrm{m}} & \underline{\mathrm{n}} \\ \text { Average } & 35 & & 1200 & 877 & 0.69 \\ & & 1150 & 1550 & 0.60 \\ & & 1100 & 2320 & 0.52 \\ & & 1050 & 3090 & 0.53 \\ & & 1000 & 4460 & 0.52 \\ \text { Average } & 45 & 1200 & 3140 & 0.56 \\ & & 1100 & 7720 & 0.46\end{array}$

TABLE 4.35

Composition Dependence of Coefficients

$\begin{array}{llllll}a_{i}=b_{0}+b_{1}(\mathrm{Si})+b_{2}(\mathrm{Na})+b_{3}(\mathrm{Li})+b_{4}(\mathrm{Fe})+b_{5}(\mathrm{Al}) & \\ \frac{a_{i}}{b_{0}} \frac{b_{1}}{a_{0}}-28.357 & +1.865 & -27.235 & +109.851 & +0.5047 & +0.2884 \\ a_{1}+81029 & -5008 & +71821 & -289822 & -1440 & -864.65 \\ a_{2}-5.57 \times 10^{7} & +3.24 \times 10^{7} & -4.57 \times 10^{7}+1.85 \times 10^{8}+1.02 \times 10^{6} & +6.4 \times 10^{5}\end{array}$


TABLE 4.36

Effect of Mixing Frit and Waste on Dissolution Rate

Frit Waste Mixed Rate (g/in.2 $\mathrm{hr})$

21

$$
\text { Composite }
$$

No

4.47

Yes

51.3

$\begin{array}{lll}\text { High Aluminum } & \text { No } & 0.57 \\ & \text { Yes } & 34.0\end{array}$

TABLE 4.37

Mixing and Homogenization of Glass Melts

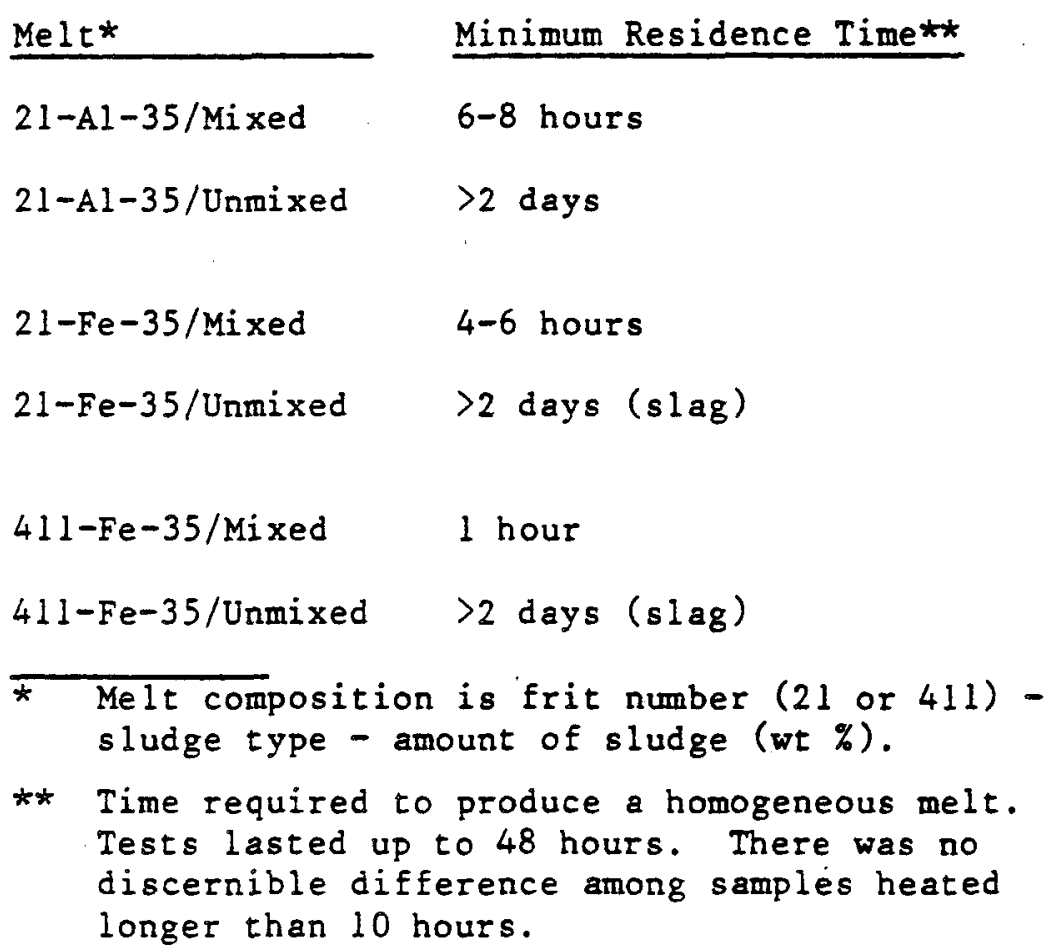

$-4.154=$ 
TABLE 4.38

Effect of Frit Particle Size on Melting Behavior of Sludge Feed

$\begin{array}{llll}\text { Frit } & \text { Particle Size (m) } & \begin{array}{l}\text { Waste Dissolving } \\ \text { Rate (g/in.2-hr) }\end{array} & \begin{array}{l}\text { Foam } \\ \text { Factora }\end{array} \\ & 0.30-1.7 & 29.0 & 0.40 \\ & <1.7 & 32.0 & 0.35 \\ & 0.15-0.30 & 48.8 & 0.15 \\ & <0.15 & 21.4 & 0.40 \\ 411^{c} & 0.30-1.7 & 19.4 & 0.40 \\ & 0.15-0.30 & 37.8 & 0.10 \\ & <0.15 & 26.0 & 0.30 \\ 21^{\mathrm{d}} & <1.7 & 22.8 & 0.20 \\ & <0.3 & 51.2 & 0.05\end{array}$

a. Measure of foam stability. Surface clearing time normalized to unit weight of the batch added to the melter.

b. Feed contained 75 wt \% Frit 22, 22.5 wt \% composite sludge, 2.5 wt \% AW-500 zeolite. Melt temperature $1150^{\circ} \mathrm{C}$.

c. Feed contained 75 wt \% Frit 411,25 wt \% composite sludge. Melt temperature $1050^{\circ} \mathrm{C}$.

d. Feed contained 75 wt \% Frit 21,25 wt \% composite sludge. Melt temperature $1150^{\circ} \mathrm{C}$. 
TABLE 4.39

Total Particle and Mass Loading in Spray Dryer Off-Gas Stream

Particle size Range, micrometer

$\underline{0.32-0.755 \quad 0.50-2.75 \quad 1.10-12.25 \quad 2.0-20.0}$

Total Particle Loading, particles/acf

$7.74+07$

$4.44+05$

$6.4+04$

$5.9+03$

Mass Laoding, g/acfa

$6.08-06$

$8.18-07$

$4.3-07$

4. $0-07$

a. Assumes a particle density of $4 \mathrm{~g} / \mathrm{cc}$.

TABLE 4.40

Composition of Supernate Used in 700-Gallon GS Tests

\begin{tabular}{ll} 
High-Caustic & Initial \\
Flowsheet & Flowsheet \\
(PTDS No. 2) & (PTDS No. 1) \\
\hline
\end{tabular}

Molarity of: $\mathrm{NaOH} \quad 1.8 \quad 0.71$

$\begin{array}{lll}\mathrm{NaNO}_{3} & 1.8 & 2.2 \\ \mathrm{NaNO}_{2} & 0.83 & 0.93 \\ \mathrm{Na}_{2} \mathrm{CO}_{3} & 0.23 & 0.25 \\ \mathrm{Na}_{2} \mathrm{SO}_{4} & 0.23 & 0.25 \\ \mathrm{NaAlO}_{2} & 0.43 & 0.42\end{array}$


TABLE 4.41

700-Gallon GS Results (PTDS No. 1 Flowsheet)

Sludge content, ppm

Type Centrate

Feed: Liquid level, in.

Volume, gal

Sludge content, ppm

Starch Added, $1 b / T$ suspended matter

Maximum Temperature, ${ }^{\circ} \mathrm{C}$

Average Settling Rate, in./hr

Product; Volume, \% of feed
Run No.

\begin{tabular}{lllllll}
\hline 1 & 2 & 3 & 4 & 5 & 6 & $\frac{7}{3}$ \\
Avg & Comp & Comp & Comp & Comp & Comp & Comp \\
61 & 62 & 63 & 62 & 62.5 & 63 & 63 \\
715 & 725 & 735 & 725 & 730 & 735 & 740 \\
4000 & 8500 & 5000 & 7300 & 4000 & 8000 & 7000 \\
25 & 12 & 20 & 14 & 12 & 8 & 9 \\
65 & 71 & 70 & 70 & 65 & 32 & 60 \\
16.0 & 12.9 & 10.2 & 10.0 & 7.8 & 10.5 & 14.0 \\
83.2 & 83.4 & 87.8 & 86.2 & 89.0 & 88.4 & 88.4 \\
150 & 80 & 50 & 30 & 25 & 30 & 16
\end{tabular}




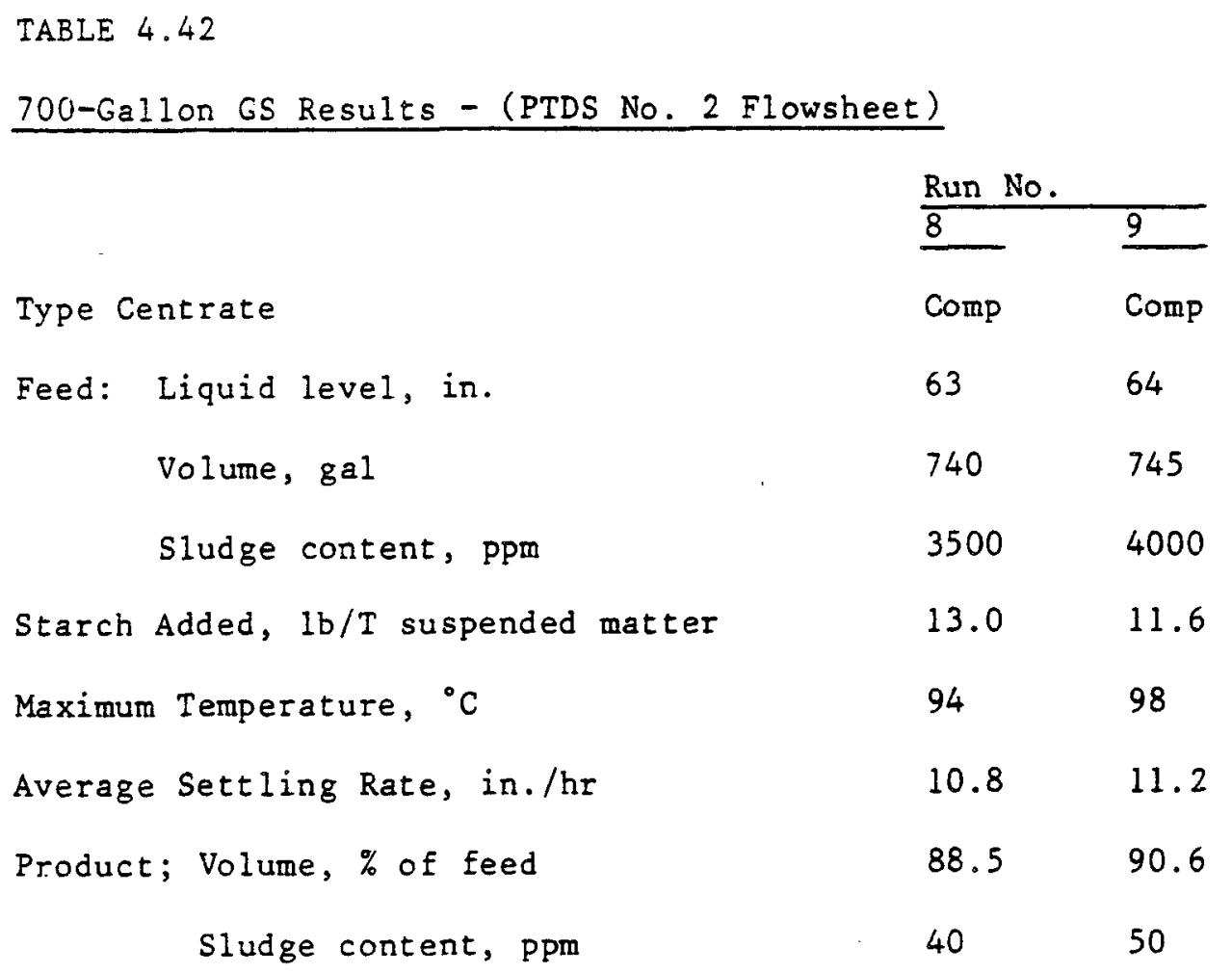


TABLE 4.43

Large-Scale GS Results

\begin{tabular}{|c|c|c|c|c|c|c|c|c|c|c|}
\hline & \multicolumn{10}{|c|}{ Run No. } \\
\hline & 1 & 2 & 3 & 4 & 5 & 6 & 7 & 8 & 9 & 10 \\
\hline Flowsheet, $\mathrm{M} \mathrm{NaOH}$ & 1.8 & 1.8 & 1.8 & 1.8 & 1.8 & 1.8 & 1.0 & 1.0 & 1.0 & 1.0 \\
\hline \multirow{3}{*}{$\begin{array}{l}\text { Feed: } 1 \text { iquid level, in. } \\
\text { volume, gal } \\
\text { sludge content; ppm* }\end{array}$} & 52.5 & 56.7 & 56.7 & 114 & 110 & 108 & 95 & 95 & 88 & 89 \\
\hline & 2550 & 2750 & 2750 & 5500 & 5350 & 5250 & 4600 & 4600 & 4250 & 4300 \\
\hline & 5750 & 13500 & 19300 & 6000 & 8500 & 9000 & 4500 & 9500 & 5300 & 13300 \\
\hline $\begin{array}{l}\text { Starch Added, } \\
1 \mathrm{~b} / \mathrm{T} \text { sludge** }\end{array}$ & 8.7 & 8.6 & 9.0 & 11.5 & 12.9 & 16.6 & 12.8 & 12.4 & 15.5 & 15.0 \\
\hline Temperature, ${ }^{\circ} \mathrm{C}$ & 65 & 65 & 65 & 65 & 65 & 35 & 65 & 45 & 40 & 40 \\
\hline $\begin{array}{l}\text { Average Settling Rate, } \\
\text { in./hr }\end{array}$ & 11.7 & 11.9 & 11.9 & 12.2 & 12.5 & 21.6 & 27.1 & 25.6 & 25.1 & 22.0 \\
\hline \multirow{2}{*}{$\begin{array}{r}\text { Decanted Product, gal } \\
\text { sludge content, ppmtt }\end{array}$} & $1975 t$ & $2200 t$ & $2200 t$ & $4925 t$ & 700 & 990 & 1000 & 1030 & 1010 & 1010 \\
\hline & 80 & 40 & 30 & 45 & 40 & 10 & 50 & 10 & 15 & 10 \\
\hline \multicolumn{11}{|c|}{$\begin{array}{l}\text { * Undecanted layer with settled sludge reslurried and resettled following Runs } 1,2,4,5,7, \text { and } 9 \text {. } \\
\text { * Total starch added to old and new feed sludge. } \\
t \text { Decanted product fed to sand filters via } 1150-g a l \text {-capacity sand filter feed tank. } \\
\dagger \dagger \text { Analyses of samples in sand filter feed tank from first decant at indicated settling rate. }\end{array}$} \\
\hline
\end{tabular}


TABLE 4.44

4-In.-Diameter Sand Filter Performance

\begin{tabular}{|c|c|c|}
\hline & Filter & \\
\hline$\ldots$ & $\begin{array}{l}\text { No. } 1 \\
\text { Primary } \\
\end{array}$ & $\begin{array}{l}\text { No. } 2 \\
\text { Polishing }\end{array}$ \\
\hline Sand Average Particle Size, um & 490 & 270 \\
\hline Sand Height, in. & 24 & 18 \\
\hline Anthracite Average Particle Size, $\mu \mathrm{m}$ & 700 & 400 \\
\hline Anthracite Height, in. & 8 & 3 \\
\hline Sludge Content in Feed, ppm & 50 & 5 \\
\hline Clean-Bed $\Delta P$ at $1.2 \mathrm{gpm} / \mathrm{ft}^{2}, \mathrm{psi}$ & 0.8 & 2.5 \\
\hline$\Delta \mathrm{P}$ Rise, psi/100 Bed Volumes & $<1$ & $<0.5$ \\
\hline Sludge Content in Product, ppm & 5 & 1 \\
\hline
\end{tabular}


TABLE 4.45

\section{Large-Scale Sand Filter Feed Results}

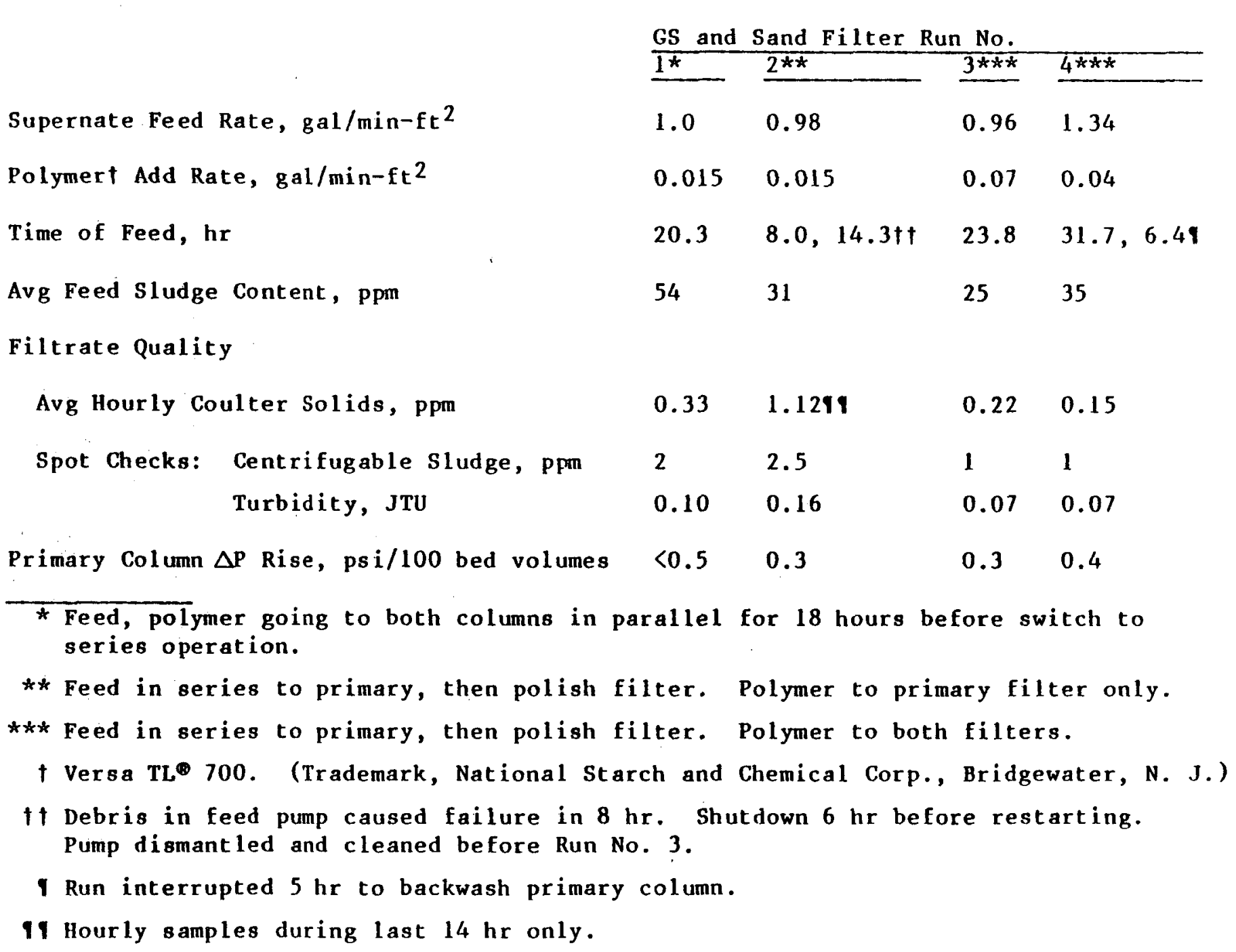


TABLE 4.46

Large-Scale Sand Filter Backwash Results

(Backwash Liquid - $2 \mathrm{M} \mathrm{NaOH)}$

GS and Sand Filter Run No.

I

Total Sludge Feed, Ib

$1.06 \quad 0.673 \quad 0.545$

Lb Sludge Removed, $75 \mathrm{gal} / \mathrm{ft}^{2}$ per wash

$\begin{array}{lllll}\text { Primary Filter: } & \text { Wash \#1 } & 0.710 & 0.469 & 0.350 \\ & \text { Wash \#2 } & 0.054 & 0.048 & 0.139 \\ & \text { Wash \#3 } & --.- & -\cdots & 0.051 \\ \text { Polishing Filter: } & \text { Wash \#1 } & 0.216 & 0.056 & 0.023 \\ & \text { Wash } \# 2 & 0.058 & 0.029 & 0.014 \\ \text { of Sludge Removed } & & 98 & 89 & 106\end{array}$


TABLE 4.47

Viscosities of Stock Solutions for Settling/Filtration

\begin{tabular}{lll} 
Biscosity of $0.1 \%$ & $\begin{array}{l}\text { Viscosity of } 8 \% \\
\text { Versa TL } 700 \text { at } \\
\text { Flojel } 60^{\circ} \text { at } \\
\text { Spindle Speed, rpm } \\
20.2^{\circ} \mathrm{C}, \mathrm{Cp} .\end{array}$ & $\begin{array}{l}\text { Temperature of } \\
18.8^{\circ} \mathrm{C}, \mathrm{Cp} .\end{array}$ \\
\hline 100 & 38 & 88 \\
50 & 35 & 73 \\
20 & 29 & 65 \\
10 & 30 & 65 \\
5 & - & 70
\end{tabular}

TABLE 4.48

Proposed Cesium Ion Exchange Cycle Schedule

$\begin{array}{lll}\text { Stream Volume } & \text { Flow Rate } & \text { Time, Flow } \\ \text { CV* Gallons } & \text { CV/hr gpm/ft } & \text { Hours } \\ \text { Direction }\end{array}$

\begin{tabular}{|c|c|c|c|c|c|c|}
\hline Load (Feed) & 20 & 30,500 & 1.67 & 1.67 & 12 & Down \\
\hline First Rinse & 5 & 7,625 & 1.67 & 1.67 & 3 & Down \\
\hline Elute & 10 & 15,250 & 1.2 & 1.2 & 8.33 & Up \\
\hline Second Rinse** & 3 & 4,575 & 1.2 & 1.2 & 2.5 & Up \\
\hline Regenerate $\dagger \dagger$ & 5 & 7,625 & 1.2 & 1.2 & 4.16 & $\mathrm{Up}_{\mathrm{p}}$ \\
\hline Standby & - & - & - & - & 1 & - \\
\hline Total & - & - & - & - & 31 & - \\
\hline \multicolumn{7}{|c|}{$\begin{array}{l}\text { * } 1 \mathrm{CV}=1 \text { column volume }=1525 \mathrm{gal}=204 \mathrm{ft}^{3} . \text { Height }=8 \mathrm{ft} . \\
\text { Diameter }-68 \mathrm{in.}\end{array}$} \\
\hline \multicolumn{7}{|c|}{$\begin{aligned} * * & \mathrm{H}_{2} \mathrm{O} . \\
+ & 2 \mathrm{M} \mathrm{NH} \mathrm{N}_{4} \mathrm{OH}-2 \mathrm{M}\left(\mathrm{NH}_{4}\right)_{2} \mathrm{CO}_{3} .\end{aligned}$} \\
\hline
\end{tabular}


TABLE 4.49

Requirements for Optimum Results in Countercurrent Ion Exchange [32]

1. During upflow service or regeneration, movement of resin particles must be held to a minimum. The bed should remain packed. Even slight bed fluidization tends to destroy the flat ionic interface and can result in increased leakage or premature breakthrough.

2. If and when the bed is backwashed and resin expansion is allowed, the amount of regenerant should be at least twice the amount used in previous cycles. Since fluidization upsets the regular arrangement of ions in the colum, the effluent end must be thoroughly regenerated to restore the full advantage of the countercurrent effect.

3. Uniform distribution is essential in both upflow and downflow to minimize channeling. Conventional laterals may not be adequate, especially for the bottom distributor. European equipment designers have exerted considerable effort to assure good distribution on upflow. One such concept involves the use of a double-layer porous disc made from fused quartz sand and pebbles in the upper and lower layers, respectively.

4. Care must be exercised to exclude air in both downflow and upflow operations. Any bubble formation in the resin bed will disturb the piston-like effect required.

5. The service run must be stopped at very nearly the same effluent level each time to achieve consistency. Preferably the cutoff point should be somewhat lower than the specified or required effluent level (be it sodium, silica, conductivity, or other parameter).

6. Decationized (or acidified) water should be used for rinsing cation exchangers and deionized water for rinsing anion exchangers. If raw water is used, the first part of the service run may be discarded to avoid contamination of the product water. Such practice is necessary only when very high-purity effluents are required. 
TABLE 4.50

Physical Properties of Duolite ARC-359 Ion Exchange Resin ${ }^{a}$

Physicai Therasteristies

16-50 mesh; black granular, macroporous, received as water-saturated $\mathrm{Na}^{+}$form, $4 \mathrm{~S}-55 \%$ moisture

Buik Density, Wet Resin

$\mathrm{Na}^{+}$form $0.70 \cdot \mathrm{g} / \mathrm{cc}$

$\mathrm{NH}_{4}{ }^{+}$form $0.72 \mathrm{~g} / \mathrm{CC}$

Specific Grovity

$\mathrm{H}^{+}$form $\quad 1.37 \mathrm{~g} / \mathrm{mL}-\mathrm{dry}$

$\mathrm{Na}_{2}{ }^{+}$form $1.60 \mathrm{~g} / \mathrm{mL}$ - dry, $1.17 \mathrm{~g} / \mathrm{mL}$ water - wet

$-\mathrm{Na}^{+}$form $\quad 1.53 \mathrm{~g} / \mathrm{mL}-\mathrm{dry}$

$\mathrm{NH}^{+}$form $1.56 \mathrm{~g} / \mathrm{mL}$ - dry, $1.17 \mathrm{~g} / \mathrm{mL}$ water - wet

Typical Wet Screen Analyses - Hycinogen Form

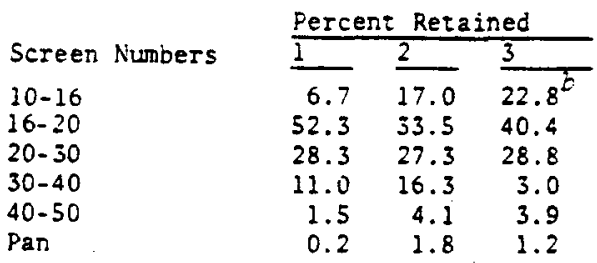

Maximum Service Temperature

$40^{\circ} \mathrm{C}$

Swezing

See Table 4.51

Bed Expension in upflow

(Duolite Bulletin TS-7719, June 21, 1977)

Wet Screen Aralysis * Batch 1, Section 4 above

\begin{tabular}{|c|c|}
\hline Flow Rate & $\begin{array}{l}\text { Bed Expansion, } \\
\text { NB Iomic Form }\end{array}$ \\
\hline $\mathrm{ft} / \mathrm{sec} \mathrm{gpm} / \mathrm{ft}^{2}$ & $13^{\circ} \mathrm{C} \quad 26^{\circ} \mathrm{C} \quad 38^{\circ} \mathrm{C}$ \\
\hline
\end{tabular}

$\begin{array}{lllll}0.0091 & 4.1 & 26 & 15 & 12\end{array}$

$\begin{array}{lllll}0.0137 & 6.1 & 47 & 34 & 28\end{array}$

$\begin{array}{lllll}0.0182 & 8.2 & 68 & 54 & 43\end{array}$

$\begin{array}{lllll}0.0228 & 10.2 & - & 72 & 58\end{array}$

$0.0268 \quad 12.0$

$-\quad-\quad 72$

$\begin{array}{lllll}0.0091 & 4.1 & 21 & 11 & - \\ 0.013 ? & 6.1 & 39 & 25 & 10\end{array}$

$\begin{array}{lllll}0.0182 & 8.2 & 57 & 39 & 26\end{array}$

$\begin{array}{lllll}0.0228 & 10.2 & 75 & 53 & 39\end{array}$

$0.0268 \quad 12.0 \quad . \quad 66 \quad 50$

Pressure trop in Doumflaw

0.1 to $0.2 \mathrm{psi} / \mathrm{ft}$ at $1.12 \mathrm{gpm} / \mathrm{ft}^{2}$ (calculated)

a. Manufacturer's information, unless othernise indicated. Information on Duolite C-3. resin is presented where it is rot available for ARC-359.

b. Determined at SRL - SED, 12/22/77.

$\therefore$. NaOH regenerated. 
TABLE 4.51

"Duolite" ARC-359 Density and Swelling Data [70]

\begin{tabular}{|c|c|c|c|c|c|}
\hline & & Basis of 1 & \& Air-Dried Res & & \\
\hline $\begin{array}{l}\text { Equilibrated } \\
\text { with Solution } \\
\text { Sodium Form } \\
\end{array}$ & $\begin{array}{l}\text { Particle } \\
\text { Density, } \\
\mathrm{g} / \mathrm{mL} \\
\end{array}$ & $\begin{array}{l}\text { Weight of } \\
\text { Swollen } \\
\text { Resin, \& }\end{array}$ & $\begin{array}{l}\text { Volume of } \\
\text { Swollen } \\
\text { Particles, mi }\end{array}$ & $\begin{array}{l}\text { BuIk Volume } \\
\text { of Swollen } \\
\text { Resin, mI }\end{array}$ & $\begin{array}{l}\text { Bulk } \\
\text { Density, } \\
\text { g/mi }\end{array}$ \\
\hline Water & 1.17 & 1.580 & 1.348 & 2.257 & 0.700 \\
\hline $0.01 \mathrm{M} \mathrm{NaOH}$ & - & 1.617 & - & - & - \\
\hline 0.05 & 1.20 & 1.776 & 1.480 & 2.500 & 0.710 \\
\hline 0.2 & 1.20 & 1.986 & 1.655 & 2.550 & 0.778 \\
\hline 0.5 & 1.24 & 2.067 & 1.667 & 2.747 & 0.752 \\
\hline 1.0 & 1.23 & 2.088 & 1.698 & 2.950 & 0.708 \\
\hline 2.0 & 1.24 & 2.122 & 1.711 & 3.000 & 0.707 \\
\hline 5.0 & 1.29 & 2.085 & 1.616 & 2.747 & 0.759 \\
\hline $0.01 \mathrm{M} \mathrm{NaNO}_{3}$ & & 1.398 & & & \\
\hline 0.05 & & 1.375 & & & \\
\hline 0.1 & & 1.414 & & & \\
\hline 0.5 & & 1.360 & & & \\
\hline 1.0 & & 1.366 & & & \\
\hline 5.0 & & 1.486 & & & \\
\hline $2 \mathrm{M}\left(\mathrm{NH}_{4}\right)_{2} \mathrm{CO}_{3}$ & & 1.526 & & & \\
\hline Amoniut Fort & & & & & \\
\hline Water & 1.17 & 1.68 & 1.44 & - & - \\
\hline$\left(\mathrm{NH}_{4}\right)_{2} \mathrm{CO}_{3}$, & & & & & \\
\hline $0.05 \mathrm{M}$ & - & 1.688 & - & - & - \\
\hline $0.2 M$ & 1.15 & 1.681 & 1.46 & 2.353 & 0.714 \\
\hline $0.5 \mathrm{M}$ & - & 1.687 & - & 2.353 & 0.717 \\
\hline $1.0 \mathrm{M}$ & 1.16 & 1.680 & 1.45 & 2.353 & 0.714 \\
\hline $2.0 \mathrm{M}$ & 1.17 & 1.690 & 1.44 & 2.252 & 0.714 \\
\hline
\end{tabular}

Swelling Data from Glass CoIum Observations

Relative Swelling

Reference Flowsheet

All Upflow Direction

\begin{tabular}{|c|c|c|c|}
\hline $\begin{array}{l}\text { 2M NaOH } \\
\text { After water rinse }\end{array}$ & $\begin{array}{l}1 \\
1\end{array}$ & 1 & Up \\
\hline $\begin{array}{l}\text { Filtered Supernate (composite) } \\
\text { After water rinse }\end{array}$ & $\begin{array}{l}1.11 \\
1.05\end{array}$ & $\begin{array}{l}0.96 \\
0.98\end{array}$ & $\begin{array}{l}\text { Down } \\
\text { Down }\end{array}$ \\
\hline $2 \mathrm{M}\left(\mathrm{Na}_{4}\right)_{2} \mathrm{CO}_{3}-2 \mathrm{M} \mathrm{Na}_{4} \mathrm{OH}$ & $\begin{array}{l}0.89 \\
0.94\end{array}$ & $\begin{array}{l}0.94 \\
0.93\end{array}$ & $\begin{array}{l}\text { Up } \\
\text { Up }\end{array}$ \\
\hline
\end{tabular}


TABLE 4.52

Ion Exchange Capacity of "Duolite" ARC-359 Resin

(Sulfonic acid exchange capacity $-2.49 \mathrm{~g} \mathrm{eq} / \mathrm{kg}$ air-dry resin)

\begin{tabular}{|c|c|c|c|c|c|}
\hline $\begin{array}{l}\text { NaOH Concentration, } \\
\text { moles/liter }\end{array}$ & $\frac{\text { Excess }^{a}}{\text { geg/kg }}$ & $\frac{\mathrm{Na}^{+} \text {Capacity }}{\text { dry resin }}$ & $\begin{array}{l}\text { Total } \mathrm{Na}^{+} \\
\mathrm{g} \text { eq } / \mathrm{kg} \\
\text { dry resin }\end{array}$ & $\begin{array}{l}\text { Capacity } \\
8 \mathrm{eq} / \mathrm{I} \\
\text { wet resin } \\
\end{array}$ & $\begin{array}{l}\text { lb eq/gal } \\
\text { wet resin }\end{array}$ \\
\hline 0.0047 & 0.776 & & 3.266 & 1.445 & 0.0120 \\
\hline 0.0114 & 1.58 & & 4.07 & 1.732 & 0.0144 \\
\hline 0.0492 & 2.02 & & 4.51 & 1.804 & 0.0150 \\
\hline 0.0987 & 2.59 & & 5.08 & 1.992 & 0.0166 \\
\hline 0.1926 & 3.13 & & 5.62 & 2.153 & 0.0180 \\
\hline 0.497 & 3.77 & & 6.26 & 2.276 & 0.0190 \\
\hline 0.964 & 4.46 & & 6.95 & 2.356 & 0.0196 \\
\hline 1.975 & 5.31 & & 7.80 & 2.600 & 0.0217 \\
\hline 4.979 & 7.97 & & 10.46 & 3.804 & 0.0317 \\
\hline
\end{tabular}

a. Excess above sulfonic acid exchange capacity.

TABLE 4.53

Effects of Feed $\mathrm{Na}^{+}$and $\mathrm{OH}^{-}$on $\mathrm{Cs}^{+}$Sorption by "Duolite" ARC-359 Resin

$\mathrm{Na}$
1
2
3
4
5

$\mathrm{Na}^{+}, \mathrm{M}$

1

2

4

5

1

2

3

4

2

3

5

6

7

8

9
10
$\underline{\mathrm{OH}^{-}, \mathrm{M}}$

0.5

0.5

0.5

0.5

0.5

1.0

1.0

1.0

1.0

1.0

2.0

2.0

2.0

5.0

5.0

5.0

5.0

5.0

5.0 d

343

142

78

57

462

199

100

70

371

176

110

347

205

132

90

66 
TABLE 4.54

Effect of $\mathrm{Cs}^{+}$Concentration on the Sorption of

$\mathrm{Cs}^{+}$by "Duolite" ARC-359 Resin from 4.75M NaNO $3-1$. ON NaOH

$\begin{array}{lll}\frac{\left[\mathrm{Cs}^{+}\right], M}{1} & \frac{\mathrm{K}_{\mathrm{C}} \text { (obs) }}{6.35} & \frac{\mathrm{K}_{\mathrm{d}} \text { (calc) }}{5.81} \\ 0.0976 & 9.01 & 9.68 \\ 0.00943 & 15.4 & 17.4 \\ 0.00402 & 19.3 & 20.1 \\ 0.000779 & 30.3 & 24.9 \\ 0.0000572 & 50.7 & 54.6 \\ 0.0 \text { (Tracer) } & 101 & 98.18\end{array}$

Two-site Equation Parameters

$$
\begin{array}{ll}
\mathrm{K}_{\mathrm{s}} \equiv /\left[\mathrm{Na}^{+}\right]=27.7 & \mathrm{Ex}_{1}=0.773 \\
\mathrm{R}_{\mathrm{s}_{2}} \equiv /\left[\mathrm{Na}^{+}\right]=23262 & \mathrm{Ex}_{2}=0.00333
\end{array}
$$

\begin{tabular}{|c|c|c|c|c|c|c|c|}
\hline \multirow{3}{*}{$\begin{array}{l}\text { Test } \\
\text { No. } \\
1\end{array}$} & \multirow{2}{*}{$\begin{array}{l}\text { Principal } \\
\text { Cations in } \\
\text { Sludge }\end{array}$} & \multicolumn{3}{|c|}{ Supernate } & \multirow[b]{2}{*}{$137 \mathrm{CB} \quad \mathrm{DF}$} & \multicolumn{2}{|c|}{$\frac{\text { Plutonizm }}{\text { Feed }}$} \\
\hline & & CV & $\frac{F L w h}{C V / h r}$ & $\frac{\text { Rate }}{g a l / \min -f t^{2}}$ & & $\begin{array}{l}\text { feed, } \\
\mu \mathrm{C} i / g a l\end{array}$ & $D F$ \\
\hline & None & 20 & 1 & 0.22 & $3.7 \times 10^{5}$ & 5 & 60 \\
\hline 2 & $\mathrm{Fe}, \mathrm{Al}, \mathrm{Mn}, \mathrm{U}$ & 20 & 1 & 0.22 & $8.0 \times 10^{5}$ & 27 & 8 \\
\hline 3 & $\mathrm{Fe}, \mathrm{Al}, \mathrm{Mn}, \mathrm{U}$ & 30 & 2 & 0.45 & $4.2 \times 10^{5}$ & 17 & 5 \\
\hline 4 & $\mathrm{Fe}, \mathrm{U}, \mathrm{Nn}, \mathrm{Na}$ & 40 & 2 & 0.45 & $3.9 \times 10^{5}$ & 65 & 38 \\
\hline 5 & $\mathrm{Fe}, \mathrm{U}, \mathrm{Na}, \mathrm{Al}$ & 60 & 3 & 0.67 & $3.7 \times 10^{50}$ & $b$ & - \\
\hline 6 & $\mathrm{Al}, \mathrm{U}, \mathrm{Fe}, \mathrm{Hg}$ & 40 & 1 & 0.22 & $4.2 \times 10^{5}$ & $b$ & - \\
\hline 7 & $\mathrm{Al}, \mathrm{U}, \mathrm{Fe}, \mathrm{Ca}$ & 40 & 2 & 0.44 & $3.7 \times 10^{5}$ & 51 & 30 \\
\hline 8 & $\mathrm{Al}, \mathrm{Fe}, \mathrm{Ca}, \mathrm{Mn}$ & 40 & 1 & 0.22 & $6.1 \times 10^{5}$ & 51 & 42 \\
\hline 9 & None & 20 & 1 & 0.22 & $2.9 \times 10^{5}$ & $25,600^{c}$ & 300 \\
\hline
\end{tabular}

TABLE 4.55

a. Average over first 40 column volumes. Others averaged over entire test.

b. Feed composition uncertain. Product composition 3.4 (in Test 5) and 2.6 (in Test 6) $\mathrm{LCi} / \mathrm{gal}$.

c. Saturated with ${ }^{238} \mathrm{Pu}$. 
TABLE 4.56

Sirontium Ion Exchange Cycle Schedule

\begin{tabular}{|c|c|c|c|c|c|c|}
\hline Stream & $\frac{\text { Thro }}{\mathrm{CV}^{\prime \prime}}$ & Gout & $\begin{array}{l}\text { Average } \\
\mathrm{CV} / \mathrm{hr}\end{array}$ & $\frac{\text { Flow Rate }}{\mathrm{gpm} / \mathrm{ft}^{2}}$ & $\begin{array}{l}\text { Time } \\
\text { Hours }\end{array}$ & $\begin{array}{l}\text { Flow } \\
\text { Direction }\end{array}$ \\
\hline Feed & 40 & 30,500 & 3,33 & 1.67 & 12 & Down \\
\hline Cs First Rinse & 10 & 7,625 & 3.33 & 1.67 & 3 & Down \\
\hline Sr First Rinse & 1.5 & 1,143 & 3.33 & 1.67 & 0.45 & Down \\
\hline Elute & 6 & 4,572 & 1 & 0.5 & 6 & Up \\
\hline Sr 2nd Rinse & 3.0 & 2,286 & 1 & 0.5 & 3 & $U_{p}$ \\
\hline Stand by & & & & & 6.55 & \\
\hline Total & & & & & 31 & \\
\hline
\end{tabular}

\# Column volume; the strontium ion exchange column will have a resin bed of 762 gallons with a sufficient freeboard to allow at least a $75 \%$ expansion of the bed during backwash.

TABLE 4.57

Sr Distribution Coefficients for Various Ion Exchange Resins

\begin{tabular}{ll} 
Resin & $\begin{array}{l}\text { Distribution } \\
\text { Coefficient }\end{array}$ \\
\cline { 1 - 2 } "Amberlite" IRC-50 & 31 \\
"Amberlite" IRC-84 & 17 \\
"Amberlite" IRC-718 & 384 \\
"Chelex" 100* & 215 \\
"Dowex" AI & 162 \\
"Dowex" CCR-2 & 20 \\
"Dowex" XFS-4132** & 306 \\
"Duolite" C-464 & 40 \\
"Duolite" ES-467 & 440 \\
\# "Chelex" 100 is an analytical grade of "Dowex" Al. \\
* "Dowex" XFS-4132 is a macroporous version of "Dowex" AI.
\end{tabular}


TABLE 4.58

Selectivity Series for "Amberlite" IRC-718

Distribution Coefficients $\mathrm{K}_{\mathrm{d}}$ for Metal Ions

in $1.0 \mathrm{M} \mathrm{NaOH}-4.75 \mathrm{M} \mathrm{NaNO}_{3}$

$\begin{array}{ll}\mathrm{Ion} & \frac{K_{d}}{\mathrm{meq} / 8 \text { dry resin per }} \\ \mathrm{meq} / \mathrm{mL} \text { liquid } \\ \mathrm{Sr} & 3250 \\ \mathrm{Hg} & 840 \\ \mathrm{Yb} & 674 \\ \mathrm{Ca} & 293 \\ \mathrm{Ba} & 176 \\ \mathrm{Ag} & 89 \\ \mathrm{Cr} & 53 \\ \mathrm{Cu} & 38 \\ \mathrm{~Pb} & 28\end{array}$

Strontium $K_{d}$ 's in Other Solutions

$2 \mathrm{M} \mathrm{NaOH}, 3.75 \mathrm{M} \mathrm{NaNO} 3$

IM NaOH, 4.15M NaNO $3,0.3 \mathrm{M} \mathrm{Na}_{2} \mathrm{SO}_{4} \quad 1040$

$1 \mathrm{M} \mathrm{NaOH}, 4.15 \mathrm{M} \mathrm{NaNO}, 0.3 \mathrm{M} \mathrm{Na} 2 \mathrm{SO}_{4} \quad 2360$ 
TABLE 4.59

Bulk Density of "Ionsiv" IE-95

$\begin{array}{ll}\frac{\text { TNX }}{\text { Data }} 55 & \text { Manufacturers } \\ \left(1 b_{m} / f t^{3}\right) & \left(1 b_{m} / f t^{3}\right)\end{array}$

Dry $\quad 46.8 \quad 40$

Hydrated $\quad 56.7 \quad 46$

"Linde Ionsiv" IE-95 is marketed as an acid resistant molecular sieve [54]. Zeolites are also known for stability at higher $\mathrm{pH} ' s(<12)$. They are resistant to high temperature, oxidation/ reduction, and ionizing radiation. They do not exhibit osmotic shock nor are they fouled by organics [56].

TABLE 4.60

Fixation of Cs-137 on Zeolites

\begin{tabular}{|c|c|c|c|}
\hline Absorbent & Composition & Size & Cs-137 Sorption* \\
\hline "Linde" AW-500 & Chabazite & 20 to 50 Mesh & $\begin{array}{l}100 \% \text { retention } \\
\text { for } 70 \mathrm{cV} \\
60 \% \text { retention } \\
\text { for } 80 \mathrm{cV}\end{array}$ \\
\hline "Zeolon" 900 & $\begin{array}{l}\text { Synthetic } \\
\text { Mordenite }\end{array}$ & 20 to 50 Mesh & $\begin{array}{l}100 \% \text { retention } \\
\text { for } 70 \mathrm{cV} \\
60 \% \text { retention } \\
\text { for } 80 \mathrm{cV}\end{array}$ \\
\hline "Zeolon" 500 & $\begin{array}{l}80 \% \text { Chabazite } \\
20 \% \text { Erionite }\end{array}$ & $\begin{array}{l}1 / 16 \text { in. } \\
\text { Pellets }\end{array}$ & $\begin{array}{l}\text { No retention } \\
\text { after } 8 \mathrm{cV}\end{array}$ \\
\hline "Vermiculite" & . & 20 to 50 Mesh & $\begin{array}{l}\text { No retention } \\
\text { after } 2 \mathrm{cV}\end{array}$ \\
\hline
\end{tabular}

* Each column volume $(100 \mathrm{ml})$ of concentrate contained Cs-137 from about 2 liters of SRP waste supernate. 

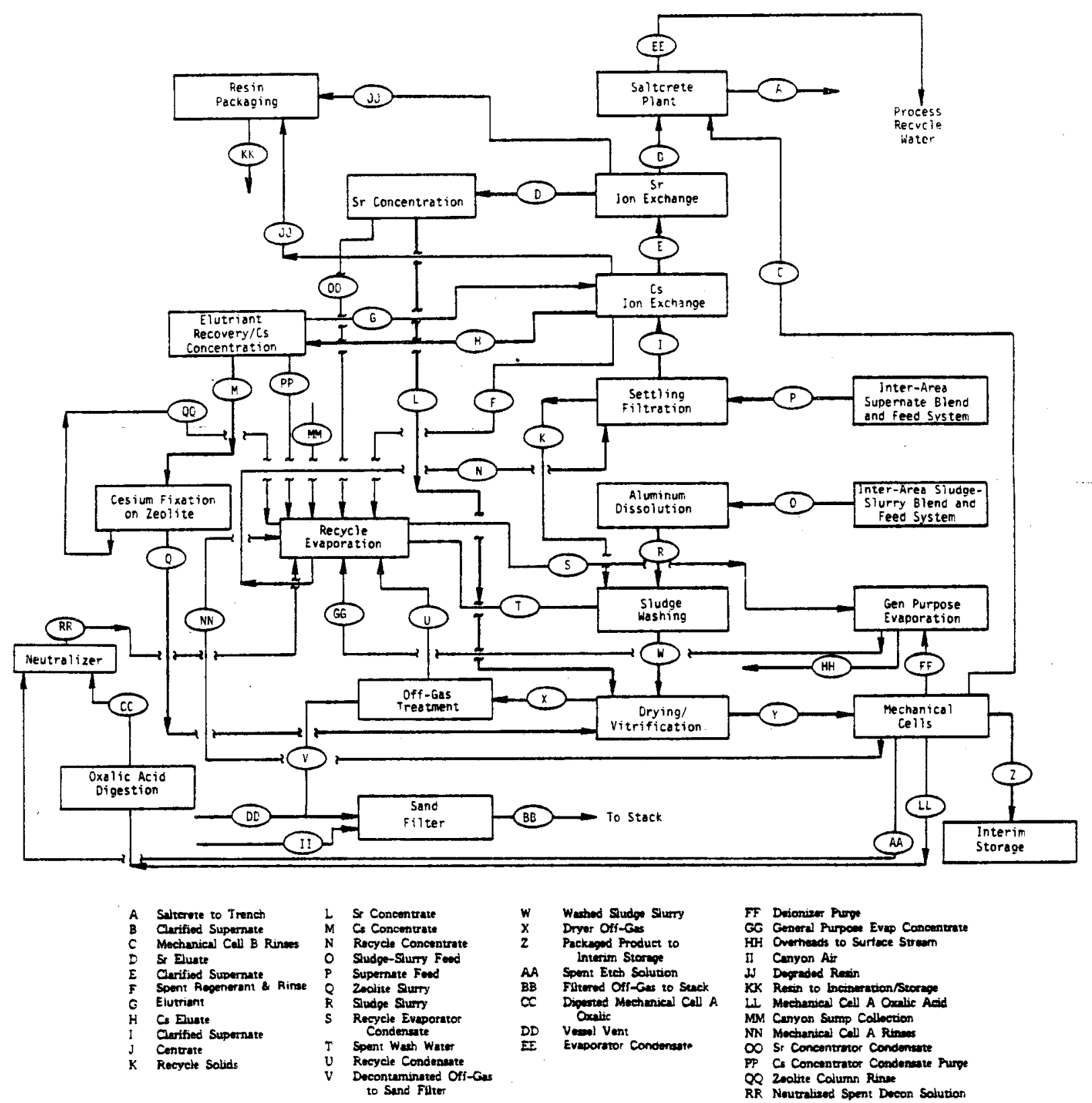

FIGURE 4.1 DWPF Overall Reference F'owsheet 


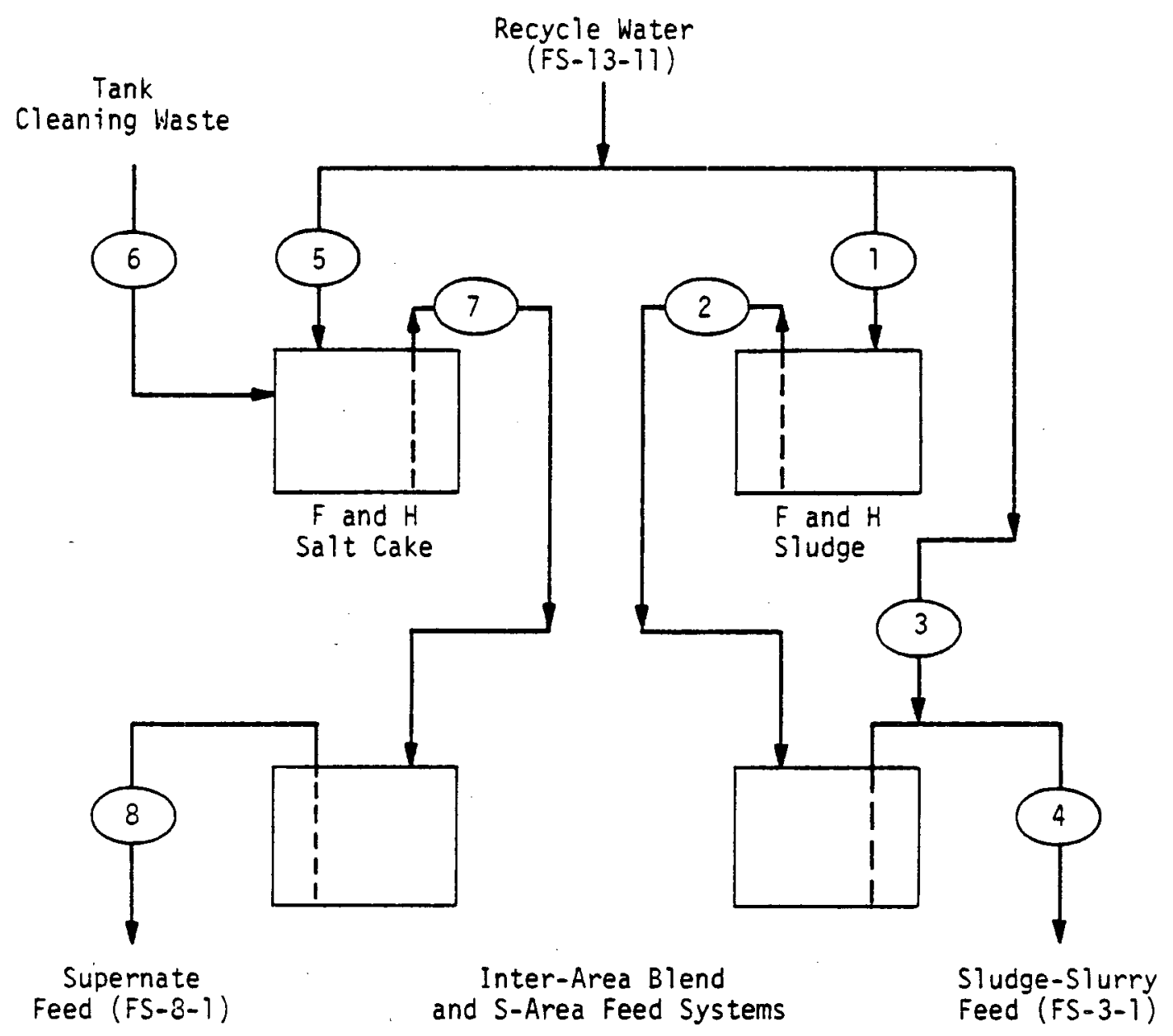

FIGURE 4.2 Sludge and Supernate Feed Preparation Flowsheet (FS-2) 


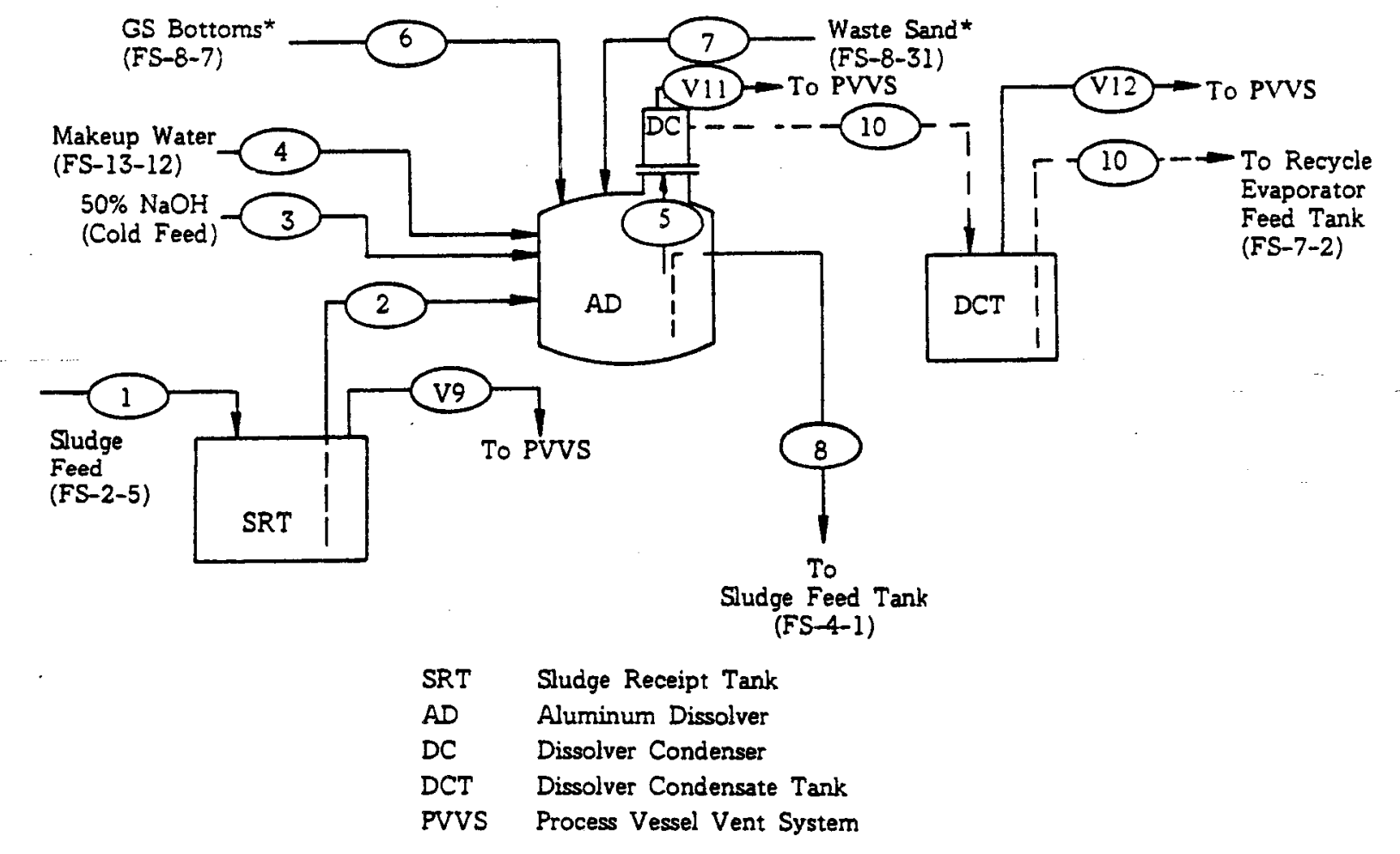

- These streams are added after the aluminum dissohing step is completed.

FIGURE 4.3 Aluminum Dissolution Flowsheet (FS-3) 


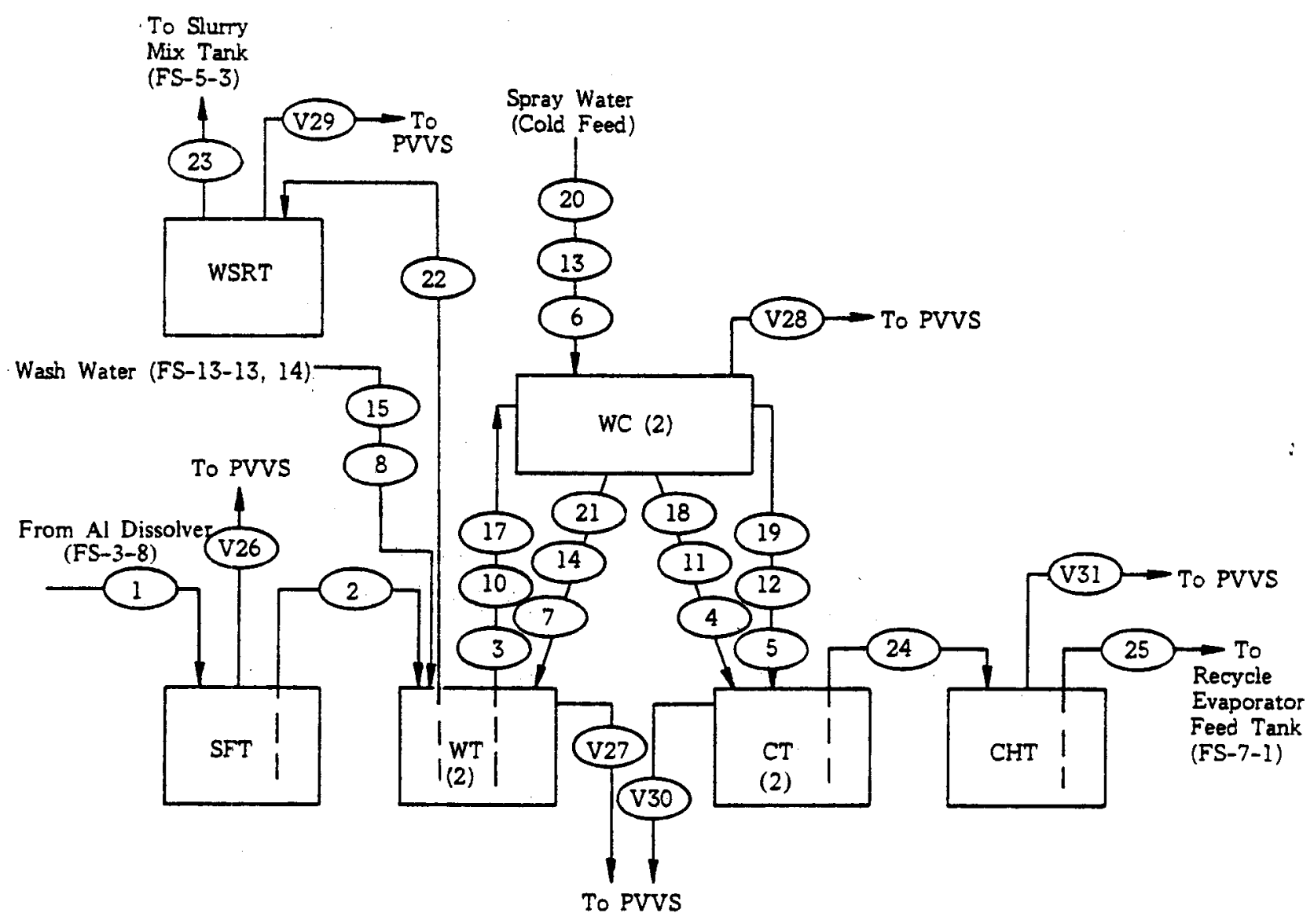

SFT Sludge Feed Tank

WT Wash Tank

WC Wash Centrifuge

CT Centrate Tank

CHT Centrate Hold Tank

WSRT Washed Sludge Run Tank

PVVS Process Vessel Vent System

FIGURE 4.4 Sludge Washing Flowsheet (FS-4) 


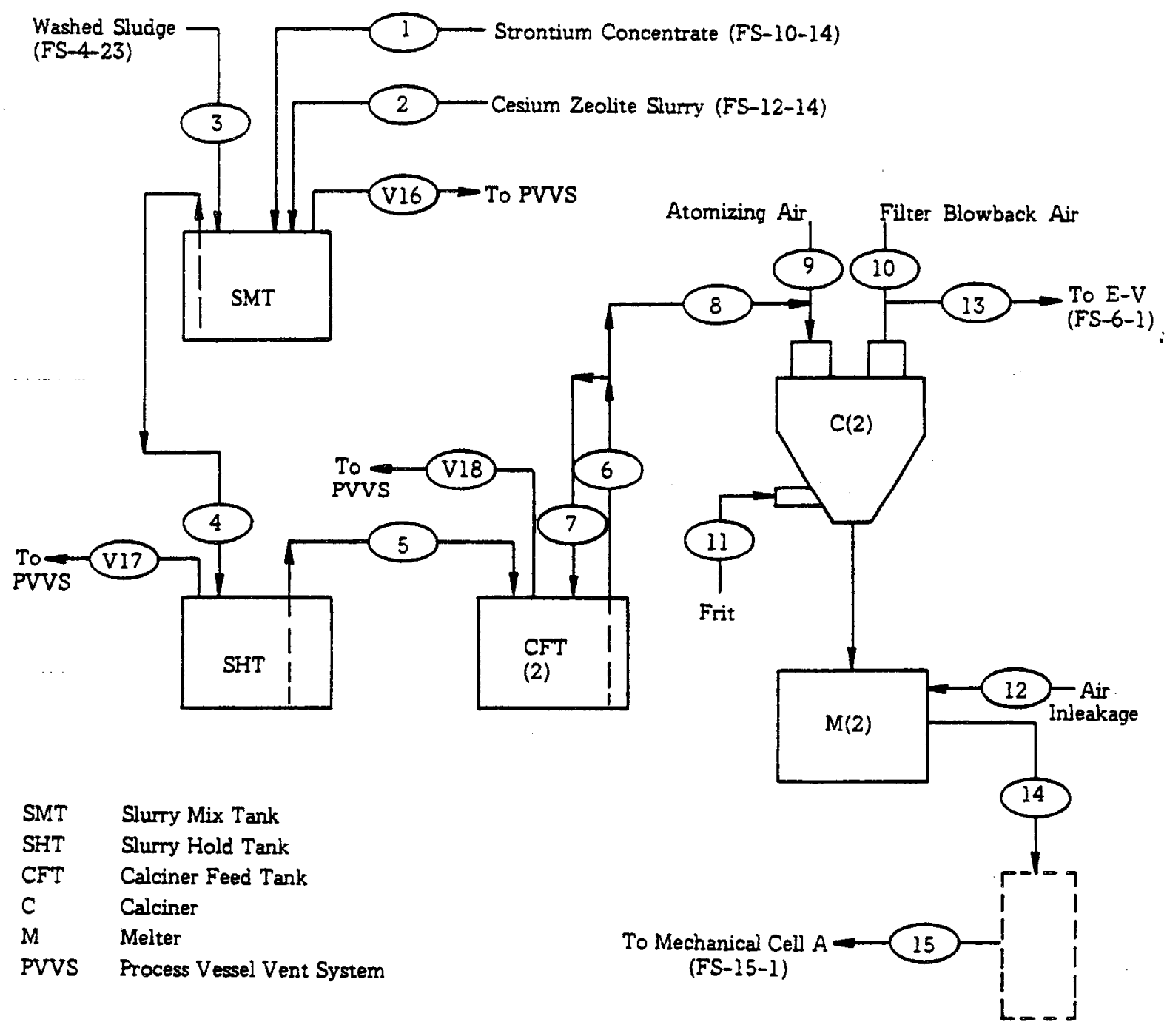

FIGURE 4.5 Spray Calcination/Vitrification Flowsheet (FS-5) 


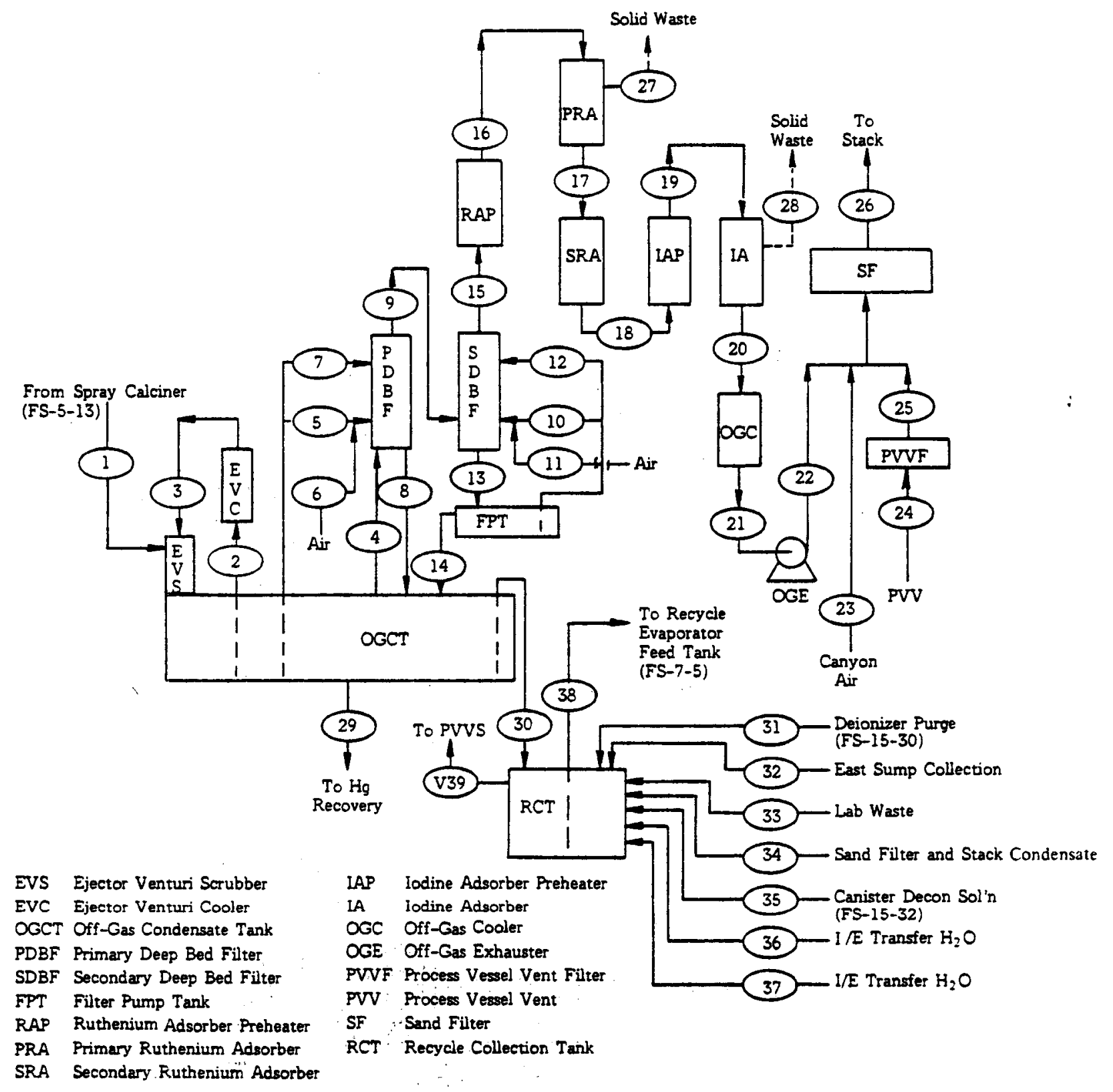

FIGURE $4: 6$ Of f-Gas Treatment Flowsheet (FS-6) 


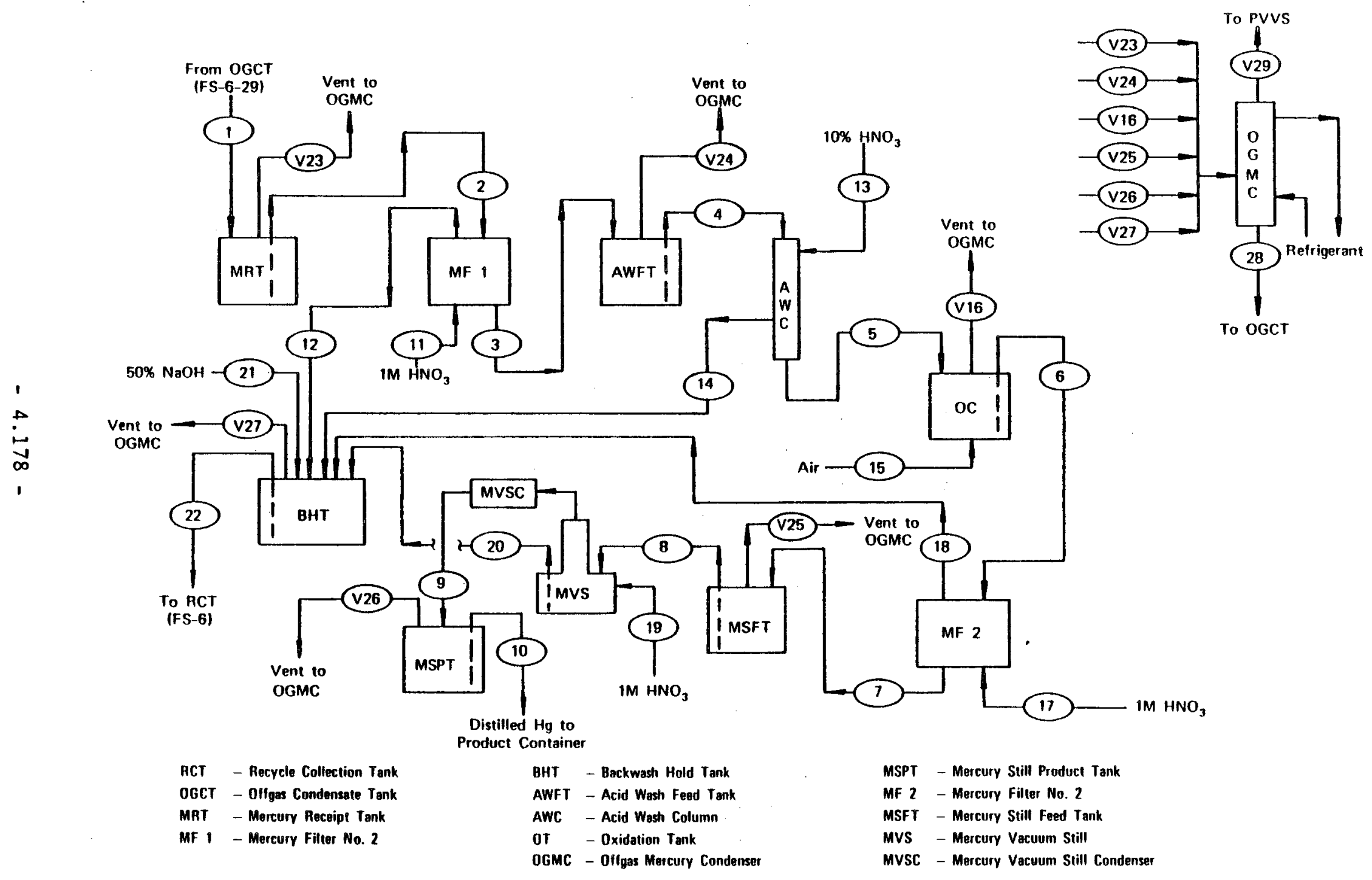

FIGURE 4.6A Mercury Recovery Flowsheet (FS-6A) 


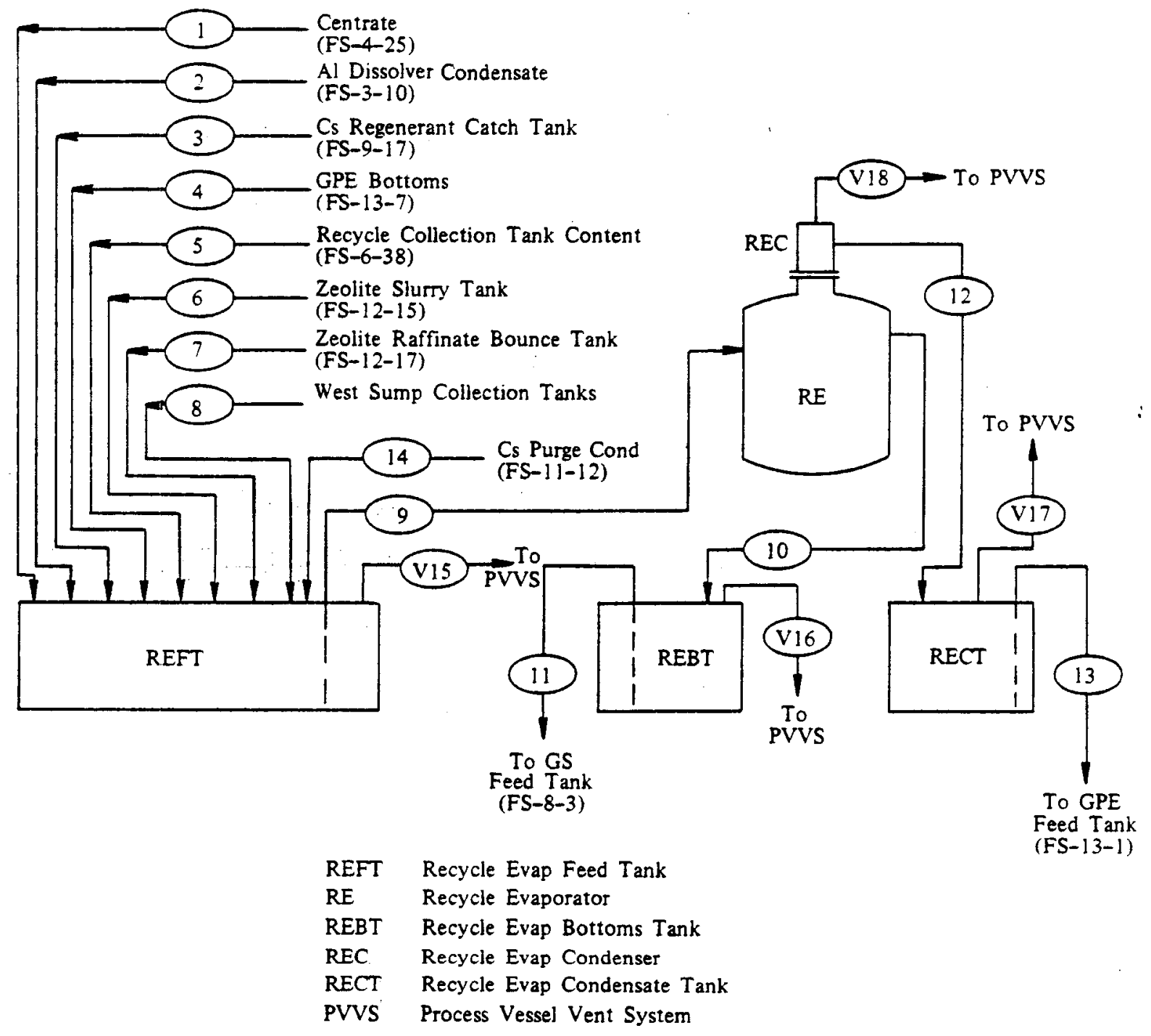

FIGURE 4.7 Recycle Evaporation.Flowsheet (FS-7) 


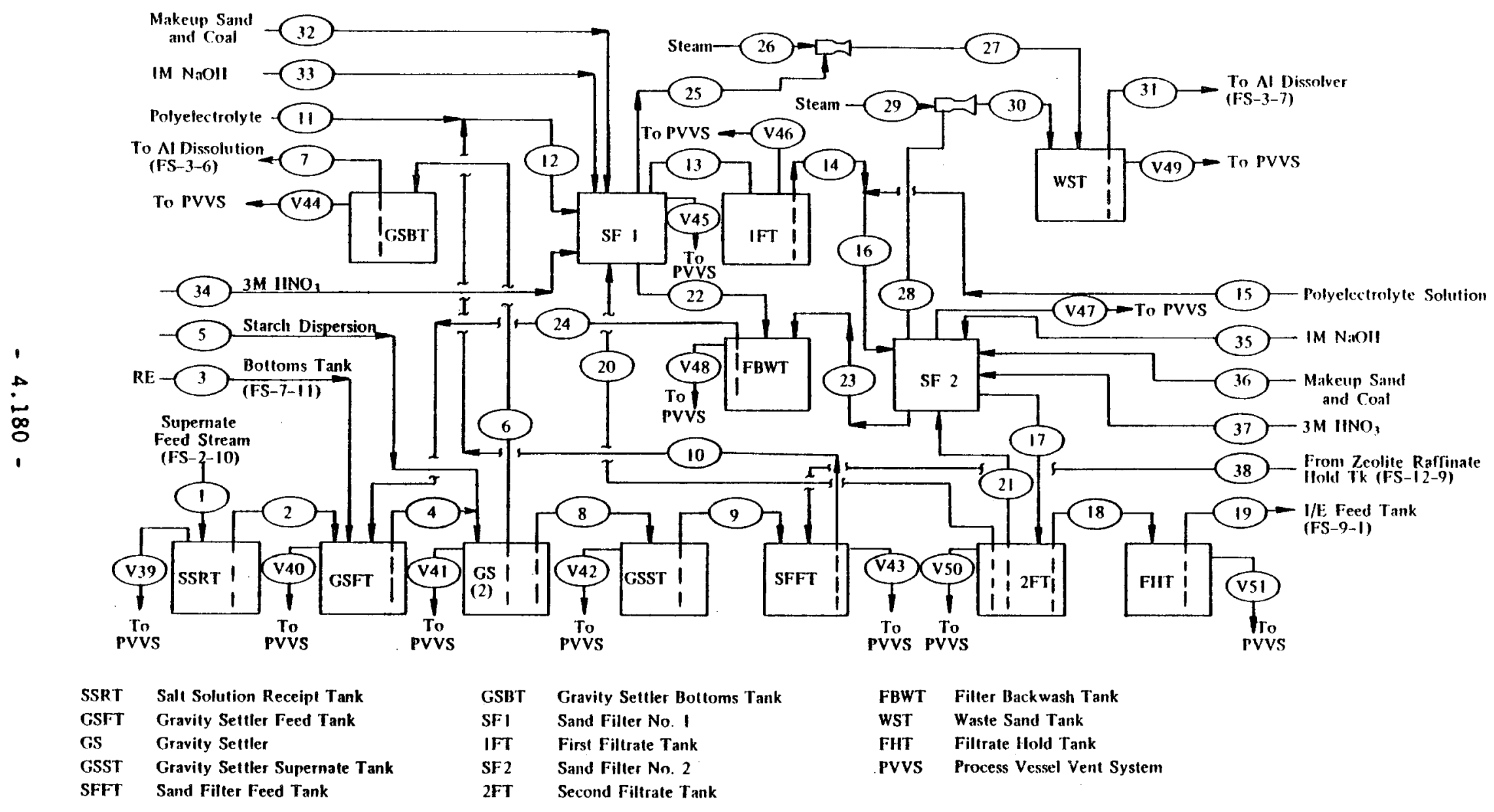

FIGURE 4.8 Settling and Filtration Flowsheet (FS-8) 


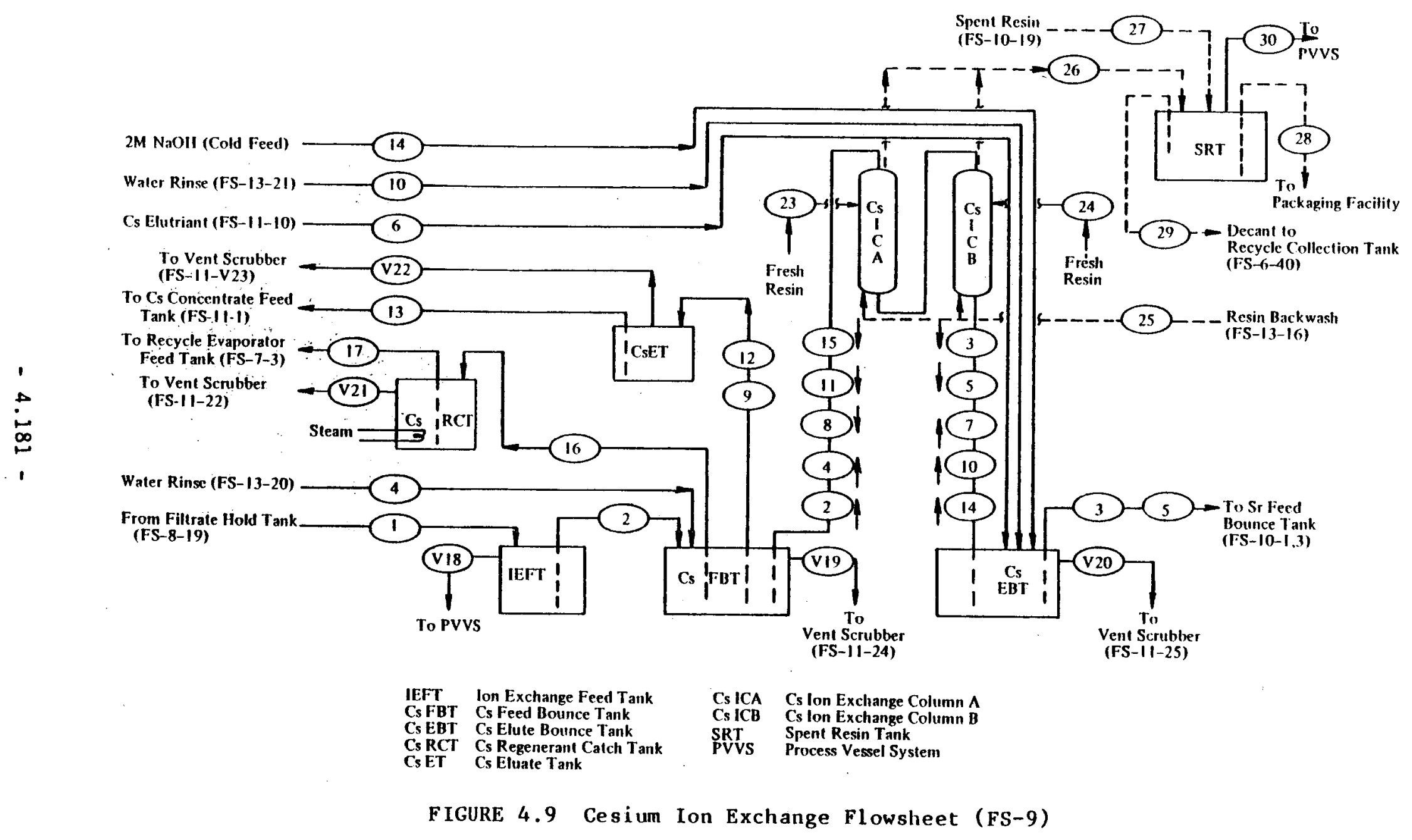




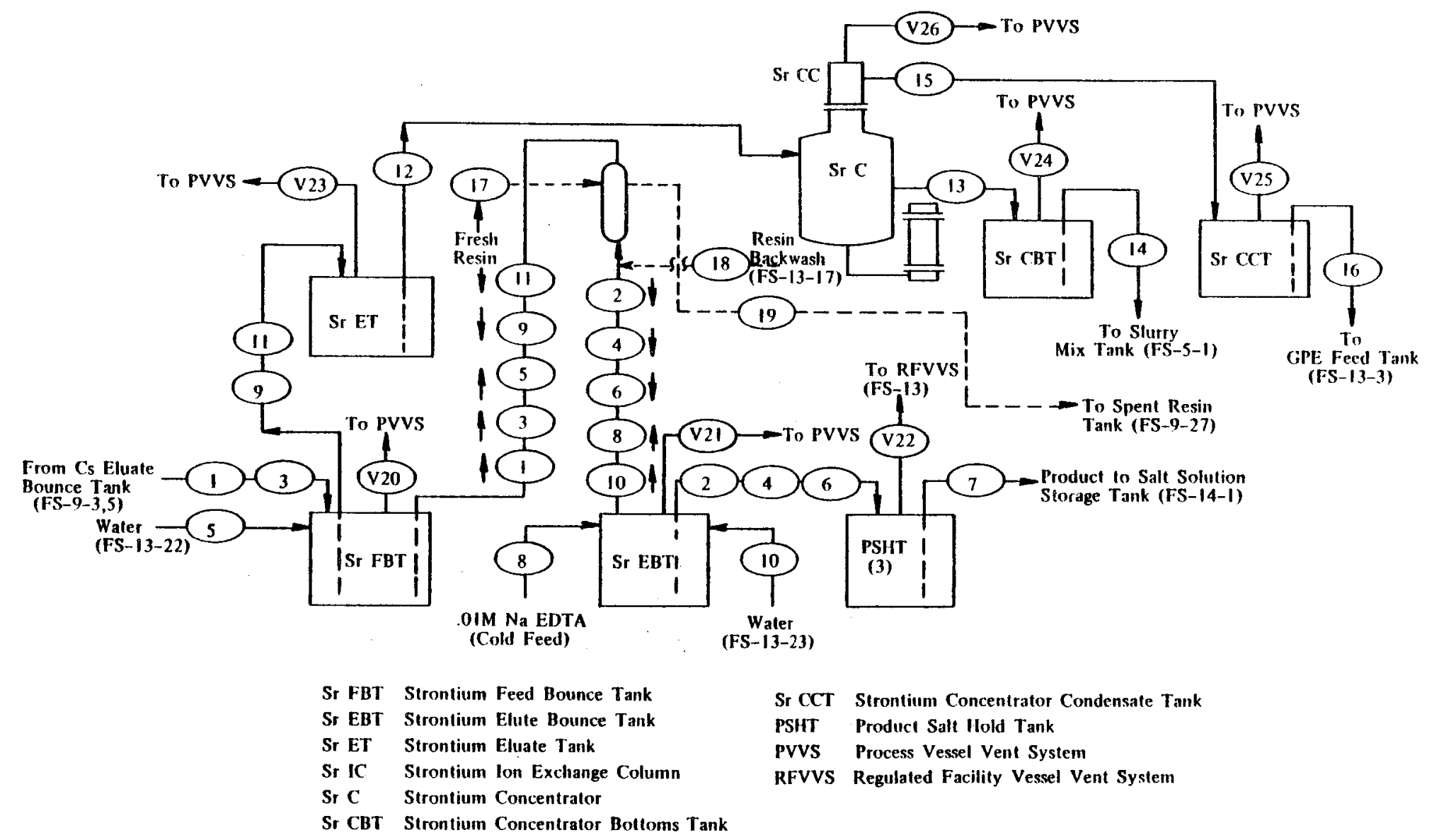

FIGURE 4.10 Strontium Ion Exchange and Concentrator Flowsheet (FS-10) 


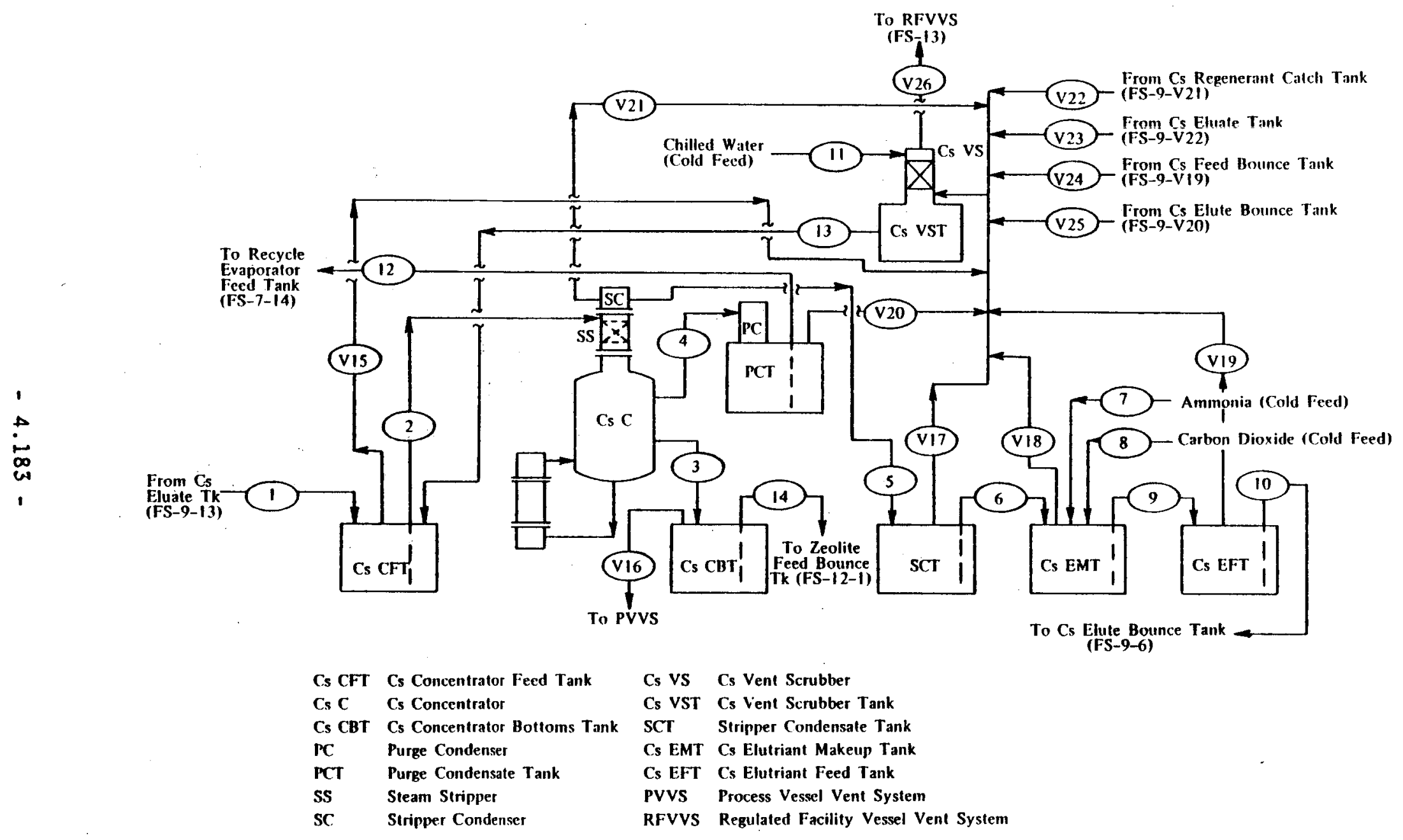

FIGURE 4.11 Cesium Elutriant Recovery and Cesium Concentration (FS-11) 


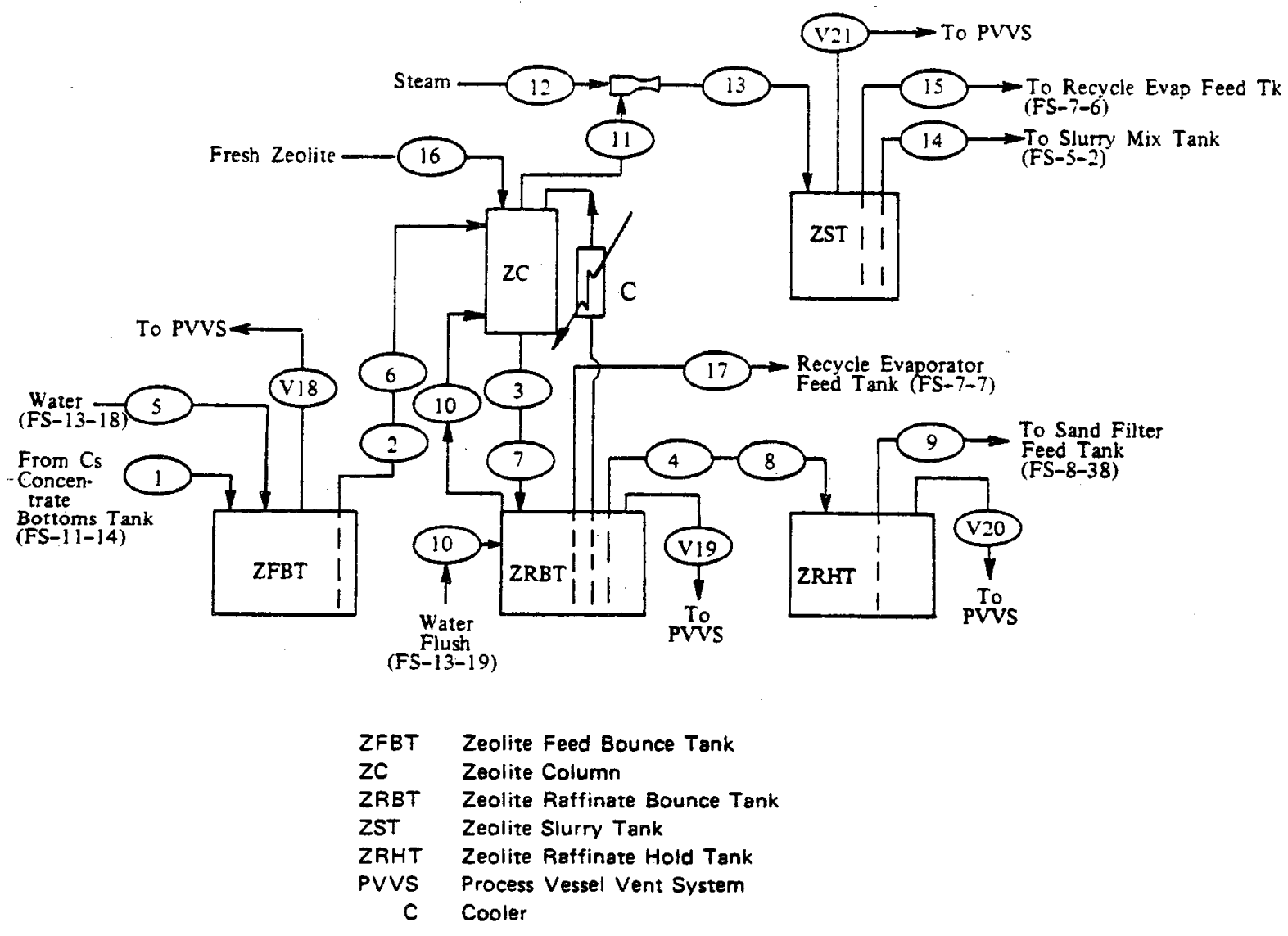

FIGURE 4.12 Cesium Fixation on Zeolite Flowsheet (FS-12) 


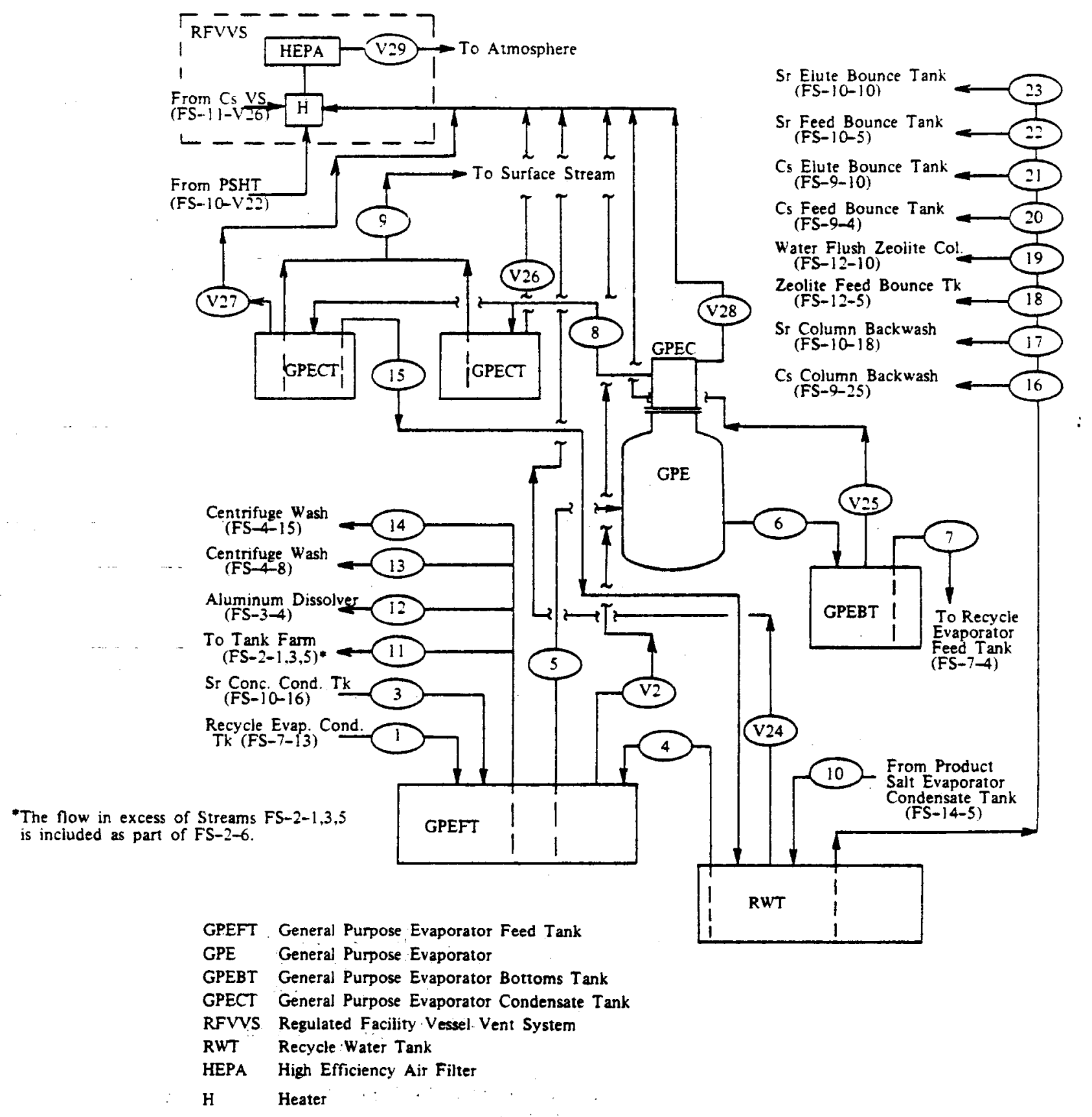

FIGURE 4.13 General-Purpose Evaporation Flowsheet (FS-13) 


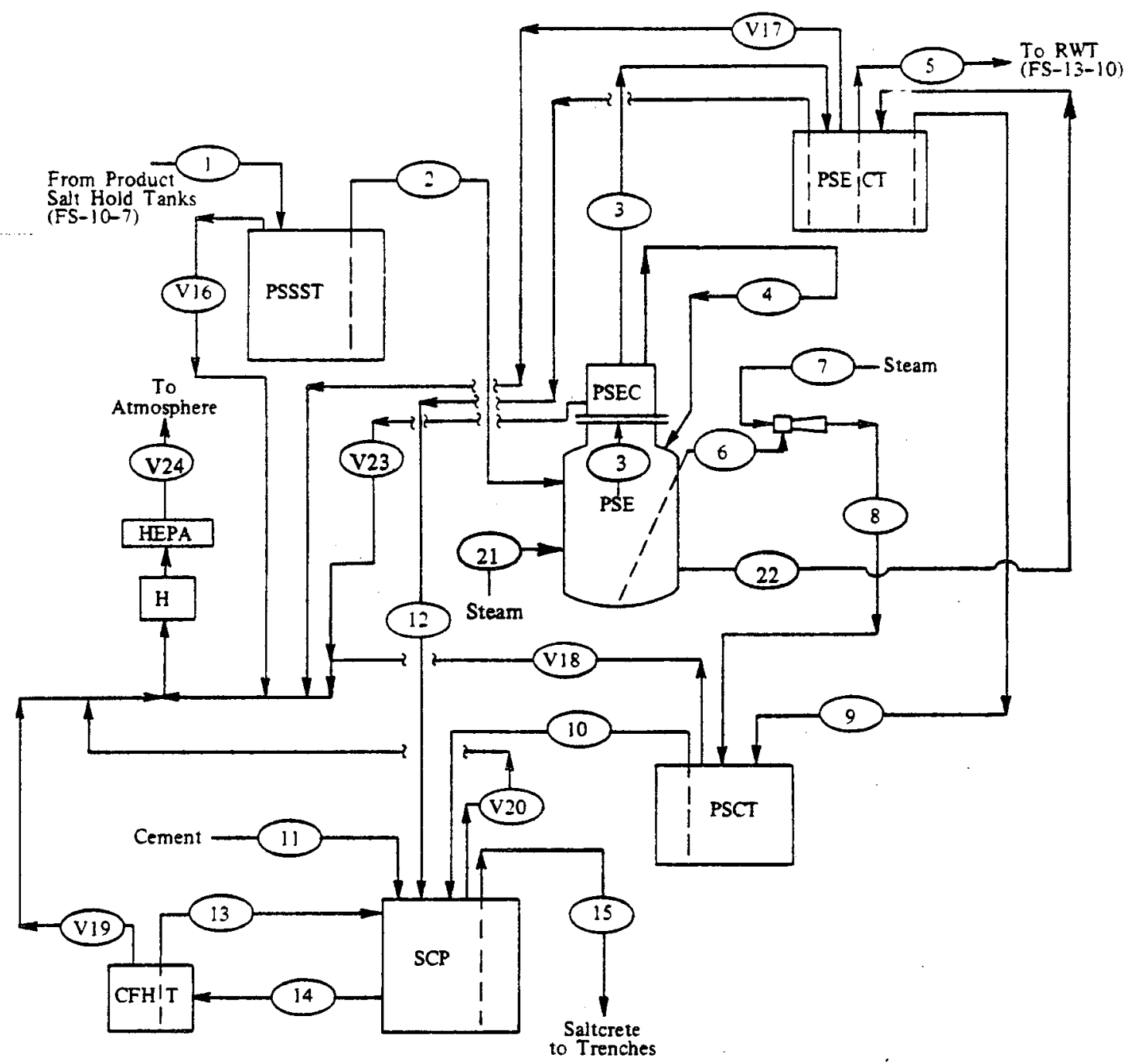

PSSST Product Salt Solution Storage Tank PSE Product Salt Evaporator

PSEC Product Salt Evaporator Condenser

PSECT Product Salt Evaporator Condensate Tank

PSCT Product Salt Concentrate Tank

SCP Saltcrete Plant

CFHT Concrete Fiush Hold Tank

H Heater

HEPA High Efficiency Air Filter

FIGURE 4.14 Product Salt Solution Concentration and Solidification in Concrete (FS-14) 


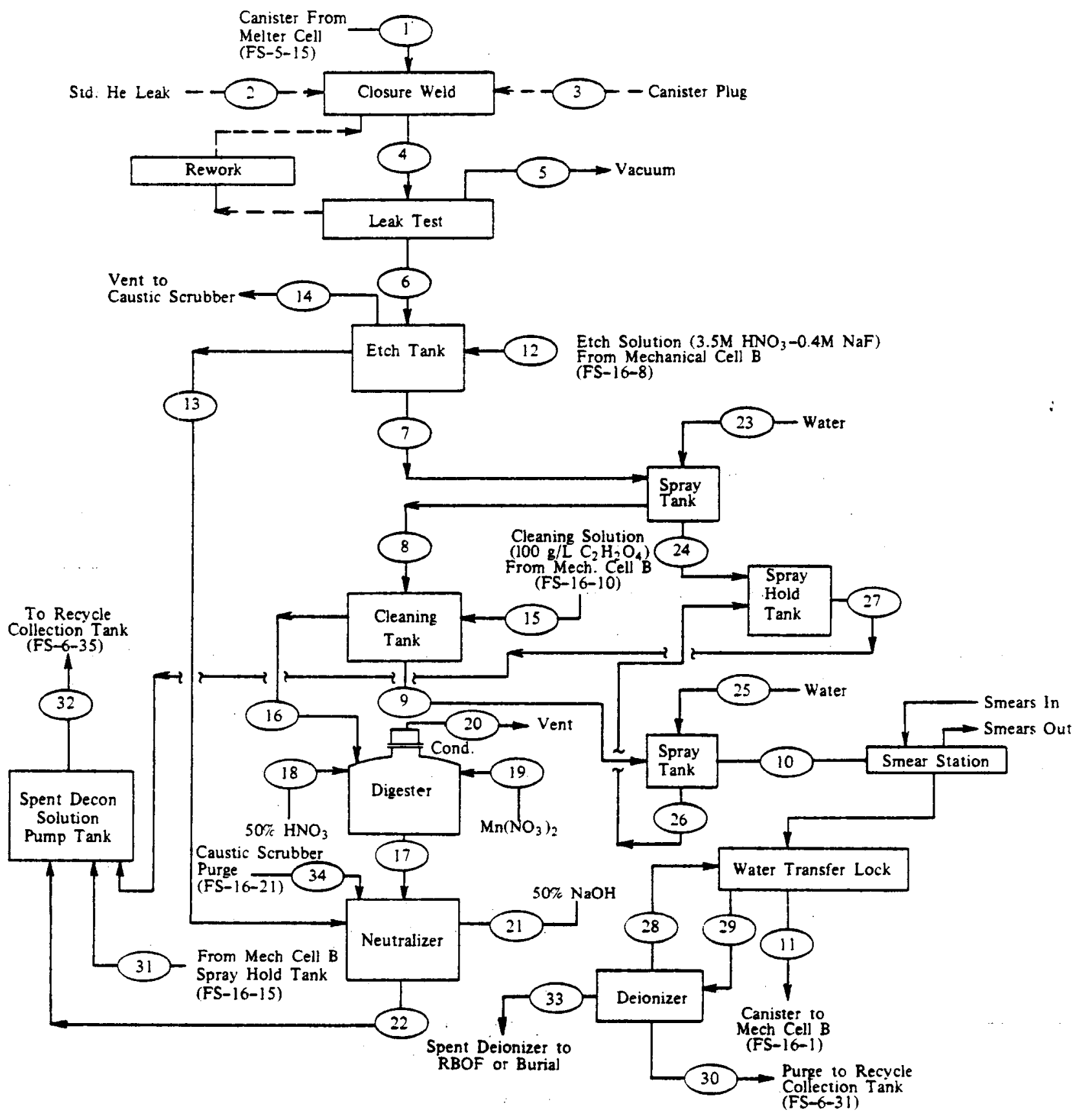

FIGURE 4.15 Mechanical Cell A Flowsheet (FS-15) 


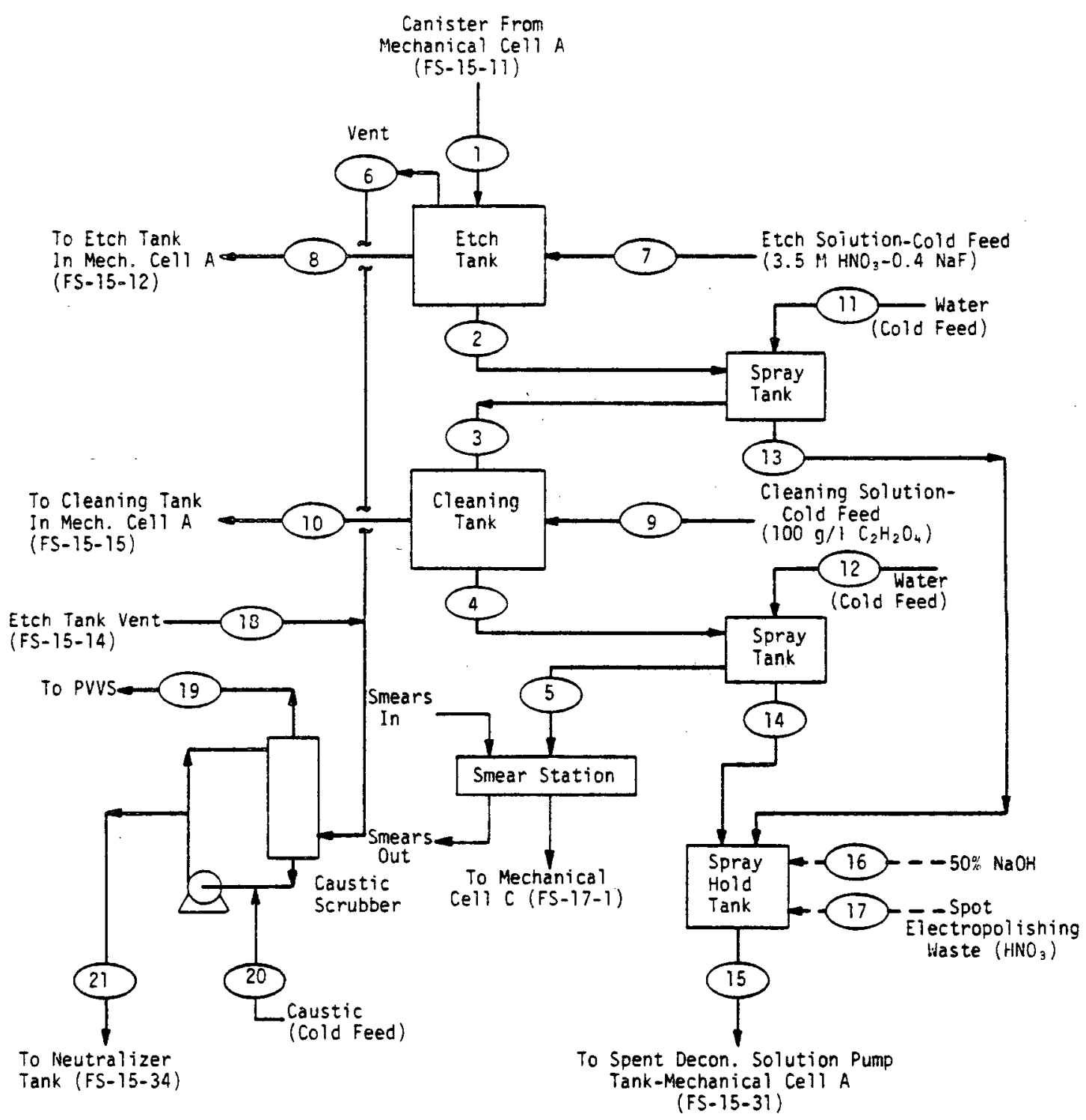

FIGURE 4.16 Mechanical Cell B Flowsheet (FS-16) 


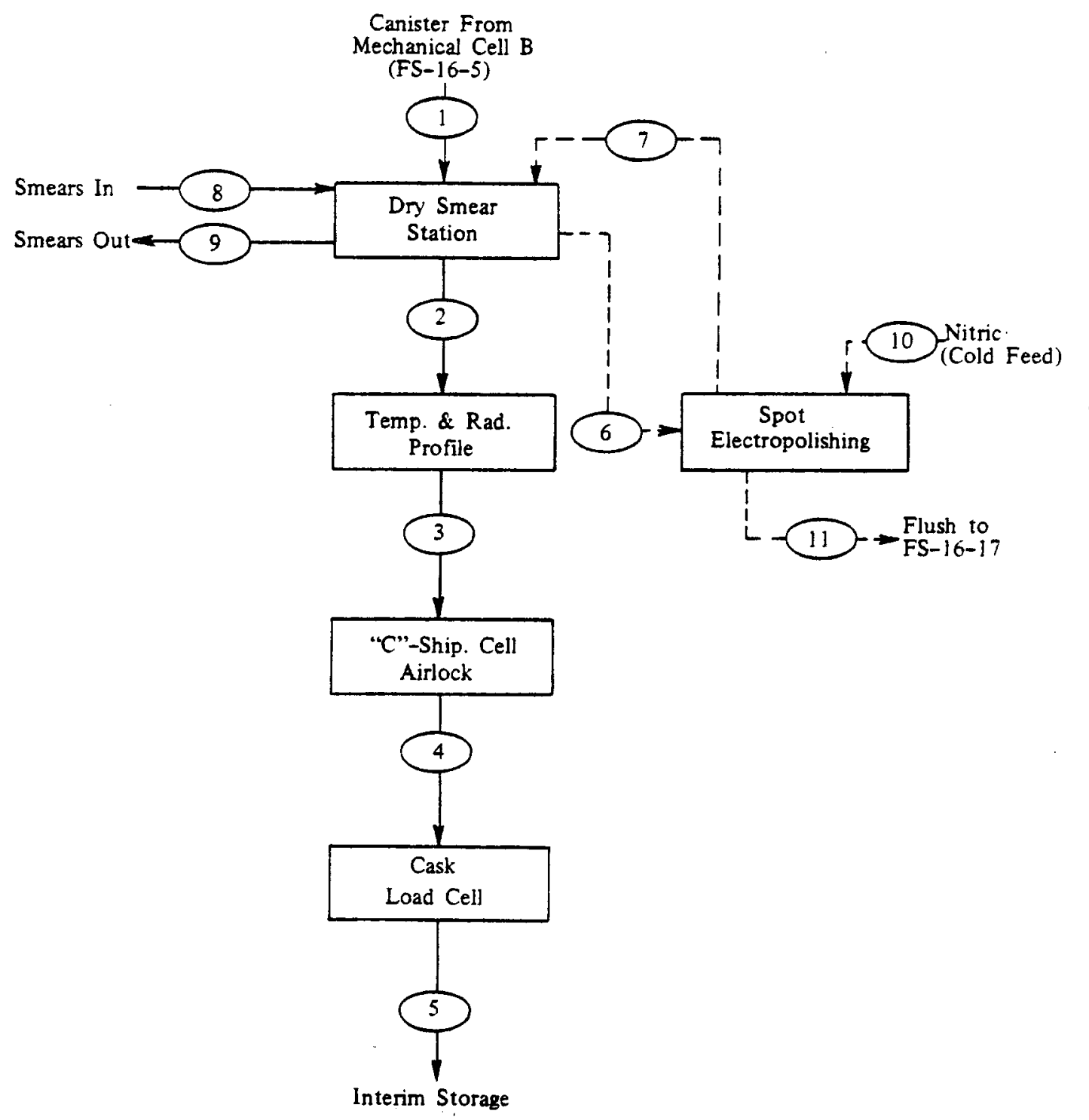

FIGURE 4.17 Mechanical Cell C Flowsheet (FS-17) 


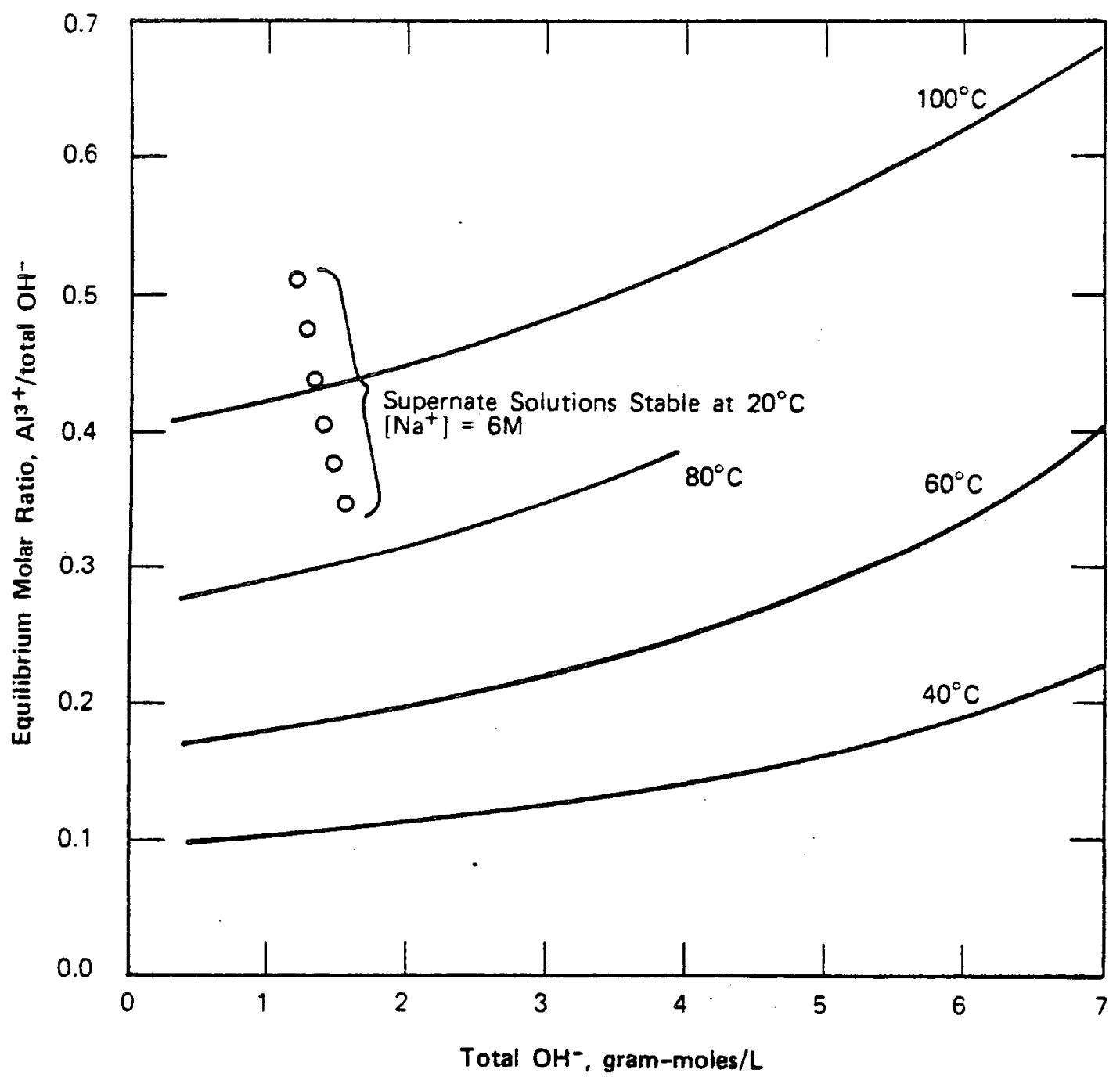

FIGURE 4.18 Solubility of Gibbsite in Caustic. Total $\mathrm{OH}^{-}=\mathrm{OH}^{-}+\mathrm{Al}^{3+}$ in solution. 


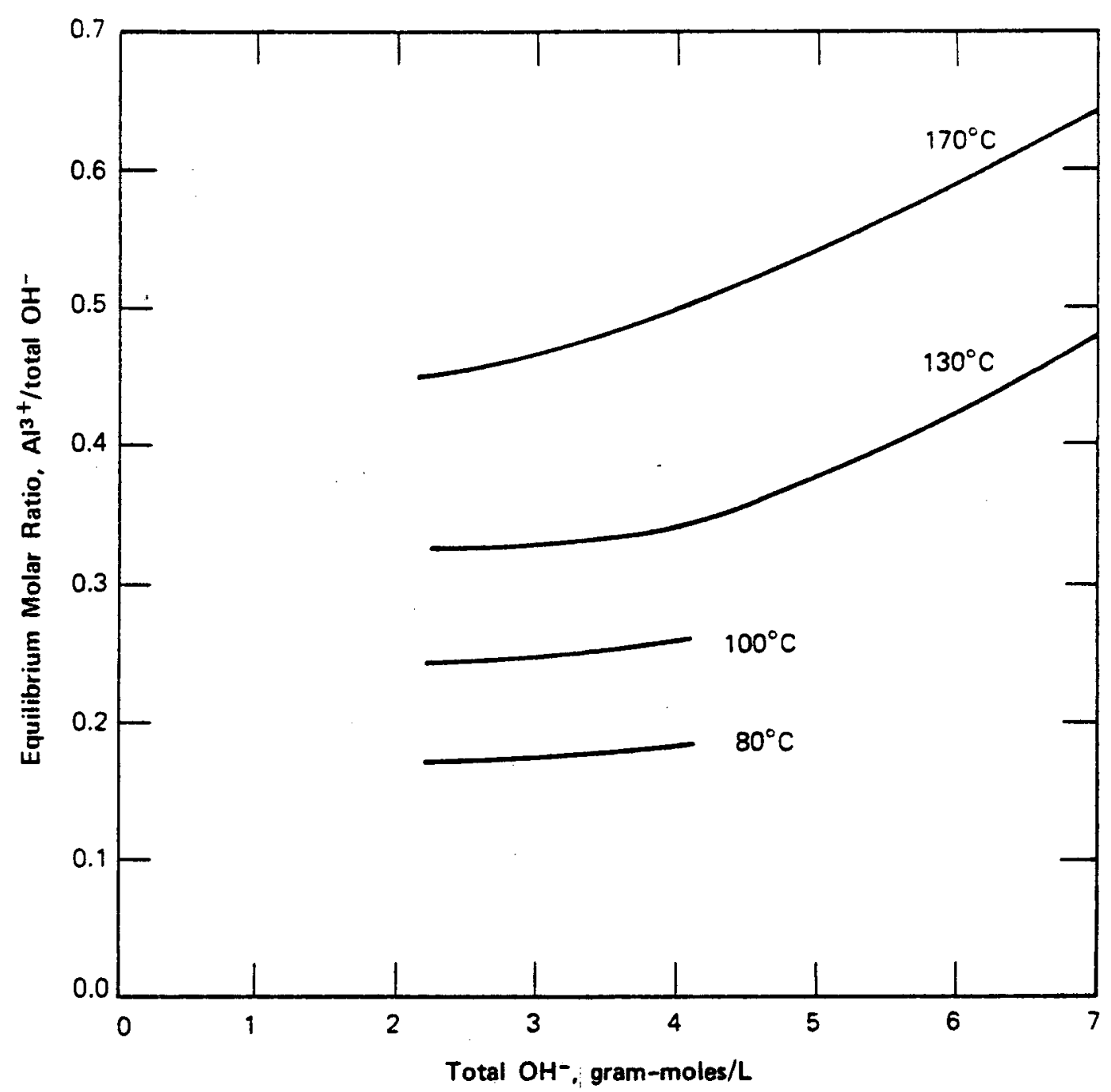

FIGURE 4.19 Solubility of Boehmite in Caustic. Total $\mathrm{OH}^{-}=\mathrm{Al}^{3+}$ in solution. 
$\ominus$

FIGURE 4.20 (Deleted)

$-4.192-$ 
FIGURE 4.21 (Deleted)

$\Theta$

$-4.193-$ 
$\ominus$

FIGURE 4.22 (Deleted)

$-4.194=$ 


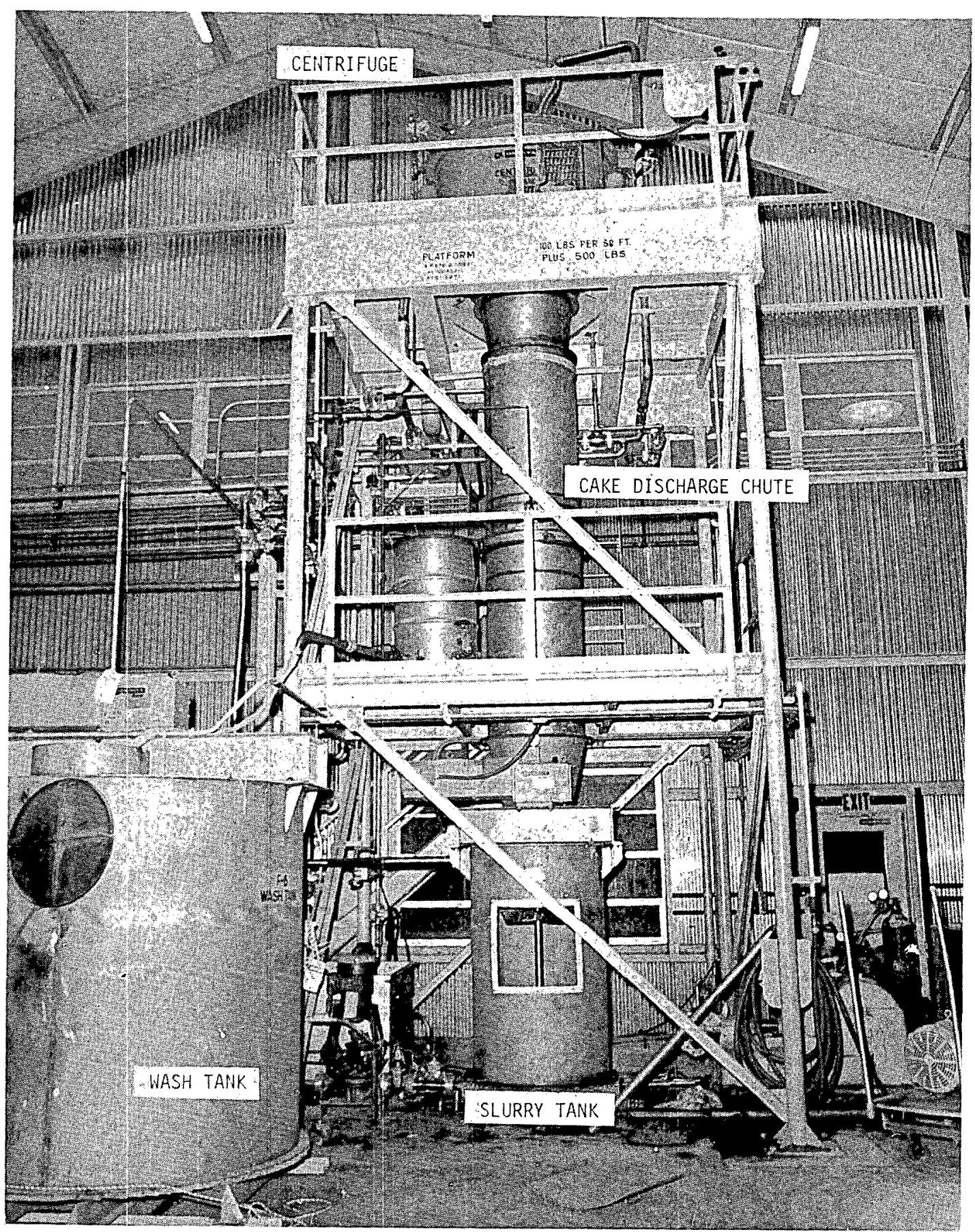

FIGURE 4.23 Large-Scale Sludge Washing Facility 


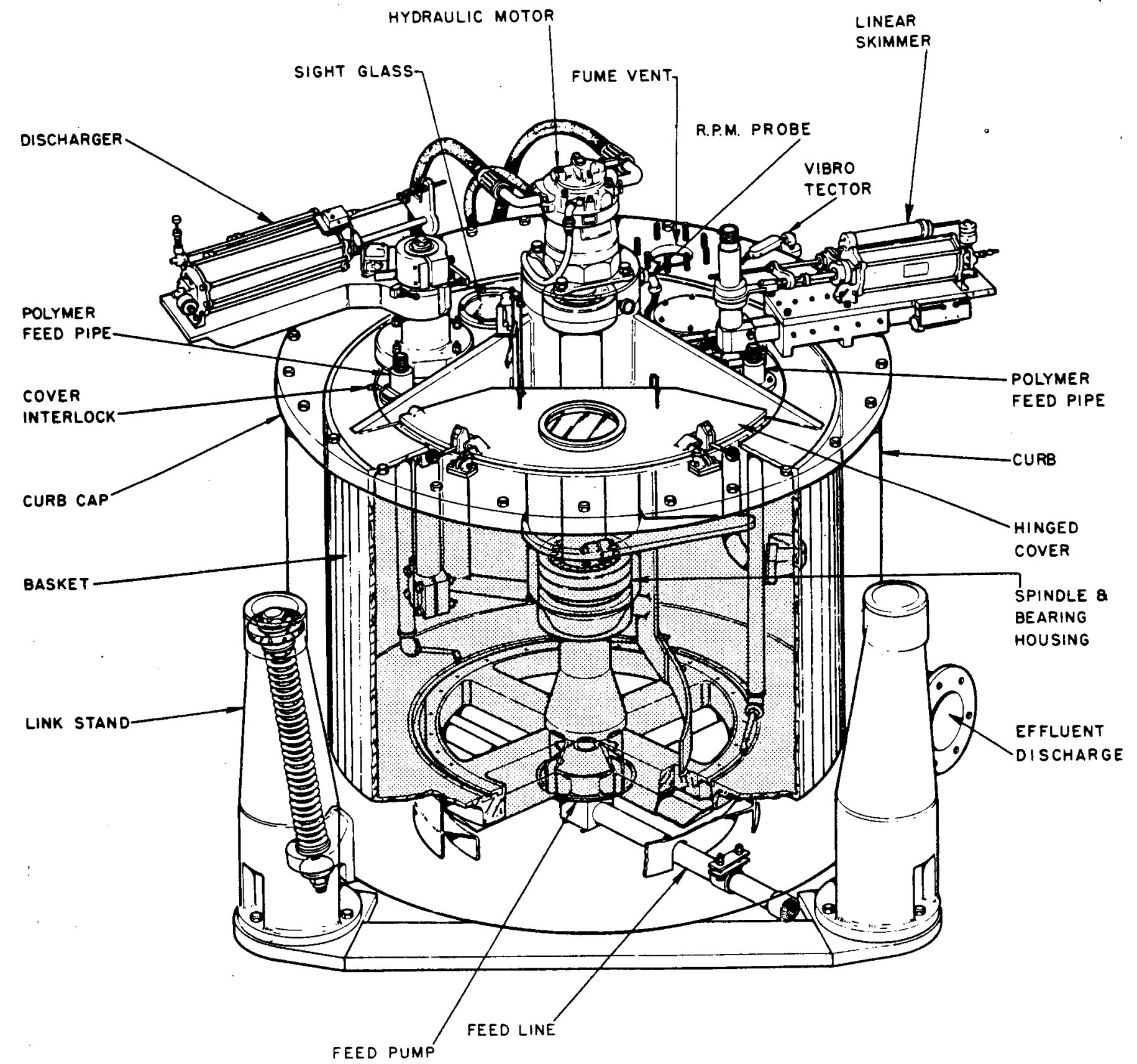

FIGURE 4.24 Delaval Centrifuge Used in Semiworks

Studies (Courtesy of the Delaval

Separator Company) 


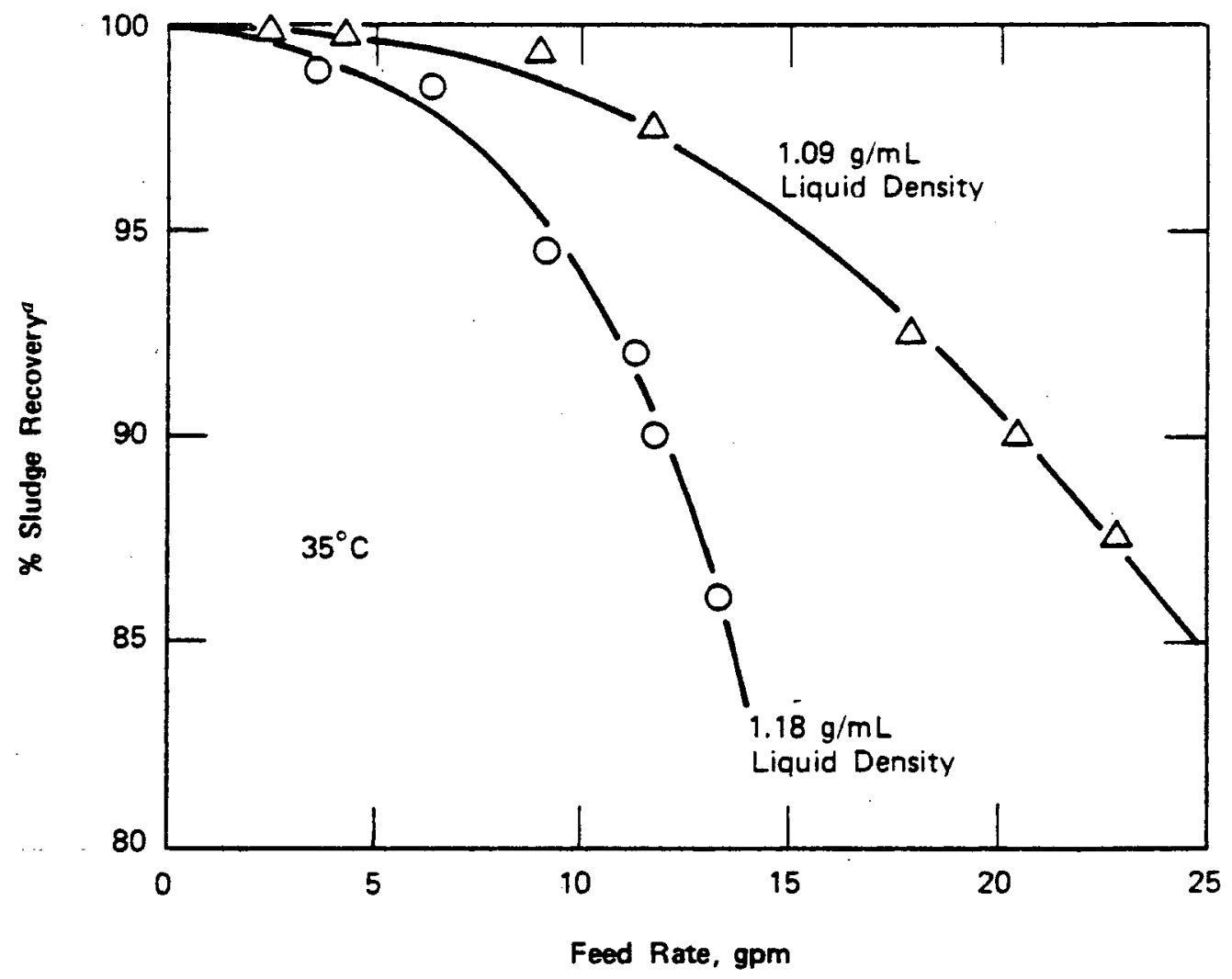

c. \% Sludge Recovery $=\frac{\text { Vol \% Sludge in Feed }- \text { Vol \% Sludge in Centrate }}{\text { Vol \% Sludge in Feed }}$ where volume \% sludge is messured by centrifuging $10 \mathrm{~mL}$ samples at $5000 \mathrm{~g}$ 's for 3 minutes

FIGURE 4.25 Sludge Separation in Large-Scale TNX Centrifuge 


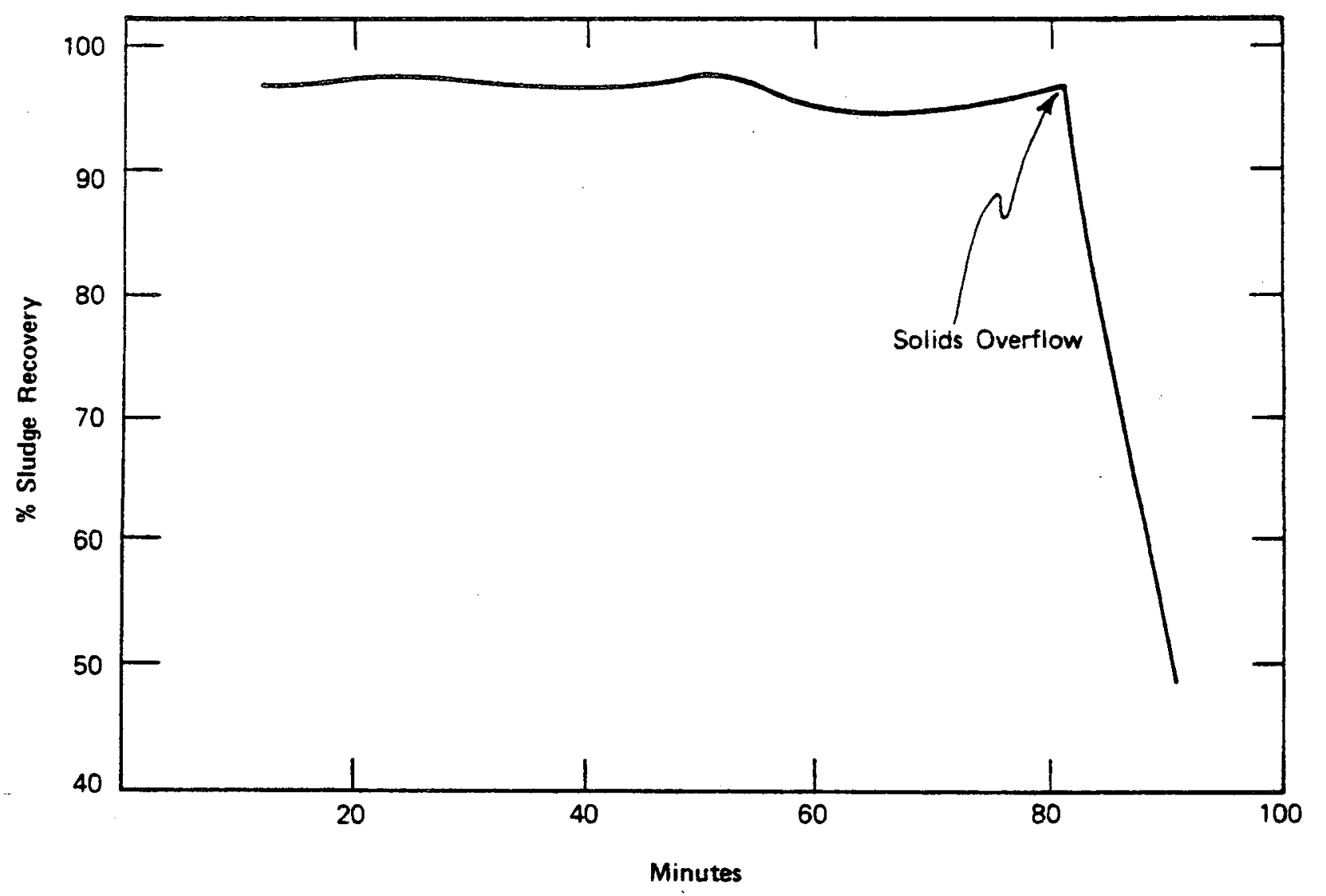

FIGURE 4.26 Sludge Recovery Versus Time in Large-Scale TNX Centrifuge 


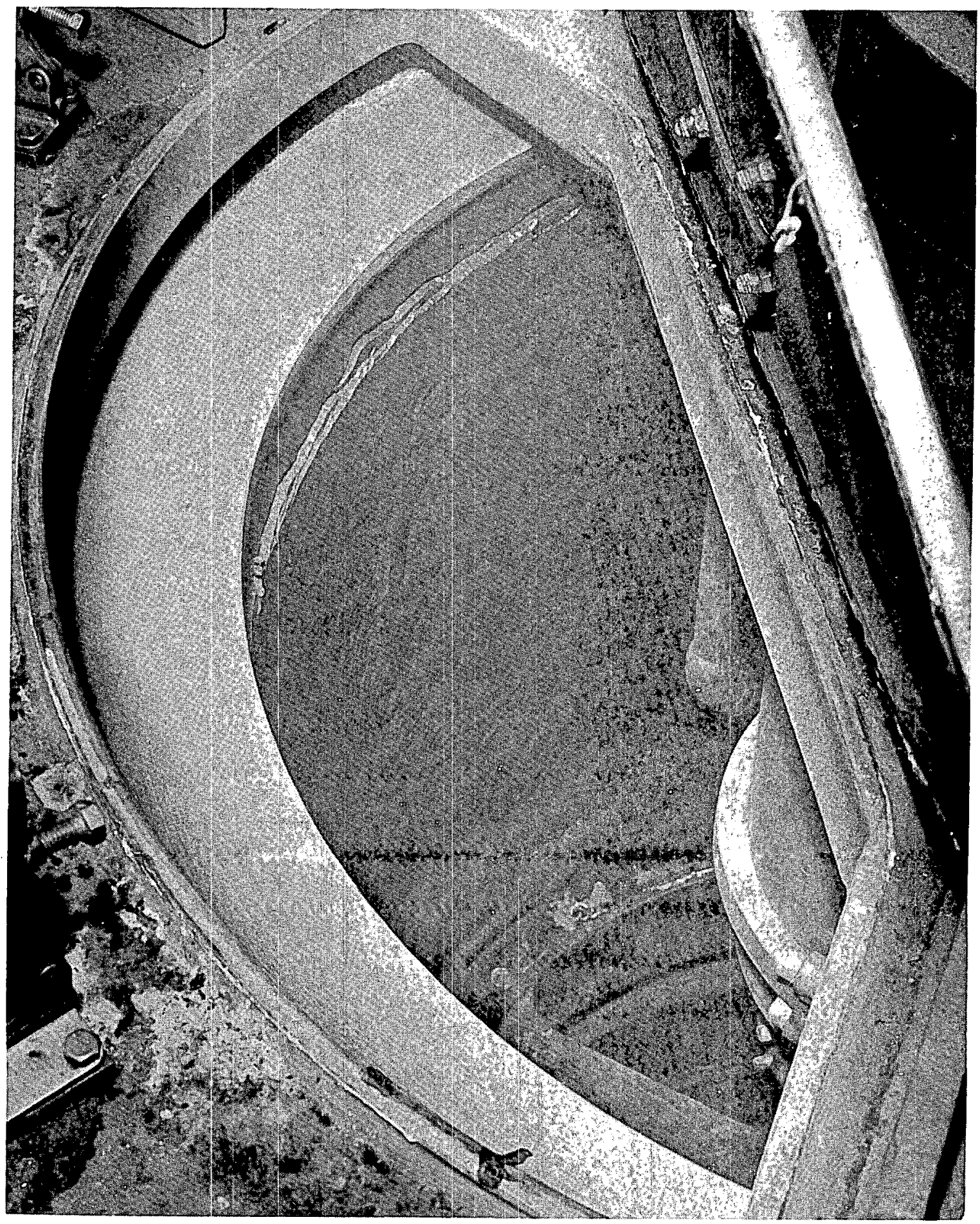

FIGURE 4.27 Sludge Cake in Large-Scale TNX Centrifuge 


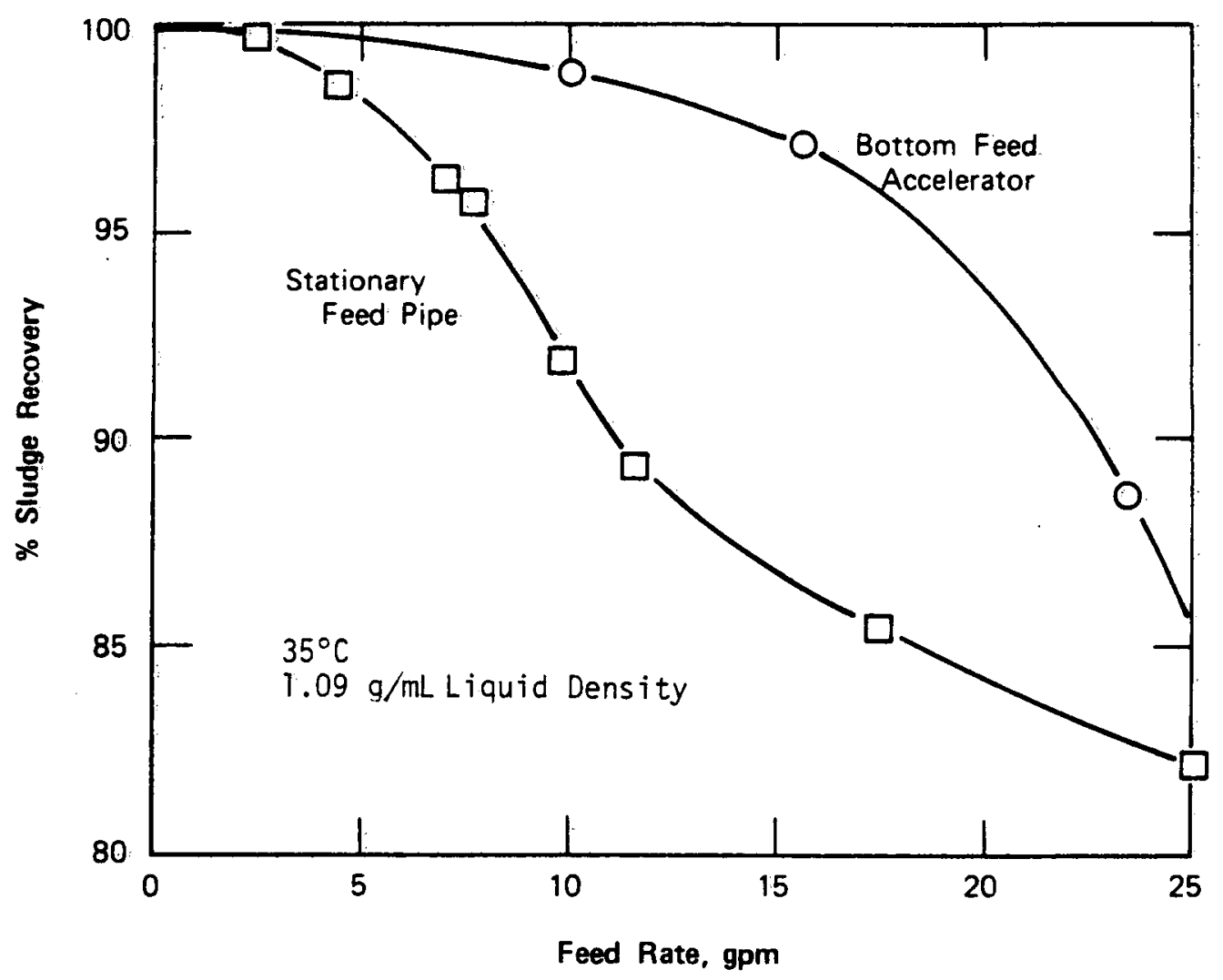

FIGURE 4.28 Effect of Feed Acceleration on Sludge Separation in Large-Scale TNX Centrifuge 


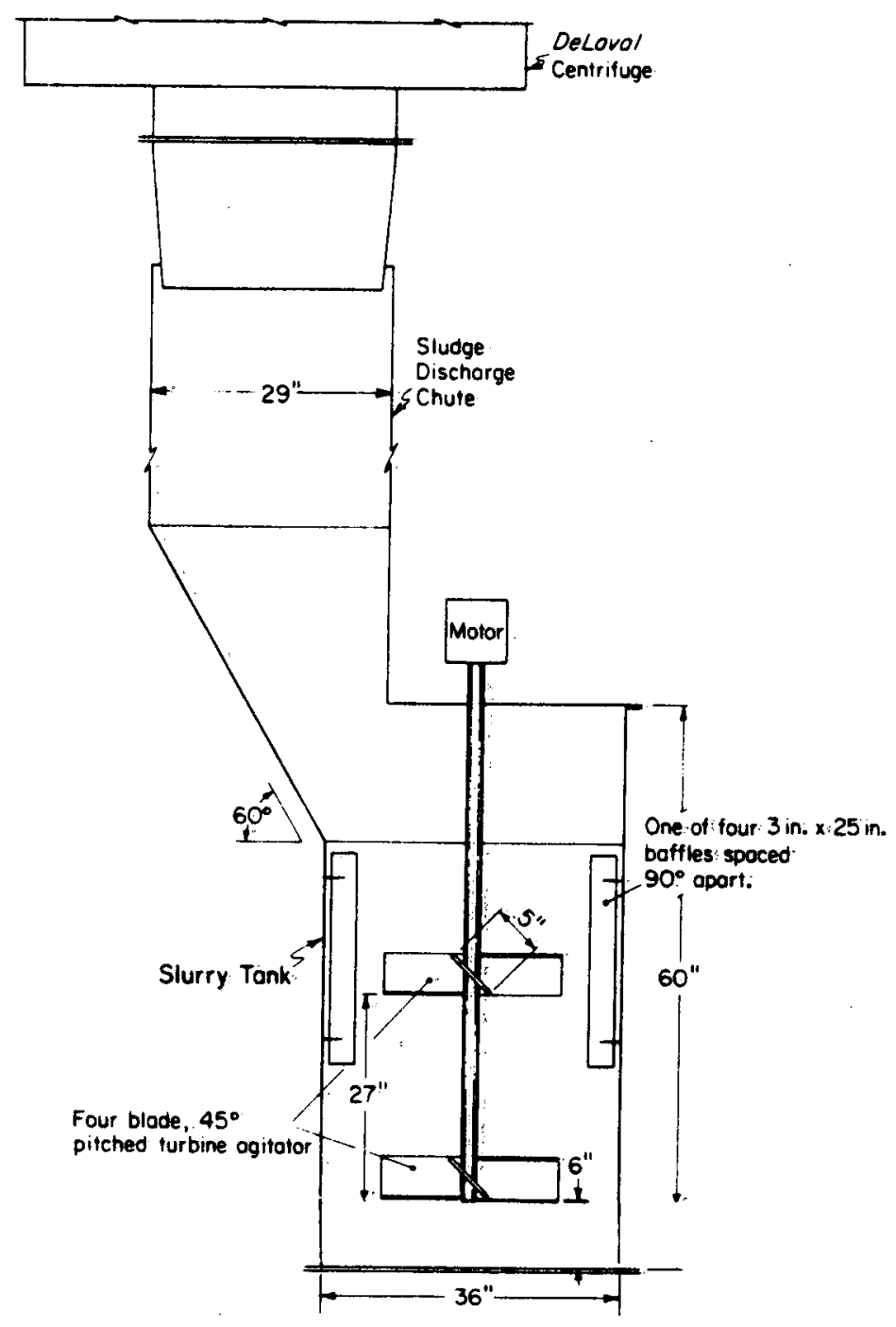

FIGURE 4.29 Large-Scale Slurry Tank 


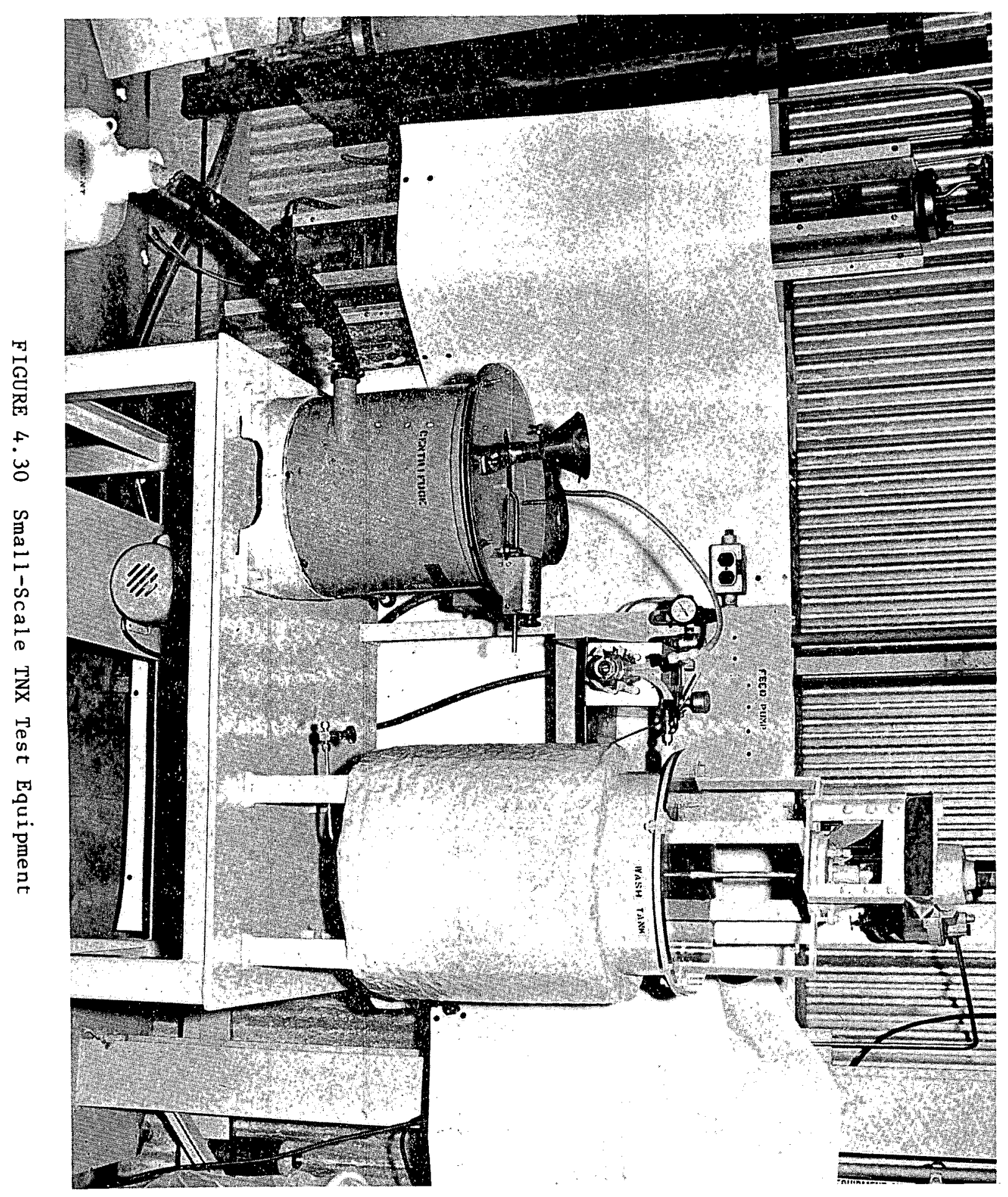




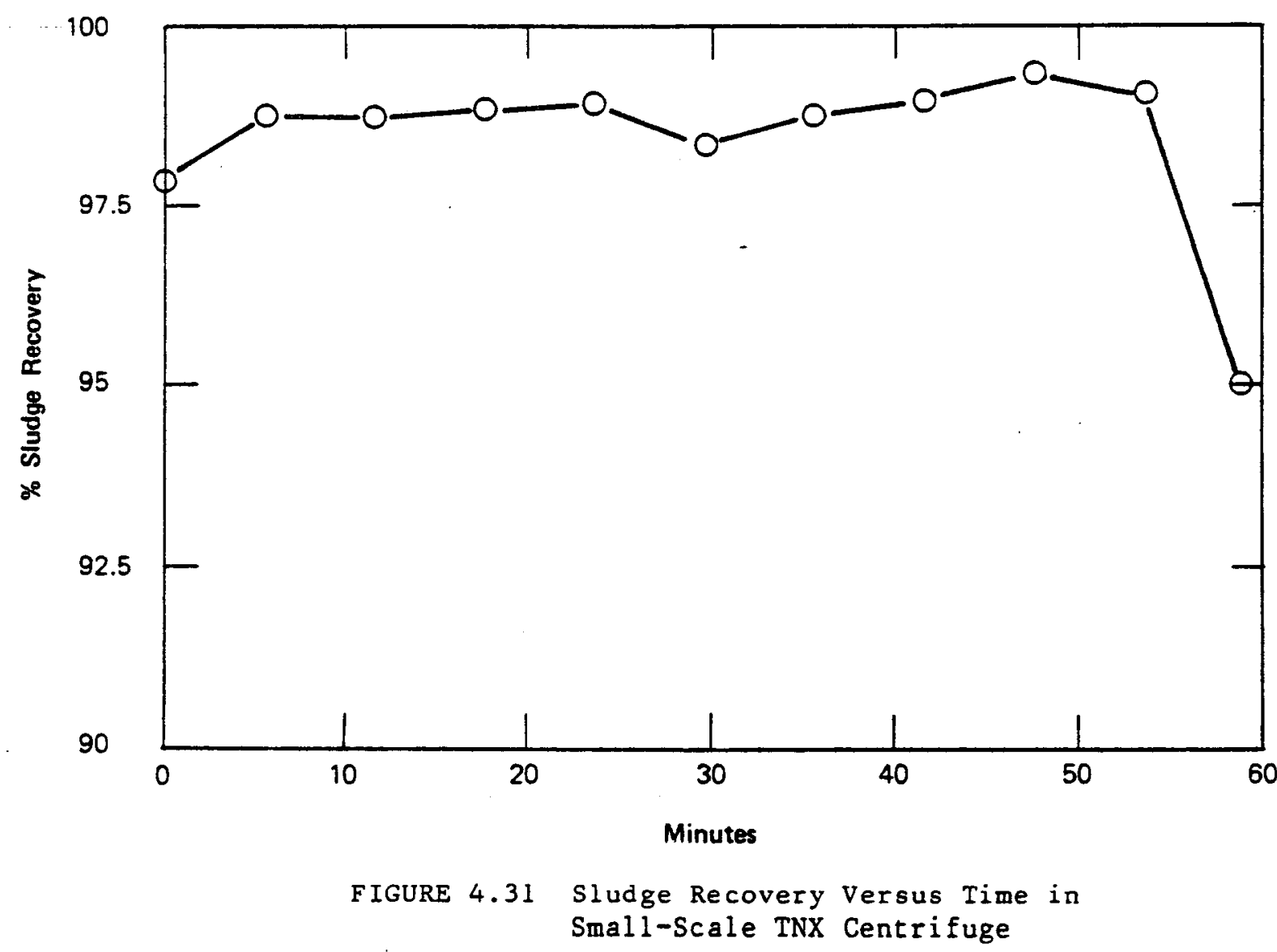

$-4.203=$ 


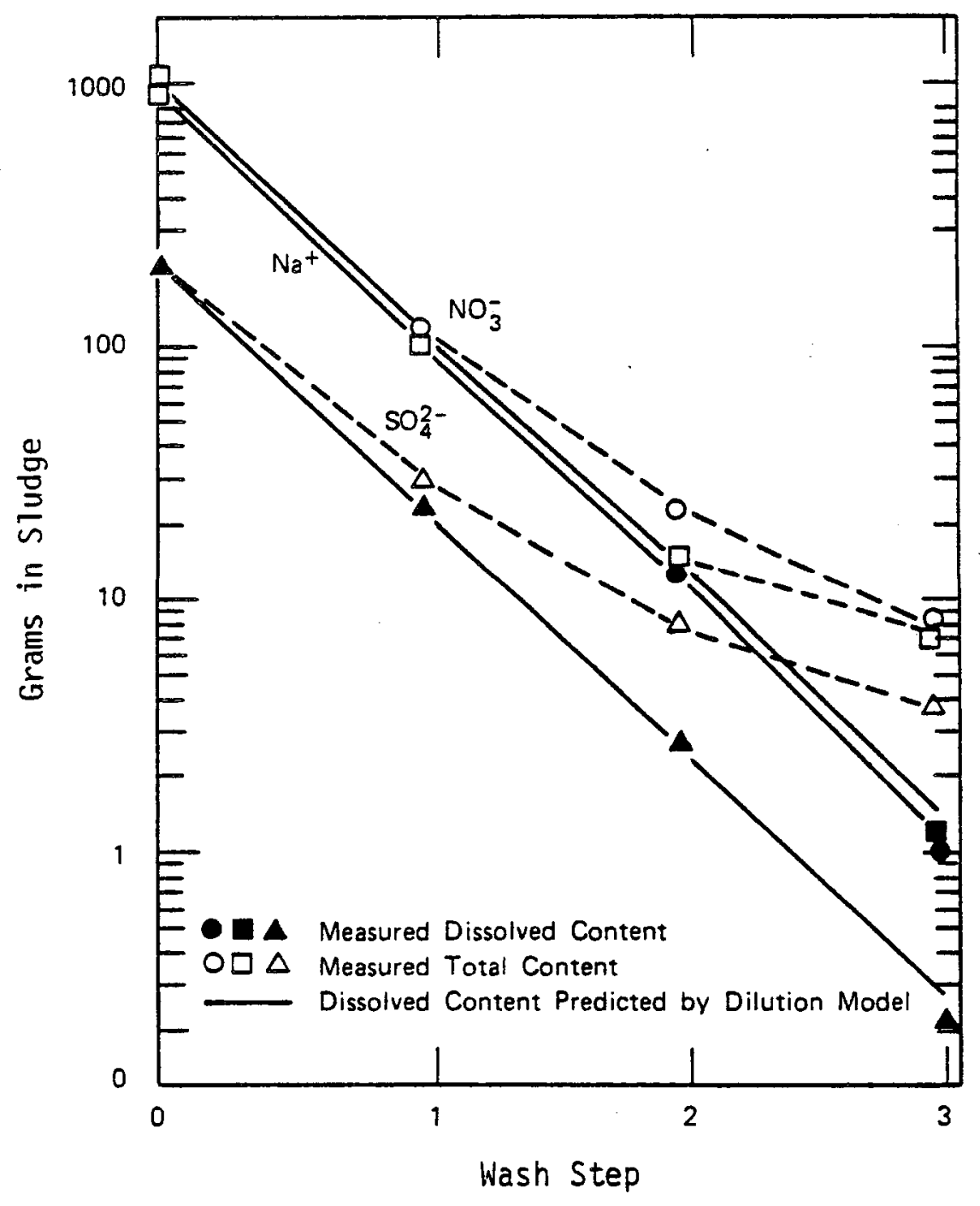

FIGURE 4.32 $\mathrm{Na}^{+}, \mathrm{NO}_{3}^{-}$, and $\mathrm{SO}_{4}{ }^{2-}$ Contents in Sludge During Washing 


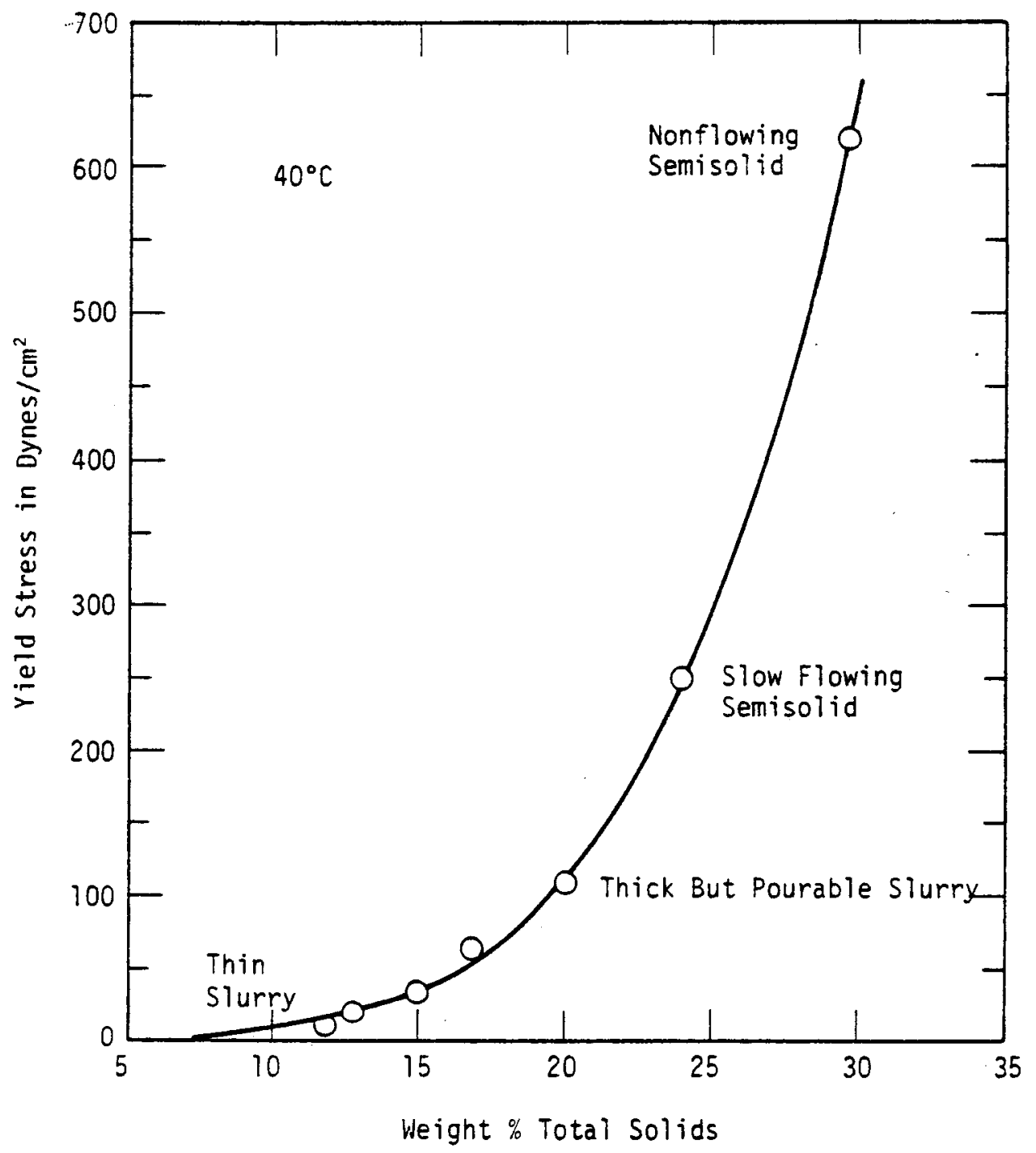

FIGURE 4.33 Yield Stress of Washed Sludge Slurry 


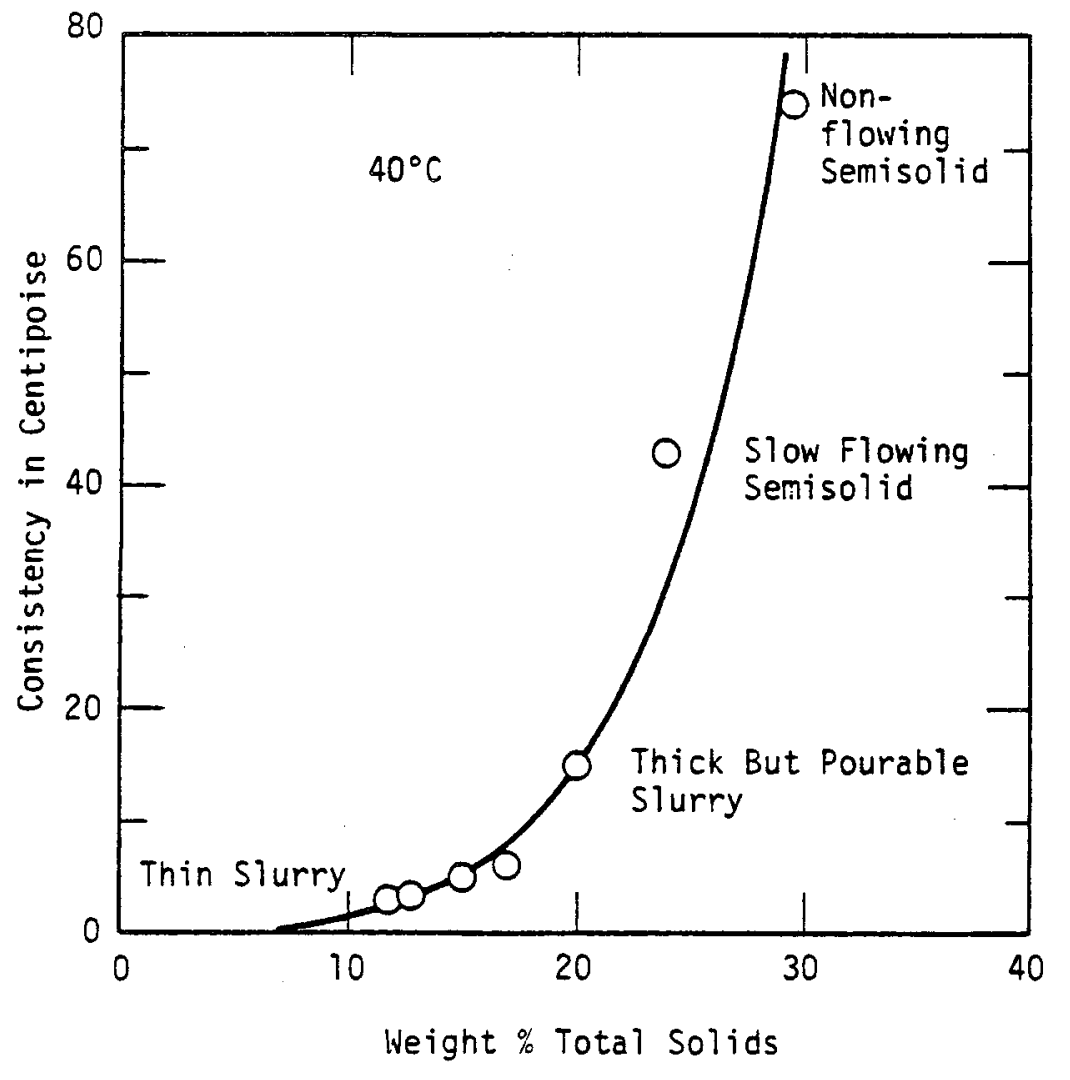

FIGURE 4.34 Consistency of Washed Sludge Slurry 


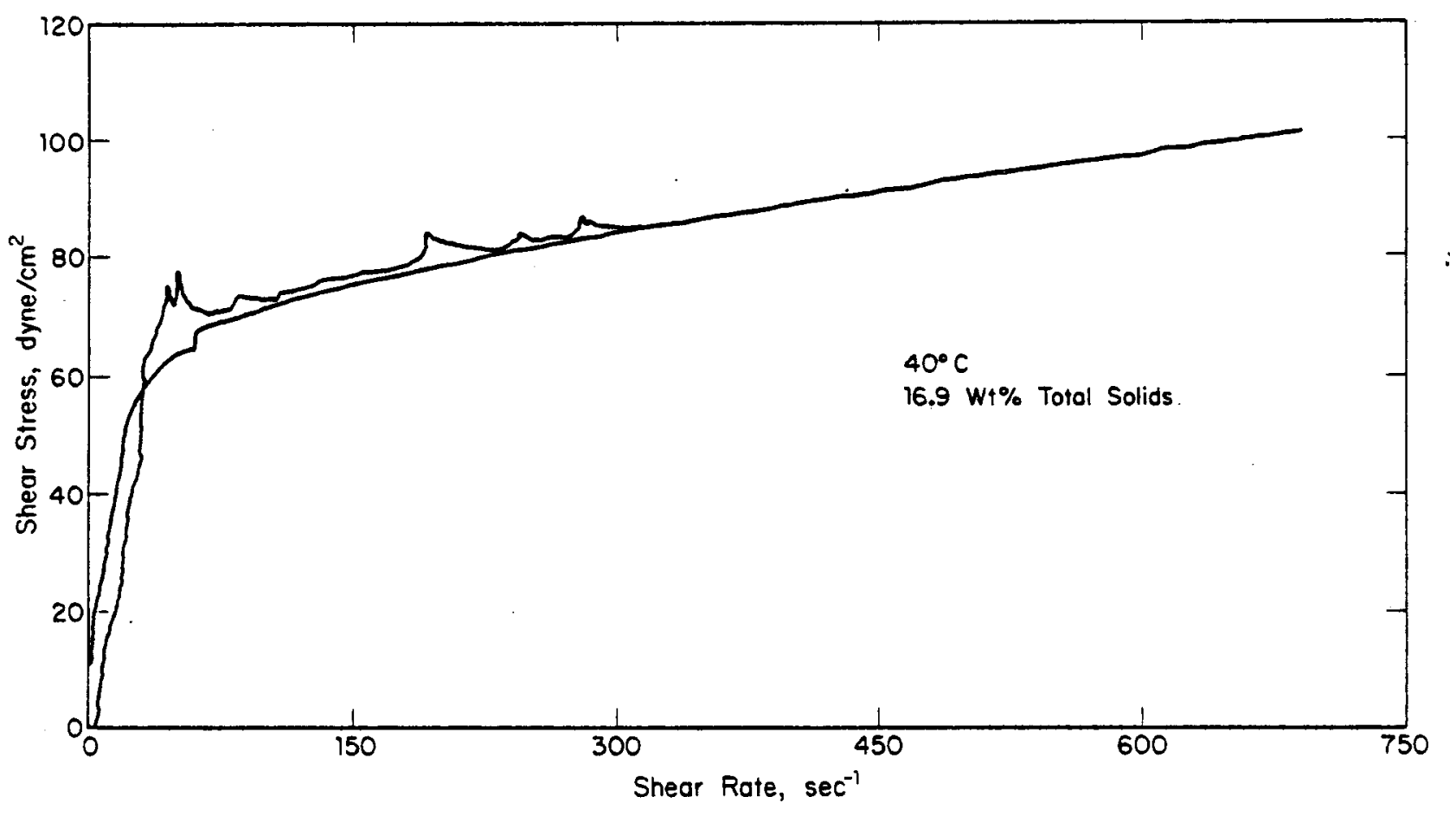

FIGURE 4.35 Washed Sludge Slurry Rheogram 


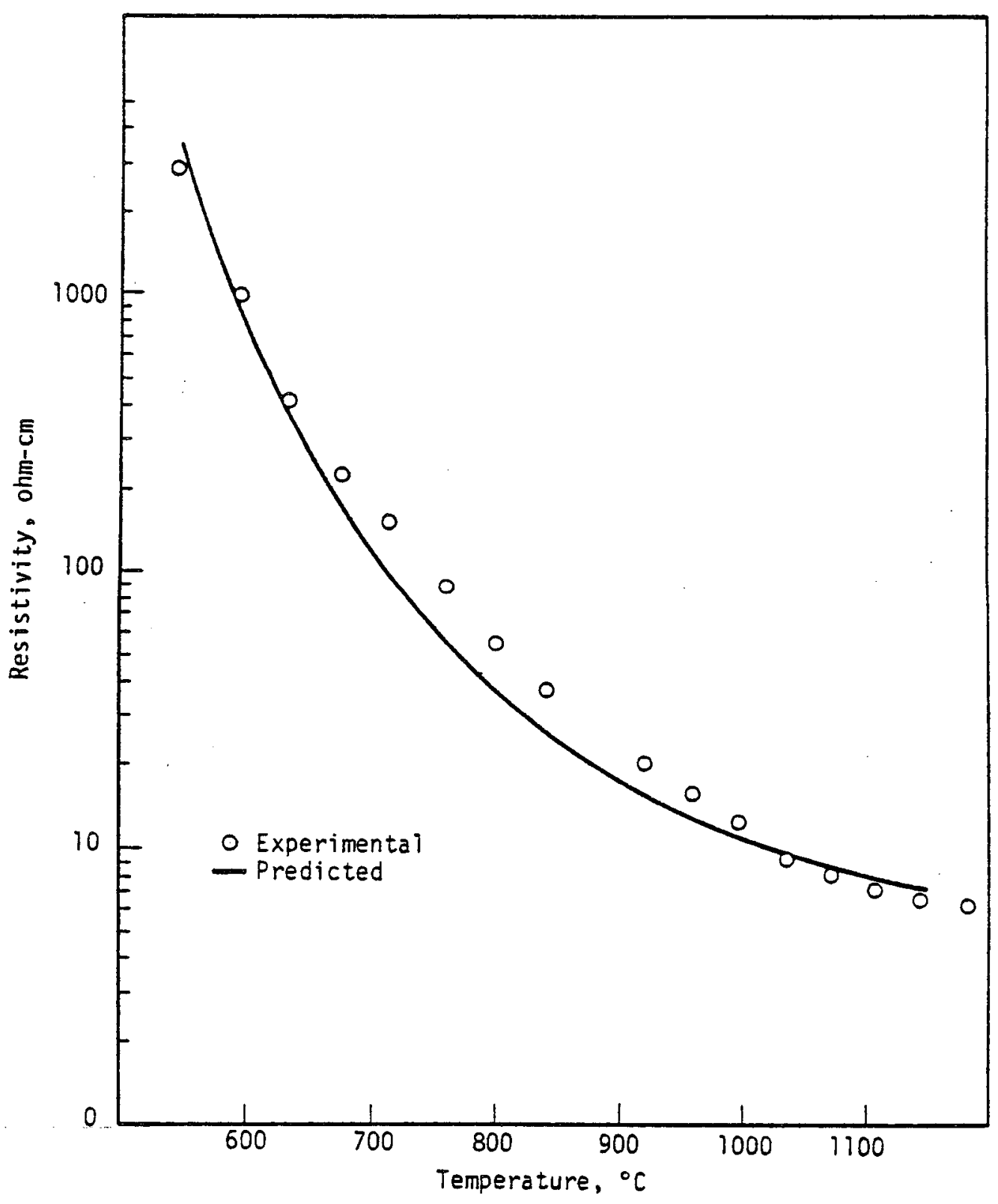

FIGURE 4.36 Resistivity of Melt Containing Frit 21-25 wt \% "Composite Sludge" 


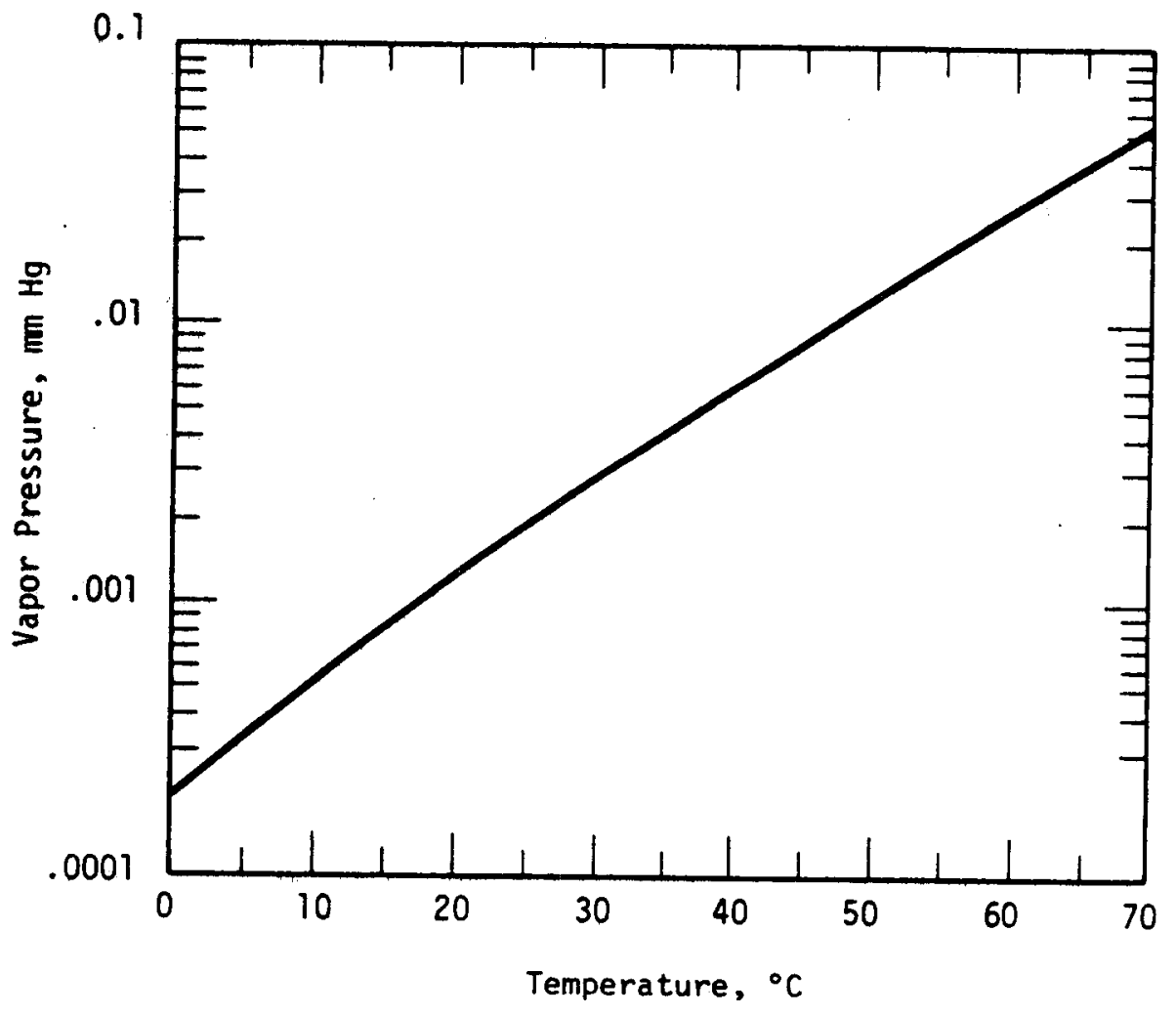

FIGURE 4.37 Vapor Pressure of Mercury 


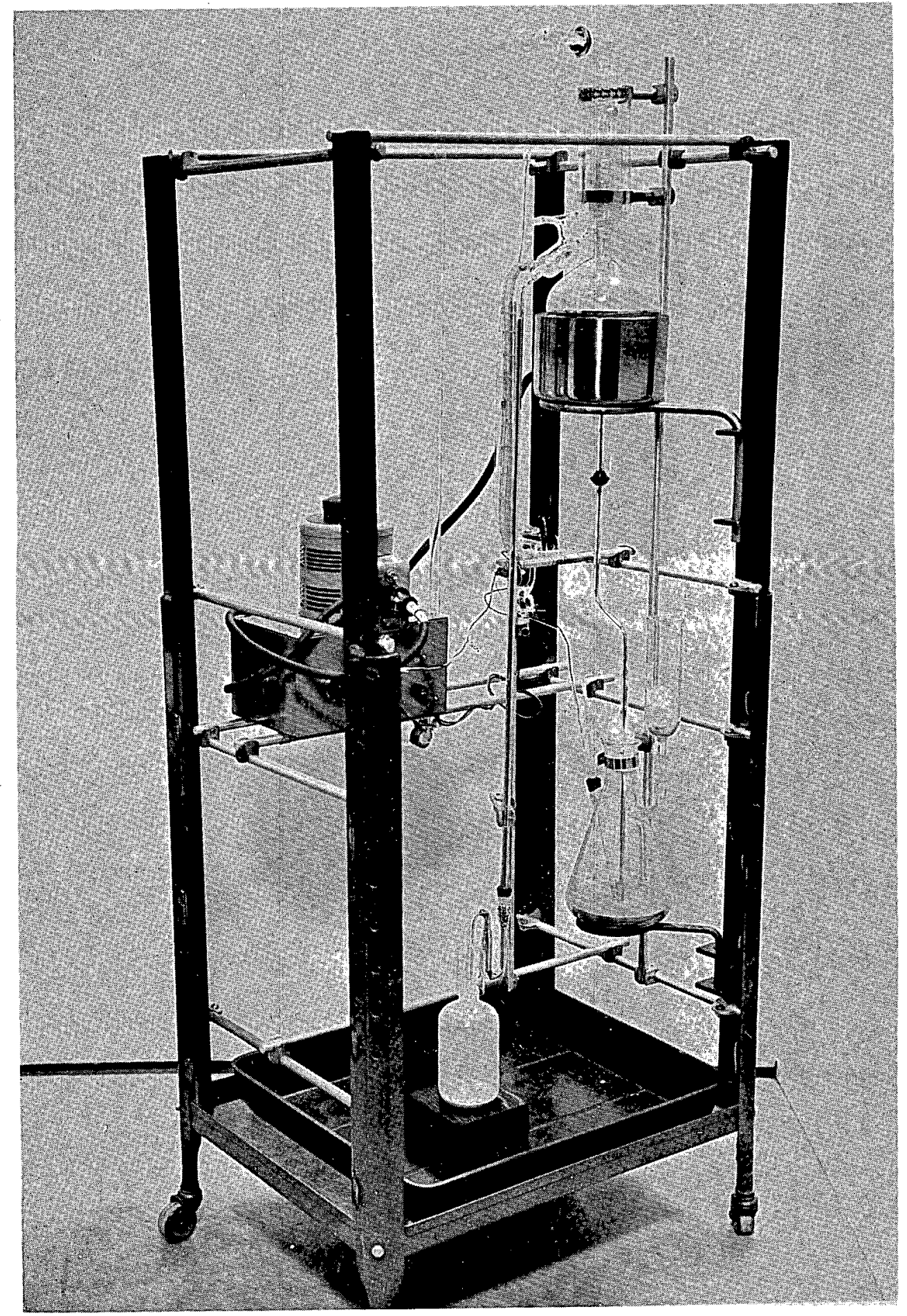

FIGURE 4.38 Savannah River Laboratory Mercury Still 


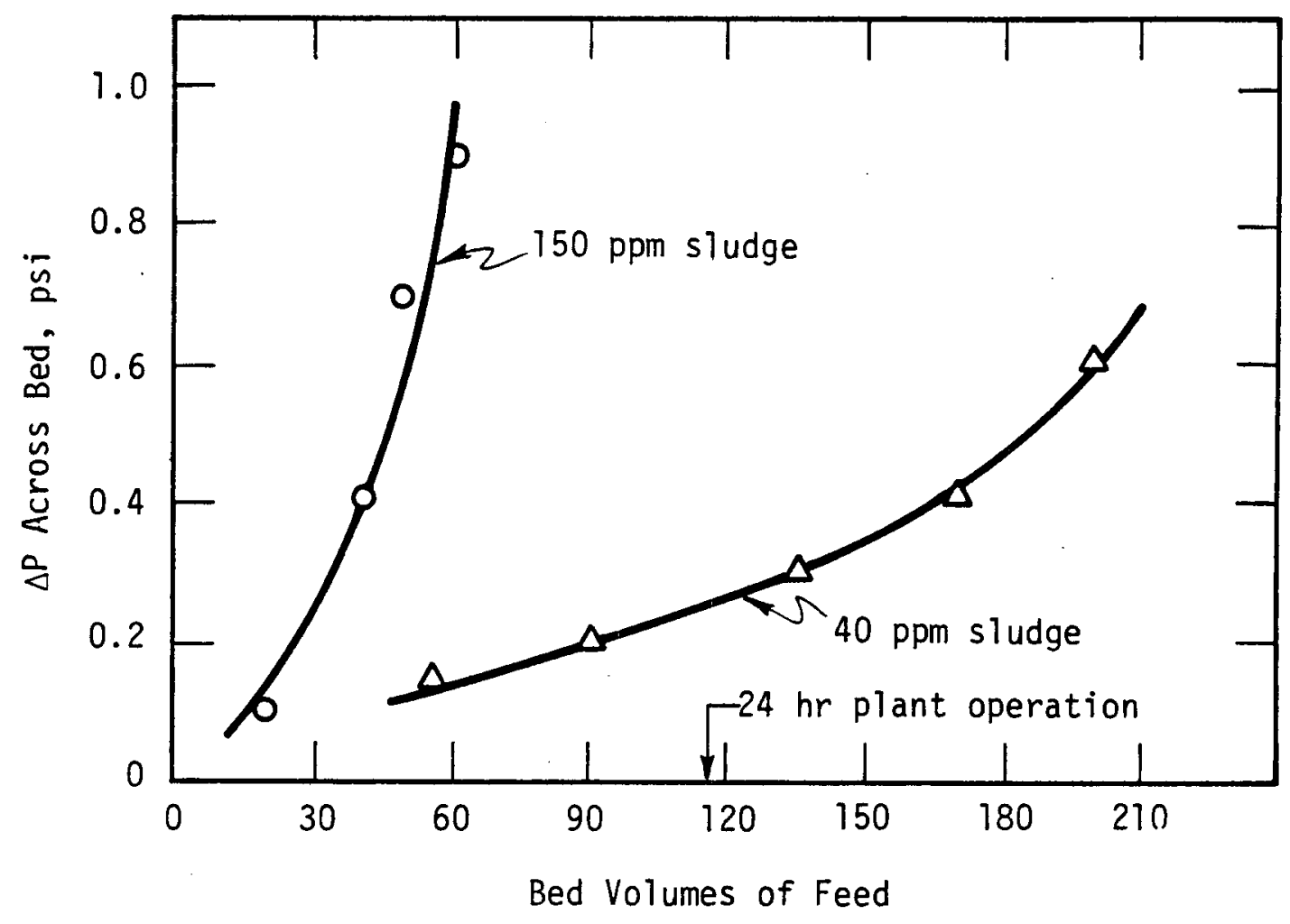

FIGURE 4.39 Effect of GS Product Sludge on Sand Bed $\triangle P$ 


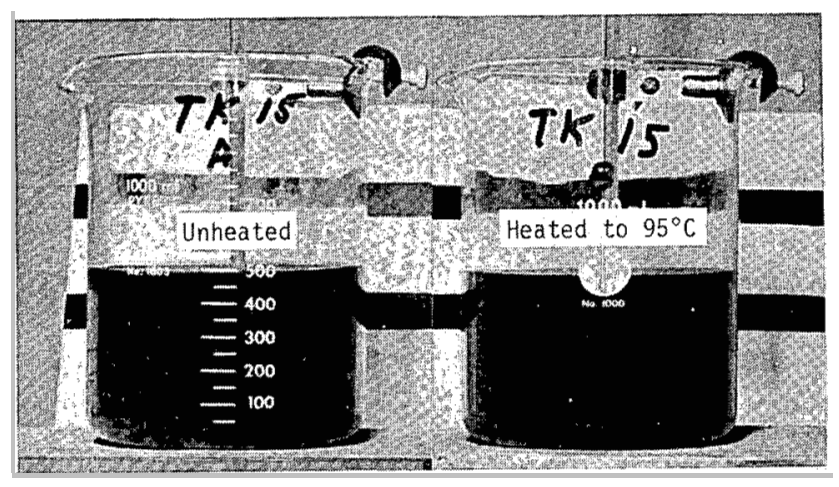

a. Elapsed Time - 0 minutes

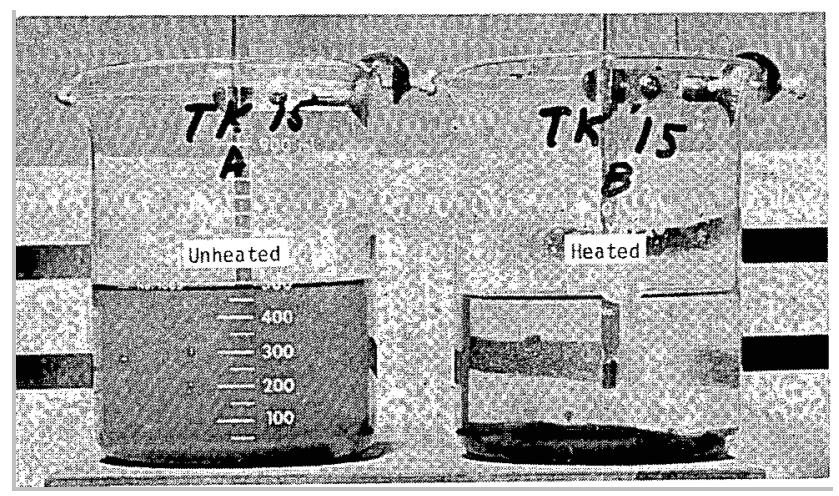

c. Elapsed Time - 16 minutes

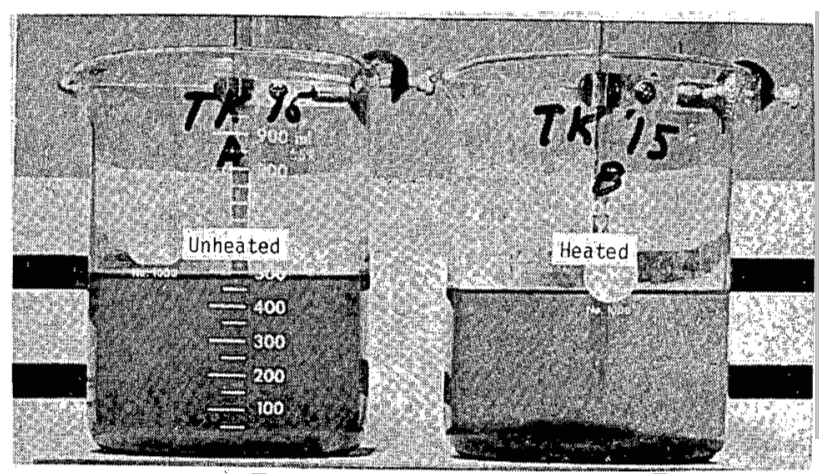

b. Elapsed Time - 8 minutes

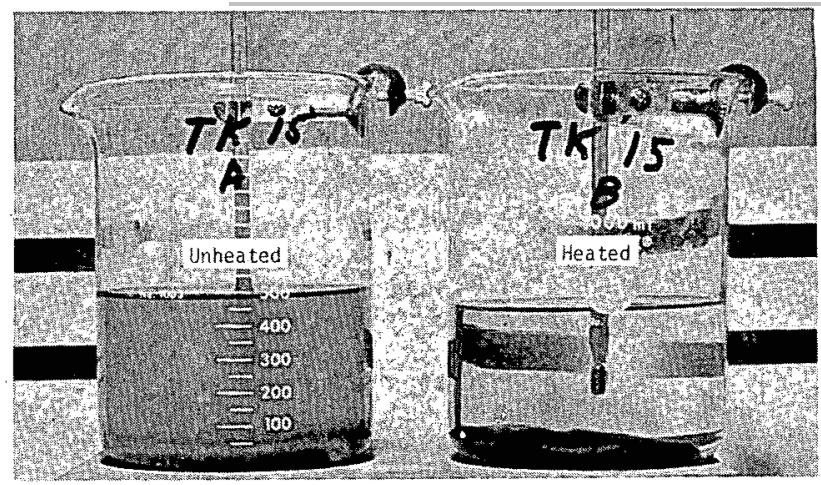

d. Elapsed Time - 25 minutes

FIGURE 4.40 Effect of Heating on the Settling Rate of Sludge 

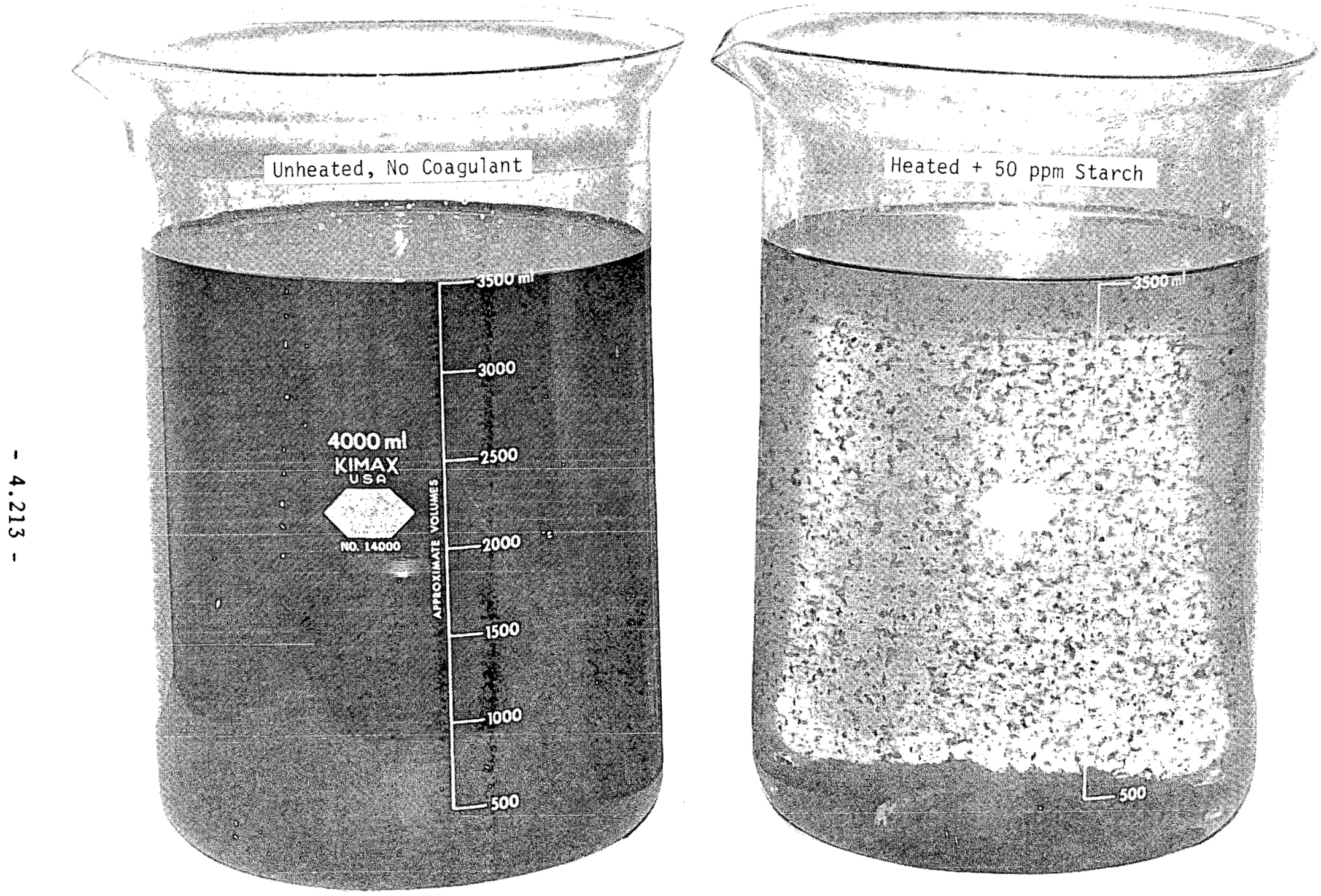

FIGURE 4.41 Destabilization of Colloidal Suspensions with Heat and Starch 


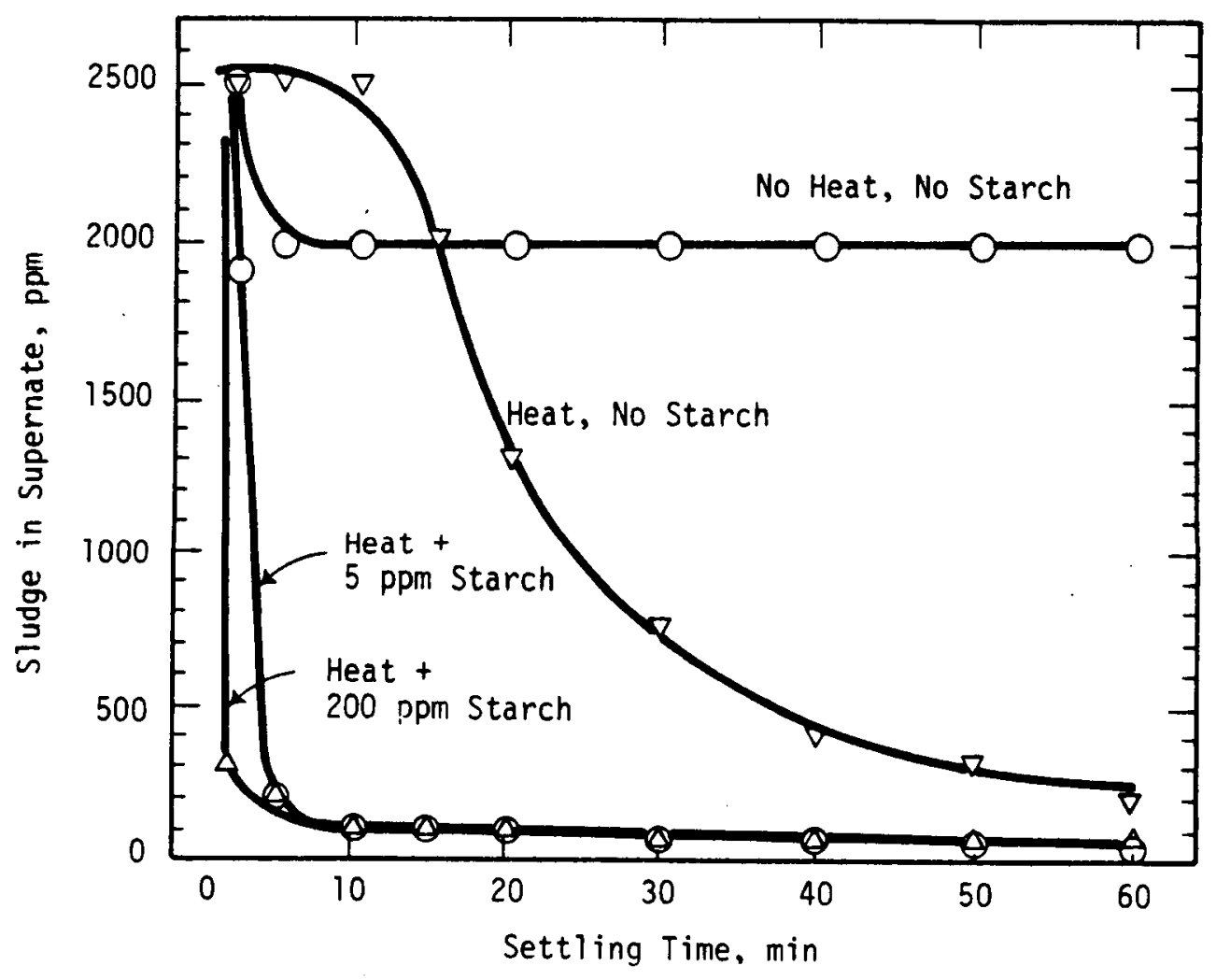

FIGURE 4.42 Effect of Heat and Starch on Agglomeration and Settling Rates 


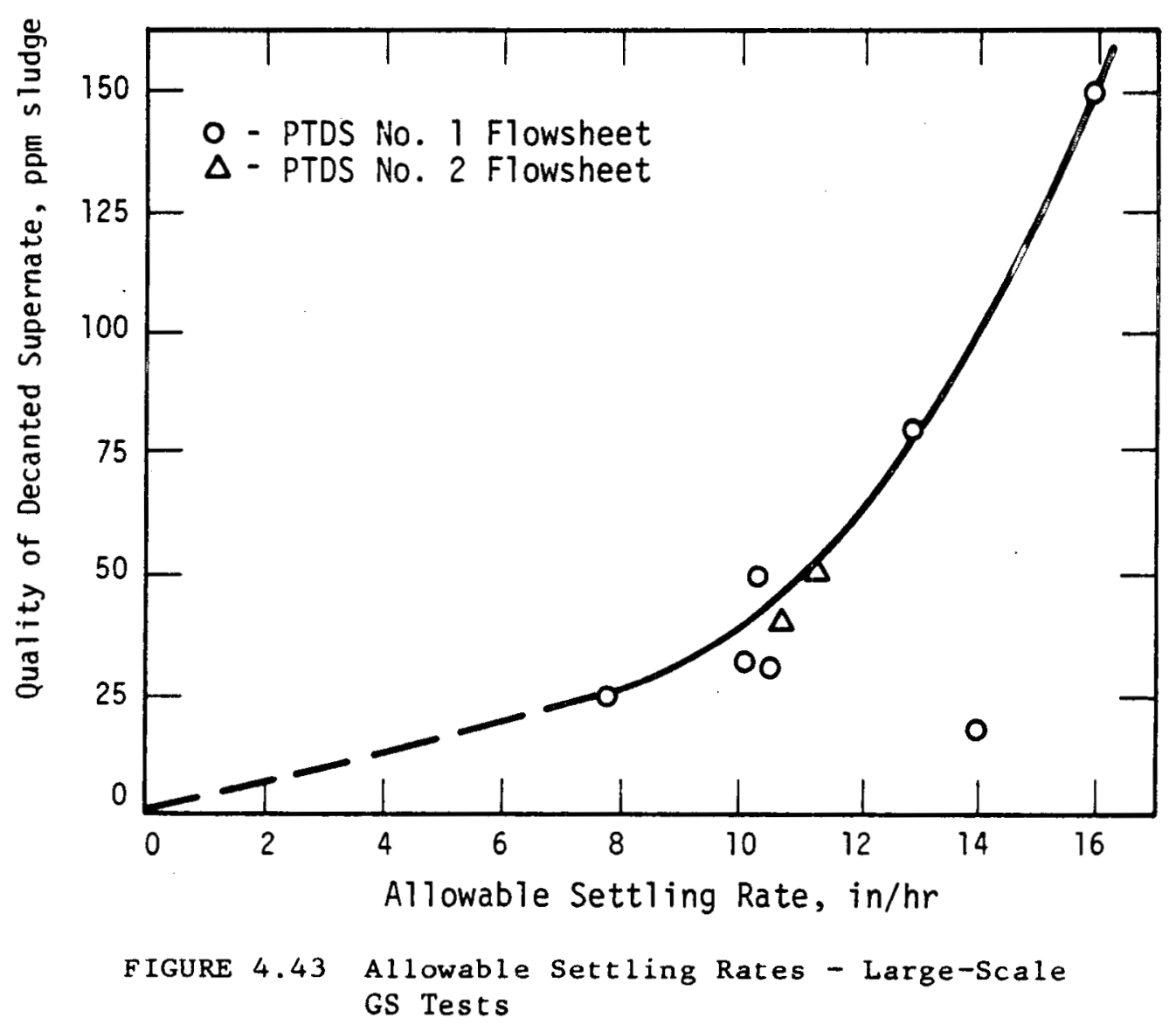

$\Theta$ 


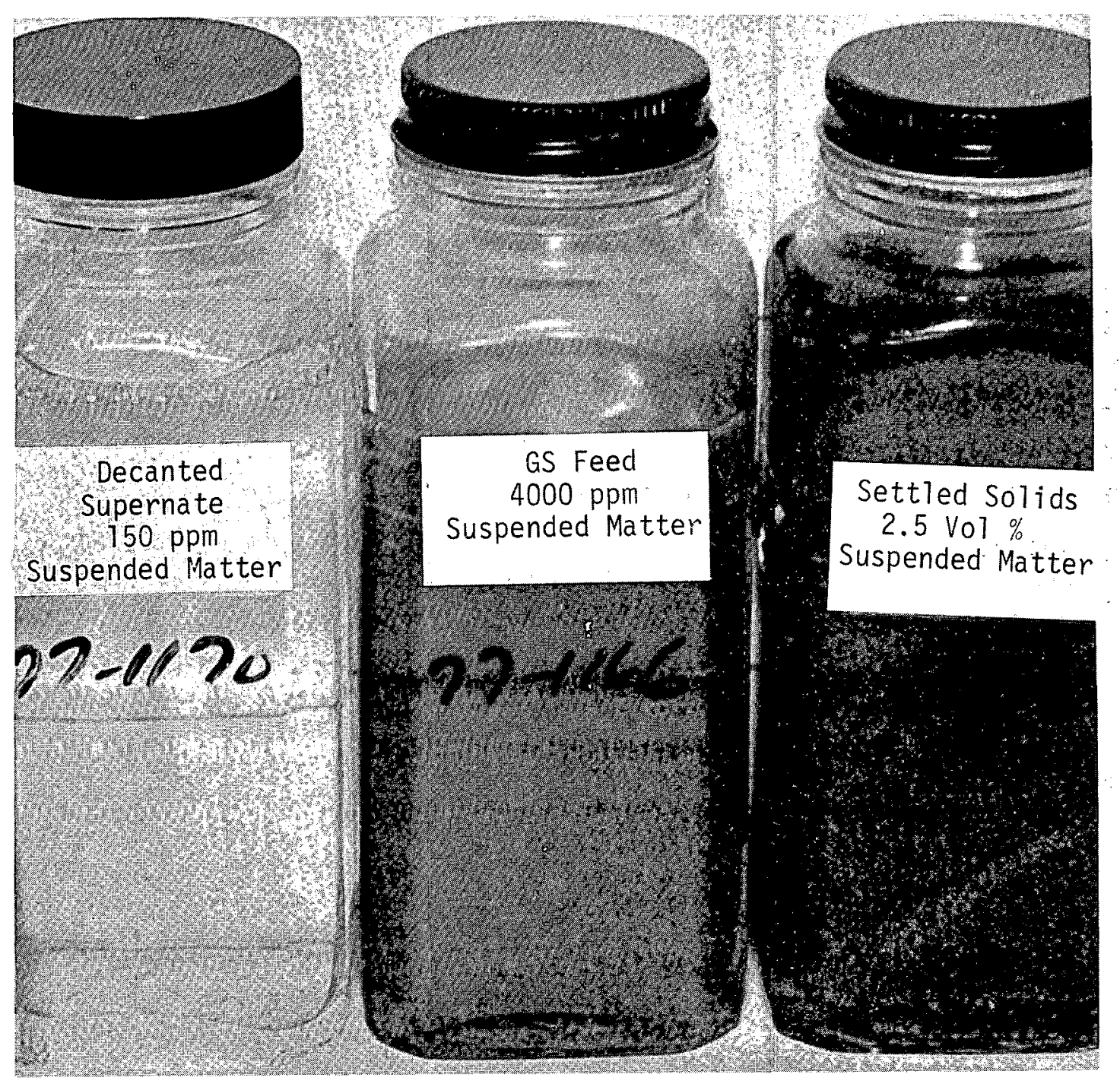

FiGuke 4.44 GS Samples trom first Large-Scale Run 


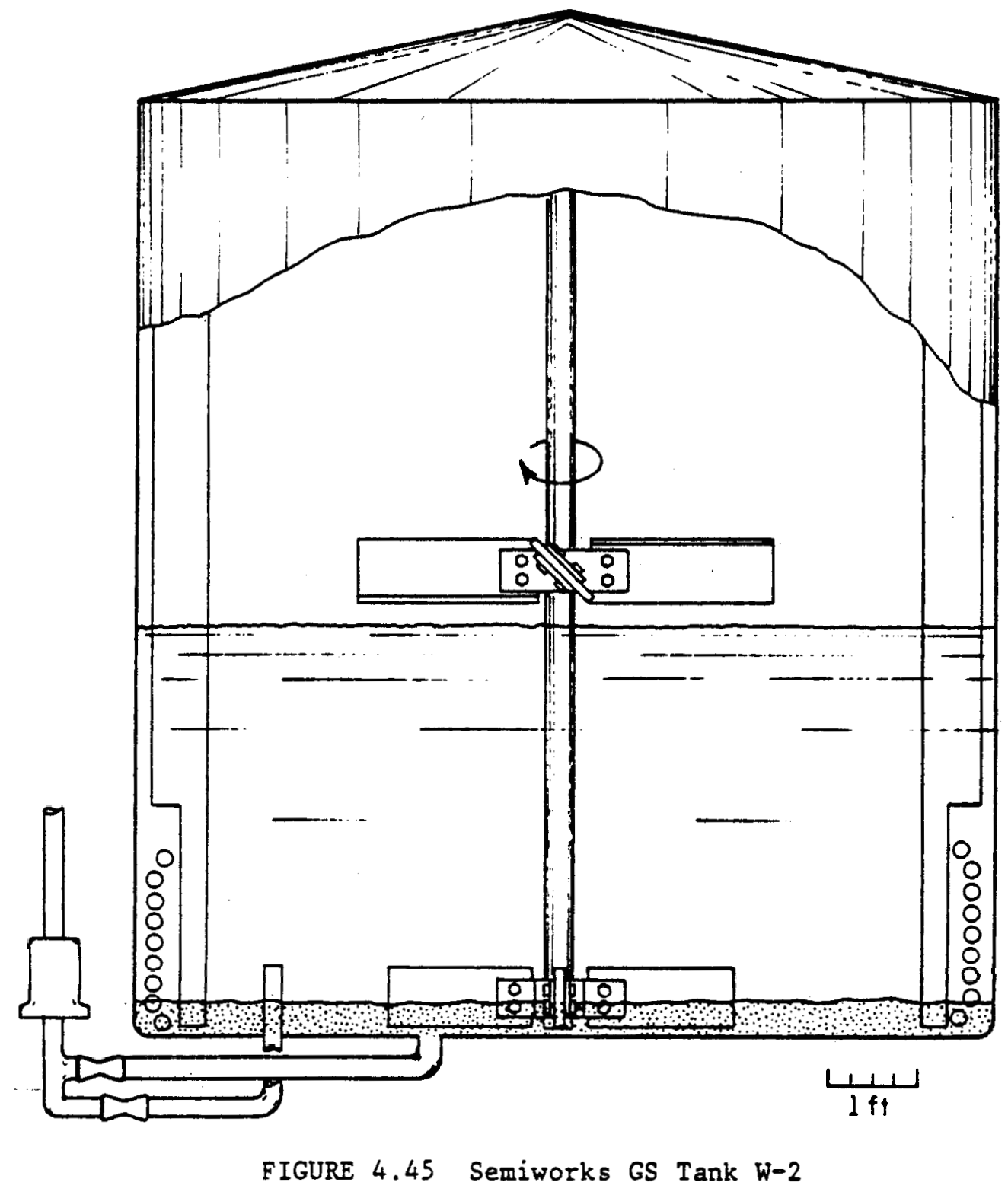




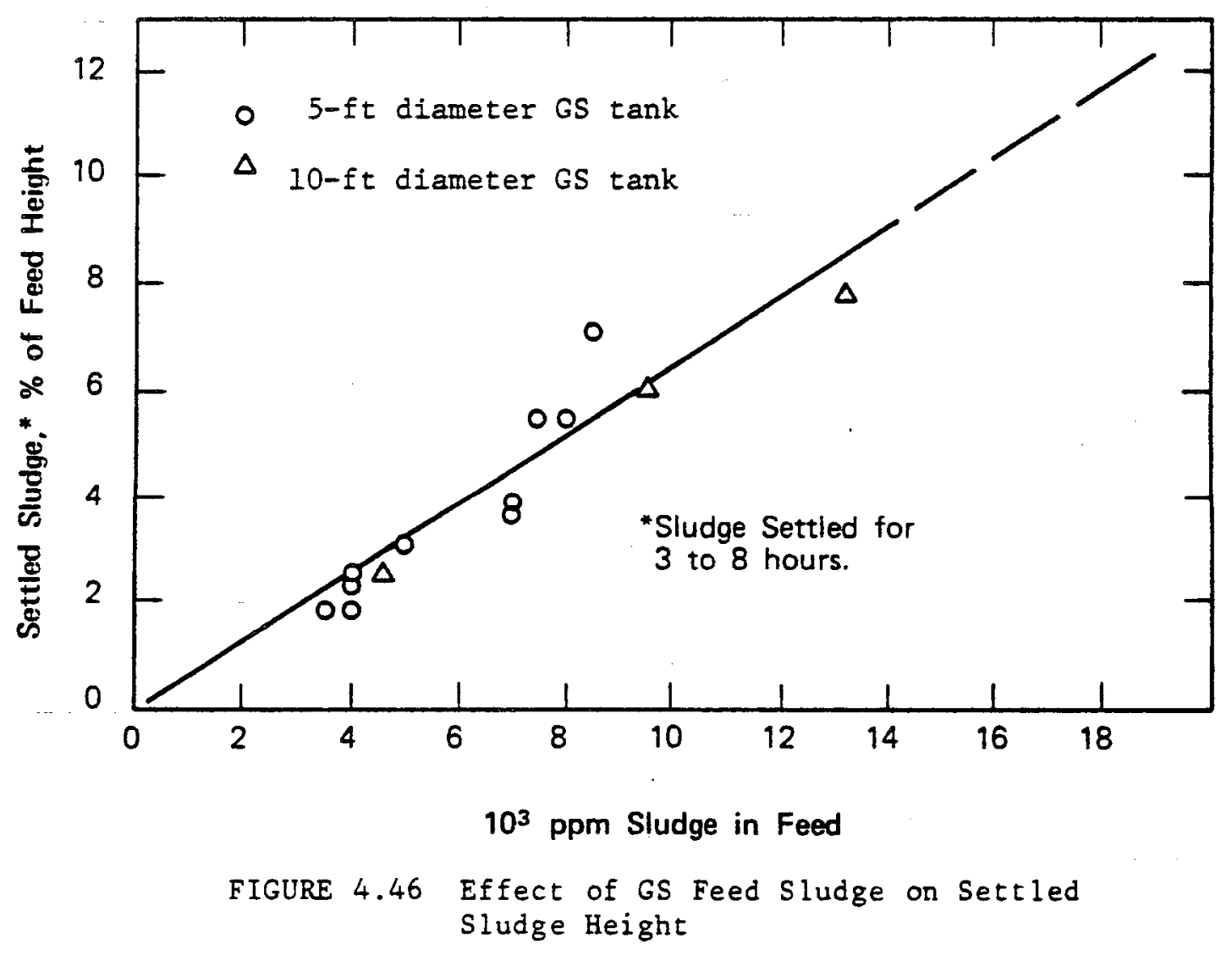




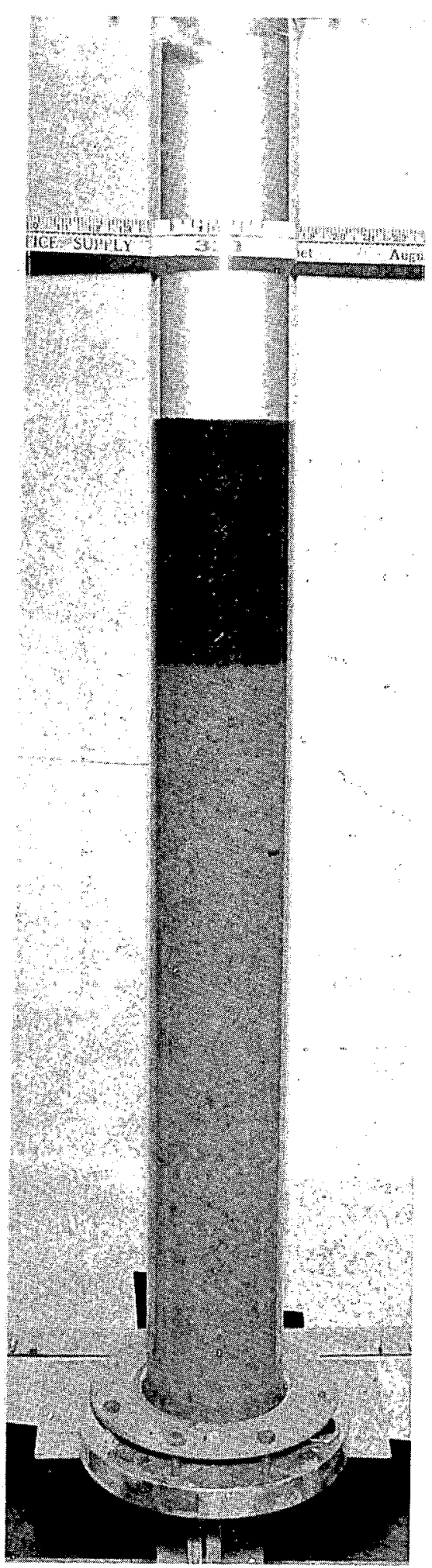

Downflow Feed

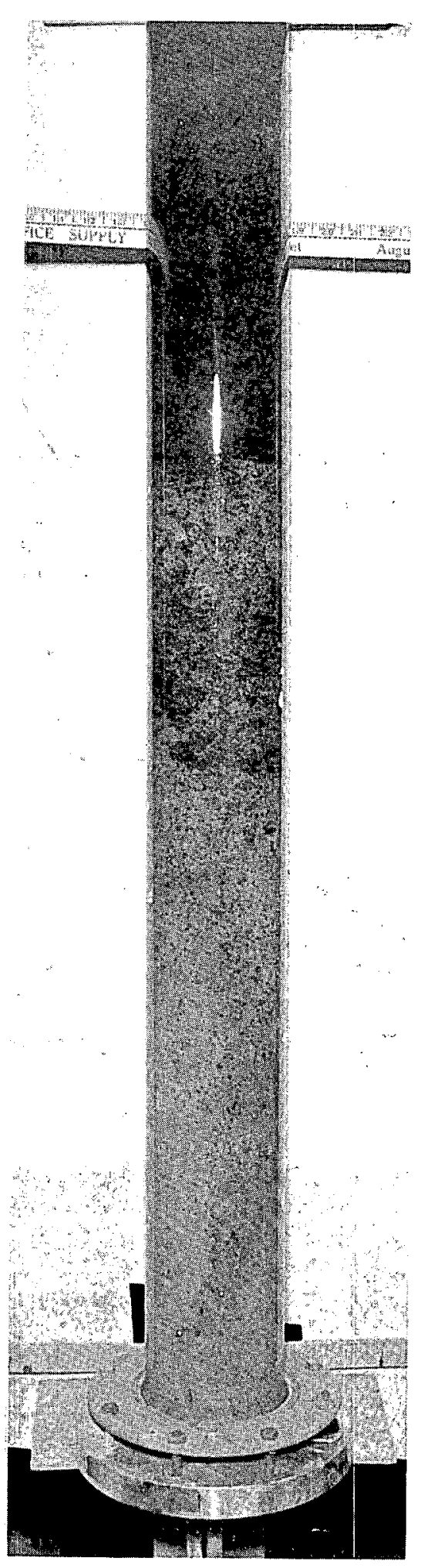

Upflow Backwash

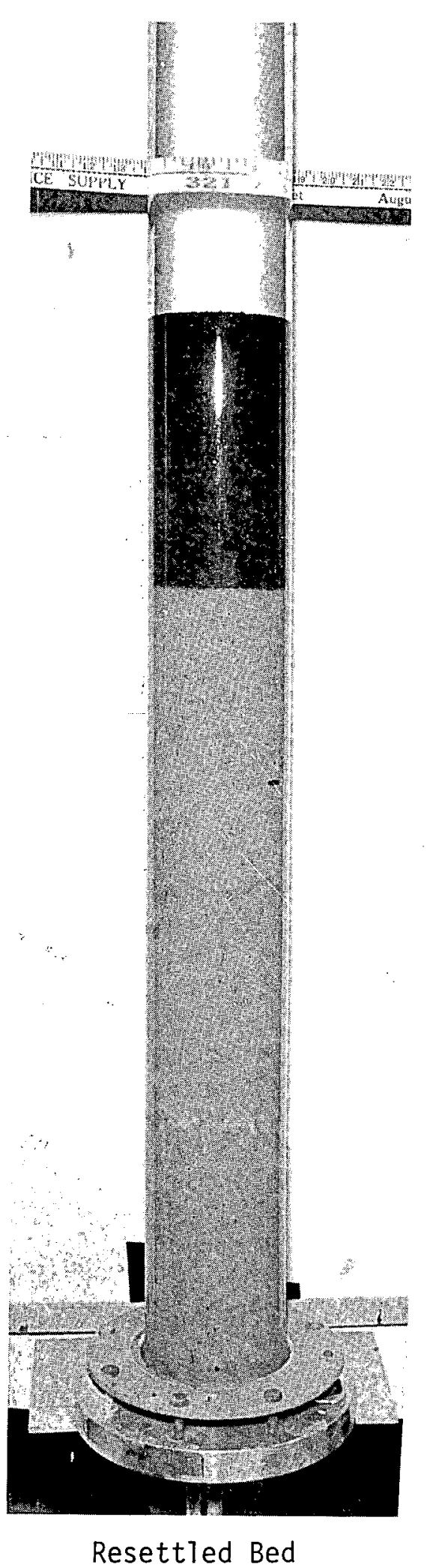

FIGURE 4.47 Sand Filtration - 1/200th P1ant Scale 


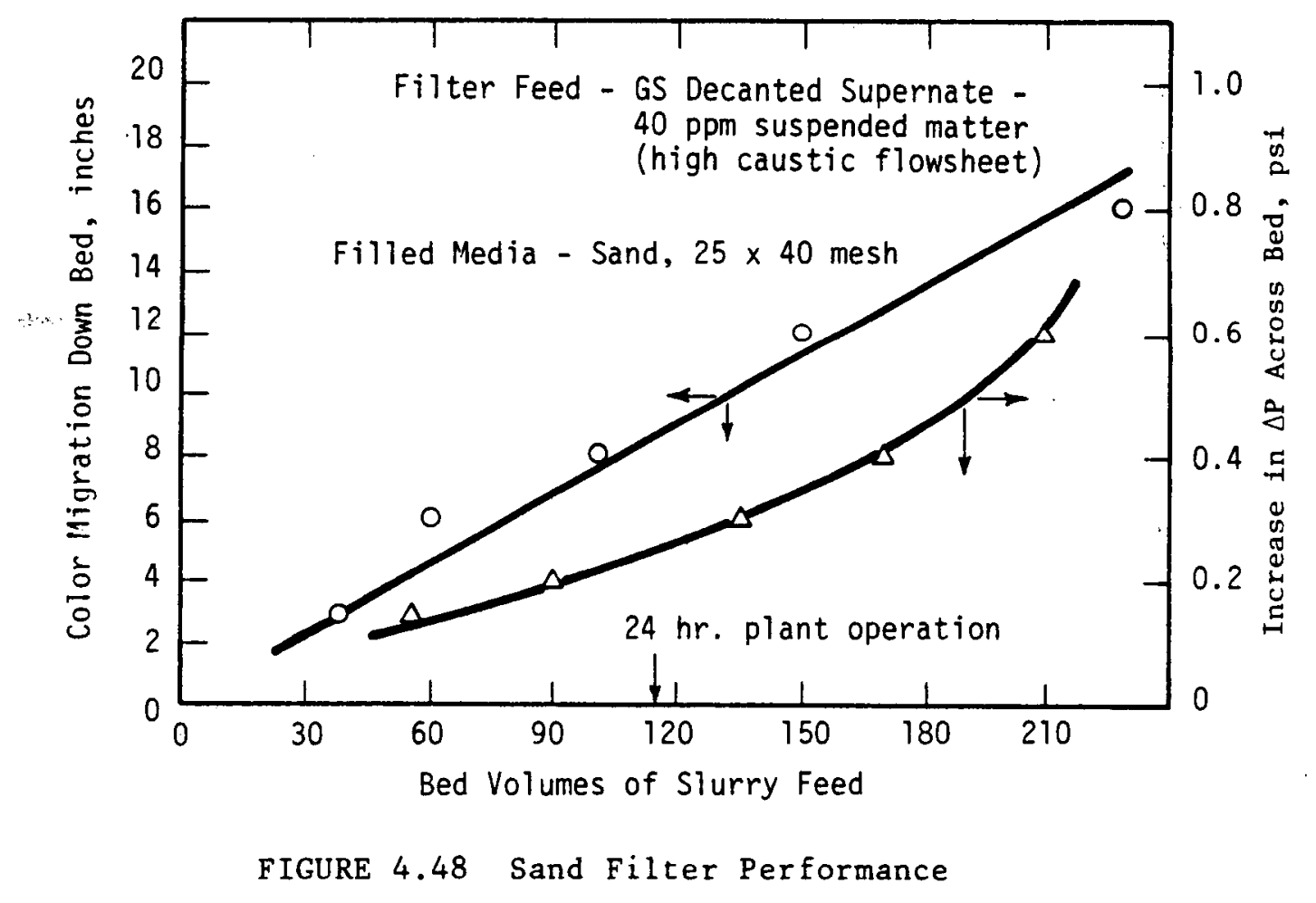



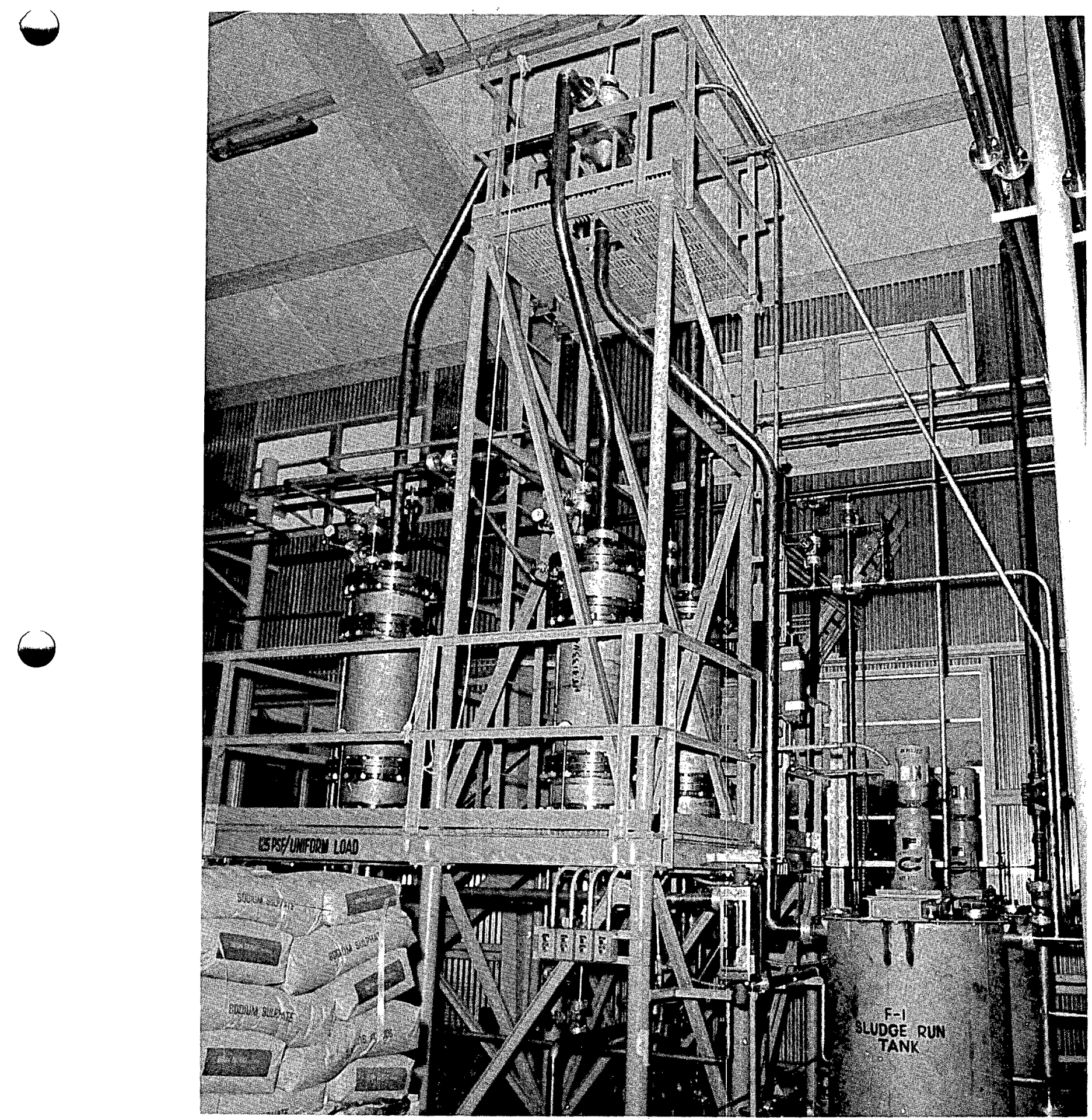

FIGURE 4.49 TNX Sand Filter Facility 


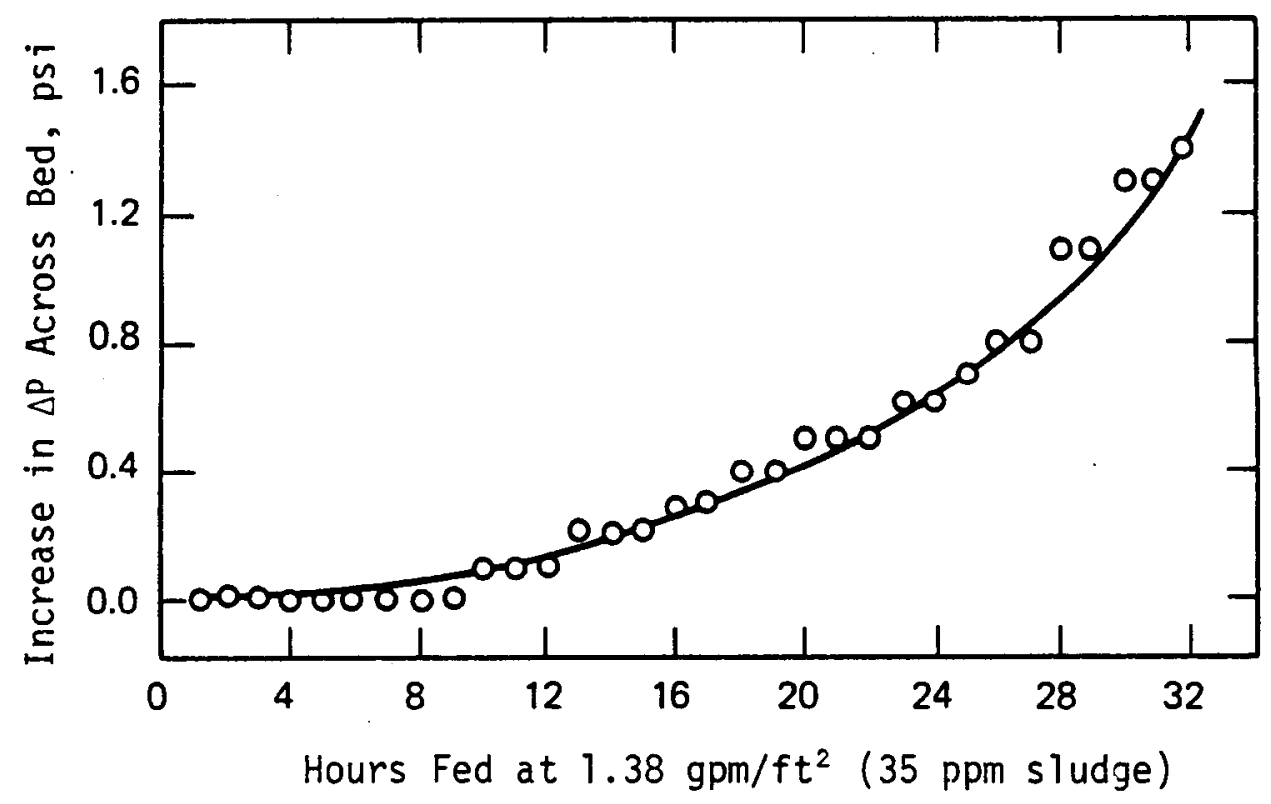

FIGURE 4.50 $\triangle P$ Rise in Large-Scale Primary Sand Bed 


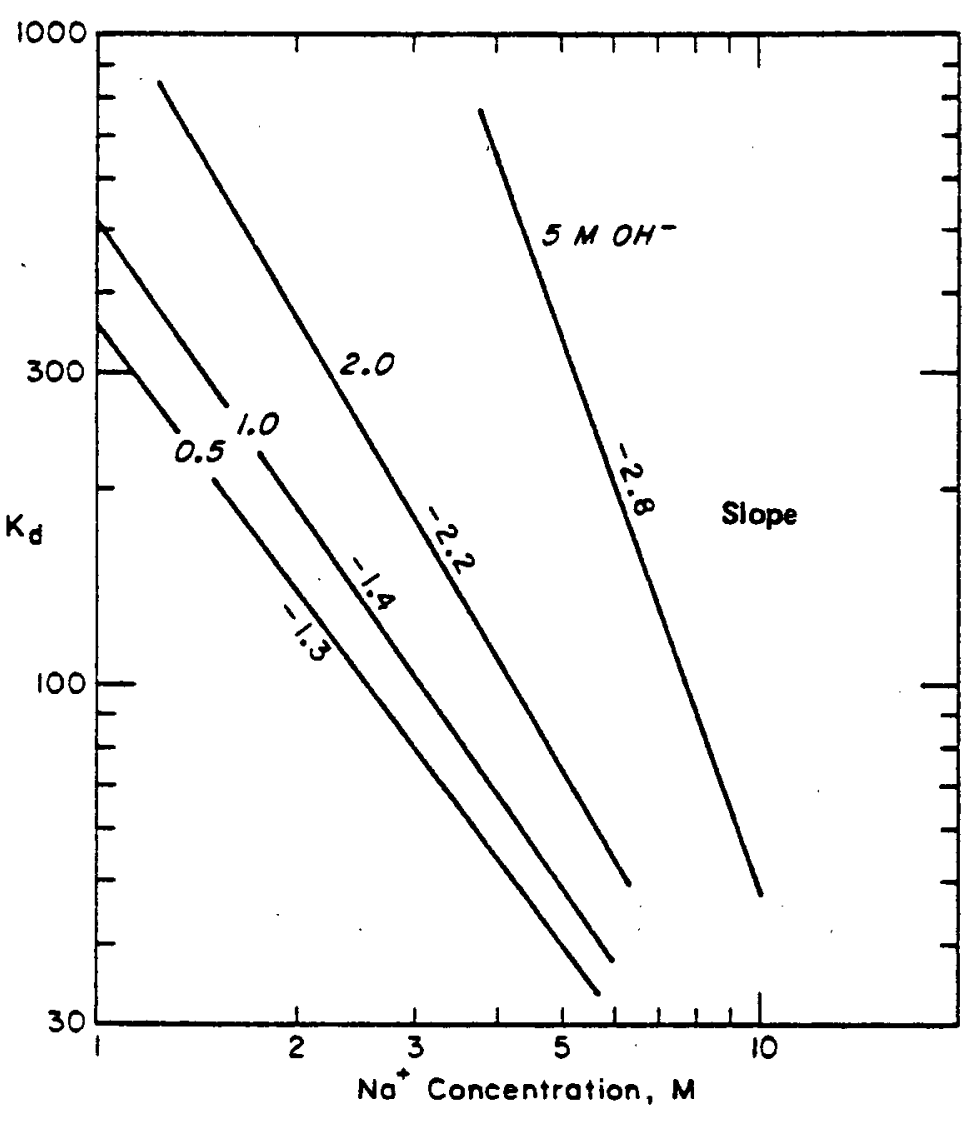

FIGURE 4.51 Cesium - "Duolite" Distribution Coeffficient 


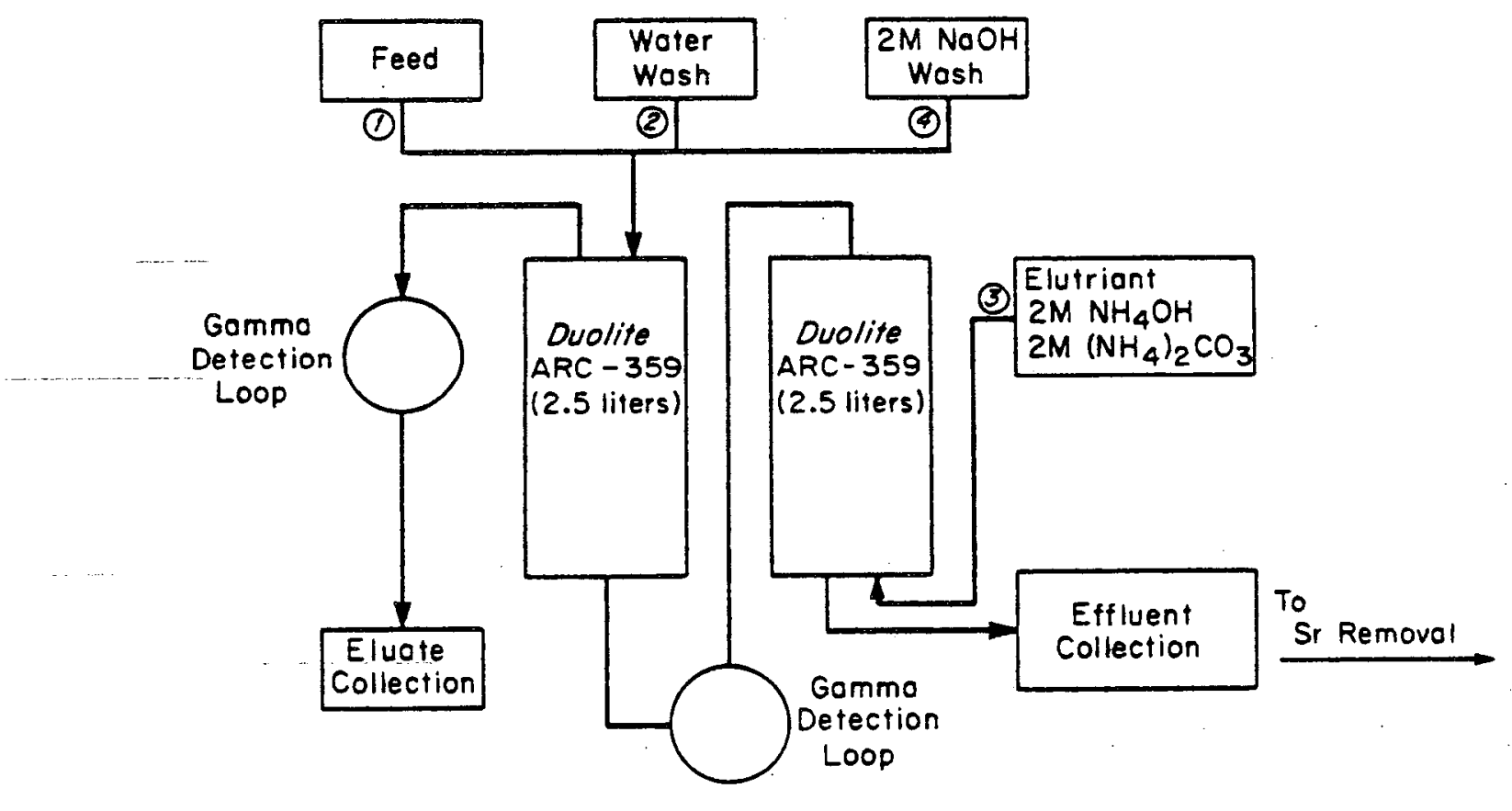

FIGURE 4.52 Apparatus for Ion Exchange Column Tests 


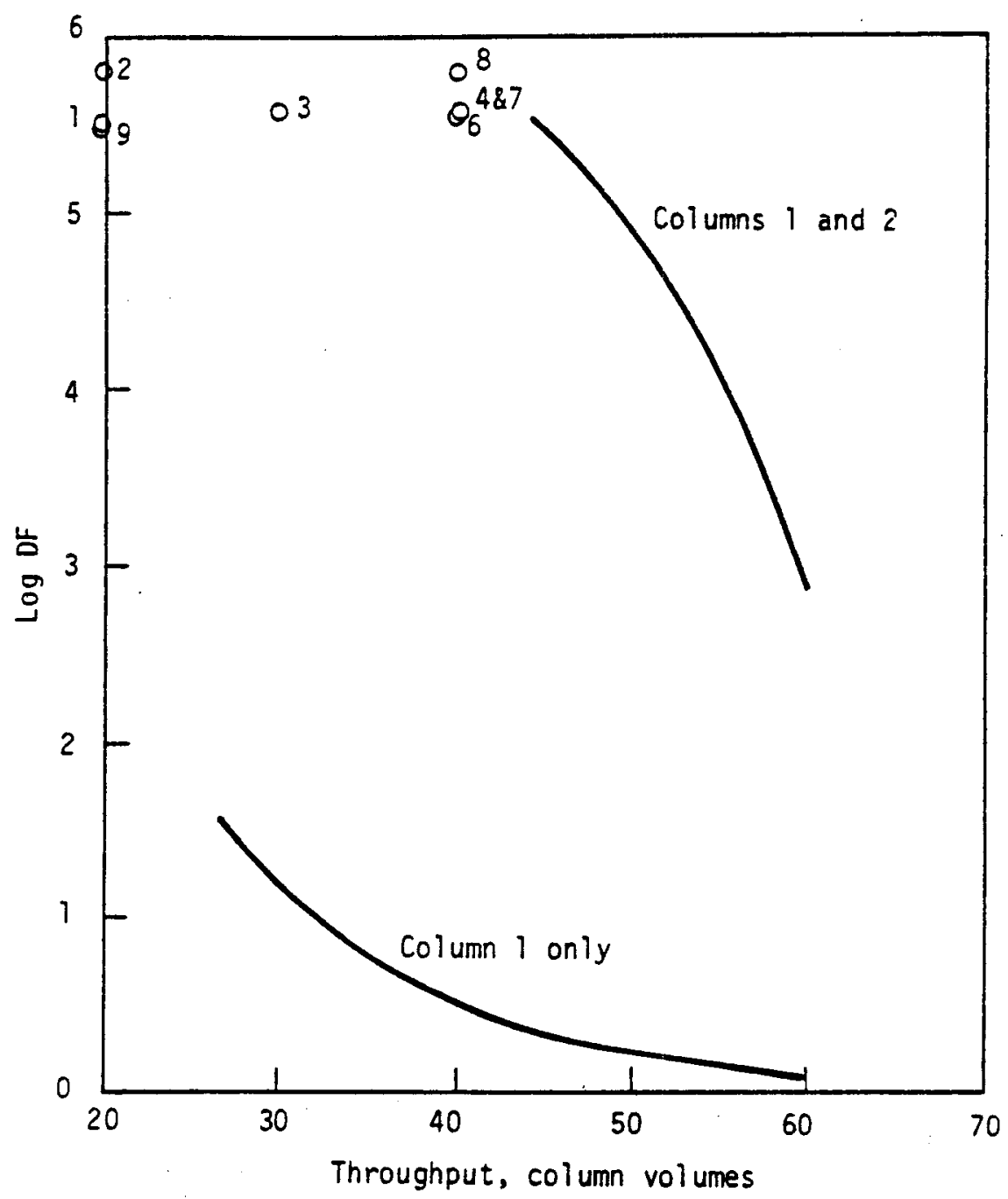

FIGURE 4.53 Cs-137 Decontamination as a Function of Throughput 


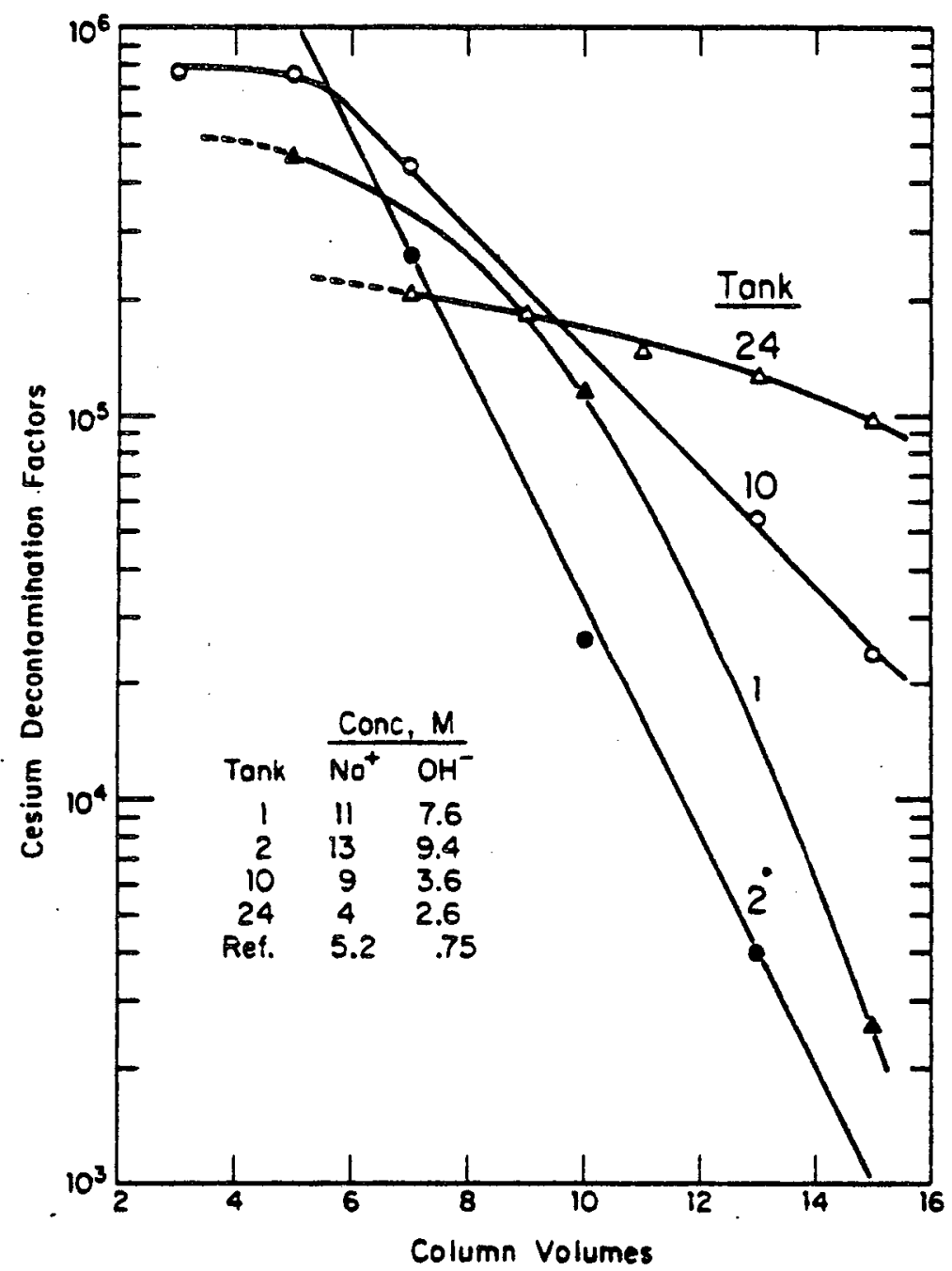

FIGURE 4.54 Cesium Decontamination Factors for SRP Waste Supernate 


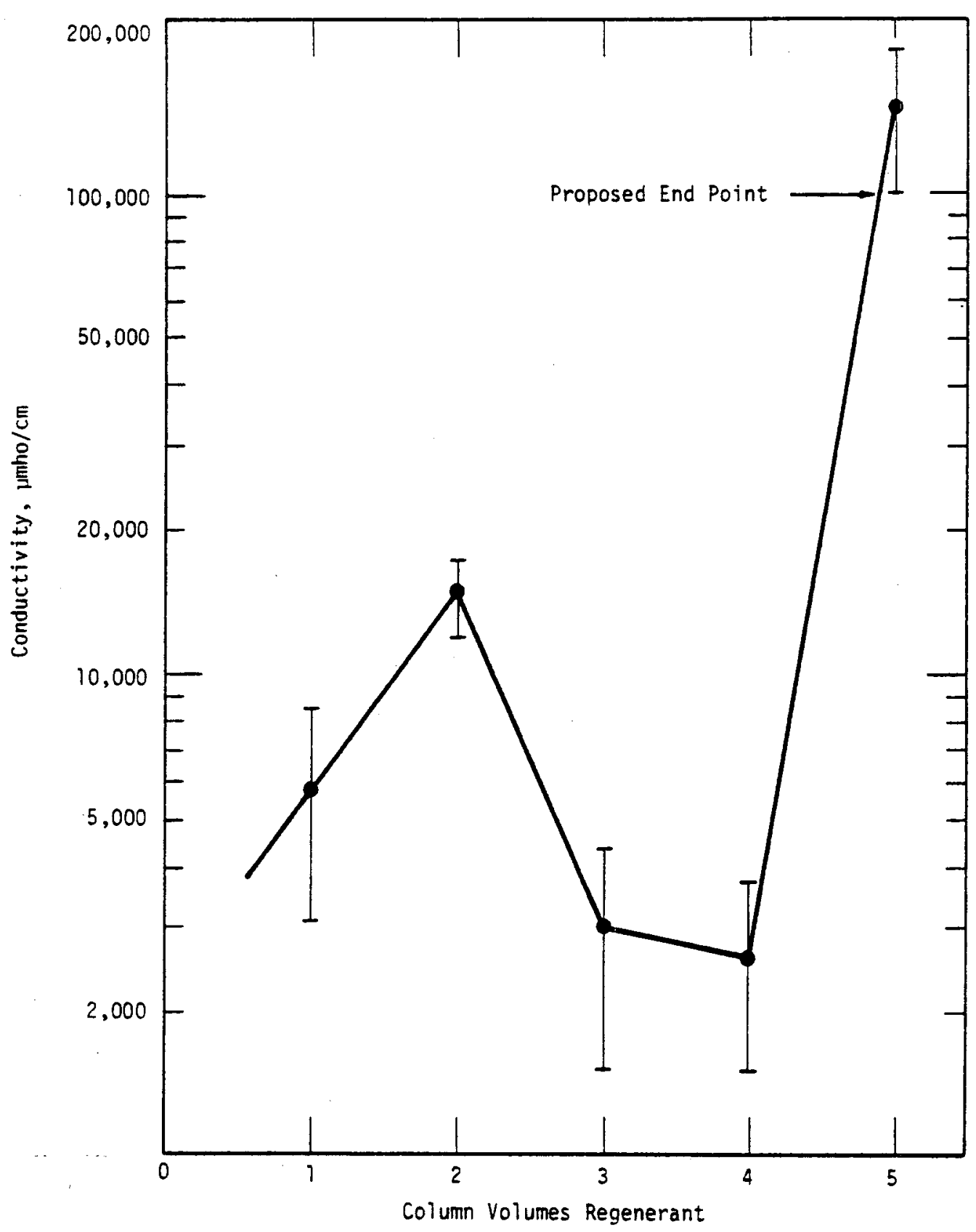

FIGURE 4.55 Electrical Conductivity Versus Regenerant Requirement 


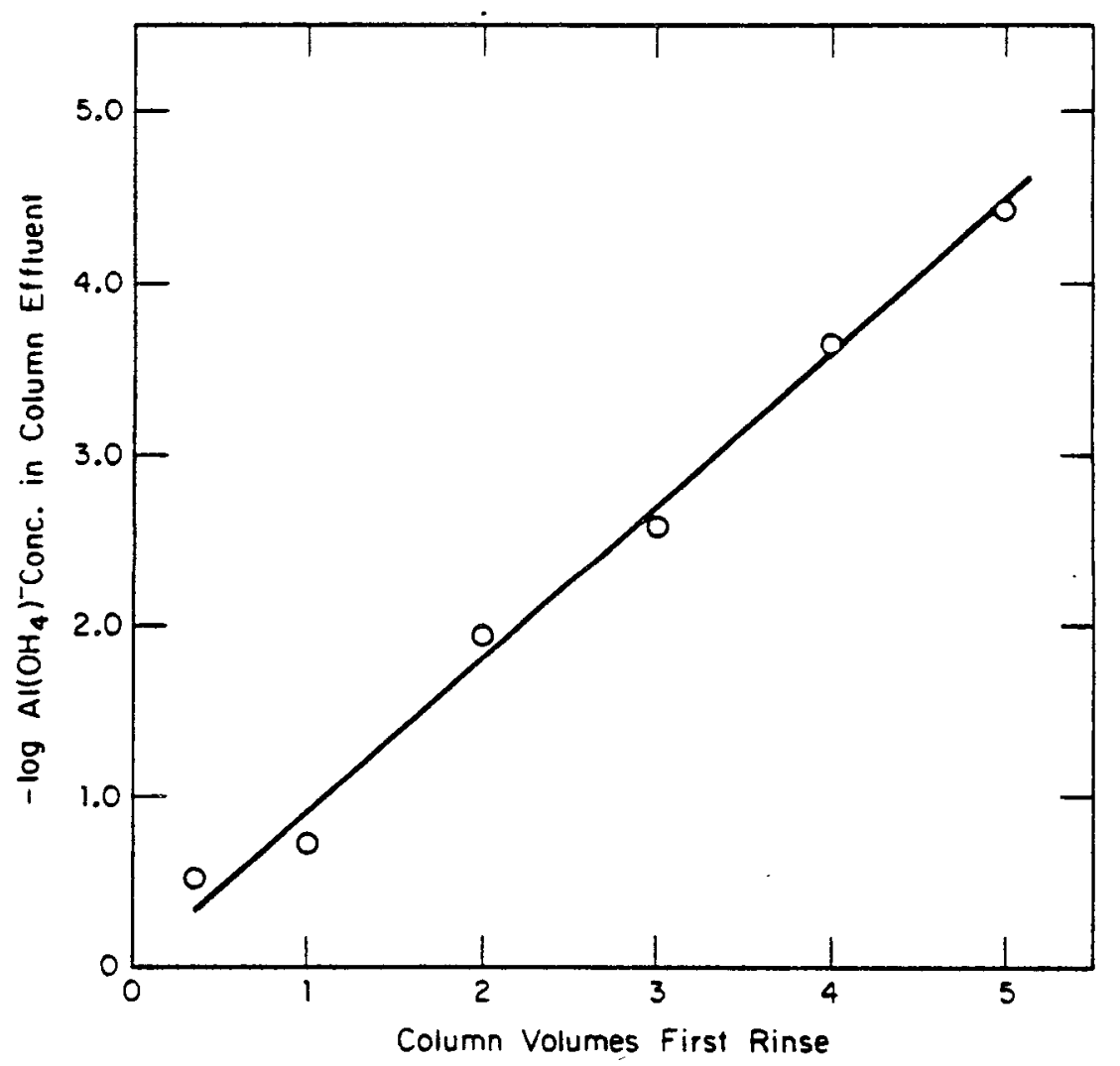

FIGURE 4.56 - Removal of $\mathrm{Al}\left(\mathrm{OH}_{4}\right)$ - During First Rinse on $3 "$ x 40" Column 


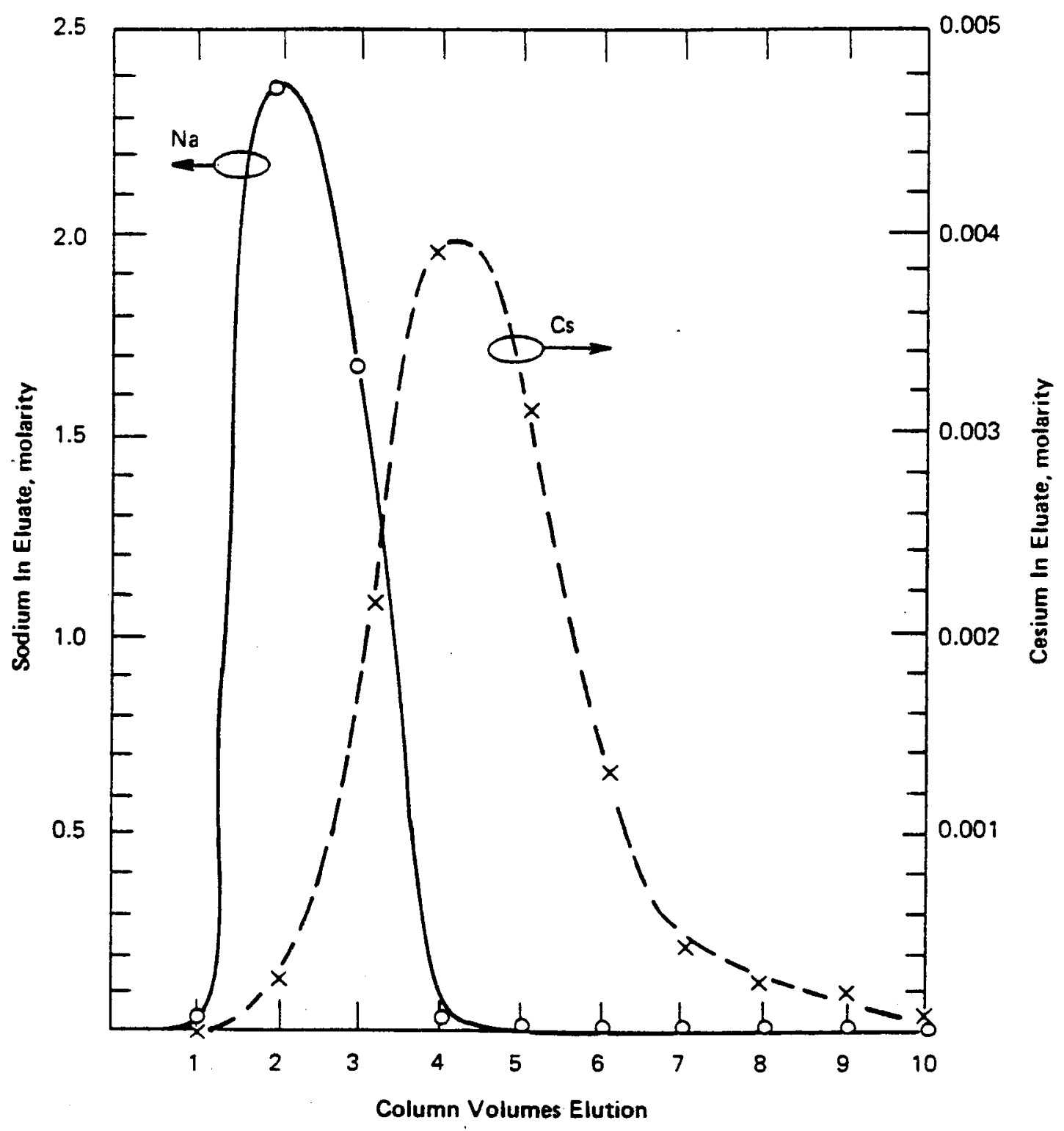

FIGURE 4.57 ICV/HR Elution Following a $60 \mathrm{cV}$ Feed Step, $C_{0}=1.87 \times 10^{-4} \mathrm{M} \mathrm{Cs}$, on $3^{\prime \prime} \times 40^{\prime \prime}$ Column 


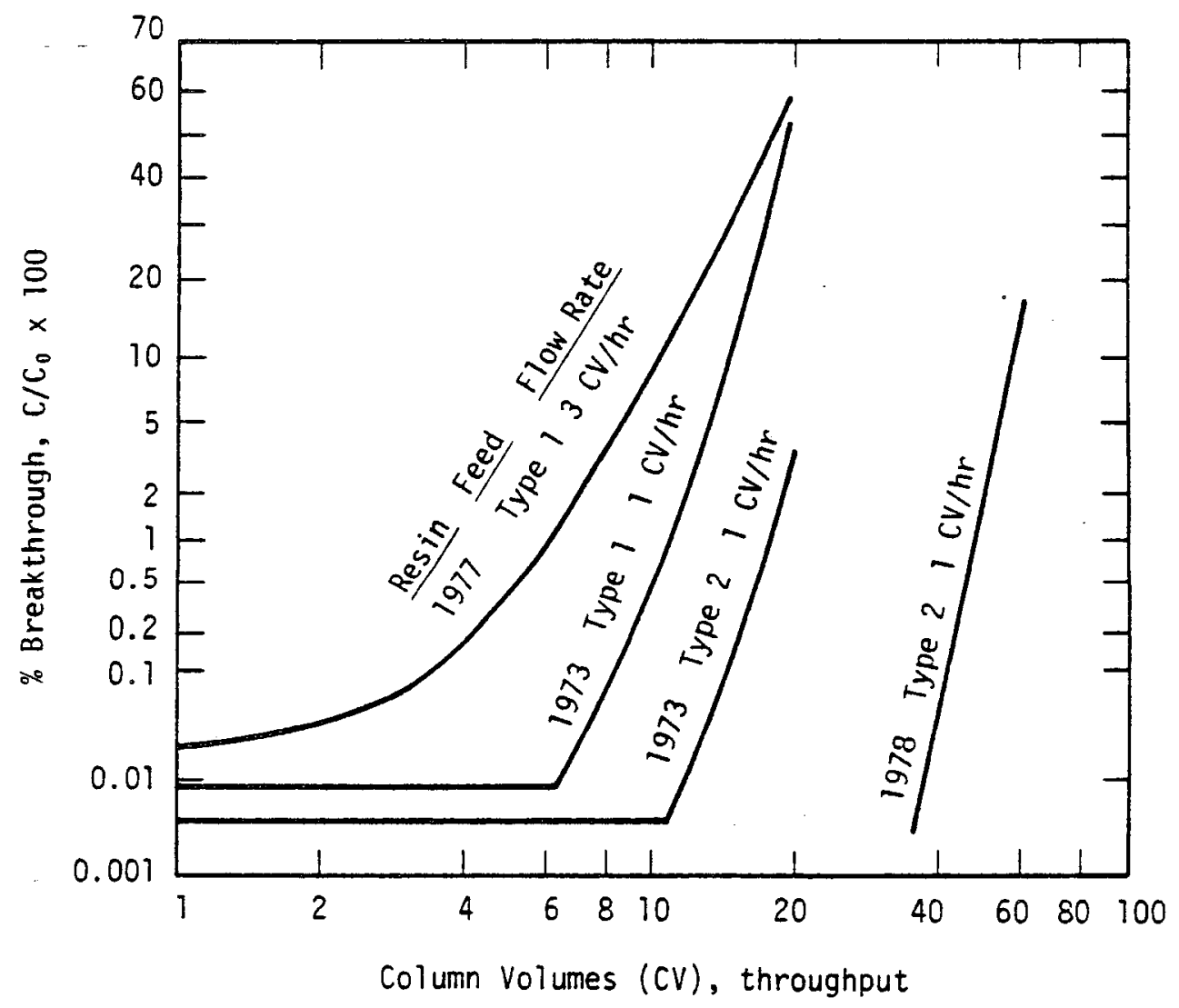

$\mathrm{Na}^{+} \mathrm{OH}^{-} \quad \mathrm{NO}_{3}^{-} \quad \mathrm{NO}_{2}^{-} \quad \mathrm{CO}_{3}^{2-} \mathrm{SO}_{4}^{2-} \quad \mathrm{AlO}$

$\begin{array}{lllllllll}\text { Feed Type 1 } & -5.3 & 1.0 & 2.06 & 1.13 & 0.27 & 0.21 & 0.41 \\ \text { Feed Type 2 } & -5.6 & 1.60 & 1.65 & 0.78 & 0.42 & 0.20 & 0.42 \\ \text { FIGURE 4.58 } & \begin{array}{l}\text { Effect of Resin Batch Feed Type on First } \\ \text { Column 1 Performance: }\end{array} C_{0}=2 \times 10^{-4} \mathrm{M}\end{array}$




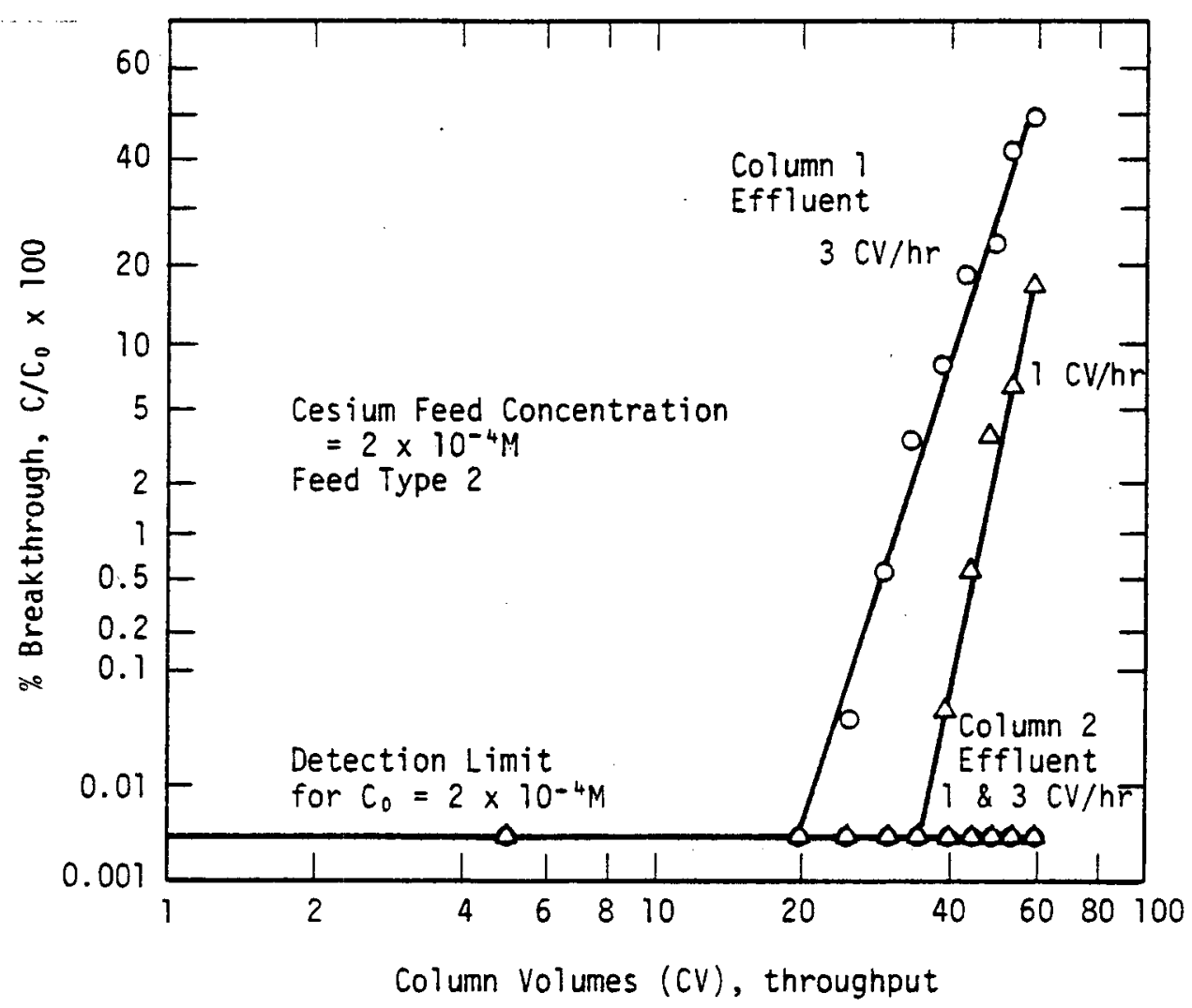

FIGURE 4.59 Typical Breakthrough Curves for 1978 Resin, Using 3"' x 40" Columns 


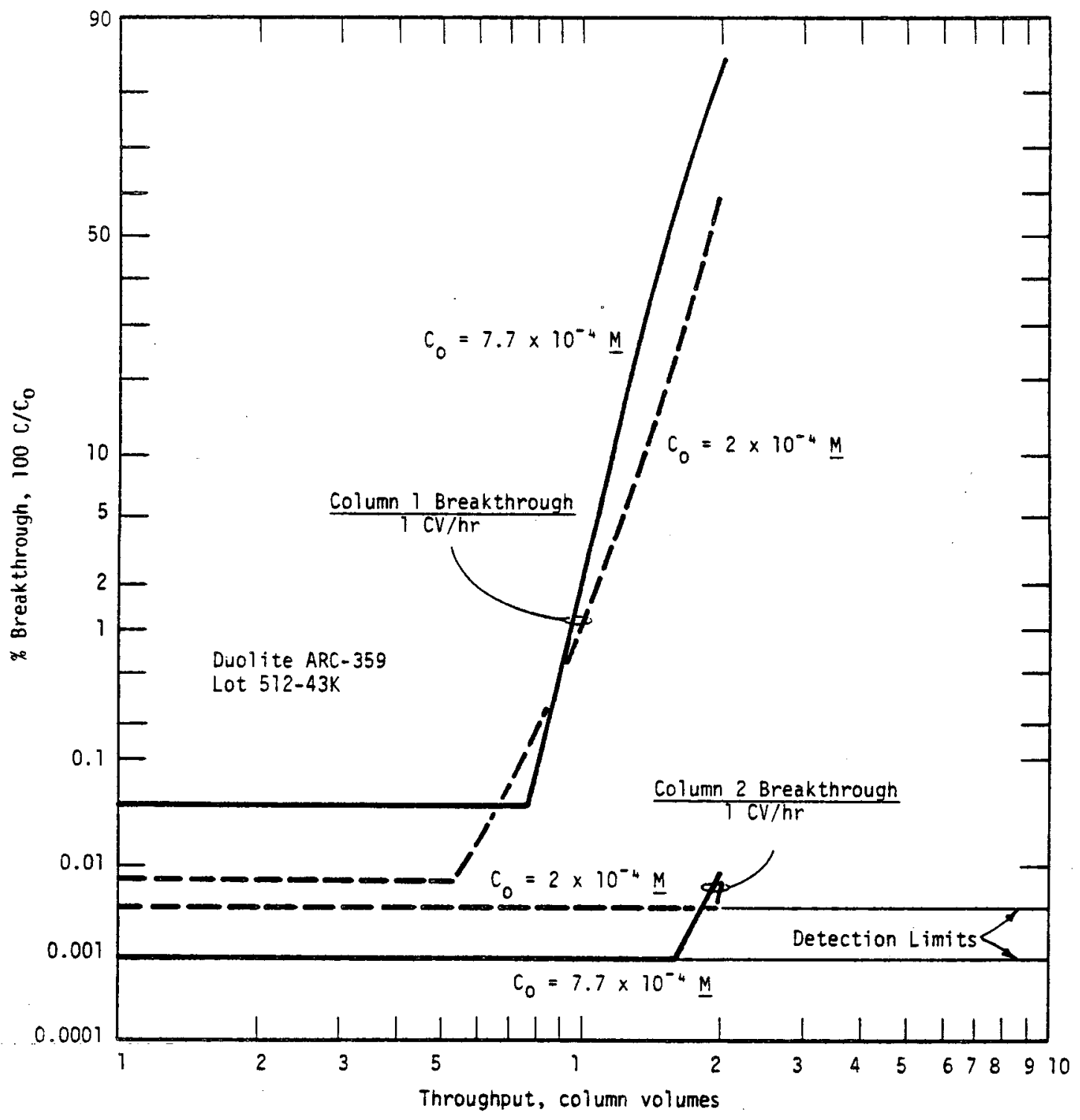

FIGURE 4.60 TNX Cesium Breakthrough Curves - Effect of Cesium Feed Concentration Using 3" x 40" Column with Feed Feed Type 1 


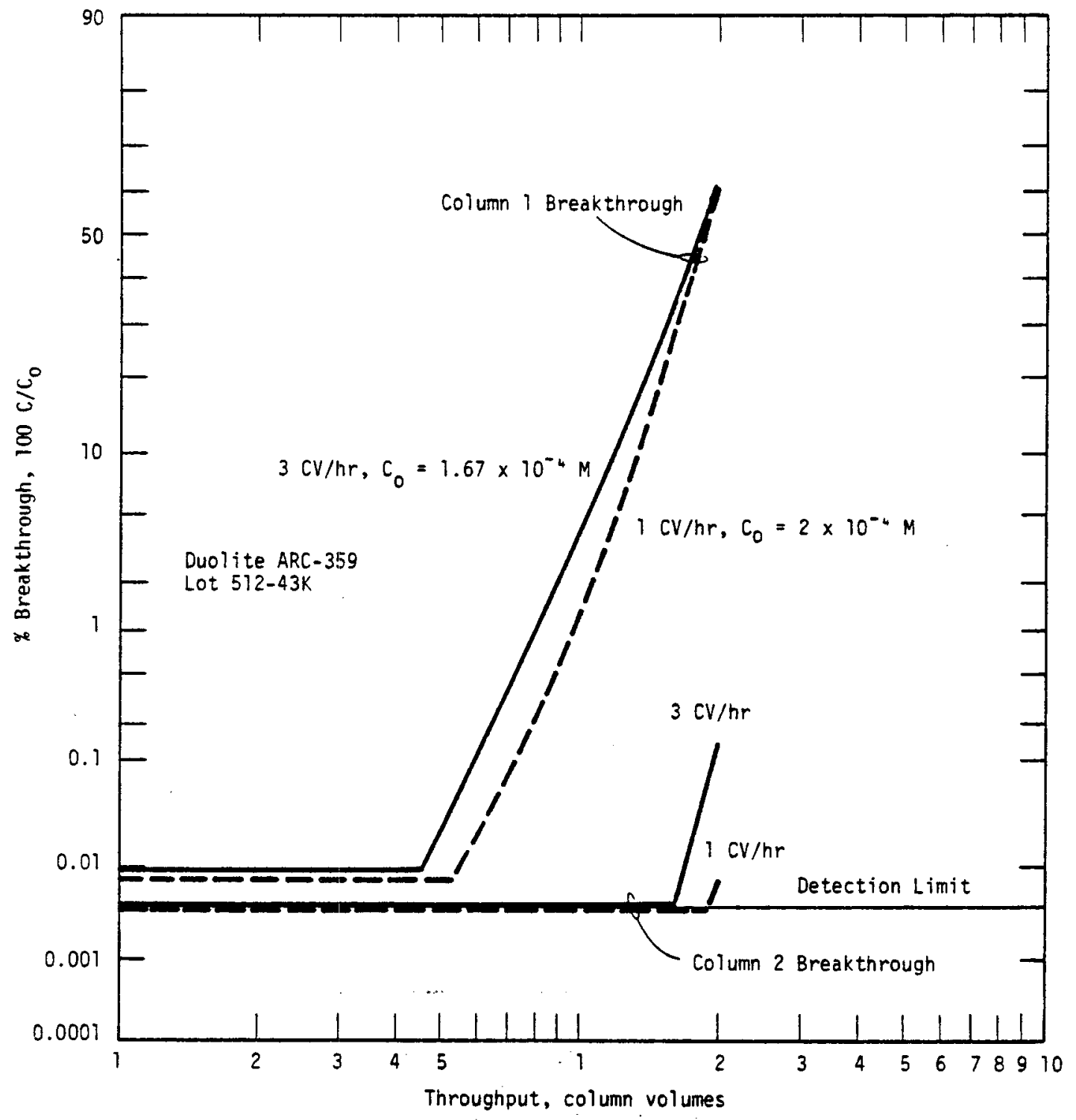

FIGURE 4.61 TNX Breakthrough Curves - Effect of Feed Rate 


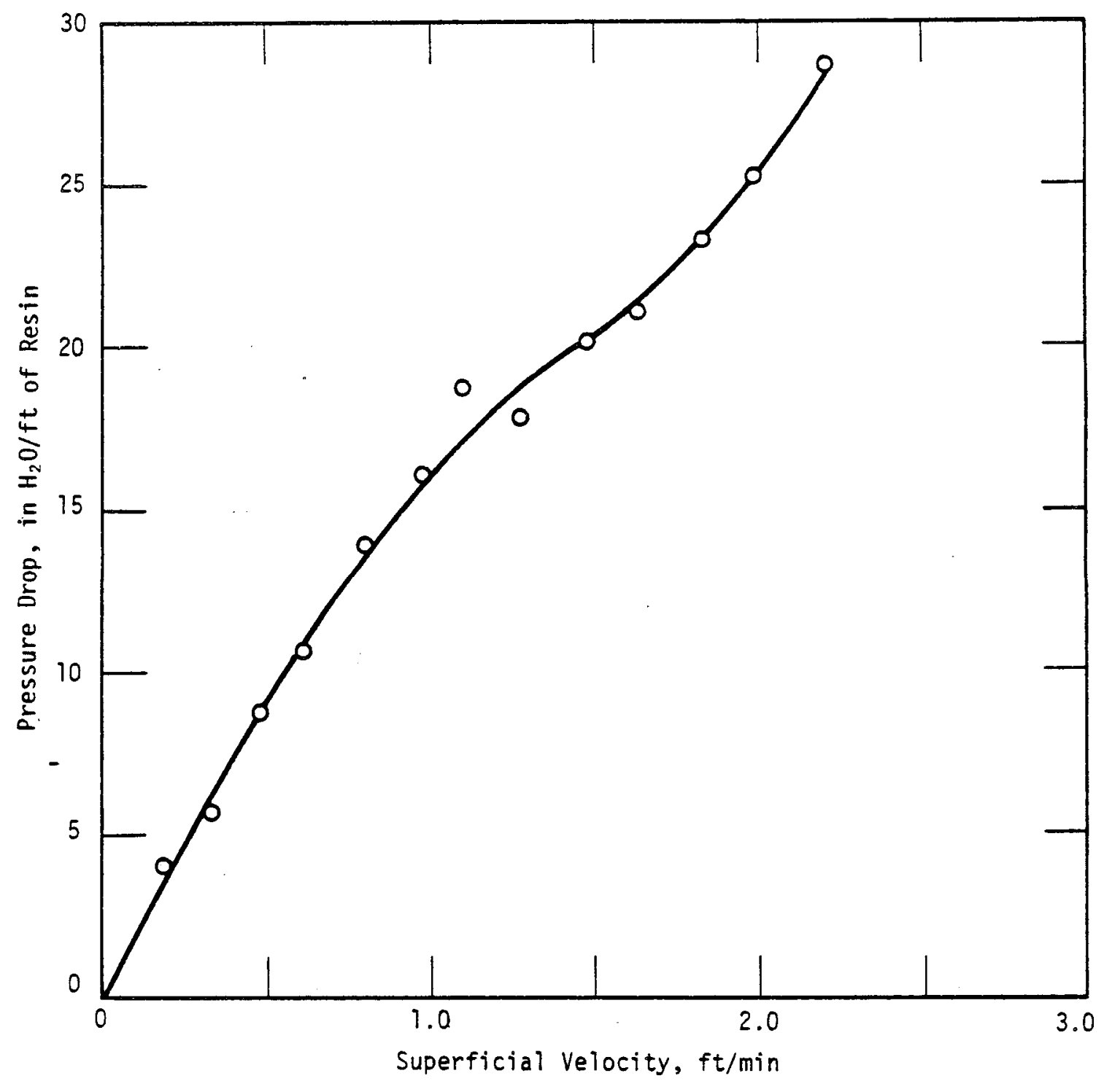

FIGURE 4.62 Downflow Pressure Drop of "Amberlite" IRC-718 


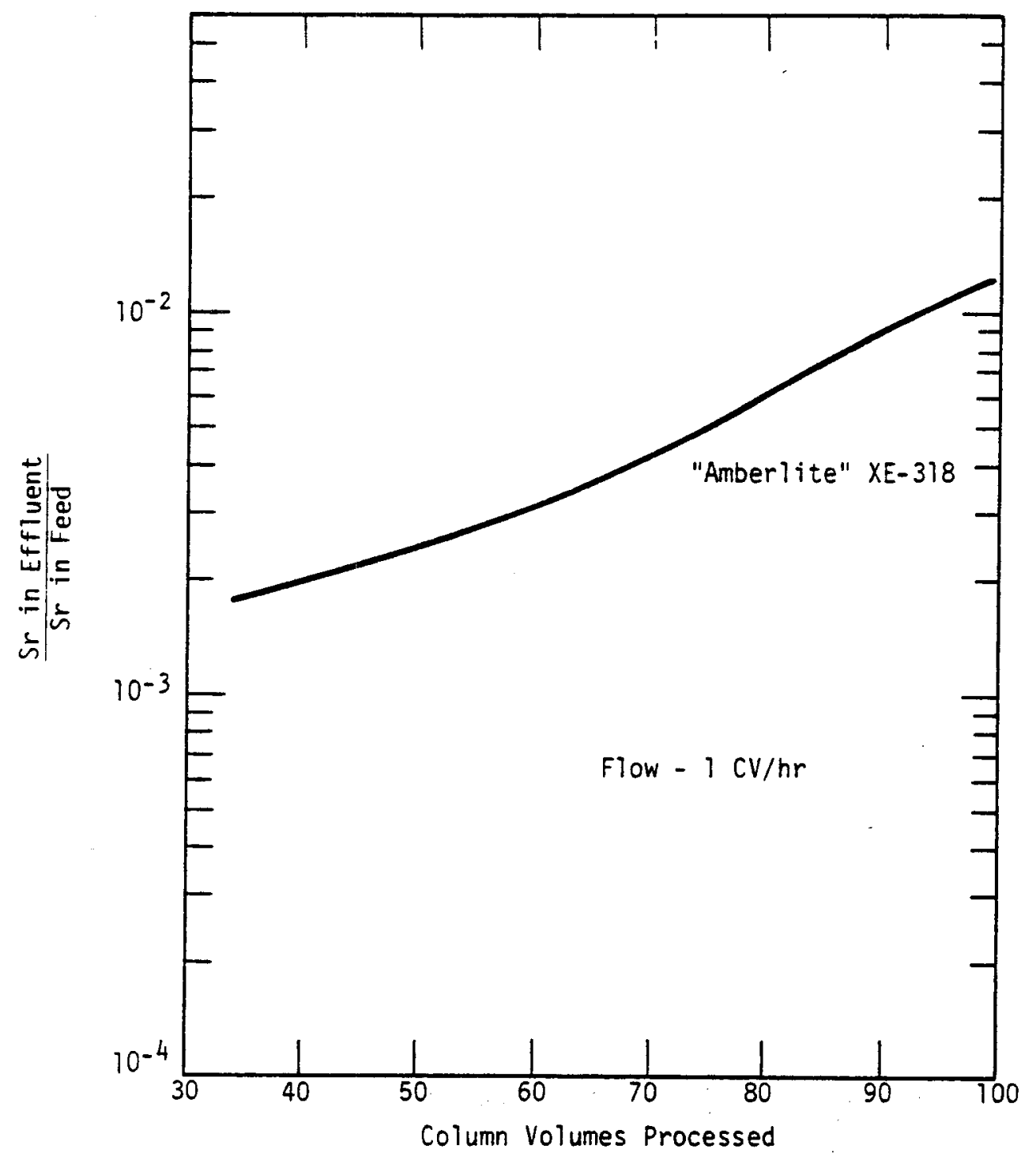

FIGURE 4.63 Column Test of "Aberlite" XE-318 (Presently manufactured as Amberlite (IRC-718) 


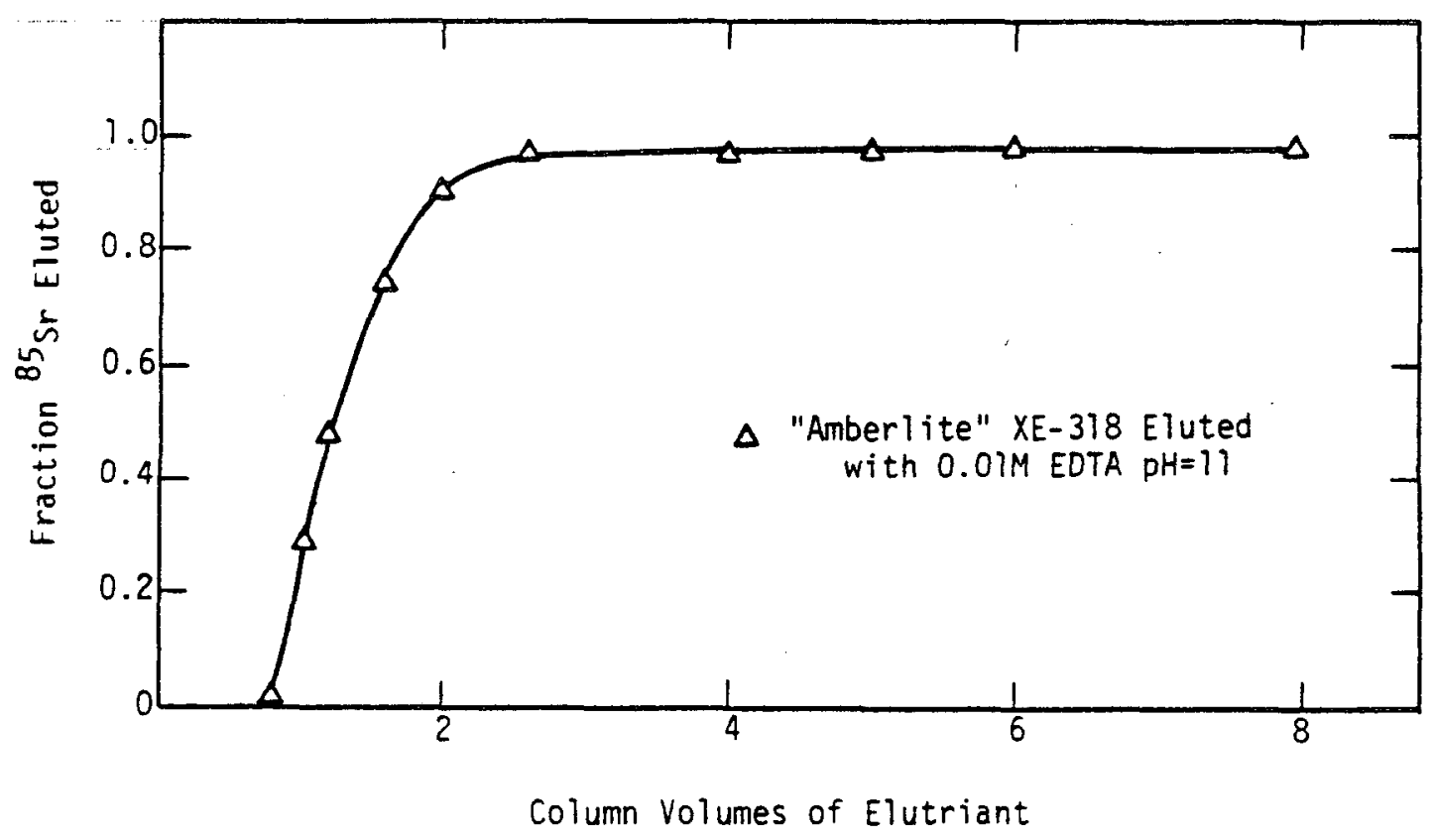

FIGURE 4.64 Elution of "Amberlite" XE-318 with EDTA (Presently manufactured as IRC-718) 


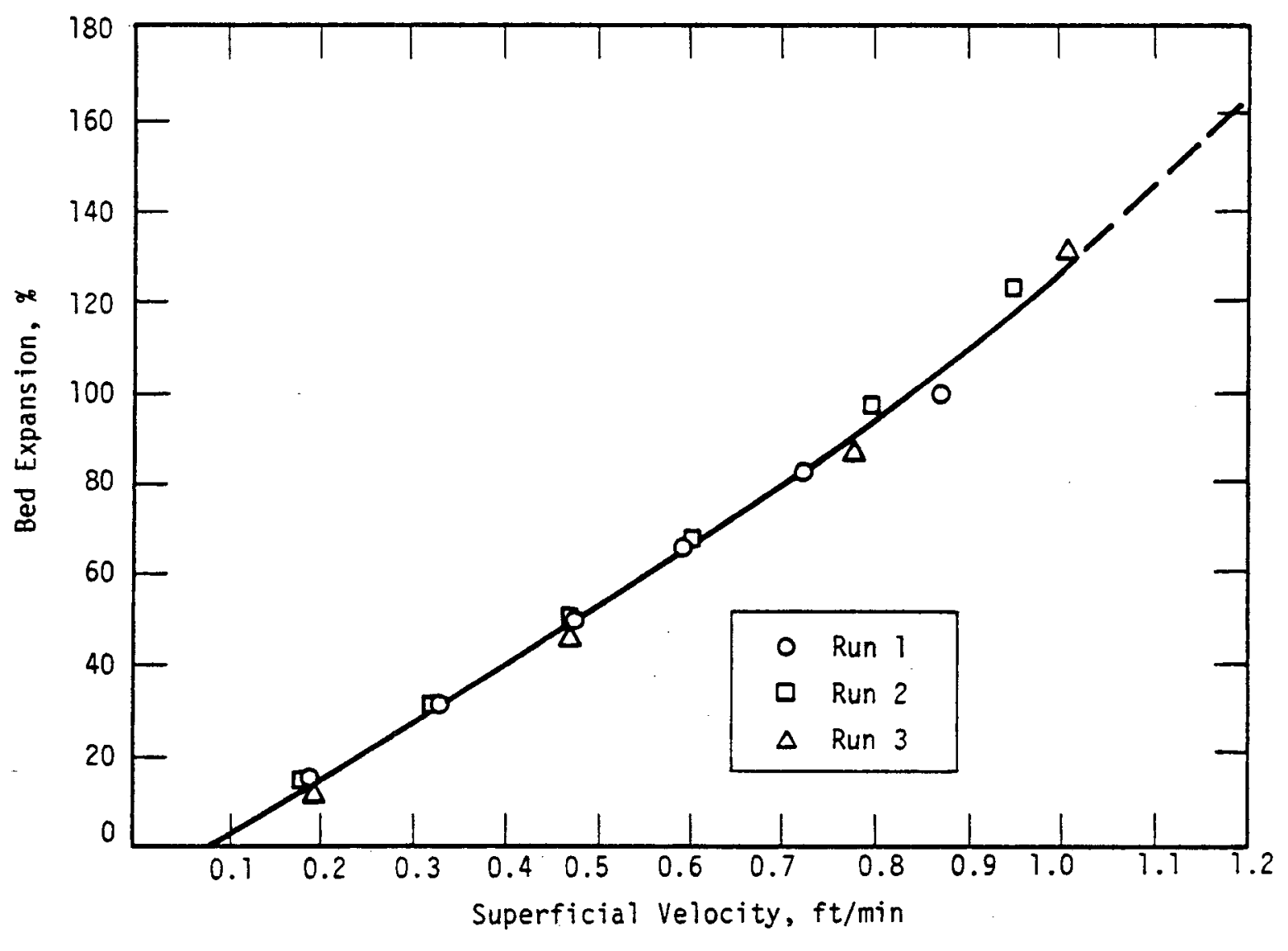

FIGURE 4.65 Upflow Expansion of "Amberlite" IRC-718 


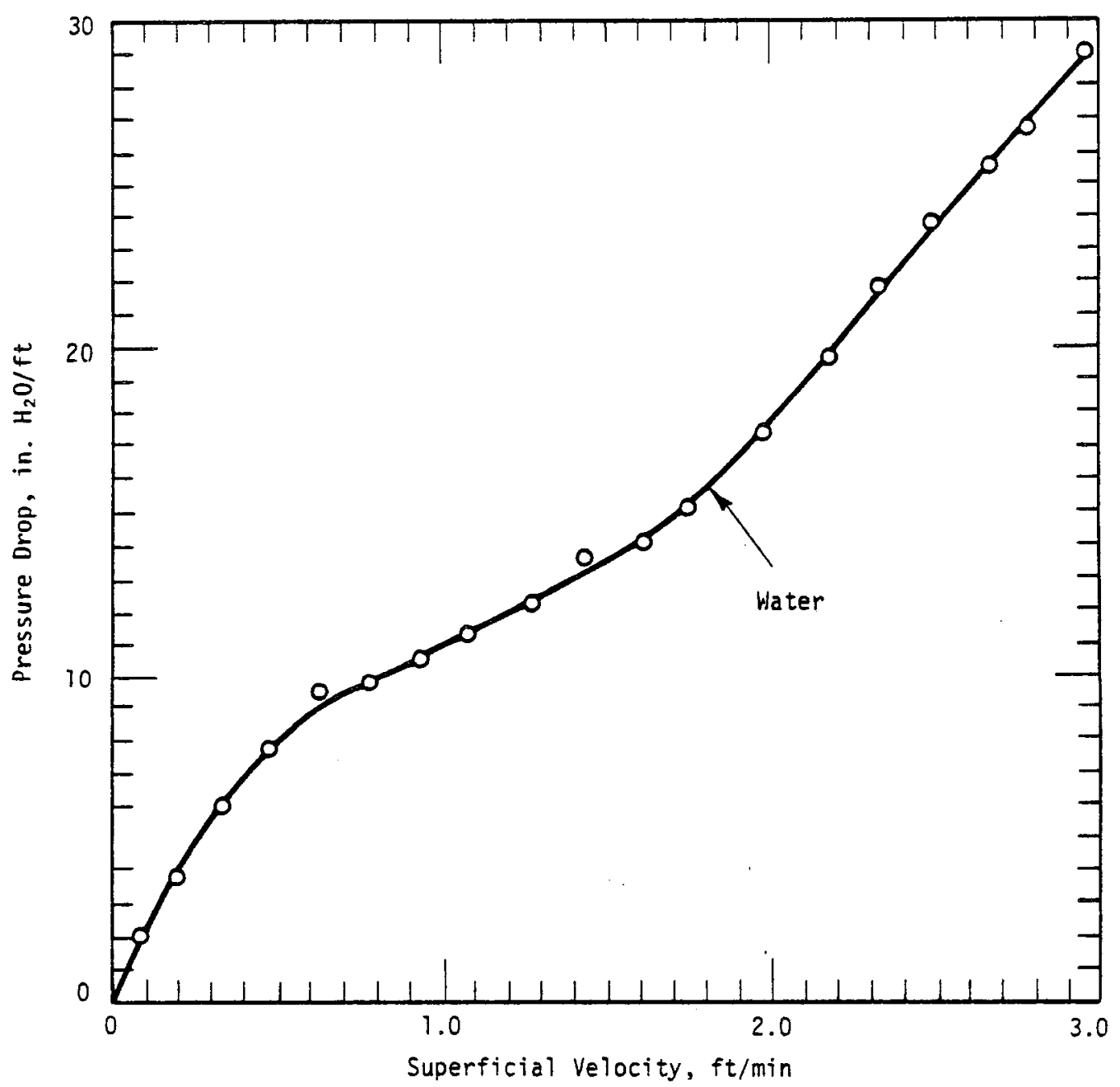

FIGURE 4.66 Downflow Pressure Drop in "Linde" AW-500 (Presently manufactured as Ionsiv IE-95) 


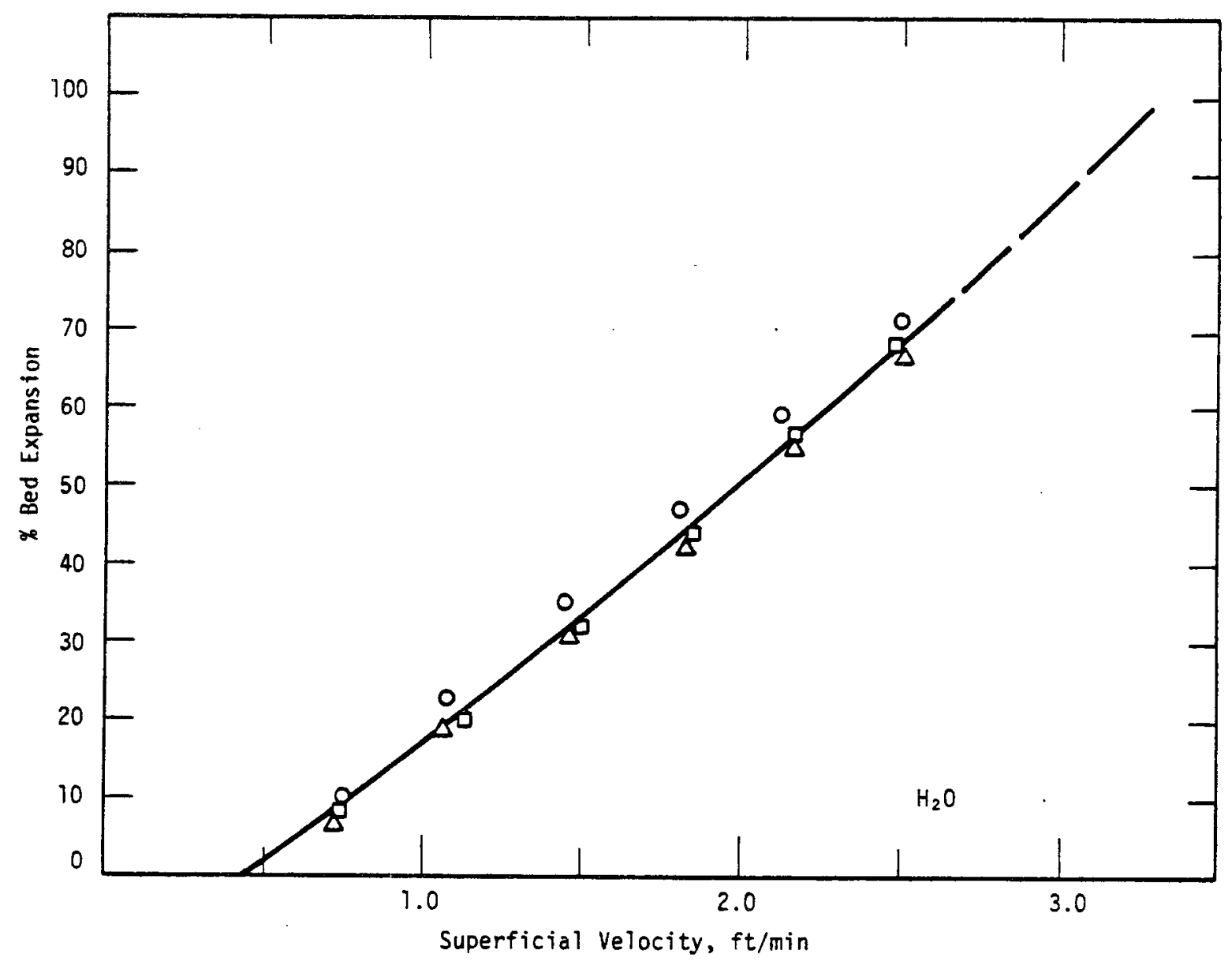

FIGURE 4.67 Upflow Expansion of "Linde" AW-500 


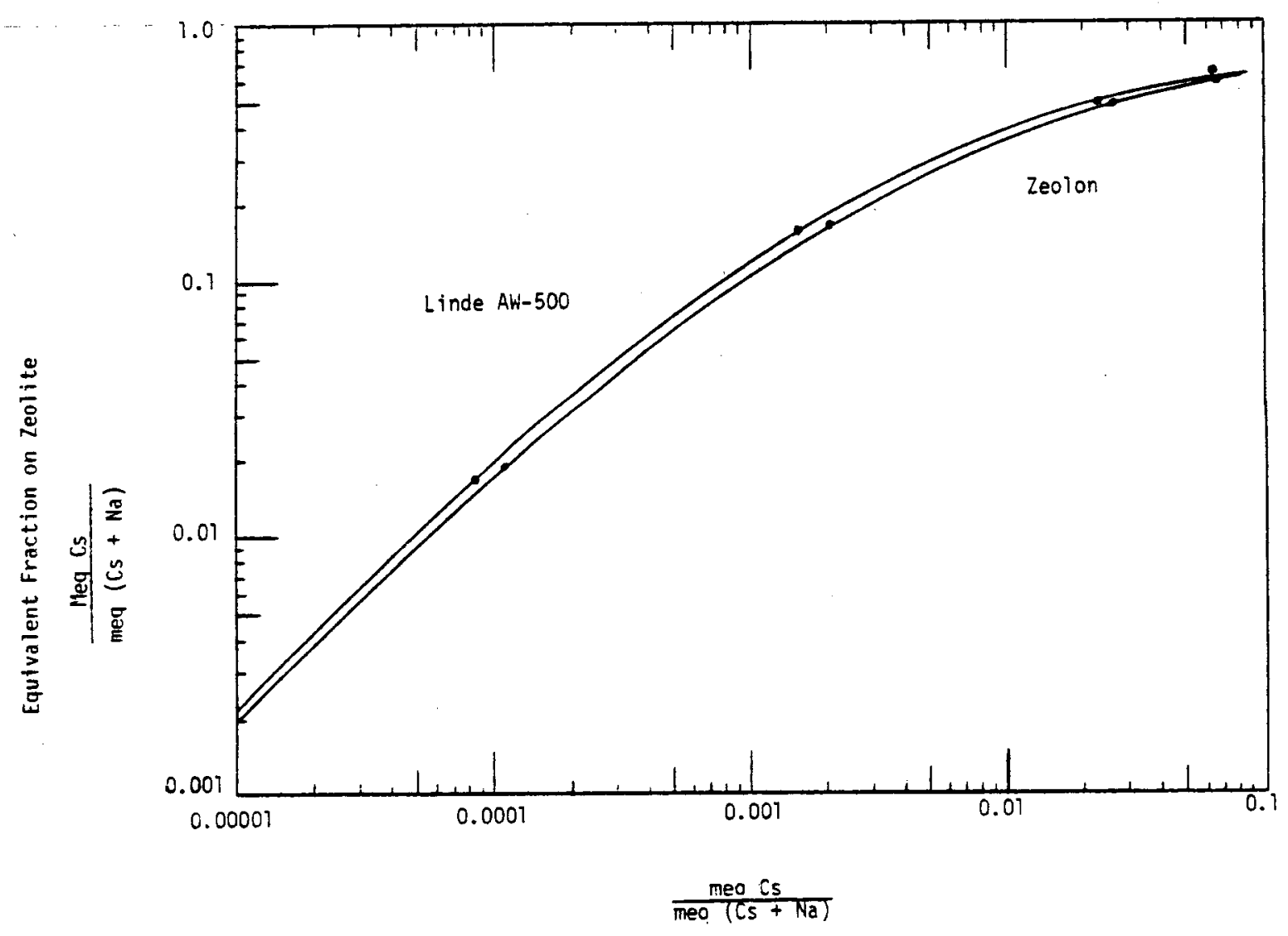

Equivalent Fraction in Equilibrium Solution FIGURE 4.68 The Effect of Sodium on the Equilibrium Cesium
Loading of "Iinde" AW-500 and Norton "Zeolon" 
5. PROCESS EQUIPMENT REQUIREMENTS

5.1 General 5.1

5.2 Process Equipment 5.1

5.2.1 Aluminum Dissolution 5.1

5.2.1.1 General: 5.1

5.2.1.2 Equipment Specifications 5.1

5.2.1.2.1 Sludge Receipt Tank 5.1

5.2.1.2.2 Aluminum Dissolver 5.2

5.2.1.2.3 Dissolver Condensate Tank 5.2

5.2.1.3 Process Control 5.2

5.2.1.3.1 Sludge Receipt Tank 5.2

5.2.1.3.2 Aluminum Dissolver 5.3

5.2.2. Sludge-Washing 5.4

5.2.2.1 General, 5.4

5.2.2.2 Equipment Specifications 5.4

5.2.2.2.1 Sludge Feed Tank 5.4

5.2 .2 .2 .2 Wash Tank 5.4

5.2 .2 .2 .3 Centrate Tank 5.4

$5.2: 2.2 .4$ Centrate Hold Tank 5.5

5.2.2.2.5 Washed Sludge Run Tank 5.5

5.2.2.2.6 Wash Centrifuge 5.5 


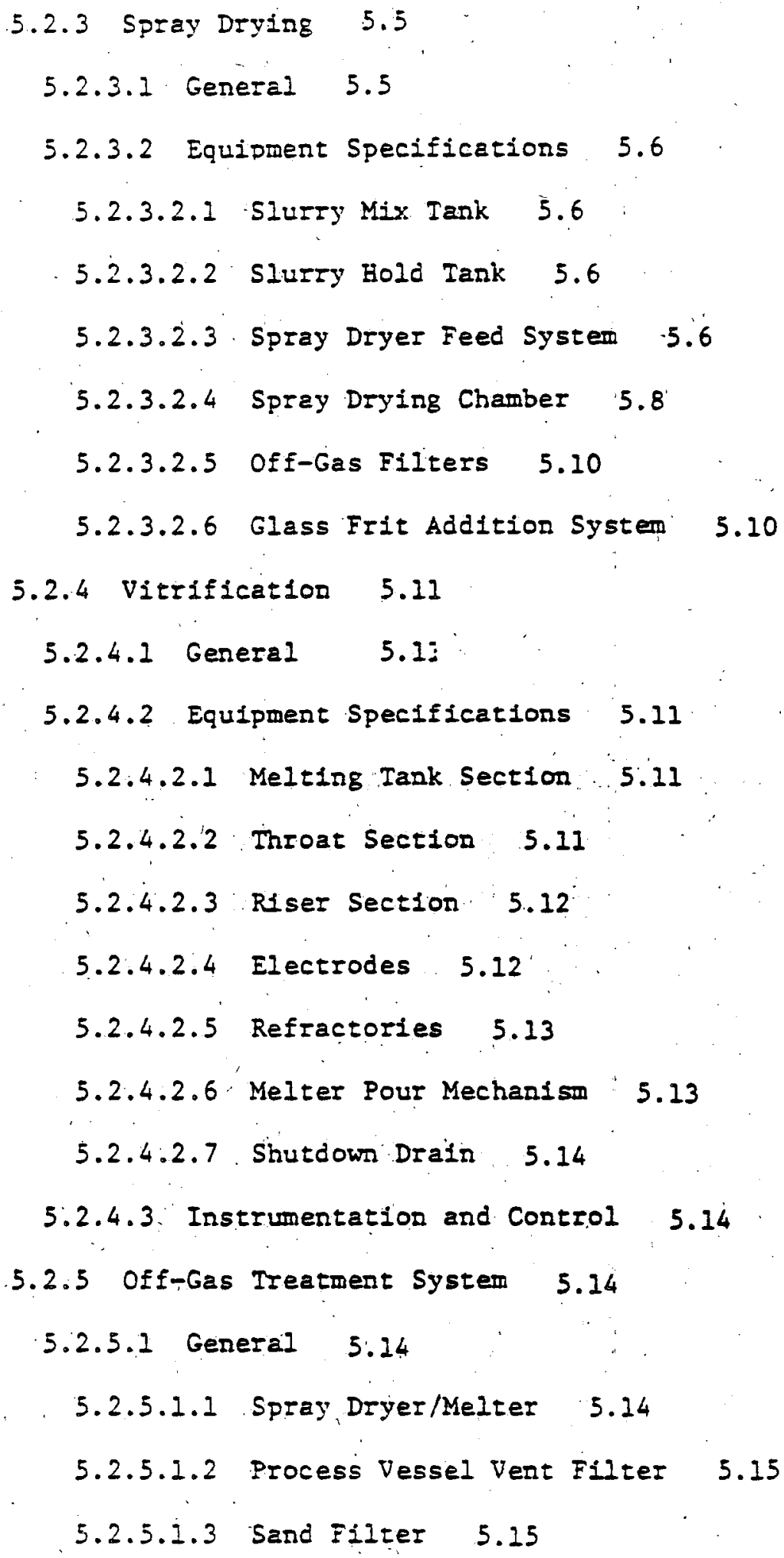




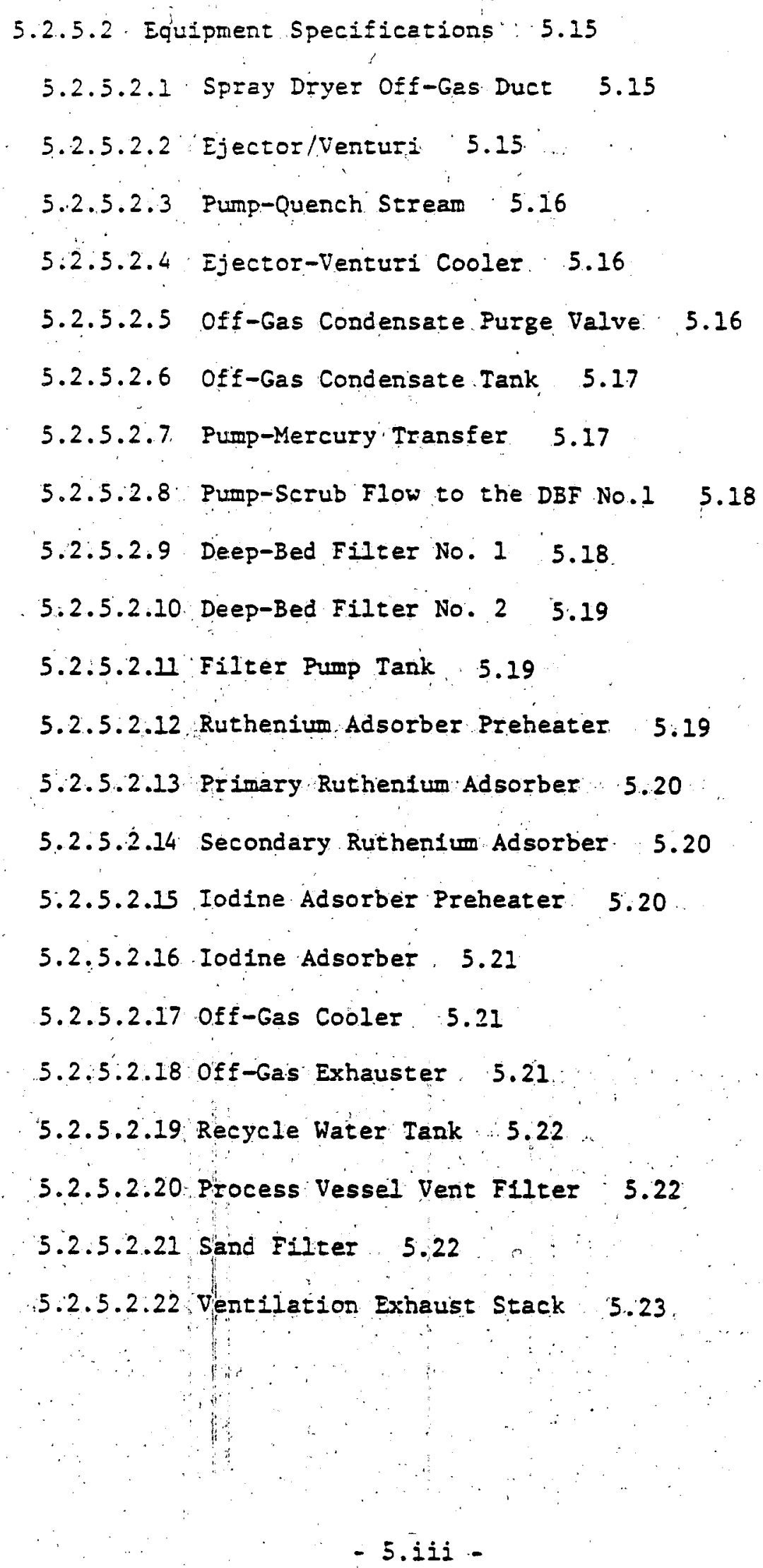


5.2.6 Mercury Recovery Facilizy 5.24

5.2 .6 .1 General 5.24

5.2.6.2 Mercury Receipt Tank , 5.25

5.2.6.3 Pump/Mercury F1lter No. 15.25

5.2.6.4 Acid Wash Feed Tank 5.25

3.2.6.5 Pump/Acid Wash 5.25

5.2.6.6 Acid Wash Colum 5.26

5.2.6.7 Backwash Hold. Tank 5.26

5.2 .6 .8 Oxidation Tank 5.26

5.2.6.9 Pump Mercury Filter No. 2. 5.27

5.2.6.10 Mercury Filter No. $2 \quad 5: 27$

5.2.6.11 Mercury Still Feed Tank 5.27

5.2.6.12 Mercury Vacuum Still/Condenser ... 5.28

5.2.6.13 Mercury St111. Product Tank 5.28

5.2.7 Recycle Concentration 5.28

5.2.7.1 General 5.28

5.2.7.2 Récycle Evaporator Feed Tank, 5.28

5.2 .7 .3 Recycle Evaporator 5.29

5.2 .7 .3 .1 Gerieral 5.29

5.2.7.3.2 Specifications $\quad 5.29$

5.2 .7 .3 .3 Services 5.29

5.2 .7 .3 .4 Conerol System 5.29

5.2.7.4 Recycle Evaporator Bottoms Tank 5.30

5.2 .7 .5 Recycle Evaporator Condensate Tank 5.30

5.2 .8 Settling and Filtration 5.30

5.2 .8 .1 General 5.30 
5.2.8.2 Salt Solution Receipt Tank 5.30

5.2 .8 .3 Gravity Settler. Feed Iank 5.30

5.2 .8 .4 Gavicy Settlers (GS) 5.31

5.2.8.5. Gravity Settler Supernate Tank 5.32.

5.2.8.6 Gravity Settler Bottoms Tank 5.32

5.2.8.7 Sand Filter Feed Tank 5.32

5.2 .8 .8 Sand Filter No: 15.33

5.2.8.9 First Filtrate Tank 5.34

5:2.8.10. Sand Filter No. $2 \quad 5.34$

5.2.8.11 Second Filtrate Tank 5.35

5.2.8.12 Filtrate Hold Tank 5.35

5.2.8.13 Filter Backwash Tank 5.35

5.2.8.14 Waste Sand Tank 5.35

5.2.8.15 Preperation of Polyelectrolyte for Addition to The Gravity Settler 5.36

5.2.8.16 Preparation of Polyelectrolyte for Addition to Sand Filters .5 .36 .

\subsubsection{Clarified Supernate Decontamination 5:37}

\subsubsection{General $: 5.37$}

5.2 .9 .2 Cesiu Ion Exchange 5.37

5.2.9.2.1 Cs Ion Exchange Columa 5.37

5.2 .9 .2 .2 Ion Exchange Feed Tank 5.37

5.2.9.2.3 Cesium Feed Bounce Tank 5.38

5.2 .9 .2 .4 Cesium Elute Bounce Tank 5.38

5.2 .9 .2 .5 Cesium Eluate Tank 5.38

5.2.9.2.6 Cesium Regenerant Catch Tank 5.38

5.2.9.2.7 Spent Resin Tank 5.39 
5.2.9.2.8 Resin Packaging Faciliry. 5.39

5.2.9.2.9 Cold Feed Facilities 5.39

5.2.9.3 Strontium Ion Exchange 5.39

5.2 .9 .3 .1 Ion Exchange Colum 5.39

5.2.9.3.2 Serontium Feed Bounce Tank 5.40

5.2.9.3.3 Product Salt Hold Tanks 5.40

5.2.9.3.4 Strontium Elute Bounce Tank 5.40

5.2.9.3.5 Strontium Eluate Tank 5.40

$5.2 .9 \cdot 3.6 \cdot$ Strontium Concentrator 5.41

5.2.9.3.7 Strontium Concentrator Bottoms Tank 5.41

5.2.9.3.8 Strontium Concentrator Condensate Tank 5.41

5.2.10 Cesium Elutriant Recovery/Eluate Concentration 5.42

5.2.10.1: General 5.42

5.2.10.2 Cesium Concentrator Feed Tank 5.42

$5.2 .10 .3 \cdot$ Steam Stripper 5.42

5.2.10.4 Cesium Concentrator. 5.42

$5.2 \cdot 10.5$ Downdraft Condenser 5.42

5.2.10.6. Stripper Condensate Tank 5.43

5.2.10.7 Cesium Elutriant Makeup Iank 5.43

5.2.10.8 Cesium Elutriant Feed Tank 5.43

5.2 .10 .9 Cesium Vent Scrubber 5.43

5.2.10.10 Purge Conderser 5.44

5.2.10.11 Purge Condensate Tank 5.44 


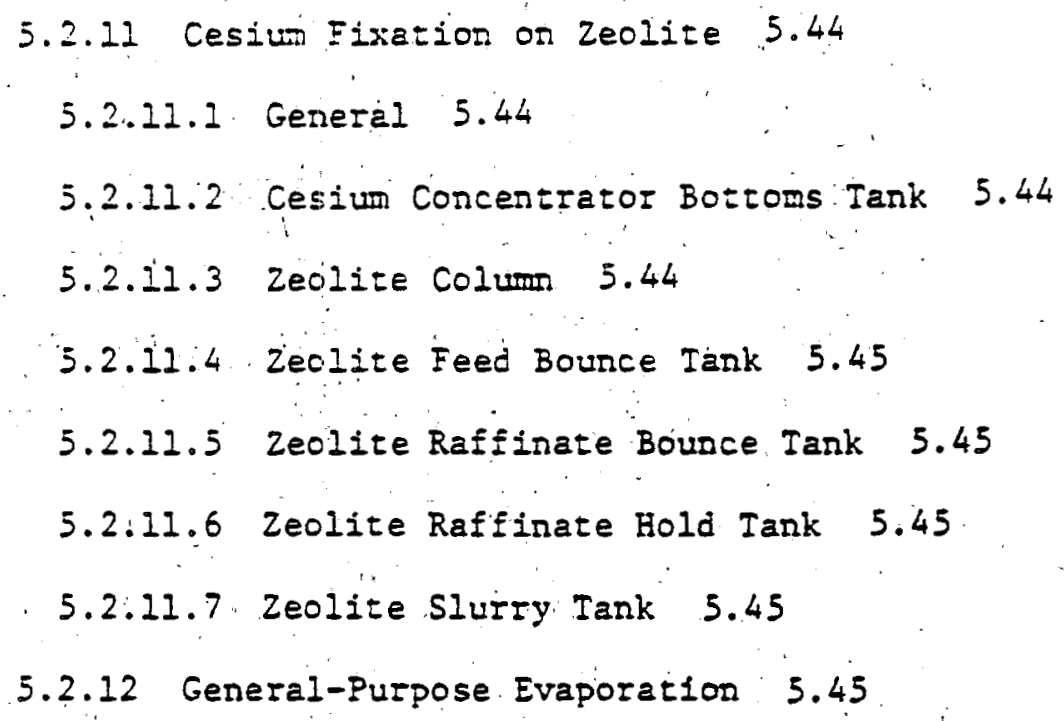


5.2.13.2.1 Generàl 5.48

5.2.23.2.2 Product Salt Solution Storage Iank 5.48

5.2 .13 .2 .3 Product Salt Evaporator 5.48

5.2 .13 .2 .4 Product Salt Evaporator Condenser 5.50

5.2.13.2.5. Product Salt Evaporator Condensate Tank 5.50

5.2.13.2.6 Product Salt Concentrare Tank 5.50

5.2 .13 .3 Saltcrete Preparation 5.51

5.2.13.3.1 General 5.51

$5.2 .13 .3 .2 \cdot$ Plant Capacity 5.51

5.2.13.3.3 Facility Description 5.51

5.2.13.4 Reference Disposal Site 5.52

5.2.13.4.1 General Design Criteria 5.52

5.2.13.4.2 Concrete Monoliths 5.52

$5.2 \cdot 13.4 .3^{\prime}$ Disposal Facility Design 5.52

5.2.14 Product Packaging/Testing/Decontamination/ Interim Storage 5.54

5.2.14.1 General Equipment and Cell Considerations '5.54

5.2.14.2 Mechanical Cell A 5.54

5.2.14.2.1 Canister Closure and Testing 5.54

5.2.14.2.2 Preliminary Canister Decontamination and Transfer 5.55

5.2.14.3 Mechanical Cell B 5.57

5.2.14.3.1 General. 5.57

5.2 .14 .3 .2 Esch Tank 5.57

5.2.14.3.3 Cleaning Tank 5.57

5.2 .24 .3 .4 Spray Tank 5.58 


5.2 .14 .3 .5 Spray Hold Tank 5.58
5.2 .14 .3 .6 Caustic Scrubber 5.58
5.2 .14 .4 Mechenical Cell C 5.58
5.2 .15 Interim Storage 5.59
5.3 References 5.78




\section{PROCESS EQUIPMENT REQUIREMENTS}

\subsection{General}

High levels of radioactivity require that the equipment be located behind heavy shielding walls. Controls should be provided for remote operation. Remote maintenance is required. Equipment is to have high reliability, low need for maintenance, and capable of remote replacement. Equipment is to be designed with provision for flushing in place and for decontamination and limited contact maintenance after remote removal.

Services (including cold feeds) for all process equipment are shown in tabular form in Tables 5.1 and 5.2 .

All cooling coils will be pressurized by an independent water source. Heating coils are pressurized by condensate and air pressure.

\subsection{Process Equipment}

\subsubsection{Aluminum Dissolution (C. T. Randal1)}

\subsubsection{General}

In this process module, solid aluminum hydroxides in sludge slurry feed are dissolved using $\mathrm{NaOH}$ as described in section 4.5.2. The aluminum-rich liquid phase and the aluminum-depleted insoluble phase are transferred as a slurry to sludge washing where the insoluble phase is separated and washed.

\subsubsection{Equipment Specifications}

\subsection{Sludge Receipt Tank}

An agitated hold tank receives batch transfers of $1: 1$ sludge slurry from blend tanks in the $\mathrm{H}$-Area waste tank farm. The tank should be cooled and requires liquid level, specific gravity, and temperature instrumentation as well as sampling capability. This tank should be capable of accommodating 3-5 days feed. 


\subsection{Aluminum Dissolver}

A dissolver which operates at near atmospheric pressure receives batch transfers of analyzed sludge slurry from the sludge receipt tank, $50 \% \mathrm{NaOH}$ from cold feed, and recycle water to achieve operating conditions specified in Section 4.5.2. The dissolver also receives gravity settler bottoms and waste filter media (sand/coal) after the dissolving step is completed for blending before being transferred to the sludge feed tank. The dissolver consists of an agitated, steam heated tank and a condenser. The capability to reflux condensate or divert it to the dissolver condensate tank should be provided. The condenser should be sized to accommodate the maximum heat duty deliverable by the steam coils. The off-gas system should be air-purged to prevent possible explosive concentrations of ammonia which may be released during dissolving. As an additional safety feature, the dissolver should be vented to relieve excess pressure or overflow to the canyon cell. The dissolver must be cooled and be equipped with a transfer device to transfer the slurry product to the sludge feed tank. Liquid level, specific gravity, temperature, and pressure instrumentation as well as sampling capability are required.

\subsection{Dissolver Condensate Tank}

A tank should be provided to accomodate drawing off dissolver overheads if required to make concentration adjustments in the dissolver. The tank should be equipped with liquid level, specific gravity, and temperature instrumentation as well as sampling capability. A transfer device is required to transfer the condensate to the recycle evaporator feed tank.

\subsubsection{Process Control}

\subsection{Sludge Receipt Tank}

\section{Function}

- Hold sludge feed slurry for S-Canyon processing.

- Provide a sludge slurry sample point.

\section{Controls}

- Liquid level.

- Sample. 
Transfers of sludge slurry from H-Area blend tanks are controlled by monitoring liquid level in this tank. Analyses of tank contents for volume percent suspended matter, density of suspended matter, weight percent aluminum in suspended matter and $\left[\mathrm{OH}^{-}\right]$are made to determine the amount of caustic and/or water to add to the dissolver.

\subsection{Aluminum Dissolver}

\section{Function}

- Dissolve insoluble aluminum hydroxides in the sludge slurry feed.

- Cool product slurry before transfer to the sludge feed tank.

- Blend recycled gravity settler bottoms and waste sand/coal with sludge after aluminum dissolution is complete.

\section{Controls}

- Liquid level.

- Dissolver pot pressure.

- Pot temperature.

- Automatic steam shut-off actuated by high pot or condenser cooling water temperature or high pot pressure.

- Condenser water/steam interlock.

Calculated quantities of sludge slurry from the sludge hold tank, $50 \%$ caustic from cold feed, and water are batched to the dissolver. For dissolution, the caustic concentration is to be increased to $5 \mathrm{M}$ while the molar ratio of $\mathrm{OH}^{-} /$unsoluble aluminum in the sludge is to be 16 . Quantities of slurry, caustic, and water are calculated based on analyses of the sludge slurry feed and maximum operating level in the dissolver.

Boiling is required for optimum dissolution of the aluminum hydroxides in the sludge. In operation, the boilup rate should be controlled to prevent overpressurizing. the dissolver pot. A pot pressure indicator with high pressure alarm should be provided. Dissolution at the boiling point will be carried out for a specific length of time ( 30 minutes - 1 hour). 


\subsubsection{Sludge Washing (D. W. Jones)}

\subsubsection{General}

Two parallel batch washing units are to be provided which consist of a wash tank, centrifuge, and centrate tank. In addition, two tanks are required for interim storage of the sludge feed and product. All tanks should be provided with suitable sampling equipment, agitation, and instrumentation for liquid level, specific gravity, and temperature. Tank heating equipment is not required. Cooling coils required only in the sludge feed tank.

\subsubsection{Equipment Specifications}

\subsection{Sludge Feed Tank}

A large, well-agitated tank is required to receive blended sludge from the aluminum dissolver composed of digested sludge, gravity-settler bottoms, and spent filter media. Sludge content in the slurry is about $12 \%$ by volume. Agitation must be sufficient to provide good mixing and maintain sludge, sand, and coal solids in suspension. Two pumps must be provided to transfer a controlled volume of feed rapidly to the two wash tanks at the start of each batch washing cycle.

\subsection{Wash Tank}

Two agitated tanks of at least 1,000 gallons capacity must be provided to receive and mix the sludge and wash water, supply feed to the centrifuge, and slurry the final washed sludge cake. Sufficient agitation must be provided for rapid cake dispersion and good solids/liquid mixing. Large lumps of cake may enter the wash tank during centrifuge discharge and must not be permitted to settle or collect on tank walls or enter the centrifuge feed system and obstruct feed flow. The mixing volume will range from 150 gallons during washed sludge slurrying to 700 gallons during sludge and wash water contacting. A variable speed pump is required to control centrifuge feed flow over a range of $1-30 \mathrm{gpm}$, and another pump is required to transfer the washed sludge slurry to the washed sludge run tank at the end of each wasing cycle.

\subsection{Centrate Tank}

Two well-agitated tanks having approvimately the same capacity as a wash tank is required to hold the centrate from the centrifuges. Instrumentation must be provided to permit on-line analysis of effluent conductivity during the final wash. The centrate will 
contain some sludge ( $<1$ vol \%), and sufficient agitation must be provided to prevent solids settling. A pump is required to transfer the centrate to the centrate hold tank after each centrate pass.

\subsection{Centrate Hold Tank}

A well-agitated tank is required to hold centrate from each centrate tank. A pump is required to transfer the centrate to the recycle evaporator feed tank.

\subsection{Washed Sludge Run Tank}

This tank receives and blends washed sludge slurry from the two washing units. Tank agitation must be sufficient to maintain sludge solids in suspension and provide good mixing. A pump is required to transfer the slurry to the slurry mix tank. The slurry will contain 45 vol \% sludge and is a Bingham plastic fluid having a yield stress of 60 dynes $/ \mathrm{cm}^{2}$ and consistency of 8 centipoise at $40^{\circ} \mathrm{C}$. Special care must be exercised in design of mixing, transfer, and storage equipment for this slurry.

\section{2 .2 .2 .6 Wash Centrifuge}

Large vertical, solid-wall, batch basket centrifuges are required for sludge dewatering in each of the processing steps. These machines are to be driven from the top and discharged through the bottom by a mechanical plow with water spray assist. Technical specifications for the wash centrifuge are listed in Table 5.3. The present design basis is for a 48-in. diameter $x$ 30-in. high basket size with a 120-gallon capacity.

\subsubsection{Spray Drying (M. H. Tennant)}

\subsubsection{General}

The current concept is that the feed for spray drying will be split to parallel spray dryer, melter, and off-gas systems. The function of the equipment in this module is to convert the sludge slurry to a powder suitable for blending with glass frit prior to vitrification. This section provides the basic data for designing the equipment required to carry out the process (described in Section 4.5.5). 


\subsubsection{Equipment Specifications}

\subsection{Slurry Mix Tank}

A tank is required to combine washed sludge from the washed sludge run tank with the cesium-zeolite slurry and the strontium concentrate. The tank must be equipped with an agitator and suitable devices to monitor liquid level, temperature, and specific gravity. Cooling coils will be required. Suitable transfer devices are required to transfer the slurry (about 17 wt \% total solids) to a slurry hold tank.

\section{2 .3 .2 .2 Sluriy Hold Tank}

A well-agitated tank is required for inventory and quality control of spray dryer feed before transfer to the calciner feed tank. The tank must be equipped with an agitator, sampler, cooling coils, and suitable devices to monitor liquid level, specific gravity, and temperature. A transfer device is required to recycle out-of-spec feed to the sludge feed tank. A second transfer device is required to transfer in-spec feed to either of two calciner feed tanks.

\section{2 .3 .2 .3 Spray Dryer Feed System}

General

The feed system is comprised of a feed tank, a recirculation loop, and a feed drawoff metering system designed to deliver feed at a relatively low flow rate $(\sim 1.0 \mathrm{gpm})$ to the spray dryer atomizing nozzle at pressures ranging from 1 to 2 atm. The concentrated slurry and low flow rates pose potential line, flow metering device, and nozzle blockage problems.

\section{Calciner Feed Tank}

A well-agitated vessel is required to receive in-spec batches of sludge slurry from the slurry hold tank for each calciner. The tank must be equipped with an agitator, sampler, and appropriate devices to monitor specific gravity, liquid level, and temperature. Cooling coils are required to maintain the feed slurry at $40^{\circ} \mathrm{C}$ or less [1]. A transfer pump is required to circulate the feed slurry about the recirculation loop at velocities no less than $5 \mathrm{ft} / \mathrm{sec}$. 
Feed Circulation Loop

Since the actual feed rate to the spray dryer nozzle is relatively low, a direct transfer from the feed tank to the spray nozzle would result in failure to maintain the solids in suspension, therefore posing potential problems of pluggage. Consequently, the nozzle feed line should branch off a feed loop that circulates the slurry through the loop back to the feed tank. The pressure in the loop must be controllable and continuously monitored. The drawoff line to the spray dryer feed nozzle, containing a flowmeter and a control valve, must be as short as possible to avoid pluggage. The circulation loop and feed drawoff line must have provisions for flushing to prevent pluggage problems when the feed system is shut down.

\section{Atomizing Nozzle}

The key to successful spray drying is proper atomization of the sludge slurry as it is sprayed into the heated chamber. The air rate to the nozzle requires a system that maintains the air flow such that a ratio of air to slurry feed is maintained at approximately $4.00 \mathrm{lb}$ air/gal feed. The slurry should be dispersed into droplets small enough to dry before striking the heated wall. If the particles do not dry, they will stick to the wall producing a scale that reduces heat transfer into the chamber. A droplet mass median diameter of about 70 micrometers is adequate for successful operation of the spray dryer based on work carried out at PNL [1].

An internal-mix atomizing nozzle designed to handle the anticipated slurry feed rate should be used to atomize the waste. A Spraying System Co. Setup No. 84 nozzle was determined by PNL to provide satisfactory performance at flow rates from 20 to 80 $\mathrm{gal} / \mathrm{hr}$. Both the fluid orifice and air cap orifice in this nozzle are $1 / 4$ inch in diameter (see Figure 5.1). Larger orifices, up to $1 / 2$ inch in diameter, are currently being tested and evaluated. To minimize orifice wear by abrasion and corrosion, and therefore, extend service life, the nozzle air cap was fabricated from $96 \%$ alumina [1].

The internal-mix nozzie will require a pressurized feed system. To assure that sludge slurry, is not pumped through the atomizing air lines to areas outside the canyon cell, pressure sensors tied in with the slurry feed pump should be located in the air and slurry lines. In addition, a radiation detector should be positioned at the location where the air line penetrates the cell wall. 
The atomizing nozzle should be incorporated into a remotely replaceable assembly to facilitate nozzle changeout. This assembly may include a remotely operated cleanout needle for removing obstructions from the liquid and air cap orifices; however, 1/4-inch or 1/2-inch orifices have not plugged when flush water has been introduced at the end of each shutdown.

An external-mix nozzle is being tested at PNL as a potential replacement for the internal-mix nozzle. Advantages of the external-mix nozzle are: (1) it does not require a pressurized slurry feed system, and (2) it is not subject to rapid wear because the slurry and atomizing air mix after leaving the nozzle. However, problems were experienced in earlier work with nonuniform droplet sizes and poor atomization caused by spray dryer chamber pressure variations resulting from filter blowback. Proper nozzle design is expected to eliminate these problems.

\subsection{Spray Drying Chamber}

The spray drying chamber is a large externally heated vertical tube into which the atomized sludge slurry is sprayed at the top center (Figure 5.2). A furnace surrounds the chamber and supplies the process heat load. The chamber wall. temperature is to be maintained between $550^{\circ} \mathrm{C}$ and $800^{\circ} \mathrm{C}$. However, for maximum capacity the chamber should be run at the highest temperature consistent with the dryer product melting point, equipment life, and existing heater technology. The furnace power output is to be controlled by temperature sensing elements located on the exterior spray chamber wall.

Sludge slurry enters the dryer as small droplets in a stream traveling at very high speed and hence, induces a high degree of turbulence in the chamber. The combination of radiant heat transfer coupled with this violent convective heat transfer allows evaporation and drying at a high rate. Important data relating spray dryer size, slurry feed rate, wall temperature, and power input are listed in Table 5.4 .

A scale which reduces dryer capacity, may deposit on the interior spray chamber walls due to this violent convective heat transfer. A side-mounted vibrator is required to keep this wall scale to an inconsequential amount. Two vibrators situated at the chamber midpoint and located $180^{\circ}$ apart are recommended for a 3-0 ft diameter chamber. Larger chambers will most likely require additional vibrators. The vibrators are to be designed for remote replacement without requiring dryer shutdown. 
The powder produced in the spray chamber falls into the cone below and mixes. with powder that is periodically discharged from the filters. Experience both at PNL and at Karlsruhe, Germany has shown that the filters should be as close to the spray drying chamber as possible. All surfaces should be sloped at least $60^{\circ}$ from horizontal to prevent powder accumulation. Further assurance of transport is provided by the mild vibration of the lower portion of the spray dryer caused by the spray chamber vibrator.

The spray dryer chamber and associated piping and hardware should be constructed of materials that are resistant to corrosive and erosive attack by the sludge slurry and are unaffected by the elevated operating temperatures. Incoloy ${ }^{\circledR} 800 \mathrm{H}$ (Huntington Alloys, Inc.) and Hastelloy ${ }^{(8)}$ (Cabot Corp.) are recommended materials of construction for these elevated operating temperatures in presence of halides.

Although it is not likely to be needed during normal operation, a pressure/vacuum relief device should be provided to vent the spray dryer to the off-gas system in the event pressure limits are exceeded. 


\section{2 .3 .2 .5 off-Gas Filters}

Because of the small particle size of the spray-dried sludge, up to $50 \%$ of the sludge may be entrained in the spray dryer offgas. Based on early experiments with various types of dust removal equipment conducted by PNL, sintered metal filters are recommended for primary effluent decontamination. The filter adopted by PNL is shown in Figure 5.3.

During operation entrained sludge particles removed from the off-gas are retained on the filter surface. With time the sludge layer thickness increases, producing a corresponding increase in filter pressure drop. Excessive pressure drop is to be prevented by use of a pulse of air to dislodge the cake. A recommended blowback system is shown in Figure 5.3 . The use of a venturi is intended to increase entrainment of filtered off-gas by the blowback air jet, thereby decreasing the amount of external air required.

The filter blowback operation should be designed to minimize dryer chamber pressure surges. Variables which affect these surges are blowback pulse duration, blowback pressure, off-gas line flow resistance, and the number of filters that are pulsed simultaneously.

Since some powder is smaller than the pore size of the filter, some particles penetrate the filter and become lodged inside. Penetration is greatest at the surface but is rapidly reduced by larger particles which bridge over the pores and act as a filter precoat. During filter blowback the precoat is partially removed and some particles are again free to enter the filter. Unfortunately, not all particles are removed during blowback resulting in a slow accumulation. The rate of accumulation can be minimized and thus, filter life maximized by designing for a filter face velocity of $4 \mathrm{ft} / \mathrm{min}$.

The filter design should be sufficiently rugged to prevent accidental breakage during handling and installation and to withstand normal operating conditions. Vibration isolation techniques are recommended to provide resistance to vibration-induced filter failure caused by the spray chamber vibrators. Filter material must be resistant to chloride and fluoride corrosion.

\section{2 .3 .2 .6 Glass Frit Addition System}

The glass forming frit should be rate fed to the spray dryer cone based on the sludge slurry feed to the atomizing nozzle. Equipment and instrumentation is needed for transporting and controlling this frit addition. The control system should permit operation over a range of feed/frit ratios. 


\section{2 .4 Vitrification (T. A. Willis)}

\section{2 .4 .1 General}

The function of the melter is to heat the spray dryer product and glass frit to the reference vitrification temperature $\left(1150^{\circ} \mathrm{C}\right)$. Two concepts to achieve vitrification have been demonstrated. The first, a continuous, Joule-heated melter, is the reference concept. An alternative vitrification process is in-can melting. Figure 5.4 is a conceptual drawing of a continuous glass melter [5].

\subsubsection{Equipment Specifications}

\subsection{Melting Tank Section}

This is the section of the continuous glass melter where the dried sludge and glass frit are heated to the reference vitrification temperature $\left(1150^{\circ} \mathrm{C}\right)$. The glass in this section must be heated to the reference molten glass temperature and achieve a viscosity of no more than 50 poise. Heating is supplied by the Joule heating effect of passing alternating current (AC) through opposing pairs of electrodes.

The melter tank horizontal surface area shall be 12 to 14 square feet. This is based upon a design capacity of 2.2 tons/day of glass production and on data from glass production of SRP simulated sludge and glass chemicals at Battelle-Pacific Northwest Laboratories [2].

The depth of the melter tank shall be approximately 2-1/2 feet to permit a residence time of at least 12 hours for molten glass at the reference vitrification temperature. There shall be an additional freeboard of $2-1 / 2$ feet above this depth to accommodate the cold cap or possible foam generation. This total depth of 5 feet in the tank is to be refractory lined and have Joule electrodes over the total 5-foot depth.

\subsection{Throat Section}

This section connects the melting tank with the riser section at the lowermost elevation. The riser shall be lined with the specified molten glass contact refractory. The throat shall be designed with the maximum cross sectional area for glass flow practicable in order to minimize refractory erosion: the slower the molten glass velocity, the lower the resulting erosion of the refractory. The glass temperature in the throat shall be maintained as close to the reference vitrification temperature $\left(1150^{\circ} \mathrm{C}\right)$ as possible. Joule electrodes firing through the throat may be necessary to maintain this temperature. 
The throat area is probably the most vulnerable area for refractory failure and will probably be the design feature which limits the melter operating lifetime. Precautions should be taken in design to minimize erosion (low velocities), corrosion (minimum refractory temperature to permit glass flow), and "upward drilling" (refractory corrosion on the throat ceiling probably caused by gases accelerating corrosion). Upward drilling may be minimized by making the refractory surface on the "ceiling" of the throat as smooth as possible, by adequate cooling, and by sloping the ceiling of the throat up in the direction of the glass flow by a minimum of $15^{\circ}$ from the horizontal.

\subsection{Riser Section}

Glass rises from the throat (a bottom underflow area) to the pour spout. The riser section will be heated independently of the Joule electrodes in the melter tank section. The molten glass temperature will be maintained as close as possible to the reference molten glass temperature of $1150^{\circ} \mathrm{C}$, so that the viscosity will be maintained less than 200 poise.

\section{2 .4 .2 .4 Electrodes}

Joule heating electrodes will be fabricated of Inconel $^{\circledR} 690$ (Huntington Alloys, Inc.). The electrical flux on the electrodes will be as uniform as possible over the surface and will not exceed 2 amps/in? during operation at steady state. The electrical flux limit of 2 amps/in? may be exceeded on startup or some limited transients, but should be held to the minimum practicable above this value.

The electrode temperature will be held to $1050^{\circ} \mathrm{C}$ or less. If internal cooling of the electrodes is necessary to maintain this $1050^{\circ} \mathrm{C}$ temperature limit, air cooling is preferred. Operation of the "Inconel" 690 electrodes above $1050^{\circ} \mathrm{C}$ can result in distortion of the electrode shape and in the metal strength. The melting point of "Inconel" 690 is 1343 to $1376^{\circ} \mathrm{C}$.

The electrodes shall extend to the top of the melter tank above the "metal line" ("metal line" is the term for molten glass liquid line). Electrical connections from the power supply to 
the electrodes shall be at the top of the electrode. In no case shall the electrode penetrate through the refractory wall of the tank.

\section{2 .4 .2 .5 Refractories}

The melter tank, throat, and riser shall be lined with Monofrax ${ }^{\circledR}$ (The Carborundum Company) K-3 DCL refractory in contact with the molten glass. The refractory shall be at least 6 inches thick. In no portion of the melter shall molten glass be in contact with opposing sides of a refractory. Such contact would cause the refractory brick to be operated at approximately molten glass temperature throughout to cause refractory corrosion.

Cooling shall be applied to the exterior of the refractory. The coolant will be forced through metal jackets surrounding the refractory. The objective of this cooling is to extend the refractory life (particularly the throat section) in order to achieve a melter life of at least two years. The preferable coolant is air as discussed in cooling of electrodes.

There are to be no penetrations through the refractory in the tank, throat, and riser sections below the pour spout level except for one bottom dratn freeze valve. The purpose of this requirement is to minimize the risk of accidental dumping of molten glass. This type design is not typical of glass industry designs which have many electrode penetrations of melter walls and floor. Such glass industry designs have led to numerous large (multiton) spills of molten glass onto plant floors.

\subsection{Melter Pour Mechanism}

The filling of canisters with molten glass from a continuous Joule-heated melter requires a means of starting and stopping the flow of molten glass. The flow of glass must be started to each empty canister and then stopped when the canlster is full. The glass flow must remain stopped while the full canister of waste glass is removed and another empty container is moved into position. This operation of filling canisters from the melter is called pouring.

The reference means of pouring is called tilt-pour. The tilt-pour method requires that the entire Joule-heated melter be tilted up to 4 degrees: forward to start the pour and then be tilted back to stop the pour. The tilt-pour method is used on the experimental prototype Joule-heated melter at PNL. The connections to the melter must all be flexible connections to accomodate the $4^{\circ}$ of melter movement on either side of vertical. The connection between the canister and the spout must be designed such that the 
volatile products evolved from the glass do not vent to the canyon ventilation system.

An alternative pour technique, involving close-coupling of the pour spout and canister and varying the pressure in the canisters, is under investigation.

\subsection{Shutdown Drain}

A freeze valve is required in the bottom of the melter to dump the contents of the melter into a ditch can in the event power is to be interrupted of such a duration to result in the melt solidifying. The drain consists of a closure plate, an opening-and-closing mechanism, and a resistance heater. The heater is used to melt the frozen glass in the drain tube before discharging the contents of the melter to the ditch can. The connection between the drain and ditch can should be designed such that the volatile products evolved from the glass melt do not enter the canyon atmosphere.

\subsubsection{Instrumentation and Control}

The power to the electrodes will be controlled by appropriate current and temperature sensing devices. Joule-heating electrodes will be air cooled. Cooling air rate will be controlled by appropriate temperature sensors on the electrodes. The electrode temperature is not to exceed $1050^{\circ} \mathrm{C}$. A device is required to monitor the level of the glass melt. Melt level should be maintained as near constant as possible during pouring. Suitable temperature sensors are required throughout the melter to maintain surveillance of the glass-melt temperature, the electrode temperature, and the temperature drop across the refractory. Emergency power is required in the event normal power is lost.

\subsubsection{Off-Gas Treatment System (L. F. Landon)}

\section{2 .5 .1 General}

\subsection{Spray Dryer/Melter}

A DF of 1000 for particulates generated in the spray dryer is assumed across the sintered metal filters for material balance purposes. However, the design of the scrubbing system should be such that in the event of total bypass of the filters, the scrub system should perform satisfactory at the higher solids load to permit an orderly shutdown of the spray dryer. 
Analyses of sludge currently stored in the waste farm indicate significant quantities of chloride and fluoride to be present. Although a thermodynamics study of the melter/spray dryer off-gas system suggests that no $\mathrm{HCl}$ and only $3.8 \%$ of the fluoride (as HF) will pass the sintered metal filters, materials selection for the part of the off-gas system that contact the scrub solution should assume all these halides enter the scrub as $\mathrm{HCl}$ and $\mathrm{HF}$. Suggested materials of construction are discussed in Section 10.

\subsection{Process Vessel Vent Filter}

Each canyon process vessel is assumed to have a 50 scfm (dry air) vapor sweep drawn from the canyon atmosphere through the tank vapor space via the overflow pipe. All vessel vents are combined into a single header and drawn through a heater and deep bed filter prior to being combined with the canyon air exhaust. It was assumed for curie balance purposes than the vessel vent air purge entered the vessel at a dry bulb temperature of $35^{\circ} \mathrm{C}$ and a wet bulb temperature of $25.6^{\circ} \mathrm{C}$. At discharge, the dry bulb temperature is unchanged but the wet bulb temperature increased to $29.4^{\circ} \mathrm{C}$.

\subsection{Sand Filter}

The canyon atmosphere is combined with the treated spray dryer off-gas and the vessel vent filter effluent and drawn through a sand filter prior to discharge to the atmosphere.

\subsubsection{Equipment Specifications}

\subsection{Spray Dryer Off-Gas Duct}

The temperature of the vapor duct between the spray dryer and ejector/venturi is to be maintained between 250 and $400^{\circ} \mathrm{C}$.

\subsection{Ejector/Venturi}

- Function: To cool the spray dryer off-gas vapor to $50^{\circ} \mathrm{C}$ and achieve condensation, solids formation, and coalescing. Design for a inlet vapor temperature of $650^{\circ} \mathrm{C}$.

- Operating Conditions: Co-current contacting of the vapor stream with a cooled $\left(40^{\circ} \mathrm{C}\right)$ circulating scrub stream. Estimated $\Delta \mathrm{P}$ across the ejector -15 in. $\mathrm{H}_{2} \mathrm{O}$. 
- Details: The backpressure across the ejector/venturi should be sufficient to route a slip stream (equivalent to the off-gas condensate rate) of the recirculation quench to the recycle collection tank. The ejector/venturies discharge to a common column that routes the condensables and noncondensables into the off-gas condensate tank.

\subsection{Pump-Quench Stream}

- Function: To circulate a portion of the contents of the off-gas condensate tank through a cooler and to each ejector/ venturi.

- Operating Conditions: Flooded suction, $50^{\circ} \mathrm{C}$.

- Details: The pump capacity will be about $200 \mathrm{gpm}$ based on a $\Delta \mathrm{T}$ of $10^{\circ} \mathrm{C}$ across the cooler. The pump should be spared and on emergency power. Discharge pressure and flow must be monitored.

\subsection{Ejector-Venturi Cooler}

- Function: To cool liquid circulating from the off-gas condensate tank from $50^{\circ} \mathrm{C}$ to $40^{\circ} \mathrm{C}$.

- Operating Conditions: Process side $-50^{\circ} \mathrm{C}$ to $40^{\circ} \mathrm{C}$ Available Inlet Cooling Water Temp $-32^{\circ} \mathrm{C}$

- Instrumentation and Control: The temperature of the process stream and cooling water stream should be monitored at the inlet and discharge of the cooler. Cooling water flow to be automatically controlled to maintain the quench stream entering the ejector/venturies at $40^{\circ} \mathrm{C}$. The shell side cooling water pressure is to be at least 15 psig greater than the quench stream pressure.

\subsection{Off-Gas Condensate Purge Valve}

- Function: To route a portion of the recirculation quench stream (equivalent to the rate at which water vapor is condensed from the spray dryer off-gas stream) to the recycle collection tank.

- Details: The nominal purge rate is about $1.0 \mathrm{gpm}$. During normal operation, this stream will contain about 0.85 wt \%. suspended solids. Total failure of the spray dryer filters could result in a suspended solids concentration of 16 wt \%. 
- Instrumentation and Control: Suitable liquid level sensors in the off-gas condensate tank must control the purge valve opening such that the liquid level in the off-gas condensate tank remains essentially constant. Because of the low purge rate, the valve should operate intermittently to allow a larger valve opening and consequently minimize the risk of valve pluggage.

\subsubsection{6 off-Gas Condensate Tank}

- Function: Provide a collection reservoir for the condensables and the source of scrub solution for the first deep bed washable filter and ejector/venturi quench.

- Operating Conditions: Temperature $-50^{\circ} \mathrm{C}$.

- Details: The tank bottom must be adequately sloped to allow mercury to drain freely to the mercury collection sump. Sump capacity - 2 liters.

- Instrumentation and Control: This tank requires suitable detection devices to monitor temperature, specific gravity, conductivity, and liquid level of its contents. The tank must be well-agitated to maintain particulates in suspension. A sampling device is required. Suitable high level and low level mercury sensors in the sump will control operation of the mercury pump. The conductivity of the tank contents should be continuously monitored.

\subsection{Pump-Mercury Transfer}

- Function: To transfer the condensed mercury from the offgas condensate tank mercury collection sump to the mercury recovery facility.

- Operating Conditions: Flooded suction $-50^{\circ} \mathrm{C}$.

- Details: Pump will be handling approximately 1.0 l1ter of mercury per day. Pump capacity $-25 \mathrm{~mL} / \mathrm{min}$ over a discharge pressure range of 5-30 psig. The pump will operate intermittently.

- Instrumentation and Control: Suitable high level and low level mercury sensors, monitoring the level of mercury collection sump, will control the operation of the pump. A transfer of mercury should be stopped before all the mercury is discharged so as to prevent transfer of the scrub solution to the mercury recovery facility. 


\subsection{Pump-Scrub Flow to the DBF No. I}

- Function: To deliver the appropriate amount of scrub solution from the off-gas condensate tank to the spray nozzles in the DBF unit.

- Operating Conditions: Flooded suction $-50^{\circ} \mathrm{C}$.

- Details: The pump discharge is split appropriately to the spray nozzle over the top of the de-entrainer pad and to the nozzle that atomizes the scrub onto the underside of the deep-bed filter pad. Design flow to the lower nozzle is $2 \mathrm{gpm}$ and to the upper nozzle $40 \mathrm{gpm}$. Air is introduced ( $5 \mathrm{scfm} / \mathrm{gpm}$ ) into the scrub flow to the lower nozzle to obtain proper atomization. The pump should be on emergency power.

- Instrumentation and Control: Suitable devices to monitor scrub flow and pressure to each spray nozzle are required.

\subsection{Deep-Bed Filter No. 1}

- Function: Scrub at least $95 \%$ of the particulates from the vapor stream.

- Operating Conditions: Temperature $-50^{\circ} \mathrm{C}$

Inlet vapor flow -77 acfm (703 miHg)

Solids load in scrub -0.85 wt \% (nominal)

$\Delta \mathrm{P}=6$ in. $\mathrm{H}_{2} \mathrm{O}$ (assumed for calculating effluent vapor flow)

Particle diameter - 0.3 micrometer nominal

Superficial face velocity - 50-100 ft/min

- Details: The filter should not experience a buildup in pressure drop for a maximum solids content in the recirculating scrub of $\leqq 1.0 \mathrm{wt} \%$. The fiber material and/or binder should be sufficiently resistant to radiation to provide a useful life of at least two years in the scrub environment.

- Instrumentation and Control: A suitable device to continuously monitor pressure drop across the filter is required. 


\subsection{Deep-Bed Filter No. 2}

- Function: Scrub at least $95 \%$ of the particulates entering the unit in the vapor stream and reduce the vapor temperature to $10^{\circ} \mathrm{C}$ to condense out mercury vapor.

- Operating Conditions: Temperature $-10^{\circ} \mathrm{C}$

Inlet vapor flow - 90 acfm $(692 \mathrm{~mm} \mathrm{Hg})$

Solids load in scrub- $20.20 \mathrm{wt} \%$ (nominal)

$\Delta \mathrm{P}-6$ in. $\mathrm{H}_{2} \mathrm{O}$ (assumed for calcu-

lating effluent vapor flow)

Superficial face velocity - 50-100 ft/min

- Details: Same as 5.2.5.2.8 and 5.2.5.2.9.

- Instrumentation and Control: Same as 5.2.5.2.8 and 5.2.5.2.9.

\subsection{Filter Pump Tank}

- Function: To provide a source of refrigerated scrub solution for the DBF \#2 such that the temperature of the vapor leaving the filter is at $10^{\circ} \mathrm{C}$.

- Operating Conditions: Tank is to contain cooling coils through which brine is circulated from an external refrigeration machine. The mercury and water that is condensed in the DBF $\# 2$ is purged to the off-gas condensate tank.

- Instrumentation and Control: The flow of refrigerant to the circulation tank coils is controlled such that the vapor temperature leaving the $\mathrm{DBWF} \# 2$ is $10^{\circ} \mathrm{C}$. The temperature of the vapor exiting the filter and the temperature of the scrub should be monitored. Liquid level monitoring is required.

\subsection{Ruthenium Adsorber Pre-Heater}

- Function: To raise the temperature of the vapor stream $10^{\circ} \mathrm{C}$ above its dew point.

- Operating Conditions: $\Delta \mathrm{P}$ - about 2 in. of water Inlet flow conditions -

$12.6 \mathrm{Ib}$-mole/ $\mathrm{hr}$ noncondensables, $0.16 \mathrm{lb}$-mole/hr water vapor

- Instrumentation and control: The steam flow to the heater is controlled such that the vapor effluent is $10^{\circ} \mathrm{C}$ above its dew point. 


\subsection{Primary Ruthenium Adsorber}

- Function: Io adsorb volatile ruthenium from the vapor stream.

- Details:

- Adsorbent: Davidson Chemicals Grade 40 - Silica Gel, 6-12 mesh

- Adsorbent Capacity: $136 \mathrm{~g}$ ruthenium/ft ${ }^{3}$

- Bed Depth: 52 in.

- Superficial Face Velocity: $0.4 \mathrm{ft} / \mathrm{sec}$ (max)

- Pressure Drop: $0.6 \mathrm{in}$. $\mathrm{H}_{2} \mathrm{O} / \mathrm{in}$. of bed at design face velocity

- Efficiency: $99 \%$ for volatile ruthenium, $50 \%$ for particulates

- Instrumentation and Control: The pressure drop across the bed should be monitored. The concentration of Ru-106 should be intermittently monitored in the effluent to detect bed breakthrough. The temperature of the adsorbent should be monitored throughout the bed.

\subsection{Secondary Ruthenium Adsorber}

- Function: To adsorb volatile ruthenium from the vapor stream.

- Details :

- Adsorbent: Davidson Chemicals Grade 40 - Silica Gel, 6-12 mesh

- Adsorbent Capacity: $136 \mathrm{~g} / \mathrm{ft}^{3}$

- Bed Depth: 52 in.

- Superficial Face Velocity: $0.4 \mathrm{ft} / \mathrm{sec}$ (max)

- Pressure Drop: 0.6 in. $\mathrm{H}_{2} \mathrm{O} / \mathrm{in}$. of bed at design face velocity

- Efficiency: 99\% for volatile ruthenium, 50\% for particulates

- Instrumentation and Control: Same as 5.2.5.2.13.

\subsection{Iodine Adsorber Preheater}

- Function: To raise the temperature of the vapor stream to $150^{\circ} \mathrm{C}$.

- Operating Conditions: $\Delta P-2$ in. of water

Inlet flow conditions -

$12.6 \mathrm{lb}$-mole/hr noncondensables,

$0.16 \mathrm{Ib}$-mole/hr water vapor 
- Instrumentation and Control: The steam flow to the heater is controlled to maintain the vapor at a temperature of $150^{\circ} \mathrm{C}$ entering the iodine adsorber.

\subsection{Iodine Adsorber}

- Function: To adsorb $I_{2}$ from the off-gas stream.

- Operating Conditions: Temperature $-150^{\circ} \mathrm{C}$

Superficial velocity $-\leq 0.4 \mathrm{ft} / \mathrm{sec}$

- Details:

- Adsorbent: $\mathrm{Ag}^{\circ} \mathrm{Z}$ (silver-exchanged mordenite)

- Capacity: $100 \mathrm{mg} \mathrm{I} / \mathrm{g}$ of adsorbent

- Bulk Density: $49.2 \mathrm{Ib} / \mathrm{ft}^{3}$

- Collection Efficiency: $99 \%$ for $I_{2}, 50 \%$ for particulates

- Pressure Drop: 0.5 in. $\mathrm{H}_{2} \mathrm{O} /$ in. bed

- Gas Residence Time: $>2$ seconds

\subsection{7 off-Gas Cooler}

- Function: Reduce the temperature of the vapor leaving the iodine adsorber to $<50^{\circ} \mathrm{C}$.

- Operating Conditions: $\Delta \mathrm{P}-2$ in. $\mathrm{H}_{2} \mathrm{O}$ Inlet flow -

$12.6 \mathrm{lb}$-mole/hr noncondensables, $0.16 \mathrm{lb}$-mole/hr water vapor

Inlet gas temperature $-150^{\circ} \mathrm{C}$

\subsection{Off-Gas Exhauster}

- Function: To draw the off-gases generated in the spray dryer/ melter through the various: off-gas treatment subsystems while maintaining a negative pressure of 10 inches of water in the spray dryer.

- Inlet Conditions: 159 acjm at 0.56 atm vacuum. Temp $-50^{\circ} \mathrm{C}$.

- Details: Exhauster should be spared and on emergency power. 
- Instrumentation and Control: Suitable devices to monitor vapor temperature and pressure at both the inlet and outlet of the exhauster are required. The spare exhauster must come online automatically if the other exhauster fails. Failure of both exhausters should automatically shut off feed to the spray dryer.

\subsection{Recycle Collection Tank}

- Function: To accumulate one day's volume of miscellaneous water streams (see Figure 4.6).

- Instrumentation and Control: Suitable devices to monitor liquid level and temperature are required. An agitator is required to keep solids in suspension. A transfer device is required to transfer to the recycle evaporator feed tank.

\subsection{Process Vessel Vent Filter}

- Function: Provide high efficiency filtration of particulate radionuclides entrained into the process vessel vents.

- Operating Conditions: Inlet flow $-\sim 3510$ acfm

Inlet vapor temperature $->10^{\circ} \mathrm{C}$ above the dew point

- Details: The vapor entering the filter is assumed to be saturated with water vapor and consequently should have its temperature raised at least $10^{\circ} \mathrm{C}$ above its dew point to avoid condensation in the filter. It is assumed a collection efficiency of at least $99.9 \%$ may be attained by the filter. The vessel vent exhaust fans should be spared and on emergency power.

- Instrumentation and Control: Instrument facilities are required to control the temperature of the vapor entering the filter and to monitor the pressure drop across the filter. Exhaust flow from the filter need be monitored.

\section{2 .5 .2 .21 Sand Filter}

- Function: Provide the final stage high-efficiency filtration for removal of radioactive particulates before discharging the canyon, vessel vent and spray dryer off-gas streams to the environment

- Operating Conditions: Inlet flow - About $3.6 \times 10^{5} \mathrm{acfm}$ Face velocity -5 to $6 \mathrm{ft} / \mathrm{min}$ 
- Details: Condensate collection facilities are required for the sand filter and the tunnels leading to the sand filter. Condensate will be pumped back to the recycle collection tank. The sand filter and associated fanhouse are to be maximum resistance facilities. Exhaust fans should be spared and on emergency power. The sand filter is assumed to be $99.9 \%$ efficient for particles of 0.3 micrometer in diameter.

- Instrumentation and Controls: Instrumentation for monitoring and controlling the liquid levels in the sumps and for measuring ventilation flow is required. The pressure drop across the sand filter must be continuously monitored.

\subsection{Ventilation Exhaust Stack}

- Function: To disperse the exhaust air from the sand filter to the atmosphere.

- Detalls: Stack height $22-1 / 2$ times the height of the adjacent buildings. A stainless steel-lined sump is required in the stack foundation for collection of condensate which is returned to the recycle collection tank. The stack should be at a distance from the adjacent buildings of at least 3 times the height of the adjacent buildings or structures.

- Instrumentation and Control: A system to continuously inventory the quantity of radioactivity being discharged to the environment is required. Details of this system are as follows:

Sampling Point - at least eight (8) stack duct inside diameters downstream from the last change of stream direction or side stream entry point into the main exhaust stream, and two (2) stack duct diameters below the point of discharge

Sampler - isokinetic sampler following ANSI Standard N13.1 criteria

Sample Collection - a primary sample collection system, plus a backup will be required per proposed appendix to 1OCFR50 for chemical reprocessing plants

- Filter paper collectors for particulates

- Charcoal or other suitable media for radioiodine, radioruthenium, etc. (may require development of improved collection system) 
In-situ Stack Monitoring

- Gross beta-gamma detection (minimum) - if individual radionuclides must be identified, a Ge-Ii system would be required for gamma emitters. Some development work would be required.

- Alpha detectors (minimum) - if individual TRU radionuclides must be identified, alpha PHA or other detection system development would be required.

After-the-Fact Stack Monitoring - collection media would be analyzed routinely and individual radionuclides quantified.

Alarms and Readout

- Audiovisual alarms from gross beta-gamma and alpha detectors should be provided at the stack, central control room, and Health Protection monitoring console (computer-based)

- Gross-count readout should be at the stack and at the Health Protection monitoring console

- Specific radionuclide data readout, if required, should be at the stack and Health Protection monitoring console

General

- Emergency power is required for all system components

- Calibration and source check facilities should be provided at the stack

\subsubsection{Mercury Recovery Facility (L. F. Landon)}

\subsubsection{General}

The reference flowsheet shows that about $1.2 \mathrm{lb} / \mathrm{hr}$ of mercury will condense and accumulate in the off-gas condensate tank. This mercury will most likely be as a sludge and will require decontamination before being placed in storage. Because of the low capacity of this facility and the need for several valving operations, a shielded facility served by masterslave manipulators is recommended. 


\subsubsection{Mercury Receipt Tank}

- Function: To accumulate condensed mercury from the off-gas condensate tank.

- Capacity: One days accumulation of mercury

- Details: A suitable device to continuously inventory the contents.

\subsubsection{Pump/Mercury Filter 非}

- Function: To remove the majority of particulates that have occluded to the mercury.

- Details: The filter is to be located on the discharge side of the mercury pump. The filter media should have a nominal particle removal rating of 40 microns. The filter should be backwashable so that when pressure drop dictates, the solids may be flushed to the backwash hold tank. Pumping capacity - 25-50 mL/min. flooded suction, positive displacement diaphragm pump.

- Instrumentation and Control: The pressure drop across the filter should be continuously monitored.

\subsubsection{Acid Wash Feed Tank}

- Function: To accumulate filtered mercury.

- Instrumentation: A suitable device is required to inventory the contents of the tank.

\subsubsection{Pump/Acid Wash}

- Function: To meter mercury to the top of the acid wash column.

- Operating Conditions: Flooded suction, positive displacement diaphragm pump.

- Pumping Capacity: $10 \mathrm{mI} / \mathrm{min}$.

- Instrumentation and Control: Suitable devices required to vary and monitor the flow rate. 


\subsubsection{Acid Wash Column}

- Function: To dissolve contaminants occluded to the mercury not removed by the primary filter.

- Operatirg Conditions: Temperature - ambient

Solvent - $10 \% \mathrm{HNO}_{3}$

Contact time - 3 seconds

- Details: The mercury must be discharged into the top of the acid column in droplets. The column length is to be selected to allow a 3-second contact with the acid as the droplets fall through the mercury column. Inward projections on $90^{\circ}$ spacing are required every 1 in. of column height. Each ring of projections should be rotated such that the mercury droplets cannot fall uninterrupted the entire length of the column. Washed mercury overflows a barometric leg into an air sparge tank.

- Material of Construction: The column is to be constructed of glass in order that the operator may observe the mercury droplets.

- Solvent Replacement: The acid must be replaced when the acid concentration falls below IM. The ability to sample the contents of the column periodically is required. Provisions to drain the acid from the column into the backwash hold tank is required.

\subsubsection{Backwash Hold Tank}

- Function: To accumulate depleted acid from the wash column, filter backflush and acid flushes of the mercury still. Caustic service to this tank is required to neutralize the waste prior to transfer back to the off-gas condensate tank. Cooling coils are required to remove heat of neutralization. A sampler is required.

- Details: A transfer device is required to periodically recycle neutralized wastes back to the off-gas condensate tank.

- Instrumentation and Control: Suitable devices are required to monitor temperature and liquid level.

\subsubsection{Oxidation Tank}

- Function: To oxidize residual contaminants, such as iron and aluminum, to facilitate their removal from the mercury by filtration. 
- Operating Conditions: Temperature - ambient

Sparge gas - air

Contact period -8 hours

- Details: Air sparge should be through a fritted plate to achieve good mercury/air contact.

- Instrumentation and Control: Suitable devices are required to monitor air flow to the tank and the liquid level in the tank.

\subsubsection{Pump Mercury Filter \#2}

- Function: To pump the mercury through mercury filter $\# 2$

- Operating Conditions: Flooded suction, positive displacement diaphragm pump.

- Details: Pumping capacity will be of the order of $25-50 \mathrm{~mL} / \mathrm{min}$.

- Instrumentation and Control: The pumping rate and discharge pressure should be monitored.

\section{2 .6 .10 Mercury Filter \#2}

- Function: To filter out the contaminant oxides formed during air oxidation.

- Operating Conditions: Temperature - ambient.

- Details: Particle removal rating - nominal - 40 microns.

The filter should be backwashable to facilitate flushing the solids into the backwash tank.

- Instrumentation and Control: The pressure drop across the filter should be continuously monitored.

\subsubsection{Mercury Still Feed Tank.}

- Function: To supply filtered feed at a controlled rate to the still

- Instrumentation: Iiquid Level 


\subsubsection{Mercury Vacuum Still/Condenser}

- Function: To provide a final decontamination step.

- Operating Conditions: System pressure - about $5 \times 10^{-2}$ torr Pot temperature - about $195^{\circ} \mathrm{C}$ Rate - $10 \mathrm{lb} / \mathrm{hr}$

- Details: The condensed mercury is to be received in the mercury still product tank.

- Instrumentation and Control: Suitable devices are required to monitor the pot temperature, vacuum, condensate temperature, power to heaters, and cooling water flow to the condenser.

\subsubsection{Mercury Still Product Tank}

- Function: To accumulate condensate from the vacuum still.

- Instrumentation: Suitable device required to monitor temperature and liquid level.

\subsubsection{Recycle Concentration (I. F. Landon)}

\subsubsection{General}

The function of this module is to dewater miscellaneous internally generated waste streams for recycle to the gravity settling/filtration module. The design of the continuous evaporators presently used for 221 Canyon service should serve as the design basis for the recycle evaporator. Present design features and specifications of the evaporators presently in service are shown on the following drawings:
D 111221
D 118284
D 137553
S5-2-2095
D 111222
D 118285
D 137599
D 118282
D 118286
D 137815
D 118283
D 118287
D 164001

\subsubsection{Recycle Evaporator Feed Tank}

A vessel is to be provided to combine miscellaneous waste streams and provide feed to the evaporator at a controlled rate. The tank is to be equipped with an agitator, sampler, and instrumentation to monitor liquid level, specific gravity, and temperature. A rate pump is required to control the feed rate to the evaporator. 


\subsubsection{Recycle Evaporator}

\section{2 .7 .3 .1 General}

Figure 5.5 is a drawing of the continuous waste evaporator currently in canyon service and should serve as a design basis for the recycle evaporator. The de-entrainment bubble cap trays must be replaced with wire-mesh separators to attain the desired overall decontamination factor $\left(10^{6}\right)$.

\subsection{Specifications}

- Capacity: 12,578 1b/hr (feed)

- Feed: Specific gravity - 1.03

Solids content - $6.3 \mathrm{wt} \%$ (soluble)

-0.079 wt \% (insoluble)

- Decontamination Factor: $10^{6}$

- Boiloff Rate: 10,297 lb/hr

- Concentrate: Specific gravity - 1.17

Temperature $-104^{\circ} \mathrm{C}$

Solids content -34.8 wt \% (soluble)

-0.44 wt \% (insoluble)

- Steam Pressure: 25 psig maximum

- Steam Consumption: 1.15 lb steam/1b overheads

- Pot Pressure: About $1-4$ in. $\mathrm{H}_{2} \mathrm{O}$

\section{2 .7 .3 .3 Services}

See Figure 5.6.

\section{$5 \cdot 2 \cdot 7.3 .4$ Control System}

The desired specific gravity is the primary operating parameter. Control philosophy will be as used in the present continuous canyon waste evaporator. Steam flow is set to achieve the desired boilup rate. Feed flow is continuous to achieve the desired specific gravity and is controlled and monitored by a Hackman hat controller. As the feed is fed to the reboiler, concentrate overflows the weir to the bottoms tank, thus maintaining constant specific gravity and liquid level. 


\subsubsection{Recycle Evaporator Bottoms Tank}

A tank is to be rrovided to receive the evaporator concentrate. The tank is to be equipped with an agitator, sampler, cooling coils, and suitable instrumentation to monitor liquid level, specific gravity, and temperature. A transfer device is to be provided to transfer contents to the gravity settler feed tank.

\subsubsection{Recycle Evaporator Condensate Tank}

A tank must be provided to collect the overheads from the evaporator condenser. The tank must be equipped with cooling coils, agitator, sampler, and suitable instrumentation to monitor temperature, specific gravity, and liquid level. A transfer pump is required to transfer condensate to the general-purpose evaporator feed tank for additional decontamination.

\subsubsection{Settling and Filtration (E. J. Weber)}

\subsubsection{General}

The function of the equipment in this module is to reduce the suspended matter in feed to the ion exchange beds to $1 \mathrm{ppm}$ or less. This section provides the basic data for designing the equipment necessary to carry out the process (described in detail in Section 4.5).

\subsubsection{Salt Solution Receipt Tank}

A tank is required to accumulate the supernate feed from the tank farm. The tank is to be equipped with a sampler, agitator, and suitable devices to monitor temperature, liquid level, and specific gravity. A transfer device is required to transfer contents to the gravity settler feed tank.

\subsubsection{Gravity Settler Feed Tank}

A tank is required to accumulate and blend recycle evaporator bottoms, waste tank supernate, and sand filter backwash. The tank contents may have to be heated as high as $95^{\circ} \mathrm{C}$ prior to transfer to the gravity settlers. The tank is to be equipped with a sampler, agitator, and suitable devices to monitor temperature, liquid level, and specific gravity. A system of pumps is required to transfer heated slurry to any gravity settler. 


\subsubsection{Gravity Settlers (GS)}

The number of gravity settlers rèquired is primarily dependent on the design maximum solids settling rate of 20 inches per hour $(1.66 \mathrm{ft} / \mathrm{hr})$. In addition, the total time cycle must include the addition and mixing of starch, the rate of receipt of slurry feed, rate of transfer of supernate and sludge, and time needed to resuspend the sludge. Miscellaneous items, such as supernate requiring rework, sampling, awaiting sample results, etc., should also be considered. Heating will be done in an upstream tank. Cooling with a water jacket should be adequate to reduce temperature of supernate to $25-30^{\circ} \mathrm{C}$ over the settling period.

\section{Additional specifications include:}

- GS bottoms recycle - $7 \%$.

- Cold feed service for receipt of starch solution.

- Standard canyon - flat bottom tank.

- Internal surfaces (other than the tank itself) must not slope more than $30^{\circ}$ with the vertical to prevent accumulation of solids.

- Variable speed agitation and baffles similar to those of the TNX W-2 tank design, but slope of the top blades is no more than $30^{\circ}$ (to prevent accumulation of solids)

- For top supernate removal, a pump is preferred. Clear supernate above the pump orifice should provide at least 8 hours of filter feed ( 120 inches). Distance below the pump orifice should accommodate several sludge batches ( 230 inches).

- I molar caustic rinse of decant pump and its suction pipe. This assumes a "U"-tube decant pipe and will reduce the solids carryover in the supernate.

- Samplers spaced at 5-inch and 10-inch levels below the decant pump orifice. Sampler effluent is recycled to gravity settler feed tank.

- A transfer device for sludge removal with suction orifice about 2 to 4 inches above tank bottom.

- Routine specific gravity and liquid level measurements. However, before: the settling phase is initiated, any air used is turned off to. the dip legs of these instruments to prevent air bubbles from disturbing settling. Temperatures are to be measured and recorded at these locations:

- In sludge layer

- In supernate near decant pump orifice

- Approximately 2 ft beneath liquid level 
Further design consideration includes knowledge of the sludge height in the settler. In the plant, samples will be taken from each slurry batch to monitor the sludge height and assure clean separation of supernate product from the sludge. The sludge concentration is analyzed by centrifuging the slurry feed in a lab unit at $10,000 \mathrm{~g}$ 's for 3 minutes. Corresponding height of the sludge layer after 3 to 8 hours settling is shown in Figure 4.46. For example, if analysis shows 6000 ppm sludge, a settled sludge height of some 3.9 inches would be expected for 100 inches of slurry feed. Consequently, the decant pump orifice should be located about 10 inches above the tank bottom to provide 6 inches of clear supernate above a single sludge batch. For three batches, the decant orifice would be raised to about 18 inches. Samples obtained from 5 to 10 inches beneath the decant orifice will confirm supernate clarity before product decanting is started.

\subsubsection{Gravity Settler Supernate Tank}

This tank receives the decanted supernate from the gravity settler units. It should be equipped with a sampler, agitator, and detection devices to monitor liquid level, temperature, and specific gravity. A transfer device is required to recycle off-spec supernate back to the gravity settler feed tank. A second transfer device is required to transfer acceptable supernate to the sand filter feed tank.

\subsubsection{Gravity Settler Bottoms Tank}

This tank receives the sludge layer that is jetted from each GS unit. It should be equipped with a sampler, agitator, and detection devices to monitor liquid level, temperature, and specific gravity. A transfer device is required to transfer tank contents to the aluminum dissolver.

\subsubsection{Sand Filter Feed Tank}

This tank receives gravity settler filtrate that meets specifications ( $\leq 50 \mathrm{ppm}$ suspended matter) from the gravity settler supernate tank and zeolite column raffinate. The tank should be equipped with an agitator, sampler, and detection devices to monitor liquid level, temperature, and specific gravity. A rate pump is required to feed the No. 1 sand filter at a flow of $1.15 \mathrm{gpm} / \mathrm{ft}^{2}$ of filter area. The tank must be equipped with 
cooling coils and chilled water to control the feed temperature at $<25^{\circ} \mathrm{C}$. Anionic polyelectrolyte solution (see Section 5.2.8.16) is delivered from Cold Feed and blended with the supernate just before entering the sand filter at a rate of $0.05 \mathrm{gpm} / \mathrm{ft}^{2}$.

\subsubsection{Sand Filter No. I}

The function of this unit is to reduce the suspended matter in supernate to about $5 \mathrm{ppm}$. Specifications are as follows:

- Downflow feed rate - $1.2 \mathrm{gpm} / \mathrm{ft}^{2}$

- Top layer - 8 in. anthracite coal, 20-30 mesh

Bottom layer $-\cdot 24$ in. sand, 25-40 mesh

- Freeboard above filter - $>60 \%$

- Backflush rate - $15 \mathrm{gpm} / \mathrm{ft}^{2}$ (liquid), $4 \mathrm{scfm} / \mathrm{ft}^{2}$ (air)

(Expected backwash frequency - 24 to 48 hours)

Provision for occasional nitric acid (3-4M) flushing of the sand filter is required to dissolve mudballs or other formations which will plug the units. It may also be necessary to dissolve excessive radioactive deposits in the filter which could reduce adsorption efficiency by destruction of polyelectrolyte. If it is determined acid flushing is required after normal backflushings, the supernate is drained, and the filter backflushed with IM $\mathrm{NaOH}$ to remove most of the $A I$ and minimize its possible precipitation in the bed. After draining the $\mathrm{NaOH}$ solution, process water is used to backwash residual caustic from the column. Adequate filter venting is necessary during careful acid addition and reaction. When mudballs or other deposits have been dissolved, the column is drained, given a water rinse, followed by a $1 \mathrm{M}$ NaOH rinse before resuming routine operations. Acidic backwashes are transferred to the filter backwash tank and made alkaline prior to recycle to GS.

Startup following the nitric acid flush may indicate replacement of filter media is required if $\Delta p$ or residual radioactivity remains too high, or adsorption efficiency (filtrate quality) is too low. Provision is therefore required for transfer of anthracite/sand to a suitable storage vessel. From storage, the contents are proportionaliy blended into the aluminum dissolving facilities. All transfers require fluidizing the media with $1 M$ $\mathrm{NaOH}$ solution before jetting. Proper grades of anthracite/sand 
are needed as replacement to the appropriate filter unit. The new media is also slurried and transferred in $1 \mathrm{M} \mathrm{NaOH}$ solution, since low $\mathrm{pH}$ in the sand filter may precipitate alumina, thus creating excessive $\Delta \mathrm{P}$.

Instrumentation requirements associated with the No. 1 sand filter are as follows:

- $\Delta \mathrm{P}$.

- Temperature of feed and effluent streams.

- Gamma monitoring just above the anthracite/sand interface external to the filter (to prevent the accumulation of radioactivity that might degrade the polyelectrolyte).

\subsubsection{First Filtrate Tank}

This tank receives the filtrate from sand filter No. 1 and feeds sand filter No. 2. It must be equipped with a sampler, agitator, and detection devices to monitor liquid level, temperature, and specific gravity. Cooling coils and chilled water are required to maintain sand filter feed $<25^{\circ} \mathrm{C}$. A rate pump feeds the No. 2 sand filter at $1.15 \mathrm{gpm} / \mathrm{ft}^{2}$. Provisions are required to introduce anionic polyelectrolyte solution into the feed to the No. 2 sand filter just before the inlet to the filter. Polyelectrolyte feed rate is $0.05 \mathrm{gpm} / \mathrm{ft}^{2}$.

\subsubsection{Sand Filter No. 2}

The function of this unit is to reduce the suspended matter in supernate to $1 \mathrm{ppm}$ or less. Specifications are as follows:

- Downflow feed rate $-1.2 \mathrm{gpm} / \mathrm{ft}^{2}$

- Top layer - 3 in. anthractte coal, 30-50 mesh

Bottom layer - 18 in. sand, 40-60 mesh

- Freeboard above filter - $>140 \%$

- Backflush rate - $15 \mathrm{gpm} / \mathrm{ft}^{2}$ (liquid), $4 \mathrm{scfm} / \mathrm{ft}{ }^{2}$ (air)

Additional specifications are as in Section 5.2.8.8. 


\subsubsection{Second Filtrate Tank}

This tank receives the filtrate from the No. 2 sand filter. It must be equipped with a sampler, agitator, and detection devices to monitor liquid level, temperature, and specific gravity. A transfer device is required to transfer off-spec filtrate to the sand filter feed tank. A second transfer device is required to transfer acceptable filtrate to the filtrate hold tank.

\subsubsection{Filtrate Hold Tank}

This tank accumulates acceptable filtrate for subsequent treatment in the ion exchange module. It also serves as the source of solution for backwashing the No. 1 and No. 2 sand filters. The vessel must accommodate an agitator, sampler, and suitable devices to monitor liquid level, temperature, and specific gravity. Two transfer devices are required:

- To backwash the sand filters.

- To transfer acceptable filtrate to the ion exchange feed tank.

\subsubsection{Filter Backwash Tank}

This tank receives backwash slurry from the Sand Filter No. 1 and the Sand Filter No. 2. Contents are periodically transferred to the gravity settler feed tank for subsequent treatment in Gravity Settlers. The tank must contain an agitator, sampler, and suitable devices to monitor liquid level, temperature, and specific gravity. This tank may also receive an occasional nitric acid flush from either sand filter. Consequently, the backwash tank will require caustic cold feed service for neutralization purposes and cooling capability.

\subsubsection{Waste Sand Tank}

This tank receives depleted filter media for subsequent transfer to the aluminum dissolver. The vessel must accommodate an agitator, sampler, and suitable devices to monitor liquid level, temperature and specific gravity. A transfer device is required for slurry transfers to the aluminum dissolver. 


\subsubsection{Preparation of Polyelectrolyte for Addition to the Gravity Settlers}

The Flojel-60 (National Starch Corp.) coagulant aid is made up in the Cold Feed Prep Area as an $8 \%$ dispersion in $1 \mathrm{M} \mathrm{NaOH}$. To a gently stirred $1 \mathrm{M}$ NaOH solution, sufficient solid Flojel-60 ${ }^{\circledR}$ is slowly sieved in to make the $8 \%$ dispersion. After all large lumps are broken and a smooth paste is formed, heat is applied. On heating to $65-70^{\circ} \mathrm{C}$ for 10-15 minutes, the starch polymer swells (but does not dissolve), and the mixture clarifies sufficiently that objects can be clearly seen through 6 to 8 inches of dispersion. After this clarity is reached and maintained 2 to 4 minutes, the mixture is cooled to room temperature. It should be used within the next two days. When properly prepared, the cooled starch has a pale green to tan translucence. Overheating or heating with large lumps causes the starch to "burn" to opaque brown or black. A sufficient quantity of $8 \%$ starch dispersion is added to each GS feed batch to produce 8 to 16 lbs of starch solids per ton of sludge as analyzed by lab centrifuge. A sludge density of 1.3 $\mathrm{g} / \mathrm{cc}$ is assumed. For 8,000 gallons of feed containing $6,000 \mathrm{ppm}$ of sludge, 3 to 6 gallons of starch dispersion is added.

\subsubsection{Preparation of Polyelectrolyte for Addition to Sand Filters}

Anionic polyelectrolyte stock solution is made up in the Cold Feed Prep Area to a $0.1 \%$ strength solution in distilled water. A sufficient weight of the white solid Versa $T^{\circledR} 700$, or equivalent, is sieved into cold water with gentle stirring to produce the clear, viscous stock solution. Sufficient stock is subsequently added to $1 \mathrm{M} \mathrm{NaOH}$ solution in a Cold Feed Tank so that a flow equivalent to $0.05 \mathrm{gpm} / \mathrm{ft}^{2}$ produces total sand bed feed containing $0.05 \mathrm{ppm}$ of solid polyelectrolyte.

The $0.1 \%$ stock solution should be used within 4 days of makeup. Stock solution should not be added to the cold Feed Tank until ready for operation. Cold Feed Tank solution should run out after 24-36 hours of operation. 
5.2.9 Clarified Supernate Decontamination (P. K. Baumgarten and D. A. Whitehurst)

\subsubsection{General}

All tanks should be constructed of stainless steel and include agitators and heating and cooling coils. These tanks should provide for temperature, liquid level, and specific gravity measurement. Sampling lines from the tanks are required. All vent lines containing $\mathrm{NH}_{3}$ must maintain a wall temperature $>70^{\circ} \mathrm{C}$.

\subsubsection{Cesium Ion Exchange}

\subsection{Cs Ion Exchange Columns}

Provide two stainless steel ion exchange columns to hold 1525 gallons of "Duolite" ARC-359 resin each. Each column should have a freeboard space above the resin which will allow at least a $75 \%$ expansion of the resin bed. Equip each column with liquid distributors both at the top and bottom of the resin bed. Provide unobstructed transfer lines for adding resin to or removing it from the columns. A Ge(Li) gamma-ray detector is mounted between the columns to monitor the Cs concentration. A similar detector after the second column is used to serve as an operating alarm.

Each I/E column is to have a nozzle for liquid level gaging, resin sampling, solids level gaging, and temperature sensing. A means of gaging the solids level in the column during backwashing or a means of monitoring the solids content of the backwash effluent is required. A variable speed pump is used to pump filtered supernate and first water rinse downflow at a rate of $42 \mathrm{gpm}$. The upflow steps, elution, second rinse, and regenerant are to use a variable speed pump which has a nominal rate of $30 \mathrm{gpm}$. A pump for backwashing the resin is to allow for variable linear velocity between 4-10 $\mathrm{gPm} / \mathrm{ft}^{2}$. A system to flush depleted resin to the cesium resin catch tank is required.

\subsection{Ion Exchange Feed Tank}

This tank is to receive clarified supernate from the filtrate hold tank. The tank should be equipped with cooling coils. A suitable transfer device is required to transfer feed to the cesium feed bounce tank. 


\subsection{Cesium Feed Bounce Tank}

This tank, with three suitable transfer devices, is used to (1) transfer downflow through the columns consecutively 20 column volumes of feed and 5 column volumes of water, and (2) receive and transfer consecutively 10 column volumes of eluate, 3 column volumes of water, and 5 column volumes of regenerant. The eluate and water rinse is pumped to the cesium eluate tank. The regenerant is transferred to the cesium regenerant catch tank. This tank is vented to the cesium vent scrubber.

\subsection{Cesium Elute Bounce Tank}

This tank, with two suitable transfer devices, is used to (1) consecutively receive 20 column volumes of feed and 3 column volumes of water, and (2) to transfer (upflow) consecutively 10 column volumes of elutriant, 3 column volumes of water, and 5 column volumes of regenerant through the ion exchange columns. The received effluent from downflow operations is transferred on to the strontium ion exchange feed bounce tank. This tank is vented to the cesium vent scrubber.

\subsection{Cesium Eluate Tank}

Provide a tank to combine the column eluate and column upflow water rinse. A suitable transfer device is required to transfer the tank contents to the cesium concentrator feed tank. This tank should be vented to the cesium vent scrubber.

\subsection{Cesium Regenerant Catch Tank}

Provide a tank to receive the regenerant effluent. A suitable transfer device is required to transfer the solution to the recycle evaporator feed tank. The tank should be vented to the cesium vent scrubber. This tank should be equipped with steam coils and an agitator. 


\subsection{Spent Resin Tank}

Provide a catch tank to receive depleted resin from the strontium ion exchange column and the cesium ion exchange columns. The tank must be provided with an agitator, sampler, and suitable devices to monitor temperature, liquid level, and specific gravity. The tank requires a transfer device to transfer resin slurry to the resin packaging facility. Provisions to decant to the recycle collection tank must be provided.

\subsection{Resin Packaging Facility}

Resin packaging facility is to include a dewatering tank, a dryer, and means to package resin in 10-50 lb containers. Moisture in the packaged resin should be less than 10\%. Temperatures above $100^{\circ} \mathrm{C}$ are to be avoided. Drying air should be filtered after use.

\subsection{Cold Feed Facilities}

Provide tank for preparing a water slurry of "Duolite" ARC-359 resin, with a final volume of $1525 \mathrm{gal}$. Provide equipment for transferring this slurry to the appropriate I/E column. Allow for makeup of smaller batches to periodically replenish resin lost during backwashing.

Provide facilities to prepare (1) water for column rinses and (2) caustic regenerant ( $2 \mathrm{M} \mathrm{NaOH}$ ) for regenerating the I/E columns. Suitable transfer devices are required to transfer these cold feeds to the appropriate bounce tanks.

\subsubsection{Strontium Ion Exchange}

\subsection{Ion Exchange Colurn}

Following the two cesium column, a stainless steel ion exchange column with a 760-galion resin batch and sufficient freeboard to allow at least $75 \%$ expansion of the resin is to be used to remove strontium. Provide resin transfer lines for moving the resin in and out of the columns. Provisions should be made to detect resin level during backwash and prevent loss of the resin via operator error. Instrumentation to measure bed temperature, bed and distributor pressure drop, and resin level are required. 
Provide for removal of samples of the resin. Normal downflow and upflow rates shall be 1.7 and $0.5 \mathrm{gpm} / \mathrm{ft} 2$, respectively. Flow rate measurements in both directions are required. Design backup systems to provide both recycle water and $2 \mathrm{M} \mathrm{NaOH}$ through the columns in the event of the failure of the primary transfer systems. Plan for valveless operation. Placement and design of the columns should keep the external radiation from exceeding $5 \times 10^{-3}$ watts-hr/g, to keep radiation-induced resin degradation minimal.

\subsection{Strontium Feed Bounce Tank}

Provide a bounce tank with two pumps to (1) receive supernate and rinse from the cesium elute bounce tank and transfer to the $\mathrm{Sr}$ column and (2) receive $\mathrm{Sr}$ column eluate and water rinse and transfer to the strontium concentrator feed tank. Provide appropriate transfer devices. This tank is vented to the process vessel vent system.

\subsection{Product Salt Hold Tanks}

Provide 3 tanks to receive clarified supernate and water rinses from the strontium elute bounce tank. The tanks are vented to the regulated facility vessel vent system.

\subsection{Strontium Elute Bounce Tank}

Provide a bounce tank with suitable transfer devices to (1) transfer decontaminated supernate from the $\mathrm{Sr}$ ion exchange column to the product salt hold tanks and (2) transfer elutriant/regenerant solution (alkaline EDTA) and water rinses to the $\mathrm{Sr}$ ion exchange column. This tank is vented to the process vessel vent system.

\subsection{Strontium Eluate Tank}

Provide a tank to accumulate eluate and water rinses for feeding the strontium concentrator. Provide the appropriate capacity transfer device for feeding the strontium concentrator. This tank is vented to the process. vessel vent system. 


\section{2 .9 .3 .6 Strontium Concentrator}

General

Provide an evaporator to reduce the water content in order to minimize the water load during spray drying. For material balance purposes, the feed is concentrated to $1.0 \mathrm{M}$ alkaline EDTA.

\section{Specifications}

- Capacity: $1950 \mathrm{lb} / \mathrm{hr}$ (feed)

- Feed: Specific gravity - 0.991

$$
\begin{aligned}
\text { Solids content } & -0.25 \text { wt } \% \text { (soluble) } \\
& -0.00 \text { wt } \% \text { (insoluble) }
\end{aligned}
$$

- Decontamination Factor: $10^{6}$

- Boiloff Rate: $1925 \mathrm{lb} / \mathrm{hr}$

- Concentrate: Specific gravity - 1.110

$$
\begin{array}{r}
\text { Temperature - about } 102^{\circ} \mathrm{C} \\
\text { Solids content }-20.2 \text { wt } \% \text { (soluble) } \\
-0.00 \text { wt } \% \text { (insoluble) }
\end{array}
$$

- Steam Pressure: 25 psig

- Steam Consumption: 1.15 Ib steam/Ib overheads

- Pot Pressure: $1-4$ in. $\mathrm{H}_{2} \mathrm{O}$

\subsection{Strontium Concentrator Bottoms Tank}

Provide a tank to receive bottoms from the strontium concentrator. Tank should be equipped with cooling coils. Provide a suitable transfer device to transfer concentrate to the slurry mix tank in the spray dryer/melter module. This tank is vented to the process vessel vent system.

\subsection{Strontium Concentrator Condensate Tank}

Provide a tank to receive overheads from the strontium concentrator. Tank should be equipped with cooling coils. Provide a suitable transfer device to transfer condensate to the recycle evaporator feed tank. This tank is vented to the process vessel vent system. 


\subsubsection{Cesium Elutriant Recovery/Eluate Concentration}

(B. R. Murphree)

\subsubsection{General}

The function of this module is to (1) strip the cesium eluate of $\mathrm{NH}_{3}$ and $\mathrm{CO}_{2}$, (2) recover the $\mathrm{NH}_{3}$ and $\mathrm{CO}_{2}$ for elutriant makeup, and (3) concentrate the cesium eluate to about $2.0 \mathrm{M}\left(\mathrm{Na}_{2} \mathrm{CO}_{3}+\mathrm{Cs}_{2} \mathrm{CO}_{3}\right)$.

NOTE: All tanks which contain ammonia are vented through the Cs vent scrubber. All vent lines containing $\mathrm{NH}_{3}$ must maintain a wall temperature $>70^{\circ} \mathrm{C}$.

\subsubsection{Cesium Concentrator Feed Tank}

A tank is required to deliver cesium eluate at a controlled rate to the steam stripper. The tank is to be equipped with an agitator, cooling coils, sampler, and suitable devices to monitor temperature, liquid level, and specific gravity.

\section{2 .10 .3 Steam Stripper}

Provide countercurrent packed stripping section to remove 99.99\% of the $\mathrm{CO}_{2}$ and $\mathrm{NH}_{3}$ from the cesium eluate. Steam to the stripper comes from the thermosiphon evaporator. The pressure drop across the stripper must be monitored. Vapor from the stripper must pass through a de-entrainment section en route to a downdraft condenser. The de-entrainer must reduce non-volatile radioactivity by a factor of $10^{6}$. The pressure drop across the de-entrainer should be monitored. Suitable temperature sensors must be incorporated in the packed bed at several levels.

\section{2 .10 .4 Cesium Concentrator}

A thermosiphon evaporator is required to concentrate cesium eluate to about 2.OM $\left(\mathrm{Na}_{2} \mathrm{CO}_{3}+\mathrm{Cs}_{2} \mathrm{CO}_{3}\right)$. The evaporator is steam heated. Suitable devices should monitor evaporator pot pressure, temperature, specific gravity, and liquid level. Provide heating steam pressure control based on produced specific gravity. Design on basis of supplying elutriant makeup water in overheads to steam stripper.

\subsubsection{Downdraft Condenser}

A downdraft condenser for the vapor stream from the steam stripper de-entrainer is required. Temperature at the inlet and 
outlet cooling water stream and the condensate stream must be measured. The pressure drop across the condenser must be monitored. An online gamma monitor to survey for cesium carryover from the steam stripper is required. Provide condensate flow rate measurement. The condenser should vent to the cesium vent scrubber.

\subsubsection{Stripper Condensate Tank}

Provide a tank to receive condensate from the downdraft condenser. The tank is to be equipped with an agitator, sampler, cooling coils (to maintain contents $<20^{\circ} \mathrm{C}$ ) and suitable systems to monitor liquid level, temperature, specific gravity, electrical conductivity, and $\mathrm{pH}$. An online gamma monitor is required to monitor for cesium carryover into the condensate. The tank should vent to the cesium vent scrubber.

\subsubsection{Cesium Elutriant Makeup Tank}

Provide a tank to receive condensate from the downdraft condenser. The tank should be sized to hold at least one cycle volume of elutriant. The tank is to be equipped with an agitator, sampler, cooling coils (to maintain contents $<20^{\circ} \mathrm{C}$ ), and suitable systems to monitor liquid level, temperature, specific gravity, electrical conductivity, and $\mathrm{pH}$. Provide aqueous ammonia from cold feed. Provide system for sparging tank contents with $\mathrm{CO}_{2}$ with maximum absorption and minimum disengagement. Tank should be vented to the cesium vent scrubber. Provide pump to transfer adjusted elutriant to the elutriant feed tank.

\subsubsection{Cesium Elutriant Feed Tank}

Provide a tank with a suitable transfer device to transfer adjusted elutriant to the cesium eluate pump tank. The tank should should be vented to the cesium vent scrubber.

\subsubsection{Cesium Vent Scrubber}

Provide a packed bed scrubber to remove $>99.9 \%$ of the $\mathrm{NH}_{3}$ by the vent scrubber feed. Provide chilied water downflow in the packed bed. Vent scrubber to the regulated facility vessel vent system. Measure bed temperature: Route liquid effluent to the cesium concentrator feed tank. 


\subsubsection{Purge Condenser}

A condenser is required to condense a steam sidestream from the cesium concentrator. Provide temperature measurement for cooling water inlet and outlet and condensate outlet. The pressure drop across the condenser must be monitored. Provide condensate flow rate measurement. Provide online gamma monitor on the condensate stream.

\subsubsection{Purge Condensate Tank}

Provide a tank to receive condensate from the cesium concentrator purge condenser. The tank should contain an agitator, sampler, cooling coils, and suitable instrumentation to monitor temperature, liquid level, and specific gravity. A suitable transfer device is required to transfer the condensate to the recycle evaporator feed tank.

\subsubsection{Cesium Fixation on Zeolite}

\subsubsection{General}

The function of this module is to (1) load cesium in the cesium concentrator bottoms onto zeolite, (2) transfer cesiumloaded zeolite to be mixed with washed sludge, and (3) recycle the cesium-depleted cesium concentrator bottoms to sand filtration. All tanks are to be equipped with samplers and instrumentation to monitor temperature, liquid level, and specific gravity.

\subsubsection{Cesium Concentrator Bottoms Tank}

Provide a tank equipped with both heating and cooling coils to receive the concentrate from the thermosiphon evaporator. The tank is to be equipped with an agitator, sampler, and suitable devices to monitor temperature, liquid level, and specific gravity. A transfer jet should transfer concentrate to the zeolite feed bounce tank.

\section{2 .11 .3 Zeolite Column}

Provide a $4.8 \mathrm{ft}$ diameter by $20 \mathrm{ft}$ high stainless steel ion exchange column. It will hold an 11 ft deep bed of Iinde Ionsiv ${ }^{(0)}$ (Union Carbide CO.) IE-95. Column shouid be designed to withstand 50 psig. Provide pressure drop measurement across the bed and temperature measurement at several points vertically in the bed. 
Provide inlet port at top of column for fresh zeolite slurry. Provide outlet port at bottom of column for removing loaded zeolite. Both ports will be blanked of when not in use. Provide steam jet to transfer zeolite slurry from column to cesium zeolite tank.

\subsubsection{Zeolite Feed Bounce Tank}

Provide a stainless steel bounce tank similar to those used in cesium and strontium ion exchange. Provide a pump to downflow feed the zeolite column. The pump must freewheel for reverse flow. Provide coils for cooling and heating. Provide temperature and level measurement.

\subsubsection{Zeolite Raffinate Bounce Tank}

Provide a stainless steel bounce tank similar to the zeolite feed bounce tank. Provide a pump to upflow water through the column. Pump must freewheel in reverse flow. Provide coils for heating and cooling.

\subsubsection{Zeolite Raffinate Hold Tank}

Provide a tank to receive the zeolite column effluent and column rise. Provide a suitable transfer device to transfer the contents to the sand filter feed tank in the filtration module.

\subsubsection{Zeolite Slurry Tank}

Provide a stainless steel tank to receive and dewater cesium-loaded zeolite slurry. Profile wire screen is desirable on the dewatering inlet. Provide gamma, temperature, and level

measurement. Provide agitator and coils for cooling.

\subsubsection{General-Purpose Evaporation (L. F. Landon)}

\subsubsection{General}

The function of this module is to decontaminate miscellaneous internally generated waste streams for release to the environment. The design of the evaporator will be identical to the recycle evaporator. 
5.2.12.2 General-Purpose Evaporator Feed Tank

See Section 5.2.7.2.

\subsubsection{General-Purpose Evaporator}

\section{2 .12 .3 .1 General}

See Section 5.2.7.3.1.

\section{2 .12 .3 .2 Specifications}

- Capacity: 10,692 Ib/hr (feed)

- Feed: Specific gravity -0.984

$$
\text { Solids content }-<0.1 \text { wt } \%
$$

- Decontamination Factor: $10^{6}$

- Boiloff Rate: 9,263 lb/hr

- Concentrate: Specific gravity -0.955

Solids content $-<1.0$ wt \%

Temperature - about $100^{\circ} \mathrm{C}$

- Steam Pressure: 25 psig maximum

- Steam Consumption: 1.15 lb steam/lt overhead

- Pot Pressure: $1-4$ in. $\mathrm{H}_{2} \mathrm{O}$

\subsection{Services}

See Figure 5.5.

\section{2 .12 .3 .4 Control System}

See Section $5.2 .7 \cdot 3.4$

\subsubsection{General-Purpose Evaporator Bottoms Tank}

A tank is to be provided to receive the evaporator concentrate. The tank is to be equipped with an agitator, sampler, cooling coils, and suitable instrumentation to monitor liquid level, specific gravity, and temperature. A transfer device is required to transfer contents to the recycle evaporator feed tank. 


\subsubsection{General-Purpose Evaporator Condensate Tanks}

Two tanks are to be provided to receive evaporator overheads. Each tank is to be equipped with an agitator, sampler, cooling coils, and suitable instrumentation to monitor liquid level, specific gravity, and temperature. Two transfer devices are to be provided per tank. One is for transferring the condensate to a surface stream. The other is for recycling off-spec condensate back to the feed tank.

These tanks are accountability tanks at which the radioactive and nonradioactive contaminants are accurately inventoried before discharging the condensate to the environment. While one tank is receiving overheads from the evaporator, the contents of the other tank are sampled for accountability analyses.

\subsubsection{Regulated Facility Vessel Vent Filter Heater}

The vapor effluents from the cesium vent scrubber and the product hold tanks are coupled with the vent purge from each vessel in the General Purpose Evaporation Module. The heater is required to raise the temperature of the vapor at least $10^{\circ} \mathrm{C}$ above its dew point to prevent condensation in the HEPA filter.

\subsubsection{High Efficiency Particulate Air (HEPA) Filter}

A single, 24" $\times 24$ " HEPA filter is required to filter the vapor prior to the release to the atmosphere. A DF of 1000 is assumed for particulates. The pressure drop across the filter should be continuously monitored.

\subsubsection{Regulated Facility Vessel Vent Exhauster}

An exhauster is required to draw the vessel vent through the HEPA filter and discharge to the atmosphere.

5.2.13 Product Salt Solution Concentration/Solidification in Concrete (H.W. Bledsoe)

\subsubsection{General}

The purpose of these facilities is to stabilize the clarified supernate from ion exchange by incorporating it in concrete and burying the saltcrete in excavated trenches at least 10 feet above the water table and beneath at least 33

feet of soil overburden. The burial site must be constructed 
and engineered to meet both NRC and EPA requirements for disposal of radioactive and chemical waste materials. Ground water and leachate monitoring systems must be installed and maintained.

\subsubsection{Feed Preparation}

\section{2 .13 .2 .1 General}

This section describes the facilities required to prepare a 50 wt \% salt solution for feed to the saltcrete plant. The flowsheet (FS-14) and material balance (MB-14) are shown on Figure 4.14 and Table 4.14 respectively.

Each process vessel is assumed to have a vapor space purge drawn from the building atmosphere. All vessel vents, as well as other potentially contaminated ventilation, are combined, heated to above its dew point and drawn through a high efficiency. particulate filter before being discharged to the atmosphere.

\subsection{Product Salt Solution Storage Tank}

A tank is required to accumulate unevaporated decontaminated salt solution from the S-Canyon ion exchange module at the Saltcrete Plant Facility. The tank should accomodate sufficient lag storage between the DWPF and the Saltcrete Facility to minimize influence on canyon attainment. The vessel should have a sampler and appropriate systems to monitor liquid level, specific gravity, and temperature. A suitable transfer device is required to feed the product salt evaporator at a controlled rate.

\subsection{Product Salt Evaporator}

General

For purposes of this PTDS, it is assumed that the evaporator will be of the bent-tube type, currently used to dewater waste in the interim waste storage facilities. 
Specifications

- Capacity: 11,707 1b/hr feed

- Feed: Specific Gravity - 1.17

Total solids content - 23 wt $\%$

- DF: $10^{6 a}$

- Boiloff rate: $4910 \mathrm{lb} / \mathrm{hr}$

- Concentrate: Specific Gravity - 1.16

Temperature - 115 to $120^{\circ} \mathrm{C}$

Total Soljds Content - 35.0 wt \%

Services

See Figure 5.6.

\section{Control System}

The desired specific gravity is the primary operating parameter. Control philosophy will be as currently used in the existing waste farm evaporators.

Feed-Rate Control - A remote air operator in the control house is used to adjust a throttling valve which regulates the feed flow to the evaporator.

Liquid-Level Control - The liquid level in the evaporator is controlled by varying the bottoms withdrawal rate with a steam lift. This is an automatic control that controls the flow of steam to the steam lift.

a. To achieve this decontamination factor, the evaporator pot should have at least 66 in. of freeboard and the bubble cap trays (see Figure 5.6) must be replaced with wire mesh separators (or a wire mesh pad added downstream of the bubble caps). 
Bottoms Concentration Control - Evaporator pot specific gravity (or temperature) is used to monitor concentration. A panel-mounted temperature recorder-controller varies the steam flow to the evaporator tube bundle by varying a control valve on the steam supply.

Foam Level - Foam level is to be monitored by a differential pressure device. This device is connected to steam-purged dip tubes in the vapor space.

\subsection{Product Salt Evaporator Condenser}

A shell and tube condenser is required to reduce the vapor temperature to $<50^{\circ} \mathrm{C}$. Cooling water to the condenser should be at a pressure 15 psig greater than the condensate.

\subsection{Product Salt Evaporator Condensate Tank}

Sufficient tank capacity is required to receive the overheads from the product salt evaporator. Tank should be equipped with samplers and appropriate instrumentation to monitor liquid level, specific gravity, and temperature. Four transfer devices are required to transfer condensate to (1) the recycle water tank, (2) the saltcrete plant, (3) the product salt concentrate tank and (4) the product salt evaporator for descaling.

\subsection{Product Salt Concentrate Tank}

The bottoms from the product salt evaporator are steam lifted to a tank sized to accommodate 1 week's concrete production. The tank should be equipped with appropriate instrumentation of monitor liquid level, specific gravity, and temperature. The concentrate temperature will be maintained by a heater (on a circulating loop) high enough to prevent salt crystallization. The tank should have an agitator and a sampler. A suitable transfer device is required to transfer the concentrate to the saltcrete plant. The vapor space should be vented through a condenser with the condensate being recycled back into the tank. 


\subsubsection{Saltcrete Preparation}

\subsection{General}

The concentrated salt solution will be mixed with cement to produce a mixture containing 56.5 wt \% cement, 15.2 wt \% salt, and 28.3 wt \% water. The mixture will be pumped to the disposal trenches from the concrete plant. The consistency of the concrete is critical. Pumped concrete must be well-mixed before feeding into the pump and occasionally remixing is required in the hopper by means of stirrers. The set-time of the saltcrete should be significantly long to preclude the premature set-up of the mixture during pumping operations. All equipment must have water flush service. The concrete plant should be centrally located to the disposal site.

\subsection{Plant Capacity}

The concrete plant should be capable of producing and pumping a nominal $70 \mathrm{yd}^{3}$ of concrete per hour. This would easily satisfy the desired disposal rate of $1000 \mathrm{yd}^{3}$ of saltcrete/ week. Ready-mix plants of the type required for this type of operation are available in numerous designs with capacities ranging from 10 to $300 \mathrm{yd}^{3} / \mathrm{hr}$. Piston pumps with 9 -inch pipes may deliver on the order of $70 \mathrm{yd}^{3}$ per hour over horizontal distances up to 1500 feet. Pumping is economical only if it can be used over long uninterrupted periods because at the beginning of each pump cycle the pipes have to be lubricated with mortar and at the end of the cycle considerable effort is required to clean the pipes. Consequently, a nominal transfer irequency of twice per week is planned. A pipe cleaning "pig" is required to clean transfer pipes.

\subsection{Facility Description}

The building to contain the evaporator and concrete plant equipment will be of normal construction. Thick walls for biological shielding are not necessary because the radiation level from 15 year aged clarified supernate from ion exchange is very low. Evaporation, mixing and pumping operations must be sufficiently remotable and within controlled ventilation zones to ensure that operating personnel are not exposed to body exposure rates in excess of $0.5 \mathrm{mrem} / \mathrm{hr}$ or are they required to wear respiratory protection during normal operation. 
Required services for this facility include steam, cooling water, flush water, electrical and normal lighting.

\subsubsection{Reference Disposal Site}

\subsection{General Design Criteria}

- The initial disposal site size should be scoped based on the waste inventory on hand at startup of the DWPF.

- The disposal site will require a water table depth below grade of approximately 60 feet (this may require mounding with backfill).

- The site must be constructed and engineered to meet both NRC and EPA requirements for disposal of radioactive waste and hazardous (chemical) waste materials.

- Trenches must have a 5-foot impermeable blanket of soil $\left(10^{-7} \mathrm{~cm} / \mathrm{sec}\right)$ on the bottom and top. A similar blanket is required on the sides of the site.

- Disposal site must have a minimum of 33 feet of soil overlying the top of the saltcrete monoliths.

\subsection{Concrete Monoliths}

The trenches are to be designed to accommodate approximately one weeks production of saltcrete.

\subsection{Disposal Facility Design}

\section{Pit Excavation and Construction}

Assuming that the sediments underlying the reference disposal site do not meet the Resource Conservation and Recovery Act proposed $10^{-7} \mathrm{~cm} / \mathrm{s}$ permeability requirement for use as a natural inplace liner, a conceptual excavation and construction plan to fulfill this requirement is outlined below.

- The entire disposal site is excavated. Sides are sloped at approximately $1-1 / 2: 1$. 
- A minimum 5-ft-thick liner of selected material $\left(\leq 10^{-7} \mathrm{~cm} / \mathrm{s}\right.$ permeability) is placed across the bottom of the entire excavation and up the sides.

- Overlying this impermeable blanket, a minimum 12-inch-thick permeable leachant drainage and collecting system is constructed. This system will consist of a graded sand and gravel drainage blanket which slopes a minimum of $1 \%$ toward collecting sumps and wells that provide accumulation and removal of leachate.

- Controlled placement of the selected backfill $\left(\leq 10^{-7} \mathrm{~cm} / \mathrm{s}\right)$ is continued for an additional $25 \mathrm{ft}$ above the drainage system (actually must backfill $>25 \mathrm{ft}$ so not to disturb leachate collection system when trenches are later excavated).

- The remainder of the pit above the impermeable material is backfilled with non-selective site material.

\section{Trench Excavation}

The site will be re-excavated to the top of the impermeable backfill and individual trenches excavated for placement of the concrete/salt mixture. The conceptual development of the disposal trenches include:

- Excavation of a pit 25-ft deep with side slopes of approximately 1-1/2:1, depending on soil stability.

- Excavation of a series of trenches (length to be determined) approximately $20 \mathrm{ft}$ wide $\mathrm{x} 25 \mathrm{ft}$ deep within the bottom of the pit.

- Saltcrete poured to a depth of $20 \mathrm{ft}$ in a trench.

- After the saltcrete in a single trench has set, it will be covered with $5 \mathrm{ft}$ of $\leq 10^{-7} \mathrm{~cm} / \mathrm{s}$ permeability material.

- As trenches are completed and filled with saltcrete, portions of the completed site are backfilled, providing the $33 \mathrm{ft}$ of design overburden.

Figure 5.7 is a conceptual sectional view of the disposal site. 
5.2.14 Product Packaging/Testing/Decontamination/Interim

Storage (J. P. Howell and W. N. Rankin)

\subsubsection{General Equipment and Cell Considerations}

The cell arrangement of "A", " $B$ ", and " $C$ " mechanical cells should be isolated from the rest of the canyon processing cells to eliminate contamination transfer. A separate ventilation system, crane, and equipment maintenance facility are required for the mechanical cells. Access to the cells from "clean" areas is required for introduction of canisters, welding accessories, machine tools, sample removal, dry smear transfer, etc. Storage space should be allocated in "A" cell for glass-filled canisters based on cell design, process equipment, and glass-pour mode of operation.

Low amounts of transferable contamination in the mechanical cells can be maintained by providing contamination barriers (distance, physical barriers, differential pressure operation) in the spray dryer melter area. The spray dryer will likely be the main contributor of transferable contamination into the relatively "clean" mechanical cells.

The mechanical cells and equipment should be designed, if possible, for remote operation and contact maintenance. " $B$ " and "C" cells should be designed for scheduled personnel entry to decontaminate the equipment and cells.

Cell viewing windows, closed circuit television (CCTV), and master-slave manipulator through-tubes should be installed at strategic locations to assist processing and maintenance requirements. Manipulators should be positioned in those locations as specified by equipment design.

\subsubsection{Mechanical Cell A}

\subsection{Canister Closure and Testing}

A portable surface pyrometer should be provided for measuring canister surface temperatures before and after joint preparation and welding operations. The instrument range should be 0 to $500^{\circ} \mathrm{C}$ with remote readout. Viewing windows and manipulators should be positioned to facilitate these measurements.

Provide space for possible ultrasonic NDT examination of the glassform structure through the canister wall. 
To verify weld integrity, SRP-EED is developing nondestructive test equipment. Process parameter control will be the primary verification technique for use with the solid state resistance upset weld. However, in the event that criteria is set forth that cannot be met by process parameter control, SRP-EED is developing an ultrasonic delta-scan technique for weld verification. Such an inspection criteria is not the reference process. However, it may be required in conjunction with the helium leak test or at some time prior to any future canister removal from the interim storage facility.

Equipment and techniques are being developed to helium leak test the canister prior to decontamination. This leak test will supplement process parameter control as a means of verifying the weld integrity and will ensure that a leaktight weld was attained. Watertight integrity of the weld is required to prevent inleakage of liquid during decontamination. Leaktight integrity of the weld is also required to prevent the escape of radioactivity in Mechanical Cell A to rework canisters that fail to meet leak specifications.

SRP-EED is developing the criteria, equipment, and instrumentation for canister closure preparation, closure method, and closure weld testing $[5,6]$. The design basis process for the closure is a solid-state resistance weld of a plug in a 4 to 6 -inch-diameter opening. The welder is capable of exerting 75,000 pounds of force on a plug while simultaneously delivering about 200,000 amps for about $1-1 / 2$ seconds. The welding parameters to be recorded remotely are force, motion, current, and weld time. CCTV should be supplied for viewing the welding operations [6].

\subsection{Preliminary Canister Decontamination and Transfer}

General

The initial canister decontamination should produce a DF of $10^{2}$ to $10^{3}$ of the transferable contamination before transfer into Mechanical Cell B. Decontamination solutions are circulated about the canister during each etch and cleaning cycle. Residence time for each decontamination cycle is one hour. Decontamination solution for this initial decontamination come from the final decontamination operation in Mechanical Cell $B$ where they were initially used. 
Etch Tank

Provide a tank to accommodate a canister about which $\mathrm{HNO}_{3}-\mathrm{NaF}$ may be circulated. Appropriate cooling and heating systems are required to maintain the temperature of the etch solution at $50^{\circ} \mathrm{C}$. A transfer device is required to transfer the spent etch solution to the neutralizer tank. The tank should be vented through a caustic scrubber.

\section{Cleaning Tank}

Provide a tank, similar to the etch tank, to accommodate a canister about which oxalic acid may be circulated. Appropriate cooling and heating systems are required to vary the temperature of the cleaning solution between $35^{\circ} \mathrm{C}$ and $90^{\circ} \mathrm{C}$. A transfer device is required to transfer the spent cleaning, solution to the digestor tank.

\section{Spray Tank (2)}

Following each decontamination step, the canister is transferred to its respective spray tank in which the canister is rinsed. Suitable transfer devices are required to transfer the rinse water to the spray hold tank.

\section{Spray Hold Tank}

Provide a tank to accommodate the canister rinse waste from each spray tank. The tank is to be equipped with a suitable liquid level device. A transfer device is required to transfer rinses to the spent decon solution pump tank.

\section{$\underline{\text { Digester }}$}

A tank, equipped with heating and cooling coils, is required in which the spent cleaning solution can be digested to destroy the oxalic acid. Nitric acid and manganese nitrate service to this tank are required. A condenser is required to condense and recycle the condensables evolved during digestion. A transfer device is required to transfer the digested solution to the neutraiizer tank. The tank should be equipped with suitable devices for monitoring liquid level, specific gravity and temperatures. A sampler is required. 
Neutralizer

Provide a tank with cooling coils in which the spent etching solution and digested cleaning solution may be neutralized. A transfer device is required to transfer the neutralized solution to the spent decon solution pump tank. The tank must be equipped with appropriate devices to measure liquid level, specific gravity and temperature. A sampler and agitator are required.

Spent Decon Solution Pump Tank

Provide a pump tank by which the spent decon solutions and rinse water may be transferred to the recycle collection tank for dewatering in the Recycle Evaporator.

\subsubsection{Mechanical Cel1 B}

\subsection{General.}

Final canister decontamination is designed to produce an additional DF of $10^{2}$ to $10^{3}$ of the remaining canister transferable surface contamination. Process decon solutions used in this cell are transferred to Mechanical Cell $A$ where they are used for preliminary decontaminating of another canister. Canisters should air dry by their own self-heating in a relatively clean area before dry smearing the surface and transfer into Mechanical Cell C.

\subsection{Etch Tank}

Size and function of the tank the same as in Mechanical Cell A. Tank is vented to a caustic scrubber. A suitable transfer device is required to transfer the spent etch solution to Mechanical Cell A.

\subsection{Cleaning Tank}

Size and function of this tank the same as in Mechanical Cell A. A suitable transfer device is required to transfer the spent cleaning solution to Mechanical Cell A. 


\subsection{Spray Tank (2)}

Size and function of these tanks the same as in Mechanical Cell A.

\subsection{Spray Hold Tank}

Provide a tank to hold the spray water from the spray tanks. Tank should be equipped with an agitator, sampler and suitable devices to measure liquid level, specific gravity and temperature. A transfer device is required to transfer contents to the spent decon solution pump tank.

\section{2 .14 .3 .6 Caustic Scrubber}

The etch tanks (Mechanical Cell A \& B) should be vented to a caustic scrubber to prevent hydrogen fluoride from entering the process vessel vent system. $\mathrm{HF}$ and $\mathrm{HNO}_{3}$ in air over etch tank contents assuming saturation at $50^{\circ} \mathrm{C}$ is as follows

Partial

Pressure, $\mathrm{mmHg}$

HF

$\mathrm{HNO}_{3}$

$\mathrm{H}_{2} \mathrm{O}$

Air
0.06

0.06

80

Balance
Concentration, ppm

Volume Weight

80

57

80

180

100,000

69,500

Balance

Balance

\section{2 .14 .4 Mechanical Cell C}

Provide remote equipment to measure canister radiation levels, surface temperature, and surface transferable contamination. Remote readout is required on the radiation meters and the surface pyrometers. Provide ability for introducing "clean" smear papers into " $\mathrm{C}$ " cell and removing "dirty" smear paper from the cell for counting. The radiation monitor should be equipped with a gamma detector for canister radiation profile survey one foot from the surface. The surface temperature measuring equipment should have a range of $0-500^{\circ} \mathrm{C}$ and be capable of measurements at the canister quarterpoints along its length. 


\section{2 .15 Interim Storage}

Provide reinforced concrete facilities to store 6500 canisters that encapsulate the glass waste. The facilities should be designed to withstand natural catastrophes such as earthquakes, flooding, and tornadoes. Provide for removal of fission product decay heat by natural convection air cooling around containers. The maximum glass temperature is $500^{\circ} \mathrm{C}$ to avoid devitrification. Filtration of the cooling air exhausted from the building is not required. A system is required to divert the building air to a HEPA filter bank automatically in the event of airborne contamination. Also, the normal building exhaust should be blocked in this emergency mode. Provision should be made for remote transfer of canister from " $C$ " cell to the storage facility. Provide air samplers to continuously monitor exhaust air for airborne activity. 
TABLF: 5.1. DWIF Services and Equipment

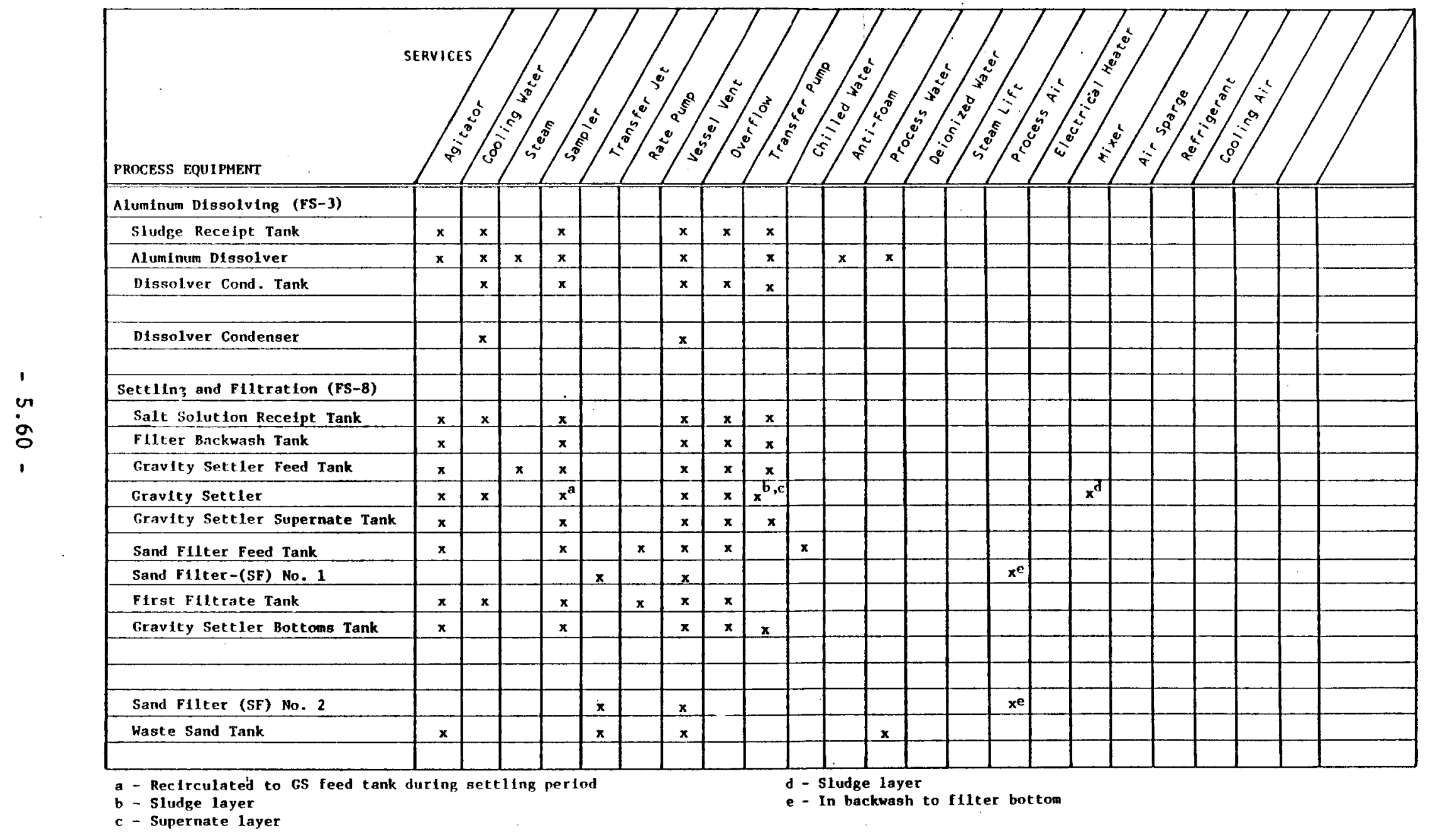


TAB1.E 5.1. DWPF Services and Equipment (Contd)

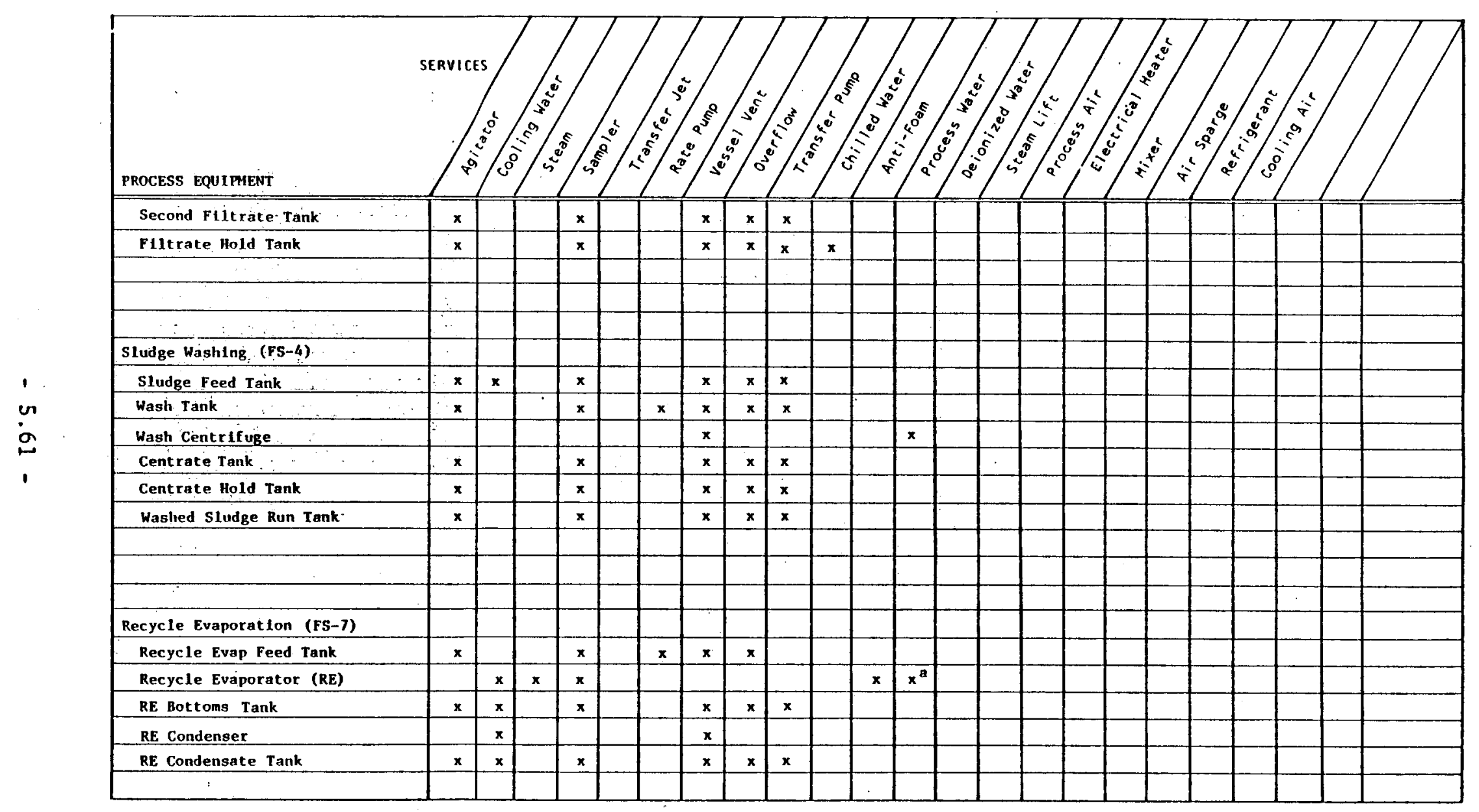

a - Spraydown of de-entrainer. 
TAB1.E 5.1. DWPF Services and Equipment (Contd)

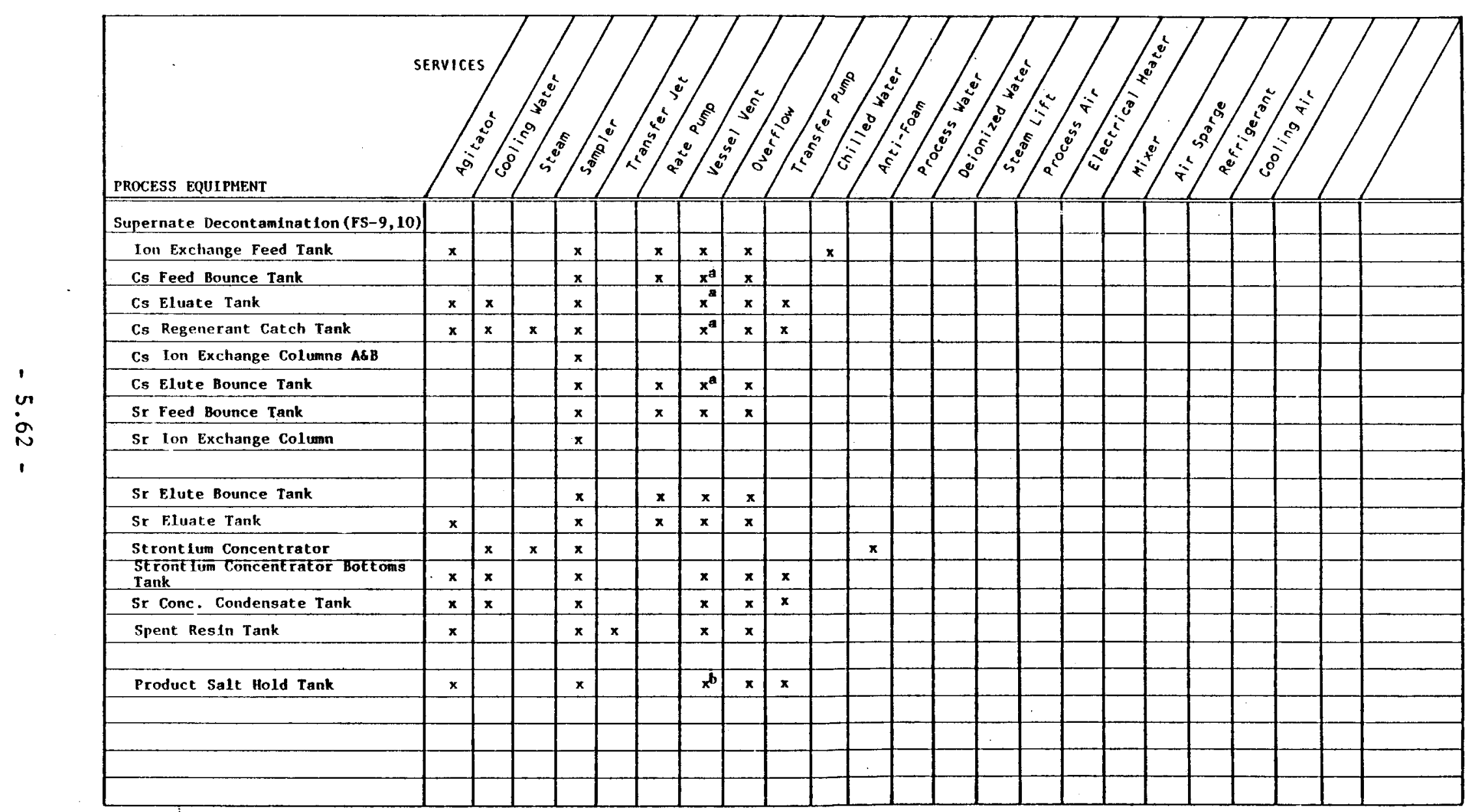

a. These tanks vent to the Regulated Facility Vessel Vent System via the Ceslum Vent Scrubber

b. Vents into the Regulated Facillty Vessel Vent System 
TARLE 5.1. DWPE Services and Equipment (Contd)

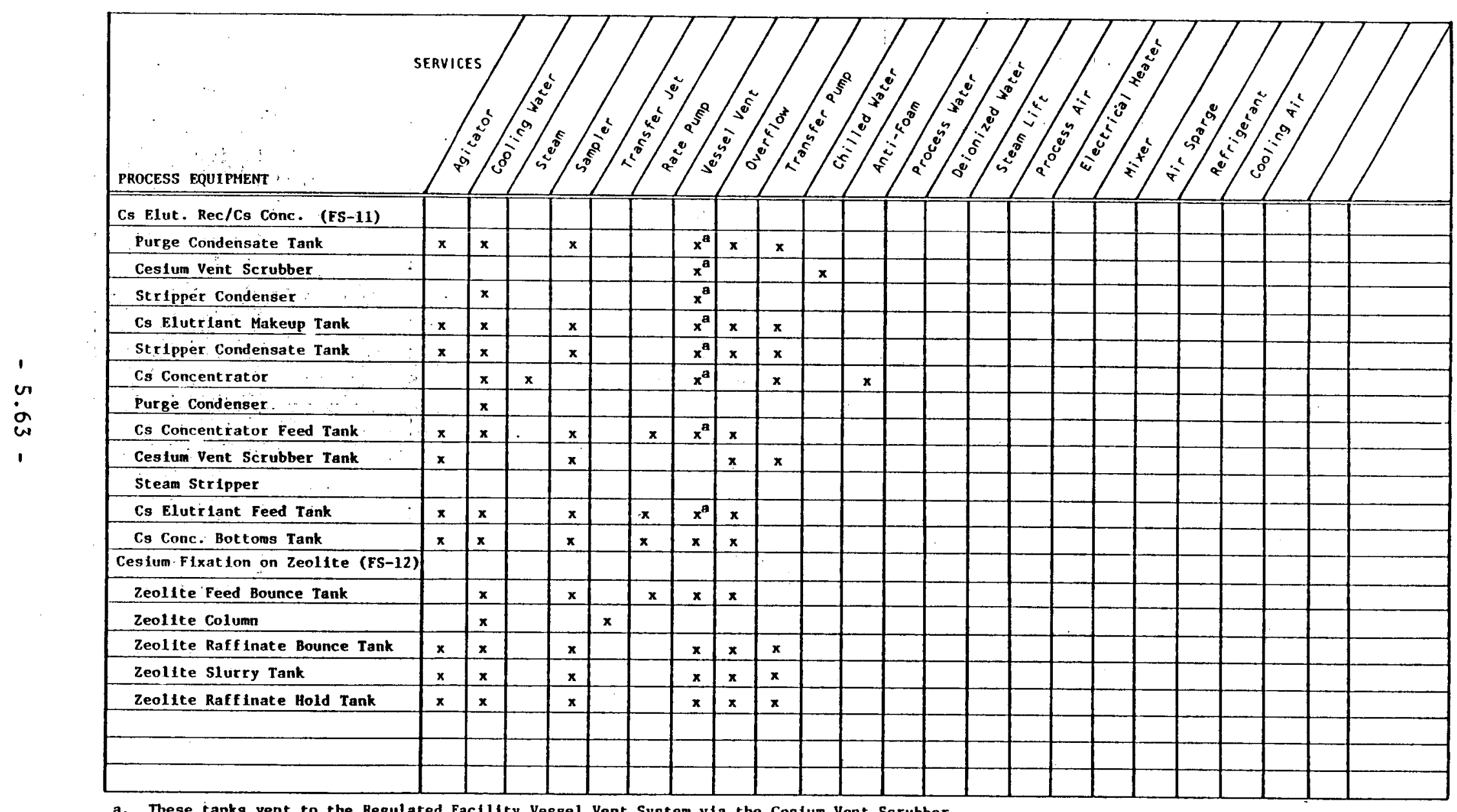

a. These tanks vent to the Regulated Facillty Vessel Vent System via the Cesium Vent Scrubber. 
TARLE 5.1. DWPF Services and Equipment (Contd)

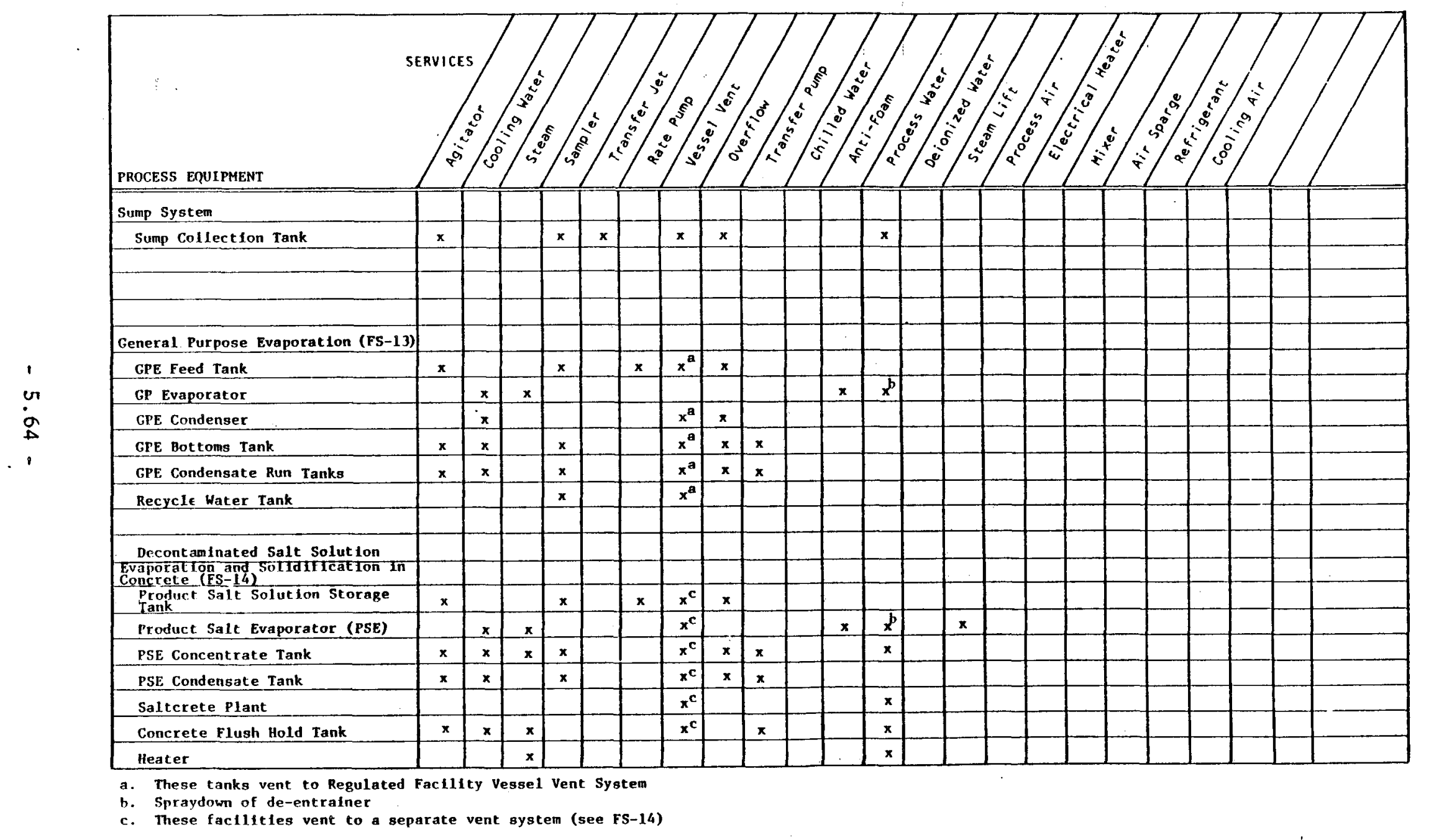


TABI,F 5.1. DWPF Services and Equipment (Contd)

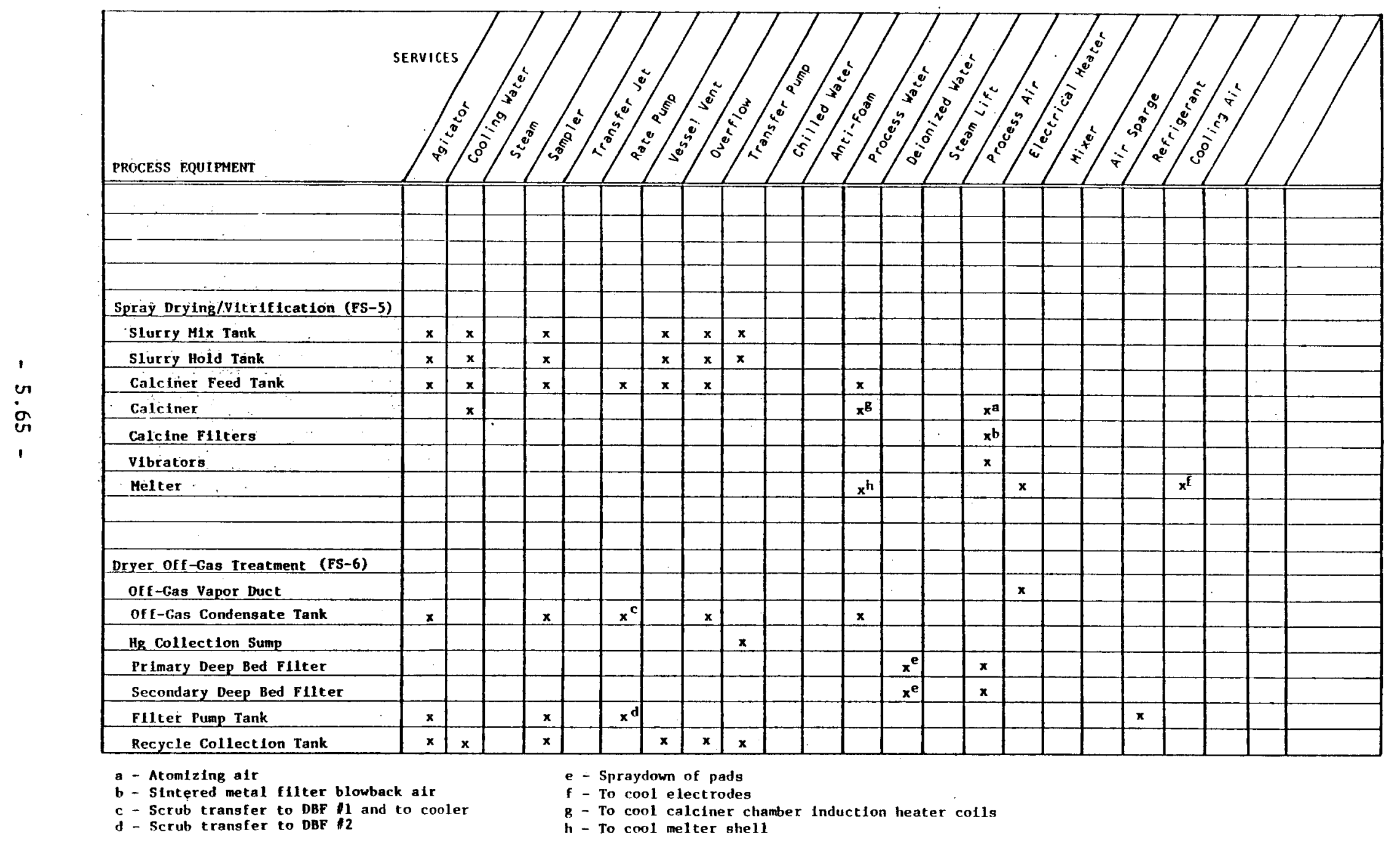


TABLE 5.1. DWPF Services and Equtpment (Contd)

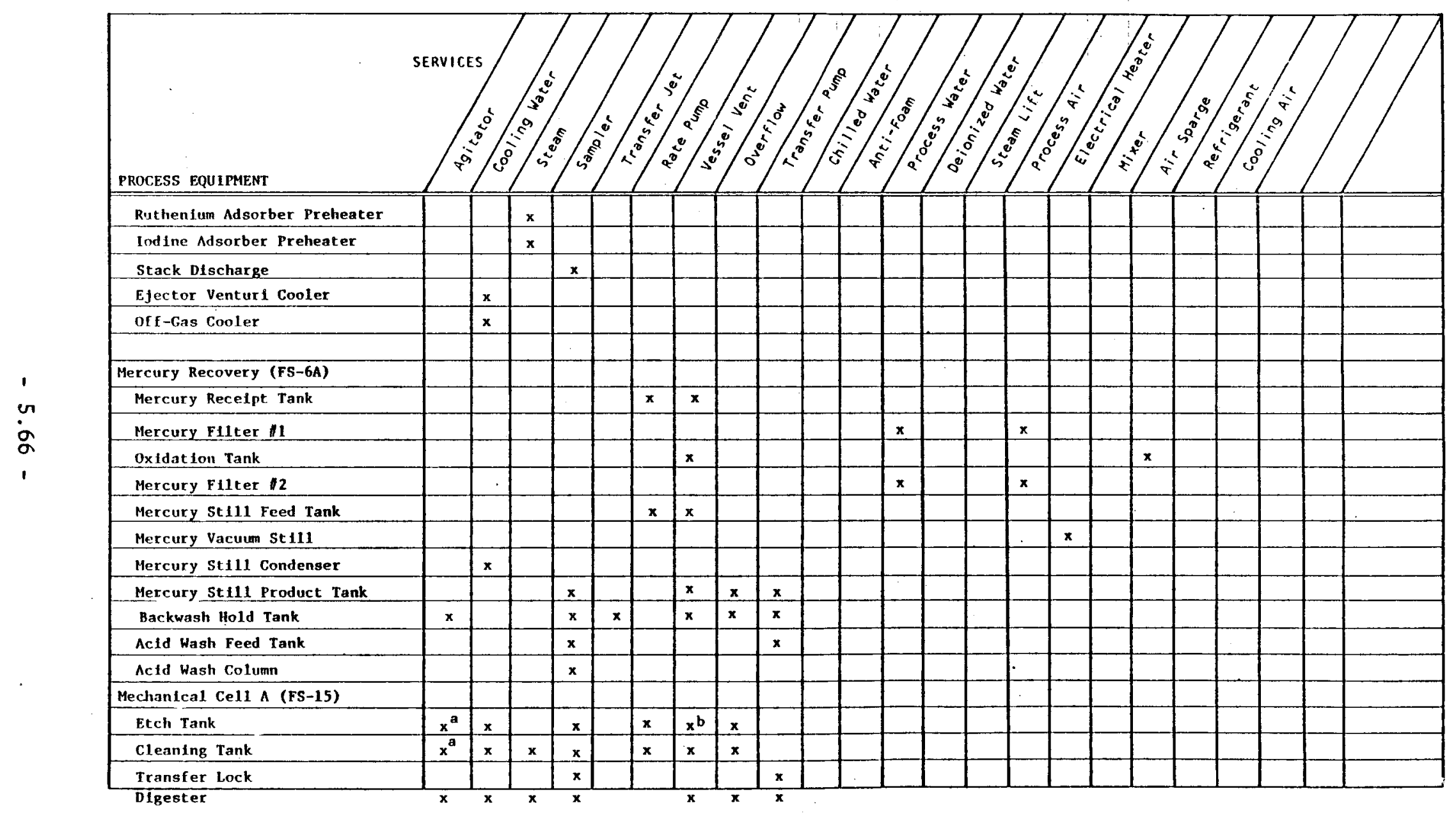

- Agitation by solution circulation

b - Vents to the Caust ic scrubber 
TABLE 5.1. DWPF Services and Equipment (Contd)

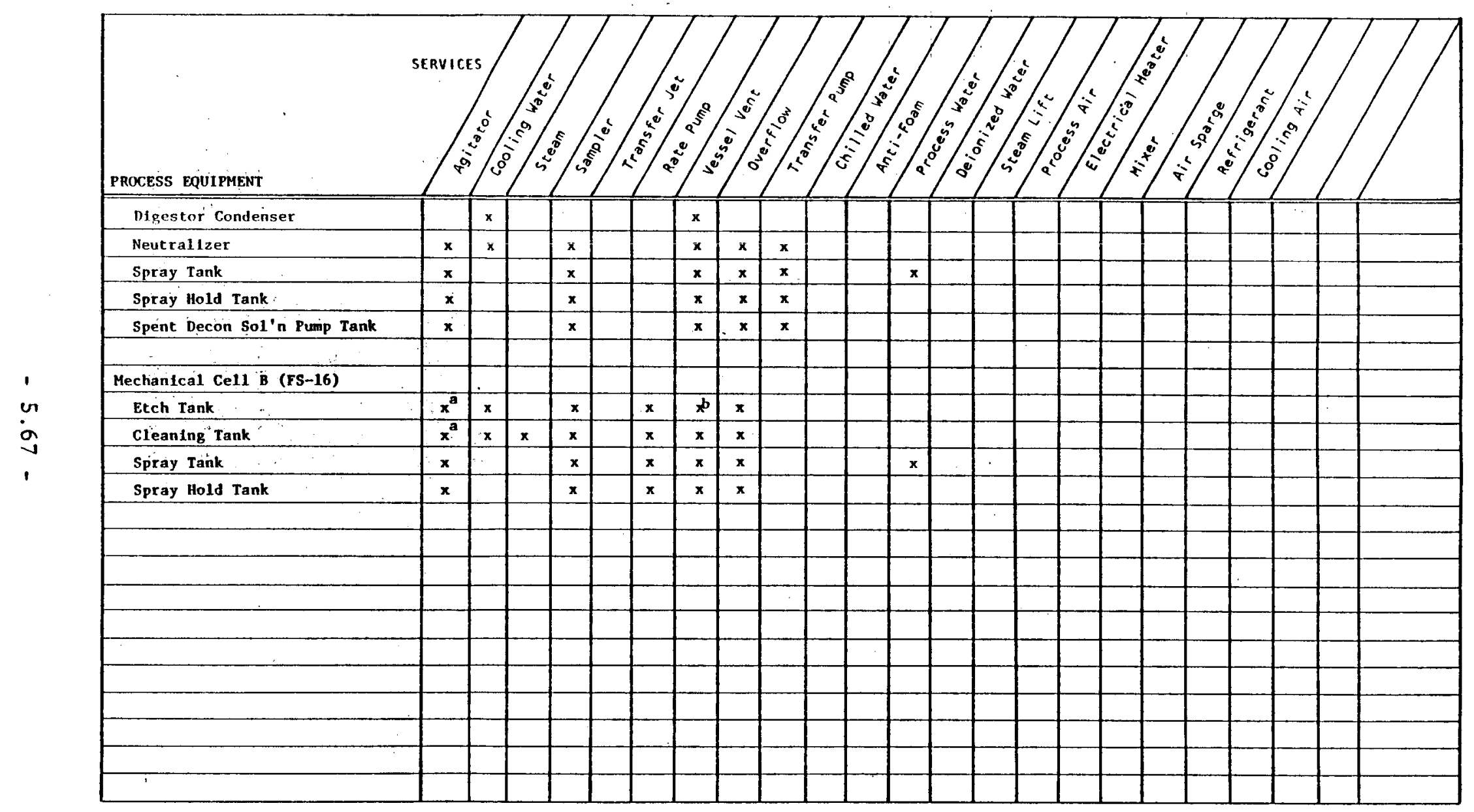

a - Agftat ion by solution cl rculation 
TABLE 5.2

Cold Feed Services

Module

Aluminum Dissolution

Settling/Fileration

Cesium and Strontium Ion Exchange

Cs Elutriant Recovery/ Cs Concentration

Spray Calcination/ Vitrification

Mercury Recovery

Mechanical Cell A

Mechanical Cell B

Mechanical Cell

Cs Fixation on Zeolite

Sludge Washing

Product Salt Solucion

Concentration and

Solidification in Concrete
Vessel

Aluminum Dissolver

Gravity Settler

Sand Filter No. 1

Sand Filter No. 2

Cs IE Columins $A$ and $B$

ST IE Column

Cs Elute Bounce Tank

Sr Elute Bounce Tank

Cs Elutrfant Makeup

Tank

Cs Vent Scrubber

Calciner

Acid Wash Column

Backwash Hold Tank

Digester

Neutralizer

Spray Tanks

Smear Station

Etch Tank

Caustic Scrubber

Cleaning Tank

Spray Hold Tank

Spray Tanks

Smear Station

Spot Electropolishting

Smear Station

Zeolite Column

Centrifuge

Saltcrete Plant
Service

$50 \% \mathrm{NaOH}$

Anti-foam

Starch Dispersion (Flojel $\left.{ }^{\circ}-60\right)$

$8 \%$ dispersion in $1 \mathrm{M} \mathrm{NaOH}$

IM NaOH

3-4M $\mathrm{HNO}_{3}$

Sand, 25-40 mesh

Anthracite, 20-30 mesh

Polyelectrolyte (Versa $\mathrm{T}^{\circ} 700$ ) -

$0.1 \%$ in distilled water

IM NaOH

3-4M $\mathrm{HNO}_{3}$

Sand, 40-60 mesh

Anthracite, 30-50 mesh

Polyelectrolyte (Versa $T^{(0700)}$ -

$0.1 \%$ in distilied water

Duolite ARC-359 Resin

Amberlite IRC-718 Resin

$2 \mathrm{M} \mathrm{NaOH}$

$0.01 \mathrm{M}$ NaEDTA - $0.001 \mathrm{M} \mathrm{NaOH}$

BM $\mathrm{NH}_{4} \mathrm{OH}$ (aqueous)

Carbon Dioxide (gas)

Chilled Water

Frit

$3 \mathrm{HNO}_{3}$

$50 \% \mathrm{NaOH}$

$50 \% \mathrm{HNO}_{3}$

$\mathrm{Mn}\left(\mathrm{NO}_{3}\right)_{2}$

$50 \% \mathrm{NaOH}$

Spray Water

Paper Smears

$3.5 \mathrm{M} \mathrm{HNO}_{3}-0.4 \mathrm{M} \mathrm{NaF}$

$\mathrm{NaOH}$

$200 \mathrm{~g} / \mathrm{L} \mathrm{C}_{2} \mathrm{H}_{2} \mathrm{O}_{4}$

$50 \% \mathrm{NaOH}$

Spray Water

Paper Smears

HNO,

Papề Smears

Zeolite

Water

Spray Water

Cement 
TABLE 5.3

Technical Specifications for Wash Centrifuge

Type

Basket Size

Speed

Centrifugal Force

Separation

Drive

Discharger

Skimmer

Feed System

Cake Density
Top-driven, bottom-unloaded, solidwall batch basket centrifuge

Minimum basket size of 48 inches in diameter by 30 inches high with 120 gallon capacity

Maximum bowl speed when plowing - $100 \mathrm{rpm}$

$900 \mathrm{~g}$ 's minimum at liquid pool surface

$98 \%$ minimum solids recovery over each of : the dewatering steps and two wash steps

$300 \mathrm{ft}-\mathrm{lb}$ minimum torque required at discharge speed

Single, knife-edge, scraping-type plow with high pressure hydraulic spray system

Single linear skimming device

Complete or nearly complete acceleration of feed required before entry into basket

$100 \mathrm{lb} / \mathrm{ft}^{3}$ maximum bulk density of wet cake in basket 
TABLE 5.4

PML Spray Dryer Basic Data

\begin{tabular}{|c|c|c|c|c|}
\hline $\begin{array}{l}\text { Spray } \\
\text { Dryer } \\
\text { Size, in. }\end{array}$ & $\begin{array}{l}\text { Waste } \\
\text { Type } \\
\end{array}$ & $\begin{array}{l}\text { Feed Rate, } \\
\text { gal/hr }\end{array}$ & $\begin{array}{l}\text { Wall } \\
\text { Temp., }{ }^{\circ} \mathrm{C}^{\mathrm{e}}\end{array}$ & $\begin{array}{l}\text { Power } \\
\text { Input, } \mathrm{kW}\end{array}$ \\
\hline $21^{a}$ & SRP & 3.96 & $2700-750$ & 45 \\
\hline 21 & SRP & 7.93 & $2700-750$ & 50 \\
\hline 21 & SRP & 13.2 & $2700-750$ & 68 \\
\hline 21 & SRP & 14.5 & $2700-750$ & 71 \\
\hline 22 & LWR & 19.8 & 700 & $280^{c}$ \\
\hline $36^{\mathrm{b}}$ & LWR & 55.5 & 800 & $225^{\mathrm{d}}$ \\
\hline 36 & SRP & 79.3 & 770 & 284 \\
\hline 36 & SRP & 66.1 & 790 & 262 \\
\hline 36 & SRP & 46.2 & 810 & 211 \\
\hline
\end{tabular}

a. 21-in.-diameter $\times 6 \mathrm{ft}$ 6-in.-long chamber; $35.7 \mathrm{ft}^{2}$ heat transfer area.

b. 36-in.-diameter x $10 \mathrm{ft} 0$-in.-long chamber; $94.3 \mathrm{ft}^{2}$ heat transfer area.

c. Maximum heater output. Wall temperature could not be maintained above 19.8 gal/hr feed rate.

d. Maximum output of heaters rated at $390 \mathrm{kw}$.

e. Estimated wall temperature based on furnace temperature and PNL experience. 


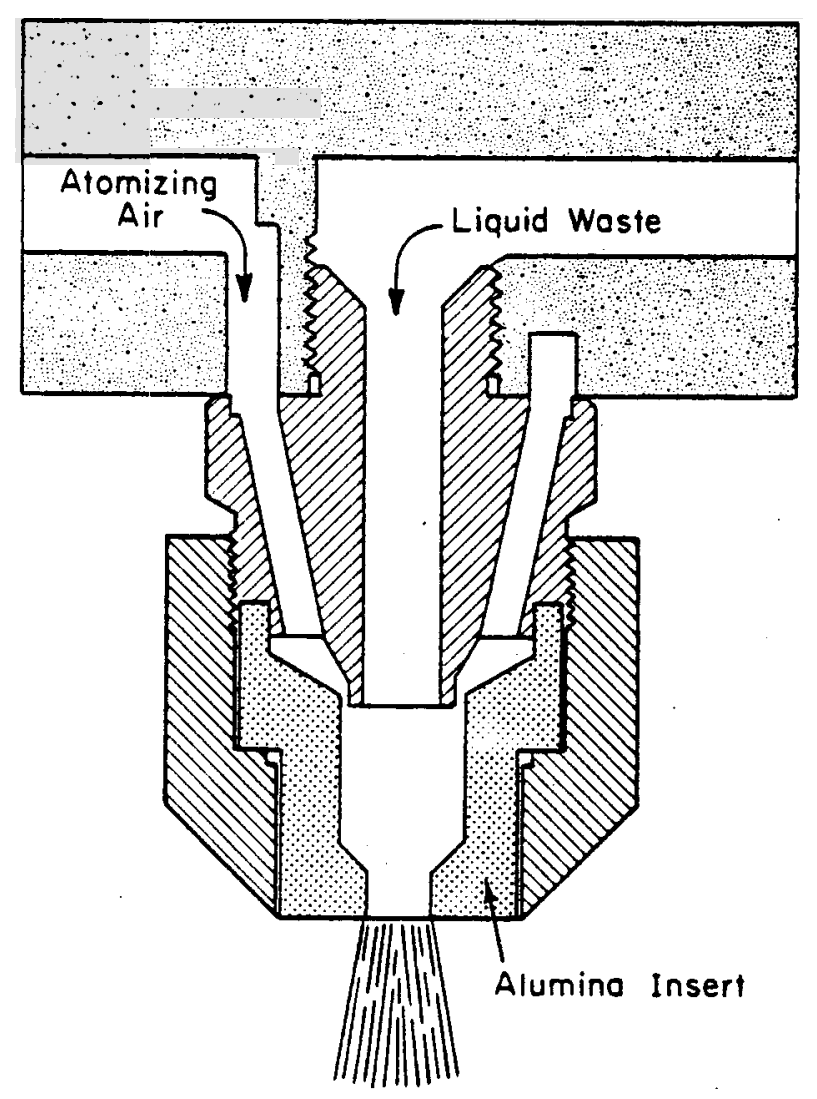

FIGURE 5.1 High-Capacity Atomizing Nozzle 


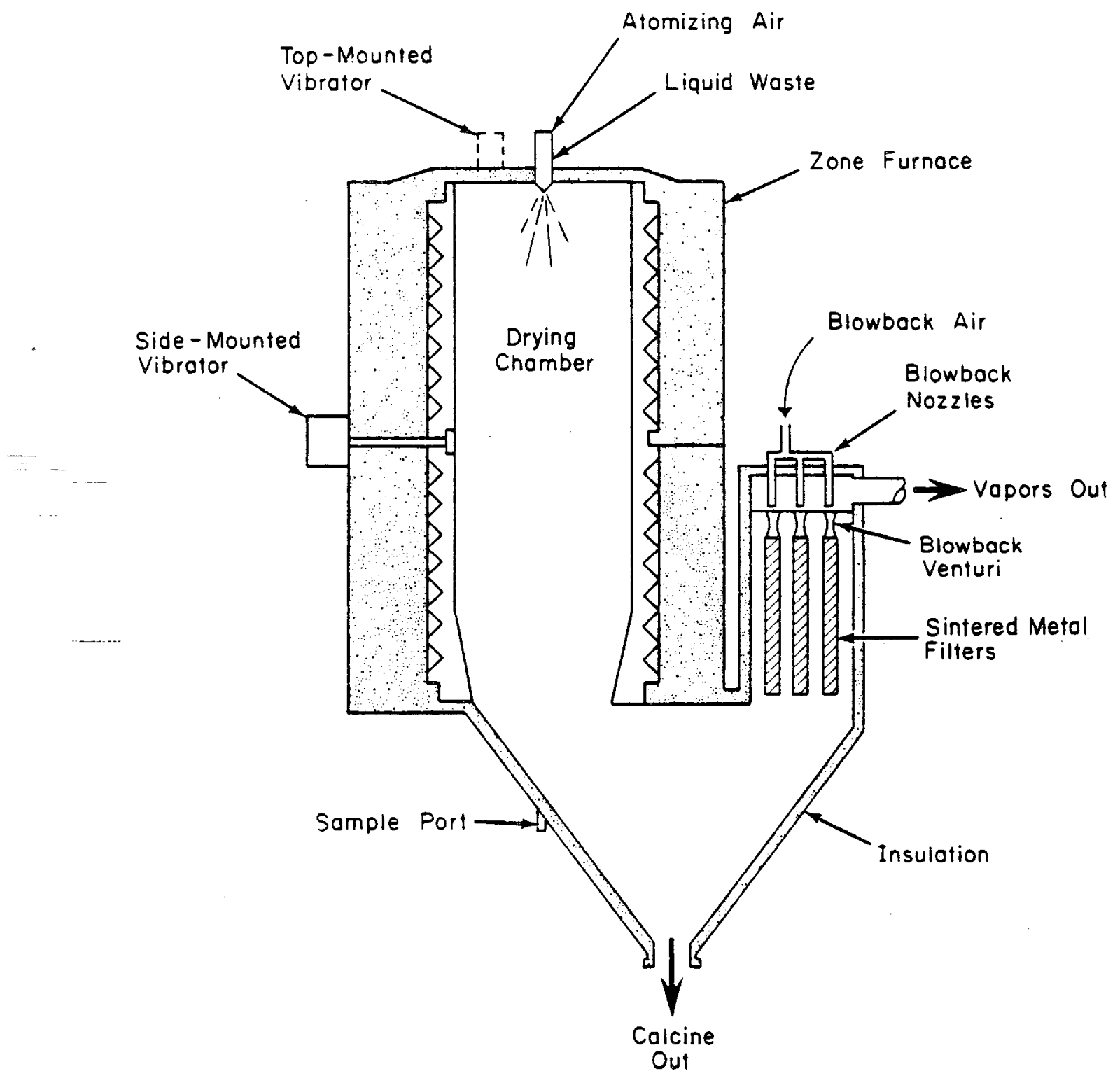

FIGURE 5.2 Conceptual Developmental Spray Dryer 

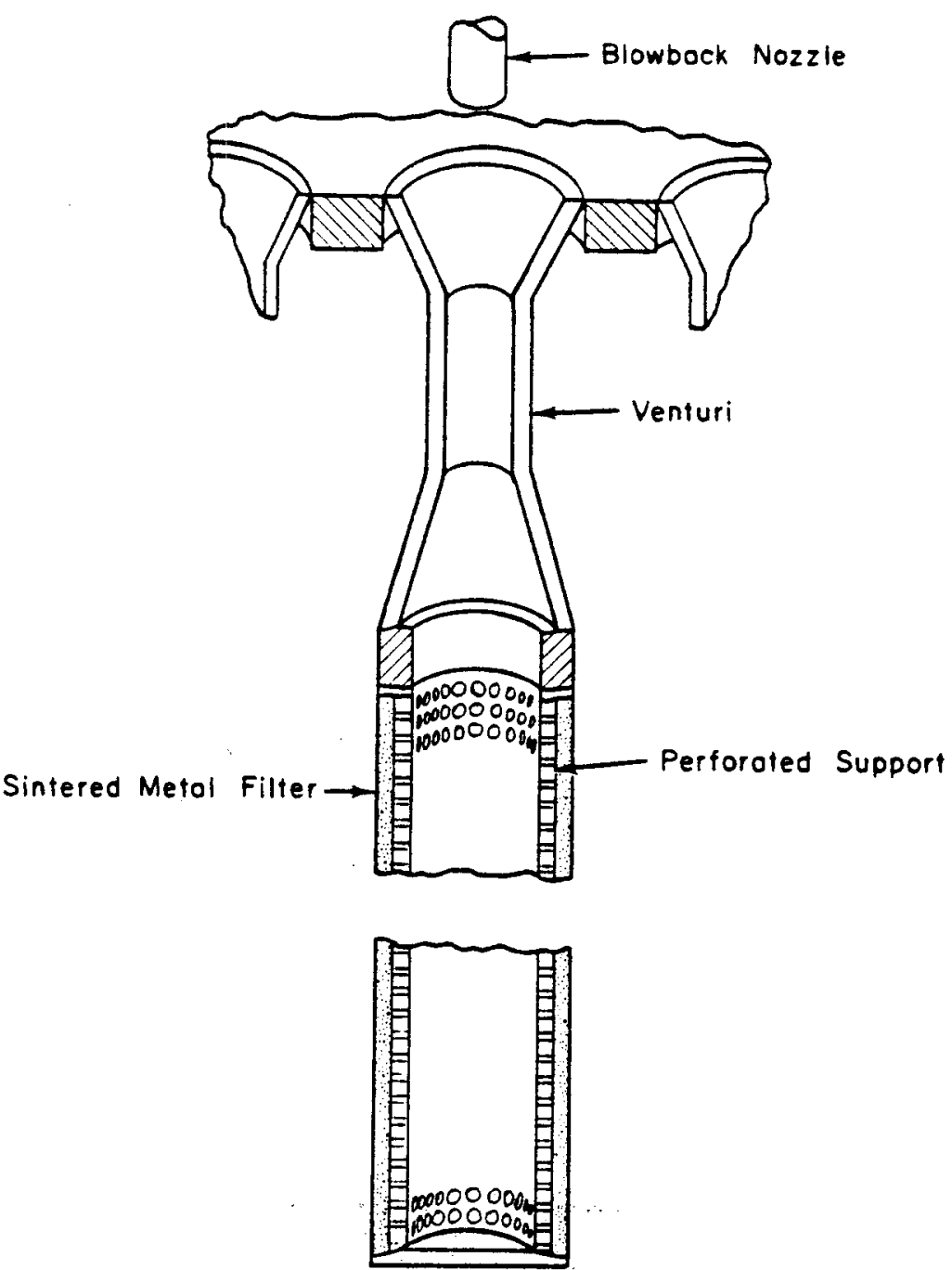

FIGURE 5.3 Spray-Dryer Filter Assembly 


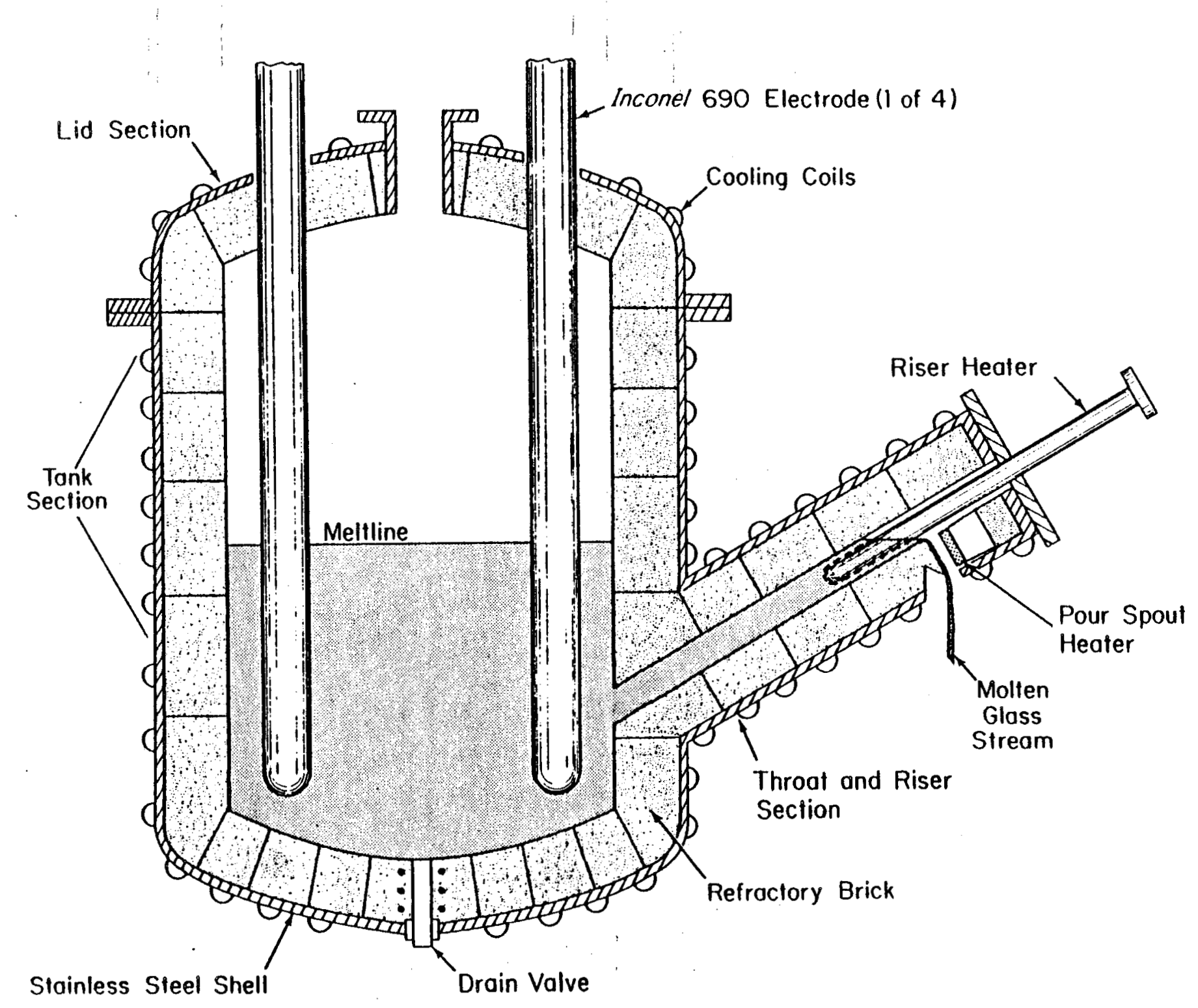

FIGURE 5.4 Joule-Heated Continuous Glass Melter 


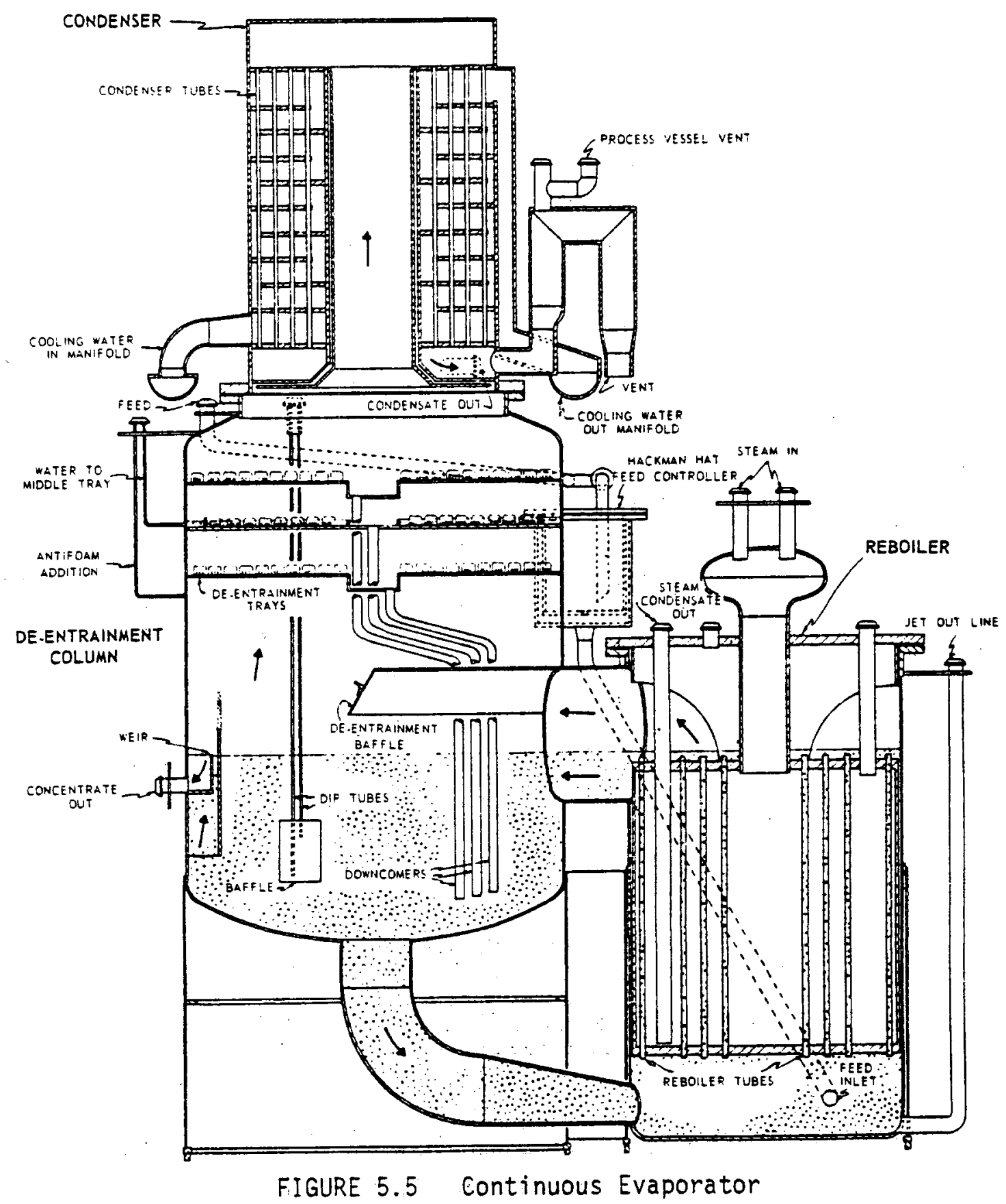

$-5.75-$ 


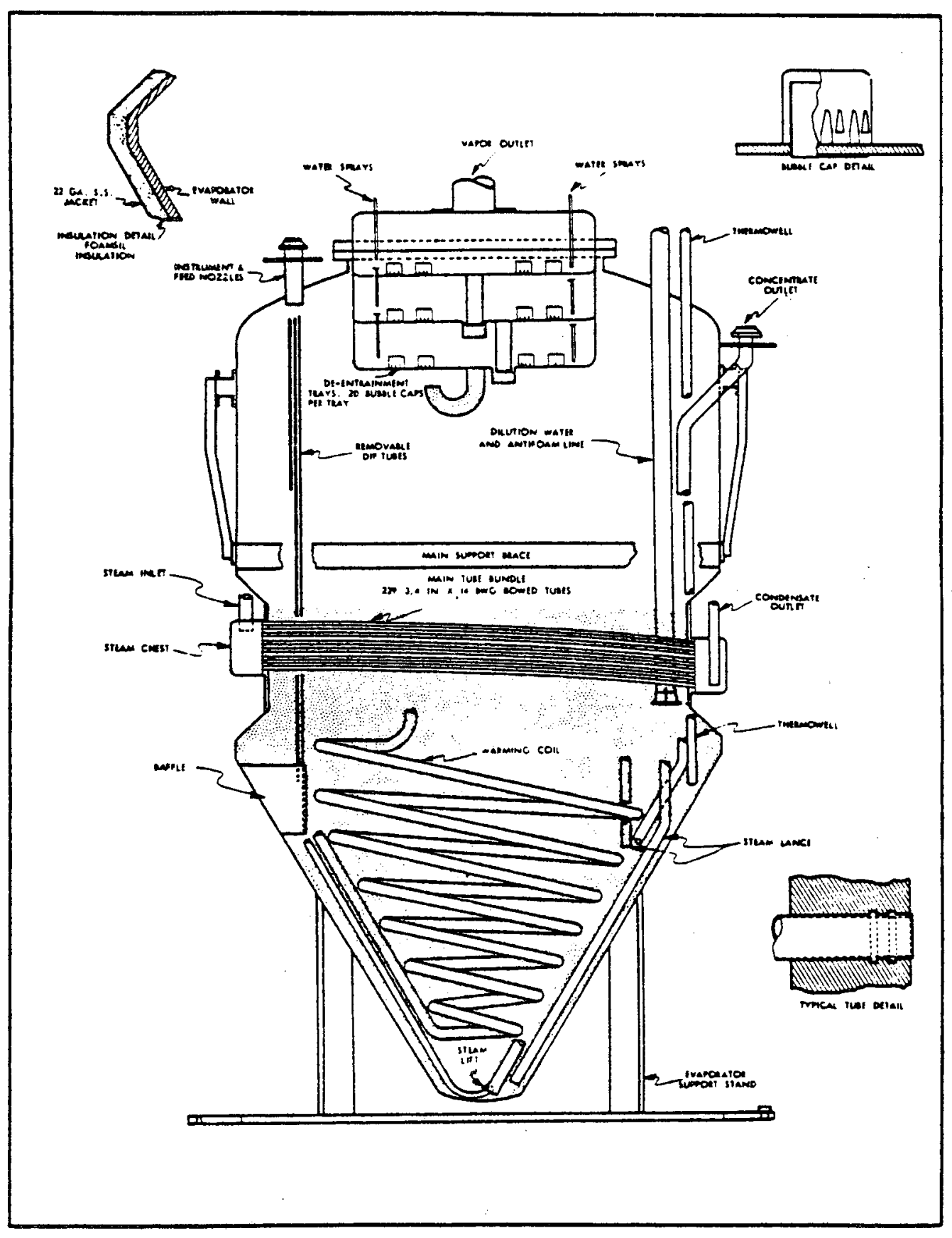

FIGURE 5.6 Bent-Tube Evaporator 


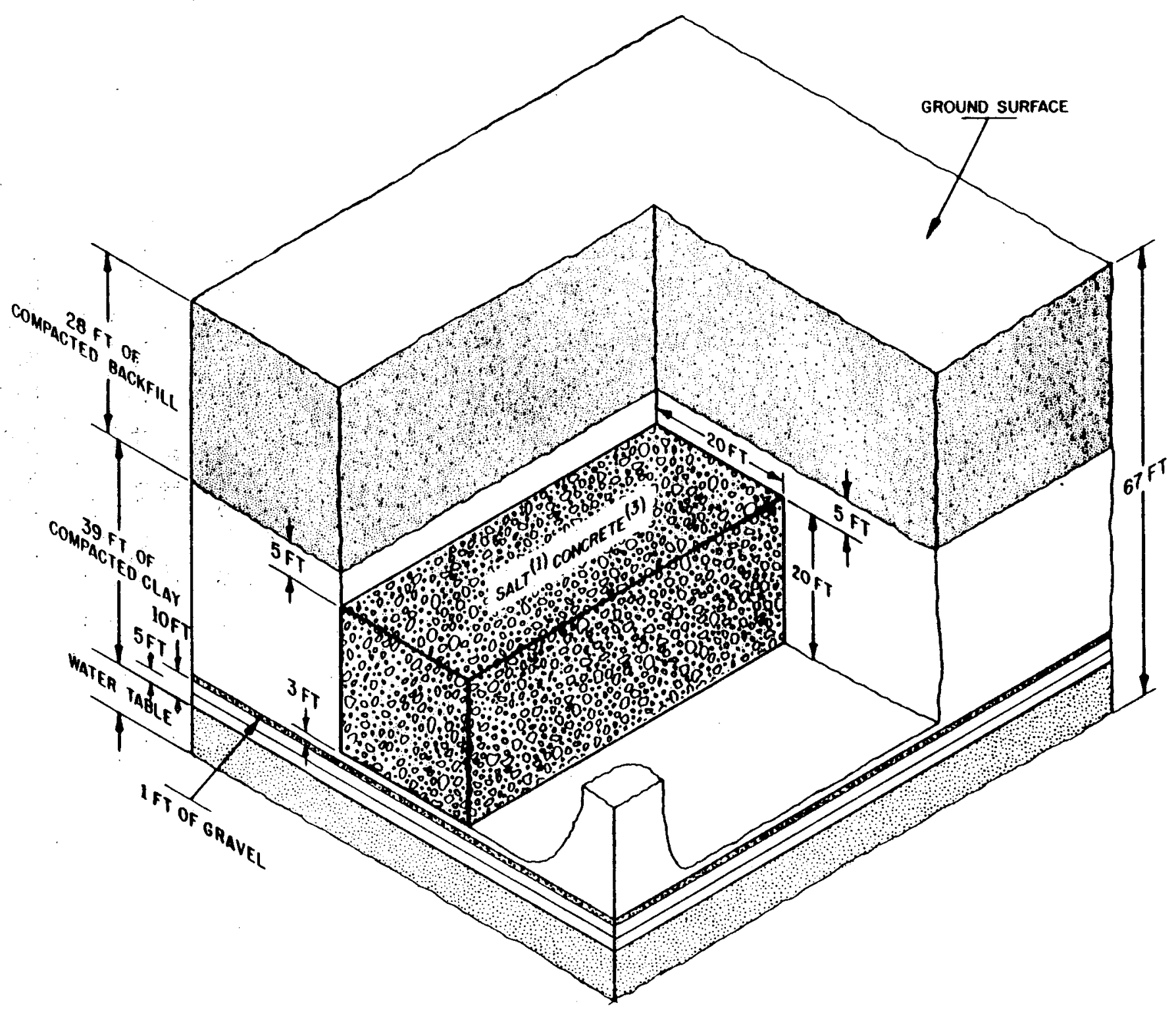

FIGURE 5.7 Disposal of Decontaminated Salt 


\subsection{REFERENCES}

1. W. F. Bonner, H. T. Blair, and L. S. Romero. Spray Solidification of Nuciear Waste. ERDA Report BNWL-2059, Battelle Northwest Laboratories, Richland, WA (1976).

2. H. L. Hull and T. A. Willis. Trip Report, Battelle, Pacific Northwest Laboratories. Continuous Electric Melting Tests, August 24-September 1, 2977. Internal Report DPST-77-450, Savannah River Laboratory, E. I. du Pont de Nemours \& Co., Aiken, SC (September 20, 1977).

3. C. B. Goodlett. Concentration of Radioactive Wastes. USAEC Report DP-1135, Savannah River Laboratory, E. I. du Pont de Nemours \& Co., Aiken, SC (1968).

4. C. B. Goodlett. Transfer of Radioactive Sturries. USAEC Report DP-1136, Savannah River Laboratory, E. I. du Pont de Nemours \& Co., Aiken, SC (1968).

5. Defense Waste Solidification Program. Minutes of Meeting of Memorandum from J. W. Joseph-L. E. WEisner to R. T. Huntoon, August 17-18, 1977 (September 8, 1977).

6. Defense Waste Solidification Progran, Conceptual Designs of Mechanical Cell Equipment. Memorandum from SRP-EED to R. T. Huntoon (October 24, 1977).

7. J. A. Ayers. Decontomination of Nuclear Reactors and Equipment. Ronald Press, 1970.

8. R. S. Ondrejcin to A. J. Hill. Carbon Steel and Stainless Steel Attack from Sludge Dissolution. Internal Report DPST-67-471, Savannah River Laboratory, E. I. du Pont de Nemours \& Co,, Aiken, SC (December 15, 1976).

S. R. S. Ondrejcin to J. D. Ellett. Removal of Phosphate from Heat Exchangers. Internal Report DPST-66-492, Savannah River Laboratory, E. I. du Pont de Nemours \& Co., Aiken, SC (August 19, 1966).

10. Defense Waste Solidification Progrom, Conceptual Designs of Mechanical Cel2 Equipment. Memorandum from SRP-EED to R. T. Huntoon (October 24, 1977). 
6. PROCESS CONTROL 6.1

6.1 General 6.1 


\section{PROCESS CONTROL}

\subsection{General}

The radioactive nature of defense waste requires that processing be achieved with minimum exposure of operating personnel to radiation and protection of the environment. Conducting this process in a remotely operated facility is an integral part of this philosophy, but makes instrumentation and control of the process difficult.

Analytical support to monitor and control the process will be provided by on-line instrumentation wherever practical. If the critical analyses can not be done on-line, sufficient hold-up capacity is required to facilitate off-line analysis to be performed.

In addition to providing support for on-line process control analyses and critical off-line analyses, analytical facilities will be required to provide a multitude of analyses required to characterize feed streams, to perform material balances, inventory discharges to the environment, etc.

Tables 6.1 and 6.2 summarize the type of on-line and off-line analyses currently considered required to control and audit the process. Estimates of the concentration of radioactivity in process streams are available in Appendix 13.7. Estimates of other measurements are available from the appropriate material balance flowsheet in Section 4. Solution temperatures will range from ambient to 100 unless specifically noted.

Where steam jets are used for solution transfer, steam flow and pressure should be monitored. Where transfer pumps are used, amperage, voltage and power should be monitored. The amperage, voltage, power and rpm should be monitored for all tank agitators. 
TABLE 6.1

DWPF On-Iine Process Control Measurements ${ }^{a}$

Process

Module

Aluminum
Dissolving

Sludge

Washing

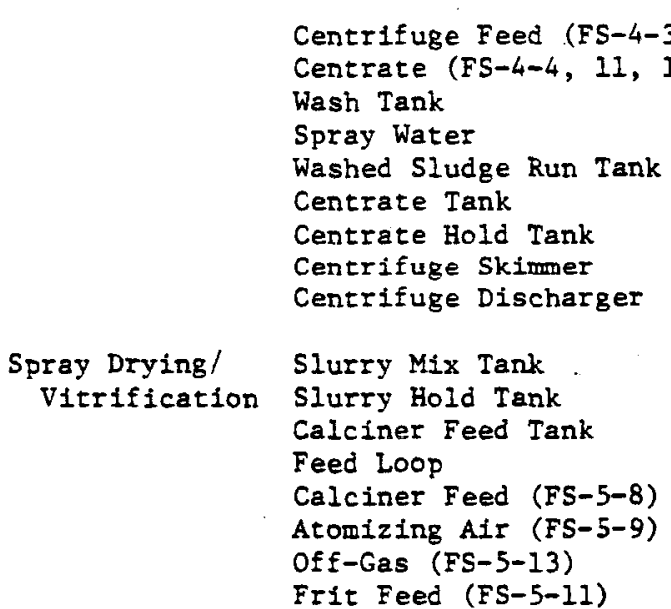

Process Stream or Vesse1

Sludge Receipt Tank

Aluminum Dissolver

Dissolver Condensate Tank

Condenser Cooling Water

Steam to Dissolver Coils

Sludge Feed Tank

Centrifuge

Centrifuge Feed (FS-4-3, 10, 17)

Centrate (FS-4-4, 11, 18)

Tank

Washed Sludge Run Tank

Frit Feed (FS-5-11)
On-IIne Measurement

LI, $S p$ G, T

LI, Sp g, T $\left(105-107^{\circ} \mathrm{C}\right), P$

LI, $S p$ G, I

$T_{\text {in, }}, T_{\text {out }}, F$

$L I, S_{P} G, I$

$T$ (Spindel Bearing). RPM (50-1400)

A, $E, W, \%$ Cake Loading, $V$

F $(1-60 \mathrm{gpm}, 7.4 \mathrm{gpm}$ nominal

$\mathrm{Cb}^{\mathrm{b}}(500-20,000$ umho/cm) Tu (5000 ppm)

SP G, LI, T

$F, P$

II, Sp G, I

II, SP G, I

IL, Sp G, T

Position

Position

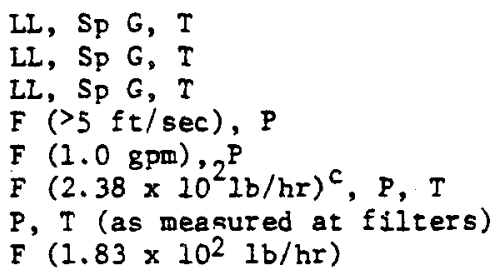
a. LL - Liquid Level Sp G - Specific Gravity
T - Temperature
$P$ - Pressure
F- Flow

b. Final Wash

c. 4 Ibs atomizing air/gal feed siurry

d. $65 \mathrm{lb}$ frit/35 lb of solids and salts in feed on a dry basis

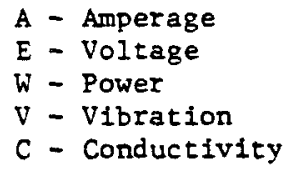

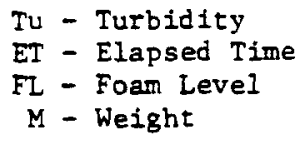


Process Stream or Vessel

Sintered Metal Filters

Spray Dryer Chamber

Filter Air: Blowback

Spray Dryer Cone

Spray Dryer Heaters

Melter

Melt

Melter Electrodes

Electrode Cooling Air

Melter Shell Cooling Water

Riser Heater

Riser Melt:

Iilt Pour

Canister

Canister Contents

\section{Off-Gas}

Treatment
Vapor Duct

Off-Gas Condensate Tank Mercury Sump

Quench Stream Pump

Quench Stream (FS-6-2)

Quench Stream (FS-6-3)

Cooling water to Cooler

Recycle Collection Tank

DBF "I Scrub Pump

Scrub to DBF \#1 Atomizing Nozzle

Atomizing Air to DBF

\#1 Atomizing Nozzle

Scrub to DBF $\# 1$

Spray Nozzle

$\mathrm{DBF} \# 1$

Filter Pumo Tank

DBF \#2 Scrub Pump

Scrub to DBF $\# 2$

Atomizing Nozzle

Atomizing Air to DBF

\#2 Atomizing Nozzle

Scrub to DBF \#2

Spray Nozzle

DBF $\# 2$

Brine to Filter

Pump Tank Coils
On-Iine Measurement

I, $\triangle P$ (about $15^{\prime \prime} \mathrm{H}_{2} \mathrm{O}$ )

I (profile, $\left.600-900^{\circ} \mathrm{C}\right), \mathrm{P}\left(-15^{\prime} \mathrm{H}_{2} \mathrm{O}\right)$

$T, P, E T$

I (profile, $300-400^{\circ} \mathrm{C}$ )

$A, E, W$

$P$ and $T$ (vapor space)

I $\left(1150^{\circ} \mathrm{C}\right), \mathrm{LL}, \mathrm{FL}$

$\mathrm{A}, \mathrm{E}, \mathrm{W}, \mathrm{T}\left(1050^{\circ} \mathrm{C}\right)$

$F, T, P$ (in), $T$ (out)

F, $T, P$ (in), $T$ (out)

E, W, T $\left(1050^{\circ} \mathrm{C}\right)$

$\mathrm{T}\left(1000^{\circ} \mathrm{C}\right)$

Position

I $\left(300-950^{\circ} \mathrm{C}\right), \mathrm{W}$

LI, W

T (about $350^{\circ} \mathrm{C}$ )

LI, Sp G, T (scrub), I (vapor), C

LI (high and low)

$A, E, W$

T, $P$

I, P, F (177 gpm)

$F, P, T(1 \pi), T$ (out)

LL, Sp G, T

$A, E, W$

F, P, I

$F, P$

F, P, T

$\Delta P\left(5-10^{\prime \prime} \mathrm{H}_{2} \mathrm{O}\right)$

LI, SP G, T, C

$A, E, W$

F, P, T

$F, P$

F, P

$\Delta P\left(5-10 " \mathrm{H}_{2} \mathrm{O}\right)$

F, I, P 
TABLE 6.2, (Contd)

Process

Module

Mercury

Recovery
Process Stream or Vesse1

Vepor from DBF \#2 (FS-6-15)

Ruthenium Adsorber Preheater

Steam to Ruthenium Adsorber

Preheater

Vapor from Heater (FS-6-16)

Primary Ru Adsorber

Vapor from Primary Ru

Adsorber (FS-6-17)

Secondary Ru Adsorber

Vapor from Secondary Ru Adsorber (FS-6-18)

Iodine Adsorber Preheater

Steam to Heater

Vapor from Heater (FS-6-19)

Iodine Adsorber

Vapor from $I_{2}$ Adsorber (FS-6-20)

Off-Gas Cooler

Exhausters

Exhauster Effluent (FS-6-22)

Canyon Air

Process Vessel Vent Filter.

Vessel Vent (FS-6-24)

Vessel Vent (FS-6-25)

Sand Filter

Stack Effluent (FS-6-26)

Mercury Receipt Tank

Ist Mercury Pump

Inlet Stream to $\mathrm{Hg}$ Filter No. 1

Mercury Filter No. 1

Acid Wash Feed Tank

Acid Wash Pump

Inlet Stream to Acid Wash Column Oxidation Tank

2nd Mercury Pump

Inlet Stream to $\mathrm{Hg}$ Filter No. 2

Mercury Filter No. 2

Mercury Still Feed Tank

Mercury Still

Still Heater

Cooling Water to Condenser

Backwash Hold Tank

Filter Backwash

Mercury Still Product Tank

Ait Flow to Oxidation Tank
On-Iine Measurement

$\mathrm{T}$

$\Delta \mathrm{P}\left(2^{\prime \prime} \mathrm{H}_{2} \mathrm{O}\right)$

$P, T, F^{2}$

T

$\Delta P\left(30^{\prime \prime} \mathrm{H}_{2} \mathrm{O}\right) \mathrm{T}$ (Ist 6" of adsorbent)

$\mathrm{T}, \mathrm{Ru}$

$\Delta P\left(30^{\prime \prime} \mathrm{H}_{2} \mathrm{O}\right)$

$\Delta P\left(2 " \mathrm{H}_{2} \mathrm{O}\right)$

$\mathrm{T}, \mathrm{F}, \mathrm{P}$

$\mathrm{T}\left(150^{\circ} \mathrm{C}\right)$

$\triangle \mathrm{P} \quad\left(48^{\prime \prime} \mathrm{H}_{2} \mathrm{O}\right)$

$\mathrm{T}\left(150^{\circ} \mathrm{C}\right), \mathrm{I}_{2}$

T

$A, E, W$

$F, P, H g, T$

$\mathrm{F}, \mathrm{T}$

$\Delta \mathrm{P}$

$\mathrm{T}$

$\Delta \mathrm{p}$

$F, I_{2}, R u, \alpha, \beta-\gamma$

II

A, E, P

$F, P$

$\Delta \mathrm{P}$

LI, $P$ (vapor)

$A, E, P$

$F$

LI, $P$ (vapor)

$A, E$, W

F, P

$\triangle \mathrm{P}$

II, P (vapor)

LI, $T, P$

A, $E, W$

F, $T, P$

LI, $T, S P G$

$F, P$

II, I

$\mathrm{F}$ 
TABLE 6.1 (Contd)

Process

Module

Recycle

Evaporation
Process Stream of Vessel

Recycle Evaporation Feed Tank

Evaporator Feed (FS-7-9)

Recycle Evaporator

De-entrainer

Cooling Water to Condenser

RE Condensate Tank

RE Bottoms Tank

Steam to Evaporator

Settling and Filtration.

Cesium Ion

Exchange
Salt Solution Receipt Tank

GS Feed Tank

GS Feed (FS-8-4)

Gravity Settler

Starch (FS-8-5)

GS Bottoms Tank

Steam to GS Feed HXX

Cooling Water to GS

GS Supernate Tank

Sand Filter Feed Tank

Sand Filter Feed (FS-8-10)

Polyelectrolyte (FS-8-11)

Sand Filter No. 1

First Filtrate Tank

Sand Filter Feed (FS-8-14)

Polyelectrolyte Feed (FS-8-15)

Sand Filter No. 2

Second Filtrate Tank

Filtrate Hold Tank

Filter Backwash Tank

Filter Air Blowback

Filter Filtrate Backwash

(FS-8-20, 21)

Waste Sand Tank

Ion Exchange Feed Tank

Feed to Cesium Feed Bounce Tank

Cs Feed Bounce Tank

Cesium Ion Exchange : Columns

Primary, and Secondary Column Effluents (during load cycle)

Water Rinse (FS-9-4)

Cs Elute Bounce Tank

Elutriant (FS-9-6)

Eluate (FS-9-9)

Water Rinse (FS-9-10)
On-Line Measurement

LI, Sp G, T

$\mathbf{F}$

LL, Sp G, T, P (vapor)

$\Delta \mathrm{P}$

$F, T, P$

LL, Sp G, T

$L L, S P G, T$

$F, T, P$

LL, Sp G, T

LL, SP G, T

$F, I$

LI, T, Sludge/Supernate Interface

F, I

LL, Sp G, I

$F, P, T$

$F, T$

LL, Sp G, T

II, $S_{P} G, I$

$F, P, T$

$F, P, T$

$\Delta P$, Gamna Level

IL, Sp G, T

F, P, T

$F, P, I$

$\Delta P$, Ganme Level

IL, Sp G, I

LL, SP G, T

LL, Sp G, I

$F, P$

F, P, T

IL, SP G, T

LL, Sp G, T

$F, P, I$

IL, Sp G

${ }_{13}{ }^{\prime} T$, Resin Level

F, I, P

II, SP G

$F, T, P$

$137 \mathrm{Cs}$

F, T, P 
TABLE 6.1 (Contd)

Process

Module

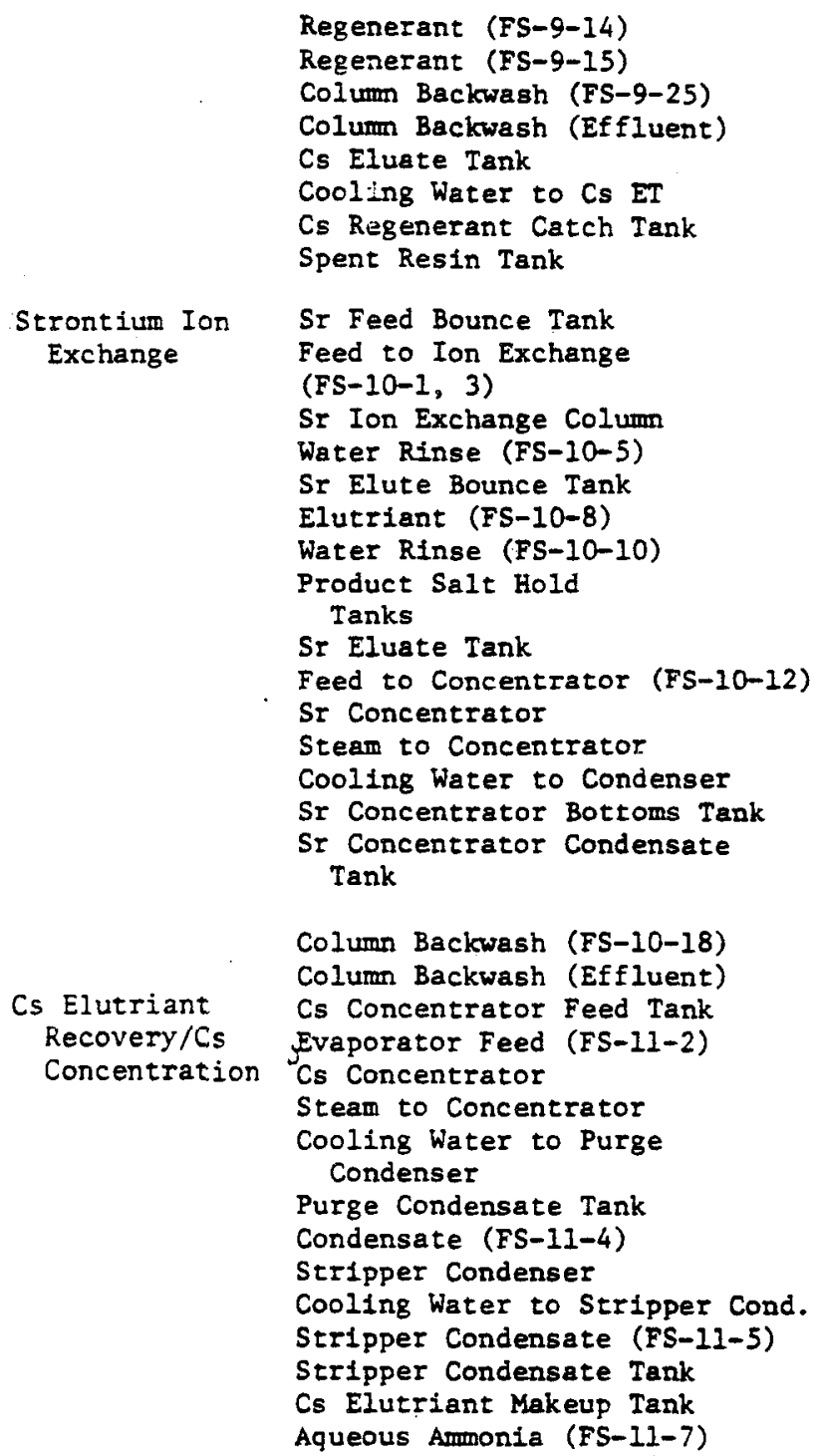

On-Iine Measurement

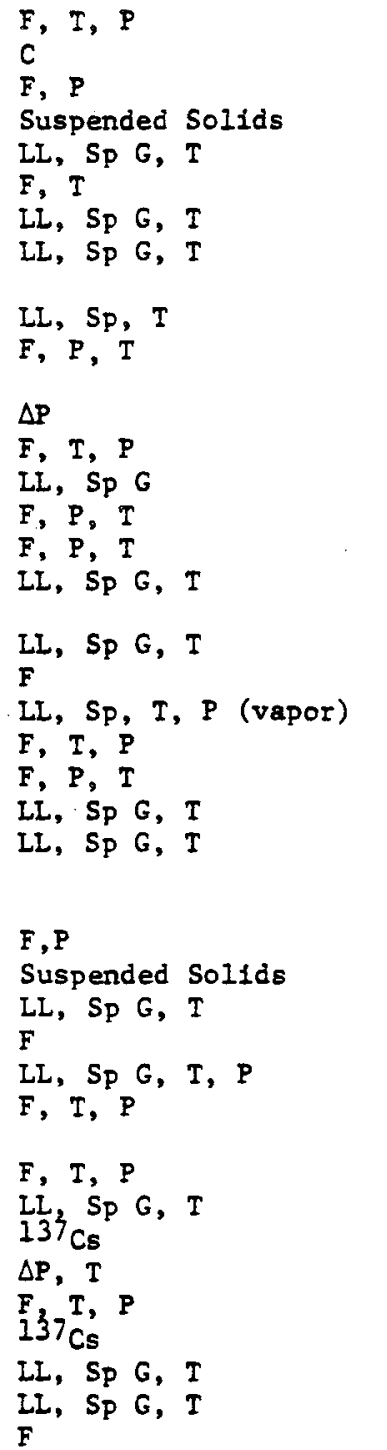


TABLE 6.1 (Contd)

\begin{tabular}{|c|c|c|}
\hline $\begin{array}{l}\text { Process } \\
\text { Module }\end{array}$ & Process Stream or Vessel & On-Iine Measurement \\
\hline $\begin{array}{l}\text { Cs Fixation } \\
\text { on Zeolite }\end{array}$ & $\begin{array}{l}\text { Cs Concentrator Bottoms Tank } \\
\text { Cooling Water to Cs CBT } \\
\text { Carbon Dioxide (FS-11-8) } \\
\text { Cs Elutriant Feed Tank } \\
\text { Cs Vent Scrubber Tank } \\
\text { Cesium Vent Scrubber } \\
\text { Chilled Water to Vent Scrubber } \\
\text { (FS-11-11) } \\
\text { Scrubber Vapor Effluent } \\
\text { (FS-11-V26) } \\
\text { Zeolite Feed Bounce Tank } \\
\text { Feed to Zeolite Column (FS-12-2) } \\
\text { Zeolite Colum } \\
\text { Cooling Water to Column } \\
\text { Zeolite Colum Effluent } \\
\text { (FS-12-3) } \\
\text { Colum Water Rinse (FS-12-5) } \\
\text { Zeolite Raffinate Bounce Tank } \\
\text { Column Backwash (FS-12-10) } \\
\text { Zeolite Slurry Tank } \\
\text { Cooling Water to ZST } \\
\text { Zeolite Raffinate Hold Tank }\end{array}$ & 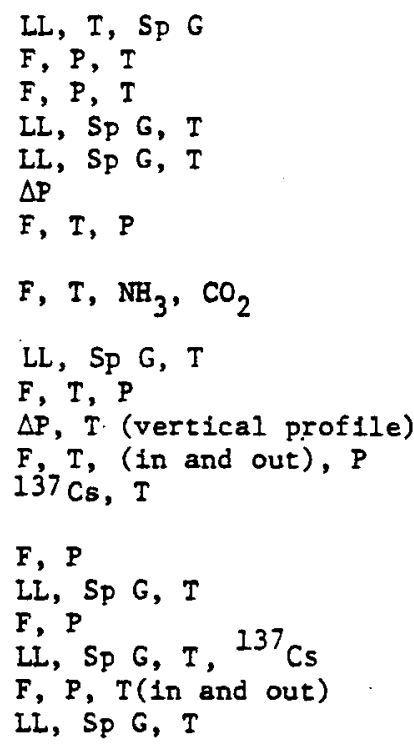 \\
\hline $\begin{array}{l}\text { General } \\
\text { Purpose } \\
\text { Evaporator }\end{array}$ & $\begin{array}{l}\text { Generall Purpose Evaporator } \\
\text { Feed Tank } \\
\text { Evaporator Feed (FS-13-5) } \\
\text { General Purpose Evaporator } \\
\text { De-entrainer } \\
\text { Steam to Eveporator } \\
\text { Cooling Water to Condenser } \\
\text { GPE Bottoms Tank } \\
\text { GPE Condensate Tanks } \\
\text { Heater } \\
\text { Steam to Heater } \\
\text { HEPA } \\
\text { Flow from HEPA (FS-13-V29) }\end{array}$ & $\begin{array}{l}\text { LL, Sp G, T } \\
F \\
\text { LI, SP G, T, P (vapor) } \\
\Delta P \\
F, T, P \\
F, T, \text { (In and out), P } \\
L I, S p G, T \\
L I, S P G, T \\
T \\
F, P \\
\Delta P, \text { gamma } \\
F\end{array}$ \\
\hline $\begin{array}{l}\text { Product Salt } \\
\text { Solution } \\
\text { Concentration } \\
\text { and Solidifi- } \\
\text { cation in } \\
\text { Concrete }\end{array}$ & $\begin{array}{l}\text { Product Salt Solution Storage } \\
\text { Tank } \\
\text { Product Salt Evaporator (PSE) } \\
\text { Feed to Product Salt Evapora- } \\
\text { tor (FS-14-2) } \\
\text { Steam to Evaporator } \\
\text { De-entrainer } \\
\text { Cooling Water to Condenser } \\
\text { PSE Condensate Tank } \\
\text { PSE Concentrate } \\
\text { Tank } \\
\text { Feed to SCP (FS-14-10) } \\
\text { Steam to Lift } \\
\text { Concrete Flush Hold Tank } \\
\text { Steam to Heater } \\
\text { HEPA } \\
\text { Flow from HEPA (FS-14-V22) }\end{array}$ & $\begin{array}{l}L I, S p G, T \\
L L, S p G, I, P \text { (vapor) } \\
F \\
F, P, T \\
\Delta P, P, T, \text { (In and out) } \\
F, P I, G, T \\
I L, S p \\
I L, S p G, I \\
F \\
F, P \\
L I, S p G, T \\
F, P \\
\Delta P, \text { garma } \\
F\end{array}$ \\
\hline
\end{tabular}


TABLE 6.1 (Conte)

\begin{tabular}{|c|c|c|}
\hline $\begin{array}{l}\text { Process } \\
\text { Module }\end{array}$ & Process Stream or Vessel & On-Line Measurement \\
\hline $\begin{array}{l}\text { Mechanical } \\
\text { Cel1 A }\end{array}$ & $\begin{array}{l}\text { Leak Test Station } \\
\text { Etch Tank } \\
\text { Cleaning Tank } \\
\text { Deionizer } \\
\text { Deionizer Prefilter } \\
\text { Deionizer Effuent (FS-15-28) } \\
\text { Delonizer Feed (FS-15-29) } \\
\text { Digester } \\
\text { Steam to Digester Coils } \\
\text { Cooling Water to } \\
\text { Digester and Condenser } \\
\text { Spray Water } \\
\text { Spray Hold Tank } \\
\text { Neutralizer } \\
\text { Spent Decon Solution } \\
\text { Pump Tank } \\
\text { Cooling Water to Neutralizer } \\
\text { Deionizer Purge }\end{array}$ & $\begin{array}{l}\text { Helium } \\
L I, S P G, T \\
L I, S P G, T \\
\Delta P \\
\Delta P \\
C, B-Y \\
F, P, T, B-Y \\
L I, S p G, T \\
F, P, T \\
F, T, P \\
\text { F, P } \\
\text { LI, SP G, T } \\
\text { LI, SP G, T } \\
\text { LI, SP G, T } \\
\text { F, P, T } \\
\text { F }\end{array}$ \\
\hline $\begin{array}{l}\text { Mechanical } \\
\text { Cell B }\end{array}$ & $\begin{array}{l}\text { Spray Water } \\
\text { Etch Tank } \\
\text { Cleaning Tank } \\
\text { Spray Hold Tank } \\
\text { HF Scrubber Scrub }\end{array}$ & $\begin{array}{l}F, P \\
L I, S p G, T \\
L I, S p G, I \\
L I, S p G, T \\
F\end{array}$ \\
\hline $\begin{array}{l}\text { Mechanical } \\
\text { Cell C }\end{array}$ & Canlster & $\begin{array}{l}\text { I (profile), Ganma } \\
\text { (profile }\end{array}$ \\
\hline $\begin{array}{l}\text { Interim } \\
\text { Storage } \\
\text { Facility }\end{array}$ & Ventilation & $F, B-\gamma^{a}$ \\
\hline
\end{tabular}

a. of the particulate air sampler filter paper. 
TABLE 6.2

DWPF Off-Line Analyses (Unless otherwise specified, the desired uncertaincy is $\pm 10 \%$

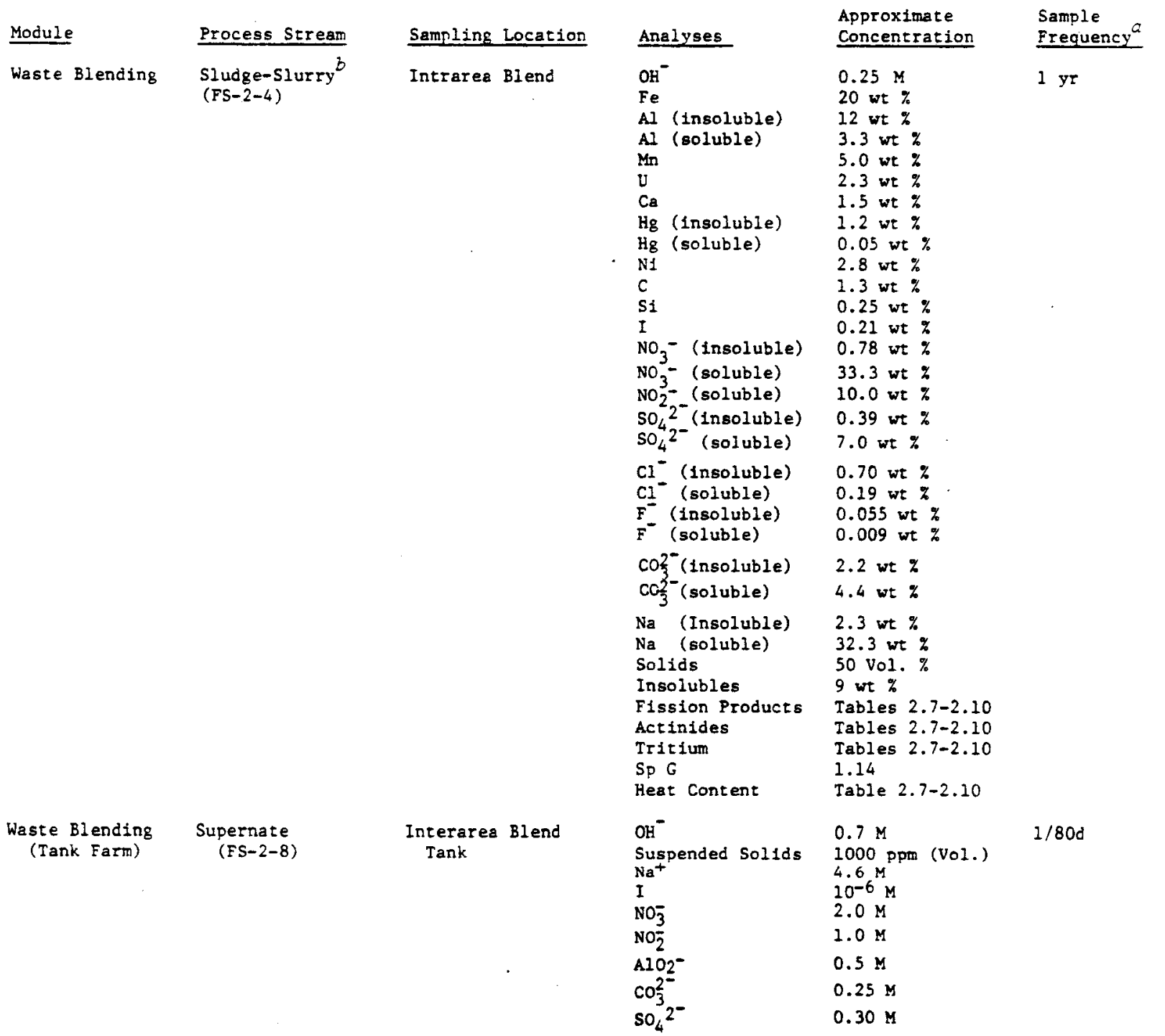


Table 0.2 (Contd)

Module

Dissolving

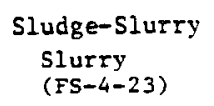

Dissolvent

Sludge Washing

Centrifuge Feed

(FS-4-3, 10, 17)

Washed Slúdge Slurry

(FS-4-23)

Spray Drying /

Vitrification

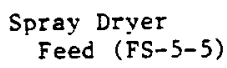

Sampling Location

Ana lyses

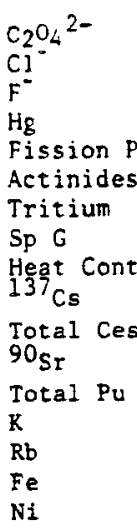

Sludge Receipt Tank

$\mathrm{OH}^{-}$

Al (insoluble)

Al Dissolver

Sludge Feed Tank

Washed Sludge Run Tank

Slurry Hold Tank

(Accountability

sample)

Sludge

$\mathrm{Na}_{4}^{+\infty} 2-a$

$\mathrm{NO}_{3}-\mathrm{a}$

Water Content

Dissolved Salt

Solids

Actinides
Approximate

Concentration

Sample

Frequency ${ }^{a}$

$0.003 \mathrm{M}$

$0.02 \mathrm{M}$

$0.002 \mathrm{M}$

Tables 2.3-2.6

Tables 2.3-2.6

Tables 2.3-2.6

1.22

Table 2.3-2.6

$2 \times 10^{9} \mathrm{~d} / \mathrm{m} / \mathrm{mL}$

$9 \times 10^{-2} \mathrm{~g} / \mathrm{gal}$

$3 \times 10^{7} \mathrm{~d} / \mathrm{m} / \mathrm{mL}$

$3 \times 10^{-9} \mathrm{~g} / \mathrm{gal}$

Trace

$2.5 \times 10^{-4} \mathrm{~g} / \mathrm{gal}$

Trace

Irace

0.3 g-moles/1 sludge

0.58 -mole/1

$1 / 3 d$

$0.07 \mathrm{~mol} / 1-*$ sludge $e^{a}$

60-80 wt \%

15-30 we \%

10-20 vol. \%

$0.1-10$ we $\%$

$0.1-5$ we $\%$

$0.1-10$ we \%

83 we \%

0.4 we \%

Fission Products

$\mathrm{Na}$

$\mathrm{Fe}$

Al

Ca

$\mathrm{Mn}$

Ni

$v$
217 wt $\%+1 \%$

1/batch

See Append̄ix 13.7

See Appendix 13.7

थ wt \%

20 .

3.5 wt \%

1.5 ey $\%$

5.5 wt $\%$

3.0 wt $\%$

2.5 wt $\%$

*Prior to addition of GS Bottoms and Waste Filter Media. 
Table 6.2 (Contd,

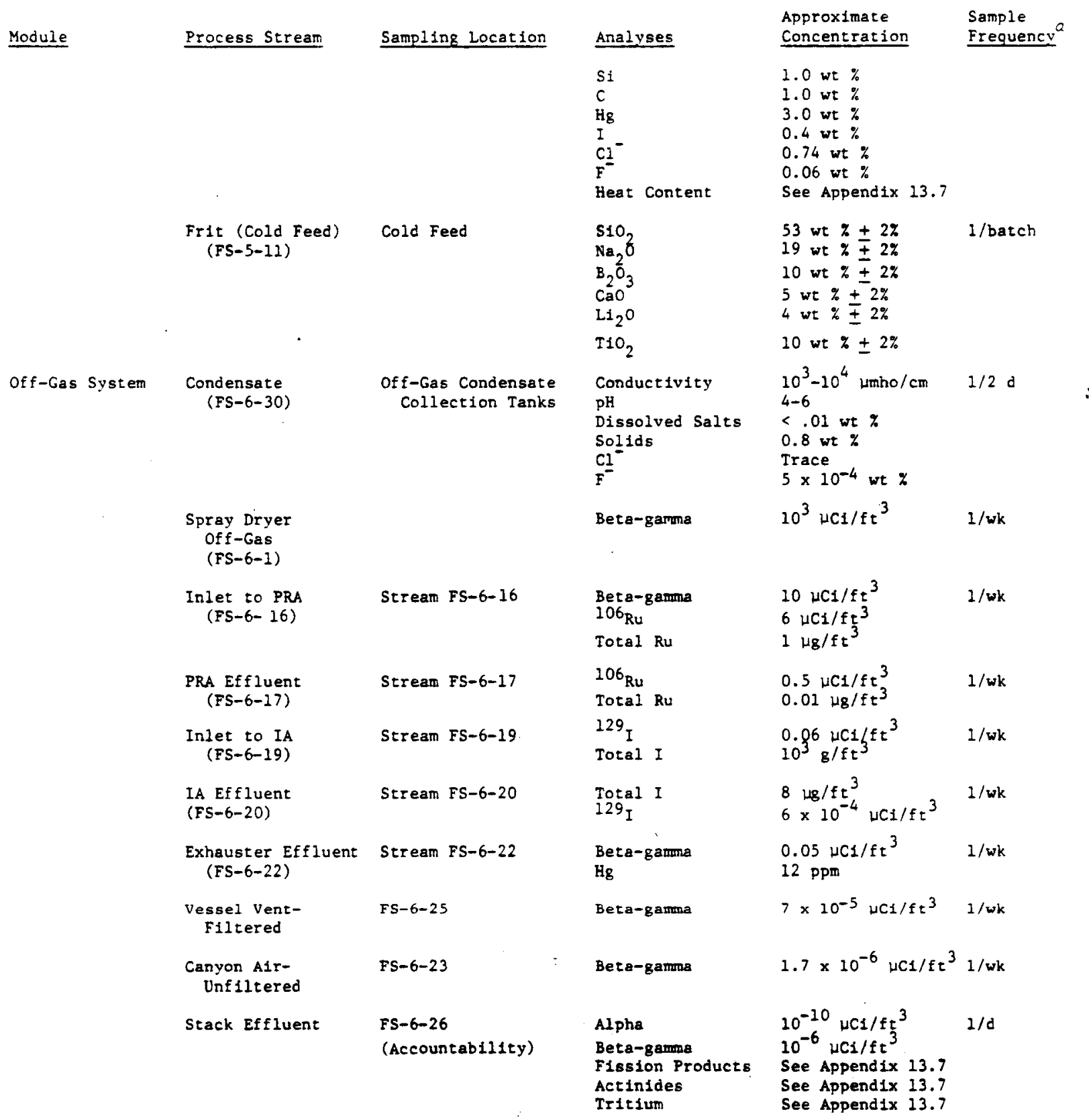


Table 6.2 (Contd)

\begin{tabular}{|c|c|c|c|c|c|}
\hline Module & Process Stream & Sampling Location & Analyses & $\begin{array}{l}\text { Approximate } \\
\text { Concentration }\end{array}$ & $\begin{array}{l}\text { Sample } \\
\text { Frequency }\end{array}$ \\
\hline \multirow[t]{3}{*}{$\begin{array}{l}\text { Recycle } \\
\text { Evaporation }\end{array}$} & Evaporator Feed & RE Feed Tank & $\begin{array}{l}\text { Total salts } \\
\text { OH } \\
\text { Beta-gamma } \\
\text { Sg G } \\
\text { Solids }\end{array}$ & $\begin{array}{l}7.0 \text { wt } \% \\
0.8 \mathrm{M} \\
6 \times 10^{8} \mathrm{~d} / \mathrm{m} / \mathrm{mL} \\
1.03 \\
0.08 \text { wt } \%\end{array}$ & $1 / d$ \\
\hline & $\begin{array}{c}\text { Evaporator } \\
\text { 3ottoms } \\
\text { (FS-7-1I) }\end{array}$ & RE Bortoms Tank & $\begin{array}{l}\text { Total Salts } \\
\text { Solids } \\
\text { OH } \\
\text { Beta-gatma } \\
\text { Sp G }\end{array}$ & $\begin{array}{l}35 \mathrm{wt} \% \\
0.5 \mathrm{wt} \% \\
5.0 \mathrm{M} \\
4 \times 10^{9} \mathrm{~d} / \mathrm{m} / \mathrm{mL} \\
1.17\end{array}$ & $1 / d$ \\
\hline & $\begin{array}{l}\text { Evaporator } \\
\text { Condensate } \\
\text { (FS-7-13) }\end{array}$ & $\begin{array}{l}\text { RE Condensate } \\
\text { Tank }\end{array}$ & $\begin{array}{l}\text { pH } \\
\text { Beta-gamma }\end{array}$ & $10^{3-9} \mathrm{~d} / \mathrm{m} / \mathrm{mL}$ & $1 / d$ \\
\hline \multirow[t]{8}{*}{$\begin{array}{l}\text { Gravity Settling/ } \\
\text { Filtration }\end{array}$} & $\begin{array}{l}\text { GS Feed } \\
(\text { FS-8-4) }\end{array}$ & GS Feed Tank & $\begin{array}{l}\text { Centrifuged Solids } \\
\mathrm{OH}^{-} \\
{ }^{\mathrm{Sr}} \\
\text { Total Pu }\end{array}$ & $\begin{array}{l}5000 \mathrm{ppm} \\
1.7 \mathrm{M} \\
10^{8} \mathrm{~d} / \mathrm{m} / \mathrm{mL} \\
10^{-2} \mathrm{~g} / \mathrm{gal}\end{array}$ & $3 / d$ \\
\hline & $\begin{array}{l}\text { Starch } \\
\quad(F S-8-5)\end{array}$ & Cold Feed & $\begin{array}{l}\mathrm{OH}^{-} \\
\mathrm{V} \text { iscosity }\end{array}$ & $\begin{array}{l}1 \mathrm{M} \\
70 \mathrm{cP}\end{array}$ & $1 / d$ \\
\hline & $\begin{array}{c}\text { GS Supernate } \\
\text { (FS-8-8) }\end{array}$ & GS Supernate Tank & $\begin{array}{l}\text { Centrifuged Solids } \\
\mathrm{OH}^{-} \\
90 \mathrm{Sr} \\
\text { Total } \mathrm{Pu}\end{array}$ & $\begin{array}{l}50 \mathrm{ppm} \\
1.8 \mathrm{M} \pm 5 \% \\
10^{7} \mathrm{~d} / \mathrm{m} / \mathrm{mL} \\
8.4 \times 10^{-4} \mathrm{~g} / \mathrm{gal}\end{array}$ & $3 / d$ \\
\hline & $\begin{array}{l}\text { Polyelectrolyte } \\
\text { (FS-8-11) }\end{array}$ & Cold Feed & $\begin{array}{l}\mathrm{OH}^{-} \\
\mathrm{Viscosity}\end{array}$ & $\begin{array}{l}1.0 \mathrm{M} \\
35 \mathrm{cp}\end{array}$ & I/d \\
\hline & $\begin{array}{l}\text { Sand Filter } \\
\text { Filtrate } \\
\quad(\text { FS-8-13, 17) }\end{array}$ & $\begin{array}{l}\text { Ist and 2nd Filtrate } \\
\text { Tanks }\end{array}$ & $\begin{array}{l}\text { Solids } \\
\text { oH } \\
90 \mathrm{St} \\
\text { Total Pu } \\
\text { Si }\end{array}$ & $\begin{array}{l}1-5 \mathrm{ppm} \\
1.6 \mathrm{M}+5 \% \\
10^{6} \mathrm{~d} / \mathrm{m} / \mathrm{mL} \\
10^{-4} \mathrm{~g} / \mathrm{ga} 1 \\
<5 \mathrm{ppm}\end{array}$ & $3 / d$ \\
\hline & $\mathrm{NaOH}$ & Cold Feed & $\mathrm{OH}^{-}$ & $1.0 \mathrm{M} \pm 5 \%$ & $3 / d$ \\
\hline & $\begin{array}{r}\text { Backwash } \\
\text { Slurry }\end{array}$ & $\begin{array}{l}\text { Filter Backwash } \\
\text { Tank }\end{array}$ & Solids & $1200 \mathrm{ppm}$ & $1 / d$ \\
\hline & Filter Media & Cold Feed & Particle Size & $\begin{array}{l}\text { Anchracite, } \\
20-50 \text { mesh } \\
\text { Sand, } 25-60 \text { mesh }\end{array}$ & $1 / 3$ mo \\
\hline
\end{tabular}

*Stock solution before dilution in $1.0 \mathrm{M} \mathrm{OH}^{-}$ 
Table 6.2 (Contd)

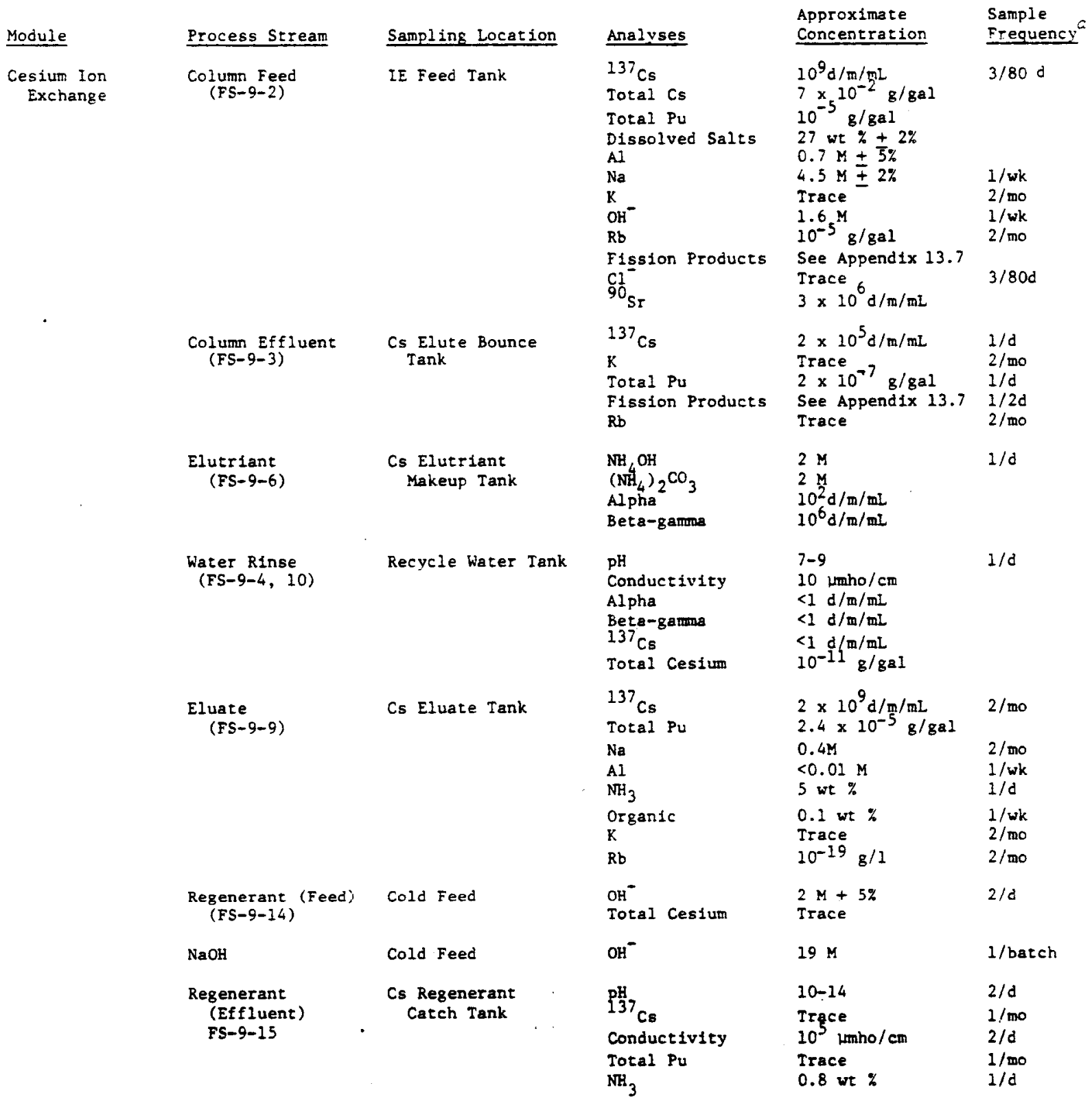


Table 6.2 (Contd)

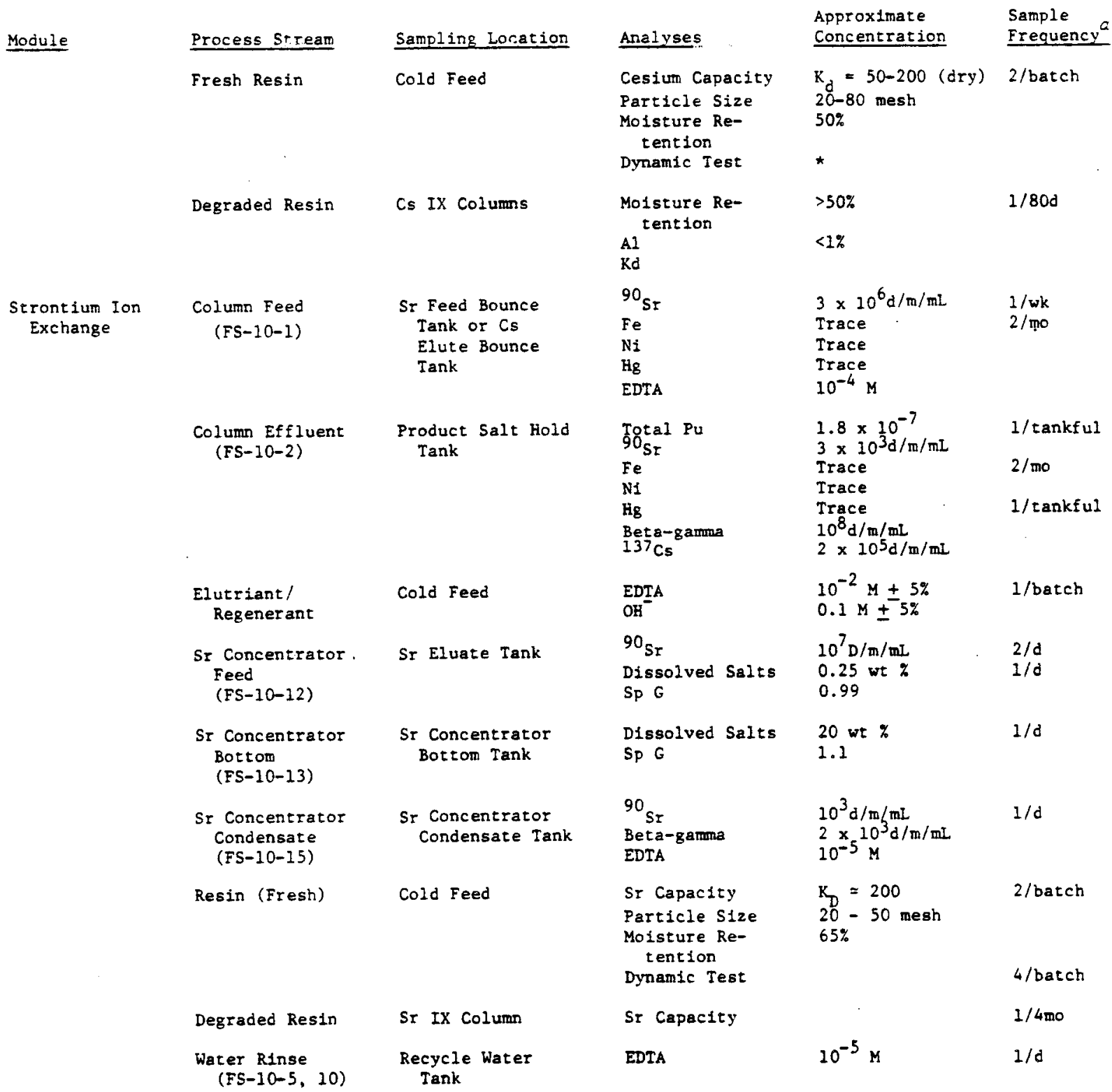

*Lab test of resin performance with tracers. Cs $D F \geq 10^{4}$ 
Table 6.2 (Contd)

\begin{tabular}{|c|c|c|c|c|c|}
\hline Module & Process Stream & Sampling Location & Analyses & $\begin{array}{l}\text { Approximate } \\
\text { Concentration }\end{array}$ & $\begin{array}{l}\text { Sample } \\
\text { Frequency }\end{array}$ \\
\hline \multirow[t]{3}{*}{$\begin{array}{l}\text { Cesium Elutriant } \\
\text { Recovery/ } \\
\text { Cesium } \\
\text { Concentration }\end{array}$} & $\begin{array}{l}\text { Purge Condensate } \\
\text { (FS-11-4) }\end{array}$ & PC Tank & $\begin{array}{l}137 \mathrm{Cs} \\
\mathrm{pH} \\
\text { Beta-gamma } \\
\mathrm{NH}_{3}\end{array}$ & $\begin{array}{l}3 \times 10^{7} \mathrm{~d} / \mathrm{m} / \mathrm{mL} \\
10^{7} \mathrm{~d} / \mathrm{m} / \mathrm{ml} \\
\text { Trace }\end{array}$ & $1 / d$ \\
\hline & $\begin{array}{l}\text { Downdraft } \\
\text { Condenser } \\
\text { Condensate } \\
\text { (FS-11-5) }\end{array}$ & $\begin{array}{c}\text { Cs Condensate } \\
\text { Run Tank }\end{array}$ & $\begin{array}{l}137 \mathrm{Cs} \\
\mathrm{NH}_{4}^{+} \\
\mathrm{Co}_{3}^{2-} \\
\mathrm{Beta-gamma}^{-}\end{array}$ & $\begin{array}{l}2 \times 10^{3} \mathrm{~d} / \mathrm{m} / \mathrm{mL} \\
6 \mathrm{M} \\
2 \mathrm{M} \\
4 \times 10^{3} \mathrm{~d} / \mathrm{m} / \mathrm{mL}\end{array}$ & $3 / d$ \\
\hline & Scrubber Vent & FS-11-22 & $\mathrm{NH}_{3}$ & $2 \mathrm{ppm}$ & $3 / d$ \\
\hline \multirow[t]{4}{*}{ Cesium Fixation } & $\begin{array}{l}\text { Colum Feed } \\
(\text { FS-12-2) }\end{array}$ & $\begin{array}{c}\text { Cs Concentrator } \\
\text { Bottoms Tank }\end{array}$ & $\begin{array}{l}\text { Dissoived Salts } \\
\mathrm{NH}_{4}^{+} \\
\mathrm{CO}_{3}^{2-} \\
137 \\
{ }^{13} \mathrm{Cs} \\
\mathrm{Na}^{+}\end{array}$ & $\begin{array}{l}18 \text { wt } \% \\
10^{-4} M \\
2 M \\
3 \times 10^{10} \mathrm{~d} / \mathrm{m} / \mathrm{ml} \\
3 \times 10^{-4} \mathrm{~g} / \mathrm{gel} \\
4 \mathrm{M}\end{array}$ & $1 / d$ \\
\hline & $\begin{array}{l}\text { Colum Effluent } \\
\text { (FS-12-3) }\end{array}$ & $\begin{array}{c}\text { Zeolite Raffinate } \\
\text { Bounce Tank }\end{array}$ & $\begin{array}{l}{ }^{137} \mathrm{Cs} \\
\text { Total } \mathrm{Pu}\end{array}$ & $\begin{array}{l}10^{8} \mathrm{~d} / \mathrm{m} / \mathrm{mL} \\
10^{-6} \mathrm{~g} / \mathrm{gal}\end{array}$ & $1 / d$ \\
\hline & Fresh Zeolite & Cold Feed & $\begin{array}{l}\text { Pafticle Size } \\
137 \text { Cs Capacity }\end{array}$ & 20-50 mesh & $1 / 2$ mo \\
\hline & $\begin{array}{l}\text { Zeolite Raffinate } \\
\text { (FS-12-9) }\end{array}$ & $\begin{array}{l}\text { Zeolite Raffinate } \\
\text { Hold Tank }\end{array}$ & ${ }^{137} \mathrm{Cs}$ & $10^{8} \mathrm{~d} / \mathrm{m} / \mathrm{mL}$ & $1 / d$ \\
\hline \multirow[t]{3}{*}{$\begin{array}{c}\text { General Purpose } \\
\text { Evaporation }\end{array}$} & $\begin{array}{l}\text { Evaporator Feed } \\
\text { (FS-13-5) }\end{array}$ & GPE Feed Tank. & $\begin{array}{l}\text { Total Salts } \\
\text { pH } \\
\text { Beta-gamma } \\
\text { Conductivity } \\
\text { Sp G }\end{array}$ & $\begin{array}{l}<0.1 \text { wt } \% \\
9-10 \\
10^{3} \mathrm{~d} / \mathrm{m} / \mathrm{mL} \\
100-200 \text { Umho } / \mathrm{cm} \\
1.0\end{array}$ & $1 / d$ \\
\hline & $\begin{array}{l}\text { Evaporator Bottoms } \\
\quad(F S-13-6)\end{array}$ & $\begin{array}{l}\text { GPE Bottoms } \\
\text { Tank }\end{array}$ & $\begin{array}{l}\text { Total Salts } \\
\text { Sp G } \\
\text { Beta-gamma }\end{array}$ & $\begin{array}{l}<0.1 \text { wt } \% \\
1.03 \\
104 \mathrm{~d} / \mathrm{m} / \mathrm{mL}\end{array}$ & $1 / \mathrm{d}$ \\
\hline & $\begin{array}{c}\text { Evaporator } \\
\text { Condensate } \\
\text { (FS-13-8) }\end{array}$ & $\begin{array}{l}\text { GPE Condensate } \\
\text { Tanks (Account- } \\
\text { ability Sample) }\end{array}$ & $\begin{array}{l}\text { pH } \\
\text { Alpha } \\
\text { Beta-gamma } \\
\text { Solids } \\
\text { Dissolved Salts } \\
\text { Fission Products } \\
\text { Actinides } \\
\text { Tritium } \\
\text { Hg }\end{array}$ & $\begin{array}{l}7-8 \\
<1 \mathrm{~d} / \mathrm{m} / \mathrm{mL} \\
<10 \mathrm{~d} / \mathrm{m} / \mathrm{mL} \\
<0.01 \text { wt } \% \\
\text { Trace } \\
\text { See Appendix } 13.7 \\
\text { See Appendix } 13.7 \\
\text { See Appendix } 13.7 \\
<1 \text { ppm }\end{array}$ & 1/batch \\
\hline
\end{tabular}


Table 6.2 (Contd)

\begin{tabular}{|c|c|c|c|c|c|}
\hline Module & Process Stream & Sampling Location & Analyses & $\begin{array}{l}\text { Approximate } \\
\text { Concentration }\end{array}$ & $\begin{array}{l}\text { Sample } \\
\text { Frequency }\end{array}$ \\
\hline \multirow{8}{*}{$\begin{array}{l}\text { Product Salt } \\
\text { Solution Con- } \\
\text { centration/ } \\
\text { Solidification } \\
\text { in Concrete }\end{array}$} & Evaporator Feed & $\begin{array}{l}\text { Product Salt Solu- } \\
\text { tion Storage Tank }\end{array}$ & $\begin{array}{l}\text { Dissolved Salts } \\
\text { OH } \\
\text { SP G }\end{array}$ & $\begin{array}{l}23 \text { wt \% } \\
1.4 \mathrm{M} \\
1.2\end{array}$ & $1 / w k$ \\
\hline & . & & $\begin{array}{l}\text { Fission Products } \\
\text { Actinides } \\
\text { Heat Content } \\
\mathrm{Hg} \\
\mathrm{Na} \\
\mathrm{AlO}_{2}{ }^{-}\end{array}$ & $\begin{array}{l}\text { See Appendix } 13.7 \\
\text { See Appendix } 13.7 \\
\text { See Appendix } 13.7 \\
10^{-4} \mathrm{M} \\
2.5 \mathrm{M} \\
0.3 \mathrm{M}\end{array}$ & \\
\hline & & & $\mathrm{NO}_{3}=$ & $1.3 \mathrm{M}$ & \\
\hline & & & $\mathrm{NO}_{2}^{-}$ & $0.6 \mathrm{M}$ & \\
\hline & & & $\mathrm{SO}_{4} 2^{-}$ & $0.15 \mathrm{M}$ & \\
\hline & & & $\mathrm{C}_{2} \mathrm{O}_{4}^{-}$ & $0.002 \mathrm{M}$ & \\
\hline & & & $\begin{array}{l}\mathrm{F}^{-} \\
\mathrm{Cl} \\
\mathrm{Trltium}\end{array}$ & $\begin{array}{l}0.001 \mathrm{M} \\
0.01 \mathrm{M} \\
\text { See Appendix } 13.7\end{array}$ & \\
\hline & $\begin{array}{l}\text { Evaporator Con- } \\
\text { densate (FS-14-3) }\end{array}$ & $\begin{array}{l}\text { PSE Conderisate } \\
\text { Tank }\end{array}$ & $\begin{array}{l}\text { Beta-Gamma } \\
\mathrm{pH}\end{array}$ & $\begin{array}{l}20^{2} \mathrm{~d} / \mathrm{m} / \mathrm{mL} \\
7-9\end{array}$ & $2 / w k$ \\
\hline \multirow[t]{7}{*}{$\begin{array}{c}\text { Mechanical } \\
\text { Cell A }\end{array}$} & $\begin{array}{l}\text { Spent Cleaning } \\
\text { Sol'n after HNO } \\
\text { and } \mathrm{Mn} \text { adjustment }\end{array}$ & Digester Tank & $\mathrm{H}^{+} 2+$ & $\begin{array}{l}1.0 \\
0.01 \mathrm{M}\end{array}$ & 1/run \\
\hline & $\begin{array}{l}\text { Digested Oxalic } \\
\text { acid (Fs }-15-17 \text { ) }\end{array}$ & Digester Tank & $\mathrm{H}^{+}$ & $0.4 \mathrm{M}$ & $1 /$ Iun \\
\hline & $\begin{array}{l}\text { Blend of Spent } \\
\text { Decon Solutions } \\
\text { (FS-15-13, 17) }\end{array}$ & Neutralizer Tank & $\mathrm{H}^{+}$ & $2.0 \mathrm{M}$ & 1/batch \\
\hline & $\begin{array}{l}\text { Neutralized Spent } \\
\text { Decon Sol'n } \\
\text { (FS-15-22) }\end{array}$ & Neutralizer Iank & $\mathrm{OH}^{-}$ & $0.17 \mathrm{M}$ & 1/batch \\
\hline & $\begin{array}{l}\text { Deionizer Feed } \\
\text { and Effluent } \\
\text { (FS-15-28, 29) }\end{array}$ & FS-15-28, 29 & $\begin{array}{l}\text { Beta-gamma } \\
\text { Conductivity } \\
\text { Turbidity }\end{array}$ & & $2 / w k$ \\
\hline & $\begin{array}{l}\text { Mechanical Cell A } \\
\text { Spent Decon Wash } \\
\text { (FS-15-32) }\end{array}$ & $\begin{array}{l}\text { Spent Decon Sol'n } \\
\text { Pump Tank }\end{array}$ & $\begin{array}{l}\mathrm{OH}^{-} \\
\text {Dissolved Salts } \\
\text { Solids }\end{array}$ & $\begin{array}{l}0.10 \mathrm{M} \\
10 \text { wt } \% \\
0.9 \text { wt \% }\end{array}$ & 1/batch \\
\hline & Canister Smears & Canister Surface & $\begin{array}{l}\text { Alpha } \\
\text { Beta-gamma }\end{array}$ & $\begin{array}{l}10^{2} \mathrm{~d} / \mathrm{m} / \mathrm{dm}^{2} \\
10^{3} \mathrm{~d} / \mathrm{m} / \mathrm{dm}^{2}\end{array}$ & $1 /$ canister \\
\hline
\end{tabular}


Table 6.2 (Contd)

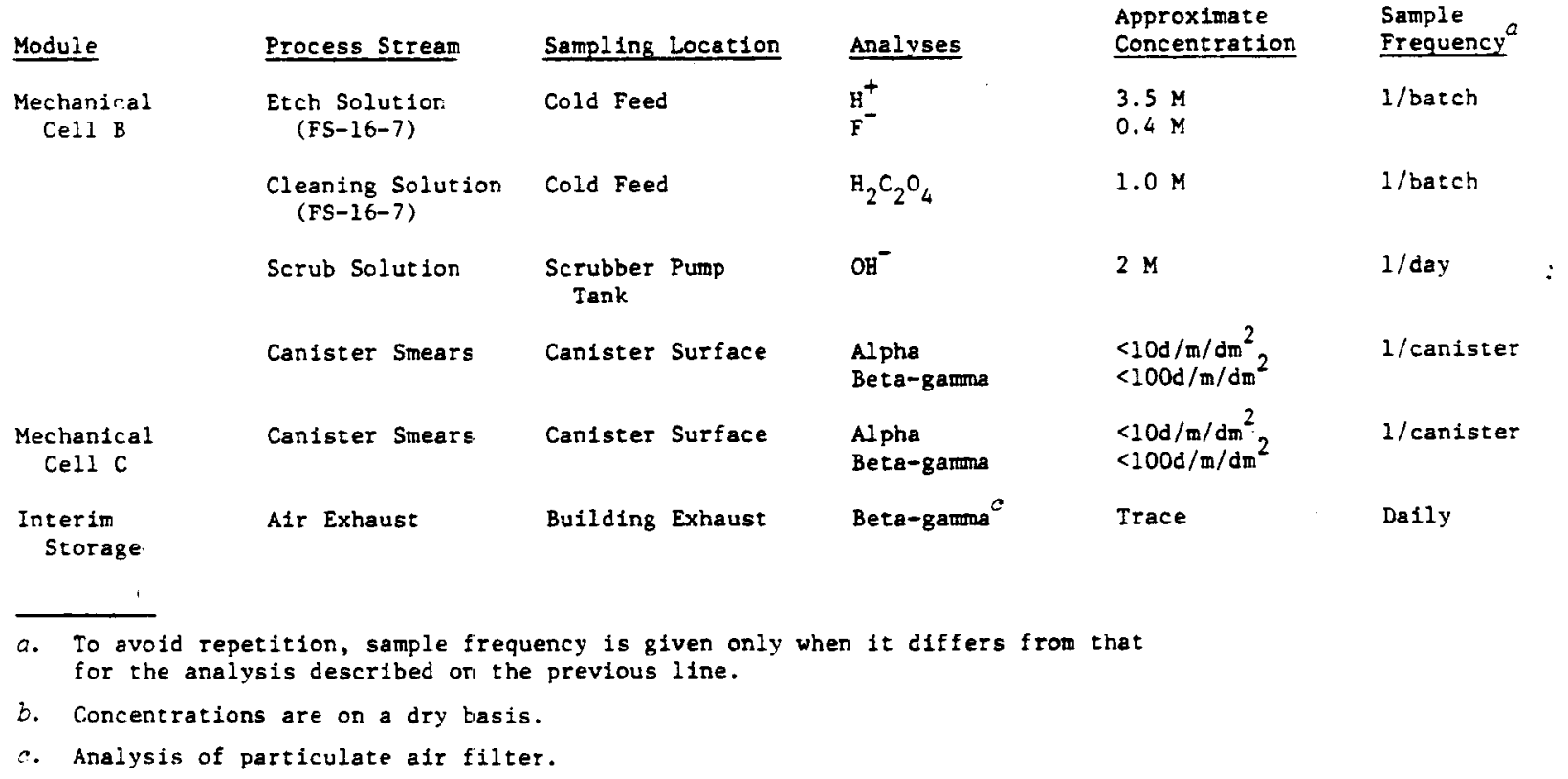


7. RADIONUCLIDE CONTENT, ACTIVITIES, AND HEAT GENERATION 7.1

\subsection{General 7.1}

7.2 Calculational Basis 7.1

7.3 Reference Waste Composition 7.2

7.4 Curie Balance 17.2

7.5 References 7.3 
7. RADIONUCLIDE CONTENT, ACTIVITIES, AND HEAT GENERATION

(J.R. Chandler)

\subsection{Geniral}

The radionuclide concentrations of each process stream must be known in order to specify biological shielding requirements, process cooling requirements, and environmental releases. The concentrations have been computed for each process stream of the reference flowsheet by using a computer model of the flowsheet.

\subsection{Calculational Basis}

The radionuclide calculations assume the following:

- Both SRP and non-SRP reactor fuels will be processed.

- Five SRP assemblies will be processed: Mark 16B, Mark 22, Mark 31A, Mark 31B, Mark 53A.

- Non-SRP reactor fuels (RBOF fuels) are two years old when processed. They have a plutonium content equal to $0.32 \%$ of their U-235 content. Non-SRP fuels have the same relative radionuclida composition as a Mark 16B assembly that has been irradiated $330 \mathrm{MWD}$, and the fission product activity at processing is $60 \mathrm{Ci} / g a l l o n$. Liquid waste is generated at 808 gallons $/ \mathrm{kg}$ of U-235 processed, and the fractions of isotopes lost to waste are the same as for the Mark 16B fuel.

- Pu-238 scrap will be processed. The plutonium distribution of the Pu-238 scrap is the same as the plutonium distribution in a Mark 53A. The Pu-238 waste generation factors are $0.17 \%$ plutonium lost to waste and 1500 gallons/kg of scrap processed.

- Pu-239 scrap will be processed. The plutonium distribution in Pu-239 scrap is the same as for ark 31A. The Pu-239 waste generation factors are $0.02 \%$ plutonium lost to waste and 475 gallons/kg of scrap processed.

- The waste generation rates are based on the average of production schedules for FY-1988, 1989, and 1990. 


\subsection{Reference Waste Composition}

Radionuclide concentrations in spent SRP assemblies were determined. with reactor production-depletion calculations [1]. Typical irradiation conditions (Table 7.1) were assumed. Radionuclide concentrations were calculated for SRP assemblies that have cooled 180 days following irradiation. Separation factors (Table 7.2 ) were applied to the radionuclide concentrations in cooled assemblies to determine the radionuclide concentrations in liquid waste. The radionuclide content of plutonium scrap and non-SRP fuels was based on the assumptions in Section 7.2.

The design basis waste blend is a blend of liquid wastes generated during reprocessing of the various spent fuels. The relative amount of each type of waste in a unit volume of waste blend is proportional to the volume of waste generated from each fuel assembly (Table 7.3). Waste blend factors in Table 7.3 are based on the estimated waste volumes for FY-1988, 1989, and 1990.

Tables 7.4 through 7.39 list the radionuclide concentrations in the reference waste blend and individual assembly wastes for five and fifteen-year ages. Results for activity, decay heat, and radiation source spectra are provided in Appendix 13.7.

\subsection{Curie Balance}

A computer model of the reference flowsheet was developed by using the SHIELD [1] system. The computer model simulates the flow of radionuclides through the DWPF. The activity, decay heat, and radiation source spectra of each process stream were calculated from the radionuclide concentrations (see Appendix 13.7). 


\subsection{References}

1. D. R. Finch, J. R. Chandler and J. P. Church, "The SHIELD System, Transactions of The American Nuclear Society, Volume 32, American Nuclear Society, Lagrange Park, IL (November 1979). 
TABLE 7.1

Calculational Bases (Beyond FY-1988)

Mark 16B Mark 22 Mark 31A Mark 31B Mark 53A

\begin{tabular}{|c|c|c|c|c|c|}
\hline $\mathrm{U}-235$ (kg/assy) & 3.360 & 3.200 & 0.671 & 0.456 & - \\
\hline $\mathrm{U}-238$ (kg/assy) & 0.767 & 0.480 & 332.85 & 225.95 & - \\
\hline $\mathrm{U}-234$ (kg/assy) & 0.087 & 0.065 & - & - & - \\
\hline $\mathrm{U}-236$ (kg/assy) & 1.680 & 0.960 & - & - & - \\
\hline Power (MW/assy) & 6.0 & 5.1 & $2.0-3.1 *$ & $2.0-3.1 *$ & Varies \\
\hline $\begin{array}{c}\text { Fission Exposure } \\
\text { (MWD/assy) }\end{array}$ & $\sim 1188$ & 21005 & 2126 & 2106 & $241 * \star$ \\
\hline Days Irradiated & 198 & 197 & 55 & 44 & \\
\hline Days Cooled $\dagger$ & 180 & 180 & 180 & 180 & 180 \\
\hline $\begin{array}{c}\text { Liquid Waste/Assy } \\
\text { (gal/assy) } \\
\text { High-heat } \\
\text { Low-heat }\end{array}$ & $\begin{array}{l}330 \\
234 \\
\end{array}$ & $\begin{array}{l}220 \\
156 \\
\end{array}$ & $\begin{array}{r}27 \\
231 \\
\end{array}$ & $\begin{array}{r}18 \\
157 \\
\end{array}$ & 588 \\
\hline Total & 564 & 376 & 258 & 175 & 588 \\
\hline
\end{tabular}

* The power increases in Mark 31 assemblies during a subcycle.

** Time when $80 \%$ plutonium content is Pu-238.

$t$ Elapsed time between the end of the assembly irradiation and processing of the assembly into its product and waste fractions. 
TABLE 7.2

Fraction of Radioactivity in Spent SRP Fuel Lost to High-Level Waste During Fuel Reprocessing

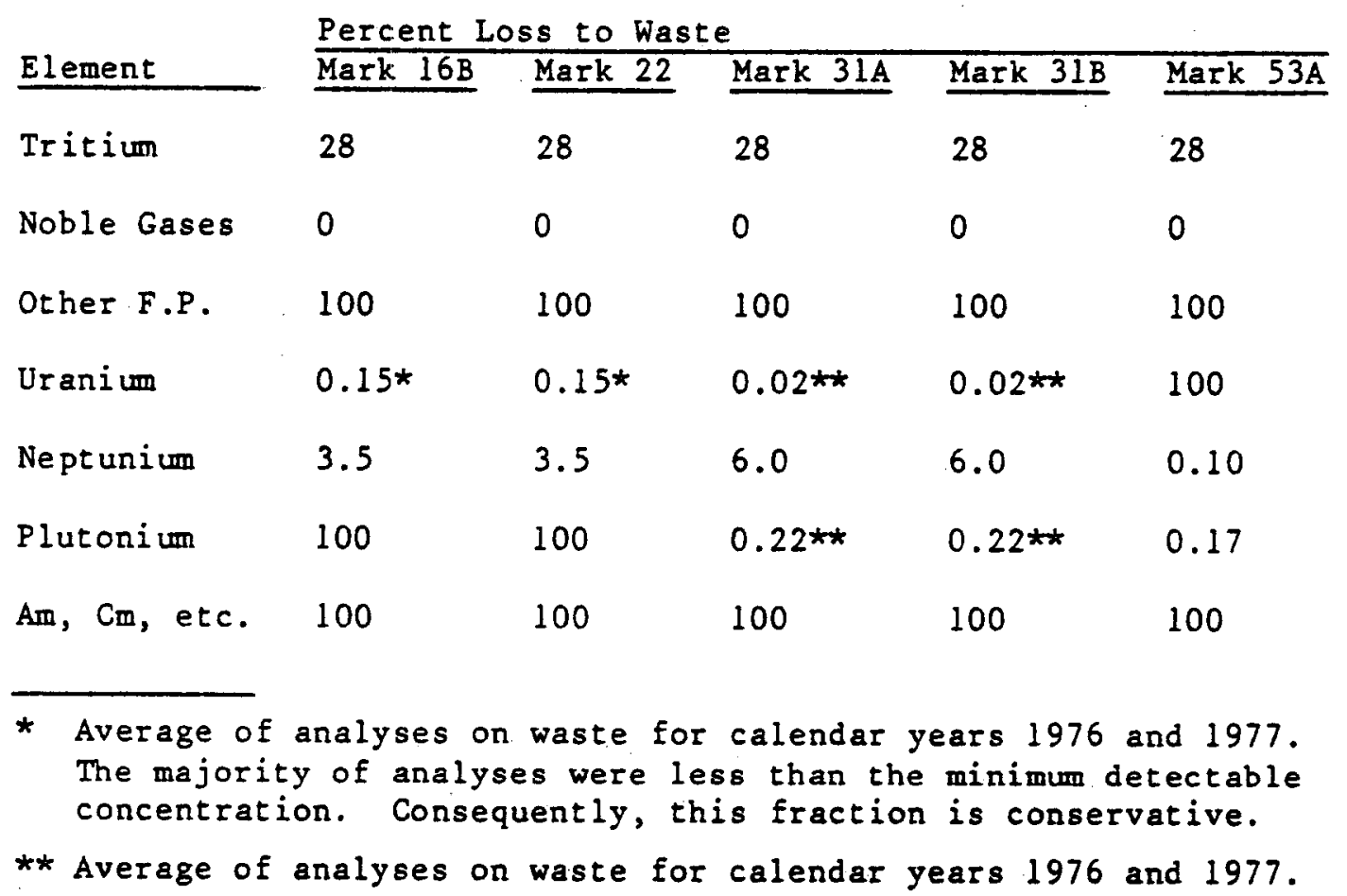


TABLE 7.3

Volume Proportion of Wastes

Assembly Fraction

Mark 16B 0.2153

Mark $22 \quad 0.1453$

Mark 3IA $\quad 0.2894$

Mark 31B $\quad 0.0652$

Mark 53A $\quad 0.0212$

$\begin{array}{ll}\mathrm{RBOF} & 0.2213\end{array}$

Pu-238 Scrap $\quad 0.0114$

Pu-239 Scrap $\quad 0.0309$ 
TABLE 7.4

ISOTOPIC CONTENT (g/gal) OF THE REFERENCE

\section{SOIIPE}

\begin{tabular}{|c|c|c|}
\hline \multicolumn{2}{|c|}{ I SOTIPE } & CUNCENIKAIIUN \\
\hline & 3 & $4.26019 E-01$ \\
\hline & b & $2.32451 t-07$ \\
\hline & ii & $6.79024 t-06$ \\
\hline CR & $5 i$ & $1.14100 E-25$ \\
\hline co & 60 & I.tBit 16E-05 \\
\hline NI & 60 & I.5BGITE-OS \\
\hline GE & 12 & $3.45245 E-01$ \\
\hline GE & 73 & $1: 19943 E-06$ \\
\hline GE & 14 & $3.001336-06$ \\
\hline GE & 16. & $1.09902 E-05$ \\
\hline & 15 & $6.70 \cup B S E-06$ \\
\hline SF & 7.7 & $1.71328 \mathrm{E}-0 \mathrm{~S}$ \\
\hline SE. & 78 & $4.35315 t-05$ \\
\hline SE & 19 & $2.30113[-04$ \\
\hline SE & 80 & $5.49828 E-04$ \\
\hline & 12 & 1.10OTIE-03 \\
\hline AR & 9! & $9.33 ? 73 \in-04$ \\
\hline KR & $B 2$ & $3.98934 E-64$ \\
\hline Ro & 85 & $4: 12 ; 245-03$ \\
\hline RA & 87 & $1.16053 \mathrm{E}-02$ \\
\hline SR ! & FA & $1.69277 t-02$ \\
\hline SR & B9 & $2.02530 E-13$ \\
\hline SR & 90 & $2.42201 E-02$ \\
\hline & 99 & $2.25271 E-02$ \\
\hline$y$ & $\begin{array}{l}90 \\
91\end{array}$ & $\begin{array}{l}6.30234 E-06 \\
4.10689 E-12\end{array}$ \\
\hline $2 R$ & 90 & $1.53124 E-03$ \\
\hline $2 R$ & 91 & $\begin{array}{l}2.82535 E-02 \\
2.899 B 3 E-02\end{array}$ \\
\hline 2R & 92 & $5.04066 E-02$ \\
\hline & & $3.21919 E-02$ \\
\hline & & $5.30919 E-11$ \\
\hline & 96. & $3.231906-02$ \\
\hline NB & 95 & $6.13422 E-11$ \\
\hline NB & $95 \mu$ & $3.716142-14$ \\
\hline $\begin{array}{l}\text { MO } \\
\text { MO }\end{array}$ & $\begin{array}{l}95 \\
96\end{array}$ & $\begin{array}{l}3.29041 E-02 \\
1.33560 E-04\end{array}$ \\
\hline HO & & $\begin{array}{l}1.33560 E-04 \\
3.14555 E-02\end{array}$ \\
\hline & & $3.11515 E-02$ \\
\hline MOL & & $3.45624 E-02$ \\
\hline IC & & $3.26185 F-02$ \\
\hline คui & & $2.96093 E-04$ \\
\hline RU1 & & $2.92142 \mathrm{E}-02$ \\
\hline & & $2.47762 E-02$ \\
\hline RU1 & & $\begin{array}{l}1.9915 \text { SUE-11 } \\
1.22329[-02\end{array}$ \\
\hline RUI & & $\begin{array}{l}1.22329[-02 \\
1.00094 E-04\end{array}$ \\
\hline $\begin{array}{l}\text { RUI } \\
\text { RHI }\end{array}$ & & $\begin{array}{l}1.00094 E-04 \\
2.61148 E-04\end{array}$ \\
\hline & & $1.57114 E-14$ \\
\hline RHI & & \\
\hline
\end{tabular}

\begin{tabular}{|c|c|}
\hline ISUICPE & CCNCENTRATIC \\
\hline IC4 & B. 64 C T4E-C4 \\
\hline Putos & $6.81607 E-63$ \\
\hline PUICo & $4.34656 E-C 3$ \\
\hline Poict & 2.CSG IJE-CJ \\
\hline POIOA & $1.22695 \mathrm{E}-\mathrm{C3}$ \\
\hline PDIIO & $4.183 C S E-C 4$ \\
\hline AGIU9 & $E .64910 E-C 4$ \\
\hline Alillo & $3.11722 E-C 7$ \\
\hline ccilo & $5.92157 \mathrm{E}-\mathrm{CS}$ \\
\hline Cc111 & $2.74512 E-C_{4}$ \\
\hline CC:112 & $1.927836-C_{4}$ \\
\hline $\cos 3$ & $1=31905 E-C 5$ \\
\hline $\operatorname{CDI14}$ & $3.14496 E-04$ \\
\hline CCIIISM & $4.25122 E-10$ \\
\hline$C \subset 116$ & $1.45332 \mathrm{E}-\mathrm{C}_{4}$ \\
\hline inils & I.173009E-C4 \\
\hline INIISM & $1.61756 t-24$ \\
\hline SN116 & $2.78324 t-65$ \\
\hline 54111 & $1.44149 t-C 4$ \\
\hline SA11日 & $1.54801 E-C 4$ \\
\hline salle & $1.50622 \mathrm{E}-\mathrm{C4}$ \\
\hline $\sin 120$ & $1.36054 E-C 4$ \\
\hline SAIZIM & $6.27615 E-C A$ \\
\hline $5 n 122$ & $1.74399 E-C_{4}$ \\
\hline $\sin 123$ & 1.66071E-C9 \\
\hline $5 n 1<4$ & $2.61203 E-C_{4}$ \\
\hline $\sin 125$ & $2.11163 E-62$ \\
\hline $\operatorname{sil} 126$ & $6.02840 E-C 4$ \\
\hline 38121 & $1.62128 E-C_{4}$ \\
\hline Se123 & $2.05150 E-64$ \\
\hline $5 B 124$ & $4.63770 E-16$ \\
\hline 58125 & $9.15235 E-c 5$ \\
\hline $5 B 126$ & $2.86732 E-12$ \\
\hline $5 B 126 M$ & $2.17922 E-14$ \\
\hline IE122 & $2.46383 E-C 6$ \\
\hline IE 124 & $1.14658 E-C 6$ \\
\hline IEI25 & $2.6228 \mathrm{BE}-\mathrm{CS}_{4}$ \\
\hline IE I25M & 1. 30OCGE-C6 \\
\hline IE126 & $1.14032 E-C 5$ \\
\hline IE I2] & $3.81258 E-12$ \\
\hline $1612 \mathrm{Im}$ & $1.10628 E-C y$ \\
\hline IEI2a & $3.11610 E-C 3$ \\
\hline IEI29 & $1.24029 E-23$ \\
\hline IEI29M & $1.34220 E-20$ \\
\hline IE 130 & $1.12822 E-02$ \\
\hline 1127 & $1.29172 E-03$ \\
\hline 1129 & $5.39414 E-C 3$ \\
\hline 1231 & $1.72500 E-12$ \\
\hline$X E I \geq I$ & $3.27580 E-10$ \\
\hline
\end{tabular}

\begin{tabular}{|c|c|}
\hline oru & \\
\hline$x \in 13<2$ & $2.35813 E-$ \\
\hline $\operatorname{csis3}$ & $4.68165 \mathrm{E}-02$ \\
\hline 5134 & $3.00427 t-04$ \\
\hline csiss & $5.83169 \mathrm{E}-03$ \\
\hline o & $1.55437 E-41$ \\
\hline 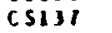 & $4.16043 E-02$ \\
\hline DA134 & $1.641576-03$ \\
\hline OA136 & I.SOIEQE-04 \\
\hline BAL $36 M$ & $1.36\} 526-54$ \\
\hline BA131 & $1.681: 1 E-03$ \\
\hline HALITIM & $6.30852 E-09$ \\
\hline UA!38 & $5.06274 E-02$ \\
\hline $0 A 140$ & 5.041 SUE -46 \\
\hline LAlis? & 4.05938 \\
\hline LALSO & e.0IIISE-4I \\
\hline CE140 & $4.1897 C E-02$ \\
\hline CEIAI & $1.42920 E-19$ \\
\hline CEl42 & $4.50515 c-02$ \\
\hline CE144 & $3.50531 E-04$ \\
\hline PA14L & $4.490 \leqq 4 E-02$ \\
\hline PK 143 & $16 E-43$ \\
\hline PHist & $1.679 C 5 E-00$ \\
\hline PRIAAM & 1.395 CQE-11 \\
\hline No14 2 & $1.59533 E-04$ \\
\hline$N u[4]$ & $5.36 U \angle 5 E-02$ \\
\hline Nu144 & $4.60641 E-02$ \\
\hline No14, & $2.963616-02$ \\
\hline No146 & $2.404 \forall 8 E-02$ \\
\hline & $1.119 \geq 2 E-5$ \\
\hline NDISO & I. 391 JUE-02 \\
\hline NU150 & 5.573 eOE-03 \\
\hline PH(4) & $2.95350 E-03$ \\
\hline PMI \&Q & $4.1955 e E-20$ \\
\hline PMILEM & S. 348 $19 E-18$ \\
\hline Smint & $9.51622 \mathrm{E}-03$ \\
\hline SMLAd & $2.10916 E-03$ \\
\hline $\sin 169$ & e.22 \\
\hline $\operatorname{Sin} 150$ & 1.160 \\
\hline & 1.04 \\
\hline SMI & $4.21144 E-03$ \\
\hline & $1.476(3 \mathrm{E}-04$ \\
\hline Evi? & $4.38967 t-05$ \\
\hline Euls & 2.359 ale-06 \\
\hline Euis] & $2.32324 E-03$ \\
\hline Euis4 & $2.59742 E-04$ \\
\hline Eu155 & $1.155 C 5 E-04$ \\
\hline EU156 & $1.01532 E-40$ \\
\hline 601 & $3.66963 E-01$ \\
\hline GOIS & $1.36112 E-04$ \\
\hline
\end{tabular}

\begin{tabular}{|c|c|}
\hline I surort & CUNCENIRATIC \\
\hline GC1S5 & $1.30750 E-04$ \\
\hline 60156 & $6.5045 C E-04$ \\
\hline Goisi & 4. Broule-ve \\
\hline Guiso & $1.58802 E-04$ \\
\hline 60160 & 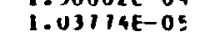 \\
\hline 18159 & 2.31SIIE-OS \\
\hline 18160 & $1.12366 \mathrm{E}-14$ \\
\hline or 160 & T.1SESCE-C1 \\
\hline Dribl & $3.9084 B E-O E$ \\
\hline orige & $2.3282 E E-06$ \\
\hline I 2200 & 4.2SGSSE-IE \\
\hline 90200 & 1.09?73t-16 \\
\hline 20212 & $2.5071 \mathrm{CE}-13$ \\
\hline 01212 & $2.318316-14$ \\
\hline P0216. & $1.00098 E-18$ \\
\hline HN220 & 3. MOCCE-IE \\
\hline RA224 & $2.18637 E-12$ \\
\hline IHZ2O & $4.26725 E-10$ \\
\hline 4232 & $2.69107 E-C E$ \\
\hline 4234 & B. $31139 E-05$ \\
\hline U235 & $2.79075 E-03$ \\
\hline 4236 & $2.02066 E-03$ \\
\hline v230 & $9.13937 E-02$ \\
\hline NP236 & $1.48004 E-I C$ \\
\hline ND231 & $1.41215 E-03$ \\
\hline PU2 36 & $1.33328 E-08$ \\
\hline PUZ37 & $4.25334 E-2 C$ \\
\hline PUL3日 & $4.94366 E-03$ \\
\hline PU239 & $1.2085 E E-02$ \\
\hline Puz40 & $2.21561 E-03$ \\
\hline Puz 41 & $9.31535 E-04$ \\
\hline PU242 & $1.15532 t-04$ \\
\hline AMZ4I & 3.546711 - 04 \\
\hline$A M 242$ & $1.985111-12$ \\
\hline$A M 242 M$ & $1.66081 \mathrm{YE}-0\}$ \\
\hline$A M 243$ & $3.24943 E-0 E$ \\
\hline CM242 & $1.140<2 E-0 S$ \\
\hline$C M 243$ & $1.2103 \mathrm{EE}-\mathrm{OE}$ \\
\hline CM244 & $2.26464 E-01$ \\
\hline cmess & $40151 E-08$ \\
\hline CM?46 & $1.042020-18$ \\
\hline CA247 & 1.905 EE-13 \\
\hline CA248 & 1. $80504 E-14$ \\
\hline $0 \times 244$ & $1.93382 E-10$ \\
\hline$C+249$ & 1.0eSGIE-IE \\
\hline CF 250 & $1.60680 \mathrm{BE}-11$ \\
\hline CF 251 & $4.61546 E-1 E$ \\
\hline$C F 252$ & $3.49008 \mathrm{~B}-15$ \\
\hline CF 253 & $3.25972 E-32$ \\
\hline
\end{tabular}




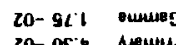

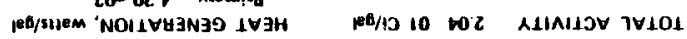

\begin{tabular}{|c|c|}
\hline 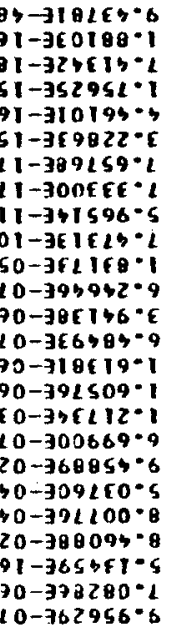 & 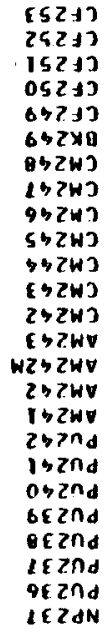 \\
\hline
\end{tabular}

\begin{tabular}{|c|c|}
\hline 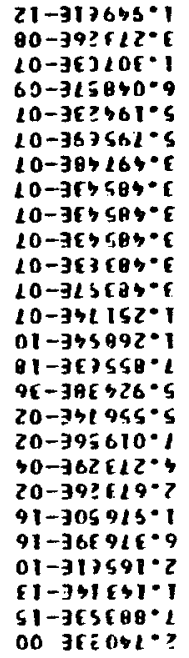 & 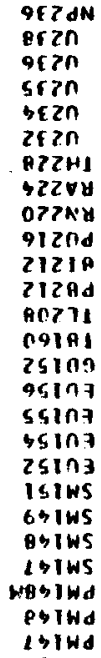 \\
\hline
\end{tabular}

\begin{tabular}{|c|c|}
\hline $\begin{array}{l}84-795865=1 \\
31-31025 s=5\end{array}$ & $\begin{array}{l}\text { IHIJY } \\
b \text { Ian }\end{array}$ \\
\hline $20-3561$ OE-1 & whil tod \\
\hline $\begin{array}{l}00 \text { BIfOII-1 } \\
\text { oE-36StSE-1 }\end{array}$ & $\Rightarrow$ bldd \\
\hline $00912811=1$ & Shige \\
\hline $65-31<180-1$ & 23130 \\
\hline $51-316125=6$ & 13130 \\
\hline $15-38<506$. & obiv \\
\hline $13-348292 \cdot 4$ & $0 \rightarrow 1$ ve \\
\hline DO J95L6E. & Hifiva \\
\hline $64-320919 \cdot 6$ & WGEIVA \\
\hline $09326164=8$ & [E]S] \\
\hline $2 b-39<9+1=1$ & $9[15]$ \\
\hline $93-356221 \cdot 7$ & SEis \\
\hline 1$)-315568 \cdot 6$ & $\rightarrow[153$ \\
\hline $13-712915.6$ & 6211 \\
\hline $91-785320^{\circ}$ & W62I3I \\
\hline $91-315$ Bas -2 & 62131 \\
\hline SJ-3OESHO०1 & $w<213 i$ \\
\hline $53-360220 \times 1$ & 12131 \\
\hline $25-3+2 E+C \cdot 2$ & WSZ13I \\
\hline $90-358211 \cdot 1$ & W92185 \\
\hline $13-366160^{\circ} 2$ & $9 ? 185$ \\
\hline $20-766505 \cdot 6$ & SZIAS \\
\hline $21-305811 \cdot \theta$ & מzias \\
\hline$N=$ & 131751 \\
\hline
\end{tabular}

$90-358512 \cdot 1 \quad 921 \mathrm{NS}$

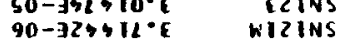
O1-35980G-6 WSIIVI

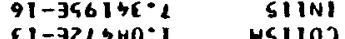
c0-31680.-1 WSTIO 90-360180.1 $1010 \mathrm{~d}$

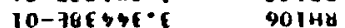
$21-315451.5$ WEOIHA 10-3Bcote. $9010 \mathrm{~d}$ $21-369695^{\circ} 2$ roing $30-366125.2$ 66 31 On- $38741 \%$ WS6 QN 90-39511.i So an $90-720040.2 \quad 56$ a $10-310550^{\circ} 1$ it $A$ 00 3\$162\% $00352120^{\circ} \mathrm{C}$ OG $4 \mathrm{~S}$ $\begin{array}{ll}60-381021^{\circ} & 68 \\ 60-365910^{\circ} 1 & 18\end{array}$ $\begin{array}{ll}60-766910^{\circ} 1 & 68 \\ 50-710609.1 & 61\end{array}$ o9 03 E0-361811:4

NOIIVHINGJNOJ GAJIOSI

NoIIVYING3VJ) FanITS!

SHVJA 9 - ONG78 IISVM JaMO

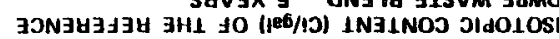


TABLE 7.6

ISOTOPIC CONTENT (g/gal) OF THE REFERENCE WSTE BLEND - 15 YEARS

\begin{tabular}{|c|c|c|c|}
\hline I SUTOPE & CUNCEN IRAIIION & ISOTOPE & CACEATAATICA \\
\hline 3 & $2.42065 E-01$ & RH103 & $2.61740 E-C_{4}$ \\
\hline ME 3 & $4.16406 E-01$ & RH103M & $2.69654 E-67$ \\
\hline$v$ ii & $6.79024 t-06$ & RHIC6 & $5.03639 E-14$ \\
\hline CR $5 !$ & $3.21021 \mathrm{E}-65$ & POLO4 & $0.64014 E-C 4$ \\
\hline Cu 60 & $4.54134 t-06$ & Poics & $6.81407 \mathrm{E}-\mathrm{C} 3$ \\
\hline N1 60 & $2.02 A 31 E-05$ & $P C 106$ & $4.64 E 54 E-C 3$ \\
\hline GE 72 & $3.45245 E-01$ & Po1C1 & 2.c997IE-C3 \\
\hline GE 73 & $1.19943 E-06$ & Polcs & $1.22655 \mathrm{E}-13$ \\
\hline is 14 & $3.00 .133 \mathrm{E}-06$ & POilo & $4.18309 \mathrm{E}-04$ \\
\hline GE 16 & $1.94902 E-05$ & AGIOQ & $6.84910 \mathrm{E}-\mathrm{C}_{4}$ \\
\hline A5 75 & $6.90685 E-06$ & $A C 110$ & $1.37165 E-11$ \\
\hline SE T? & J.11 $328 E-05$ & ccilo & $5.95324 E-C 5$ \\
\hline SE $7 B$ & $9.35315 E-05$ & coili & $2.195728-14$ \\
\hline $5 E^{2} 79$ & $2.30688 \mathrm{E}-04$ & CCI12 & $1.92783 \mathrm{E}-\mathrm{C} 4$ \\
\hline SE $B O$ & $5.49828 E-04$ & coilis & $1.31905 E-C 5$ \\
\hline SE $B 2$ & 1.109 TIE-03 & & $3.14456 \mathrm{E}-64$ \\
\hline BR AI & $9.33173 \mathrm{E}-04$ & CCIISM & $5.66611 E-43$ \\
\hline$K R \quad B Z$ & $3.96934 E-46$ & ccilb & $1.45332 \mathrm{E}-\mathrm{C}_{4}$ \\
\hline RE. 85 & $4.12124 \mathrm{E}-03$ & 11115 & $1.179 C 9 E-C 4$ \\
\hline RB A1 & $1.16053 \mathrm{E}-02$ & IALI5M & $3.59612 t-49$ \\
\hline SR BO & $1.68277 E-02$ & SA116 & $2.78324 E-C 3$ \\
\hline SR. 89 & $1.45232 \mathrm{E}-34$ & Shi17 & $1.44149 E-C 4$ \\
\hline SR 90 & $1.89250 E-02$ & snilo & $1.54481 E-C 4$ \\
\hline$Y 89$ & $2.23271 E-02$ & $\operatorname{sil} 19$ & $1.50422 E-C 4$ \\
\hline & $\$ .92463 \mathrm{E}-06$ & $\sin 120$ & $1.56054 E-C 4$ \\
\hline & $1.43341 E-31$ & SNIZIM & $5.46312 E-C B$ \\
\hline 2990 & A.B5JU1E-03 & Sniz2 & $1.74399 E-C 4$ \\
\hline 2A 91 & $2.92551 E-02$ & $5 M 123$ & $1.097845-17$ \\
\hline 92 & $2.89983 \mathrm{E}-02$ & $5 A 1<4$ & $2.61283 \mathrm{E}-\mathrm{C4}$ \\
\hline$[R 93$ & $3.04042 E-02$ & $5 A 126$ & $0.02036 E-C 4$ \\
\hline IR 94 & $3.21979 t-02$ & SE12i & $1.62135 E-C 4$ \\
\hline & $8.68 / 88 E-28$ & $\sec 123$ & $2.05193 E-C_{4}$ \\
\hline $2 A 96$ & $3.23190 \mathrm{E}-02$ & Sel24 & $2.52358 E-34$ \\
\hline NA 95 & $1.00311 E-21$ & SE125 & $7.22536 \mathrm{E}-\mathrm{C6}$ \\
\hline Na 95N & $6.07684 E-31$ & 58126 & $2.86729 E-12$ \\
\hline 95 & $3.29041 E-02$ & SE126M & $2.17920 E-14$ \\
\hline MO 96 & $1.33560 E-04$ & 16122 & $2.463636-06$ \\
\hline 40 97 & $3.14555 E-02$ & IEI26 & $1.14858 E-16$ \\
\hline & $3.17515 E-02$ & TEL25 & $3.47783 t-64$ \\
\hline M0100 & $3.45624 E-02$ & 1ELLSM & $1.02633 E-C 7$ \\
\hline IC 99 & $3.26175 E-02$ & $1 E 126$ & $1.14074 E-C 5$ \\
\hline RUI 00 & $2.96093 \mathrm{E}-04$ & JE127 & $3.168116-22$ \\
\hline & $2.82142 E-02$ & IE127M & S.04946E-20 \\
\hline & $2.47762 E-02$ & IE128 & $3.1161 \mathrm{CE}-03$ \\
\hline RU103 & 1.37 & IELZY & $1.49298 \mathrm{E}-56$ \\
\hline RU104 & $1.22329 E-02$ & IEI29M & $1.61564 E-53$ \\
\hline RU106 & 1.04AA3E-0 ? & IE130 & $1.12822 E-C 2$ \\
\hline
\end{tabular}

\begin{tabular}{|c|c|c|c|}
\hline SOTOPE & IRATICN & I SOIOPE & CONCENTHATICN \\
\hline 1127 & $1.29152 t-03$ & GQ15I & $4.67881 E-0 E$ \\
\hline 1129 & $5.39474 E-03$ & 60150 & $1.38002 t-04$ \\
\hline XEEISI & $3.27300 E-10$ & GC160 & $1.03714 E-05$ \\
\hline$x \in 1 S 2$ & $2.35813 E-20$ & 10158 & $2.31571 E-C E$ \\
\hline $\operatorname{csi3} 3$ & $4.60165 t-02$ & 16160 & $6.96593 \mathrm{E}-3 \mathrm{C}$ \\
\hline Csiss & $1.03056 E-05$ & Dri6o & $1.13650 \mathrm{E}-01$ \\
\hline csijs & S.03ICTE-03 & Dr161 & $3.90848 E-0 E$ \\
\hline Csi3) & $3.28819 E-02$ & DY162 & $2.32 \forall 2 E E-0 t$ \\
\hline BAlBS & 1.13 LIt-0j & $\operatorname{ILC\theta }$ & $9.00850 t-16$ \\
\hline BA136 & $1.5 C 764 E-04$ & PBZCO & $5.95923 E-I C$ \\
\hline BALIJI & $1.61419 E-02$ & PQ212 & $3.36119 E-13$ \\
\hline BALJiNA & $5.011245-09$ & 81212 & 5. COAUSE-14 \\
\hline BAI30 & $5.06214 E-02$ & PO216 & $2.13913 t-10$ \\
\hline Laiso & $4.85920 \mathrm{E}-02$ & RN2Z0 & $0.07585 E-16$ \\
\hline CE 140 & $4.105706-02$ & $R A 2<4$ & $4.616625-12$ \\
\hline CEIAI & $2.26560 E-5 j$ & IH220 & Y.cos3 3E- IC \\
\hline CE142 & $4.50575 t-02$ & 0232 & $3.56164 E-08$ \\
\hline CEL144 & $4.17144 E-08$ & 0234 & B.31116E-OS \\
\hline PRI41 & $4.49054 E-02$ & U235 & $2.79875 t-03$ \\
\hline PR144 & $2.013 ? 3 E-12$ & 4236 & $2.02066 E-03$ \\
\hline PMIS4M & $1.00605 E-14$ & 6238 & $5.73931 \mathrm{E}-02$ \\
\hline Nolitz & $1.59533 E-04$ & NP236 & $1.41995 \mathrm{E}-1 \mathrm{C}$ \\
\hline NO 14$\}$ & $5.36025 E-02$ & NP231 & $1.41214 E-03$ \\
\hline Nu144 & $4.64147 E-02$ & PU236 & $1.11226 \mathrm{E}-0 \mathrm{~S}$ \\
\hline Nolas & $2.96341 E-02$ & PUZJI & $3.40003 E-44$ \\
\hline$N O 146$ & $2.40468 E-C 2$ & PU23e & $4.56819 E-03$ \\
\hline NDits & $1.39110 t-02$ & Pu239 & $1.28021 E-0 E$ \\
\hline NU150 & $3.5736 \mathrm{CE}-03$ & PU24C & $2.21326 E-03$ \\
\hline PAlal & $2.10253 E-04$ & PUZ41 & $5.05004 E-04$ \\
\hline PMiqu & $1.14379 E-46$ & PU242 & $1.15530 E-04$ \\
\hline PMisan & $1.275496-46$ & $A M Z 41$ & $6.98483 E-04$ \\
\hline SMial & $1.22559 \mathrm{E}-02$ & AM242 & I.891:IE-12 \\
\hline SA146 & $2.10916 E-03$ & $\triangle M Z 42 M$ & $1.58683 \mathrm{E}-01$ \\
\hline SM149 & $0.227 E 4 E-04$ & $A M 243$ & $3.24637 \mathrm{E}-0 E$ \\
\hline $5 n i 50$ & $1.16680 E-02$ & CR242 & $3.84269 \mathrm{E}-1 \mathrm{C}$ \\
\hline SAISI & $9.73450 E-04$ & CH243 & $9.49041 E-0 S$ \\
\hline SM152 & $4.21144 E-03$ & CM244 & $1.54445 E-01$ \\
\hline SHIS4 & $7.476 C 3 E-04$ & CA245 & 4.33 ISIE-OS \\
\hline Evisi & 1.192 I5E-04 & CM246 & 1.939IIE-IC \\
\hline tuise & $1.38312 \mathrm{E}-06$ & CH24) & $7.90585 \mathrm{E}-13$ \\
\hline EU153 & $2.32334 E-03$ & CA248 & $1.80504 E-14$ \\
\hline EU154 & $1.15 Y 49 t-04$ & $6 \times 245$ & $6.09242 E-22$ \\
\hline Euiss & $2.12278 E-05$ & CF 245 & $1.08134 E-1 E$ \\
\hline G0152 & $3.66963 \mathrm{E}-07$ & CF 250 & $9.45 E 74 E-18$ \\
\hline & $2.199(2 E-04$ & CF2S1 & $4.63951 E-1 E$ \\
\hline & Ban & & \\
\hline
\end{tabular}

I. 04 A A3E-O

60156

$6.50450 t-04$ 
TABLE 7.7 ISOTOPIC CONTENT (Ci/gal) OF THE REFERENCE WLEND - 15 YEARS

\begin{tabular}{|c|c|c|c|c|c|}
\hline I SOIOPE & CUNCEN IRATICN & I SCICPE & COACENTAAIIICA & ISOTOPE & CCNCENIRATICN \\
\hline & $E-03$ & $5 A 126$ & $71264 E-C 6$ & SHI & $2.76558 t-10$ \\
\hline co 60 & $5.15334 E-03$ & Se124 & $\begin{array}{l}41834 E-30 \\
0\end{array}$ & $\operatorname{SM148}$ & $0.37639 E-16$ \\
\hline SE 19 & $1.60084 E-05$ & 58125 & $7.57513 E-C 3$ & SH149 & $1.516 \leq 0 t-16$ \\
\hline RB A? & $1.01639 E-04$ & SB126 & $2.39797 E-C 1$ & SHISI & $2.48114 E-02$ \\
\hline SR 89 & $4.10187 E-30$ & 581264 & $1.71284 E-C 6$ & EuIs2 & $2.50636 \mathrm{E}-04$ \\
\hline Sh 90 & 2.67GOSE OO & TEL125M & $1.84988 E-C 3$ & EU154 & $3.133 \leq 5 t-02$ \\
\hline$\checkmark 40$ & $2.67+74 E 00$ & IE127 & $0.36129 E-16$ & Euis5 & 1. उCQE9E-02 \\
\hline Y 91 & I. $.02202 E-26$ & IEILIM & $8.54241 E-16$ & 60152 & $1.85563 \mathrm{E}-18$ \\
\hline 2R 93 & $2.04301 E-04$ & IE129 & $3.11105 E-49$ & 18160 & $1.866: 3 E-26$ \\
\hline IR OS & $1.82362 \mathrm{E}-23$ & IE129M & $4.89988 \mathrm{BE}-45$ & IL208 & $2.61619 E-C 7$ \\
\hline NB 95 & $3.93193 E-23$ & 1129 & $5.41620 E-C 1$ & PBz1L & $1.44834 E-07$ \\
\hline NB $95 \mathrm{M}$ & $2.31599 E-25$ & $\operatorname{csi34}$ & $1.34596 E-C 2$ & B1212 & $7.44833 \mathrm{t}-07$ \\
\hline IC 99 & $5.32975 E-04$ & $c \leq 135$ & $6.72293 E-C 6$ & P0216 & $1.44848 E-07$ \\
\hline & $4.39488 E-40$ & Csi3) & $2.85310 E \mathrm{CC}$ & RN2ZO & $1.44848 E-07$ \\
\hline RUI08 & $3.504396-04$ & EAlsin & $2.69903 E 00$ & RA224 & $1.446488-07$ \\
\hline RHIOBM & $0.79840 E-40$ & CE141 & $t .45350 E-49$ & TH228 & $1.449 \in 2 E-07$ \\
\hline RHL 06 & $3.50439 E-04$ & CEIG & $1.00177 E-C 9$ & 0232 & $1.66644 E-67$ \\
\hline polor & $1.00103 E-06$ & CEISA & $1.52224 E-C 4$ & $\sqrt{234}$ & $5.194 C 8 E-07$ \\
\hline AG110 & $6.49212 E-08$ & PRit4 & $1.52229 t-64$ & บ235 & 6.C4BSTE-CQ \\
\hline CotisM & $2.41191 E^{2}-30$ & PRIAAM & I.e26)11E-C6 & 0236 & $1.307(3 t-0)$ \\
\hline INits & 1.341 Y5E- 16 & NO144 & $5.45430 E-14$ & U238 & $3.213 \mathrm{a6E}-\mathrm{C \theta}$ \\
\hline initsm & $2.11909 E-42$ & Priat & $1.550526-C 1$ & $N P 236$ & $1.94949 E-12$ \\
\hline SNI214 & $3.23329 E-06$ & PMISQ & $1.08024 E-41$ & NP231 & $5.956<6 E-07$ \\
\hline SNI23 & $9.04113 E-14$ & PrIGEN & $2.72628 E-40$ & & \\
\hline & & & IIr 1.130 & & \\
\hline & & & & C.m & $2.37-02$ \\
\hline
\end{tabular}

\begin{tabular}{|c|c|}
\hline 010 & NCENTR \\
\hline Pu231 & $6.22749 E-07$ \\
\hline $\begin{array}{l}\text { PU231 } \\
\text { PU238 }\end{array}$ & $\begin{array}{l}4.11414 E-4 C \\
1.81826 E-02\end{array}$ \\
\hline PU234 & $0.00 \$ 45 E-04$ \\
\hline PU240 & $5.03227 E-04$ \\
\hline PUट41 & $3.90211 E-02$ \\
\hline PU242 & $6.69893 E-01$ \\
\hline An2 41 & $2.391371 E-03$ \\
\hline $\operatorname{AM2} 42$ & 1.53417E-06 \\
\hline AM24ZH & I.54181E-0E \\
\hline ANZ43 & $6.91883 \mathrm{E}-07$ \\
\hline CH242 & $1.27250 E-06$ \\
\hline $\mathrm{CM}_{4} 3$ & $4.89187 E-07$ \\
\hline $\begin{array}{l}\text { CM244 } \\
\text { CM245 }\end{array}$ & $1.24921 E-05$ \\
\hline CM245 & $1.46102 E-1 C$ \\
\hline CM246 & $5.95641 E-12$ \\
\hline$C^{*}+2$ & $1.33299 \mathrm{E}-11$ \\
\hline CA248 & $1.65165 \mathrm{E}-11$ \\
\hline $8 \times 269$ & $1.01111 \mathrm{E}-1 \mathrm{e}$ \\
\hline$C F 249$ & $4.45146 E-16$ \\
\hline CF 250 & $1.0338 \mathrm{CE}-1 \mathrm{~S}$ \\
\hline CF251 & 1. $35642 E-10$ \\
\hline 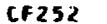 & $1.35901 E-11$ \\
\hline
\end{tabular}

CF 252

$.35901 E-11$ 


\begin{tabular}{|c|c|c|c|c|c|c|c|c|}
\hline & $\begin{array}{l}\text { TABLE } 7 . \\
\text { ISOTOPIC } \\
\text { FUEL AS: }\end{array}$ & $\begin{array}{l}\text { NTENT (g/assembly) } \\
\text { BLY - } 5 \text { YEARS }\end{array}$ & A MAAK 16 & & & & & \\
\hline & I SIITOPE & CONCEN IRAIIIUN & ISCICPE & CENCEAIRATILN & I SUIGPE & CLNCENIRATICN & I SUIOPE & CUNCENIKATICN \\
\hline & H & $3.41125 E-04$ & HHICG & $0.23182 E-C \theta$ & $x \in(31$ & C.14961E-0) & 60154 & $1.62445 E-01$ \\
\hline & HE 1 & $1.45913 E-04$ & P0104 & $5.03037 \mathrm{t}-\mathrm{CL}$ & $x \in 132$ & $1.52456 E-17$ & Gu15s & $0.67645 e-02$ \\
\hline & v si & $1.34124 E-03$ & Polos & S.10880E CU & (sis) & $4.268 C 9 E 01$ & c0156 & $5.18164 E-01$ \\
\hline & CR Si & $1.23354 E-22$ & Pulog & $2.98399 \mathrm{EO}$ & C5134 & $3.69354 E-01$ & G0151 & 9.0SASTE-OS \\
\hline & $\cos 60$ & $1.83544 t-02$ & POLIOI & $1.19834 \mathrm{E} \mathrm{CO}$ & CS135 & $4.974 E 2 E 00$ & 60150 & I.c7919E-0I \\
\hline & NI 60 & $1.113285-02$ & POLOB & $6.14540 E-C 1$ & C5136 & $1.53274 E-45$ & 60160 & $3.21368 E-03$ \\
\hline & GE 12 & $2.33131 E-04$ & PD110 & $2.13602 E-C 1$ & CS13) & $3.03268 E$ OI & 18159 & $1.21421 E-02$ \\
\hline & GE 13 & $9.52012 E-04$ & A6109 & $2.83510 E-C 1$ & DA134 & $1.13123 E$ OO & 18100 & $1.0946 \mathrm{EE}-11$ \\
\hline & GE 14 & $2.531146-03$ & AGIIU & $3.0014 B E-C 4$ & BA136 & $1.211 \in \| E-01$ & Dr160 & $7.06967 E-04$ \\
\hline & GE 16 & I.BIAB3E-02 & ccilo & $5.561191-C 2$ & HAISGM & $6.60911 \mathrm{E}-52$ & Orial & $1.30395 E-03$ \\
\hline & is is & $6.02024 E-03$ & colii & $1.51638 E-C 1$ & OALIT & $1.90823 E 00$ & Drisz & $9.1900 E E-04$ \\
\hline & SE 11 & 3.395 SIE- 02 & cliiz & I.14911E-CI & UALBIM & $5.840 C O E-06$ & 11208 & $6.31212 E-13$ \\
\hline & SE IA & $4.56460 E-02$ & Colis & $2.06061 E-03$ & BAL38 & $4.11080 E$ O1 & $P B<C \theta$ & $1.44516 E-01$ \\
\hline & SE 19 & $2.12387 t-01$ & CCII4 & $2.05647 E-C 1$ & BA140 & $4.40520 E-43$ & PB212 & $3.72360 E-I C$ \\
\hline & SE 90 & 5.11 Bott-0i & CoIISM & $1.84516 E-13$ & CAI39 & $4.50510 E$ OL & B 1212 & $3.53155 E-11$ \\
\hline & SE 82 & $1.03647 t 00$ & Co116 & $5.04944 E-C 2$ & CA140 & $6.64414 E-44$ & $P 0216$ & $1.48037 E-15$ \\
\hline & AH BI & R. .66 A GIE-01 & inits & $6.16389 E-C 2$ & CE 140 & 4.454 SUE OL & HN220 & $5.61153 \mathrm{E}-13$ \\
\hline & KR A2 & $3.46110 \mathrm{E}-4 \mathrm{I}$ & IAIISA & $1.01002 E-22$ & CEISI & $1.257 \varepsilon 0 E-16$ & KAL2 & $3.24956 E-05$ \\
\hline 1 & KB AS & 4.46553600 & SnI16 & $2.86528 E-C 2$ & CE 142 & $4.19310 E$ OL & IH 228 & 6.33BESE-0? \\
\hline & RB BI & $1.103558: 01$ & snili & $9.61687 E-C 2$ & CE 144 & $3.66226 \mathrm{E}-01$ & 0232 & $4.15] 49 E-05$ \\
\hline$y$ & SR NH & 1.60027 t 01 & SA11日 & $1.01912 E-C 1$ & PR 141 & $4.15610 E$ O1 & 0234 & $1.05035 E-01$ \\
\hline : & SA BO & $2.062776-10$ & $5 n 119$ & $1.032 \mathrm{CIE}-\mathrm{Cl}$ & PH143 & $1.5696 \mathrm{BE}-40$ & U2 15 & $2.82737 E$ OC \\
\hline セ & SR 90 & $2.320480 \mathrm{OI}$ & $\sin 120$ & I.OBI2LE-CI & PHIS4 & $1.54531 \mathrm{E}-05$ & 0236 & $2.01254 E 00$ \\
\hline$\omega$ & $r d 9$ & 2.16466501 & SAI2IM & $3.02937 E-C 5$ & PRIA4I4 & $1.12642 E-0 \theta$ & 0238 & $1.10435 E$ OC \\
\hline 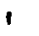 & $r 90$ & $6.01911 t-03$ & $5 n 122$ & $1.21555 E-C I$ & NU 142 & $2.117 \leq 5 E-01$ & NP237 & $1.93446 E$ OC \\
\hline & $r 9 i$ & $4.41730 t-39$ & $5 A 123$ & $2.63429 E-16$ & NOI4 3 & 5.153ELE OI & PU236 & $2.11594 E-05$ \\
\hline & $\angle R \quad 90$ & $3.26435 E 00$ & $\operatorname{sn} 1<4$ & $1.92454 \mathrm{E}-\mathrm{Cl}$ & No144 & $4.51439 E$ O1 & PU238 & 7.C8519E OC \\
\hline & IR $9 !$ & $2.60098 E$ OI & $\sin (2)$ & $1.68383 E-6 C$ & Nulas & 2.124126 ol & PQ239 & $1.58095 E$ O1 \\
\hline & IR 92 & $2.14062 E$ OI & $5 n 126$ & $4.12 E 61 E-C 1$ & Nuits & $2.28 d 85 E$ OI & PU240 & $3.17580 E 00$ \\
\hline & IR 99 & $1.19035 \mathrm{~L} \mathrm{~J}$ & Sel21 & $1.12110 E-C 1$ & No14I & & Pu241 & 1.3021SE OC \\
\hline & LA 94 & $1.02224 E$ OI & seizi & $1.4584 \mathrm{LE}-\mathrm{Cl}$ & NOI4O & $1.21135 E$ OI & PU242 & $2.55154 E-01$ \\
\hline & 2R 95 & $5.32<41 E-00$ & 58124 & $4.98544 E-13$ & NO150 & $4.94913 E$ OO & AMLAL & $3.53736 E-01$ \\
\hline & 1496 & $3.01005 E$ OI & 58125 & $6.16375 \mathrm{E}-\mathrm{C2}$ & PMLA! & $2.476 \mathrm{C3E} 00$ & $\operatorname{AM} 242$ & $1.04354 E-05$ \\
\hline & NB 45 & $6.14954 E-08$ & 58126 & $2.24912 \mathrm{E}-\mathrm{C} 9$ & $P, 414 \theta$ & $5.24169 \mathrm{E}-17$ & AM242M & $1.54194 E-04$ \\
\hline & NQ. $95 \mathrm{~N}$ & $3.72541 \mathrm{t}-11$ & $58126 \mathrm{M}$ & $1.10438 \mathrm{E}-11$ & PMISAM & $5.04520 \mathrm{E}-15$ & $\operatorname{AM243}$ & $\begin{array}{l}0.42214 E-03 \\
1.2801 E-0 E\end{array}$ \\
\hline & MO 95 & $1.06633 E \quad 01$ & IE 122 & $2.63 E 66 E-C 3$ & $\sin 141$ & $1.31363 E 00$ & CN242 & $1.28 \mathrm{U} 17 \mathrm{E}-0 \mathrm{E}$ \\
\hline & MO 96 & $1.11165 E-01$ & $1 E 124$ & $1.22 E 31 E-C 3$ & $5 \sin 48$ & $2.51131 E$ 0O & CM243 & $1.56304 c-05$ \\
\hline & MO 11 & 2.910000 O1 & IEI25 & $1.01640 \mathrm{E}-01$ & 54149 & $4.52717 E-01$ & CM244 & $5.87070 \mathrm{E}-04$ \\
\hline & MC 9 A & 2.931918 ol & TEI25M & $8.60165 \mathrm{E}-\mathrm{CH}$ & $\sec 150$ & 1.17664 E UI & CA245 & $1.12333 \mathrm{E}-05$ \\
\hline & MCIOOO & 3.1I85TE OI & $1 E 126$ & $9.029 C 7 E-C 3$ & smisi & $5.10121 E-01$ & CM246 & $5.02016 E-01$ \\
\hline & 1C 94 & $2.99326 E \quad 01$ & IE 127 & $3.19033 \mathrm{E}-\mathrm{CQ}$ & SH1S2 & 3.051 TOE 00 & CM24) & $2.04227 E-C 5$ \\
\hline & RUI 00 & $3.16411 E-01$ & TE12IM & $9.11252 E-C 1$ & $5 M 154$ & $6.05153 E-01$ & CM248 & $4.65408 E-11$ \\
\hline & RULOL & $2.51133 \mathrm{E}$ OI & It 128 & $2.61286 t 00$ & EUISI & $1.56459 E-02$ & BK249 & $5.06532 E-15$ \\
\hline & RU10? & $2.23489 \mathrm{E}$ OI & TEI29 & $9.25751 E-21$ & EU152 & $1.64 \theta C 9 E-03$ & C+249 & $2.85422 E-13$ \\
\hline & RULOI & $6.23528 \mathrm{E}-14$ & TELI29M & $1.00182 E-11$ & EU153 & $2.261 \mathrm{EBE}$ OC & CF250 & $4.20939 t-14$ \\
\hline & RUIO" & 1.014021 o1 & It 130 & $1.00461 E C 1$ & Euls4 & $9.14412 \mathrm{E}-01$ & CF251 & $1.22478 E-14$ \\
\hline & RU106 & $6.65124 E-02$ & 1121 & $1.03573 \mathrm{E} \mathrm{CO}$ & EUiss & $B .154 E 2 E-02$ & CF252 & $9.165716-16$ \\
\hline & $\begin{array}{l}\text { RHIDI } \\
\text { RHIDIM }\end{array}$ & $2.04221 E-01$ & 1129 & $\begin{array}{l}4.65 J C 4 E \text { OC } \\
5.06570 E-69\end{array}$ & $\begin{array}{l}\text { EU156 } \\
\text { G0152 }\end{array}$ & $1.049 C 2 E-38$ & $C+253$ & $6.53916 E-45$ \\
\hline & RHIDJM & & 1131 & $5.06570 E-69$ & G0152 & $4.31836 E-04$ & & \\
\hline
\end{tabular}


TABLE 7.9

ISOTOPIC CONTENT (Ci/assembly) OF A MARK 168
FUEL ASSEMBLY - 5 YEARS

\begin{tabular}{|c|c|}
\hline soro & UNCEI \\
\hline H 3 & $3.35355 E 00$ \\
\hline $\begin{array}{ll}\text { CR } & 51 \\
\text { CO } & 60\end{array}$ & $\begin{array}{l}1.13525 E-17 \\
2.08219 E-01\end{array}$ \\
\hline $\begin{array}{l}\text { Co } \\
\text { SE } 19\end{array}$ & $\begin{array}{l}2.08210 E \text { O1 } \\
1.4 A 121 E-02\end{array}$ \\
\hline RA 01 & $9.66485 E-07$ \\
\hline SR $\quad 39$ & $5.82602 E-06$ \\
\hline & $\begin{array}{l}3.283568 \\
03\end{array}$ \\
\hline & $3.28443 E 03$ \\
\hline$r 91$ & $1.08274 E-04$ \\
\hline LR 93 & $1.53632 E-01$ \\
\hline & $1.11191 \mathrm{E}-\mathrm{U}\}$ \\
\hline NB 95 & $2.41046 E-03$ \\
\hline $95 \mathrm{M}$ & 1.41981E-05 \\
\hline 109 & $5.08106 t-01$ \\
\hline RUIO3 & $1.79155 L-09$ \\
\hline & 2.22234402 \\
\hline & $3.19962 E-09$ \\
\hline RHIOG & $2.22234 E 02$ \\
\hline PDlor & $6.16947 E-04$ \\
\hline AGIIO & $1.41505 E 00$ \\
\hline CDI15H & $9.70136 E-11$ \\
\hline IN115 & $3 . \cap 3912 E-13$ \\
\hline IAIISH & $4.24708 E-15$ \\
\hline SNIZ1M & $2.47625 E-03$ \\
\hline SNIZ3 & $2.16945 E-02$ \\
\hline SNI26 & $1.34156 E-03$ \\
\hline
\end{tabular}

\begin{tabular}{|c|c|}
\hline$G I$ & ACEN \\
\hline SET & $8.12128 E-C 9$ \\
\hline & \\
\hline seiz & $5 B E-C_{4}$ \\
\hline 581264 & $1.34356 E-[3$ \\
\hline DEI2S & I.13170E CI \\
\hline IELI & $8.42586 \mathrm{E}-03$ \\
\hline IEL127M & $8.60230 E-C 3$ \\
\hline IE 129 & 1.9290 IE-13 \\
\hline & \\
\hline 1129 & $E-c 4$ \\
\hline $\operatorname{cs} 134$ & $4.78938 \mathrm{E} 02$ \\
\hline & $5.13574 E-C 3$ \\
\hline & $5.561 \mathrm{COE}-40$ \\
\hline cs & $3.32494 E$ OS \\
\hline $3 \mathrm{~A}$ & $1.78146 E-40$ \\
\hline EAL $37 \mathrm{M}$ & $3.14539 E$ CB \\
\hline OALI 40 & $3.21443 E-3 \theta$ \\
\hline LAL & $3.69925 \mathrm{SE}-38$ \\
\hline CEI & $3.58305 E-12$ \\
\hline CELS & $1.00687 E-C 6$ \\
\hline CEI & $1.16838 \mathrm{CE} C 3$ \\
\hline PRI & I.055IIE-35 \\
\hline$p_{k 1}$ & $1.16042 E \mathrm{C}^{3}$ \\
\hline PRis & 1.4U2CIE CI \\
\hline NO14 & $5.34387 E-11$ \\
\hline
\end{tabular}

\begin{tabular}{|c|c|}
\hline SUTOF & LACEN IRA \\
\hline 1 & $1.044,3 E-$ \\
\hline & \\
\hline PMISO & $0.610,7 E-12$ \\
\hline PML 48M & $1.24536 E-10$ \\
\hline .54161 & 1.678CLE-07 \\
\hline 5.4148 & $7.592 \geq 2 E-13$ \\
\hline $5 M 149$ & $1.68156 E-13$ \\
\hline SMLSI & $1.300 I 3 E$ OL \\
\hline EUIS2 & 2.985 ZIE-OI \\
\hline EuIS4 & d.SIUESE OI \\
\hline EUISS & $3.923 \mathrm{C6E}$ OL \\
\hline EULS6 & $3.08360 E-33$ \\
\hline 60152 & $5.24413 E-15$ \\
\hline 10160 & $1.2360 \mathrm{LE}-07$ \\
\hline$i<208$ & $1.85466 \mathrm{E}-04$ \\
\hline $98<12$ & $5.113 \div 3 E-04$ \\
\hline e1212 & $5.173 \mathrm{COE}-04$ \\
\hline PCi216 & $5.17559 E-04$ \\
\hline RN220 & $5.17560 E-04$ \\
\hline RA224 & $3.17560 E-04$ \\
\hline IH228 & $5.19516 E-04$ \\
\hline 4232 & $9253 \mathrm{dE}$ \\
\hline 62 & $0.66945 E-04$ \\
\hline 0235 & $6.11043 E-06$ \\
\hline 4236 & $1.81425 E-04$ \\
\hline
\end{tabular}

I SUICPE

\[ 238 \]
NP237
PU236

PU236

PU238

PU2J9

PU240

PU241

PU242

AM241

AM242M

AM243

CA242

CM243

CM244

CM245

CM246

CM241

CA248
BK2 499

BK2 249
CF 249

CF 250

CF25I

CF 252

CGNCENIRATICN

3.11151E-0?

$1.15554 \mathrm{E}-02$

$1.21260 E$ 02

$9.82467 E-01$

T. $22079 E-C 1$

1. $31315 E$ O2

9.214IE OC

$1.21411 E$ OC
$1.49010 E-03$

$1.49078 \mathrm{~T}-03$

$1.68002 \mathrm{E}-03$

$4.23925 E-03$

$0.06644 E-04$

$4.74845 E-02$
$1.93361 E-0 E$

1.

$1.09425 E-13$

B. $456895-12$

$1.160496-12$

$4.60066 \mathrm{E}-12$

$1.94202 E-14$

$4.92754 E-1.3$
$8.47233 E-44$

TOTAL ACTIVITY 1.91 O4 Ci/assY MEAT GENERATION, watts/esSY Primary 4.23 o1 
TABLE 7.10

ISOTOPIC CONTENT Ig/assembly) OF A MAAK 160

\begin{tabular}{|c|c|c|c|c|c|c|c|c|}
\hline \multicolumn{2}{|c|}{ ISOIOPE } & CUNCENIRATIUN & I SUTOPE & CCNCENIRATICA & I SCTUPE & CCNCENIRATION & I SOTCPE & CONCENIRAIICN \\
\hline & 3 & $1.91231 E-04$ & N+103 & $2.04227 E-C I$ & It 130 & 1.004 (1t 01 & 60155 & $1.45 C 88 E-C 1$ \\
\hline & 3 & $2.95001 E-04$ & RHIOJN & $2.10395 E-44$ & 1121 & $1.03573 \mathrm{EE} 00$ & GO156 & $3.78364 \mathrm{E}-01$ \\
\hline & 51 & T.34124E-03 & RHIC6 & $t .53627 E-11$ & $112 y$ & $4.053 C 4 E 00$ & G0151 & $9.03057 E-04$ \\
\hline CR & 51 & $3.41072 \mathrm{E}-02$ & PCIC4 & $5.03037 E-C 1$ & XEI3i & $2.149 E I E-C 7$ & 60150 & 1.crotge-oi \\
\hline co & 60 & $4.90960 E-03$ & PDios & S.18800E CO & $x \in 132$ & $1.52456 E-17$ & 60160 & $5.21368 \mathrm{E}-03$ \\
\hline NI & 60. & $3.05167 E-02$ & Pu106 & $3.05043 E 00$ & $\operatorname{csi33}$ & $4.26 \forall C 4 E$ OI & 10159 & $1.21421 E-02$ \\
\hline GF 1 & 12 & $2.33131 E-04$ & PoICT & $1.198348 \mathrm{CO}$ & csist & $1.277 \leq 2 t-02$ & TO160 & $0.10623 \mathrm{E}-21$ \\
\hline GF; ? & 73 & $9.52072 E-04$ & Poice & $6.14540 E-C 1$ & csiss & $4.57462 E 00$ & or 160 & $1.06967 \mathrm{E}-0 \mathrm{~A}$ \\
\hline GE & 14 & $2.55114 E-03$ & PC110 & $2.13602 \mathrm{E}-\mathrm{Cl}$ & CSIB & $3.04434 E$ OI & ortbi & $1.30355 t-03$ \\
\hline GE 7 & 16 & I.ALSB3E-02 & AGico & $2=83570 \mathrm{E}-\mathrm{Cl}$ & SAl 34 & 2.080 cot 00 & uris & 5.190 OCE-C4 \\
\hline As 1 & 15 & $6.02024 E-03$ & Aullo & $1.3008 E E-C \theta$ & BAL36 & I.ZIIEIE-OI & IIZCy & $1.42261 \mathrm{E}-12$ \\
\hline SE & 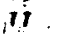 & 3.3958 IE-D2 & ccilo & $5.59171 E-12$ & Bais? & 1.579160 OI & PQZCQ & 1.SI BCSE-OE \\
\hline SE & 18 & $8.56460 \mathrm{E}-02$ & cail & $1.57 \in 58 E-C 1$ & GALIJIM & $4.63876 E-06$ & PB212 & $8.39214 E-1 C$ \\
\hline SE 7 & 79 & $2.12365 E-01$ & Ccliz & $1.14911 t-c 1$ & Jaiso & $4.11000 \mathrm{O} 1$ & 81212 & $1.45961 E-11$ \\
\hline SWE 8 & 80. & $5.11361 E-01$ & Co11? & $2.06061 E-C 3$ & LAI39 & $4.50370 E$ OI & P0216 & $3.34849 E-15$ \\
\hline SE & 42 & $1.0364 \mathrm{TE} 00$ & CC114 & $2 \cdot C 5047 E-C 1$ & CEIAO & $4.454580 \mathrm{OI}$ & RN220 & $1.26416 E-12$ \\
\hline$\theta R^{\prime}$ & nI & $0.6601861 t-01$ & CCIISM & $4.10219 E-40$ & CEIGI & $1.593 \mathrm{ESE}-50$ & RA224 & $1.3205 t t-c s$ \\
\hline KR: & 92 & $3.44110 E-41$ & CDI16 & $5.84944 E-C 2$ & CEIS? & 4.193 JOE OL & IH 228 & $1.422 B 2 t-06$ \\
\hline$R B$ & 85 & 4.46553100 & laits & $c .16309 \mathrm{E}-\mathrm{C2}$ & CElat & 4.5053 IE-05 & 6232 & $5.59115 E-05$ \\
\hline$R B$ & $\forall i$ & $1.10355 E$ or & INIISM & $1.55889 \mathrm{E}-46$ & PA(A) & 4.156 ICE OI & U234 & $1.05833 \mathrm{E}-01$ \\
\hline SA & B8 & $1.60021 E$ OI & $\operatorname{sil116}$ & $2.06928 E-C 2$ & PR144 & $2.10354 E-09$ & (2335 & $2.82137 E$ OC \\
\hline SR R & ng & $1.47919 E-31$ & shiti & $5.616 C 7 E-C 2$ & PRIG4H & $1.05135 t-11$ & 4236 & $2.81254 t$ OC \\
\hline SR Y & 90 & $1.01322 E$ OL & snilo & I.CTOIZE-CI & No142 & $2.111 \leq 5 \hat{E}-01$ & 1236 & 1. 10433E OC \\
\hline & & $2.14466 E$ OI & SAlis & I.C3207E-CI & No143 & \$.15361E OI & MP231 & $1.93946 E$ OC \\
\hline$v=9$ & & $4.110206-03$ & SN120 & $1.08121 E-01$ & NO14h & 4.551 COE OI & Puz36 & $1.91316 \mathrm{E}-06$ \\
\hline & $9 i$ & $1.62394 E-26$ & SniziM & $4.37709 E-C 5$ & NDiss & 2.12912601 & PU230 & G.54rust OC \\
\hline 9 & 90 & $8.33 B I S E$ OO & $\sin 122$ & $1.21555 E-C 1$ & 10146 & $2.28 B E S E$ OI & PU239 & 1.580491 OI \\
\hline in 9 & 91 & 2.680 SGE OL & $5 A 123$ & T.90018E- IS & NO148 & 1.211 isE DI & Puz 40 & $3.11244 E$ OC \\
\hline ZR 9 & 92 & $2.74062 E$ OI & $\operatorname{sn} 124$ & $1.92459 E-C I$ & Nuiso & $4.94913 E$ 00 & Pu241 & $8.125916-01$ \\
\hline CR 9 & 93 & $3.19032 \mathrm{E}$ OI & SA126 & $0.128+2 \mathrm{E}-\mathrm{Cl}$ & PM147 & $1.16240 \mathrm{E}-0 \mathrm{i}$ & PU242 & $2.55152 t-01$ \\
\hline IR 9 & 94 & $3.02229 \mathrm{OEI}$ & seizi & 1.1211 IE-CI & PA168 & $1.25010 E-43$ & $\operatorname{Am} 2+1$ & $0.33455 E-01$ \\
\hline IR 9 & 95 & $0.10356 E-25$ & 50123 & $1.45843 t-(1)$ & PMisam & $1.394(4 E-41$ & AM242 & $1.76135 E-09$ \\
\hline in 9 & 96 & $3.01005 E$ Oi & 58124 & $2.71325 E-31$ & SMist & 9.67345600 & $\triangle M 242 M$ & $1.673211-04$ \\
\hline NA 9 & 95 & $1.00561 E-24$ & SE125 & 5.3396 TE-03 & $5 M 148$ & $2.31131 \mathrm{E} 00$ & A 4243 & $0.41423 t-03$ \\
\hline No . 9 & 954 & $6.09202 E-28$ & Se126 & $2.26910 E-C 9$ & 54149 & $4.52111 \mathrm{t}-01$ & $\mathrm{CN} 242$ & $3.56154 t-01$ \\
\hline MO ? & 95 & $3.06633 t 01$ & $58126 \mathrm{M}$ & $1.10936 \mathrm{E}-11$ & SMiso & 1.17664E OI & $\mathrm{CM}_{243}$ & 1.22554 E-05 \\
\hline м0 9 & 96 & $1.11165 E-01$ & $1 E 122$ & $2.63866 E-C 3$ & SHISi & $4.13655 \mathrm{E}-01$ & CA244 & $4.00312 k-04$ \\
\hline & 91 & $2.91060 E$ O1 & IEI24 & $1.22531 E-C 3$ & SAL52 & 3.051 IOE OO & CA245 & $1.12241 E-05$ \\
\hline & & 2.931916 O1 & $1 E 125$ & $2.50822 E-01$ & SM154 & 6.05153E-01 & CM246 & $5.02080 E-01$ \\
\hline MClO & & $3.1785 T E$ OI & IEI25H & $1.58461 E-C 5$ & Euisi & $5.63263 E-02$ & CH24] & $2.04221 E-C 5$ \\
\hline ic ? & & $2.79816 E$ OI & $1 E 126$ & $9.03233 E-C 3$ & Evis2 & $5.66032 E-04$ & CM248 & $4.654 C 6 E-11$ \\
\hline RUIO & & 3.1641IE-OI & IEI27 & $2.60970 E-19$ & EU153 & 2.261 EQE OO & Bर249 & I.5958IE-1E \\
\hline RUIO & & 2.571335 O1 & IE12 IM & $1.45440 E-11$ & EUIS4 & $1.40577 E-01$ & CF 249 & $2.84011 E-13$ \\
\hline RUIO: & & $2.23469 E$ OI & 16128 & $2.67286 E 00$ & Ev155 & $1.92229 \mathrm{E}-02$ & CF 250 & $2.411815-14$ \\
\hline RUIO & & $1.07016 \mathrm{E}-41$ & IE129 & $1.114365-33$ & Golse & $4.31826 E-04$ & CF 231 & $1.21530 E-14$ \\
\hline RUIO & & $1.01482 E$ OI & IEIT9M & $1.20592 E-30$ & 60154 & 3.367 JEE-OI & CF252 & $0.62237 \mathrm{~F}-11$ \\
\hline RUIO & & $6.96945 E-05$ & & & & & & \\
\hline
\end{tabular}


TABLE 7.11

(Ci/assembly) OF A MARK 168

SEMBLY - 15 YEARS

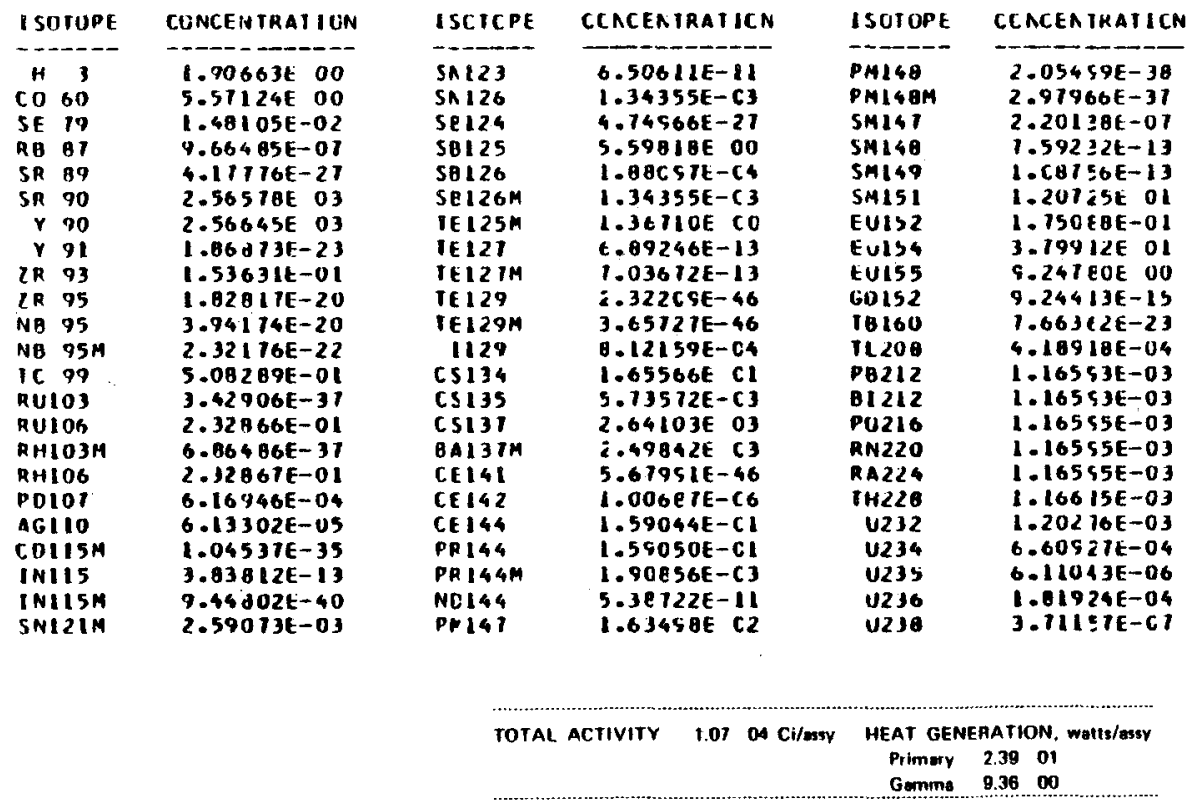

\begin{tabular}{|c|c|}
\hline UTC & CNCENTAATICI \\
\hline NP231 & $1.3660 \div E-03$ \\
\hline PUZ36 & $1.01634 \mathrm{E}-03$ \\
\hline PUZ38 & $1.12050 E 02$ \\
\hline PUz39 & $9.82184 E-01$ \\
\hline PLZ40 & $7.21315 E-01$ \\
\hline PUzal & 0.19830801 \\
\hline & $5.73759 E-C 4$ \\
\hline $\begin{array}{l}104241 \\
A M 2\end{array}$ & $2.860 \mathrm{AE}$ OC \\
\hline AMR 2 & $1.42432 \mathrm{E}-03$ \\
\hline$\triangle M 242 H$ & $1-43146 E-03$ \\
\hline AM243 & $1.079245-03$ \\
\hline$C M 242$ & $1.1013 \theta 0-03$ \\
\hline CMZ43 & $6.325 C B E-04$ \\
\hline Cri244 & $3.23836 \mathrm{E}-02$ \\
\hline CM245 & $\begin{array}{l}1.93203 \mathrm{E}-0 \mathrm{E} \\
1.93\end{array}$ \\
\hline CA246 & $1.54220 E-01$ \\
\hline CM2 41 & $1.89429 \mathrm{E}-13$ \\
\hline$C M 248$ & $1.97442 E-13$ \\
\hline $3 k 249$ & $2.66431 \mathrm{~L}-15$ \\
\hline$F 24$ & $1.16599 E-12$ \\
\hline & $0014 E-$ \\
\hline 51 & 1.9278 \\
\hline & $3.56024 E$ \\
\hline
\end{tabular}
Gemma 9.36 
TABLE 7.12

ISOTOPIC CONTENT (g/O /SEMbIY) OF A MARK 22

\begin{tabular}{|c|c|c|}
\hline \multicolumn{2}{|c|}{ I SOTOPE } & CONCEN IRA I ION \\
\hline & & $2.93815 E-04$ \\
\hline & & $1.23504 E-04$ \\
\hline & & $4.44962 E-03$ \\
\hline CA & 51 & $1.47699 k-23$ \\
\hline co & 60 & $1.112566-02$ \\
\hline NI & 60 & 1.03851E-02 \\
\hline GE & 12 & $2.118116-04$ \\
\hline GE & 13 & B.8T\&C7E-04 \\
\hline & 14 & $2.35901 \mathrm{E}-03$ \\
\hline GE & 16 & $1.6438 .7 E-02$ \\
\hline As: & 15 & $5: 46009 E-03$ \\
\hline SE. & 17 & $3.06616 E-02$ \\
\hline SE & p & $1.12167 E-02$ \\
\hline SE & 19 & I.ABI 95E-0I \\
\hline SE & 80 & $9.52518 E-01$ \\
\hline SE. & B2 & $9: 13960 \mathrm{E}-01$ \\
\hline$B R$ & BI & $1.65163 \mathrm{E}-01$ \\
\hline$\times R$ & 82 & $3.19463 E-41$ \\
\hline & 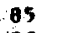 & $3.94019 E$ 0O \\
\hline R日: & B! & $9.12928 E 00$ \\
\hline SR: & 88 & 1.411B4E OI \\
\hline SR & 89 & $1.17553 E=10$ \\
\hline SR & 90 & $2.04504 E 01$ \\
\hline & A9 & 1 .B9OTRE OI \\
\hline & 90 & $5.32142 E-03$ \\
\hline & 91 & 3.80753E-09 \\
\hline IR & 90 & $2.8 B 564 E 00$ \\
\hline $2 \mathrm{R}$ & 91 & $2.36327 E 01$ \\
\hline IR & 92 & $2.41649 E 01$ \\
\hline IR & 93 & 5.18810E Ol \\
\hline IR & & $2.66422 E 01$ \\
\hline $2 R$ & & $4.59453 \mathrm{E}-08$ \\
\hline $\begin{array}{l}2 R \\
\text { NB }\end{array}$ & & $2.65309 E$ O1 \\
\hline NB. & 95 & $5.30850 E-08$ \\
\hline mo & 95 & $\begin{array}{l}3.215916-11 \\
2.101916 \text { OI }\end{array}$ \\
\hline mo & 96 & $1.663946-01$ \\
\hline MO & & $2.56643 E 01$ \\
\hline mol & & $2.50509 E 01$ \\
\hline & & $2.64213 E$ OI \\
\hline RUI & & $3.19915 E-01$ \\
\hline RUI & & 2.265316 \\
\hline RUI & & 1.91641601 \\
\hline RU1 & & $5.33817 E-14$ \\
\hline $\begin{array}{l}\text { RUI } \\
\text { RUI }\end{array}$ & & $8.75185 E 00$ \\
\hline RHI & & $1.14843 \mathrm{E}-01$ \\
\hline & & $1.04949 E-$ \\
\hline
\end{tabular}

\begin{tabular}{|c|c|}
\hline CIGP & CNCENTRATI \\
\hline RH106 & $5.4451 .8 E-C 8$ \\
\hline Pulou & I. $54543 \mathrm{E}$ CO \\
\hline P0IOS & $4.55923 E 00$ \\
\hline P0106 & $2.58601 E 00$ \\
\hline Po107 & 1.0541JE CO \\
\hline polc B & $5.38131 E-C 1$ \\
\hline poi1o & l.855ETE-Ci \\
\hline$A 6109$ & $2.45935 E-C E$ \\
\hline AGIIO & $2.40866 \mathrm{E}-04$ \\
\hline $\operatorname{ccilo}$ & $5.42639 E-C 2$ \\
\hline Ccil: & $!-40140 E-C !$ \\
\hline coili & I.03414E-CI \\
\hline Co113 & $2.15013 E-C 3$ \\
\hline ccii & $1.85300 \mathrm{E}-\mathrm{Cl}$ \\
\hline CDIISM & $1.61451 \mathrm{E}-15$ \\
\hline CO116 & 8.94893E-C2 \\
\hline iniis & $5.3840 I E-C 2$ \\
\hline IAIISM & $6.15345 \mathrm{E}-22$ \\
\hline SA116 & $2.80514 E-02$ \\
\hline SAl1 & $8.70731 \mathrm{E}-02$ \\
\hline SAile & $5.17493 E-C 2$ \\
\hline SNIII & $9.36124 E-C 2$ \\
\hline $5 A 120$ & $9.19969 E-02$ \\
\hline SNIZIM & $4.53310 E-C 5$ \\
\hline SA122 & $1.100 E 1 E-01$ \\
\hline SA123 & $2.34331 \mathrm{E}-\mathrm{CG}_{6}$ \\
\hline SA 124 & I.T3ITIE-CE \\
\hline SA 125 & $6.56024 E-60$ \\
\hline $\sin 126$ & $4.24557 E-C I$ \\
\hline 38121 & I.0107SE-CI \\
\hline $5 e 123$ & $1.31100 \mathrm{~B}-\mathrm{Cl}$ \\
\hline SB124 & $4.95120 E-13$ \\
\hline 58125 & $6.0 T 1 E I E-C 2$ \\
\hline 58126 & $2.02143 E-C 9$ \\
\hline $58126 M$ & $1.53633 \mathrm{E}-11$ \\
\hline IEI 22 & $2.65001 \mathrm{E}-\mathrm{C} 3$ \\
\hline IEII4 & $1.24152 E-C 3$ \\
\hline IE 125 & $1.60946 \mathrm{E}-\mathrm{Cl}$ \\
\hline IEI25M & $8.62450 E-C 4$ \\
\hline & E.C1984E-C3 \\
\hline IE $\{2\}$ & $2.81264 E-C 9$ \\
\hline IEIRTM & $8.034 C 9 E-C 7$ \\
\hline IEI 28 & $2.38320 E \mathrm{CO}$ \\
\hline IEI29 & $1.51010 E-21$ \\
\hline IEIZ9M & $8.62496 E-18$ \\
\hline TE130 & $8.89562 E$ CO \\
\hline 1127 & $9.213195-C 1$ \\
\hline 1129 & $4.13156 \mathrm{E} C O$ \\
\hline
\end{tabular}

\begin{tabular}{|c|c|}
\hline עו & CNCEAIRAI \\
\hline$|1+1|$ & $4.319: 2 E$ \\
\hline$X E[31$ & $1.03169 E-07$ \\
\hline$X E 132$ & $1.29532 t-11$ \\
\hline $\operatorname{csi33}$ & $3.743 \mathrm{S \theta E}$ OI \\
\hline $\operatorname{css} 134$ & $3.36049 \mathrm{E}-01$ \\
\hline csiss & $5.0843 \forall E 00$ \\
\hline $\operatorname{cs} 130$ & $1.13617 E-43$ \\
\hline Esi & $3.31736 E$ OI \\
\hline BAI34 & $1.61258 E$ OO \\
\hline BA136 & $1.11714 E-01$ \\
\hline UA1364 & $0.26189 E-52$ \\
\hline UAL31 & $5.5 C$ S6E GU \\
\hline DALBIM & $5.14620 E-06$ \\
\hline UALS & 4.ISUEAE OI \\
\hline BAI & $3.153 \leq 1 E-43$ \\
\hline CA139 & $3.57260 E$ OI \\
\hline $\operatorname{lA} 140$ & $5.66130 t-44$ \\
\hline CEI4O & $3.92389 \mathrm{E} \mathrm{OI}$ \\
\hline CE14I & $1.078 C 6 E-16$ \\
\hline CE142 & $3.69384 E$ OI \\
\hline CEI & $3.20163 \mathrm{E}-01$ \\
\hline PRI & $9.66849 E$ OI \\
\hline PHI & $1.338<0 E-40$ \\
\hline PH144 & $1.35347 \mathrm{E}-03$ \\
\hline PR 144M & $0.16125 E-C E$ \\
\hline NU142 & $1.82830 \mathrm{E}-02$ \\
\hline NO143 & $3.69551 E$ OI \\
\hline No144 & $3.67252 E$ OI \\
\hline NU145 & $2.39953 E$ O1 \\
\hline & $1.930: 26$ o1 \\
\hline & $1.10030 E-50$ \\
\hline$N O 148$ & $1.12684 E$ OL \\
\hline No150 & $4.36312 E 00$ \\
\hline PMISI & $2.09935 E$ O0 \\
\hline PMIS & $4.544 \leq 9 E-11$ \\
\hline PMi & $5.51354 E-15$ \\
\hline SML4T & $0.26752 E 00$ \\
\hline SNI \& & $2.20954 E 00$ \\
\hline 54149 & $4.21341 \mathrm{E}-01$ \\
\hline SMI & $1.06648 \mathrm{E} 01$ \\
\hline SMISL & $4.98912 E-01$ \\
\hline SMLS & $3.24242 E 00$ \\
\hline SMIS & $5.32410 E-01$ \\
\hline Evisi & $1.52358 E-02$ \\
\hline EUIS & $1.482: 7 E-03$ \\
\hline & 00 \\
\hline & \\
\hline & \\
\hline
\end{tabular}

\begin{tabular}{|c|c|}
\hline uic & CNG \\
\hline 1 & 5.9312 \\
\hline 60152 & $3.95244 E-C 4$ \\
\hline Go154 & $1.50725 E-01$ \\
\hline 60155 & $8.49201 E-C Z$ \\
\hline CD156 & $5.01326 E-01$ \\
\hline 60151 & $0.10047 E-04$ \\
\hline Go158 & 9.454 EIE-CZ \\
\hline G0160 & $4.6245 E E-0]$ \\
\hline 18159 & $1.12494 E-02$ \\
\hline $1 B 160$ & $1.07740 E-11$ \\
\hline DY 160 & $7.05377 E-04$ \\
\hline BY161 & $1.15917 \mathrm{E}-\mathrm{C} 3$ \\
\hline Dr 162 & $7.90109 t-04$ \\
\hline $112 \mathrm{CE}$ & $3.12517 \mathrm{E}-13$ \\
\hline PBLCE & $1.21139 E-0 E$ \\
\hline Pष212 & $1.84358 \mathrm{E}-1 \mathrm{C}$ \\
\hline 01212 & $1.74049 E-11$ \\
\hline PU216 & $1.35914 E-16$ \\
\hline $\operatorname{RN} 220$ & $2.778256-13$ \\
\hline$K A 2<4$ & $1.600 \mathrm{~d} 7 \mathrm{E}-05$ \\
\hline IHZ22O & $3.13825 E-01$ \\
\hline 0232 & $2.05328 E-05$ \\
\hline 0234 & $1.7115 \leq 6-02$ \\
\hline$\sqrt{23} 3$ & $2.83326 E$ OC \\
\hline 0236 & $1.12995 E$ OC \\
\hline 0238 & $0.83473 E-01$ \\
\hline NP236 & $3.82991 E-01$ \\
\hline NP231 & $1.45100 E 00$ \\
\hline PU236 & I.CTSEAE-OE \\
\hline PU231 & $1.10066 \mathrm{E}-16$ \\
\hline Q 0238 & $5.61043 E$ OC \\
\hline Qu239 & 1.278B4E O1 \\
\hline PUz40 & $2.31312 E$ OC \\
\hline Pu241 & $1.10516 E$ OC \\
\hline Puz 42 & $2.00201 E-01$ \\
\hline$A M 241$ & $3.00912 E-01$ \\
\hline AMZ4Z & $1.69221 E-C S$ \\
\hline$A M 242 M$ & $1.41542 E-04$ \\
\hline$A M Z 43$ & $1.49403 E-05$ \\
\hline CA24 & $1.10214 E-0 E$ \\
\hline$C A 243$ & $1.42451 E-05$ \\
\hline CA244 & $5.883 C 4 E-0 E$ \\
\hline CN245 & $1.368 z 1 E-01$ \\
\hline $\operatorname{CN246}$ & $5.83114 E-05$ \\
\hline CM241 & $2.83855 E-11$ \\
\hline & \\
\hline & \\
\hline & \\
\hline
\end{tabular}


TABLE 7.13

(SOTOPIC CONTENT (Ci/essembly) OF A MARK 22

ASSEMBLY - 5 YEARS

\begin{tabular}{|c|c|c|}
\hline & OTOP & UNCEN IRAI \\
\hline & & $84022 \mathrm{E}$ \\
\hline & 5i & 6.8B094E-18 \\
\hline & 60 & $1.26249 E \mathrm{OI}$ \\
\hline & 19 & $1.31248 E-02$ \\
\hline & 87 & $0.52090 E-01$ \\
\hline SR & 69 & $5.01474 E-06$ \\
\hline SR & 90 & $2.89382 E \quad 03$ \\
\hline & 90 & $2.29457 E$ O3 \\
\hline & 91 & $9.33274 E-05$ \\
\hline & 93 & $2.102865-01$ \\
\hline & 75 & $9.65073 E-04$ \\
\hline & 95 & $2.08000 \mathrm{E}-03$ \\
\hline & & $1.22564 E-05$ \\
\hline & & $4.47929 E-01$ \\
\hline RU1 & & $1.71049 E-09$ \\
\hline RUI & & $1.93955 E \quad 02$ \\
\hline & $103 \mathrm{M}$ & $3.42634 E-09$ \\
\hline & & $1.93995 E 02$ \\
\hline pot & & $5.42703 E-04$ \\
\hline$A G 1$ & 110 & $1.31129 E 00$ \\
\hline CDi & iism & $4.12641 E-11$ \\
\hline INE & & $3.35251 E-13$ \\
\hline INI & $115 n$ & $3.12945 E-15$ \\
\hline SN! & & $2.68257 E-0$ \\
\hline & & $1.92981 E-02$ \\
\hline
\end{tabular}

\begin{tabular}{|c|c|}
\hline ISCIOPE & CCACENIRAIIIC \\
\hline $5 A 126$ & $1.2 C 7 E 4 E-C 3$ \\
\hline 58124 & $6.66126 E-09$ \\
\hline SBI2S & $t=36354 E C 1$ \\
\hline SEI26 & $1.69056 E-C_{4}$ \\
\hline$S B 126 M$ & $1.20154 E-C 3$ \\
\hline TE125M & $1.55449 E \mathrm{CI}$ \\
\hline IE12\} & $7.42645 E-03$ \\
\hline IEIRTM & $1.58392 E-C 3$ \\
\hline IE 129 & $1.66080 E-13$ \\
\hline IEI29M & $2.61515 E-13$ \\
\hline 1129 & $1.22256 E-C 4$ \\
\hline $\operatorname{csi34}$ & $4.61436 E \mathrm{CZ}$ \\
\hline$C 5135$ & $5.06203 E-03$ \\
\hline C5i36 & $5.27359 E-40$ \\
\hline $\operatorname{cs}(3)$ & $2.92993 E$ C3 \\
\hline BA136M & $1.68760 E-40$ \\
\hline EAL37K & $2.77111 \mathrm{C}$ C3 \\
\hline $\begin{array}{l}\text { BALCO } \\
\text { CA140 }\end{array}$ & \\
\hline $\begin{array}{l}\text { LA } 140 \\
\text { CE } 141\end{array}$ & $\begin{array}{l}3.15204 E-38 \\
3.071 C 1 E-12\end{array}$ \\
\hline CEI42 & e.86839E-C7 \\
\hline CE144 & $1.02333 E \mathrm{C} 3$ \\
\hline PRIS3 & $9.00632 E-36$ \\
\hline PA144 & $1.02337 \mathrm{CB}$ \\
\hline PR144M & $1.229 C 2 E \mathrm{CL}$ \\
\hline
\end{tabular}

TOtal ACrivitr 1.68 OA Ci/OSOS

\begin{tabular}{|c|c|c|c|}
\hline I SUIUPE & GLACENIAATION & I SOICPE & CCNCENIRAIICN \\
\hline $\begin{array}{l}\text { No144 } \\
\text { NO14t }\end{array}$ & $\begin{array}{l}4.584 C 7 E-11 \\
8.89456 E-46\end{array}$ & $\begin{array}{l}\mathbf{U 2 3 6} \\
\mathbf{U 2 3 8}\end{array}$ & $\begin{array}{l}1.11859 E-04 \\
2.2970 E E-01\end{array}$ \\
\hline phis? & 1.94ISIE 03 & NP236 & $5.04510 E-C 5$ \\
\hline PMLI4O & $E .12021 \mathrm{E}-12$ & NP231 & $1.02259 E-03$ \\
\hline PMLSUM & $1.1185 J E-10$ & PU236 & 5.DIAISE-C? \\
\hline $\sin 147$ & $1.42639 \mathrm{E}-07$ & PU231 & $1.32810 \mathrm{E}-12$ \\
\hline SMISt & $6.92169 E-13$ & PU230 & $9.60202 E 01$ \\
\hline SHitg & $1.01214 E-13$ & PU239 & $1.94124 E-01$ \\
\hline SH151 & $1.21163 \mathrm{O}$ OI & PU240 & $5.25932 \mathrm{E}-\mathrm{O} i$ \\
\hline EU152 & $2.68541 E-01$ & PU241 & $1.11561 E$ 02 \\
\hline EU154 & $1.80539 E$ OI & PU242 & $1.64045 E-04$ \\
\hline EU155 & $3.836 C 0 E$ OI & $A M 24 I$ & $1.03301 E$ OC \\
\hline Euis6 & $3.26176 \mathrm{E}-33$ & AM242 & $1.36846 E-03$ \\
\hline G1) 152 & $8.461 C 4 E-15$ & $A N 242 M$ & I.J1S3 ZE-OS \\
\hline 10160 & $1.21670 \mathrm{E}-07$ & $A M 243$ & $1.49659 E-05$ \\
\hline 11200 & $9.20230 E-C 5$ & CA242 & $3.651711 E-03$ \\
\hline$P 8212$ & $2.56129 \mathrm{E}-04$ & CN243 & $1.35201 E-04$ \\
\hline 01212 & $2.56118 \mathrm{E}-04$ & CM244 & $4.15843 E-04$ \\
\hline P0216 & $2.56246 E-04$ & CH245 & $2.35512 E-C E$ \\
\hline RN220 & $2.56246 E-04$ & CM246 & I.19111E-05 \\
\hline RA224 & $2.56246 E-04$ & CM24) & $2.63290 E-15$ \\
\hline TH228 & $2.57211 E-04$ & CA248 & $3.11915 E-15$ \\
\hline & $41225 E-04$ & $B \times 249$ & $0.34633 \mathrm{E}-16$ \\
\hline & 34 & CF 249 & $1.12302 E-16$ \\
\hline
\end{tabular}
Primery 3.69 o1 
TABLE 7.14

ISOTOPIC CONTENT (g/assembly) OF A MARK 22
ASSEMBLY - 15 YEARS

ISOTUPE CONCENIRAIIUN

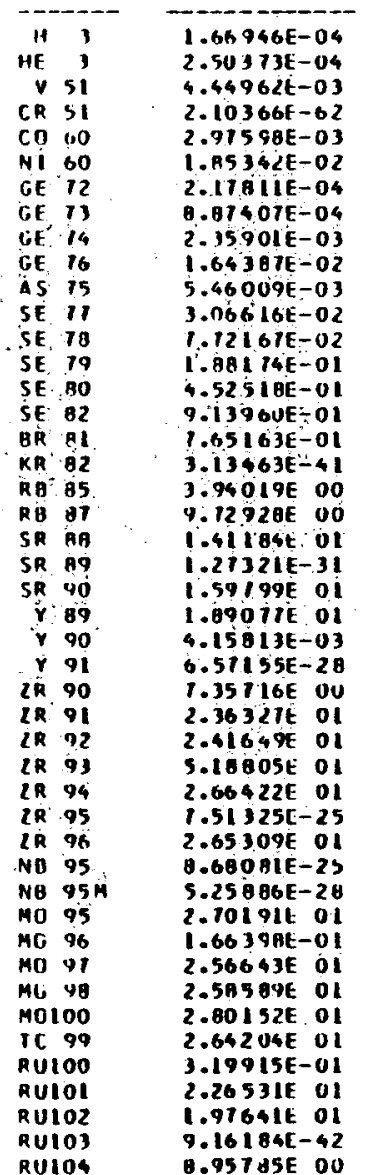

I SUICPE

CLNCENIRATICA

RE $6.08384 E-C 5$

Rhiloe

PoIC 4

PDIOS

PUIC6

Polc

Poice
PoIIO

Asiog

Alilio

CCI10

CCIII

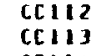

-10
$.0033 E-C 1$

$5.16510 E-11$

$1.54543 E$ CO

$4.55923 E 00$

2.044018 co

$5.38131 E-01$

1.89581E-CI

$2.45935 t-C$

$1.26065 E-C \theta$

$3.45538 \mathrm{E}-\mathrm{C2}$

$1.40140 E-C I$

1.C3414E-C1

CC114 $1.85380 t-C$

CDIISM $\quad 3.601$ C3E-40

COI16 $\quad 0.94853 E-C 2$

INIISM l.36024E-46

SN116 2.80514E-C

$\begin{array}{ll}\text { SAI11 } & 8.1 C 731 E-C 2 \\ \text { SNI18 } & 5.11453 \mathrm{E}-\mathrm{CL}\end{array}$

Sn!19

Y.36124E-C2

SA1:O S.19969E-C

SA121M 3.54590E-C

SA122

SA 124

$1.02152 E-15$
$1.13111 E-c 1$

SA 126

$4.24994 E-01$

1.OICBIE-C1

SBI23

SEI 24

$2.69459 \mathrm{E}-31$

SB125 4.19327E-C

SQ12EM $1.53632 E-11$

IE122 $2.69881 E-C$

IE124 $1.24152 E-03$

TEI25 $2.256 E 3 E-C$

IEI25M T.808ESE-CS

IE126 $0.02219 E-C$

IE 121

IEI IIM

$2.30015 \mathrm{E}-19$

$0.51151 E-11$
$2.30520 E$ CO

COACEN IRATION

$\begin{array}{ll}\text { TELI29M } & 1.030 \text { alE-5C } \\ \text { TEI30 } & 8.09542 E \text { OO }\end{array}$

$4.270 i 9 t-01$

$4.13756 E$ OO

1.031 EQE-07

$1.29532 \mathrm{E}-17$

$3.14358 t 61$

$1.230640-02$

$3.08438 t 00$
$2.08266 E$
2.01

$2.68266 E 01$

1.11714E-O1

$1.24551 \mathrm{E} \mathrm{OI}$

4.COTETE-06

4 . 15UEAE CI

$3.57260 E$ OI

I. ICUSSE-5O

$3.65364 t$ OI

$4.36623 E-C 5$

$4.36623 E-C S$
$3.66849 E ~ 01$

$1.04240 E-09$

$9.21104 E-12$
$1.02830 E-01$

$1.62830 E-01$
$3.69551 \mathrm{OL}$

3.90459t OI

$2.39953 E$
1.930
.126

1.12664 OI

$4.36312 E$ 0O

$1.49428 \mathrm{E}-01$

$1.17924 t-43$

I.315C2t-41

D.217EAE 0O
2.28954 OD

1.06048E OI

4.066486
$4.63058 \mathrm{O}-01$
3.244242600

$4.630582-01$
$3.24242 E$ OO

$5.32910 \mathrm{t}-01$

$5.30951 t-02$

0.693 : $3 E-O 4$

2.050 IE 00

$1.30251 t-01$
$1.01952 E-C 2$

$3.55244 E-04$

goisa

60155

G0156

G0151

60160

IB154

OY 160

DYiti

or 162

IL2CA

PB20日

PHZ12
O1212

01212

PO216

RN22C

IHL2O

प232

U234

0235
0236

U238

NP2 236

NP23

PUL36

PU230

PU259

PU240

Puzal

PU242

AM242

AM242

CML 42

$\mathrm{CM} 243$

CM244

CM245

CM246

CM241

CA248

CF 249

$3.1225 E E-C 1$

$5.01326 E-01$

O.100STE-UG

$9.62458 E-03$

1.12894t-0z

$1.05317 E-C 4$

$1.15917 \mathrm{E}-03$

1.901 C $5 e-04$

7.cujcat-1?

. $14065 E-1 C$

$.93665 E-16$
.934 Et- 11

$1.65534 t-15$

$3.61495 E-05$

1.033 IIE-OI

a. $16652 \mathrm{E}-\mathrm{CS}$

7.7113 JE-0z

$2.03326 E$ OC

$1.12953 E \mathrm{CC}$

$6.83413 \mathrm{JE}-01$

$6.03474-01$
$3.82414 t-01$
$1.43099 t$ CC
$9.45740 E-01$

8.019IAE-4I

5.18430 OC

1.2784 IE OL

2.31068E OC

$6.90041 E-01$

$2.00150 t-01$

. $016035-05$

$1.016836-05$

$97 t-0$

$3.27481 t-0$ ?

1.11 ICIE-OS

.01213E-0E

$1.36 \mid C 9 E-07$

2.0385eE-11

1. $35222 E-13$

$2.14041 E-17$ 
TABLE 7.15

ISOTOPIC CONTENT (Ci/assembly) OF A MARK 22

ASSEMBLY - 15 VEARS

\begin{tabular}{|c|c|c|c|c|c|}
\hline I SOTOPE & CONCENIRATICN & I SETCPE & CCACEAIRAIICN & I SUIUPE & CCACEN IRATIION \\
\hline+3 & $1.61382 E 00$ & $5 n 123$ & $5.78144 \mathrm{E}-11$ & PHIAB & $1.53051 E-38$ \\
\hline $\cos 60$ & $3.37103 E$ 00 & $5 n 126$ & $1.20154 \mathrm{E}-03$ & PMISUM & $2.01017 t-37$ \\
\hline SE TO & $1.31234 E-02$ & SBIEA & $4.71699 E-27$ & SHIAT & I.B7013E-OI \\
\hline RB $8 T$ & $8.52090 E-01$ & 58125 & $5.02531 \mathrm{E} \mathrm{CO}$ & $\operatorname{SAl} 48$ & $6.92169 t-13$ \\
\hline 5n 84 & $3.54601 E-21$ & 58126 & $1.69055 E-04$ & $\sin 149$ & $1.01219 E-13$ \\
\hline SR 90 & 2.26122603 & SBI264 & $1.20754 E-C 3$ & SHISI & I.18024E O1 \\
\hline$r 90$ & $2.26181 E 03$ & TE125N & $1.22720 E \mathrm{CO}$ & EVI52 & $1.515 C 4 t-01$ \\
\hline Y 91 & $1.610715-23$ & IE121 & $6.07650 E-13$ & Eviss & $3.520 C 5 E$ O1 \\
\hline 2R 93 & $2.10285 E-01$ & IE127M & $6.20368 E-13$ & Eviss & $9.04359 E \quad 00$ \\
\hline IR 95 & $1.57815 E-20$ & 11129 & $1.99916 E-46$ & 00152 & $8.461 C 4 E-15$ \\
\hline NB 95 & $3.40266[-20$ & IC129M & $3.14066 t-46$ & 18160 & $1.54266 E-23$ \\
\hline NB $95 \mathrm{M}$ & $2.00424 E-22$ & 1125 & $7.22255 E-C 4$ & IL 208 & $2.070 \subseteq 3 E-04$ \\
\hline IC 99 & $4.41915 E-01$ & c5134 & $1.59516 \mathrm{E}$ OI & PBZIZ & $5.163 \mathrm{E} 1 \mathrm{E}-04$ \\
\hline Ruto3 & $2.03569 E-37$ & $c \subseteq 135$ & $5.86202 E-C 3$ & 01212 & $5.16360 E-04$ \\
\hline RUI 06 & $2.03276 E-01$ & $\operatorname{csi37}$ & $2.32727 E \mathrm{CB}$ & P0216 & $5.16353 \mathrm{E}-04$ \\
\hline RHIOSM & $5.81115 E-31$ & OA137M & $2.20160 E \mathrm{CB}$ & AN 220 & $5.76353 \mathrm{E}-04$ \\
\hline RH106 & $2.03276 E-01$ & CEI4! & $4.86821 E-46$ & RA224 & $5.16353 E-04$ \\
\hline P0101 & $5.42103 E-04$ & $C t 142$ & R.EO839E-CI & TH228 & $5,164 E \theta E-04$ \\
\hline AG110 & $5.94335 E-05$ & CE144 & $1.39300 E-C 1$ & 0232 & $5.54579 E-C 4$ \\
\hline CoIisN & $9.11525 E-36$ & PRi44 & $i .393 \mathrm{CsE}-\mathrm{Cl}$ & 0234 & 4.815 TSE-04 \\
\hline INIIS & $3.352511-13$ & PHis4N & $1.67163 t-03$ & U2J5 & $6.123168-06$ \\
\hline INII5M & $0.29258 E-40$ & N0144 & $4.62204 E-11$ & 0236 & $1.11859 E-04$ \\
\hline SN121M & $2.33504 E-03$ & PP147 & $1.38 \in 24 E \mathrm{CZ}$ & 0238 & $2.297(6 E-C)$ \\
\hline
\end{tabular}

\begin{tabular}{|c|c|}
\hline & 80 \\
\hline NPZ11 & $1.0225 E E-03$ \\
\hline & $5.02411 t-04$ \\
\hline Pu231 & $1.06464 E-36$ \\
\hline PU238 & $0.07273 E 01$ \\
\hline Puz39 & $7.94495 \mathrm{E}-01$ \\
\hline PUट40 & $5.25376 E-01$ \\
\hline Pu241 & 6.9619 CE O \\
\hline PU242 & $1.64035 \mathrm{E}-04$ \\
\hline AMPQ1 & \\
\hline AM? & $\begin{array}{l}2.431180 \text { oC } \\
1.30745 t-03\end{array}$ \\
\hline $\begin{array}{ll}A M 242 \\
A M 2421\end{array}$ & $1.31401 E-C$ ? \\
\hline AMR 3 & $1.49518 \mathrm{E}-05$ \\
\hline CM242 & $1.00444 E-03$ \\
\hline$M 243$ & $5.16474 E-04$ \\
\hline CA244 & $3.24516 E-04$ \\
\hline $\operatorname{cs} 245$ & $2.153205-08$ \\
\hline & \\
\hline & \\
\hline & $6329 \mathrm{CE}-13$ \\
\hline 248 & $11909 E-15$ \\
\hline $3 \times 24$ & $.62548 E-19$ \\
\hline 5249 & $.12192 t-1$ \\
\hline
\end{tabular}

TOTAL ACTIVITY $9.4403 \mathrm{Cl} /$ assy 
TABLE 7.16 ISOTOPIC CONTENT (g/assembly) OF A MARK 31 A

\begin{tabular}{|c|c|c|c|c|c|c|c|}
\hline I SOTOPE & CONCENIRATIUN & ISUTUPE & CCACENIRATILN & I SUTUPt & CCNCEN IRATILN & I SUICPE & CCACENIRAIICN \\
\hline H 3 & $3.64403 E-05$ & R+103H & $4.41203 E-17$ & 1129 & $1.046(9 E-0)$ & EULSS & C. $15354 E-C 2$ \\
\hline HE 3 & $1.54957 E-05$ & HHICG & $3.17259 \mathrm{E}-\mathrm{C} 8$ & 1131 & $2.811 \leq 4 E-69$ & Evis6 & $4.00088 E-3 E$ \\
\hline$v 51$ & $1.80 J 39 E-03$ & PDI04 & $2.51804 E-C 2$ & $X E 131$ & $1.192<4 t-01$ & Gu152 & $1.15010 \mathrm{E}-05$ \\
\hline CR 51 & $3.0253 \mathrm{LE}-23$ & polus & $1.47667 E \mathrm{CO}$ & $X E 132$ & $0.62444 E-18$ & 60154 & $5.11193 \mathrm{t}-03$ \\
\hline Co 60 & $4.50139 E-03$ & PDico & $1.18954 E$ CO & $\operatorname{csc3s}$ & $5.2 A 1 \leq 1 E 00$ & 60155 & $2.9325 \in E-02$ \\
\hline NI 60 & $4.201180 E-03$ & PDIOI & $1.21014 t-C 1$ & [51]4 & $6.30561 E-0.3$ & 60156 & $1.20495 E-01$ \\
\hline GE 12 & $9.25505 E-05$ & POICA & $4.837 C 6 t-C 1$ & $\operatorname{cstus}$ & $5.40142 E-01$ & Gulst & $2.504 C 9 E-03$ \\
\hline GE 13 & $2.18633 \mathrm{E}-\mathrm{U} 4$ & pol10 & $1.62057 \mathrm{TE}-\mathrm{CI}$ & 65136 & $6.850<0 E-45$ & Goiso & $4.46584 E-02$ \\
\hline GE 74 & $4.40341 E-04$ & AGLOQ & $3 . C 7350 E-C I$ & $\operatorname{csi3} 1$ & 4.59243600 & 60160 & $4.01692 \mathrm{E}-0 ?$ \\
\hline GE 76 & $2.21161 E-03$ & AGIIO & $c .32184 t-C 5$ & WAISY & $3.13244 E-02$ & 18159 & $0.36916 E-C ?$ \\
\hline as 75 & $9.33979 E-U 4$ & Coilo & $1.03570 t-C 2$ & UALIS & 3. j06 15E-02 & 10160 & $2.12151 E-12$ \\
\hline SE II & $3.40755[-03$ & ccili & $C .83102 E-C 2$ & BAI JGM & C.ULULIE-52 & urico & $5.66] C 8 E-05$ \\
\hline SE 78 & 1.00BSIE- U2 & col12 & $C .34183 E-C 2$ & UA137 & $0.536 \geqslant 1 E-01$ & uriol & $1.95500 E-03$ \\
\hline SE T? & $2.51379 t-02$ & colis & $7.02305 E-C 3$ & UALIPM & $6.45164 E-07$ & JYi6z & 1.10911E-03 \\
\hline $5[00$ & $5.64404 E-02$ & col14 & $5.25052 E-C 2$ & OALBH & $5.2 \leq 261 E$ OC & $12<0 \theta$ & $0.38584 E-15$ \\
\hline SE B2 & 1.12441E-01 & CCIISM & $2.139316-15$ & UAI 40 & $1.059: 1 E-43$ & PALUE & $9.21261 t-13$ \\
\hline UR AI & $9.68138 \mathrm{E}-02$ & Co116 & $3.95666 \mathrm{E}-\mathrm{C2}$ & LAIBS & $5.11455 E 00$ & $P B<12$ & $4.44653 \mathrm{E}-16$ \\
\hline KR 82 & $9.09891 E-42$ & IA115 & $4.24447 E-C 2$ & LAl40 & $2.004<2 E-44$ & 81212 & $4.64114 E-11$ \\
\hline RB 85 & $4.29481 t-01$ & INIISM & $0.12 \theta \leq 1 E-22$ & CElou & 5.01 , 60E OO & PQ216 & I.SIZSSE-2I \\
\hline RB OI & $1.09113 \mathrm{E} .00$ & SAl16 & $3.34158 E-C 3$ & CEt41 & $3.12212 \mathrm{E}-17$ & AN 220 & $7.44865 E-15$ \\
\hline SR AB & $1.50715 E .00$ & Sn127 & $4.03945 E-C 2$ & CE142 & $4.668 J 2 E 00$ & RAL24 & $4.31342 E-15$ \\
\hline SR 89 & $3.871316-11$ & $\operatorname{sit18}$ & $4.02414 E-C 2$ & CEI44 & $4.600 ? 3 E-02$ & $\operatorname{IH} 22 \theta$ & $0.35955 \mathrm{E}-13$ \\
\hline SR 90 & $2.16483 E 00$ & SA119 & $4.01159 E-C 2$ & PHiti & $4.74043 E$ OO & 0232 & $1.55524 \mathrm{E}-11$ \\
\hline$r 89$ & $2.00451 E 00$ & $\sin 120$ & $4.09255 E-C 2$ & PAI \& & $6.18930 E-41$ & 0234 & $1.42444 E-11$ \\
\hline$\checkmark 90$ & $5.63111 \mathrm{t}-04$ & $\operatorname{sil} 121 \mathrm{~A}$ & $1.11056 E-C 5$ & PAl 44 & $1.94114 E-06$ & 6235 & $1.20018 E-01$ \\
\hline $9 \mathrm{i}$ & A.06968E-10 & SN122 & $4.52321 E-C 2$ & PHI४4M & $5.70 S ! I E-09$ & U236 & 3.J3TEAE-03 \\
\hline iR 90 & $2.91041 E-01$ & $\sin 123$ & $1.25431 E-C 6$ & No142 & $2.421(6 E-0) 3$ & U238 & $1.02619 E 01$ \\
\hline ZR 91 & $2.57614 \mathrm{E} 00$ & $5 n 124$ & $6.06533 E-C 2$ & NLO163 & $6.15452 E 00$ & NP231 & $1.21204 E-02$ \\
\hline IR 92 & $2.11837 f$ OO & SA125 & $1.09614 E-59$ & Nuls. & $4.25173 E$ OO & Pu2 36 & $000+340 E-12$ \\
\hline 2R Q3 & 3.04ค B6E OO & SA126 & I. $1993 \mathrm{PE}-\mathrm{CI}$ & Nulas & 3.14643500 & Pu238 & $1.26153 E-04$ \\
\hline iR 94 & $3.15103 E$ OO & 58121 & $4.25176 E-02$ & Nij146 & $2.537 t 6 E 00$ & Pu239 & $1.96113 E-01$ \\
\hline ZR 95 & $1.05536 E-08$ & SB123 & $5.119 \forall B E-C 2$ & No14 7 & 5.901 ZUE-51 & Puz40 & $4.585 C 9 E-02$ \\
\hline iR 96 & $3.32821 E 00$ & 58124 & $6.00014 E-14$ & Nulad & 1.55822000 & Pu241 & $5.120236-03$ \\
\hline NB 95 & $1.21236 \mathrm{E}-00$ & SE12E & $2.39017 E-C 2$ & Nolso & $7.31005 E-01$ & PU242 & $2.13365 \mathrm{SE}-04$ \\
\hline NB 95N & $1.38690 E-12$ & $5 e 126$ & $5.7 C 46$ CE -10 & PMLST & $4.81671 t-01$ & AHZ4I & $1.336686-02$ \\
\hline MO 95 & 3.35309600 & $58126 M$ & $4.33560 \mathrm{E}-12$ & PM148 & $6.64771 E-18$ & AM242 & $4.18541 E-1 C$ \\
\hline & $1.41172 \mathrm{E}-03$ & 16122 & $2.06319 E-C 4$ & PM140M & $1.41518 E-16$ & $A M Z 42 M$ & $4.002566-05$ \\
\hline MO 91 & $3.35843 E$ OO & IE124 & $5.81409 E-C 5$ & $\sin 147$ & $1.33410 E 00$ & AML4 3 & $4.04810 E-0 E$ \\
\hline MO 98 & $3.44525 E \quad 00$ & IE125 & $0.18511 E-02$ & $\operatorname{Sin} 440$ & $7.534: 7 E-02$ & CM242 & $2.09258 E-01$ \\
\hline MOLOO & $9.83255 E$ UO & IEILSN & $3.39514 E-C 4$ & $5 M 149$ & $1.71816 E-01$ & CM243 & $4.89169 E-01$ \\
\hline 1699 & $3.59495 E$ OU & $1 E 126$ & $2.22512 \mathrm{E}-\mathrm{C} 3$ & $\sin 150$ & l.UIItie ou & CM244 & $6.52966 E-0 E$ \\
\hline RULOO & $9.07126 t-03$ & IE127 & $1.10461 E-C 9$ & $\sin 151$ & $2.58838 E-01$ & CH245 & $3.12061 E-I C$ \\
\hline RU101 & $3.30128 E$ OO & IE127M & $3.15 \leq 23 \mathrm{E}-\mathrm{C7}$ & SML152 & $3.149(4 E-0)$ & CM246 & $3.51380 E-12$ \\
\hline RU102 & $3.06311 t$ No & $1 E 128$ & $4.66552 \mathrm{E}-\mathrm{Cl}$ & 5,4154 & $1.36251 E-01$ & CM247 & $3.66001 E-15$ \\
\hline RUIOS & $2.49746 E-14$ & IE 129 & 4.CI5TIE-2I & EUISI & $S . S \angle 142 E-C 3$ & CM248 & $1.92565 E-11$ \\
\hline RUIO4 & $2.09 \mathrm{~d}+8 E$ OO & TELI29M & $4.41 C 58 E-18$ & EU152 & $4.84 ל$ ISE-04 & $8 \times 249$ & $1.05654 E-23$ \\
\hline PUIO6 & 3.3A285E-02 & IEI3U & 1.4608 IE CO & EUISs & $2.621 \leq 7 E-01$ & CF 249 & $5.80164 E-22$ \\
\hline
\end{tabular}


TABLE 7.17

ISO TOPIC CONTENT (CI/assembly) OF A MARK 31A

\begin{tabular}{|c|c|c|}
\hline & CIOPE & CONCEN IRAI ION \\
\hline & 3 & $3.56124 E-01$ \\
\hline & 51 & $2.1 A 415 E-18$ \\
\hline & & $5.10803 E 00$ \\
\hline & 19 & $1.75314 E-03$ \\
\hline RB & 87 & $7.12344 E-08$ \\
\hline SR & & $1.093400-06$ \\
\hline & & $3.06332 E \quad 02$ \\
\hline & 90 & $3.06412 \mathrm{c}^{\circ} \quad 02$ \\
\hline & 71 & $1.91774 \mathrm{E}-05$ \\
\hline & 93 & $1.23578 E-02$ \\
\hline & & $2.21676 E-04$ \\
\hline NB & 95 & $4.17957 E-04$ \\
\hline & $95 \mathrm{M}$ & $2 . A 1527 E-06$ \\
\hline & & $6.09665 E-02$ \\
\hline & & $9.00574 E-10$ \\
\hline RUI & & $1.130296 \quad 02$ \\
\hline $\mathrm{FHI}$ & $103 M$ & $1.60212 E-09$ \\
\hline RH1 & & $1.13029 E 02$ \\
\hline Po1 & & $3.14323 E-04$ \\
\hline AGI & 110 & $2.9 A 332 E-01$ \\
\hline $\cos$ & $115 \mathrm{M}$ & $5.45080 E-11$ \\
\hline INI & 115 & $2.64255 E-13$ \\
\hline $\begin{array}{l}\text { INE } \\
\text { SNI }\end{array}$ & $115 \mathrm{M}$ & $09805 t-0$ \\
\hline SN1 & & $6.92805 t-04$ \\
\hline & & \\
\hline
\end{tabular}

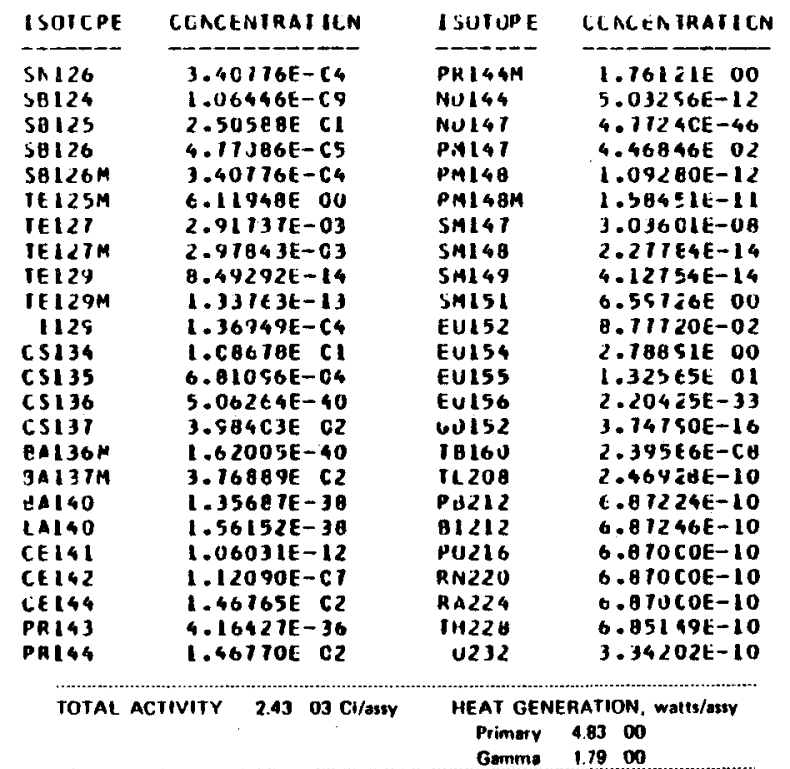

CCNCENIRATILN

0234

B. $09569 \mathrm{E}-2 \mathrm{C}$

$2.59380 \mathrm{E}-01$

$2.41163 \mathrm{E}-01$

$2.36140 E-05$

Q.5418CE-DE

$2.15905 \mathrm{E}-03$

$4.15905 E-03$
$4.94115 E-C 8$

$\begin{array}{ll}\text { PUZ40 } & 1.04251 E-02 \\ \text { PUZ41 } & 5.16586 E-01 \\ \text { PU242 } & 8.14299 E-01\end{array}$

$\begin{array}{ll}\text { PUZ40 } & 1.04251 E-02 \\ \text { PUZ41 } & 5.16586 E-01 \\ \text { PU242 } & 8.14299 E-01\end{array}$

PU242 O.14299E-0I

AM241 2.51814E-O1

AM242 $3.86911 E-04$

AM2 42M 3.88911E-04

AH243 3 C.01885-C

$\begin{array}{ll}C H 242 & 6.92952 E-C 4 \\ C M 243 & 2.52454 E-05\end{array}$

CM244 $5.28145 E-0 E$

CM245 $\quad 0.40436 E-11$

CH246 1.01931E-12

CM247 3.39401E-15

CA248 $\quad 8.17016 E-2 C$

$\begin{array}{ll}\text { BK249 } & 1.16396 E-20 \\ \text { CF249 } & 2.31513 E-21\end{array}$

Primary 4.8300 
TABLE 7.18

ISOTOPIC CONTENT (g/assembly) OF A MARK $31 A$

\begin{tabular}{|c|c|c|c|}
\hline I SOPOPE & CONCEN IRAII ICN & ISCIOPE & CCACEATHAIICN \\
\hline 3 & $2.09327 E-05$ & RLIO6 & $3.54470 E-C 5$ \\
\hline HE 3 & $3.13933 E-05$ & RHIOS & $E .18332 E-C 2$ \\
\hline$v 51$ & $1.60039 \mathrm{E}-03$ & RHIO3M & $d .43046 E-45$ \\
\hline CR 51 & $0.51178 \mathrm{E}-63$ & $R+106$ & $2.32434 t-11$ \\
\hline CU 60 & $1.204 C A E-03$ & POI04 & $2 \cdot \leq 1 \theta C 4 E-C 2$ \\
\hline NI 60 & $1.49890 E-03$ & PD105 & $1.47 E 67 E$ CO \\
\hline GE 12 & $9.25505 E-09$ & PO106 & $1.22333 \mathrm{COO}$ \\
\hline & $2.18633 E-04$ & POICI. & $1.2 / C 12 E-C 1$ \\
\hline Ge 14 & $4-40341 \mathrm{E}-04$ & POICE & $\triangle=B 3 T C B E-C I$ \\
\hline CE: 16 & $2.21161 E-03$ & POIIO & $1.62 C S 7 E-C I$ \\
\hline 15. 15 & $9.33979 E-04$ & AG 109 & 3.c735OE-Cl \\
\hline SE:II & $3.90755 E-03$ & AGIIO & $2.74262 \mathrm{E}-09$ \\
\hline SE IB & I.00851E-02 & Cc:110 & $1.04201 E-c 2$ \\
\hline SE 79 & $2.51353 E-C 2$ & $\cos 11$ & $5.831 \mathrm{CZE}-\mathrm{C2}$ \\
\hline SE 60 & $5.64404 t-02$ & $\cot 12$ & $6.39183 E-C 2$ \\
\hline SE B2 & $1.12441 E-01$ & $\cos 13$ & $1.02365 E-c 3$ \\
\hline Bर & $9.68938 E-02$ & Col14 & $5.250 \leq 2 E-C 2$ \\
\hline KA B2 & $9.09891 E-42$ & Cc115M & $4.13687 E-40$ \\
\hline RE 55 & $4.29481 E-01$ & CD116 & $3.95066 E-C 2$ \\
\hline RB .87 & $1.06173 E 00$ & In115 & $4.24647 E-C 2$ \\
\hline SA $\mathrm{dB}$ & $1.50715 E 00$ & IAIISM & $1.807416-46$ \\
\hline SR 99 & $2.17606 \mathrm{E}-32$ & $5 n 116$ & $3.36758 E-C 3$ \\
\hline SR 90 & $1.69160 E 00$ & $\operatorname{sic17}$ & $4.03945 E-C_{2}$ \\
\hline & $2.00451 E 00$ & SA118 & $6 . C 2414 E-C 2$ \\
\hline & $4.40170 E-04$ & SA119 & $4.01159 E-C 2$ \\
\hline 4 & $1.39260 \mathrm{E}-20$ & $\operatorname{sn} 120$ & $4.09295 E-C 2$ \\
\hline IR 90 & $1.64384 E-01$ & $\operatorname{SA} 1214$ & $1.01093 E-65$ \\
\hline 2R 91 & 2.57611E 00 & $5 A 122$ & $4.52521 t-c_{2}$ \\
\hline CR 92 & 2.11日3JE 00 & $\operatorname{sn} 123$ & $3.16163 E-15$ \\
\hline IR 93 & $3.04385 E$ OO & SA124 & $0.06533 E-C 2$ \\
\hline IR 04 & 3.15 TOJE DO & $5 n 126$ & $1.19936 E-01$ \\
\hline $2 A 95$ & $1.72519 E-25$ & setiz & $4.25191 E-C 2$ \\
\hline LR 96 & 3.32 82 TE OO & 58123 & $=.12000 E-C 2$ \\
\hline NB 95. & I.99396E-25 & $\operatorname{sel24}$ & $3-30933 E-32$ \\
\hline NA 95M & $1.20795 E-28$ & SB125 & $1.88654 E-C 3$ \\
\hline MO 95 & $3.35309 \mathrm{E} 00$ & 54126 & $5.70456 E-10$ \\
\hline MO 96 & $1.41172 t-03$ & $58126 M$ & $4.33558 E-12$ \\
\hline MO 98 & $\begin{array}{l}3.35843 E \\
3.40\end{array}$ & $1 E 122$ & $2.06319 E-C 4$ \\
\hline & $3.44525 E 00$ & 16129 & $5.81409 E-C S$ \\
\hline Motoo & $3.03255 E 00$ & IE125 & $8.41851 E-C 2$ \\
\hline IC 99 & 3.59484E OU & IE 125M & $2.68 C 32 E-C 5$ \\
\hline RUIUO & $9.07126 t-03$ & IE126 & $2.22595 \mathrm{E}-\mathrm{C3}$ \\
\hline RU101 & $3.30128 E 00$ & IE12! & S.C3573E-20 \\
\hline RU102 & $3.06311 E 00$ & IEIIIM & $2.5 B C S 9 E-11$ \\
\hline RU103 & $4.28809 E-42$ & IE128 & $4.66552 \mathrm{E}-\mathrm{Cl}$ \\
\hline RUIOL & $2.09898 E \quad 00$ & TE 129 & $4.906 C 4 E-\$ 4$ \\
\hline
\end{tabular}

\begin{tabular}{|c|c|c|c|}
\hline OTOPE & CCNCEN & I SUICPE & \\
\hline $29 m$ & $30915 t-51$ & 60152 & $1.15018 E-05$ \\
\hline TEI30 & $1.46067 t 00$ & 60154 & 1.CUYCBE-0Z \\
\hline 1121 & $2.39666 t-01$ & 60155 & $5.03056 E-02$ \\
\hline 1129 & $7.846 C 9 E-01$ & 60136 & $1.20455 E-C 1$ \\
\hline$X E\{1\}$ & $1.19224 t-07$ & Go1st & $2.509 C 9 E-03$ \\
\hline$x \in 132$ & $0.62444 E-18$ & GoIsA & $4.46584 E-02$ \\
\hline Cs133 & $5.281 \leq 11$ OU & G0160 & $4.07892 E-03$ \\
\hline CS134 & $2.858 E \theta t-04$ & 10159 & $8.36576 t-03$ \\
\hline $\operatorname{csiss}$ & $5.90142 t-0 !$ & 14160 & $1.31522 E-27$ \\
\hline CSIST & $3.64760 E$ OO & or $1 \in 0$ & $5.663 C \mathrm{BE}-0 \leq$ \\
\hline BA134 & $4.54159 E-02$ & OY161 & $1.955006-03$ \\
\hline BALB6 & $3.30615 t-02$ & OY 162 & $1.109116-03$ \\
\hline BAIS1 & 1.598Z3E 00 & 12200 & $3.46195 E-19$ \\
\hline $8 A 191 M$ & $5.538 \geq 0 t-07$ & PBZCG & $1.62601 \mathrm{E}-1 \mathrm{a}$ \\
\hline BA:38 & $5.252 E 1 E 00$ & PH212 & $3.22193 \mathrm{E}-16$ \\
\hline LAily & 5.11453E 0O & 81212 & $3 . \operatorname{cs585E-11}$ \\
\hline$C E 140$ & $5.01340 E 00$ & PC216 & $1.20554 E-21$ \\
\hline CEL4I & $5.90036 E-51$ & RN220 & $4.65329 E-15$ \\
\hline CE142 & $4.66872 E 00$ & RA224 & $2.81048 E-15$ \\
\hline CE144 & $6.262111 E-06$ & $\ln 228$ & $5.46153 \mathrm{E}-13$ \\
\hline PRIA1 & $4.14043 E 00$ & 4232 & $2.08454 t-11$ \\
\hline PR164 & $2.64235 E-10$ & U234 & $1.42441 E-11$ \\
\hline PR164A & $1.32115 t-18$ & 6235 & 1.20018E-01 \\
\hline No142 & 2.421 COE -03 & 0236 & 3.131C4E-03 \\
\hline AD143 & $0.154 \div 2 E 00$ & 4238 & $1.02619 E 01$ \\
\hline NO144 & 4.29113600 & NP231 & $1.212 C 4 E-02$ \\
\hline$N 0145$ & 3.14643600 & PU236 & T.04564E-13 \\
\hline NO166 & $2.33160 E$ DO & PU230 & $1.18066 E-04$ \\
\hline NOI 48 & $1.55832 E \quad 00$ & PU239 & $7.95944 E-01$ \\
\hline NO150 & $1.316 E 5 E-01$ & Puz4C & $4.50023 E-02$ \\
\hline PM141 & $3.42844 E-02$ & Pu241 & $3.19325 E-03$ \\
\hline PH160 & $1.58542 E-44$ & PuL42 & $2.13672 E-04$ \\
\hline PMLGOH & $1.16157 E-42$ & AN241 & $7.41016 E-02$ \\
\hline SMIG] & 1.781 GSE OO & $\operatorname{An} 242$ & $4.51211 E-I C$ \\
\hline 54148 & $1.53457 E-02$ & $A M 242 M$ & $3.82414 E-05$ \\
\hline 34149 & $1.71810 E-01$ & $A N 263$ & $4.0442 E E-06$ \\
\hline 54150 & 1.011 EIE 00 & $\operatorname{CA2} 42$ & $9.26063 E-08$ \\
\hline SM151 & $2.40236 E-01$ & $\mathrm{CN} 243$ & $3.83560 t-01$ \\
\hline $5 M 152$ & $5.749 C 4 E-01$ & CA244 & $4.45311 E-0 E$ \\
\hline SMLS4 & $1.302 \leqslant 1 E-01$ & CM24: & $3.11151 E-1 C$ \\
\hline EU151 & $2.05236 E-02$ & CN246 & $3.50666 E-12$ \\
\hline Evisz & $2.84211 E-04$ & CA247 & $3.66001 E-15$ \\
\hline EU153 & 621 & CN248 & $109581 F-11$ \\
\hline 0154 & 6061 & $0 \times 249$ & $3 \cdot 1$ \\
\hline EU155 & $49564 E-03$ & CF 249 & $5.79186 E-22$ \\
\hline
\end{tabular}


TABLE 7.19 ISOTOPIC CONTENT (Ci/assembly) OF A MARK 31A ASSEMBLY - 15 YEARS

ISOTUPE CONCENIRAIIUN ISUTOPE CGAC

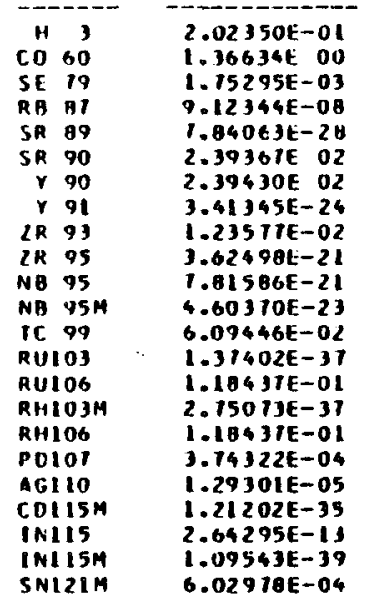

SA123 3.09785E-11

SA 126

$3.09785 E-11$
$3.40173 t-04$

ISUTUPE CCNCENIPAIIUN

ISOIGPE

CONCENIRAIIICA

PML48M $3.71851 E-3 \theta$

SM141 $4.05413 E-0 R$

SM148 $2.21114 E-14$

$\begin{array}{llll}\text { SE126 } & 4.77082 E-C 5 & \text { SM148 } & 2.27154 E-14 \\ \text { SE126M } & 3.40173 E-C 4 & \text { SM149 } & 4.121 E 4 E-14 \\ \text { IE125M } & 4.83105 E-C 1 & \text { SM151 } & 6.12313 E-00\end{array}$

IEI2TM 2.83105E-CI EUIS2 $5.14758 E-02$

IE127M 2.43637E-13 EU154 $1.24458 E 00$

IE129M $1.022914 E-46 \quad$ GO152 $3.74750 E-16$

$1129 \quad 1.36949 \mathrm{E}-\mathrm{C4} \quad 18160 \quad 1.48566 \mathrm{E}-23$

$\begin{array}{llll}\text { CS134 } 3.15692 E-C I & \text { TL208 } & 1.60832 \mathrm{E}-10\end{array}$

CS135 G.81C53E-C4 Pa212 4.47626t-10

CS137 3.16456E C2 $01212 \quad 4.47626 t-10$

BA137M $2.99367 E$ C2 $\quad$ P0216 $4.47626 E-10$

CEI4

CE144 $1.95702 E-C 2 \quad$ TH228

PRIA4 I.55789E-C2 U232 $4.47943 E-10$

PRI44M 2.39743E-C4 U234 $0.89544 E-20$

NO144 3.CB14IE-12 U2J5 $2.59300 E-C T$

$4236-2.41763 E-07$

NP231 B.54117E-0E

PU236 1.742916-1C

PU230 $2.02065 E-03$

PU239 4.94632E-02

PU240 $1.041402-02$

PU242

AM241 2.54357E-01

AM242 $3.69126 E-04$

AN242M 3.1150CE-O4

AM243 $\quad 0.01126 E^{-0}$ ?

CM242 $\quad 3.06663 E-04$

CA243 $1.97950 E-05$

CM244 $3.601 E 6 E-0 E$

CM246 I.0173E-12

CM247 $3.39401 E-15$

CM240 O.17000E-20

OK249 $5.55729 E-24$
CF249 $2.37113 E-21$

TOTAL ACTIVITY 1.14 03 Ci/sssY HEAT GENERATION, Watts/ass

(


TABLE 7.20

ISOTOPIC CONTENT (g/ansembly) OF A MARK 316

ASSEMBLY - 5 YEAAS

\begin{tabular}{|c|c|c|c|c|c|}
\hline I SUTRP & CUNCENTAATI UN & I SUIOPE & COACENIKATIICN & I SUTUPE & CCACENIKATICN \\
\hline 3 & $3.04125 E-05$ & KHIO3N & $3.83171 \mathrm{E}-17$ & 1129 & $3.602(8 E-01$ \\
\hline HE ${ }^{3}{ }^{3}$ & $1.30192 E-05$ & RHIO6 & $2.24280 \mathrm{C}-\mathrm{CB}$ & 1131 & $2.35644 E-69$ \\
\hline$\checkmark 5 i$ & $6.10537 \mathrm{E}-04$ & P0104 & $1.40449 E-C 2$ & $x \in 131$ & $1.084 C 6 E-07$ \\
\hline CR 51 & $1.02592 \mathrm{E}-23$ & poios & $1.01725 E$ CC & $X E 132$ & $8.15369 \mathrm{E}-18$ \\
\hline 1060 & $1.52633 \mathrm{E}-03$ & polo6 & $6.65952 \mathrm{E}-\mathrm{Cl}$ & (5)133 & $3.9062 B E 00$ \\
\hline NI 60 & $1.42474 \mathrm{E}-03$ & poict & $5.11851 E-01$ & CSI34 & $5.01254 \mathrm{E}-03$ \\
\hline GE 12 & $5.53713 E-05$ & $P C 1 C B$ & $3.4 C 648 E-C 1$ & $\operatorname{csis} 5$ & $3.19443 E-01$ \\
\hline GE 13 & $1.37 / 13 E-U_{4}$ & PDilc & $1.10862 E-C I$ & $\operatorname{csis} 30$ & 5.115 JOE-45 \\
\hline GE 14 & Z.dA363E-04 & AGilo? & $2.15690 E-C 1$ & Csist & $3.344 C 1 E$ UO \\
\hline GE. 16 & $1.55584 E-03$ & AGIIO & $3.65282 E-C 5$ & UÁLIS & $2.22250 \mathrm{E}-\mathrm{C2}$ \\
\hline AS IS & $6.31582 E-04$ & ceito & $5.92384 E-C 3$ & BA I 36 & $2.36832 \mathrm{E}-02$ \\
\hline SE II & $2.19837 \mathrm{E}-03$ & Ccili & $6.49111 E-C 2$ & BAI BOH & $5.068 C 2 E-52$ \\
\hline SE 18 & $1.31296 \mathrm{E}-03$ & coliz & $4.02720 \mathrm{E}-\mathrm{C2}$ & OAL3\} & $4.18556 \mathrm{E}-01$ \\
\hline SE & & C[il] & $3.82119 E-C 3$ & BALIIIH & $5.11919 E-01$ \\
\hline SE & 4.196 A4E- 02 & CC114 & S. BOC C $\theta E-C Z$ & BAI 3B & 3.9C44TE CO \\
\hline SE $B 2$ & $8.28415 E-02$ & CDIISM & $1.39619 E-15$ & OA140 & $1.65368 E-43$ \\
\hline OR BI & $1.16440 \mathrm{E}-02$ & CDI16 & $2.42721 E-62$ & LALIS & $\begin{array}{l}1.65368 E-43 \\
3.79213 E 00\end{array}$ \\
\hline KR B2 & $9.27800 E-42$ & Inils & $2.39721 E-C 2$ & LAL 40 & $2.49416 E-44$ \\
\hline AB 05 & $3.21904 E-01$ & inilsa & $5.30491 E-22$ & LEI40 & $3.72176 \mathrm{t}$ ou \\
\hline RB d? & $1.03076 E-01$ & snilio & $1.69151 E-03$ & CEI4I & $3.03910 E-11$ \\
\hline SR 9 SH & $1.13258 \mathrm{E} \cdot 00$ & salit & $2.47253 \mathrm{E}-\mathrm{C2}$ & Ct 142 & $3.47329 E$ OO \\
\hline SR Q9 & $3.11481 \mathrm{E}-11$ & SALE & $2.48050 E-C 2$ & CLIS4 & $3.472: 5 E-02$ \\
\hline SR $O 0$ & 1.63334500 & $\operatorname{sil} 119$ & $2.46585 E-C 2$ & PN141 & 3.ES18COE OU \\
\hline$Y 89$ & $1.50845 E 00$ & $\sin 120$ & $2.52302 E-C 2$ & PRIS\} & $5.49790 E-41$ \\
\hline$\because>90$ & $\$ .25010 \mathrm{E}-04$ & SALIIM & B.453SIE-06 & PR144 & $1.46513 \mathrm{E}-06$ \\
\hline $79 \mathbf{i}$ & $6.43038 E-10$ & $\operatorname{sil} 122$ & $2.79453 \mathrm{E}-\mathrm{C2}$ & PH144M & $1.325 \leq 2 E-09$ \\
\hline $2 n 90$ & $2.18766 t-01$ & $3 N 123$ & O.OSC SQE-CI & NU142 & $1.51319 E-03$ \\
\hline 2R 91 & 1.93399600 & SA124 & $3.01732 E-C 2$ & No143 & 4. ECTCYE OO \\
\hline in 92 & $2.03504 E 00$ & SA125 & $8.85006 E-60$ & NO144 & $3.16922 E$ UU \\
\hline \{R 93 & $2.27691 E 00$ & $\sin 126$ & $1.99308 E-C 2$ & Nulas & $2.330 E 5 E 00$ \\
\hline 2R 94 & $2.36145 E 00$ & SB121 & $2.63023 \mathrm{E}-\mathrm{C} 2$ & Nul46 & $1.80752 E 00$ \\
\hline LR 95 & $0.27053 E-09$ & 58123 & $3.18014 E-C 2$ & No14 & $3.27623 E-51$ \\
\hline $2 R 36$ & $2.47302 E 00$ & 58124 & $3.56239 \mathrm{E}-14$ & Nois & $1.14059 E$ OO \\
\hline NB 95. & $4.55576 E-09$ & SEI2S & $1.5492 .2 E-C 2$ & NDiso & $5.30014 E-01$ \\
\hline NO $95 \mathrm{~N}$ & $5.78091 E-12$ & SeI26 & 3.80179E- 10 & PHISI & $3.628 \mathrm{IBE}-0 \mathrm{I}$ \\
\hline MO 95. & $2.49325 E 00$ & $58126 \mathrm{M}$ & $2.00944 E-12$ & PMISO & 3.655 E6E-18 \\
\hline & $0.66615 E-04$ & IE 122 & 1.64059E-C4 & PMI4QM & 4.C76E1E-16 \\
\hline & $2.48665 \mathrm{E} 00$ & IEL24 & $5.56240 E-C 5$ & SH14I & $5.59870 E-01$ \\
\hline & 2.54135600 & IEI25 & 3.98439E-02 & SMI40 & $4.16218 E-02$ \\
\hline mo100 & $2.83398 E$ OO & TEI25M & $2.20059 E-C 4$ & $5 M 149$ & $1.3 \cos 1 t-01$ \\
\hline & $2.65499 E 00$ & IEI26 & $1.56421 E-C 3$ & SMISO & $1.1453 J E-O I$ \\
\hline Ruioo & 6.75 Q7YE-03 & IEILI & $1.04419 \mathrm{E}-10$ & Sitisi & $1.158 \leq 5 E-01$ \\
\hline Ruiot & $2.41715 E$ OO & TEIIIM & $2.24205 E-C 7$ & SHISZ & $4.2131 U E-01$ \\
\hline RUioz & $2.22317 E 00$ & IEILB & $3.284 E 5 E-C L$ & SHIS4 & $9.19056 E-02$ \\
\hline RU103 & $1.95203 E-14$ & 1E129 & $3.19250 E-21$ & EUISI & $6.124 i 6 E-C 3$ \\
\hline Rullos & $1.49244 E \quad 00$ & IEI29M & $3.45481 E-18$ & Euls2 & $3.11325 E-04$ \\
\hline RUio6 & $2.39144 E-02$ & IEI 30 & I.0SICEE OO & EU153 & $1.03830 E-01$ \\
\hline RH103 & $6.39353 \mathrm{~F}-02$ & 1127 & $1.65043 \mathrm{E}-\mathrm{Cl}$ & EUIS4 & $6.837 \geq 5 E-03$ \\
\hline
\end{tabular}

\begin{tabular}{|c|c|}
\hline DICPE & nC \\
\hline EUISS & 1.80 \\
\hline Evis6 & $3.32066 E-3 e$ \\
\hline Guisz & $1.05567 E-05$ \\
\hline GD154 & $3.42201 E-63$ \\
\hline 60155 & $1.90195 E-0 z$ \\
\hline G0156 & $0.58418 E-02$ \\
\hline GuIsi & $1.04508 \mathrm{E}-03$ \\
\hline Guisa & $3.094795-02$ \\
\hline 60160 & $2.00003 E-6 ?$ \\
\hline 18159 & $5.18015 E-03$ \\
\hline 10160 & $1.21225 \mathrm{t}-12$ \\
\hline Ur 160 & 3.351SEE-CS \\
\hline oYibl & $1.33534 \mathrm{E}-03$ \\
\hline ijY162 & $1.43153 \mathrm{E}-04$ \\
\hline 11208 & $9.82037 E-1 E$ \\
\hline$P 8200$ & $1.07880 E-O E$ \\
\hline PB212 & $5.19212 \mathrm{E}-12$ \\
\hline 81212 & $5.49436 E-13$ \\
\hline Pli216 & $2.31050 E-11$ \\
\hline AN22C & E.122EIE-IS \\
\hline AAZ24 & $5.05130 E-11$ \\
\hline I IHZ28 & $5.10951 E-0 S$ \\
\hline 4292 & 1.0212 \\
\hline U234 & $9.10505 E-1 E$ \\
\hline U235 & $1.44615 E-02$ \\
\hline 4236 & $2.153595-0 ?$ \\
\hline 0238 & $4.11112 E$ OI \\
\hline NP231 & $7.46641 E-03$ \\
\hline Pu236 & $9.384226-08$ \\
\hline PL238 & $0.68281 E-05$ \\
\hline PU239 & $3.58907 E-01$ \\
\hline PU240 & $3.41355 E-02$ \\
\hline Pu241 & $3.23854 \mathrm{E}-03$ \\
\hline Pu242 & $1.49294 \mathrm{E}-04$ \\
\hline Amzai & $4.56437 E-02$ \\
\hline AM242 & $2.42053 E-10$ \\
\hline AM242M & $2.02454 E-05$ \\
\hline AM243 & $2.292 \theta 3 E-0 E$ \\
\hline CA242 & $1.08512 \mathrm{E}-01$ \\
\hline $\operatorname{CM243}$ & $2.20290 E-01$ \\
\hline CN244 & $3.059606-08$ \\
\hline CM24s & $1.36912 E-1 C$ \\
\hline CM246 & $1.41484 E-12$ \\
\hline $\mathrm{cm} 241$ & $1.14004 E-15$ \\
\hline $\operatorname{CM} 24 \theta$ & 16 \\
\hline $8 \times 249$ & $31 E-24$ \\
\hline$C+248$ & $1.556916-28$ \\
\hline
\end{tabular}


TABLE 7.21

ASSEMBLY CONTENT (Ci/assembly) OF A MARK 318

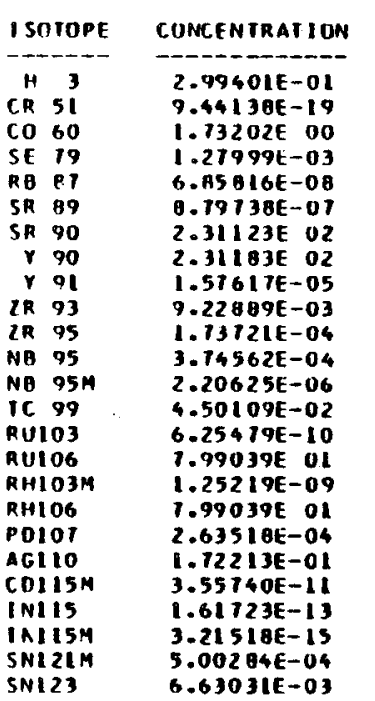

\begin{tabular}{|c|c|}
\hline I SOTUPE & CCACENIRATICN \\
\hline $\begin{array}{l}\operatorname{Sn} 126 \\
S B 124\end{array}$ & $2.271 C 8 E-C 4$ \\
\hline $\begin{array}{l}\text { SB124 } \\
\text { SH125 }\end{array}$ & $\begin{array}{l}6.23612 E-10 \\
1.62421 E-01\end{array}$ \\
\hline 58125 & $1.62421 E 01$ \\
\hline 58126 & $3.17951 E-C 5$ \\
\hline $5 B 126 M$ & $2.271 C \theta E-04$ \\
\hline IE125M & $3.56639 \mathrm{CO}$ \\
\hline TE 121 & $2.073 C 4 E-03$ \\
\hline IE12IM & $2.11643 E-03$ \\
\hline TE 129 & $6.65249 E-14$ \\
\hline TEI29A & $1.04716 E-13$ \\
\hline 1129 & S.17811E-05 \\
\hline $\operatorname{cs134}$ & $6.49620 \mathrm{COO}$ \\
\hline csi3s & $3.60301 E-C 4$ \\
\hline $\operatorname{csi} 36$ & $4.26853 \mathrm{E}-40$ \\
\hline $\operatorname{csi37}$ & $2.94872 E$ C2 \\
\hline BAL36A & $1.36553 E-40$ \\
\hline EALIII & $2.78949 E 02$ \\
\hline BA160 & $1.206 \in \theta E-3 \theta$ \\
\hline LAL40 & $1.30060 \mathrm{E}-38$ \\
\hline CELLI & $8.65736 E-13$ \\
\hline CE142 & $0.3380 \mathrm{OE}-\mathrm{C} 8$ \\
\hline CELA4 & $1.10115 E \mathrm{C2}$ \\
\hline PPI43 & $3.699 C 9 E-36$ \\
\hline & $1.10179 E$ O2 \\
\hline
\end{tabular}

\begin{tabular}{|c|c|}
\hline \multicolumn{2}{|l|}{ I surupt } \\
\hline PRIS4M & $1.32933 E$ \\
\hline Nu144 & $1.151 \leq 3 E-12$ \\
\hline Ni 147 & $4.26657 E-46$ \\
\hline PM147 & $3.36642 E 02$ \\
\hline PMI 48 & $6.00576 E-13$ \\
\hline PMISBM & $6.11390 E-12$ \\
\hline $\operatorname{Sn} 14$ & $2.21540 E-08$ \\
\hline SM16甘 & $1.25049 \mathrm{E}-14$ \\
\hline $5 M 149$ & $3.14619 E-14$ \\
\hline SMLS1 & $4.48227 E 00$ \\
\hline Eu152 & $6.83454 E-02$ \\
\hline Eu154 & 1.84780E \\
\hline EU155 & $6.51151 E 00$ \\
\hline EUL56 & $1.82949 E-33$ \\
\hline 60152 & $2.259 E 9 E-16$ \\
\hline 10160 & $1.36858 E-08$ \\
\hline 112208 & $2.891 \in 9 E-66$ \\
\hline Pu212 & C.C4786E-06 \\
\hline 01212 & E.C4E11E-06 \\
\hline P0216 & B. $C 4523 E-06$ \\
\hline RN220 & e.04523E-06 \\
\hline RA224 & $0.04323 E-06$ \\
\hline $\operatorname{tH} 228$ & $8.02355 \mathrm{E}-06$ \\
\hline & $3.51574 E$ \\
\hline
\end{tabular}

CONCENIRATICN

4234

$6.06002 E-2 C$

4235

$1.11742 \mathrm{E}-01$

$1.60350 \mathrm{E}-05$

NP231 $5.26192 \mathrm{E}-06$

PU236 4.50525E-0

PU23日 $1.14314 E-03$

PU240 $7.16134 E-0$

PU241 3.26739E-01

PU242 $5.69763 E-07$

AN241 $1.56660 E-01$

AM242 $1.95137 E-04$

AM242A 1.96118E-04

CH242 3.59335 E-04

CH243 $1.136096-05$

CK244 2.47456E-OC

CA245 2.35668E-11

CA246 $4.34565 E-13$

CH241 $1.05743 E-15$

CH248 $2.13094 E-2$

CF249 $4.13372 E-21$

TOTAL ACTIVITY 1.8003 Ci/assY HEAT GENERATION, WOIT/assY 


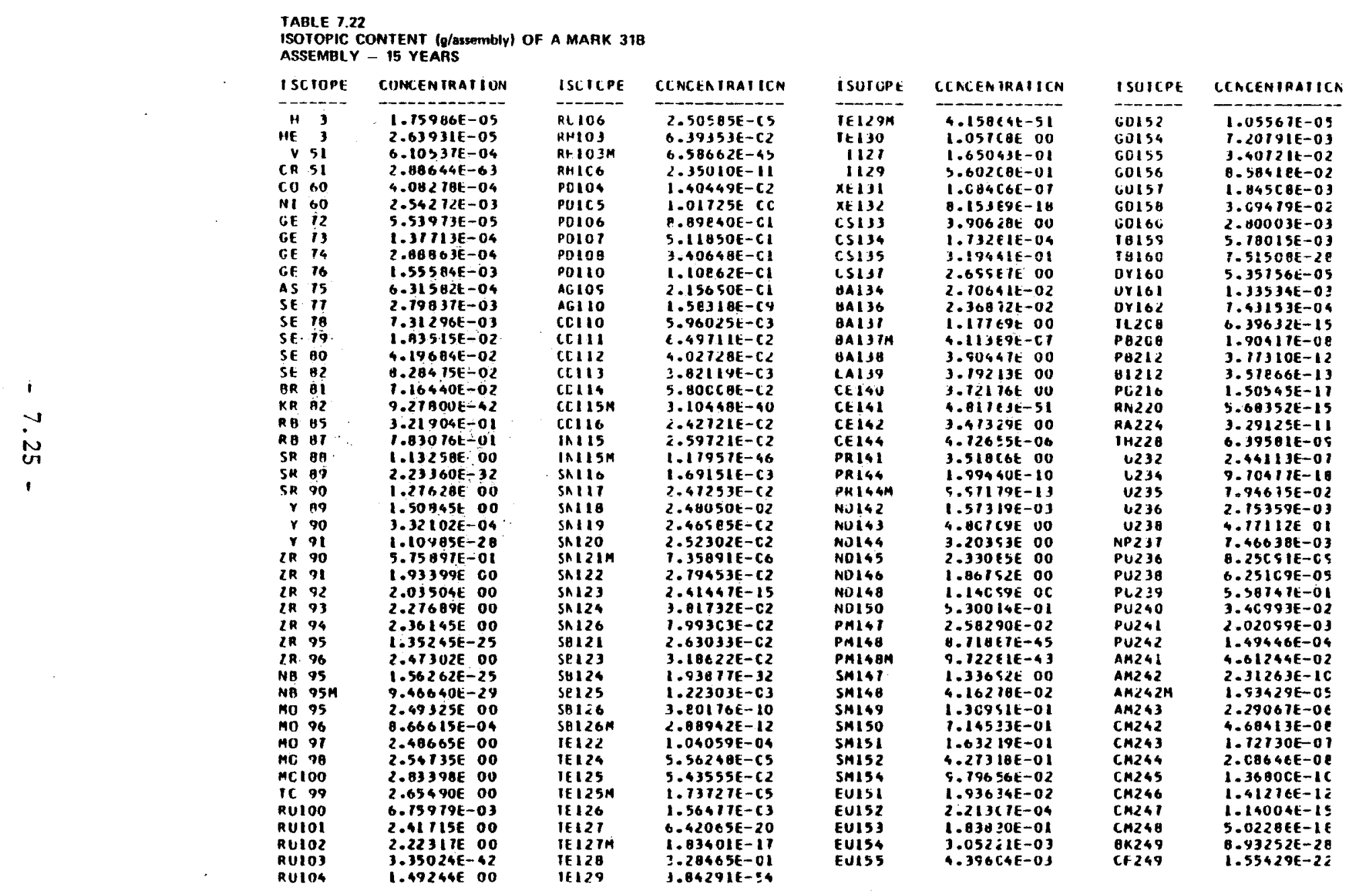


TABLE 7.23

ISOTOPIC CONTENT (Ci/sssembly) OF A MARK 318

ASSEMBLY - 15 YEARS

\begin{tabular}{|c|c|c|}
\hline & Ur & \\
\hline & 3 & $1.701206-01$ \\
\hline & 60 & $4.63299 \mathrm{E}-01$ \\
\hline SE & 19 & $1.21985 t-03$ \\
\hline RB & 87 & 6.05 म16E-08 \\
\hline SR & & $6.30849 E-20$ \\
\hline SR & 90 & $1.80599 E 02$ \\
\hline & 70 & $1.80646 E 02$ \\
\hline $2 \pi$ & 91 & $\begin{array}{l}2.12037 \mathrm{E}-24 \\
4.23883 E-03\end{array}$ \\
\hline $2 R$ & 95 & $2.04079 \mathrm{E}-21$ \\
\hline NB & 95 & $6.12507 E-21$ \\
\hline No & $95 M$ & $3.60780 E-23$ \\
\hline & & 4.50094E-02 \\
\hline $\begin{array}{l}\text { RuI } \\
\text { Rut }\end{array}$ & & $\begin{array}{l}1.07350 \mathrm{E}-37 \\
0.37200 \mathrm{E}-02\end{array}$ \\
\hline R+1 & $103 m$ & $2.14911 E-31$ \\
\hline RHI & & $0.37268 \mathrm{E}-02$ \\
\hline & & $2.63918 E-04$ \\
\hline AGI & & $1.46393 \mathrm{E}-06$ \\
\hline COI & $115 \mathrm{M}$ & $1.91004 E-36$ \\
\hline INI & 115 & $1.61723 E-13$ \\
\hline SNI & & $\begin{array}{l}7.14909 E-40 \\
4.35482 E-04\end{array}$ \\
\hline
\end{tabular}

\begin{tabular}{|c|c|}
\hline iTt & CACENIRAI \\
\hline SNIE & 1.50841 \\
\hline $5 n 126$ & $2.27106 t$ \\
\hline SE124 & $3.39389 E-2 \theta$ \\
\hline 58125 & $1.28224 E 00$ \\
\hline 58126 & $3.17948 E-C 5$ \\
\hline$S B 1264$ & $2.27106 E-04$ \\
\hline IEI? & 3.13 \\
\hline JE12 & 1.655 \\
\hline JE127M & $1.73125 E-13$ \\
\hline IE 129 & $8.001816-47$ \\
\hline IEL29M & $1.26122 \mathrm{E}-46$ \\
\hline 1129 & S.71810E-CS \\
\hline $\operatorname{csi34}$ & $2.24570 E-C I$ \\
\hline $\operatorname{cst35}$ & $3.68300 E-C 4$ \\
\hline Csist & $2.34220 E$ C2 \\
\hline EA137M & $2.21512 E(2$ \\
\hline CE141 & $1.37236 E-46$ \\
\hline CE 142 & $E .3388 \mathrm{BE}-\mathrm{CB}$ \\
\hline CE144 & $1.50192 E-C 2$ \\
\hline & 1.5CISIE-C2 \\
\hline 4 & 1. 0 cs5 3E-C4 \\
\hline & $3.79263 t$ \\
\hline
\end{tabular}

P

$\frac{\text { I SUTOPE }}{\text { PHIGT }}$ PM14

SM148
SMI48

SHISO

EUIS2 $4.16014 E 00$

EU154 8.26863 E-0

EUIS5 $2.11486 E$ 0O

GDIs2 2.235 EE-16

IL 200 (1.00345E-24

PA212 $5.24200 E-06$

B1212 5.242 COE-06

P0216 5.242 C1E-06

RN220 3.242 C1E-06

RA224 5.242 COE-06

TH228 $5.242 C 3 E-06$

J232 $3.24572 E-06$

U234 $6.06065 E-20$

HEAT GENERATION, watis/ossY Primery 1.17 Bo

\begin{tabular}{|c|c|}
\hline DICPE & ONCENTRATIC \\
\hline 0236 & $1.70112 t-07$ \\
\hline U238 & $1.60350 E-05$ \\
\hline NP231 & $5.26151 E-08$ \\
\hline PU236 & $4.38320 E-06$ \\
\hline PU238 & $1.00505 E_{-03}$ \\
\hline PU239 & $3.47229 E-02$ \\
\hline PU240 & $1.75313 E-03$ \\
\hline PU24I & $2.03900 E-01$ \\
\hline Pu242 & $5.10345 E-07$ \\
\hline AM24 & $i .58310 E-01$ \\
\hline AMR 42 & $1.87011 E-04$ \\
\hline AM242N & $1.07949 E-04$ \\
\hline$A K 243$ & $4.57153 \mathrm{E}-07$ \\
\hline CH242 & I.551RAE-04 \\
\hline $\mathrm{CA}_{243}$ & $8.91437 t-06$ \\
\hline CN244 & $1.68161 E-06$ \\
\hline C12245 & $2.3547 \in E-1$ \\
\hline inz & $4.33948 E-13$ \\
\hline CA24) & $1.05763 \mathrm{E}-18$ \\
\hline CM248 & $2.13 C O S E-2 C$ \\
\hline BK249 & $1.49134 E-24$ \\
\hline CF249 & $6.36311 E-22$ \\
\hline
\end{tabular}




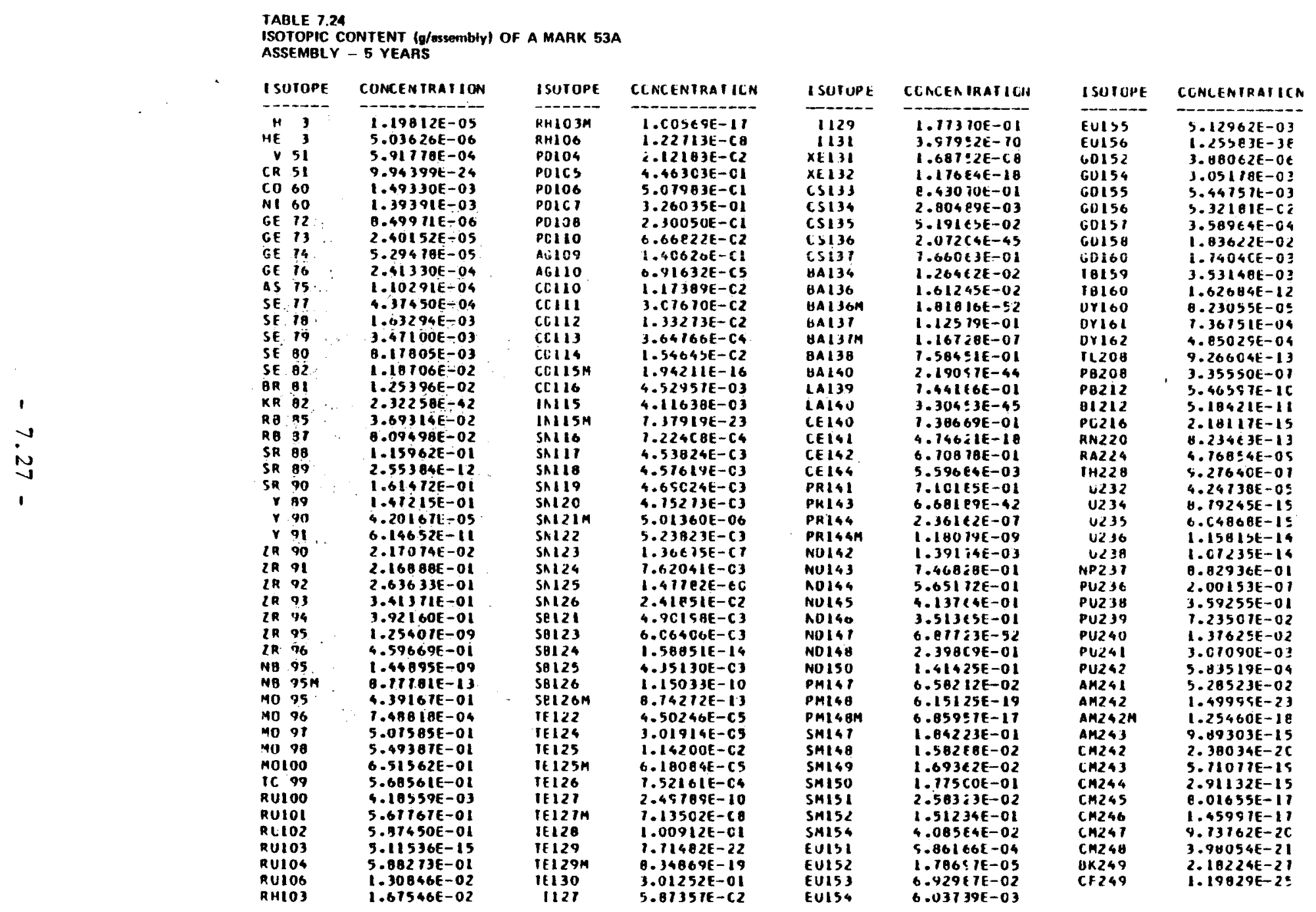


TABLE 7.25

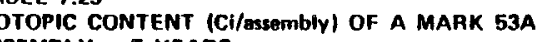

\begin{tabular}{|c|c|}
\hline I SOTOPE & NCEN TRATIION \\
\hline H 3 & $1.15810 E-01$ \\
\hline CR $5 i$ & $9.15129 E-19$ \\
\hline CO 60 & $1.69454 E 00$ \\
\hline SE 19 & $2.42011 \mathrm{E}-04$ \\
\hline RB A1 & $1.08959 E-09$ \\
\hline SA 89 & $1.21298 \mathrm{E}-00$ \\
\hline SR 90 & $2.28490 E$ OI \\
\hline$r 90$ & $2.20549 E$ OI \\
\hline$r 91$ & $1.50659 E-06$ \\
\hline 2R 93 & $1.38366 \mathrm{E}-03$ \\
\hline LA 95 & $2.63415 E-05$ \\
\hline NB 95 & $5.67952 E-05$ \\
\hline NB PSH & $3.34536 E-07$ \\
\hline & $9.63900 \mathrm{E}-03$ \\
\hline & $1.63910 \mathrm{E}-10$ \\
\hline RU106 & 4.371BTE OI \\
\hline RHIO3H & $3.28142 E-10$ \\
\hline RHIO6 & $4.37180 E 01$ \\
\hline & $1.67854 E-04$ \\
\hline 16110 & $3.26071 E-01$ \\
\hline COIISM & $4.94838 E-12$ \\
\hline INI Is & $2.56319 E-14$ \\
\hline INIISM & $4.47234 E-16$ \\
\hline SN121M & 2.96691 E-04 \\
\hline $5 N 123$ & $1.12557 E-03$ \\
\hline
\end{tabular}

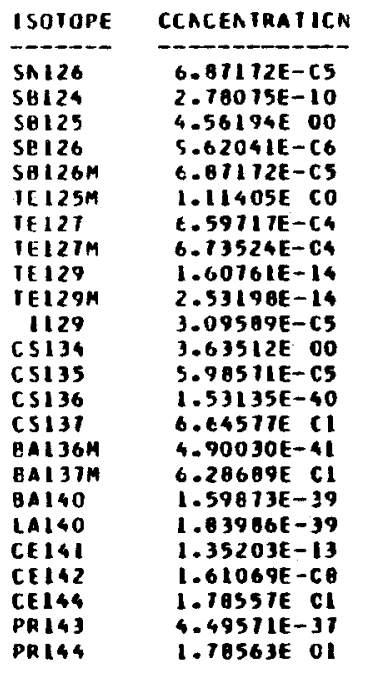

ISUTOPE

DAIGAH DOTOPE COACNIRAIION

I SOIOPE

CUNCENIRATICA

$\begin{array}{ll}2.14272 E-01 \\ \text { NO144 } & .69016 E-13\end{array}$

NO14 $\quad 5.56175 E-4$

PMIST $6.10625 E$ OI

PAI68 $1.01119 E-1$

PMIS1 1 (.

SMI4 $4.19225 E-09$

5 SAl49 $4006857 E-15$

SMLSI $\quad 0.58413 E-01$

EUI52 $3.23678 E-03$

EVIS4 l.631EIE DO

EUISS 2.467.78E 00

EU156 6.918 E9E-34

I0160 $1.037115-08$

$2.720405-04$

PE212 $7.59351 E-04$

$01212 \quad 7.593 \in 2 E-04$

7.594 E9E-0

$1.554 E 9 E-04$

?.594E9E-04

$1.60292 \mathrm{E}-04$

4232

$.12113 E-04$

$\begin{array}{ll}U 234 & 5.49 C 51 E-11 \\ U 235 & 1.30122 E-2 C\end{array}$

$U 235$
4236

$\begin{array}{ll}\text { U236 } & 7.49127 E-15 \\ \text { U238 } & 3.60399 E-2.1\end{array}$

NP237 $\quad 6.22241 E-04$

(2)

PUz39 4.49610 S1E

PU240 3.12918E-03

PU261 3.09827E-O

PU242 2.22694E-0

AM241 $1.814 C 2 E-01$

AM242 $1.21291 E-17$

AH24 $1.21965 E-1$

CM242

CM243 $3094725 E-17$

CA264 $2.354798-13$

CM265 1.37990E-17

CM246 4.48448E-18

CM267 $9.03204 E-24$

CM248 $1.68065 E-23$

BK249 3.64338E-24

TOTAL ACTIVITY $3.8202 \mathrm{Ci}$

MEAT GENERATION, walts/ssSY

Primary 8.89 -0

$$
-
$$


TABLE 7.26

ISOLOPIC CONTENT (g/assembly) OF A MARK 53 A
ASSEMBLY - 15 YEARS

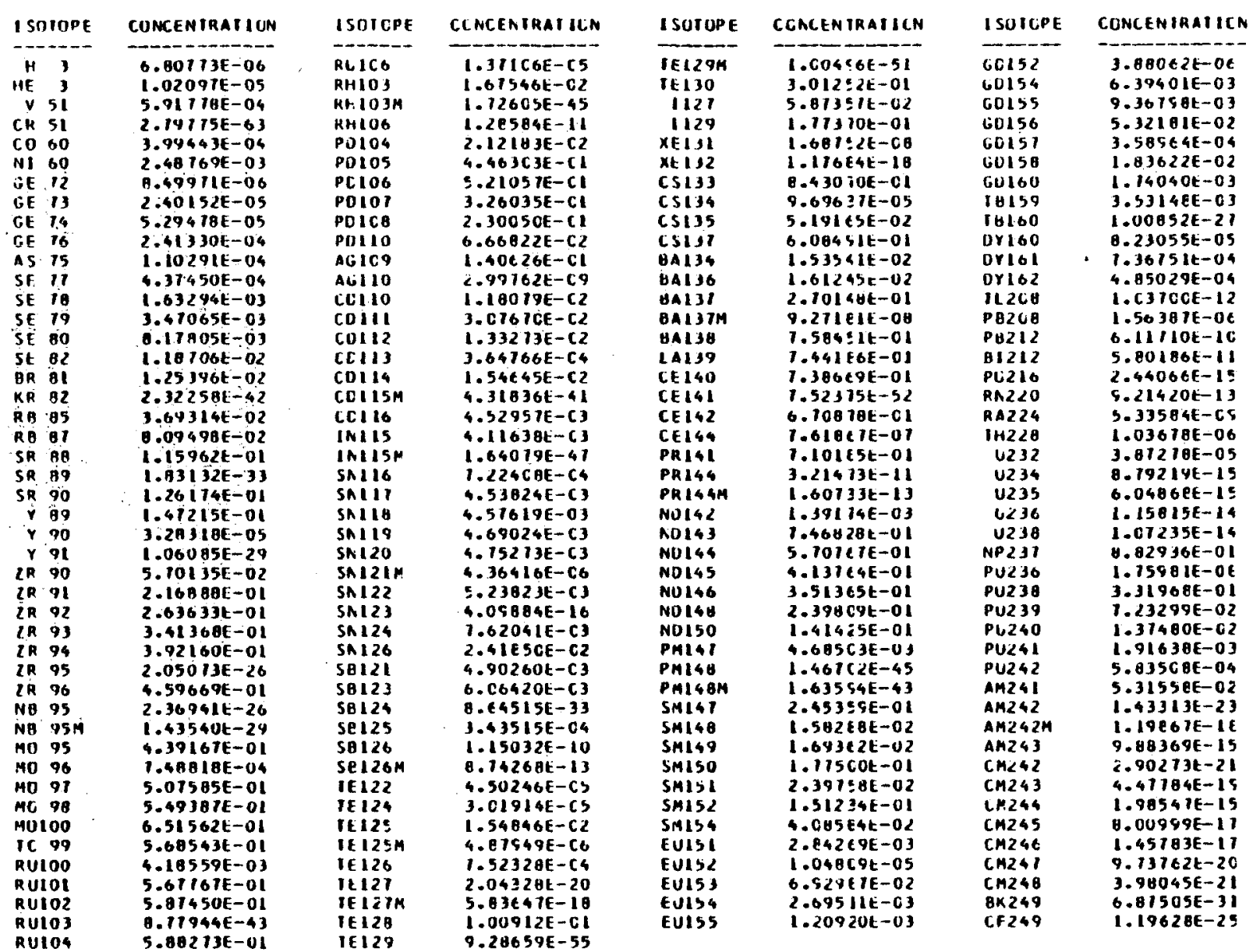


TABLE 7.27 ISOTOPIC CONTENT (Ci/assembly) OF A MARK 53A MBLY - 15 YEARS

\begin{tabular}{|c|c|c|}
\hline & 5010 & (1) \\
\hline & 3 & $6.50082 E-02$ \\
\hline & 60 & $4.53273 t-01$ \\
\hline SE & 19 & $2.42045 E-04$ \\
\hline RB & AI & $1.08459 E-09$ \\
\hline SR & ค9 & $5.17233 E-29$ \\
\hline SR & 90 & 1.785416 OI \\
\hline & 90 & $1.18580 E$ DI \\
\hline & 91 & $2.60028 t-25$ \\
\hline$Z \mathbf{R}$ & 93 & $1.38365 \mathrm{E}-03$ \\
\hline LR & 95 & $4.30133 E-22$ \\
\hline NB & 95 & $9.28151 E-22$ \\
\hline & $95 \mathrm{M}$ & $5.47054 E-24$ \\
\hline & & $9.6386 \mathrm{BE}-03$ \\
\hline RUI & 1103 & $2.01316 E-38$ \\
\hline RUI & & $4.5810 S E-02$ \\
\hline & $1103 \mathrm{M}$ & $5.63186 E-38$ \\
\hline RHI & & $4.58105 E-02$ \\
\hline & & $1.67854 \mathrm{E}-04$ \\
\hline$A G$ & 110 & $1.41323 E-05$ \\
\hline Co & 31154 & $1.10029 E-36$ \\
\hline & & $2.56319 E-14$ \\
\hline IN II & $1115 n$ & $9.94445 t-41$ \\
\hline & & \\
\hline
\end{tabular}

\begin{tabular}{|c|c|}
\hline ISCTOPE & CNCEA IRAIIIGA \\
\hline $\sin 123$ & $3.31556 E-12$ \\
\hline SA12 & $6.07161 E-C S$ \\
\hline 58124 & $1.513376-28$ \\
\hline 312 & $2.60144 \mathrm{E}-\mathrm{Cl}$ \\
\hline SOLI & $9.62034 E-16$ \\
\hline SE126M & $0.81161 E-C S$ \\
\hline TEIZEN & $8.19489 \mathrm{E}-\mathrm{C2}$ \\
\hline IEI2I & $5.39651 E-14$ \\
\hline TEIZTM & $5.50945 E-14$ \\
\hline $1 E 129$ & $1.93513 E-41$ \\
\hline & $3.04782 E-41$ \\
\hline 1129 & $3.05589 E-C 5$ \\
\hline $\operatorname{csi34}$ & $1.25664 \mathrm{E}-\mathrm{Cl}$ \\
\hline CSI35 & $5.28569 E-C S$ \\
\hline CSi3) & $5.27880 E$ CI \\
\hline EAIJIM & $4.99375 \mathrm{CI}$ \\
\hline CEIAl & $2.14327 E-41$ \\
\hline CEI42 & $1.61009 E-C \theta$ \\
\hline CEI & $2.43059 E-C 3$ \\
\hline & $2.43667 \mathrm{E}-\mathrm{C3}$ \\
\hline PRIA4M & $2.91675 E-C 5$ \\
\hline A.0144 & $6.15640 E-13$ \\
\hline
\end{tabular}

ISUICPE

CACENIRAIION $4.34612 t 00$ $\begin{array}{ll}\text { PHI41 } & 4.34632100 \\ \text { PHI48 } & 2.41159 t-40\end{array}$ PHI48M $3.49671 \mathrm{E}-39$ SMI61 $5.58363 t-09$ SMI4U $4.18533 t-15$

SHIS9 4.060 STE-1S

$\begin{array}{ll}\text { SAISI } & 0.11094 E-0 \\ \text { EUIS2 } & 1.89843 E-03\end{array}$

EUI54 $7.20355 E-0$

EU155 5.e1729t-0

IBI60

TL248 3.053E3E-04

Po212 $8.49054 \mathrm{E}-04$

$01212 \quad 0.49855 E-04$

P0216 0.49843t-04

RN220 $9.49843 \mathrm{E}-04$

AA224 $0.49843 E-04$

IH228 $\quad 0.49751 E-0$

U235

TOTAL ACTIVITY $1.5202 \mathrm{CI} /$ sessY

HEAT GENERATION, watr/assY
ISOTOPE GHCENIRATIOA

U236 T.49127E-15

U238 $\quad 3.60399 t-21$

Q.22243E-04

PUZ3O $5.68151 E 00$

PU239 4.49485E-0?

PUZ4O $3.12587 E-03$

PU241 $1.93346 \mathrm{E}-01$

PU242 $2.22690 \mathrm{O}-0 \mathrm{O}$

AM241 $1.02444 E-0$

TH242 1.1589 CE- 11

$\begin{array}{ll}A M 2424 & 1.16471 E-11 \\ \text { AM243 } & 1.97250 E-15\end{array}$

CM242 $9.61230 E-1$

CA243 2.31095E-11

CM244 1.60593E-13

CA245 1.37877E-11

$4.47791 E-10$

CK248 $9.03204 E-2$

$\begin{array}{ll}\text { CK248 } & 1.68665 E-23 \\ \text { BK249 } & 1.14783 E-21 \\ \text { CF249 } & 9.89747 E-25\end{array}$

$4.097478-25$

$\begin{array}{ll}\text { Primary } & 3.73-01 \\ \text { Gemmana } 1.91-0\end{array}$ 
TABLE 7.28

ISOTOPIC CONTENT (O/ $/ \mathrm{Kg}$ U.235) OF AN OFFSITE

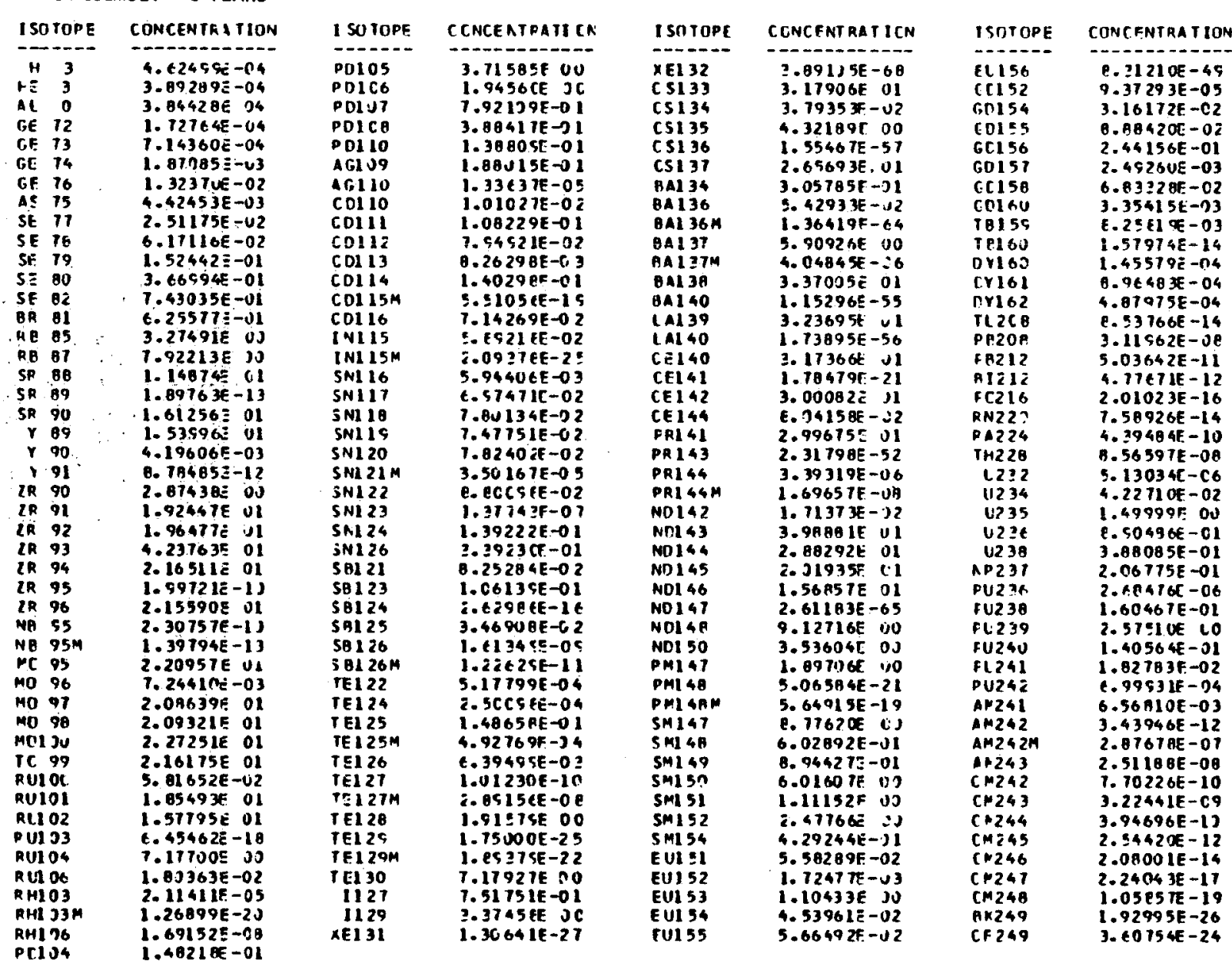


TABLE 7.29

FUEL ASEMBIENT (CI $\mathrm{kg}$ U-235) OF AN OFFSITE

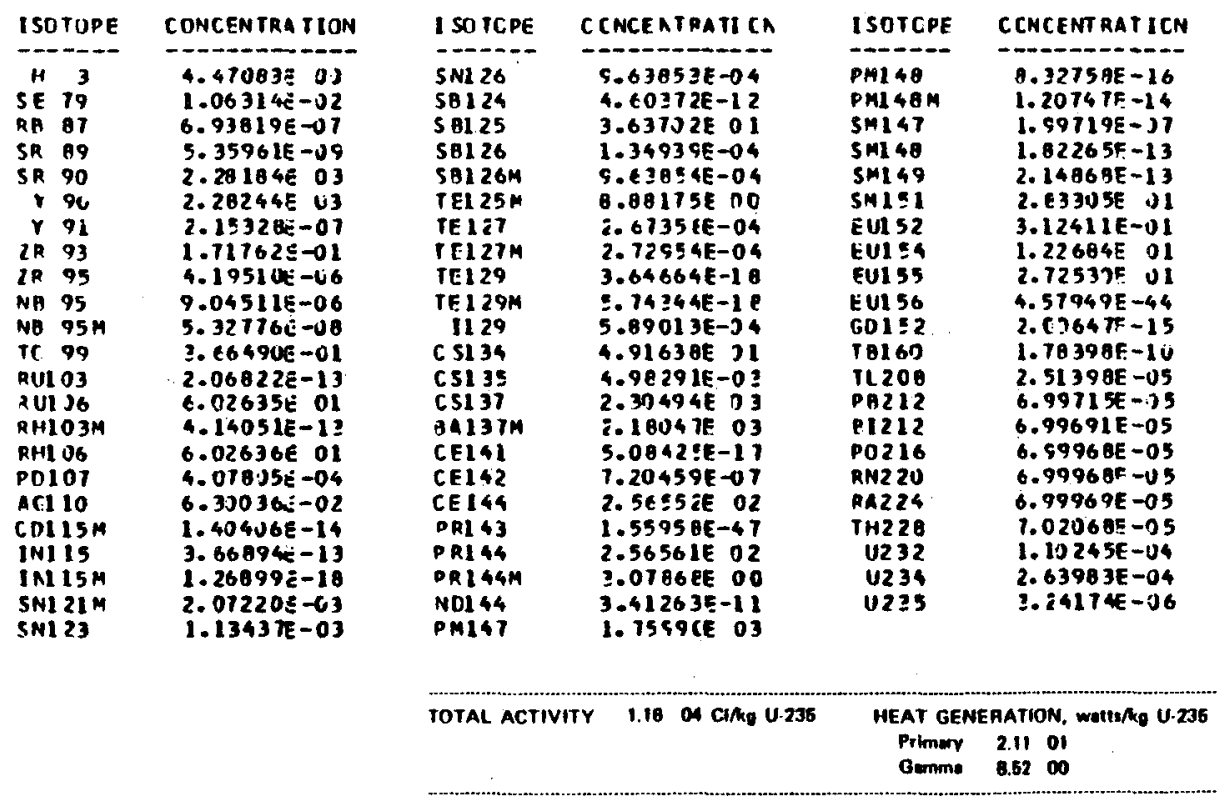

\begin{tabular}{|c|c|}
\hline ISOTOPE & CNC \\
\hline $\begin{array}{l}4.23 t \\
0238\end{array}$ & $\begin{array}{l}5.755945-05 \\
1.30430 E-07\end{array}$ \\
\hline AP237 & $1.45724 E-04$ \\
\hline PU236 & 100 \\
\hline FU23 & 2.746 \\
\hline PL2 =s & $1.60028 E-01$ \\
\hline PU240 & $3.19599 E-02$ \\
\hline 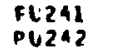 & $\begin{array}{l}1.84412 E 00 \\
2.07121 E-C 6\end{array}$ \\
\hline $\begin{array}{l}P(242 \\
\operatorname{Pan} 241\end{array}$ & $\begin{array}{l}2.67121 E-C 6 \\
2.25434 E-02\end{array}$ \\
\hline$A m 242$ & $2.70133 \mathrm{E}-06$ \\
\hline A19242M & $2.7952 \pi E-06$ \\
\hline ande3 & $\begin{array}{l}5.01299 E-09 \\
2.5505 B E-06\end{array}$ \\
\hline $\begin{array}{l}\cos 242 \\
\cos 243\end{array}$ & $\begin{array}{l}2.3505 \text { BE -06 } \\
1.68407 E-07\end{array}$ \\
\hline CP264 & $3.19245 E-00$ \\
\hline & 4.37530 \\
\hline & $0.38901 E-15$ \\
\hline CP & $2.07008 E-21$ \\
\hline & $4.49 C 85 E-22$ \\
\hline $\begin{array}{l}8 \times 249 \\
\text { CF } 249\end{array}$ & $\begin{array}{l}3.22218 E-23 \\
1.47690 E-23\end{array}$ \\
\hline & \\
\hline
\end{tabular}

$3.22218 E-23$
$1.47690 E-23$ 
TABLE 7.30

ISOTOPIC CONTENT (QRAg U.235) OF AN OFFSITE

FUEL ASSEMBLY - 15 YEARS

\begin{tabular}{|c|c|c|c|c|}
\hline \multicolumn{2}{|c|}{ I SUTOPE } & CNCENTRATICA & ISOTOPE & CNCENTAATIO \\
\hline & 3 & $62792 E-04$ & RHICG & $1.11: 44 E-1$ \\
\hline & 3 & $88996 \div-04$ & PD104 & $1.48218 E-0$ \\
\hline & $u$ & $3-84420304$ & PO1 05 & $3.71585 E 0$ \\
\hline & 72 & $1.72764 E-04$ & POI06 & $1.5636 \pi E$ \\
\hline GE & 73 & $7.14361 E-C 4$ & Polv7 & T.92108E-0 \\
\hline EF & 74 & 1.01 & $\mathbf{P}$ & 3.8 \\
\hline GE & 76 & $1.32370 E-02$ & pol & $1.2080 S E-01$ \\
\hline As & 15 & $4.42455:-63$ & AGIOS & $\begin{array}{r}1.88015 E-01 \\
\because .7519 \mathrm{KE}-1 \mathrm{C}\end{array}$ \\
\hline $\begin{array}{l}\text { SE } \\
\text { SE }\end{array}$ & $\begin{array}{l}77 \\
78\end{array}$ & $\begin{array}{l}2-511755-02 \\
6.11115=-02\end{array}$ & $\begin{array}{l}\text { AG110 } \\
\text { CDIIS }\end{array}$ & $\begin{array}{l}=.7519 E E-1 C \\
1.0116 C E-02\end{array}$ \\
\hline & is & 1. $52426=-01$ & coili & 1.082 \\
\hline SE 8 & 80 & $3.66994 \mathrm{E}-01$ & CD & 7.94 \\
\hline SE & 62: & $7.43034 E-J 1$ & $\operatorname{col13}$ & $8.26300 \mathrm{E}-73$ \\
\hline $\begin{array}{l}B P \\
\text { PB }\end{array}$ & A1 & $\begin{array}{l}6.25579 E-01 \\
3.27491 E J J\end{array}$ & $\begin{array}{l}C 0114 \\
C 0115 M\end{array}$ & $\begin{array}{l}1.40255 F-01 \\
1.22 \leq 2 \leq E-42\end{array}$ \\
\hline RP & 67 & $7.92213 E 00$ & Col 16 & T.1427(E-)2 \\
\hline & & $1.14874 E$ & INI & 5.892 \\
\hline SR & A9. & 1.360 & INI & $4.6>-6$ \\
\hline $2 \pi$ & 90 & 1. 260uSE O1 & SN1 16 & $5.94404 E-03$ \\
\hline & $x i$ & 3. $27079 E-C 3$ & 5 N118 & $\begin{array}{l}0.57465 E-02 \\
7.80131 E-32\end{array}$ \\
\hline & $9 i$ & $1.51616 E-30$ & SN119 & $7.4775 \mathrm{ZE}-02$ \\
\hline & & - $>$ & & $7.82<0$ \\
\hline & & I. & & 3. U4AIOE \\
\hline & 92 & 1.9647 & SN1 & $\begin{array}{l}\text { E. } 0010 C E-02 \\
4.13083 E-16\end{array}$ \\
\hline $2 \pi$ & 94 & $2.16511=61$ & SNI 24 & $\begin{array}{l}1.13083 E-16 \\
1.39223 F-01\end{array}$ \\
\hline IR & 95 & $3.26587 E-27$ & SNI26 & $3-2922 \mathrm{~F}-01$ \\
\hline 2A & 96 & 2.15 & & $0.25331 E-32$ \\
\hline NB & & $3.71338 \mathrm{E}-27$ & 58 & 1. 0E13 SF-01 \\
\hline & $95 \mathrm{H}$ & $2.20593 \varepsilon-30$ & SB124 & $1.43122 E-34$ \\
\hline & 95. & $2.2095 \pi E 01$ & $\begin{array}{l}58125 \\
58126\end{array}$ & $\begin{array}{l}2.73868 E-03 \\
1.6134 \mathrm{EE-OS}\end{array}$ \\
\hline MO & & 2.006398 Ol & $50126 \mathrm{M}$ & $1.226285-11$ \\
\hline & & 2.09321E OI & TE & $5.17799 E-04$ \\
\hline & & $\begin{array}{r}27251601 \\
16160 \mathrm{G}\end{array}$ & $\begin{array}{l}\text { TE124 } \\
\text { TE125 }\end{array}$ & $\begin{array}{l}2.50096 E-04 \\
1.01 \cup 63 \mathrm{~F}-31\end{array}$ \\
\hline PUt & & $\begin{array}{l}2.16160 \mathrm{E} \text { U1 } \\
5.01650 \mathrm{-02}\end{array}$ & $\begin{array}{l}\text { TE125 } \\
\text { TE125M }\end{array}$ & 1.85016E-05 \\
\hline RUi & & $1.85493 \hat{E}$ or & TEI & $0.35736 E$ \\
\hline RUI? & & 1. $37795 E$ Ui & TEI & $0.20053 E-21$ \\
\hline RUIO & & $1.13775 t^{-45}$ & TE1 & $2.3652 \mathrm{TE}-18$ \\
\hline & & 7. 1773UE UJ & & $\begin{array}{l}1.91579 E \text { on } \\
8\end{array}$ \\
\hline Rul? & 106 & $\begin{array}{l}1.00091 E-03 \\
2.11411 \varepsilon-05\end{array}$ & $\begin{array}{l}\text { TFI 29 } \\
\text { TEI 29M }\end{array}$ & $\begin{array}{l}\text { Z. } 10642 E-5 e \\
\text { i. } 27945 E-5\end{array}$ \\
\hline & & $2.17786=-$ & TEI 30 & $7.17927 E 00$ \\
\hline
\end{tabular}

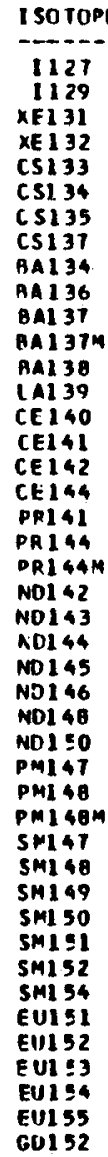

C onc 7. $51740 E-01$ 2. $37456 E$ CO 1. $30641 E-27$ 3. $39105 E-60$ 1.31140E-D3 4.321860 00 2.11042E DI 3. $4240 B E-01$ 5. $429335-02$ $1.13742 E$ JI 3. $21572 E-06$

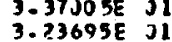
3.1736 TE OI 2. $02912 E-55$ 3. ODOB3E UI $2.99675 E$ O $4.61893 E-10$ 2. $30942 \varepsilon-12$ 1. T1373E-02 $2.89096 E$ OI 2.01935E UI 1. $36857 F$ U1 9.12715E 0 1. $35029 E-01$ 1.2001 of: -47 I. $34721 E-43$ 6. $02092 E-01$ $6.01607 E$ OO 1. 03164E 00 2.47166000 4. $29244 E-01$ $1.351128-01$
$1.011616-0$ 1.10433500 $1.33539 E-02$
$9.372975-05$

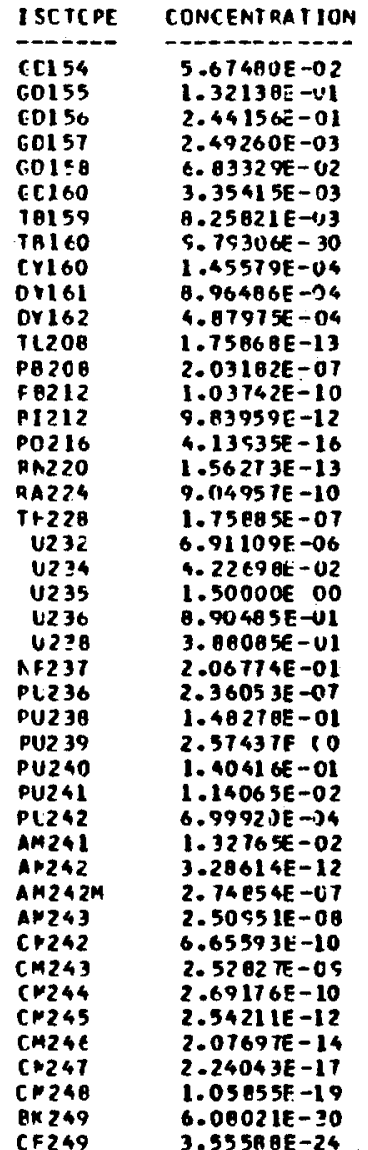


TABLE 7.31

CONTENT (CI/kg U.235) OF AN OFFsITE

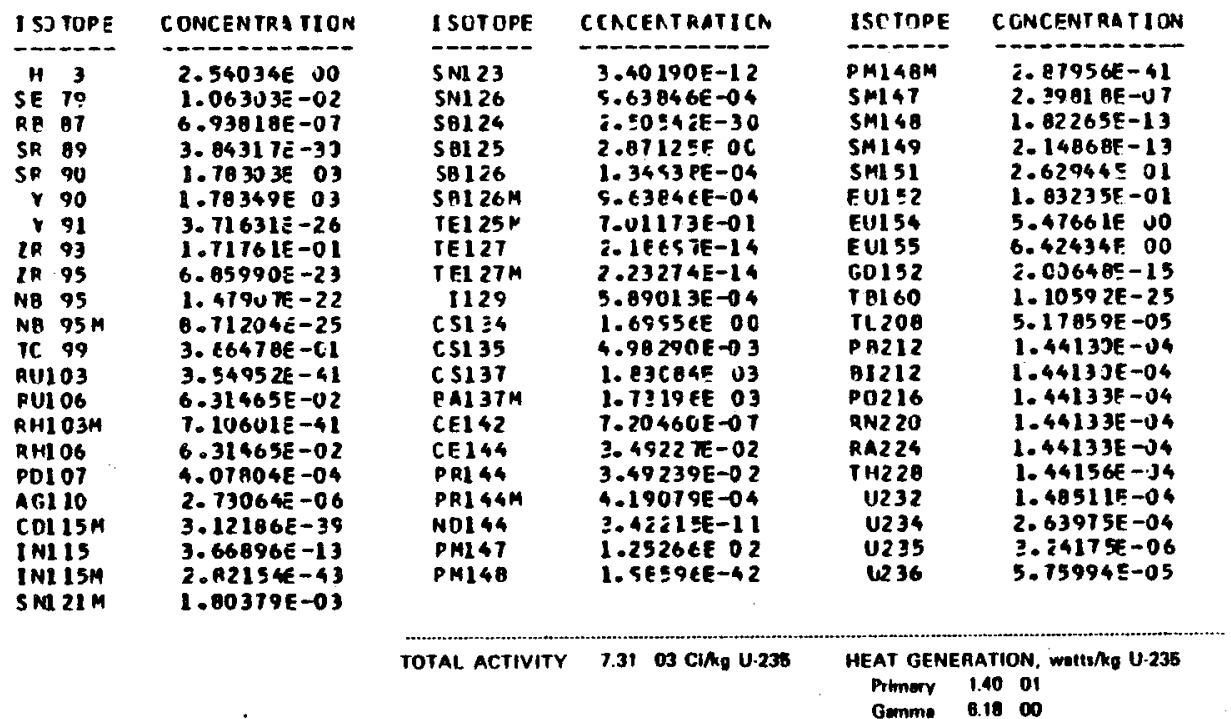

I SO TOPE CONCENTRA TION

$1238 \quad 1.30430 E-07$

PU2 $36 \quad 1.25400 F-04$

PL238 2.53773E 10

PU239 1.5998 ZE-01

FU2 66 $3.19262 E-02$

PU241 $1.15081 E$ OO

PU2 42 2.67117E-06

AN242

A.242M $2.670678-06$

$\begin{array}{ll}A M 242 M & 2.67067 E-06 \\ \text { AM24? } & 5.0027 E-C 9\end{array}$

Cr242 $2.20409 E-06$

Cr243 $\quad$ I.3048JE-CI

CM244 2.1712 UE-CB

CP245 $\quad 4.37579 E-13$

Cस246 $\quad 6.37967 E-15$

CM247 2.0780 BE-21

Crर240

CF $249 \quad 1.01513 E-26$ 
TABLE 7.32

ISOTOPIC CONTENT $(\mathrm{g} / \mathrm{kg}$ PU) OF PLUTONIUM-238 SCRAP - 5 YEARS

\begin{tabular}{|c|c|c|c|c|c|c|c|}
\hline I SOTOPE & CONCENTRATION & I SUTCPE & CCNCENIRAIICN & ISOTOPE & CCACENTKAIICN & I SETCPE & CONCENTRATICA \\
\hline $\begin{array}{l}\text { TL20B } \\
\text { PB208 } \\
\text { PB212 } \\
\text { B } 1212\end{array}$ & $\begin{array}{l}1.36175 E-16 \\
3.06683 E-09 \\
B .15111 E-12 \\
7.73070 E-13\end{array}$ & $\begin{array}{l}F C 216 \\
R \wedge 220 \\
R A 224 \\
\ln 220\end{array}$ & $\begin{array}{l}3.25376 E-17 \\
1.22840 E-14 \\
7.11348 E-11 \\
1.387 \in 4 E-C 8\end{array}$ & $\begin{array}{r}\cup 232 \\
P \cup 236 \\
P \cup 238 \\
P \cup 239\end{array}$ & $\begin{array}{l}9.14534 t-C ? \\
4.79242 E-07 \\
1.12523 E C C \\
3.22272 t-01\end{array}$ & $\begin{array}{l}\text { PU24C } \\
\text { PU241 } \\
\text { PU242 } \\
\text { AM241 }\end{array}$ & $\begin{array}{l}1.18415 E-01 \\
5.38794 E-02 \\
3.04226 E-02 \\
1.27115 E-02\end{array}$ \\
\hline
\end{tabular}

TABLE 7.30

ISOTOPIC CONTENT (Ci/kg Pu) OF PLUTONIUM-238

SCRAP - 5 YEARS

\begin{tabular}{|c|c|c|c|c|c|}
\hline ISCTOPE & CONCE VTRATIUN & I SOTCPE & EENTRATICN & ISCTOPE & CCACEAIRATILI \\
\hline \multirow[t]{2}{*}{$\begin{array}{l}T L 208 \\
P B 212 \\
B 1212 \\
P 0216\end{array}$} & $\begin{array}{l}4.06867 \mathrm{E}-06 \\
1.13244 \mathrm{E}-05 \\
1.13239 \mathrm{E}-05 \\
1.13297 \mathrm{E}-05\end{array}$ & $\begin{array}{r}R \wedge 220 \\
R A 224 \\
T+228 \\
L 232\end{array}$ & $\begin{array}{l}13297 E-65 \\
13297 E-65 \\
13721 E-65 \\
76523 E-C 5\end{array}$ & $\begin{array}{l}P \cup 236 \\
P \cup 238 \\
P \cup 239 \\
P \cup 240\end{array}$ & $\begin{array}{l}2.545 \$ 1 E-04 \\
1.92578 E \mathrm{Cl} \\
2.0 C 2.74 E-02 \\
2.7 C 149 E-C 2\end{array}$ \\
\hline & & TOTAL ACTIVITY & 2.48 O1 Ci $/ \mathrm{kg}_{\mathrm{qu}}$ & $\begin{array}{l}\text { HEAT GENEI } \\
\text { Primary } \\
\text { Gamma }\end{array}$ & $\begin{array}{l}\text { RATION, watzs/kg Pu } \\
6.40-01 \\
1.86-04\end{array}$ \\
\hline
\end{tabular}

TABLE 7.34

ISOTOPIC CONTENT (O/kg PU) OF PLUTONIUM-238

SCRAP - 15 YEARS

\begin{tabular}{|c|c|}
\hline I SOTOPE & CONCENTRATION \\
\hline $\begin{array}{l}T 1208 \\
P B 208 \\
P B 212 \\
B 1212\end{array}$ & $\begin{array}{l}3.13256 E-14 \\
3.32856 E-08 \\
1.847 E 5 E-11 \\
1.75261 E-12\end{array}$ \\
\hline
\end{tabular}

\begin{tabular}{|c|c|}
\hline SCICFE & CCACENTRATICN \\
\hline $\begin{array}{l}P C Z 16 \\
R A 220 \\
R A<24 \\
\operatorname{In} 228\end{array}$ & $\begin{array}{l}7.37257 E-17 \\
2.78351 E-14 \\
1.01190 E-1 C \\
3.13287 E-C 8\end{array}$ \\
\hline
\end{tabular}

ISOTOPE
PU232
PU216
PU238
PU239

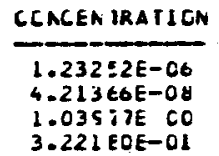

\begin{tabular}{l} 
ISUIOPE \\
\hline PU241 \\
PU242 \\
AM241
\end{tabular}

CLNCENTRATICA

$5.43554 E C C$

$1.16104 E-O 4$

$4.36290 E-02$

\begin{tabular}{ll} 
ISOICPE & CCACENIRATICN \\
\hline PL24E & $\frac{1.18690 E-C 1}{3.36229 E-02}$ \\
PU241 & $3.04221 E-02$ \\
PU242 & $3.25917 E-02$
\end{tabular}

TABLE 7.35

ISOTOPIC CONTENT (Ci/kg PU) OF PLUTONIUM-238 SCRAP - 15 YEARS

\begin{tabular}{|c|c|c|c|c|c|}
\hline ISCTOPE & CUNCEN TRATION & ISCTCPE & CENTRATICN & I SOTUPE & LCNLEN IRATICI \\
\hline \multirow[t]{2}{*}{$\begin{array}{l}T \angle 2 C B \\
P B 212 \\
B 1212 \\
P C 216\end{array}$} & $\begin{array}{l}9.22403 E-06 \\
2.56123 E-05 \\
2.56722 E-05 \\
2.56728 E-05\end{array}$ & $\begin{array}{r}R A=200 \\
R A 2 \geq 4 \\
1+2 \geq 6 \\
L \geq \geq 2\end{array}$ & $\begin{array}{l}56720 E-C S \\
56720 E-C 5 \\
56771 E-C 5 \\
64854 E-C 5\end{array}$ & $\begin{array}{l}P \cup 236 \\
P \cup 238 \\
P \cup 239 \\
P \cup 240\end{array}$ & $\begin{array}{l}2.23845 E-C 5 \\
1.779: 2 E 01 \\
2.00226 E-02 \\
2.69864 E-02\end{array}$ \\
\hline & & TOTAL ACTIVITY & $2.1301 \mathrm{Ci} / \mathrm{kg} \mathrm{P}_{U}$ & $\begin{array}{l}\text { HEAT GEN } \\
\text { Primary } \\
\text { Gomms }\end{array}$ & $\begin{array}{l}\text { RATION, watrs/kg Pu } \\
5.94-01 \\
1.82-04\end{array}$ \\
\hline
\end{tabular}

TABLE 7.36

ISOTOPIC CONTENT (g/kg PU) OF PLUTONIUM-239

SCRAP - 5 YEARS

\begin{tabular}{|c|c|c|c|c|c|c|c|}
\hline I SGTOPE & CONCENTRATION & ISOTOPE & CCNCENTRATICA & ISOTLPE & CCNCENIRATION & I SOTGPE & CGNCENTRATICN \\
\hline $\begin{array}{l}11208 \\
P B 20 B \\
P B 212 \\
81212\end{array}$ & $\begin{array}{l}1.54597 E-20 \\
3.43132 E-15 \\
9.11990 E-18 \\
8.64953 E-19\end{array}$ & $\begin{array}{l}P C=16 \\
\operatorname{RA220} \\
\operatorname{RA} \angle 24 \\
T+228\end{array}$ & $\begin{array}{l}3.04548 E-23 \\
1.37435 E-20 \\
1.95454 E-17 \\
1.55256 E-14\end{array}$ & $\begin{array}{r}U 232 \\
P \cup 236 \\
P \cup 238 \\
P \cup 239\end{array}$ & $\begin{array}{l}1.223<3 E-12 \\
5.362 \mathrm{CIE}-13 \\
1.56117 \mathrm{E}-\mathrm{C6} \\
1.975 \mathrm{COE}-\mathrm{Cl}\end{array}$ & $\begin{array}{l}P \cup 240 \\
P \cup 241 \\
P \cup 242 \\
A M 241\end{array}$ & $\begin{array}{l}1.11248 E-02 \\
1.14603 E-03 \\
5.01359 E-05 \\
2.70376 E-C 4\end{array}$ \\
\hline
\end{tabular}


TABLE 7.37

ISOTOPIC CONTENT (Ci/kg Pu) OF PLUTONIUM-239 SCRAP - 5 YEARS

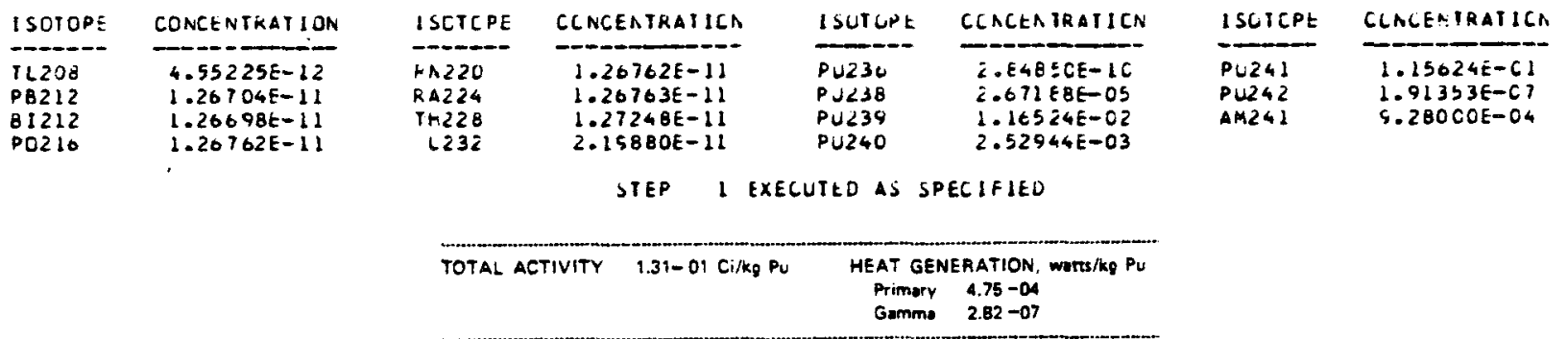

TABLE 7.38

ISOTOPIC CONTENT $(\mathrm{g} / \mathrm{kg}$ PU) OF PLUTONIUM.239

SCRAP - 15 YEARS

\begin{tabular}{|c|c|c|c|c|c|c|c|}
\hline I SOTUPE & CONCEN IRATION & ISCTCPE & CCNCENIRATICN & ISOTUPE & CCNCENTRATION & I SUTCPE & CONCENTRATICA \\
\hline $\begin{array}{l}\text { YL208 } \\
\text { PE } 208 \\
\text { PEZ } 12 \\
B 1212\end{array}$ & $\begin{array}{l}3.50486 E-20 \\
1.72418 E-14 \\
2.06747 E-17 \\
1.96092 E-18\end{array}$ & $\begin{array}{l}F C=16 \\
R A 220 \\
R A=24 \\
I H .228\end{array}$ & $\begin{array}{l}E .24524 E-23 \\
3.11435 E-20 \\
1.80347 E-16 \\
3.50523 E-14\end{array}$ & $\begin{array}{r}\cup 232 \\
P \cup 236 \\
P \cup 238 \\
P \cup 239\end{array}$ & $\begin{array}{l}1.379 C 1 E-12 \\
4.71446 E-14 \\
1.44259 E-06 \\
1.87452 E-C 1\end{array}$ & $\begin{array}{l}\text { PL24C } \\
\text { PU241 } \\
\text { PU242 } \\
\text { AK241 }\end{array}$ & $\begin{array}{l}1.11131 E-O E \\
7.15169 E-O 4 \\
5.01389 E-O 5 \\
6.93233 E-04\end{array}$ \\
\hline
\end{tabular}

TABLE 7.39

ISOTOPIC CONTENT (Ci/kg Pu) OF PLUTONIUM-239

SCRAP - 15 YEARS

\begin{tabular}{ll} 
ISOTOPE & CONCENTRATICN \\
\hline TL2OB & $\frac{1.03203 E-11}{\text { PB212 }}$ \\
B1212 & $2.87235 E-11$ \\
PC216 & $2.87235 E-11$ \\
& $2.87241 E-11$
\end{tabular}

ISCTCPE
RA220
RA224
IT 228

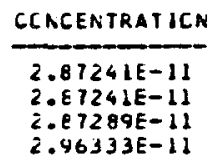

\begin{tabular}{|c|c|}
\hline I SOT OPE & CCNCENTRATICN \\
\hline $\begin{array}{l}P \cup 230 \\
P \cup 238 \\
P \cup 239 \\
P \cup 240\end{array}$ & $\begin{array}{l}2.50449 E-11 \\
2.46854 E-05 \\
1.164 \$ 1 E-02 \\
2.52677 E-C 3\end{array}$ \\
\hline
\end{tabular}

I SOICPE

Pᄂ241

PU242

AN241

CONCENTRATICN

$7.22543 t-6 z$

$1.91350 E-C 7$

STEP I EXECUIED AS SPECIFIEO

TOTAL ACTIVITY 8.87-02 CI/kg PU HEAT GENERATION, wattikg PU
Primary $5.22-04$
Gamma $4.81-07$


8. EFFLUENT CONTROL AND ESTIMATED RELEASES TO THE ENVIRONMENT

8.1 Effluent Control 8.1

\section{1 .1 Genera 1 B. 8}

8.1.2 Regulatory Aspects 8.1

8.1.3 SRP Operating Standards

8.1

8.1.4. Seepage Basin Criteria 8.2

8.2 Estimated Releases to the Environment 8.3

\subsection{References 8.13}


8. EFFLUENT CONTROL AND ESTIMATED RELEASES TO THE ENVIRONMENT

(W. L. Marter)

\subsection{Effluent Control}

\section{1 .1 General}

Defense waste processing must be designed and operated in such a manner that liquid and gaseous effluents meet established standards for releases of radioactivity to the environment. In adapting these standards for a specific aspect of operations, such as waste solidification, it must be recognized that releases of radioactivity will continue from other operational activities at SRP, i.e., the release of radioactive materials must be apportioned to all existing sources on the plant site. These include the normal releases from operating areas as well as migratory losses from existing seepage basins and burial ground, and possibly the release involved in decomissioning production facilities.

\subsubsection{Regulatory Aspects}

See Section 11.

\subsubsection{SRP Operating Standards}

The Savannah River Plant currently operates under a Technical Standard for release of radioactivity from the plant site. This standard does not specify amounts of radioactive nuclides that can be released in gaseous or liquid effluents, but rather, limits releases such that the annual exposure to an offsite individual will not exceed the limits shown in Table 8.1 .

Again, these dose limits apply to all releases from all operations at SRP and only a portion of the limits could be assigned to a waste processing facility. No simple formula can be provided that enables the direct calculation of the amounts of individual radionuclides that can be released and yet remain within the technical standard. It is necessary to determine the identity of nuclides to be released, the amount of release, and the mode of release, i.e. gaseous or liquid. From this information, environmental dose commitments can be calculated and a judgment made as to acceptability of the releases. This analysis provides the contribution to environmental dose from each radionuclide by each 
mode of release and thus would serve as guidance in determining those aspects of effluent control that might require improved performance.

\section{1 .4 Seepage Basin Criteria}

Current DOE policy [2] states that establishment of new seepage basins is to be avoided to avoid accumulation of radioactivity in soil, unless the radioactivity (1) is retrievable, or (2) does not build up above an acceptable level. Fission products in basins currently in use at SRP are not reasonably retrievable because of dispersion through large amounts of soil. The "acceptable level" for buildup of radioactivity in soil has already been exceeded in many basins from the standpoint that basin sites cannot be released for unrestricted use at time of seepage basin decomissioning.

The current criteria for use of seepage basins require that the release of fission products, activation products, uranium, and thorium be limited to the lowest practical level consistent with sound waste management practices. Transuranic release limits are set as low as practicable. At most, releases must be lower than values listed in Reference 3 to avoid buildup of radionuclides in the soil. Except in seepage basins already exceeding the reference values, the intention of the limit in transuranic concentrations in soil is to avoid the need for soil removal upon decomisisioning of seepage basins.

The seepage basin criteria were used as the basis for reactivating the $P$ and $C$ Areas seepage basins in 1979. Consequently, the reference process assumes that the activity levels in aqueous effluents will be reduced to the lowest practical level and to levels well below those concentrations prescribed for release to uncontrolled areas [4].

\subsection{Estimated Releases to the Environment}

The annual discharge of radioactive contaminants to the atmosphere and plant streams was estimated. Tables 8.2 through 8.10 summarize these data for 5- and 15-year-aged feed to the DWPF. Table 8.11 compares these estimated releases to 1978 SRP releases. Offsite dose calculations from the estimated DWPF releases were not completed at the time this document was issued. However, for comparison purposes, the offsite dose from the previously, estimated DWPF releases (DPSTD-77-2), which are greater than the current estimate, is compared to the offsite dose from SRP 1978 releases in the following two paragraphs. 
Offitite dose from 1978 SRP atmospheric releases was 112 manrem (calculated with NRC GASPAR code for the 80-km population).* Approximately $92 \%$ of this population dose was from tritium. Particulates only accounted for $0.86 \%$ of the dose. The offsite dose for the estimated DWPF releases was 0.124 man-rem with approximately $75 \%$ from tritium and $25 \%$ from particulates. This dose is only $0.11 \%$ of the dose from normal SRP releases and is judged acceptable.

Offsite dose from 1978 SRP aqueous releases was 16 man-rem downstream from SRP (calculated with NRC LADTAP code).* Tritium accounted for $78 \%$ of this dose. Although DWPF releases would cause a population dose of 4.7 man-rem, a $29 \%$ increase of the dose from normal SRP releases, the population dose would still be only $0.02 \%$ of the dose from natural sources to the population groups considered. Dose to an individual from consuming 2 liters of river water per day would be 0.13 mrem from DWPF releases and 0.35 mrem from SRP 1978 releases, a total of $0.48 \mathrm{mrem}$, well within the $4 \mathrm{mrem}$ limit specified by the EPA** for public drinking water supplies. The anticipated DWPF releases to liquid effluents are therefore judged acceptable.

TABLE 8.1

Savannah River Plant Annual Exposure Operating Guides

Type of Exposure

Whole Body

Gonads

Bone Marrow

Gastrointestinal Tract

Bone

Thyroid

All Other Organs
Dose Limit, mrem/yr

10

10

10

30

30

30

30

* Doses previously published in PTDS \#2 were calculated with SRL computer codes and will differ slightly from these doses calculated with NRC computer codes.

* National Interim Primary Drinking Water Regulations, 40 CFR 141. 
TABLE 8.2

ESTIMATED ANNUAL AQUEOUS RELEASES TO THE ENVIRONMENT - 5 YEARS

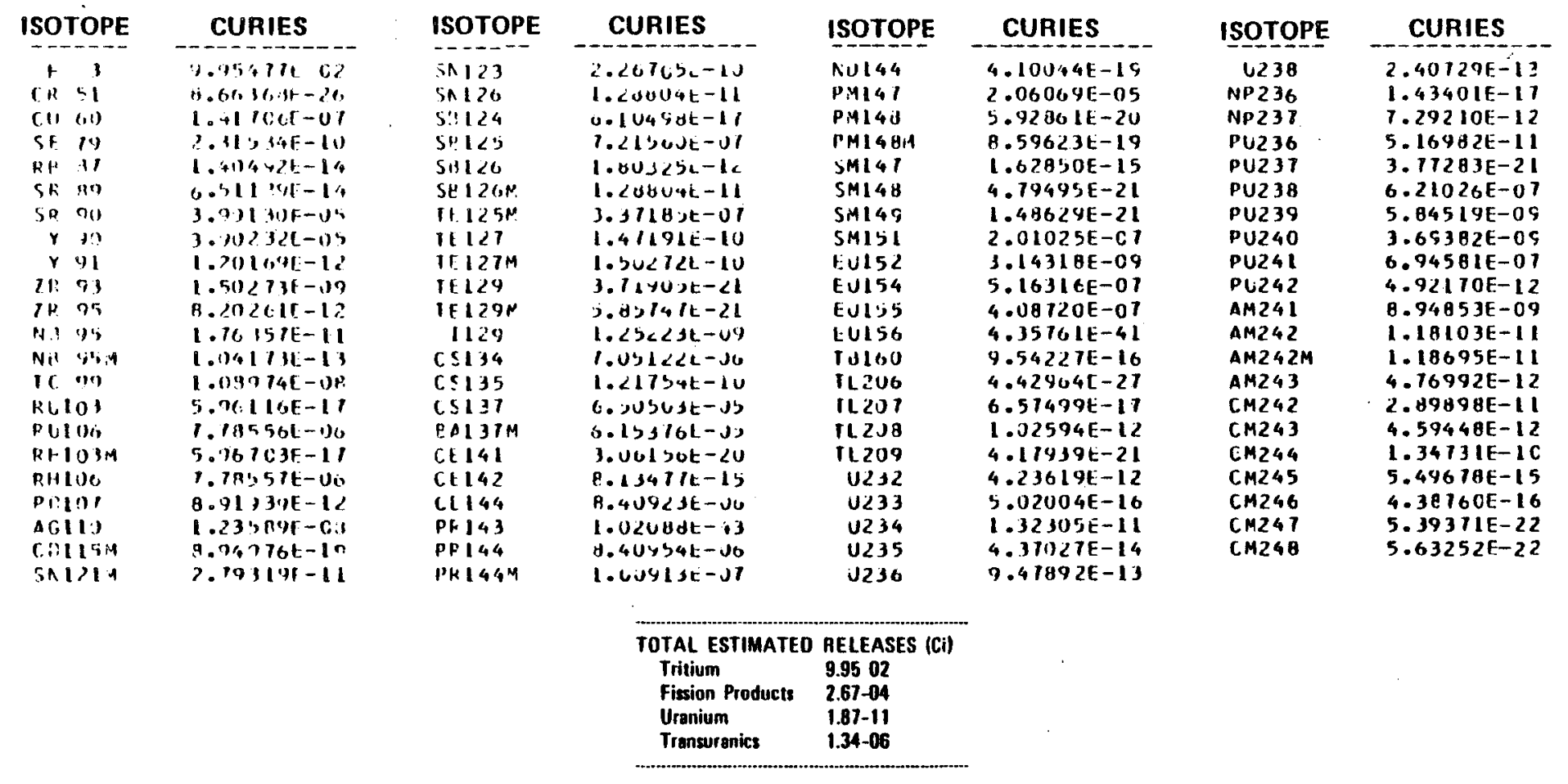


TABLE 8.3

ESTIMATED ANNUAL AOUEOUS RELEASES TO THE ENVIRONMENT - 15 YEARS

I

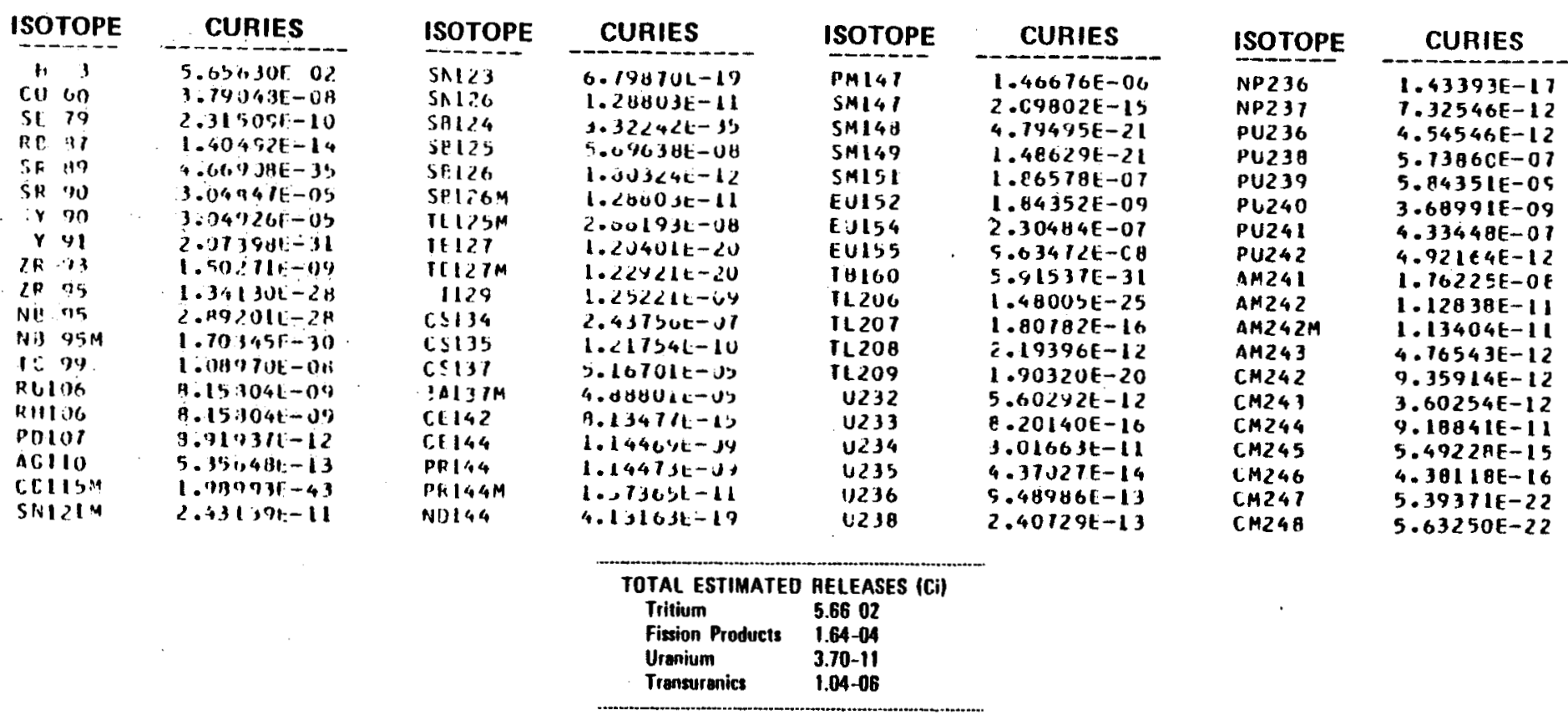

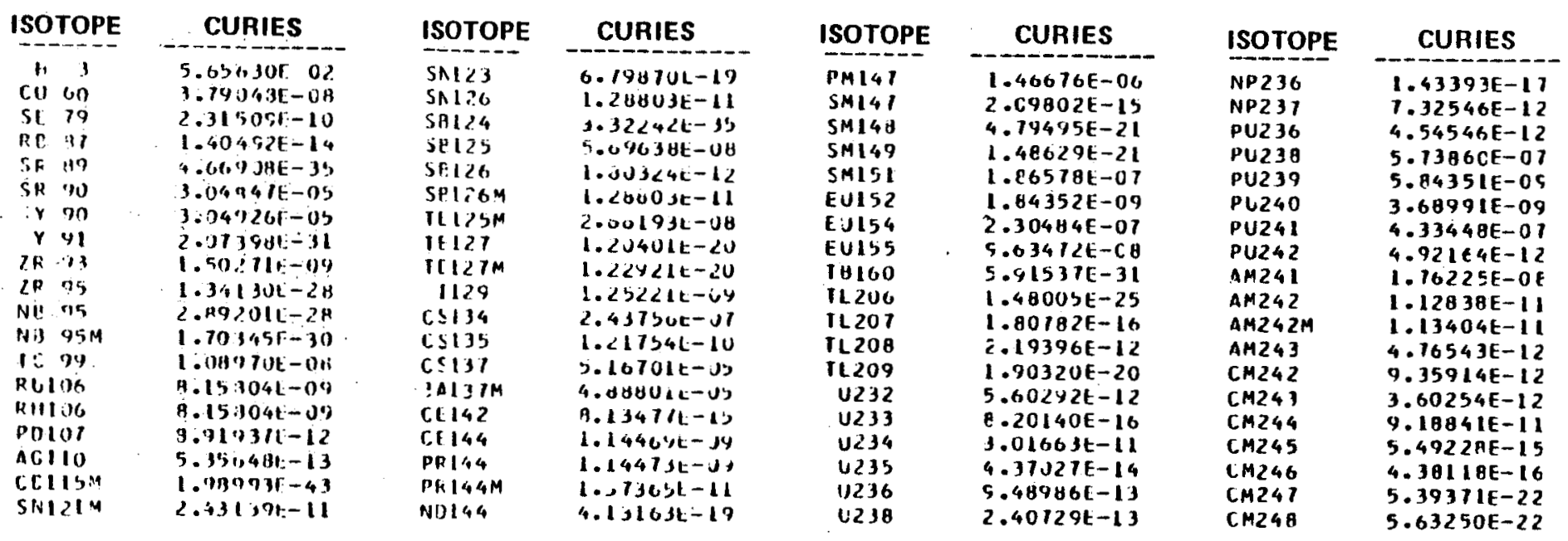


TABEL 8.4

ESTIMATED ANNUAL ATMOSPHERIC RELEASES TO THE ENVIRONMENT - 5 YEARS SOURCE - SAND FILTER STACK

\begin{tabular}{|c|c|c|}
\hline \multicolumn{2}{|c|}{ ISOTOPS } & CURIES \\
\hline 11 & 3 & $2.81 .231 E$ OI \\
\hline & & $1.14+22 F-24$ \\
\hline col & 67 & $2.57(1) 2(-1) t$ \\
\hline SF & 19 & $1.13 / 220-07$ \\
\hline RP & 87 & $6.49262 !-12$ \\
\hline sin & HQ & $1.706501-13$ \\
\hline SP & 90 & $4.6113 \mathrm{HF}-04$ \\
\hline$r$ & G.J & $4.61: 59 t-U^{4}$ \\
\hline & 3 & $1.427260-11$ \\
\hline $2 \mathrm{~K}$ & 73 & $2.749718-0 R$ \\
\hline & 95 & $1.50)$ JAE-10 \\
\hline N13 & 95 & $1.23+996-10$ \\
\hline N" & 75,4 & 1.305 AHE -12 \\
\hline ic & & 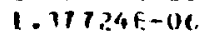 \\
\hline RUI & 103 & $4.121726-13$ \\
\hline Rut & & $5.19394 F-112$ \\
\hline P.HI & 1034 & $4.131 / 1 F-13$ \\
\hline RHI & & $5.391000-02$ \\
\hline p'נl & & 1.JP IOUE-IU \\
\hline$A 61$ & 10 & $1 .+1 / 365-07$ \\
\hline cri & 1514 & 1. $38 \cdot 3616-11$ \\
\hline SAI & $121 \mathrm{M}$ & $4.75291 E-111$ \\
\hline SNI & & 4.1)1 1945-0? \\
\hline
\end{tabular}

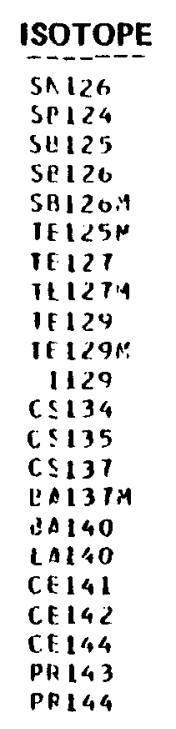

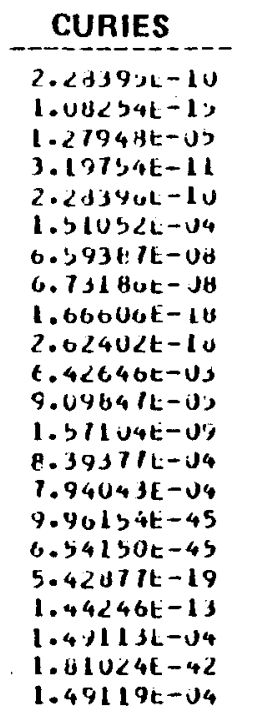

\begin{tabular}{|c|c|}
\hline ISOTOPE & CURIES \\
\hline $\begin{array}{l}\text { PK 144M } \\
\text { INU144 } \\
\text { PHI 141 }\end{array}$ & $\begin{array}{l}1.78939 E-06 \\
1.27693 E-18 \\
3.65404 E-04\end{array}$ \\
\hline PM148 & $1.05127 t-18$ \\
\hline $\begin{array}{l}\text { PMI4BM } \\
S M 147\end{array}$ & $\begin{array}{l}1.524<9 E-11 \\
2.80167 E-14\end{array}$ \\
\hline $\begin{array}{l}S M 148 \\
5.4149\end{array}$ & $\begin{array}{l}8.50243 E-20 \\
2.63551 E-20\end{array}$ \\
\hline Sinisi & $3.56460 \mathrm{E}-06$ \\
\hline EUI54 & $9.44420 E-06$ \\
\hline Euiss & $7.47609 E-06$ \\
\hline EUISO & $1.51012 \mathrm{E}-40$ \\
\hline 13160 & $1.64204 \mathrm{E}-14$ \\
\hline TL206 & $6.87286 \mathrm{E}-26$ \\
\hline 11207 & $1.02015 E-15$ \\
\hline TL20y & $1.54180 E-11$ \\
\hline 12209 & $6.48456 E-20$ \\
\hline U232 & $1.74863 E-11$ \\
\hline U233 & $9.18239 E-15$ \\
\hline 0234 & $2.42006 E-10$ \\
\hline 0235 & $1.49388 E-13$ \\
\hline
\end{tabular}

ISOTOPE

0236

1,238
$N P 236$

NP2 36
NP2 231

NP237
PU2 36

PU2 36

PU231

PU238

PU239

PU240

PU241

PUट242

AM242

AM242.

AM2 $42 M$

AM243

CM242

CM243

C.M244

CM245

CM246

CM247

CM248

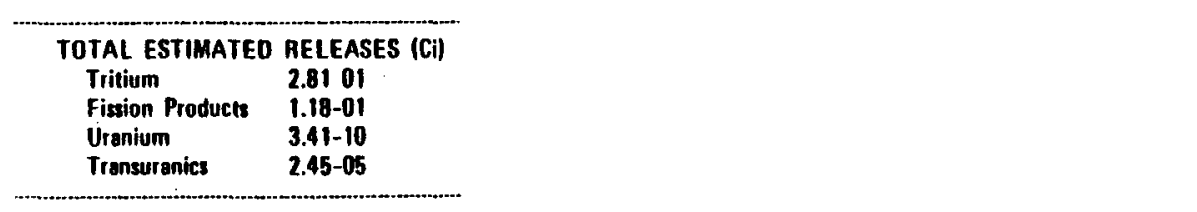




\section{TABLE 8.5}

ESTIMATED ANNUAL ATMOSPHERIC RELEASES TO THE ENVIRONMENT - 16 YEARS SOUACE - SAND FILTER STACK

\begin{tabular}{|c|c|}
\hline ISOTOPE & CURIES \\
\hline+3 & $1.59 \mathrm{OC} \triangle \mathrm{E}$ OI \\
\hline CC 60 & $6.933365-07$ \\
\hline SF 19 & $1.03111 E-U 1$ \\
\hline$n+47$ & $6.492 A 2 L-12$ \\
\hline SR IT & 5.520 UAE -34 \\
\hline Sp 71 & $\left.3 . h(1) v^{\prime}\right) t-n 4$ \\
\hline$\times 9$ & $3.609 c_{4} 1-04$ \\
\hline i & $2.45460,5-70$ \\
\hline LR is & 2.74 is $64 t-313$ \\
\hline $2 F+5$ & $2.453+4 E-27$ \\
\hline NA 25 & 5.287OIt-27 \\
\hline Nก $35 \mathrm{M}$ & $3.115 \times 10-29$ \\
\hline IC. 9 & 1.RTIIUC-1)6 \\
\hline RULio' & $7.08 \div 07 \mathrm{E}-41$ \\
\hline Rilot, & 3.64.7917-11 \\
\hline$R+1:) 1 M$ & $7.199101 F-41$ \\
\hline$R+1,16$ & $5.64 .941 t-05$ \\
\hline Prop? & $1.38390 E-10$ \\
\hline$A G 110$ & $8.31090 E-12$ \\
\hline CO115M & $3.0015 J f-42$ \\
\hline SALPIM & $4.311361-10$ \\
\hline
\end{tabular}

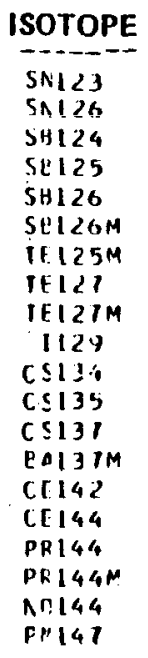

\begin{tabular}{|c|}
\hline CURIES \\
\hline $\begin{array}{l}1.20343 t-17 \\
? .28344 t-10\end{array}$ \\
\hline 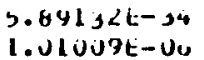 \\
\hline $\begin{array}{l}3.197321-11 \\
2.20345 t-10\end{array}$ \\
\hline $\begin{array}{l}1.19249 t-32 \\
5.39311 t-10 \\
5.5005 \% t-13\end{array}$ \\
\hline $0.4263 u t-u s$ \\
\hline $\begin{array}{l}\text { S.14DJut-Uu } \\
\text { l.sIIUSE-US }\end{array}$ \\
\hline $\begin{array}{l}0.6072 x-34 \\
1.3071) 0-34\end{array}$ \\
\hline $\begin{array}{l}1.44<4 a t-1\} \\
2.0<47 d t-U b\end{array}$ \\
\hline $2.02 \% 64 t-6 u$ \\
\hline $\begin{array}{l}2.43317 t-10 \\
1.30026 t-18 \\
2.60001 t-45\end{array}$ \\
\hline
\end{tabular}

\begin{tabular}{lc} 
ISOTOPE & CURIES \\
\hline PM148 & $2.5 C 706 E-45$ \\
YM148M & $3.53513 E-44$ \\
SM147 & $3.12023 E-14$ \\
SM148 & $8.50243 E-20$ \\
SM149 & $2.63551 E-20$ \\
SM151 & $3.30841 E-06$ \\
EU152 & $3.37208 E-08$ \\
EU154 & $4.21591 E-06$ \\
EU155 & $1.76233 E-06$ \\
IB160 & $1.64892 E-29$ \\
IL206 & $2.29639 E-24$ \\
IL2U7 & $2.80493 E-15$ \\
IL208 & $3.40407 E-11$ \\
IL209 & $2.45294 E-19$ \\
U232 & $1.02486 E-10$ \\
U23 & $1.50016 E-14$ \\
U234 & $5.51786 E-10$ \\
U235 & $1.99388 E-13$ \\
U236 & $1.13584 E-11$ \\
U238 & $4.40329 E-12$
\end{tabular}

\begin{tabular}{|c|c|}
\hline ISOTOPE & CURIES \\
\hline NP236 & $2.622 E 7 E-1 E$ \\
\hline N9237 & $1.33993 E-10$ \\
\hline PU2 36 & $8.3333 \in E-11$ \\
\hline PU231 & $5.54201 E-44$ \\
\hline PUL3A & 1.052 CEE-05 \\
\hline PU239 & $1.07131 E-01$ \\
\hline PU240 & $6.16486 E-08$ \\
\hline PUZ4I & $7.94656 E-0 E$ \\
\hline PUZ42 & $9.02304 E-11$ \\
\hline AM241 & $3.22342 \mathrm{E}-07$ \\
\hline $\operatorname{AM} 242$ & 2.0635 IE-IC \\
\hline AM242M & $2.07432 E-1 C$ \\
\hline $\operatorname{AM} 243$ & A.71665E-11 \\
\hline $\mathrm{CH} 242$ & $1.71192 \mathrm{E}-10$ \\
\hline $\mathrm{CM} 243$ & $6.58957 E-11$ \\
\hline CM244 & $1.68065 E-05$ \\
\hline CM245 & $1.00462 \mathrm{E}-13$ \\
\hline CM246 & $0.01383 E-15$ \\
\hline $\mathrm{CN}_{24} 4$ & $9.86590 E-21$ \\
\hline & \\
\hline
\end{tabular}

\begin{tabular}{ll}
\hline TOTAL ESTIMATEO RELEASES (Ci) \\
Tritium & 1.6001 \\
Fission Producis & $8.55-03$ \\
Uranium & $6.76-10$ \\
Transuranics & $1.90-05$ \\
\hline
\end{tabular}


TABLË 8.6

ESTIMATED ANNUAL ATMOSPHEAIC RELEASES TO THE ENVIRONMENT - 5 YEARS SOURCE - REGULATED FACILITY VESSEL VENT

\section{ISOTOPE}

\begin{tabular}{|c|c|c|}
\hline \\
\hline & 3 & 3.965810 \\
\hline c!n & 5 & $\therefore 421511-20$ \\
\hline cli & $0: 1$ & $1.07 \div 3.3 E-(1)$. \\
\hline$s F$ & 19 & $4.471174-11$ \\
\hline P:s & $b 1$ & $1.136 .911-10$ \\
\hline SR & 90 & 1.010 .35 If -18 \\
\hline Sk & 3) & $6.00193 t-10$ \\
\hline & 3.) & $1 .+13511-10$ \\
\hline$r$ & 11 & $1.97194 t-11$ \\
\hline 12 & 23 & $1.14352 t-11$ \\
\hline 12 & 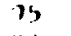 & $0.34 t(i, f-14$ \\
\hline N" & 95 & $1.34 \div 6121-14$ \\
\hline NI & $35: 4$ & $7.921116-10$ \\
\hline IC & 93 & $1.53145 t-0.4$ \\
\hline R.j 1 & 1.) 3 & $1.12+10 F-11$ \\
\hline Rut & & $7.30 .435-00$ \\
\hline RM & $\ln 3.4$ & $1.131135-17$ \\
\hline P.NI & & $0.304440-106$ \\
\hline$r 01$ & $1: 17$ & $1.001191-12$ \\
\hline$r_{1}$ & 1) & $4.167691-.14$ \\
\hline c1 & $15 \mathrm{M}$ & $3 .: 11<! 96-19$ \\
\hline & $1:$ & ?. \\
\hline
\end{tabular}

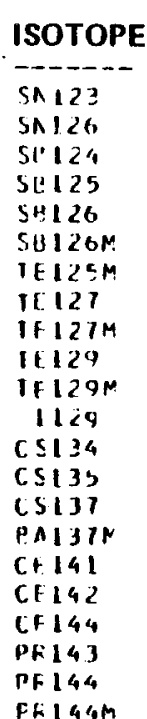

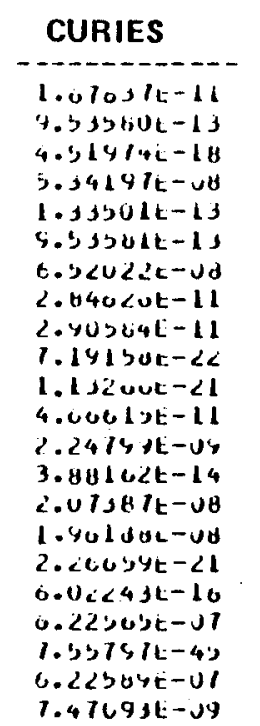

ISOTOPE

NU144

PMI4T

PMI 48

PMI48

PMI4BM

SMI 147

SM 148

SMI49

SMis?

EU152

EUIST

EUISS

EUISO

I 160

ILZU6

IL207

IL 200

rLzug

U212

U233

$\cup<14$

$\checkmark 235$

U230

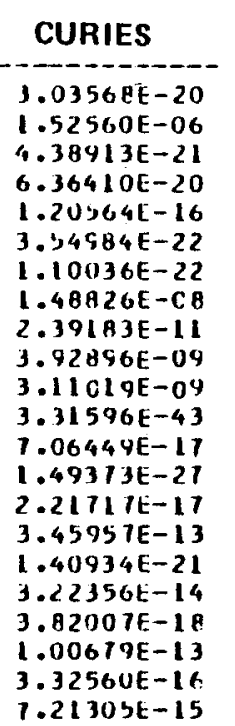

ISOTOPE

4238

NP236

NP236

NP237
PU236

PU236

PU2 37

PU238

PU239

PU240

PU2 1

PU2: 2

AM241

$\triangle M 242$

AMZ42M

AM243

CM242

CM243

CM244

CM245

CM246

CM24

CM248

CM248

CURIES

$1.831 E 6 E-15$

$.09122 E-19$

$.54897 E-14$

$3.466 C 8 E-29$

$5.406 \mathrm{CE}-25$

.

.

. 3934 E 13

$6.381 C 8 E-11$

$4.52153 E-16$

.

A.9

S

$.49622 E-14$

$1.02525 \mathrm{E}-12$

$4.1 \forall 284 E-17$

$3.33 E 79 E-1 E$

$4.10439 E-24$
$4.28611 E-24$
TOTAL ESTIMATEO RELEASES (CI)
Tritium
Fission Producls 3.9700
Uranium 1.42-13
Transuranics
$.42-13$


TABLE 8.7

ESTIMATED ANNUAL ATMOSPHERIC RELEASES TO THE ENVIRONMENT - 15 YEARS SOURCE - REGULATED FACILITY VESSEL VENT

\begin{tabular}{|c|c|}
\hline ISOTOPE & CURIES \\
\hline H 3 & $\therefore 2533$ IE 00 \\
\hline C. & $2.314441 E-10$ \\
\hline SE 19 & $4.47611 \mathrm{E}-\mathrm{il}$ \\
\hline R: $: 17$ & $1.136915-16$ \\
\hline SN 19 & 1.061 y2c-40 \\
\hline St: 10 & $5.00 \div 441-10$ \\
\hline$y \quad r: 0$ & 5.:UU B USE -10 \\
\hline$r 91$ & 36 - 36 - 3 \\
\hline 2R:O3 & $1.14 .3901:-11$ \\
\hline $2 " \because 5$ & (.0? I Od:-31) \\
\hline 11175 & $2.2001700-30$ \\
\hline iNR 254 & $1.29: 264-32$ \\
\hline IC 21 & $1.53+400 !-0 t$ \\
\hline RU101 & $1.22 \geq 64 t-44$ \\
\hline rulorn & $? .14957 t-09$ \\
\hline RHIIOJM & i.27 inst-44 \\
\hline (2111.16 & $9.162581-09$ \\
\hline ? & $3.1007141-12$ \\
\hline $\operatorname{nul(1)}$ & $1.016 ? 81-13$ \\
\hline Cr.11,:1 & $6.110331:-1.4$ \\
\hline
\end{tabular}

\begin{tabular}{|c|c|c|}
\hline ISOTOPE & CURIES & ISOTOPE \\
\hline $\operatorname{si121M}$ & $1.8 U U O S E-12$ & PM147 \\
\hline $\sin 123$ & $5.0 \Omega 30 L-20$ & $5 \operatorname{si1447}$ \\
\hline $5 n 126$ & S.23513t-13 & $\operatorname{SMLAB}$ \\
\hline $5: 124$ & $2.4397 v c-30$ & 5.1149 \\
\hline 59124 & $1 . \angle 172 \angle L-J \theta$ & SMISI \\
\hline $5+126$ & $1.33 \times 1 t-13$ & EU152 \\
\hline $5 B 126 \mathrm{M}$ & Y.S5574t-a & tU154 \\
\hline IEIEうM & $3.14730 t-04$ & EUt5s \\
\hline $1+1<1$ & $2.1 \angle 8<\angle t-\angle 1$ & 10100 \\
\hline $11121 \mathrm{M}$ & $2.3 / u+3 t-21$ & IL206 \\
\hline 1124 & 4 -ovoutt-11 & IL2C7 \\
\hline CS5134 & $1.17120 t-11$ & ILLOA \\
\hline$c \leq 135$ & $3.00101 t-14$ & 11209 \\
\hline $0 \leq|3|$ & $1.04730 t-00$ & ᄂ232 \\
\hline CAI I IM & 1.Jלdste-UB & 0233 \\
\hline$C+142$ & $0.0 .224 \mathrm{SL}-10$ & U234 \\
\hline CE 144 & $0.41+3,1-11$ & 0235 \\
\hline PF $1: 4$ & $3.4140 / \mathrm{t}-11$ & 0236 \\
\hline PK I:4i: & 1. Ulught- $2<$ & 0230 \\
\hline \multirow[t]{5}{*}{ NU144 } & S.U'b $18 t-\angle U$ & \\
\hline & TOTAL ESTIMATED & RELEASES (C) \\
\hline & Tritium & 2.2500 \\
\hline & Fission Products & $2.00-07$ \\
\hline & $\begin{array}{l}\text { Uranuum } \\
\text { Transuranics }\end{array}$ & $\begin{array}{l}2.81-13 \\
2.28-10\end{array}$ \\
\hline
\end{tabular}

\begin{tabular}{|c|c|}
\hline SOTOPE & CURIES \\
\hline $\begin{array}{l}N P 236 \\
N P 237\end{array}$ & $\begin{array}{l}1.09116 E-15 \\
5.57436 E-14\end{array}$ \\
\hline PU236 & $4.11588 E-16$ \\
\hline pu23e & $5.27203 E-11$ \\
\hline PL239 & $5.36840 E-13$ \\
\hline PU240 & $3.38989 E-13$ \\
\hline 01.241 & $3.98201 \mathrm{TE}-11$ \\
\hline$P 6242$ & $4.52148 E-16$ \\
\hline AM241 & $1.34101 E-10$ \\
\hline $\operatorname{AM} 242$ & $8.586: 3 E-14$ \\
\hline$A M 242 M$ & $8.62959 E-14$ \\
\hline $\operatorname{AM} 243$ & $3.626 ! 1 E-14$ \\
\hline $\operatorname{CM} 242$ & $7.12190 \mathrm{E}-14$ \\
\hline CM243 & $2.1414 \mathrm{CE}-14$ \\
\hline CM244 & $6.99204 E-13$ \\
\hline CM24S & $4.17942 E-17$ \\
\hline CM246 & $3.33389 \mathrm{E}-1 \mathrm{e}$ \\
\hline (M24) & $4.10439 E-24$ \\
\hline $\operatorname{CM} 218$ & $4.28610 E-24$ \\
\hline
\end{tabular}


TABLE 8.8

ESTIMATEO ANNUAL ATMOSPHERIC RELEASES TO THE ENVIRONMENT - 5 YEARS SOURCE - PRODUCT SALT CONCENTRATION/SOLIDIFICATION VESSEL VENT

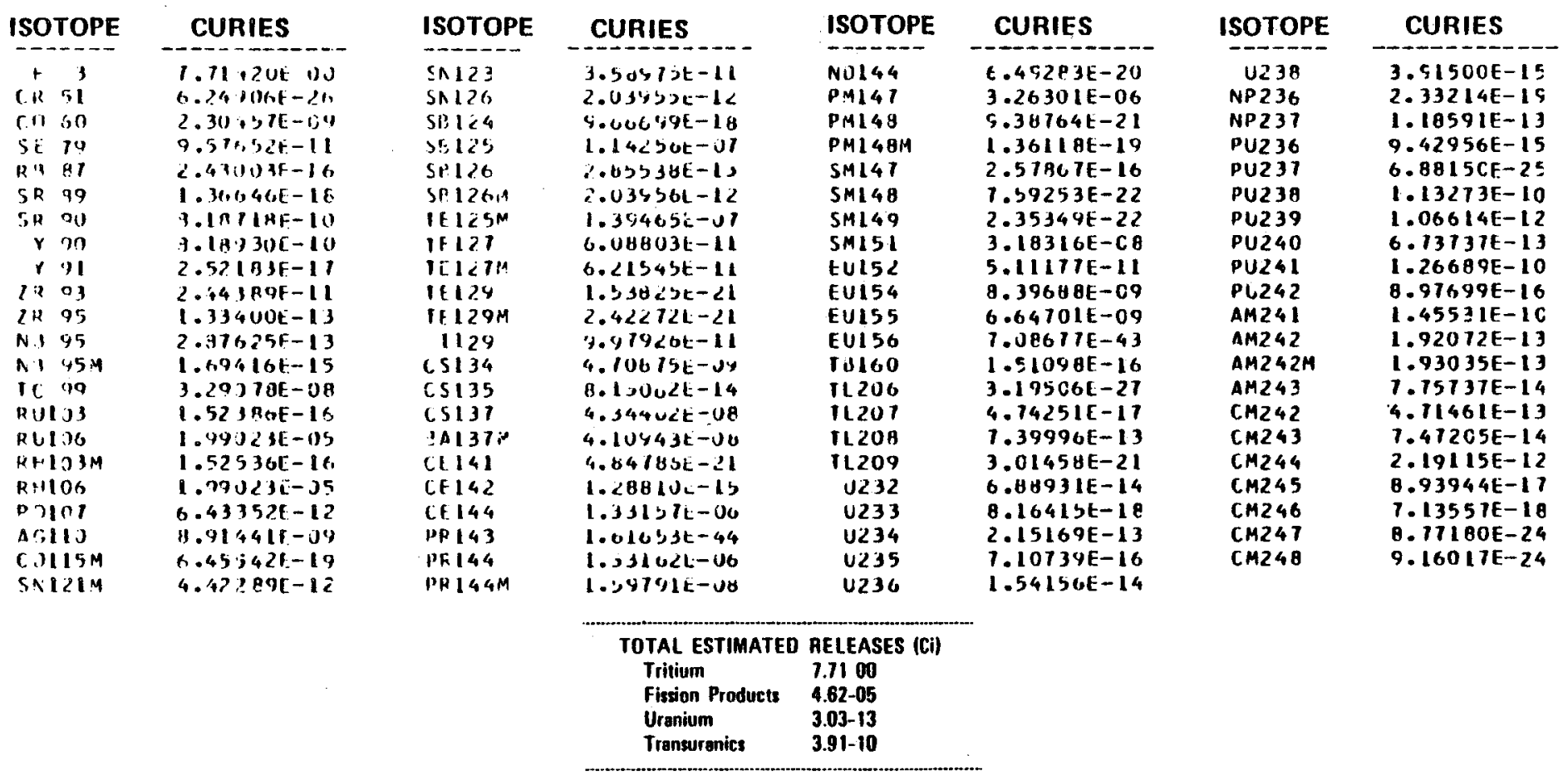


TABLE 8.9

ESTIMATED ANNUAL ATMOSPHEAIC RELEASES TO THE ENVIRONMENT - 15 YEARS

SOURCE - PRODUCT SALT CONCENTRATION/SOLIDIFICATION VESSEL VENT

\section{ISOTOPE}

\begin{tabular}{|c|c|c|}
\hline & 3 & $4.3 n 321 E$ oO \\
\hline & $\omega 0$ & $0.16447 t-10$ \\
\hline & 14 & $9.1775471-11$ \\
\hline$F P$ & 17 & $? \cdot 13,003 F-16$ \\
\hline & 19 & a. 79 A 39t-40 \\
\hline Sk & to & G.39.742E-10 \\
\hline r & 94 & $0.19+100-10$ \\
\hline & ? & $4.35231 E-36$ \\
\hline $2 \mathrm{R}$ & 93 & $\angle A C j A$ IE-II \\
\hline & 95 & $2.13138 F \div 30$ \\
\hline & יזו & $4.713201-30$ \\
\hline $\mathrm{N} !$ & $9 \mathrm{gm}$ & $2.17,310-32$ \\
\hline & & 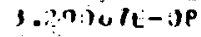 \\
\hline$P(\mathbf{I}$ & & $70015751:-44$ \\
\hline pu! & 166 & $? .03545 E-048$ \\
\hline R+I & 13 nt & $2.31784 t-44$ \\
\hline $\mathrm{HI}$ & 1,6 & $2.0454 x-i) \theta$ \\
\hline $\operatorname{pel}$ & 111 & $6.43351 t-12$ \\
\hline 16 & 10 & $1.3636(0)=-13$ \\
\hline
\end{tabular}

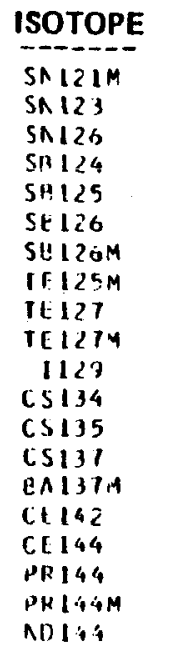

\begin{tabular}{|c|c|c|}
\hline CURIES & ISOTOPE & CURIES \\
\hline 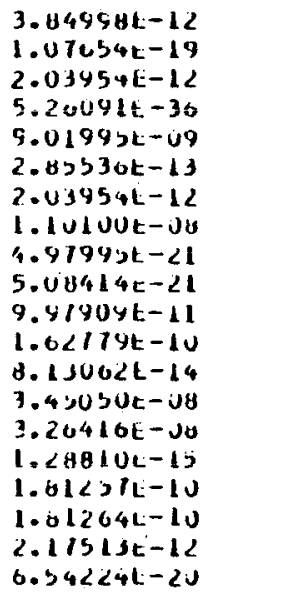 & 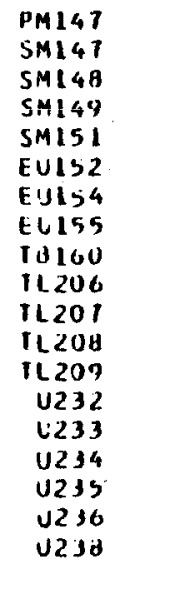 & $\begin{array}{l}2.32254 E-07 \\
3.32214 E-16 \\
1.59253 E-22 \\
2.35349 E-22 \\
2.95439 E-08 \\
2.99815 E-11 \\
3.14837 E-09 \\
1.56690 E-09 \\
9.30669 E-32 \\
1.03755 E-25 \\
1.30396 E-16 \\
1.53249 E-12 \\
1.37217 E-20 \\
9.11203 E-14 \\
1.33380 E-17 \\
4.40594 E-13 \\
1.10139 E-10 \\
1.54334 E-14 \\
3.91500 E-15\end{array}$ \\
\hline $\begin{array}{l}\text { TOTAL ESTIMATEO } \\
\text { Tritium } \\
\text { Fission Products } \\
\text { Uranium } \\
\text { Trensuranics }\end{array}$ & $\begin{array}{l}\text { RELEASES (Ci) } \\
4.3800 \\
4.31-07 \\
6.01-13 \\
4.75-10\end{array}$ & \\
\hline
\end{tabular}

\begin{tabular}{ll} 
ISOTOPE & CURIES \\
\hline NP23E & $2.3320 C E-15$ \\
NP237 & $1.19134 E-13$ \\
PU236 & $8.29 C 73 E-16$ \\
PU236 & $1.0467 C E-10$ \\
PU239 & $1.06583 E-12$ \\
PU240 & $6.13024 E-13$ \\
PU241 & $7.90596 E-11$ \\
PU242 & $8.97540 E-16$ \\
AM241 & $2.86597 E-10$ \\
AM242 & $1.83510 E-13$ \\
AM242M & $1.84430 E-13$ \\
AM243 & $1.15068 E-14$ \\
CM242 & $1.52209 E-13$ \\
CM243 & $5.85884 E-14$ \\
CM244 & $1.49432 E-12$ \\
CM245 & $8.93215 E-17$ \\
CM24E & $7.12510 E-1 E$ \\
CM247 & $8.17180 E-24$ \\
CM248 & $9.16014 E-24$
\end{tabular}


TABLE 8.10

Estimated Total Annual Releases ( $\mathrm{C}$ ) to the Environment

\begin{tabular}{|c|c|c|c|c|}
\hline \multirow[b]{2}{*}{ Isotopic Group } & \multicolumn{2}{|c|}{ Atmosphere } & \multicolumn{2}{|l|}{ Aqueous } \\
\hline & $5-Y_{r}$ & $15-Y r$ & $5-Y r$ & $15-Y r$ \\
\hline Tritium & $3.98+01$ & $2.26+01$ & $9.95+02$ & $5.65+02$ \\
\hline Fissioil Products & $1.18-01$ & $8.55-03$ & $2.67-04$ & $1.64-04$ \\
\hline Uranium & $3.41-10$ & $6.77-10$ & $1.87-11$ & $3.70-11$ \\
\hline Transuranics & $2.45-05$ & $1.90-05$ & $1.34-06$ & $1.04-06$ \\
\hline
\end{tabular}

TABLE 8.11

Comparison of Annual Radioactive Releases (Ci) SRP VS. DWPF

\begin{tabular}{|c|c|c|c|c|c|c|}
\hline \multirow[b]{3}{*}{ Isotopic Group } & \multirow{2}{*}{\multicolumn{3}{|c|}{$\frac{\text { Folnt o1 }}{\text { Atmosphere }}$}} & \multirow{2}{*}{\multicolumn{3}{|c|}{$\frac{\text { Aqueous }}{D W P F}$}} \\
\hline & & & & & & \\
\hline & SRP* & $5-Y r$ & $15-Y r$ & SRP* & $5-Y_{r}$ & $15-Y_{r}$ \\
\hline Tritium & $3.8+05$ & $3.98+01$ & $2.26+01$ & $4.0+04$ & $9.95+02$ & $5.65+02$ \\
\hline Fission Products** & $1.11+01$ & $1.18-01$ & $8.55-03$ & $7.7-01$ & $2.67-04$ & $1.64-04$ \\
\hline Uranium & $3.1-03$ & $3.41-10$ & $6.77-10$ & $5.6-02$ & $1.87-11$ & $3.70-11$ \\
\hline Transuranics & $8.5-03$ & $2.45-05$ & $1.90-05$ & $5.8-03$ & $1.34-06$ & $1.04-06$ \\
\hline
\end{tabular}

* 1978 Releases.

** Does not include noble gases. 


\subsection{References}

1. Deleted.

2. Plan for Management of AEC-Generated Wastes. USAEC Report WASH-1202(73), E. I. du Pont de Nemours \& Company (Inc.), Savannah River Laboratory, Aiken, SC (July 1973).

3. Deleted.

4. Standards for Radiation Protection. ERDA Manual, Chapter 0524. U.S. Energy Research and Development Administration, Washington, DC. 


\section{SAFETY ANALYSIS 9.1}

\subsection{Nuclear and process Safety 9.1}

\subsection{Hazards Analysis 9.2}

\subsubsection{Potential Effects from Normal Operations 9.2}

\subsubsection{Occupational Radiation Exposures 9.2}

9.2 .1 .2 Non-Nuclear Occupational Risks 9.3

\subsubsection{Off site Radiation Exposures 9.3}

9.2 .1 .4 Nonradioactive pollutants 99.4

\subsubsection{Potential Effects from Abnormal Events 9.5}

\section{2 .2 .1 General 9.5}

\subsubsection{Occupational Radiat ion Expsoures 9.6}

9.2 .2 .3 Non-Nuclear Occupational Risks 99.7

\subsubsection{Offite Radiation Exposures 9.7}

9.2.2.5 Offite Land Contamination 9.8

\subsubsection{Nonradioactive Pollutants 9.8}

\subsection{References 9.38}


9. SAFETY ANALYSIS (M. W. Lee)

\subsection{Nuclear and Process Safety}

Potential incidents from trivial to major accidents, that could adversely affect the nuclear and process safety of the DWPF and /or could contaminate onsite or offsite populacions have been identified. The possible causes of each inciderit, its consequence, the expected frequency of the occurrence and applicable safety features have been identified $[1-6]$. These incidents were abstracted from a literature review of related nuclear facilities and from historical records of simllar unit operations at the Savannah River Plant. A more detailed analysis of possible causes and consequences using fault tree and cause-consequence techniques will be made during the preparation of the Safety Analysis Report for the DWPF prior to plant startup.

Engineered safety features were selected to either reduce the frequency of the postulated event or to mitigate its consequence. Safety features which reduce the frequency of events include modifications of process equipment; suggested administrative controls, warning alarms, interlock systems, and negative feedback controls. Examples of mitigating safety features are fire suppression system emergency cooling and power systems, explosion limiting devices, and redundant equipment with alarms.

A Iist of potential incidents, the areas where they may occur, and the identified applicable engineered safety features to mitigate or prevent the incidents are summarized in Tables 9.1 through 9.3 . 


\subsection{Hazards Analysis*}

\subsubsection{Potential Effects from Normal Operations \\ 9.2.1.1 Occupational Radiation Exposures}

Most of the operations necessary to implement the DWPF plans will result in small amounts of radiation exposure to the involved personnel. DOE places restrictions on radiation exposures of workers. The DOE radiation protection standard is 5 rems to the whole body each year and/or 3 rems each calendar quarter [7]. Extensive efforts are made, beyond those required to ensure compliance, with the objective of reducing worker exposure to amounts that are as low as reasonably achievable (ALARA). These efforts include detailed planning of work, which involves radiation exposure potential, to reduce exposure time and to provide adequate shielding. The execution of such work is carried out under written procedures that are approved by health physics specialists. These procedures specify the time limits for the work and the protective clothing and equipment for the work. Depending on the radiation and contamination potential, the work-may be continuously monitored by health physicists.

Experience with operation of the Savannah River Plant indicates that actual personnel exposures can be expected to be considerably less than the DOE standards as a result of the ALARA policy. For example, a summary of SRP occupational dose for 1965 to 1975 is shown in Table 9.4. The annual average dose per monitored employee ranged from 2.7 to 3.7 rems, with the exception of a single apparent dose of 24.8 rems to an employee in 1971 that was not substantiated in follow-up investigations.

Work done in the irradiated fuel reprocessing areas at SRP is similar in many important aspects to work that would be done in conjunction with waste processing. Table 9.5 gives exposure experience for workers involved in the reprocessing activities, excluding those whose jobs involve no potential occupational exposure. As can be seen by comparing Tables 9.4 and 9.5 , there is 11ttle difference in the exposure received by the average plant employee and those involved specifically with processing operations. The radiation exposures of workers in new waste management facilities should be expected to be even lower than workers in present SRP processing buildings because of the greater shielding and improved equipment for handing radioactive material.

* This chapter is an excerpt from the Draft Programatic Environmental Impact Statement for Management of Defense High-Level Radioactive Waste, Savannah River Plant, issued in March 1978. 
Table 9.6 gives results of estimating the occupational exposures by two different techniques: the assumption was made that individual doses would be the same as the average SRP experience for 1965.to 1975 and it was assumed that individual doses would be equal to the DOE standards discussed above. The latter is a very conservative assumption because, even if the potential for such exposures existed, it would be impractical, and undesirable, to rotate and schedule all employees so that everyone received exposure up to the DOE Iimit.

\subsubsection{Non-Nuclear Occupational Risks}

Some non-nuclear risk of injuries, and death exists during construction of new facilities and during the operating campaign. (For minor injuries, only first aid is required and no days are lost from work; major injuries involve one or more lost workdays.) Experience with many construction activities at SRP and from 26 years of operation has shown that these risks can be low in magnitude and below those experienced in many other industrial activities. Tables 9.8 and 9.9 give the results of estimating the number of occupational casualties during construction of new facilities and for the operating phases, respectively.

\subsubsection{Offsite Radiation Exposures}

All facilities will be designed and operated such that radioactive releases from normal operations will be within the overall EPA criteria for such releases and within specific DOE and NRC standards. The current DOE standards for offsite radiation exposures are shown in Table 9.10 [7].

Although the facilities must be operated to fall within the limits discussed above, they will also be operated with the objective of keeping exposures as low as reasonably achievable. In all likelihood, this will result in extremely low, if not zero, exposures from the long-term storage or disposal facilities, and offsite exposures from the handing and processing operations that are comparable to those currently experienced from similar activities at SRP. In 197.6, these exposures to a hypothetical maximum individual* were below 1 mrem from all SRP activities and included contributions from the reactors and from isotopes such as $\mathrm{H}-3$, $\mathrm{Kr}-85, \mathrm{Ar}-41$, and $\mathrm{Xe}-133,135$, that would not be released in significant quantities in the waste handling and processing operations. Routine releases from SRP are discussed more fully in Reference 8.

* Maximum individuals are assumed to be at the site boundary under conditions of maximum probable exposure. 


\subsubsection{Nonradioactive Pollutants}

No mechanisms have been identified for chemical releases under normal conditions for the storage or disposai modes and, therefore, the following discussion is concentrated on processing operations.

When the waste is fixed in glass, there will be releases from the processing operations to the atmosphere and to the onsite streams of chemicals such as $\mathrm{Hg}, \mathrm{NO}_{x}, \mathrm{NH}_{3}, \mathrm{CO}_{2}, \mathrm{NaOH}$, $\mathrm{NaNO}_{3}$, and heated water. These releases, when combined with those from other activities at SRP, must be within emission standards set by South Carolina and Georgia and the Federal Government $[9,10]$. Some of the more important standards are shown in Table 9.11. In addition to the limits imposed by the above standards, SRP operates under National Pollutant Discharge Elimination System (NPDES) permits that limit the discharge of pollutants to tributaries of the Savannah River [11].

Waste management policy at SRP is to limit releases of potentially polluting chemicals to levels that are lower than those required by the standards and permits, to the extent that is reasonably achievable. This policy is implemented by operating controls and by appropriate engineered systems. The extent to which these systems are needed and the releases to the environment that are to be expected will be determined as the research and development program proceeds and detailed design studies are made. Operation of similar processes and pollution abatement devices at SRP is described in detail in Reference 8 , where it is shown that SRP emissions to the atmosphere have been far below the standards shown in Table 9.11, with the exception of particulates from some of the coal-burning power plants. Electrostatic precipitators have been installed on the largest power plants, and prototype improvements are being tested on other plants to ensure conformity with South Carolina emission standards for particulates.

Water that discharges from the SRP creeks to the Savannah River now meets Federal and South Carolina regulations. However, a project has been submitted to DOE for FY-1978 funding [12] that would bring most discharges from individual operating sites into compliance with NPDES Permit No. SC 0000175 before those discharges enter the creeks. Most of the water covered in the project is runoff from coal piles and ash basins, and is of low pH and has high suspended solids. 
In addition to the emissions to water and air described above, there will be low levels of occupational exposure to nonradioactive pollutants of sone workers. Such exposures would occur during processing operations, but not during transportation, storage, or disposal. Reference 13 specifies limits and controls required for exposure to chemicals as legislated by the Occupational Health and Safety Act. Concentrations in air of chemicals to which the worker is exposed will normally be maintained by engineering controls such as ventilation at less than the action level values specified in Subpart $z$ of Reference 13. Potential exposure of the worker is limited because the chemicals are normally introduced into the process within ventilated enclosures designed to contain radioactivity. Exposures may occur in storage areas, during transport of chemicals from the storage areas, and during preparation of the chemicals for the processes. When concentrations are above an action level, routine monitoring is required rather than audit monitoring. When threshold limit values are exceeded, workers will wear personal protective equipment including respiratory protection as prescribed in Subpart I of Reference 13. Engineering controls would be added or modified to reduce transient high concentrations to less than threshold limit values. Records are required for each worker exposed to chemicals at concentrations greater than threshold limit values.

\subsubsection{Potential Effects from Abnormal Events}

\subsubsection{General}

Details of consequences and probabilities of a wide range of abnormal events will be published in the Safety Analysis Report dealing with all aspects of the DWPF. Such analyses must await detailed systen design based on results of the research and development program. One of the primary purposes of the program is to influence the design of various parts of the facility to ensure a high degree of confidence in acceptable safety regarding abnormal events.

Preliminary analyses have, however, been reported in Reference 8 for risks from unusual events that might occur in all operations involved. Events considered were major process incidents, natural events such as tornadoes and earthquakes, sabotage, airplane crash, and abandonment. The magnitudes were chosen to be upper bounds of credible occurrences. This approach provides a sound physical basis to obtain release fractions, to follow environmental pathways, and to calculate radiation exposures. Detailed results from Reference 8 are reviewed in the discussion below. In general, they show that consequences alone, without regard for probabilities, do not pose any disaster potential for the offsite populations. Individual doses that occur are comparable to back- 
ground doses in most cases. It is expected that when formal analyses are made of all systems, the results will show much lower risks.

Some of the important physical reasons why the hazards associated with the waste are limited include:

- Very large amounts of energy are required to create waste particles small enough to be widely distributed through the airborne pathway. This is true on a per curie basis for the salt cake and sludge currently stored in tanks as well as for the high-integrity forms like glass.

- There are no inherent internal sources of high energy in the waste management systems. Energy required to release radioactive particles would have to be introduced externally and in some abnormal manner.

- There are no radioactive noble gases or significant amounts of easily volatilized radioactive elements in the waste that could contribute to potential doses from the airborne pathway.

- High-integrity waste forms and engineered surface storage facilities can impose major barriers against waste migration.

- Iiquid releases from SRP would be absorbed in the soil or diluted many orders of magnitude by the onsite creeks and swamps and by the Savannah River before reaching drinking water users. Even if diversion systems fail and no corrective actions are taken, no large individual doses can occur.

- The SRP waste facilities are within a large exclusion area surrounded by land of low population density.

An added level of accident protection to both workers and offsite population is provided by the design of waste management facilities. The construction methods and materials that meet routine radiation shielding requirements and that ensure adequate resistance to earthquakes and tornadoes also provide resistance and containment for other unlikely incidents.

\subsubsection{Occupational Radiation Exposures}

All the very low probability events that have some potential for releasing radioactive materials offsite also have the potential for exposing working personnel to high radiation exposures. These events include major process incidents, tornadoes and earthquakes of incredible magnitude, sabotage, and airplane crash. The distribution of radiation effects among the personnel at the site 
is impossible to predict because it would depend upon precise details of location of the personnel and corrective actions relative to the chain of events under way. This is in contrast to the predictability of offsite effects, where the major determinants are amount of activity released and meteorology or water flow patterns. Furthermore, the radiation would probably be a small contributor to the worker casualties in these unlikely events; most of the casualties would be from explosive forces, falling buildings, tornado-driven missiles, fire, saboteur gunfire, etc.

Even though consequences mentioned above are possible, their occurrence is extermely unlikely. This fact is generally illustrated by formal safety analyses of existing and designed nuclear systems, and by the experience of the commercial and defense nuclear enterprises over the past thirty years. When this low probability of occurrence is considered, the resulting occupational risk (the product of consequence times probability) from radiation exposure is negligible.

\subsubsection{Non-Nuclear Occupational Rüsks}

The non-nuclear risks to onsite workers from abnormal events are in the same category as the risks discussed above for radiation exposures, in the sense that casualties are possible but the likelihood of occurrence is so small that the risks are negligible. The number of casualties possible for each abnormal event is difficult or impossible to estimate because of the mitigating effects of forewarning, corrective action, etc. However, there has been no mechanisw identified that would increase the nonnuclear risks above those normally experienced in any large industrial operation. In practice, the unusually heavy construction of the waste management facilities would probably provide greater worker protection against abnormal events than that afforded by most other industrial facilities.

\subsubsection{Offsite Radiation Exposures}

Analyses have previously been reported (Reference 14) whtch make estimates, using pessimistic assumptions where necessary, of the offsite radiation exposures that might occur for a variety of abnormal events. The events considered were major process incidents; natural occurrences such as tornadoes, earthquakes, floods, and meteorite impact; sabotage, airplane crash; and abandonment. The analyses considered the four major modules: removal from tanks, processing, transportation, and storage. The results are 
given as consequences (measured by radiation dose commitment)* to maximum offsite individuals and to the offsite population within $150 \mathrm{~km}$. The consequences were then multiplied by an estimate of annual probability of occurrence to obtain annual risk. Finally, the annual risk was integrated for 300 years, accounting for radioactive decay and population growth, to obtain total risk for the period. (After 300 years of decay, individual doses that could occur from any of the events analyzed are negligible.) These data are given in Table 9.12. They show that there is no disaster potential to the offsite population from abnormal events. Although some of the maximum individual doses are of concern, they could occur to only a limited number of people and are calculated assuming no corrective actions are taken. Doses to average individuals in the nearby population would be thousands to tens of thousands of times lower, depending upon pathways, and therefore would be inconsequential compared to even the variation in natural background in the local area.

\subsubsection{Offsite Land Contamination}

Levels of radionuclide deposition that would require evacuation of people and restrictions on farming and milk production are discussed in more detail in Reference 14 and are given below in Table 9.13. The deposition limits were derived from the dose criteria given in Table 9.14 which are also discussed in Reference 14 .

Only two operational modules have potential for causing offsite land contamination for any of the abnormal events considered. These two are sabotage during removal of waste from tanks and sabotage during processing waste to glass. The consequences, if each of these events did occur, are given in Tables 9.15 and 9.16 , respectively, in terms of land contaminated and people evacuated.

\subsubsection{Nonradioactive Pollutants}

There will be no unusually large stores of chemicals required for implementation of any of the alternative plans. Therefore, there is little potential for pollutant release to the environment for the abnormal events considered. Furthermore, mitigating features such as sand filters and liquid diversion systems would be expected to retain most accidental releases. Operations have been

* Table IV-6 in the Draft Programmatic Environmental Impact Statement for Management of Defense High-Level Radioactive Waste, Savannah River Plant, issued March 1978. 
conducted over the past 27 years at SRP using large quantities of such chemicals as nitric acid and hydrogen sulfide with no adverse effect on the environment, as discussed in Reference 8. Similar experience for releases attributable to abnormal events is expected to apply to any future waste management operations.

When the high-activity fraction is separated from the waste and subsequently processed to glass, there will remain about 19 million gallons of decontaminated salt cake. This salt could be stored in decontaminated waste tanks existing after processing, and would be subject to occurrence of the abnormal events discussed previously. The worst of these would be abandonment, with subsequent filling of the tanks with rainwater and runoff to the Savannah River. This scenario was analyzed in Reference 14, and the consequences are given in Table 9.17. Not only is this event considered very unlikely, but also the river would not be polluted above drinking water standards even if no corrective actions were taken. 
TABLE 9.1

Operational Areas in the DWPF

Operational Area

Incidents

General

$1-27$

Waste Removal and Blending

$28-49$

Evaporation and Salt Solidification

$50-62$

Aluminum Dissolving

$63-66$

Centrifugation

$67-71$

Sand Filtration

$72-76$

Supernate Decontamination (Ion Exchange)

$77-83$

Elutriant Recovery $\left(\mathrm{NH}_{3}\right.$ and $\left.\mathrm{CO}_{2}\right)$

$84-90$

Recycle Concentration

91

Spray Drying

94-105

Glass Melting

106-109

Mechanical Cell

111

Crane Operation

$112-119$

Electric Power Supply

120-122

Water Supply

$123-129$

Steam Generation and Distribution

$130-132$

Sampling

$133-139$

Ventilation System

$140-147$

Gang Valve Operation

$148-150$

Compressed Air and Gas Systems

$151-152$ 
TABLE 9.2

Potential Incidents

\begin{tabular}{|c|c|c|}
\hline $\begin{array}{l}\text { Incident } \\
\text { Number }\end{array}$ & Incidents & $\begin{array}{l}\text { Applicable Engineered } \\
\text { Safety Features }\end{array}$ \\
\hline & (General) & \\
\hline 1 & Earthquake greater than safe shutdown & 1,216 \\
\hline 2 & Meteorite impact & * \\
\hline 3 & Hurricane or tornado & 1,216 \\
\hline 4 & Flood & 2 \\
\hline 5 & Large aircraft impact & * \\
\hline 6 & Sabotage & 3 \\
\hline 7 & Total loss of cooling capability & 1,4 \\
\hline 8 & Loss of electric power & $5,11,166,167,168,169$ \\
\hline 9 & Adverse effects of lightning & $5,7,48$ \\
\hline 10 & Adverse winter operating conditions & 6,8 \\
\hline 11 & Fire & $9,10,60$ \\
\hline 12 & Criticality & 12,38 \\
\hline 13 & Transfer error & $13,14,15,16$ \\
\hline 14 & Vessel overflow & $17,18,19,20,21,52,200$ \\
\hline 15 & Transfer line pluggage & $\begin{array}{l}19,20,21,22,23,53,54 \\
113,114,115,116,117,118\end{array}$ \\
\hline 16 & Vessit and line leakage & $19,20,21,25,42,200$ \\
\hline 17 & Sucl:back & $26,27,28,29,30,31$ \\
\hline 18 & Siphoning & 32 \\
\hline 19 & Coil fallure & $17,33,34,35$ \\
\hline 20 & $\begin{array}{l}\text { Vessel or piping rupture from impact } \\
\text { of dropped equipment }\end{array}$ & $19,20,21,36,61,62$ \\
\hline 21 & Chemical addition error & $13,14,37,200$ \\
\hline 22 & Uncontrolled chemical reaction & $\begin{array}{l}13,14,17,18,20,38,39 \\
43,44,200\end{array}$ \\
\hline 23 & Instrument line pluggage & 41,42 \\
\hline 24 & Release during equipment removal & 35,34 \\
\hline 25 & $\begin{array}{l}\text { Loss of instrument or process } \\
\text { compressed atr }\end{array}$ & $11,46,47,52$ \\
\hline 26 & $\begin{array}{l}\text { Temperature excursion in solids } \\
\text { (Sludge) settling out of feed streams }\end{array}$ & 40 \\
\hline 27 & Leakage through cell or canyon wall & $20,21,25,49,50,51$ \\
\hline
\end{tabular}


TABLE 9.2, Contd

Incident

Number

Incidents

(Waste Removal and Blending)

28

29

30

31

32

33

34

35

36

37

38

39

40

41

42

43

44

45

46

47

48

49
Overflow of pump pit

overflow of waste tank

Waste tank explosion

Overflow of diversion box

Boiling waste tank

Activity bypasses waste tank filter

Failure of seal between waste

removal platform and tank

Increased air activity in waste

lanks from slurrying activity

Overstressing of waste tank components

Potential for high personnel exposure during installation, removal, and maintenance of sludge pumps

Loss of tank ventilation

Underground equipment crushed by heavy vehicles

Below ground leaks from waste tanks

Pump tank explosion

Above ground release from process line

Release from segregated water

Airborne release from diversion box

Contamination spread from localized

spill

Tank damage from vortex formation

Rapid corrosion of carbon steel tanks

Failure of support structure for tank sludge pumps

Opening of self-heated cracks in tank
Applicable Engineered

Safety Features

$17,19,20,59$

$17,18,35,55,59$

$5,56,57,58,59$

$19,20,35,59,63$

65,66

$60,67,68$

*

*

69

$45,70,71,72,73$

$5,57,58$

$12,74,75,76$

20

$5,56,59,64$

$35,59,77,78$

*

*

59

*

38

*

$68,79,89$ 
TABLE 9.2, Contd

Incident

Number

-

Incidents

(Evaporation and Salt Solidification)

50

51

52

53

54

55

56

57

58

59

60

61

62

63

64

65

66

67

68

69

70

71

Overflow of evaporator cell

Leak through evaporator cell

Evaporator expiosion

Chemical Oxidation of Iuthenium to volatile ruthenium tetraoxide

Evaporator eructation

Evaporator leak

Overflow of CTS pit

CTS tank explosion

Spill from CTS cleanout port

Erronous transfer of evaporator materials

Collapse of salt cake storage tank

Release of activity from segregated water

Major liquid release from waste tank riser

(Aluminum Dissolving)

Explosion in the off-gas system

Pressurization of the dissolver

Dissolver pot coils not submerged during shutdown

High liquid level in dissolver

(Centrifugation)

Severe vibration of centrifuge

Centrifuge missile

Excessive cake compaction

Failure of centrifuge suspension. system

Centrifuge plow breaks
Applicable Engineered Safety Features

59

$\star$

$38,40,52,82,83$

*

17,52

$19,20,21$

$20,59,63$

$40,53,59,81$

*

14

-

*

17,59

81

$52,84,85$

17,86

17,18

87,88

87,88

89

87,88

89,90 


\begin{tabular}{|c|c|c|}
\hline $\begin{array}{l}\text { Incident } \\
\text { Number } \\
\end{array}$ & Incidents & $\begin{array}{l}\text { Applicable Engineered } \\
\text { Safety Features }\end{array}$ \\
\hline & (Sand Filtration) & \\
\hline 72 & Overflow of sand filter & 17,18 \\
\hline 73 & Fire in or around sand filter & $\star$ \\
\hline 74 & Hydraulic surge & * \\
\hline 75 & Failure of backflush system to operate & 18 \\
\hline 76 & $\begin{array}{l}\text { Introduction of nitric acid into } \\
\text { caustic and ammonia bearing streams } \\
\text { (Supernate Decontamination) }\end{array}$ & 13,38 \\
\hline 77 & Cs breaktrhough of Duolite 0 column & $22,23,24,38$ \\
\hline 78 & Precipitation in ion exchange column & $18,35,91$ \\
\hline 79 & Overheating of zeolite column & $39,40,92$ \\
\hline 80 & High temperature ion exchange colum & 39,40 \\
\hline 81 & Line and sampler pluggage by resin & 42 \\
\hline 82 & Uncontrolled reaction of resin & $19,40,93$ \\
\hline 83 & $\begin{array}{l}\text { Improper resin level } \\
\text { (Elutriant Recovery) }\end{array}$ & * \\
\hline 84 & $\begin{array}{l}\text { Farming in elutriant recovery } \\
\text { concentrator reboller }\end{array}$ & $23,35,94$ \\
\hline 85 & $\begin{array}{l}\text { Pluggage of elutriant recovery } \\
\text { condenser }\end{array}$ & 53,95 \\
\hline 86 & $\begin{array}{l}\text { Contamination of Cs elutriant } \\
\text { makeup by Cs }\end{array}$ & 53,96 \\
\hline 87 & Ammonia compounds & 13 \\
\hline 88 & Overheat of concentrator reboiler & $17,40,54,82$ \\
\hline 89 & Overpressurizarion of concentrator & 52,97 \\
\hline 90 & $\begin{array}{l}\text { Pluggage of elutriant recovery vent } \\
\text { system } \\
\text { (Recycle Concentration) }\end{array}$ & 40,98 \\
\hline 91 & $\begin{array}{l}\text { Accumulation of ion exchange resin } \\
\text { in evaporator }\end{array}$ & * \\
\hline 92 & Evaporator leakage & 99 \\
\hline 93 & Explosion in evaporator & $38,40,52,82,83$ \\
\hline
\end{tabular}




\begin{tabular}{|c|c|c|}
\hline $\begin{array}{l}\text { Incident } \\
\text { Number }\end{array}$ & Incidents & $\begin{array}{l}\text { Applicable Engineered } \\
\text { Safety Features }\end{array}$ \\
\hline & (Spray Drying) & \\
\hline 94 & $\begin{array}{l}\text { High temperature breach of the spray } \\
\text { dryer }\end{array}$ & $\begin{array}{l}40,100,101,102,103,104, \\
105\end{array}$ \\
\hline 95 & $\begin{array}{l}\text { Spray dryer breach from internal } \\
\text { corrosion }\end{array}$ & 40,106 \\
\hline 96 & Spray dryer breach from thermal shock & $40,53,107,108,109$ \\
\hline 97 & Spray dryer breach from pressurization & $\begin{array}{l}42,110,111,145,146 \\
147,148\end{array}$ \\
\hline 98 & Spray dryer breach from impact & 1 \\
\hline 99 & $\begin{array}{l}\text { Bypass or failure of sintered metal } \\
\text { filters }\end{array}$ & $53,149,150$ \\
\hline 100 & $\begin{array}{l}\text { HEPA filter system breached } \\
\text { (not applicable) }\end{array}$ & $151,152,153$ \\
\hline 101 & Energetic airborne release & $\begin{array}{l}40,100,101,102,103, \\
104\end{array}$ \\
\hline 102 & High ruthenium adsorber bed temperature & $154, .155$ \\
\hline 103 & $\begin{array}{l}\text { Increased volatilization of } \mathrm{RuO}_{4} \text { and } \\
\text { localized } \mathrm{RuO}_{2} \text { depositon }\end{array}$ & $40,102,103,104$ \\
\hline 104 & $\begin{array}{l}\text { Excessive solvent oxidation in spray } \\
\text { dryer }\end{array}$ & 38 \\
\hline 105 & $\begin{array}{l}\text { Abnormal nitrate and/or water in } \\
\text { spray dryer } \\
\text { (Vitrification) }\end{array}$ & $\begin{array}{l}40,100,101,102,103, \\
104\end{array}$ \\
\hline 106 & Steam explosion & $135,136,137,156,157$ \\
\hline 107 & Refractory collapse or spalling & $\begin{array}{l}123,138,139,140,141 \\
142,143,144\end{array}$ \\
\hline 108 & Electrical shorting & $124,125,126,127,128,141$ \\
\hline 109 & Ma jor glass spili & $\begin{array}{l}112,129,130,131,132,133 \\
134,144\end{array}$ \\
\hline 110 & $\begin{array}{l}\text { Release of airborne activity to cell or } \\
\text { ventilation system } \\
\text { (Mechanical Cell) }\end{array}$ & $\begin{array}{l}112,119,129,130,131, \\
132,133,134,144\end{array}$ \\
\hline 111 & Failure of high level waste canister & $99,120,121,122$ \\
\hline
\end{tabular}


TABLE 9.2, Contd

Incident

Number

,

Incidents

(Crane Operatins)

112

113

114

115

116

117

118

119

120

121

123

124

125

126

127

128

129

130

131

132 the cab mishandling crane control center equipment system

(Water Supply)

return pump process vessel equipment
Personnel exposure in crane $c a b$

Contamination of crane external to

Contamination of work areas by crane

Disengagement from crane hook

Damage to equipment by mishandiing of

Crane cable failure

Failure of crane movement control

optical system failure in hot crane

(Electric Power Supply)

Failure to supply power to a motor

Failure to supply power to operating

Failure of emergency diesel generator

Failure of well pump

Cooling tower system failure

Failure of cooling water supply header

Failure of heat exchanger

Failure of recirculating cooling water 190

Closed-loop cooling water contamination

Radioactive leakage to the environment through cooling water

(Steas Generation and Distribution)

Leak in steam or cooling coil within

High stean pressure in process

Failure of steam supply
Applicable Engineered

Safety Features

158,159

160

$\star$

$\star$

*

161,162

163,164

165

170,171

$6,170,172,173,174$, $175,176,177,178,179$

$180,181,182,183,184$, $185,186,187,188,189$

$190,191,192,193$

*

52,194

*

$33,195,196$

38,197

$33,195,197,198$

82

$40,52,199$ 
IABLE 9.2, Contd

\begin{tabular}{|c|c|c|}
\hline $\begin{array}{l}\text { Incident } \\
\text { ivumber }\end{array}$ & Incidents & $\begin{array}{l}\text { Applicable Engineerec } \\
\text { Safery Features }\end{array}$ \\
\hline & (Sampling) & \\
\hline 133 & Broken sample vial & 201 \\
\hline 134 & $\begin{array}{l}\text { Pailure to survey person or material } \\
\text { prior to removal from sample aisle }\end{array}$ & 202 \\
\hline 135 & Air reversal & $53,204,205,215$ \\
\hline 136 & $\begin{array}{l}\text { Failure to obtain sample or analysis } \\
\text { or delayed analysis }\end{array}$ & $\star$ \\
\hline 137 & Sample spill & 204 \\
\hline 138 & Sampler pressurization & $42,52,204$ \\
\hline 139 & $\begin{array}{l}\text { Failure of radiation monitoring devices } \\
\text { (Ventilation System) }\end{array}$ & 5,206 \\
\hline 140 & Loss of stack condensate to environment & 68,207 \\
\hline 141 & Sand filter depression & $208,209,210$ \\
\hline 142 & Water accumulation in the sand filter & 19,68 \\
\hline 143 & Fan failure & 5,211 \\
\hline 144 & $\begin{array}{l}\text { Circuit breaker switch failure in vent } \\
\text { system }\end{array}$ & 212 \\
\hline 145 & $\begin{array}{l}\text { Vacuum loss in process vessel vent } \\
\text { system }\end{array}$ & $6,52,82,213$ \\
\hline 146 & Damper failure & 214,215 \\
\hline 147 & $\begin{array}{l}\text { HEPA Filter failute (not applicable) } \\
\text { (Gang Valve Operation) }\end{array}$ & 53,60 \\
\hline 148 & $\begin{array}{l}\text { Severe potential radiation exposure to } \\
\text { personnel in the gang valve corridors }\end{array}$ & 27,29 \\
\hline 149 & Fallure of gang valve & 203 \\
\hline 150 & $\begin{array}{l}\text { Failure to survey person or material } \\
\text { prior to removal from gang valve } \\
\text { corridor }\end{array}$ & 202 \\
\hline
\end{tabular}


TABLE 9.2 , Contd

Incident

Number

Incidents

(Compressed Air and Gas System)

151

Compressed air system faiure

Breathing air system failure material
Applicable Engineered

Safety Features

$113,217,218$

$38,113,218,219,220,221$

* Incidents which have no safety feature listed are $2,5,34,35,43,44,46,48$, $51,53,58,60,61,73,74,83,91,114,115,116,124,126$, and 136. Most of these can be prevented by administrative control. 
TABLE 9.3

\section{Engineered Safety Features}

\begin{tabular}{|c|c|c|}
\hline Number & Safery Features & Applicable Incidents \\
\hline 1 & $\begin{array}{l}\text { Canyon processing areas to conform to } \\
\text { maximum design criteria as defined by } \\
\text { Building Specification } 7096\end{array}$ & $1,3,7,98$ \\
\hline 2 & Site selection free from flooding & 4 \\
\hline 3 & $\begin{array}{l}\text { Restricted and guarded area for all } \\
\text { facilities }\end{array}$ & 6 \\
\hline 4 & $\begin{array}{l}\text { Capability for temporary emergency } \\
\text { supply of cooling water to canyon } \\
\text { vessels }\end{array}$ & 7 \\
\hline 5 & $\begin{array}{l}\text { Automatically started emergency } \\
\text { diesel power for critical equipient }\end{array}$ & $\begin{array}{l}8,9,30,38,41,139 \\
143\end{array}$ \\
\hline 6 & $\begin{array}{l}\text { Lightning protection in electric } \\
\text { circuitry }\end{array}$ & $9,121,144$ \\
\hline 7 & Lightning rods on elevated equipment & 9 \\
\hline 8 & $\begin{array}{l}\text { Steam tracing or thermal insulation } \\
\text { on liquid bearing lines exposed to } \\
\text { weather }\end{array}$ & 10 \\
\hline 9 & Fire suppression system & 11 \\
\hline 10 & $\begin{array}{l}\text { Temperature sensing fire detectors in } \\
\text { cells }\end{array}$ & 11 \\
\hline 11 & $\begin{array}{l}\text { Automatic restarter on criticá: } \\
\text { equipment }\end{array}$ & 8,25 \\
\hline 12 & $\begin{array}{l}\text { Neutron monitor to detect build } 1=0 \text { : } \\
\text { fissile materials }\end{array}$ & 12,39 \\
\hline 13 & $\begin{array}{l}\text { Dedicated piping for nitric acic and } \\
\text { ammonia cold feed lines }\end{array}$ & $13,21,22,76,87$ \\
\hline 14 & $\begin{array}{l}\text { All valves clearly labeled and } \\
\text { identified }\end{array}$ & $13,21,22,59$ \\
\hline 15 & Key lock transfer switches & 13 \\
\hline 16 & Remotely controlled valves & 13 \\
\hline 17 & $\begin{array}{l}\text { Liquid level instrumentation with } \\
\text { fault indicate light }\end{array}$ & $\begin{array}{l}14,19,22,28,29 \\
54,62,65,66,72,88\end{array}$ \\
\hline 18 & High liquid level alarm & $14,22,29,66,72,75,78$ \\
\hline 19 & Stainless steel lined sump & $\begin{array}{l}14,15,16,20,28,31,55, \\
82,142\end{array}$ \\
\hline 20 & $\begin{array}{l}\text { Radiation alarms to detect leaks } \\
\text { or spills }\end{array}$ & $\begin{array}{l}14,15,16,20,22,27,28, \\
31,40,55,56\end{array}$ \\
\hline
\end{tabular}




\begin{tabular}{|c|c|c|}
\hline Number & Safety Features & Applicable Incidents \\
\hline 21 & $\begin{array}{l}\text { Separation of sump alarms from sump } \\
\text { pump control circuitry }\end{array}$ & $14,15,16,20,27,55$ \\
\hline 22 & Liquid flow meter & 15,77 \\
\hline 23 & Liquid flow rate control & $15,77,84$ \\
\hline 24 & Alarm for excessive flow & 77 \\
\hline 25 & $\begin{array}{l}\text { Avoidance of expansion joints where } \\
\text { possible }\end{array}$ & 16,27 \\
\hline 26 & $\begin{array}{l}\text { Pneumatic-electric interfaces located } \\
\text { in areas normally not occupied by } \\
\text { personnel }\end{array}$ & 17 \\
\hline 27 & $\begin{array}{l}\text { Gang valves located as high as possible } \\
\text { above vessel level }\end{array}$ & 17,148 \\
\hline 28 & $\begin{array}{l}\text { Seal pots on cold chemical addition } \\
\text { lines }\end{array}$ & 17 \\
\hline 29 & $\begin{array}{l}\text { Automatic air blow of gang valves if } \\
\text { steam supply fails }\end{array}$ & 17,148 \\
\hline 30 & $\begin{array}{l}\text { Double containment of gang valves and } \\
\text { lines }\end{array}$ & 17 \\
\hline 31 & $\begin{array}{l}\text { Shielded lines from gang valves to } \\
\text { process vessel }\end{array}$ & 17 \\
\hline 32 & Siphon breaker on discharge piping & 18 \\
\hline 33 & "Cash" coil presure regulator & $18,128,130$ \\
\hline 34 & $\begin{array}{l}\text { Closed loop cooling system on cooling } \\
\text { coils only }\end{array}$ & 19 \\
\hline 35 & Gamma radiation monitor & $19,24,29,31,42,77,84$ \\
\hline 36 & Protection of piping from dropped loads & 20 \\
\hline 37 & Color coding of cold chemical systems & 21 \\
\hline 38 & Sampling and analysis capability & $\begin{array}{l}12,22,47,52,76,77,93 \\
104,129,152\end{array}$ \\
\hline 39 & High temperature alarm & $22,79,80$ \\
\hline 40 & Temperature instrumentation & $\begin{array}{l}26,52,57,79,80,82,88 \\
90,93,94,95,96,101,103 \\
105,132\end{array}$ \\
\hline 41 & Diversity in control instruments & 23 \\
\hline 42 & $\begin{array}{l}\text { Blowdown capability for plugged } \\
\text { instruments and samplers }\end{array}$ & $16,23,81,136,138$ \\
\hline
\end{tabular}




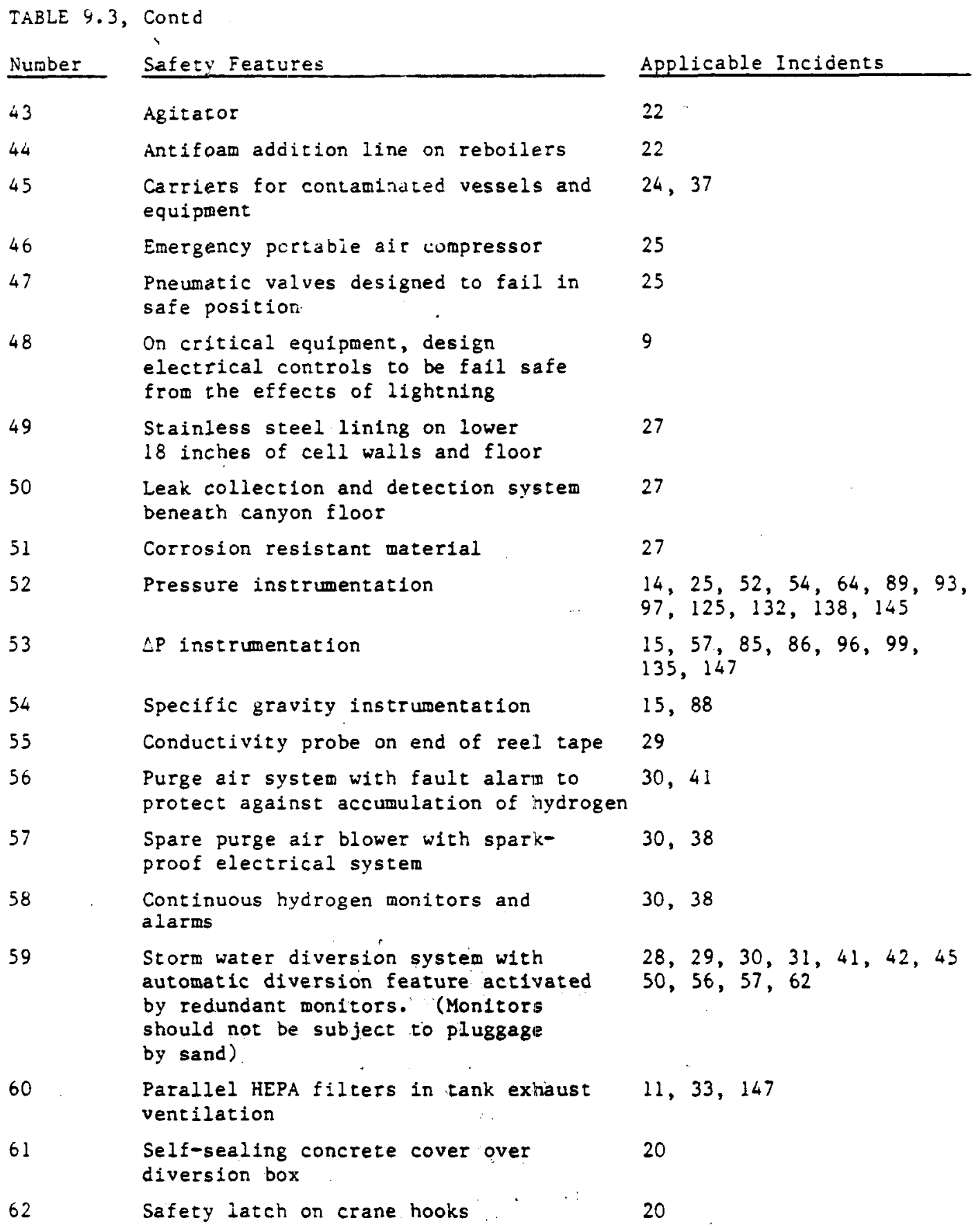




\begin{tabular}{|c|c|c|}
\hline jumber & Safery Features & Applicable Incidents \\
\hline 63 & $\begin{array}{l}\text { Stainless steel lined diversion box } \\
\text { cell }\end{array}$ & 31,56 \\
\hline 64 & $\begin{array}{l}\text { Continuous monitoring of purge air } \\
\text { flow from pump tank }\end{array}$ & 41 \\
\hline 65 & $\begin{array}{l}\text { Cooling water flow alarms for waste } \\
\text { tanks }\end{array}$ & 32 \\
\hline 66 & Reflux condensers on waste tanks & 32 \\
\hline 67 & $\begin{array}{l}\text { Continuous radioactive monitors and } \\
\text { alarms of tank ventilation exhaust }\end{array}$ & 33 \\
\hline 68 & $\begin{array}{l}\text { Dehumidifier in tank ventilation } \\
\text { exhaust }\end{array}$ & $33,49,140,142$ \\
\hline 69 & $\begin{array}{l}\text { Vibration measuring equipment for } \\
\text { tanks during sludge slurrying }\end{array}$ & 36 \\
\hline 70 & $\begin{array}{l}\text { Spray ring for decontamination of } \\
\text { slurry pumps during removal }\end{array}$ & 37 \\
\hline 71 & Shielded crane for slurry pump removal & 37 \\
\hline 72 & $\begin{array}{l}\text { Streamlined housing and connection } \\
\text { design for slurry pumps }\end{array}$ & 37 \\
\hline 73 & $\begin{array}{l}\text { Remote, shielded decontamination and } \\
\text { maintenance facility for slurry pumps }\end{array}$ & 37 \\
\hline 74 & Minimize pipe lines under roadways & 39 \\
\hline 75 & $\begin{array}{l}\text { Provide adequate protection for buried } \\
\text { lines in immediate area of tanks, } \\
\text { diversion boxes, etc. from heavy } \\
\text { equipment loads }\end{array}$ & 39 \\
\hline 76 & $\begin{array}{l}\text { Specify and post load bearing } \\
\text { capacities near vital equipment }\end{array}$ & 39 \\
\hline 77 & $\begin{array}{l}\text { Flush water system pressure higher } \\
\text { than process system pressure }\end{array}$ & 42 \\
\hline 78 & $\begin{array}{l}\text { Double containment of flush water } \\
\text { lines from process to control valves }\end{array}$ & 42 \\
\hline 79 & $\begin{array}{l}\text { Availability of pump-out equipment } \\
\text { for waste tank and annular space }\end{array}$ & 49 \\
\hline 81 & Air purge maintained & 57,63 \\
\hline 82 & Pressure relief valve & $52,88,93,131,145$ \\
\hline 83 & $\begin{array}{l}\text { Interiock steam supply with } \\
\text { temperature and pressute controls }\end{array}$ & 52,93 \\
\hline
\end{tabular}


TABIEE 9.3, Contd

\begin{tabular}{|c|c|c|}
\hline Number & Safety Features & Applicable Incidents \\
\hline 84 & $\begin{array}{l}\text { Interlock operation control with } \\
\text { condenser cooling water }\end{array}$ & 64 \\
\hline 85 & $\begin{array}{l}\text { Vent dissolver off-gas condenser to } \\
\text { canyon }\end{array}$ & 64 \\
\hline 86 & Vent dissolver to vessel vent system & 65 \\
\hline 87 & $\begin{array}{l}\text { Automatic centrifuge braking if } \\
\text { vibration is severe }\end{array}$ & $67,68,70$ \\
\hline 88 & $\begin{array}{l}\text { Vibration frequency and amplitude } \\
\text { readout }\end{array}$ & $67,68,70$ \\
\hline 89 & High pressure spray in centrifuge & 69,71 \\
\hline 90 & $\begin{array}{l}\text { Interlock to prevent plowing at high } \\
\text { speed in centrifuge }\end{array}$ & 71 \\
\hline 91 & $\begin{array}{l}\text { Conductivity meter on spent regenerated } \\
\text { solution on Cs column }\end{array}$ & 78 \\
\hline 92 & $\begin{array}{l}\text { Circulated cooling water through } \\
\text { zeolite column }\end{array}$ & 79 \\
\hline 93 & Keep resin submerged in liquid & 82 \\
\hline 94 & Stean stripper & 84 \\
\hline 95 & $\begin{array}{l}\text { Down draft condenser on elutriant } \\
\text { recovery }\end{array}$ & 85 \\
\hline 96 & $\begin{array}{l}\text { Demister at vapor stream exit on } \\
\text { stripper }\end{array}$ & 86 \\
\hline 97 & $\begin{array}{l}\text { Pressure relief through purge } \\
\text { condenser }\end{array}$ & 89 \\
\hline 98 & Heat tracing & 90 \\
\hline 99 & $100 \%$ weld inspection & 92,111 \\
\hline 100 & High temperature shut offs provided & $94,101,105$ \\
\hline 101 & $\begin{array}{l}\text { Temperature monitor for waste input } \\
\text { stream of spray dryer }\end{array}$ & $94,101,105$ \\
\hline 102 & $\begin{array}{l}\text { Current and voltage are monitored for } \\
\text { spray dryer heaters: }\end{array}$ & $94,101,103,105$ \\
\hline 103 & $\begin{array}{l}\text { Coolant flow is monitored for spray } \\
\text { dryer heaters }\end{array}$ & $94,101,103,105$ \\
\hline 104 & $\begin{array}{l}\text { Automatic system shutdown for spray } \\
\text { dryer heaters when malfunction occurs }\end{array}$ & $94,101,103,105$ \\
\hline
\end{tabular}




\begin{tabular}{|c|c|c|}
\hline Nuaber & Safety Features & Applicable Incidents \\
\hline 105 & $\begin{array}{l}\text { Sloped surfaces of cone }\left(60^{\circ} \text { from }\right. \\
\text { horizontal) to reduce calcine } \\
\text { accumulation on chamber surface }\end{array}$ & 94 \\
\hline 106 & $\begin{array}{l}\text { Corrosive resistant materials } \\
\text { ("Incoloy" } 800 \mathrm{H} \text { or "hastelloy } \mathrm{C}^{\prime \prime} \text { ) for } \\
\text { spray dryer construction to minimize } \\
\text { corrosion }\end{array}$ & 95 \\
\hline 107 & $\begin{array}{l}\text { Temperature instrumentation and } \\
\text { controls on cooling water flow to } \\
\text { induction heater coil }\end{array}$ & 96 \\
\hline 108 & $\begin{array}{l}\text { Differential pressure measurement } \\
\text { across feed nozzie }\end{array}$ & 96 \\
\hline 109 & $\begin{array}{l}\text { Remotely operated cleanout needle for } \\
\text { mix nozzle }\end{array}$ & 96 \\
\hline 110 & Design resistance to pressurization & 97 \\
\hline 111 & $\begin{array}{l}\text { Pressure monitors with shutdown inter- } \\
\text { locks for high spray dryer pressure }\end{array}$ & 97 \\
\hline 112 & $\begin{array}{l}\text { No uncontained penetration through } \\
\text { refractory or containment shell below } \\
\text { melt line }\end{array}$ & 109,110 \\
\hline 113 & $\begin{array}{l}\text { Redundant compressed air with auto- } \\
\text { matic starter }\end{array}$ & $15,151,152$ \\
\hline 114 & $\begin{array}{l}\text { Molten glass level control devices with } \\
\text { backup thermocouple level sensors }\end{array}$ & 15 \\
\hline 115 & $\begin{array}{l}\text { Alarms to indicate power loss, com- } \\
\text { pressed air loss, low vacuum, and } \\
\text { instrument faults in the glass melting } \\
\text { process }\end{array}$ & 15 \\
\hline 116 & $\begin{array}{l}\text { Use of current control or electrodes } \\
\text { to maintain uniform condition }\end{array}$ & 15 \\
\hline 117 & Aluminum dissolving & 15 \\
\hline 118 & Adequate canyon exhaust filtration & 15 \\
\hline 119 & $\begin{array}{l}\text { Cell flush system designed to prevent } \\
\text { splashing of water on hot equipment } \\
\text { and to prevent accumulation of water } \\
\text { on the floor }\end{array}$ & 210 \\
\hline 120 & $\begin{array}{l}\text { Radiation monitors for airborne con- } \\
\text { tamination }\end{array}$ & 111 \\
\hline 121 & Weld inspection and testing & 111 \\
\hline 122 & Q/A constructed overpack & 111 \\
\hline
\end{tabular}


TABLE 9.3, Contd

Number Safery Features

123 Cylindrical design minimizes proba- 107

bility of refractory collapse

124 Grounding of melter shell and floating 108 electrodes

125 Use of insulated power cables rather 108 than bus bars

126

128

130

131

132

133

134

108

108

108

106

Two dump canisters with total volume greater than that of the melter and with shroud to protect against entrance of water

Use of air cooling for electrodes 106

Engineered controls for minimizing

106 glass spills, such as level and weight control

Strategically placed thermocouples on melter outer surface to detect erosion or corrosion of the liner, especially in throat area

Low glass velocities
Applicable Incidents

108,110

109,110

109,110

109,110

109,110

109,110 
TABLE 9.3, Contd

Number

142

143

144

145

146

147
Safety Features

Redundancy in power supply to reduce thermal shock from repeated recoveries from loss of power

Avoidance of startup using liquid sodium hydroxide for normal operation

Refractory specifications include use of void-free and dense refractory special block finishes involving diamond truing and grinding, joints made as thin as possible, and optimized block size

Maximun voltage less than 300 to reduce amount of current carried by refractory

Water cooled steel shell provides secondary jacket for glass containment so that failure of refractory will not result in loss of glass

Pressure relief device, such as seal pot, provided

Filter blowback sequenced to avoid pressurizing spray dryer

off-gas blower spared

Interlock to shutdown feed and filter blowback for exhauster failure

Online particulate analyzer

off-gas system designed to handle total filter failure

Sequential filter units

Sand filter for calcining filter system

Fire resistant filter housings

Temperature instrumentation and alarms

Gamma monitor with alart downstream of adsorber

Sloped flooring to enhance rapid water drainage and removal to remotely

located sump
Applicable Incidents

107

107,108

107

107

$107,109,110$

97

97

97

97

99

99

100

100

100

102

102

106 
TABLE 9.3, Contd

Number

157

158

159

160

161

162

163

164

165

166

167

168

169

170

171

172

173

174

\section{Safety Features}

Stainless steel lining on celi floor

Double filters in series on the crane cab air conditioner

Install controlled access to the crane 112 $\mathrm{cab}$

Provide emergency exit on the crane cab 113

Crane cable overload devices 117

Provide dead man control on the crane 117

Redundant design for the crane brake 118

Provide spare impact wrench

Redundant optical system on the crane

$c a b$

Multiple source of electrical genera

tion (onplant as well as offplant)

Electric power taken from a loop with power cowing from either direction on the loop

Redundant transformers each capable of carrying the entire area electrical load

Autonatic tie-in of double ended area loop

Redundant, vital equipment automatically supplied power from separate motor control centers

Uninterruptable instrument power supplies

Safety related electrical equipment, including conduit switchgear and motor control centers, shall be designed to meet seismic criteria and environmental conditions

Redundant routings of power and control cables, for safety related circuits, shall be run separately.

Control and power cables shall be run separately
118

\section{Applicable Incidents}

106

112

18

119

8

8

8

8

120,121

120

121

121

121 
TABLE 9.3, Contd

Number Safety Features

175 The electrical power systems important to safery shall be designed to include the capability for periodically testing the operability and functional performance of those system components and the operability of the system as a wtole

176 Concrete that encases buried concuit for power distribution is dyed red to indicate contents
Cable encasements for safety related functions are maximu resistance construction

Proximity of liquid-bearing lines above motor control center should be avoided where possible

Proximity of electrical equipment to thermally hot process equipment should be avoided where possible

Two separate maximum resistance emergency power system

Primary oil supply tanks (day tanks) for diesels are maximum resistance construction

Either diesel is sized to carry full area emergency load with capability for manual switch-over when one fails

Install emergency generator operating indication

Autotransfer to emergency power, not responsive to momentary surges, sequential loading, automatic reset

Provided battery charger

Diesel generator room is heated to maintain temperatures above freezing

All emergency electric equipment should be located to protect against steam, water or process fluid leaks which could cause ambient temperatures or humidity to rise to a level causing electrical equipment malfunction
Applicable Incidents

121

121 


\begin{tabular}{|c|c|c|}
\hline Number & Safety Features & Applicable Incidents \\
\hline 188 & $\begin{array}{l}\text { Emergency electrical equipment should } \\
\text { be protected from potential accident- } \\
\text { generated flooding }\end{array}$ & 122 \\
\hline 189 & $\begin{array}{l}\text { Fire within one electrical enclosure } \\
\text { should not spread to redundant electric } \\
\text { equipnent }\end{array}$ & 122 \\
\hline 190 & $\begin{array}{l}\text { Install redundant backup pump with } \\
\text { automatic start }\end{array}$ & 123,127 \\
\hline 191 & $\begin{array}{l}\text { Install diesel power or steam driven } \\
\text { pump backup }\end{array}$ & 123 \\
\hline 192 & $\begin{array}{l}\text { Sufficient inventory of water in } \\
\text { cooling tower to achieve safe shutdown }\end{array}$ & 123 \\
\hline 193 & Design pump for cold weather condition & 123 \\
\hline 194 & Pressure sensor and alarms. & 125 \\
\hline 195 & Water diversion to retention basin & 128,130 \\
\hline 196 & $\begin{array}{l}\text { Activity monitor for closed-loop } \\
\text { cooling water }\end{array}$ & 128 \\
\hline 197 & $\begin{array}{l}\text { Activity monitor and alarms in steam } \\
\text { condensate discharge }\end{array}$ & 130 \\
\hline 199 & $\begin{array}{l}\text { Design pressure reducing station for } \\
\text { winter conditions }\end{array}$ & 132 \\
\hline 200 & $\begin{array}{l}\text { Dikes or curbing to contain vessel } \\
\text { contents }\end{array}$ & $14,16,21,22$ \\
\hline 201 & $\begin{array}{l}\text { Redesign of vial retainer of sample } \\
\text { vial }\end{array}$ & 133 \\
\hline 202 & $\begin{array}{l}\text { Sensitive monitoring equipment at exits } \\
\text { to unregulated areas }\end{array}$ & 134,250 \\
\hline 203 & $\begin{array}{l}\text { Alternative pumpout equipment in case } \\
\text { of gang valve failure. }\end{array}$ & 149 \\
\hline 204 & Use of shielded sample cell & $135,136,137,138$ \\
\hline 205 & Pressure differential alarm & 135 \\
\hline 206 & $\begin{array}{l}\text { Redundant air monitors powered by } \\
\text { separate electrical source }\end{array}$ & 139 \\
\hline 207 & Stack with acid resistant brick liner & 140 \\
\hline 208 & $\begin{array}{l}\text { Depression gauge and alarn for sand } \\
\text { filter }\end{array}$ & 141 \\
\hline
\end{tabular}


TABLE 9.3, Contd

Number

209

210

211

212

213

214

215

216

217

218

219

220
Safety Features

Stainless steel sand bed support over lateral ducts

Roof and sides of sand filter sealed to prevent water from leaking into sand

Parallel for system with automatic start

Circuit breaker switch in weather proof box

Redundant vacuum system with bypass valving capability

Automatic and manual control capability on dampers

Air reversal warning system

Stack located far enough from important structures so that it would not cause significant damage if it fell

Automatic isolation of system if

loss of compressed air occurs

Instrumentation and alarms for system pressure and compressor operability

Filtration system for removal of oil and other impurities from breathing air

Redesign of breathing air connections to prevent against accidental connection of other gases

kink-resistant breathing air hoses
Applicable Incidents

141

141

143

144

145

146

135,146

1,3

151

151,152

152

152

152 
TABLE 9.4

SRP Whole Body Occupational Dose

\begin{tabular}{|c|c|c|c|c|}
\hline Year & $\begin{array}{l}\text { Number of } \\
\text { Employees } \\
\text { Monitored }\end{array}$ & $\begin{array}{l}\text { Total } \\
\text { Dose, } \\
\text { rem }\end{array}$ & $\begin{array}{l}\text { Average Dose } \\
\text { per Monitored } \\
\text { Employee, rem }\end{array}$ & $\begin{array}{l}\text { Maximum } \\
\text { Individual } \\
\text { Exposure, rem }\end{array}$ \\
\hline 1965 & 4977 & 2340 & 0.47 & 2.9 \\
\hline 1966 & 5032 & 2074 & 0.41 & 3.4 \\
\hline 1967 & 5041 & 2604 & 0.52 & 3.0 \\
\hline 1968 & 4875 & 2412 & 0.49 & 3.3 \\
\hline 1969 & 4705 & 2758 & 0.59 & 3.2 \\
\hline 1970 & 4626 & 2353 & 0.51 & 3.7 \\
\hline 1971 & 4836 & 2401 & 0.50 & $3.3(24.8)$ \\
\hline 1972 & 5210 & 1711 & 0.33 & 3.4 \\
\hline 1973 & 5005 & 1488 & 0.30 & 2.7 \\
\hline 1974 & 5138 & 1367 & 0.27 & 3.1 \\
\hline \multirow[t]{2}{*}{1975} & 5263 & 1161 & 0.22 & 2.7 \\
\hline & Average Ove & Period & 0.42 & \\
\hline
\end{tabular}

TABLE 9.5

SRP Reprocessing Area Whole Body Occupational Dose

\begin{tabular}{|c|c|c|c|c|c|}
\hline & $\begin{array}{l}\text { Number } \\
\text { Employe } \\
\text { Monitor }\end{array}$ & red & $\begin{array}{l}\text { Total } \\
\text { Dose, } \\
\text { rem }\end{array}$ & $\begin{array}{l}\text { Average Dose } \\
\text { per Monitored } \\
\text { Employee, rem }\end{array}$ & $\begin{array}{l}\text { Maximum } \\
\text { Individual } \\
\text { Exposure, rem }\end{array}$ \\
\hline \multicolumn{6}{|l|}{ Year } \\
\hline 1965 & 1501 & & 916 & 0.61 & 2.8 \\
\hline 1966 & 1497 & & 928 & 0.62 & 3.1 \\
\hline 1967 & 1489 & & 980 & 0.66 & 3.0 \\
\hline 1968 & 1454 & & $829^{\circ}$ & 0.57 & 2.9 \\
\hline 1969 & 1441 & & 994 & 0.69 & 2.9 \\
\hline 1970 & 1378 & & 868 & 0.63 & 2.6 \\
\hline 1971 & 1567 & & 815 & 0.52 & 2.8 \\
\hline 1972 & 1756 & & .685 & 0.39 & 2.9 \\
\hline 1973 & 1613 & $\therefore$ & 742 & 0.46 & 2.7 \\
\hline 1974 & 1674 & & 720 & 0.43 & 2.9 \\
\hline \multirow[t]{2}{*}{1975} & 1781 & & 570 & 0.32 & 2.7 \\
\hline & Average & Over & Period & 0.54 & \\
\hline
\end{tabular}


TABLE 9.6

Occupational Radiation Exposure

Basis: Process to Glass; Ship to Offsite Geologic Disposal

Operational Module

Removal from tanks

Processing

Transportation

Storage

Total/max.yr (rem)

Total for campaign (rem)a

\section{Rem/Year in Maximum Year}

SRP Experience DOE Standards

$4.2 \quad 5.0 \times 10^{1}$
$2.31 \times 10^{2}$
$2.75 \times 10^{3}$

$1.40 \times 10^{2}$

$1.40 \times 10^{2}$

0

0

$3.75 \times 10^{2} \quad 2.94 \times 10^{3}$

$3.75 \times 10^{3}$

$2.94 \times 10^{3}$

$\overline{a . ~ S e e ~ T a b l e ~} 9.7$ for campaign times.

TABLE 9.7

Manpower and Time Requirements

\begin{tabular}{lll} 
Operation & $\begin{array}{l}\text { No. of } \\
\text { Employees }\end{array}$ & Time Required \\
\cline { 1 - 2 } $\begin{array}{l}\text { Reconstitute, transfer from } \\
\text { old to new tank }\end{array}$ & 6 & 6 months \\
$\begin{array}{l}\text { Decontaminate old tank } \\
\text { Remove } 60 \text { million gallons from } \\
\text { present tanks, transfer to new } \\
\text { processing building }\end{array}$ & 6 & 6 months \\
$\begin{array}{l}\text { Process } 60 \text { million gallons to } \\
\text { glass, } 10 \text {-year time }\end{array}$ & 550 & 10 years \\
Transport glass offsite & $\begin{array}{l}\text { Use DWD } \\
\text { treatment }\end{array}$ & 10 years
\end{tabular}

a. Includes supervision and overhead. 
TABLE 9.8

Non-Nuclear Occupational Casualties During Construction of New Facilities

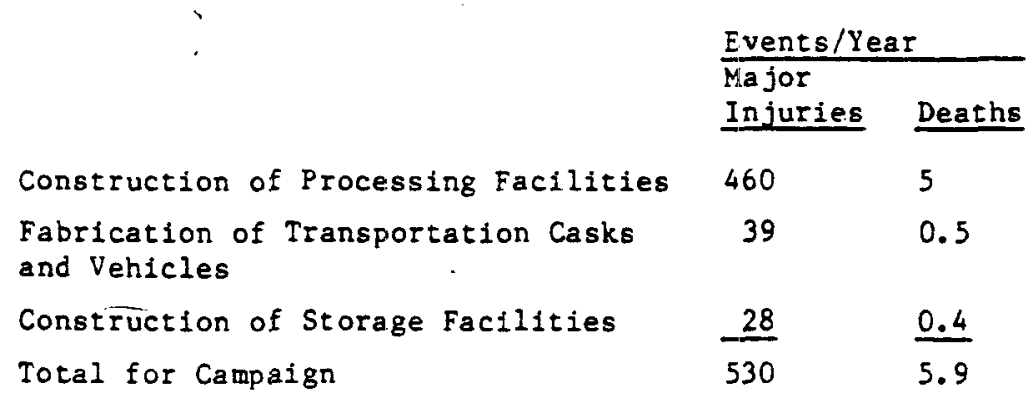

TABLE 9.9

Non-Nuclear Occupational Casualties During the Operational Campaign

\begin{tabular}{lccl} 
& \multicolumn{2}{c}{ Events/Year } \\
\cline { 2 - 3 } & $\begin{array}{l}\text { Minor } \\
\text { Injuries }\end{array}$ & $\begin{array}{lll}\text { Ma jor } \\
\text { Injuries }\end{array}$ & Deaths \\
\cline { 2 - 3 } Removal from Tanks & 1.5 & 0.0013 & 0.00016 \\
Processing & 80.5 & 0.078 & 0.0089 \\
Transportation & - & 1.6 & 0.052 \\
Storage & 0.58 & 0.0051 & 0.00006 \\
Total per Year & 83 & 1.7 & 0.061 \\
Total for Campaign & 990 & 16 & 0.63
\end{tabular}

TABLE 9.10

DOE Radiation Exposure Limits to offsite Individuals, mrem

\begin{tabular}{lll} 
Type of Exposure & $\begin{array}{l}\text { Maximum } \\
\text { Individual } \\
\text { Dose }\end{array}$ & $\begin{array}{l}\text { Average } \\
\text { Population } \\
\text { Dose }\end{array}$ \\
\hline Whole Body & 500 & 170 \\
Gonads & 500 & 170 \\
Bone Marrow & 500 & 170 \\
G. I. Iract & 1500 & 500 \\
Bone & 1500 & 500 \\
Thyroid & 1500 & 500 \\
Other Organs & 1500 & 500 \\
&
\end{tabular}


TABLE 9.11

Typical State and Federal Air and Water Quality Standardsa $[9,10]$

\begin{tabular}{|c|c|c|c|}
\hline Pollutant & $\begin{array}{l}\text { Limiting } \\
\text { Concentrations }\end{array}$ & Comment & \\
\hline $\mathrm{SO}_{2}$ & $80 \mathrm{~g} / \mathrm{m}^{3}$ & Ambient alr, $\mathrm{SC}$ & \\
\hline $\mathrm{SO}_{2}$ & $43 \mathrm{~g} / \mathrm{m}^{3}$ & Ambient air, GA & \\
\hline $\mathrm{SO}_{2}$ & $1300 \mathrm{~g} / \mathrm{m}^{3}$ & One-hour, air, SC & \\
\hline $\mathrm{SO}_{2}$ & $715 \mathrm{~g} / \mathrm{m}^{3}$ & One-hour, air, GA & \\
\hline $\mathrm{SO}_{2}$ & $3.51 \mathrm{~b} / 10^{6} \mathrm{Btu}$ & Air emission, $S C$ & \\
\hline Particulates (Fly Ash) & $0.61 \mathrm{~b} / 10^{6} \mathrm{Btu}$ & Air emission, $\mathrm{SC}$ & \\
\hline $\mathrm{NO}_{\mathbf{x}}$ & $100 \mathrm{~g} / \mathrm{m}^{3}$ & Ambient afr, $\mathrm{SC}$ and $\mathrm{GA}$ & \\
\hline $\mathrm{H}_{2} \mathrm{~S}$ & $10 \mathrm{ppm}, 8 \mathrm{hr}$ & Air, detectable effects & \\
\hline Nonmethane Hydrocarbons & $130 \mathrm{~g} / \mathrm{m}^{3}$ & Three-hour, air, SC & \\
\hline Sulfate & $250 \mathrm{ppm}$ & Drinking water standard, & Federal \\
\hline Chloride & $250 \mathrm{ppm}$ & Drinking water standard, & Federal \\
\hline Nitrate & $10 \mathrm{ppm}$ & Drinking water standard, & Federal \\
\hline Barium & $1 \mathrm{ppm}$ & Drinking water standard, & Federal \\
\hline Iron & $0.3 \mathrm{ppm}$ & Drinking water standard, & Federal \\
\hline Boron & $1 \mathrm{ppm}$ & Drinking water standard, & Federal \\
\hline Zinc & 5 pp⿴囗十 & Drinking water standard, & Federal \\
\hline Chromium & 0.05 & Drinking water standard, & Federal \\
\hline Manganese & $0.05 \mathrm{ppm}$ & Drinking water standard, & Federal \\
\hline Arsenic & $0.05 \mathrm{ppm}$ & Drinking water standard, & Federal \\
\hline Mercury & $0.002 \mathrm{ppm}$ & Drinking water standard, & Federal \\
\hline Copper & $1 \mathrm{ppm}$ & Drinking water standard, & Federal \\
\hline Phenob & $0.001 \mathrm{ppm}$ & Drinking water standard, & Federal \\
\hline
\end{tabular}

a. The above listing is not meant to imply that all the chemicals would be released from the waste management facilities. 
TABLE 9.12 、

Summary of Risks for Processing Waste to Glass (glass stored in offsite geologic storage)

\begin{tabular}{|c|c|c|c|c|}
\hline Event & $\begin{array}{l}\text { Maximum } \\
\text { Individual } \\
\text { Dose, rema } \\
\end{array}$ & $\begin{array}{l}\text { Population Dose } \\
\text { for Maximum Year, } \\
\text { man-reno }\end{array}$ & $\begin{array}{l}\text { Probability } \\
\text { Events/Year }\end{array}$ & $\begin{array}{l}\text { Maximum Risk } \\
\text { man-rem/Year }\end{array}$ \\
\hline \multicolumn{5}{|l|}{ Removal from Tanks } \\
\hline Routine Releases & Negligible & 1.4 & 1.0 & 1.4 \\
\hline Sludge Spill & $5.0 \times 10^{-4}$ & $1.5 \times 10^{1}$ & $5.0 \times 10^{-2}$ & $7.5 \times 10^{-1}$ \\
\hline Spill at Inlet & $1.2 \times 10^{-3}$ & $3.7 \times 10^{1}$ & $5.0 \times 10^{-2}$ & 1.9 \\
\hline Tornado & $2.0 \times 10^{-3}$ & $5.4 \times 10^{1}$ & $6.0 \times 10^{-4}$ & $3.2 \times 10^{2}$ \\
\hline Spill & $2.0 \times 10^{-2}$ & $1.1 \times 10^{3}$ & $5.0 \times 10^{-3}$ & 5.4 \\
\hline Explosion & 7.8 & $3.0 \times 10^{4}$ & $1.0 \times 10^{-4}$ & 3.0 \\
\hline Sabotage & $1.2 \times 10^{2}$ & $3.5 \times 10^{5}$ & $1.0 \times 10^{-5}$ & 3.5 \\
\hline Below-Ground Leaks & $1.5 \times 10^{-1}$ & $1.7 \times 10^{5}$ & $1.0 \times 10^{-5}$ & 1.7 \\
\hline \multicolumn{5}{|l|}{ Processing } \\
\hline Routine Releases & $2.2 \times 10^{-5}$ & 3.0 & 1.0 & 3.0 \\
\hline Process Incidents & $<1.0 \times 10^{-5}$ & $4.2 \times 10^{-1}$ & 1.0 & $4.2 \times 10^{-1}$ \\
\hline Sabotage & $4.2 \times 10^{1}$ & $8.9 \times 10^{4}$ & $1.0 \times 10^{-5}$ & $8.9 \times 10^{-1}$ \\
\hline Airplane Crash & $1.5 \times 10^{-1}$ & $3.1 \times 10^{2}$ & $7.0 \times 10^{-8}$ & $2.2 \times 10^{-5}$ \\
\hline \multicolumn{5}{|l|}{ Transportation } \\
\hline Routine Exposures & $5.0 \times 10^{-3}$ & $6.3 \times 10^{1}$ & 1.0 & $6.3 \times 10^{1}$ \\
\hline Accidents & $6.9 \times 10^{-1}$ & $1.2 \times 10^{2}$ & $1.3 \times 10^{-4}$ & $1.5 \times 10^{-2}$ \\
\hline \multicolumn{5}{|l|}{ Storage } \\
\hline Expected Releases & Negligible & $1.3 \times 10^{2}$ & 1.0 & $1.3 \times 10^{2}$ \\
\hline $\begin{array}{l}\text { Time-Integrated Risk, } \\
\text { man-remb }\end{array}$ & \multicolumn{4}{|c|}{$9.0 \times 10^{2}$} \\
\hline
\end{tabular}


TABLE 9.13 、

Radionuclide Deposition Limits for Evacuation and Restrictions on Famming, $\mathrm{Ci} / \mathrm{m}^{2}$

$\begin{array}{llllll}\text { Isotope } & \begin{array}{l}\text { Evacuation } \\ \text { Direct } \\ \text { Radiation }\end{array} & \frac{\text { Inhalation }}{\text { Restrictions on Farming }} & \begin{array}{l}\text { First Year } \\ \text { Fonger }\end{array} \\ \text { Sr-90 } & - & 2 \times 10^{-4} & 4 \times 10^{-5} & \frac{2 \times 10^{-4}}{2 \times 10^{-5}} \\ \text { Cs-137 } & 3 \times 10^{-5} & 1 \times 10^{-3} & 2 \times 10^{-6} & 8 \times 10^{-5} \\ \text { Pu-238, 239 } & - & 1 \times 10^{-7} & - & -\end{array}$

TABLE 9.14

Radiation Dose Criteria.

Evacuation Limits

External Irradiation 10 rem to whole body in 30 years

Inhalation $\quad 75$ rem to critical organ in 50 years

Farming Restrictions

(Short Term)
S -90
4 rem to bone marrow in first year ${ }^{a}$
Cs -137
5 rem to whole body in first year ${ }^{a}$

Farming Restrictions

$(>1$ year $)$
Sr -90
( 5 rem to bone marrow in 50 years)/year
Cs -137
(1 rem to whole body in 50 years)/year

a. The 50-year dose comitments due to these exposures in the first year are about $25 \mathrm{rem}$ to the bone marrow from SI-90 and $5 \mathrm{rem}$ to the whole body from Cs-137. (Almost all the dose from $\mathrm{Cs}-137$ is received in the year in which it is ingested.) 
TABLE 9.15

Contamination Effects from Sabotage During Removal of Waste from Tanks

Distance from

Release, km

Acres

15-20

Decontaminated

People Moved

$20-25$

$8.5 \times 10^{3}$

$2.2 \times 10^{3}$

$25-30$

$1.1 \times 10^{4}$

$3.2 \times 10^{2}$

30-3:

$1.3 \times 10^{4}$

0

$35-40$

$1.6 \times 10^{4}$

0

$1.8 \times 10^{4}$

0

$40-45$

$2.1 \times 10^{4}$

0

45-50

$2.3 \times 10^{4}$

0

50-55

$2.5 \times 10^{4}$

0

$55-60$

0

0

Total offsite

$1.3 \times 10^{5}$

$2.5 \times 10^{3}$

Table 9.16

Contamination Effects from Sabotage During Waste Processing

Distance from

Release, $\mathrm{km}$

Acres

People

$15-20$

Decont aminated

Moved

$20-25$

$8.5 \times 10^{3}$

0

Total Offsite

0

0

$8.5 \times 10^{3} \quad 0$

TABLE 9.17

\begin{tabular}{|c|c|c|}
\hline Component & $\begin{array}{l}\text { River Water } \\
\text { Concentration }\end{array}$ & $\begin{array}{l}\text { EPA Drinking } \\
\text { Warer Standard }\end{array}$ \\
\hline$C s-137$ & $1.1 \times 10^{-3} \mathrm{nCi} / \mathrm{L}$ & $<8 \times 10^{-3} \mathrm{nCi} / 2$ \\
\hline$S z-90$ & $2.2 \times 10^{-4} \mathrm{nCi} / \mathrm{L}$ & $8 \times 10^{-3} \mathrm{nCi} / \mathrm{L}$ \\
\hline Pu (total) & $6.2 \times 10^{-4} \mathrm{nCi} / \mathrm{L}$ & $1.5 \times 10^{-2} \mathrm{nCi} / \mathrm{L}$ \\
\hline $\mathrm{U}$ & $5.8 \times 10^{-6} \mathrm{mg} / \mathrm{L}$ & $5.0 \times 10^{-1} \mathrm{mg} / \mathrm{L}$ \\
\hline $\mathrm{Hg}$ & $1.4 \times 10^{-4} \mathrm{mg} / \mathrm{L}$ & $2.0 \times 10^{-3} \mathrm{mg} / \mathrm{L}$ \\
\hline $\mathrm{NO}_{3}+\mathrm{NO}_{2}$ & $2.0 \times 10^{-1} \mathrm{mg} / \mathrm{L}$ & $>1.0 \mathrm{mg} / \mathrm{L}$ \\
\hline
\end{tabular}




\subsection{REFERENCES}

1. W. S. Durant. Potential Incidents Applicable to the Defense Waste Processing Facility - Waste Removal and Blending, Evaporation and Salt Solidification. Internal Report DPST-78-403, Savannah River Laboratory, E. I. du Pont de Nemours and Company, Aiken, SC 29801 (June 1978).

2. W. S. Durant. Potential Incidents Applicable to the Defense Waste Processing Facility - Sludge Supermate Separation. Internal Report DPST-78-445, Savannah River Laboratory, E. I. du Pont de Nemours and Company, Aiken, SC 29801 (November 1978).

3. M. W. Lee. Potential Incidents Applicable to the Defense Waste Processing Facility - Supemate Treatment. Internal Report DPST-78-509, Savannah River Laboratory, E. I. Du Pont de Nemours and Company, Aiken, SC 29801 (August 1978).

4. W. S. Durant and E. W. Holtscheiter. Potential Incidents Applicable to the Defense Waste Processing Facility Sludge Treatment. Internal Report DPST-78-510, Savannah River Laboratory, E. I. Du Pont de Nemours and Company, Aiken, SC 29801 (January 1979).

5. W. S. Durant and M. W. Lee. Potential Incidents Applicable to the Defense Waste Processing Facility - Auxiliaries. Internal Report DPST-78-550, Savannah River Laboratory, E. I. Du Pont de Nemours and Company, Aiken, SC 29801 (January 1979).

6. M. W. Iee. Potential Incidents Applicable to the Defense Waste Processing Facility - Iodine Adsorption and Adsorber Recovery Process. Internal Report DPST-78-510 (addendum), Savannah River Laboratory, E. I. du Pont de Nemours and Company, Aiken, SC 29801 (1978)

7. DOE Manual Chapter 0524. Standards for Radiation Protection. (April 8, 1975).

8. Final Environmental Statement, Waste Management Operations, Savannah River Plant. Report DOE-1537 (October 1977).

9. Air Polzution Control Regulations and Standards for the State of South Carolina. South Carolina Pollution Control Authority, Columbia, SC (1972). 
10. Fublic Health Service Drinking Water Standards, 1962. U.S. Department of Health, Education, and Welfare, Washington, DC (1962).

11. NPDES Permit SC 0023710, issued 2-15-75; and NPDES Permit SC 0000175, issued 11-19-76.

12. Project 78-SR-023 (9.2 mizzion). Submitted by DOE for FY-1978 funding.

13. U.S. Code of Federal Regulation, Titie 29, Part 1910, "Occupational Safety and Health Standards."

14. Alternatives for Long-Term Management of Defense High-Level Radioactive Waste - Savannah River Plant. Report DOE-77-42 (May 1977). 
10. MATERIALS OF CONSTRUCTION 10.1

10.1 General Considerations 10.1

10.2 External Piping 10.1

10.3. Internal Piping 10.2

10.4 Separation Facilitiès 10.2

10.5 Spray Dryer 10.2

10.6 Off-Gas System 10.3

10.7 Melter System 10.4

10.7:1 Joule-Heated Ceramic Melter 10.4

10.7.2 Melter Materials Experimental Program 10.5

10.8 Canister Materials Experimental Program 10.5

10.9 Mechanical Cells $A$ and $B \quad 10.5$

10.10 References 10.6 
10. MATERIALS OF CONSTRUCTION (G. G. Wicks)

\subsection{General Considerations}

The basic material of construction that will be used in the DWPF will be $304 \mathrm{~L}$ stainless steel, which has good corrosion resistance to high-level waste at most of the anticipated working temperatures. In addition, Type 304L stainless steel is a ductile material with good fatigue properties, low sensitization during welding which means good resistance toward stress-corrosion cracking, and is a material of good strength that is cost-effective. . Type 304L stainless steel has been used extensively at Savannah River with good experience. Although Type 304L stainless steel, as well as Types 316 or $316 \mathrm{~L}$ stainless steel, can be used in many areas of the solidification operation, there are certain areas that will require special materials. For example, in areas subjected to halides and their acid solutions, especially at elevated temperatures, nickel-based alloys such as "Hastelloy", "Inconel", or "Incoloy" will be desirable.

Areas of interest include external piping, tanks, separation facilities, salt-handling operations, spray dryer, off-gas system, the ceramic melter, and glass-waste canisters. Materials selection will be determined by material specifications, working experience at Savannah River and Battelle Northwest Laboratories, and in several instances, by current experimental programs.

For solutions containing nitric acid, Types $304 \mathrm{~L}, 321$, and 347 stainless steels can be used for processing these solutions over a wide range of temperatures and concentrations. Stainless steels or higher nickel. alloys with relatively high chrome content (Types 309,310 , and $20 \mathrm{Cr}-29 \mathrm{Ni}$ ) would provide better resistance to corrosion by nitric acid containing chloride ions.

\subsection{External Piping}

Coaxial pipes will be used to transport the feed streams from the diversion box into the Waste Processing Facility. The inner pipe or pipes, which will be in contact with the waste, should be constructed from Type $304 \mathrm{~L}$ stainless steel. The outer jacket may be constructed from a mild steel. This coaxial pipe arrangement is currently being used for transferring waste into and out of storage tanks. 


\subsection{Internal Piping}

Piping to be used inside the Waste Processing Facility will be constructed of Type 304 I stainless steel.

\subsection{Separation Facilities}

Piping, valves, and joints will be made primarily of Type $304 \mathrm{I}$ stainless steel. Equipment, such as commercially available parts of the centrifuge and other components, can also be constructed of either Types 316 or 3161 stainless steel. These alloys offer better corrosion resistance as well as being less susceptible to pitting, compared to Type 304L stainless steel.

\subsection{Spray Dryer}

The leading materials candidates for constructing the spray dryer are the nickel-based alloys "Hastelloy" $\mathrm{C}-4^{*}$ and "Incoloy" $800 \mathrm{H}$ ("Incoloy" $800 \mathrm{H}$ has been selected by Wilmington Engineering for constructing the TNX calciner).

The present conditions for materials of construction of the SRP spray dryer are: (1) a maximum wall temperature of $950^{\circ} \mathrm{C}$, (2) internal working temperatures in the range of $250-600^{\circ} \mathrm{C}$, and (3) compatibility with chlorides and fluorides. An additional limitation is that the spray dryer material should also be compatible with nitric acid.

In general, superalloys which exhibit good to excellent corrosion resistance toward chlorides, fluorides, and nitric acid include "Hastelloy" C-276, "Hastelloy" C-4, "Hastelloy" X, "Inconel" 617, "Inconel" 625, "Incoloy" 800H, and "Incoloy" 825. The "Hastelloy" alloys are especially suited to $\mathrm{HCl}$ and HF environments.

A recent analysis at SRI indicates that significant quantities of chlorides and fluorides along with water vapor will be present in drying and melting operations. In addition, small amounts of

\footnotetext{
* "Hastelloy" C-4 is no longer a candidate alloy because tests have demonstrated that this alloy has very low resistance to penetration by molten glass and possibly vapors from glass melt [I].
} 
$\mathrm{HCl}$ and $\mathrm{HF}$ acids could also form from chemical reactions within the dryer and condense from temperature changes during shutdown and startup. However, since operating temperatures will be above the dew point, large quantities of the acids would not be anticipated and their effects should be minimal. Assessments of "Incoloy" $800 \mathrm{H}$ and the benefits of using higher corrosionresistant but more expensive alloys for plant use, such as "Hastelloy" C-4, will continue to be investigated.

"Hastelloy" C-4 is a nickel-chromium-molybdenum alloy that is characterized by outstanding high-temperature stability, corrosion resistance, ductility, and resistance to stress-corrosion cracking. In addition, this alloy has good resistance to $\mathrm{HCl}$ and HF acids, although it is more expensive than some nickel-based alloys.

"Incoloy" $800 \mathrm{H}$ is a nickel-iron-chromium alloy with good corrosion, oxidation, and strength properties at elevated temperatures. In addition, it also has good resistance against scaling, stress-corrosion cracking and has been used within Du Pont for many years. It is not as resistant to $\mathrm{HCl}$ and $\mathrm{HF}$ as "Hastelloy" C-4. "Incoloy" $800 \mathrm{H}$ is one of the less expensive nickel-based alloys and is readily available.

Spray dryers have been constructed and operated successfully at other sites. In general, these materials of construction were subjected to significantly lower processing temperatures and different environments than those considered for drying of SRP waste. For example, at Battelle-Pacific Northwest Laboratory, a spray dryer was constructed from Type 310 stainless steel ( $25 \mathrm{Cr}-$ 20Ni) for use with simulated glass-waste compositions that were chlorine deficient. No detectable corrosion of the 3/8-in.-thick wall was observed after 552 hours of feed calcining with six associated heating and cooling cycles. The calciner vessel used at the Idaho Chemical Processing Plant in the high-level Waste Calcining Facility (WCF) was constructed of Type 347 stainless steel. This material was used in conjunction with a fluidized bed and showed no severe corrosion after 13 years of operation. Baffle plates were made from Type 310 stainless steel. In the new WCF, Type 347 stainless steel ( $18 \mathrm{Cr}-10 \mathrm{Ni})$ has been selected for the vessel, baffle plates, and other internal parts.

\subsection{Off-Gas System.}

Equipment at the beginning of the off-gas system could experience significant corrosion, so the leading materials of construction are high corrosion-resistantalloys, such as the nickel-based materials 
"Incoloy" 800H, "Inconel" 625, "Hastelloy" B and C-4. These alloys generally provide good protection against halides at temperatures lower than those in the spray dryer and would be used in the wet scrubber system, including the ejector venturi, deep-bed washable filters, pumps, heat exchanger, and off-gas condensate collection tank.

"Incoloy" $800 \mathrm{H}$ or "Hastelloy" C-4 could be used in the first parts of the off-gas system where moderate temperatures and halogens are potentially anticipated. For areas near the ejector venturi where HCl or HF can form (temperatures below the dew point), "Hastelloy" B or "Inconel" 625 are recomnended. Due to fabrication considerations, "Inconel" 600 is the reference material for the sintered filters.

Beyond wet scrubbing, 304L stainless steel can be used if relatively low temperatures and halide content are produced. However, if the $\mathrm{Cl}^{-}$content is greater than $250 \mathrm{ppm}, 300$ series stainless steel should not be used (Engineering Department Standard No. 5992) due to possible stress-corrosion cracking. In this case, either the high-nickel alloys used earlier should be employed or the $\mathrm{pH}$ of the solution should be increased. For example, for a molar ratio of $\mathrm{NO}_{3}^{-} / \mathrm{CI}^{-}>1$, no cracking is observed at $260^{\circ} \mathrm{C}$ if the $\mathrm{pH}$ is over 10 [2].

In the Idaho Chemical Processing Plant solidification process, Type 304L stainless steel is used extensively in the off-gas system. For equipment exposed to the highest erosion and corrosion effects, such as the quench tower and related pumps, higherintegrity materials of Type 347 stainless steel and Carpenter ${ }^{\circledR} 20$ (trademark of Carpenter Technology Corp.) are used. A nickelchromium alloy, ARMCO Nitronic 50 (trademark of Armco Steel Corp.), is being considered for future scrubber pump construction at the facility.

\subsection{Melter System}

\subsubsection{Joule-Heated Ceramic Melter}

The corrosion/erosion resistance of electrode and refractory materials to be used in the ceramic melter are currently being evaluated at SRI. These components comprise the principal elements of a Joule-heated continuous ceramic melter, the reference melting concept for incorporation and solidification of waste into a glass matrix. This selection will depend on corrosion/erosion resistance and the associated lifetime of the materials, as well as electrical resistivity, thermal shock resistance, thermal expansion and conductivity, and cost and availability of the material. The wear 
of electrode and refractory materials will most likely determine the lifetime of the melters. The leading refractory candidate is "Monofrax" $\mathrm{K}-3$ and the leading electrode candidate is "Inconel" 690.

\subsubsection{Melter Materials Experimental. Program}

The corrosion/erosion resistance of electrode and refractory materials will be studied by two basic techniques. First, a crucible or finger test is being used that is a modification of a standard ASTM test for "Static Corrosion of Refractories by Molten Glass" [3]. These tests provide a good relative comparison of the corrosion resistance for materials of interest over the temperature range of concern.

A second experimental technique will evaluate the attack of molten glass under simulated service conditions for the leading refractory and electrode materials determined from the previous finger tests. This is accomplished by constructing a mini-melter which will subject the refractory to molten glass only on one side while maintaining a temperature gradient through the refractory. These experiments are a modification of the ASTM "Simulated Service Test for Corrosion Resistance of Refractories to Molten Glass" [4].

Additional erosion studies will be made by suspending refractory and electrode samples on rods and rotating them in the molten glass.

\subsection{Canister Materials Experimental Program}

Long-term materials compatibility tests between candidate canister metals and simulated glass-waste compositions have been in progress since 1974. Canister metals in this study included $304 \mathrm{~L}$ stainless steel, Cor-Ten ${ }^{\circledR}$ A (trademark of U.S. Steel), "Inconel" 600, and AISI 1020 low carbon steel. Supplementary studies will use simulated wastes of average, high iron and high aluminum content with Type 21 frit, and additional canister candidate materials. The leading material for canisters to be used in the ceramic melting process is Type 304L stainless steel.

\subsection{Mechanical Cells A and B}

The etch tank and associated piping in each cell will be exposed to $3.5 \mathrm{M} \mathrm{HNO}_{3}-0.4 \mathrm{M} \mathrm{NaF}$ solutions (or vapors) at nominally $50^{\circ} \mathrm{C}$. Several candidate materials of construction to adequately 
resist attack from these solutions and vapors have been identified. In decreasing order of preference they are "Inconel"* 671, 690,

"Haynes"** 25, "Ferralium"*t*, and "Inconel" 625.

\subsection{References}

1. W. N. Rankin. Attack of High-Strength, Oxidation-Resistant Alloys During In-Can Melting of Simulated Waste Glasses. Internal Report DP-MS-79-39 (Rev.), proposed for presentation at Corrosion/80 NACE Meeting, Chicago, Illinois, March 6-10, 1980.

2. J. H. Phillips and W. J. Singley. "Evaluation of Performance of Screening Tests of Inhibitors to Prevent Chloride Stress Corrosion." Corrosion 15, 450t (1959).

3. ASTM-0621-68. American Society for Testing and Materials Part 17, revised 1973.

4. ASTM-0622-68. American Society for Testing and Materials Part 17, revised 1973.

5. Deleted.

* Trademark of International Nickel Co.

** Trademark of Union Carbide Corporation.

$* * *$ Trademark of Cabot Corporation. 


\section{REGULATORY REQUIREMENTS 11.1}

\subsection{General 11.1}

\subsection{Current Regulations 111}

\subsubsection{Nonradioactive Releases 11.1}

\subsubsection{Radioactive Releases 11.2}

\section{2 .3 Occupational Radiation Exposure 11.2}

\subsubsection{Ptoduct and Shipping Container Specifications 11.2}

\subsection{Future Related Regulations 11.3}

ans
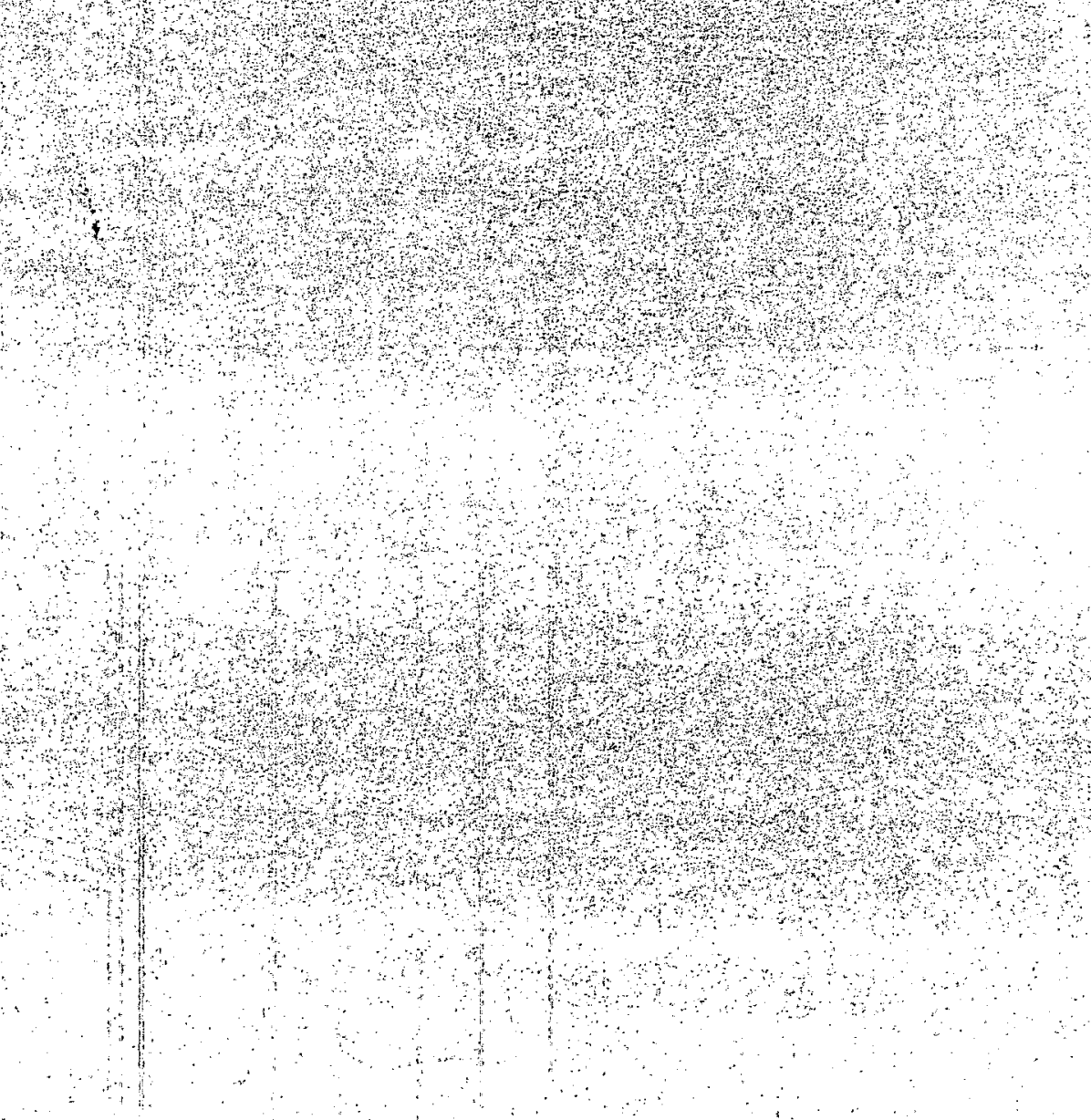
11. REGULATORY REQUIREMENTS (E. J. Hennelly)

\subsection{General}

The regulatory aspects of the DWPF are complex because the completed facility must comply with the pertinent regulations at the time of startup, which is still about a decade away, and because many of the regulations that will be in effect then are yet to be issued. Therefore, a key requirement of the regulatory effort associated with the solidification program will be to anticipate and prepare for the regulatory situation at startup. A successful regulatory effort will reduce the delays and costs that would result from retrofitting to meet unanticipated controls.

Regulations pertaining to nonradioactive releases can be forecast with some confidence because Congress has established long lead times for implementation. For example, limits for discharges to streams in the mid-1980s are now being proposed by EPA. In addition, criteria and regulations for long-term disposal of radioactive waste being formulated by EPA and NRC (e.g., 10 CFR 60), and many of these regulations will be applicable when the DWPF operations begin.

A major uncertainty involves the future licensing authority of NRC for DOE solidification facilities. NRC does not now have this authority. NRC-DOE-Du Pont information exchanges will mitigate the impact of this possible extension of NRC jurisdiction.

\subsection{Current Regulations}

\section{2 .1 Nonradioactive Releases}

The major environmental laws pertaining to nonradioactive releases from a waste processing facility are the Federal Water Pollution Control Act and Clean Air Act. These Acts established the bases for the EPA water regulations and the South Carolina air quality standards. The Acts established national long-term goals for air and water release.

In addition, EPA and SC DHEC are giving increased attention to the effects on ground-water quality of solid waste disposal practices because of the provisions of the Resource Conservation and Recovery ACt (RCRA) of 1976. Use of seepage basins and landfills for disposal of nonradioactive liquid and solid wastes may be restricted by future SC DHEC regulations, to be published in 
1980, that will implement RCRA. Incorporation of ion exchange effluent into concrete with subsequent disposal on the Savannah River Plant will also be conducted in accordance with these regulations as well as with regulations covering disposal of radioactive waste, if applicable.

\subsubsection{Radioactive Releases}

Limits on radioactive releases are now controlled primarily by DOE Manual Chapter 0524. The EPA regulations ( 40 CFR 190) that pertain only to releases from commercial nuclear cycle facilities provide recent guidance on acceptable limits for public exposure. The EPA guidelines represent the future trend, and should be carefully considered in establishing release guides for the waste processing facility. The offsite dose from SRP operations is substantially below the EPA limit. The contribution from the waste processing operations should result in minimal offsite dose to allow the SRP total to continue to remain well within the EPA limits.

\subsubsection{Occupational Radiation Exposure}

Exposure guides for plant wastes are given in DOE Manual Chapter 0524. A more restrictive limit ( 1 rem/yr for planned exposures) is included in the DOE criteria for new plutonium facilities. The limit of $1 \mathrm{rem} / \mathrm{yr}$ for planned exposures, although not now required for a waste processing facility, represents the most current DOE position on personnel exposure and a likely requirement for the future.

\subsubsection{Product and Shipping Container Specifications}

The only current regulatory requirement for the product is that it be a solid. EPA is now preparing criteria and NRC is in the process of preparing regulations that will give more specific guidance for acceptable commercial waste forms. Preliminary guidance from these agencies indicates the following properties may be important for all solidified high-level waste:

- uniformity of solid

- heat output limit

- radiation level limit

- chemical composition of solid

- fissile content accountability

- leachability limit 
Each property may require some means of verifying that it is within prescrived limits.

The recent NRC Regulation $10 \mathrm{CF} 71$ requires an NRC license for shipment of DOE waste. To obtain a license, DOE will need an NRC-approved quality assurance plan for manufacture of shipping containers.

NRC Regulation 10 CFR 71.42, "Special Requirements for Plutonium Shipments After June 17, 1978," requires a double barrier to accidental release of radioactivity. Both barriers must meet requirements of Regulatory Guide 7.6, "Stress Allowables for the Design of Shipping Cask Containment Vessels."

\subsection{Future Related Regulations}

Recently NRC and EPA have become very active in the preparation of Federal regulations regarding the permanent disposal of high-level radioactive waste. NRC is expected to issue for comment a draft Regulation 10 CFR 60, "Disposal of High-Level Radioactive Waste," in February 1980. The draft has already recelved some preliminary review by DOE and their subcontractors. The final regulation (probably due in 1981) will prescribe all of the Federal regulations for licensing a high-level waste repository. EPA recently (November 1979) presented their latest draft criteria for high-level waste disposal. The NRC regulations must be compatible with the EPA criteria. Each of these two documents would apply to a defense waste repository. Currently it is believed that the glass waste form that is proposed to be made in the DWPF will be acceptable in a licensed repository and that a salt repository will also, in combination with appropriate overpack material, meet any of the proposed EPA criteria and NRC regulations. It is for these reasons that the DWPF construction and operations are currently believed to be decoupled from the proposed NRC and EPA mandated regulatory requirements. It will be necessary to follow the development of these criteria and regulations during 1980 and 1981 to reaffirm the decoupling and to adjust, as necessary, any current or proposed SRP-DWPF operations to meet future regulatory requirements. Frequent DOE-NRC information exchanges would be helpful in planning for the future regulatory situations. 
12. SOLID WASTE HANDIING 12.1

12.1 General 12.1

.12.2 Solid Waste Description 12.1

12.3 Waste Treatment Processés 12.2

12.3.1 Process Equipment 12.2

12.3.2 Contained Process Wastes 12.2

12.3.3 Job Control Wastes 12.2

12.3.4 Process Upset Wastes 12.2

12.4 Waste Treatment Facilities 12.3 
12. SOLID WASTE HANDIING (H. E. Hootman)

\subsection{General}

Solid wastes will arise from normal process operations and from the repair, replacement, or retirement of process equipment. Processing of these wastes will be determined primarily by the composition of the material, its size, and the degree and type of radioactive contamination assocjated with the waste. Facilities for "hot" and "warm" canyon maintenance as well as decontamination will be integrated into the DWPF design and will serve the same function as that of similar operations in present SRP fuel reprocessing canyons (e.g. repair or decontamination of process vessels and equipment).

Process waste will be primarily contaminated with fission product $\beta-\gamma$ emitters. TRU contamination will be present in some of the waste; however, an assay of the TRU contamination will be hindered by the extremely high $\beta-\gamma$ fission product emitter background radiation. A continuation of present waste management practices is proposed for these wastes (e.g. encapsulation and storage in a monitored burial ground facility).

\subsection{Solid Waste Description}

Normal contaminated operating solid wastes generated in the DWPF will include such materials as maintenance, job control and decontamination resides as cellulosic wipes, plastic sheets, gloves, protective clothing, and contaminated small tools. On a less regular basis, failed process tanks, jumpers, filters, and adsorbent beds will have to be removed from the process and prepared for storage. The most infrequent types of waste to be considered might result from process upsets where a process vessel such as a glass melter would fail containing a full charge of vitrified HLW. The treatment of such waste will require provision for the separation of the contaminated process equipment from the vitrified HLW waste and separate disposition of the residues.

A more detailed breakdown of anticipated solid waste arisings is shown in Table 12.1 . 


\subsection{Waste Treatment Processes}

Processing contaminated DWPF wastes consists mainly of containerizing the wastes for shipment to an onsite storage (burial ground area). The amount of mechanical disassembly or decontamination employed on the noncombustible wastes will vary with the type of material involved.

\subsubsection{Process Equipment}

Failed tools and process equipment are usually decontaminated to remove as much of the surface contamination as possible before the equipment leaves the building. Decontamination involves the removal of radioactive contamination by either mechanical or chemical means. This can be accomplished with high pressure sprays, detergent and acid or alkaline washes applied both internally and externally.

\subsubsection{Contained Process Wastes}

Absorber columns and resin beds, if they cannot be regenerated, should be simply sealed in their containers, decontaminated on the container surfaces and shipped to a burial ground.

\subsubsection{Job Control Wastes}

Both combustible and noncombustible job control wastes are shipped untreated in standard cardboard radioactive waste cartons to the burial ground for trench burial. Contaminated scrap, welding slag, fluxes and rod tips and other process created wastes are shipped in appropriate containers to a burial ground in a shielded cask car.

\subsubsection{Process Upset Wastes}

During the course of normal operation very little residue of the HLW will be associated with materials removed from the DWPF and present SRP reprocessing canyon techniques can be employed. However, because of the vitrification process used in the DWPF, it is possible that occasions may arise where the molten glass and HLW mixture solidifies in the glass melter, is dumped from the melter to an emergency receiver or spills outside of a glass canister. In these cases, the equipment will be packaged and shipped to a repository under specified regulations. 


\subsection{Waste Treatment Facilities}

The solid waste handing facilities are to be closely coupled with the process functions of the DWPF. Design of process equipment, cranes, hot and warm maintenance cells, and decontamination facilities should provide the dual function of process maintenance and waste maragement operations. Provisions should be made for shipping the largest process equipment (i.e. $12 \mathrm{ft} \times 12 \mathrm{ft} \times 20 \mathrm{ft}$ spray dryer) and the heaviest (30-ton glass melter) process equipment to the burial ground by railroad car. Smaller equipment may be transported in a shielded cask car. Much of the job control waste may be shipped by regulated truck because of its relatively low level of radioactivity.

TABLE 12.1

DWPF Solid Waste Generation

Waste Type

$\frac{\text { Volumes, } f t^{3}}{\text { Unit Annuala }}$

A. Normal Process

1. Combustible

2. Noncombustible

a. Job control

20,000

b. Miscellaneous

5,000

3. Resin beds

5,000

488

4. Adsorber colums

a. Silica gel

b. Zeolite

1

40

5. Filters

a. Deep Bed Washable Filter $4 \quad 16$

b. Sintered metal $34 \quad 68$

B. Process Equipment

1. Spray Dryer

$2880 \quad 576$

2. Glass melter

138

69

3. Centrifuge

$75 \quad 38$

4. Pumps

5. Valves

6. Jumpers

20

7. Vessels

$\begin{array}{ll}0.5 & 5 \\ 100 & 25\end{array}$

8. Vessel vents

$100 \quad 20$

$960 \quad 144$

a. Assumes 20-year DWPF operation. 
13. APPENDICES

13.1 Buildings $221-F$ and $221-H$ Waste volumes and Compositions 13.1 .1

13.2 Bases for Determining DWPF Feed Stream Composition 13.2.1

13.3 Detailed Siudge Analyses 13.3.1

13.4 Detailed Supernate Analyses 13.4.1

13.5 Models of Physical Properties of SRP Waste Glass, to be issued

13.6 Radiation Stability of Glass Waste Form, to be issued

13.7 Isotopic Content of DWPF Process Streams 13.7.1

13.8 Spray Calciner/Melter off-Gas Compositions, to be issued

13.9. Bases for Determining Radionuclides in Sludge and Supernate Feeds 
APPENDIX 13.1

BUILDINGS 221-F AND 221-H WASTE VOLURES AND COMPOSITIONS 13.1 .1

13.1.1 Building 221-F Waste Volumes and Compositions 13.1 .1

13.1.1.1: Sumary 13.1.1

13.1.1.2 Discussion 13.1.1

13.1.2 Building 221-H Waste Volumes and Compositions 13.1 .2

13.1.2.1 Summary 13.1.2

13.1.2.2 Discussion 13.1 .2

13.1 .3 References 13.1 .4

$-13: 1.1-$ 


\subsection{BUILDINGS 221-F AND 221-H WASTE VOLUMES AND COMPOSITIONS}

Waste volumes and compositions for $221-F$ and $H$ canyon operations' were requested for predicting waste produced during the late 1980 's. These volume and composition data were primarily required for computing the radionuclide inventory of the reference feed to the DWPF. However, the data also allow determination of the range in chemical composition of DWPF feed in the event that feed is not blended or if a decision is made to process either F- or H-Area waste separately. Sections 13.1.1 and 13.1.2 are essentially reproductions of reports prepared by the Separations Te:alnology Department $[1,2]$.

\subsubsection{Building 221-F Waste Volumes and Compositions}

\subsubsection{Summary}

High-heat and low-heat wastes transferred from Building 221-F to Building 241-F were assayed and the volumes and compositions tabulated. Compositions are tabulated on the basis of processing one metric ton of uranium (MTU). Purex wastes from HAW and LAW evaporator concentrates were tabulated in an earlier letter [3]. This appendix discusses those wastes and also all others going into high-heat waste and low-heat waste storage in Building $241-F$ from Buildings $221-F, 211-F$, and A-Line.

\subsubsection{Discussion}

Figures 13.1-1 through 13.1-4 show the flowsheets for highheat and low-heat waste transferred to Building 241-F. The compositions of some of the individual streams vary widely, especially those of low-heat waste streams. For this reason, compositions of some minor streams are now shown. However, typical compositions for the major streams are shown in Tables 13.1-1 and 13.1-2. The total waste coming directly from Purex is also included in the tables. The total volume of high-heat waste is $249 \mathrm{I} / \mathrm{MTU}$ at a density of $1.25 \mathrm{~g} / \mathrm{mL}$. The total volume of low-heat waste is $1696 \mathrm{~L} / \mathrm{MTU}$ at a density of $1.22 \mathrm{~g} / \mathrm{mL}$. Typical uranium throughput was 100 MTU/month.

Tables 13.1-1 and 13.1-2 are based on using Mark 31A targets. For Mark 31B targets, only the coating waste is different from that of Mark 31N. Coating waste composition for Mark 31 B targets is shown in Table 13:1-2: 
The larger quantity of coating waste from Mark $31 B$ targets causes the total low-heat waste to be greater than Mark $31 \mathrm{~A}$ low-heat waste by a factor of 1.15 .

Table 13.1-3 shows the percentage of high- and low-heat waste generated directly from Purex operation. HAW evaporator concentrate was $72.9 \%$ of total high-heat waste. IAW evaporator concentrate was $15.4 \%$ of the total low-heat waste transferred to Building 241-F.

\subsubsection{Building 221-H Waste Volumes and Compositions}

\subsubsection{Sumary}

Waste volumes and composition data for H-Area canyon operations have been requested for predicting waste generation during the late $1980^{\prime} \mathrm{s}$. Current HM and frame waste generation rates are expected to be applicable to future operations when properly adjusted for changes in fuel or target designs and flowsheet improvements. Aluminum is the waste-controlling constituent in the HM process where $61 \mathrm{~L}$ of waste per kilogram of aluminum is calculated as compared with $59 \mathrm{~L} / \mathrm{kg}$ Al received for waste storage (Table 13.1-4).

The flowsheet for processing Pu-238 shows $8020 \mathrm{~L}$ of low-heat waste for each kilogram of Pu-238 as compared with receipts of $9300 \mathrm{~L} / \mathrm{kg}$ Pu-238 for waste storage (Table 13.1-4).

Composition and the streams contributing to the wastes for HM and Pu-238 processing are presented in Tables 13.1-5 through $13.1-8$.

\subsubsection{Discussion}

HM waste calculations are based on current solvent extraction flowsheets [ 1 ] for Mark $16 B$ and Mark 22 fuels. Since HM processing is aluminum-limited, forecasts can be adjusted for changes in fuel types on the basis of aluminum ratio. This study used $10.5 \mathrm{~kg}$ aluminum per Mark I6B or Mark 22 fuel tube.

The IAW stream carries the aluminum and nitric acid and is the main contributor to the high-heat waste (Table 13.1-5). When that stream is concentrated, the next largest contributor is the caustic required to neutralize excess acid, convert aluminum to the soluble aluminate ion, and provide $1.2 \mathrm{M} \mathrm{NaOH}$ excess for corrosion protection of the waste tanks. Since 4 moles of caustic are required for each mole of aluminum, any factor influencing aluminum has a corresponding effect on the volume and concentration of high-heat waste. 
The principal contributor to low-heat waste is the $2 \mathrm{AW}$ stream, but spent solvent washes and waste from decontamination make significant contributions (Table 13.1-6). Low-activity waste feeds contain less salts than do high-activity waste feeds and hence, permit greater volume reduction - 4.12 vs. 1.83 prior to discharge to waste storage.

Another contributor to low-heat waste is frame operations to recover Pu-238 and Np-237. Actual waste generation by the frame process is about $9300 \mathrm{~L} / \mathrm{kg} \mathrm{Pu}-238$ recovered as compared to the flowsheet amount of $8020 \mathrm{~L} / \mathrm{kg} \mathrm{Pu}-238$. The flowsheet volume does not include dissolver heel or sump material processing, extra decontamination washes, or product recycles which occur occasionally. The waste generated relates best to resin column runs. Plutonium recovery per column run depends primarily upon target design, the amount of plutonium scrap processed, and the amount of plutonium recycled from waste recovery. Recent experience shows 280 grams of Pu-238 recovered per Column RC-1 run (initial resin column for decontamination) and is the basis for the frame waste flowsheet (Figure 13.1-5 and Table 13.1-7). Current operation processes Mark 53A targets, and waste volume should remain unchanged if new targets contain similar amounts of actinides and aluminum.

The ratio of neptunium to Pu-238 in process feed has varied widely, averaging 3.45 in the past three years. If that ratio applies, low-heat wastes generated from frame processing total $2700 \mathrm{~L} / \mathrm{kg}$ neptunium recovered.

Frame waste composition, Table 13.1-8, was developed from the flowsheet (Table 13.1-7) and is currently the best estimate of the actual wastes. Components present in the low-heat waste were converted to the ionic state and the metallic cations were balanced with hydroxyl anions. The major component in frame waste is sodium nitrate, resulting from neutralization of large amounts of nitric acid. 


\subsubsection{References}

1. T. G. Campbell and D. F. Chostner. Buizding 221-F Waste Volumes and Compositions. Internal Memorandum to J. I. Womack, DPSPU-78-272-198. E. I. du Pont de Nemours \& Co., Aiken, SC (November 30, 1978).

2. C. J. Thomas and T. M. Thompson. HM Waste Volumes and Comprsition. Internal Memorandum to J. I. Womack, DPSPU-78-272-178. E. I. du Pont de Nemours \& Co., Aiken, SC (October 23, 1978).

3. D. F. Chostner. Furex Waste Volumes and Compositions. Internal Memorandum DPSPU-77-272-268, E. I. du Pont de Nemours \& Co., Aiken, SC (October 21, 1977).

4. J. H. Hershey and G. M. Johnson. Waste Management Revised Waste Generation Factors. Internal Memorandum to J. A. Porter, E. I. du Pont de Nemours \& Co., Aiken, SC (Decembér 7, 1977). 
TABLE 13.1-1

High-Heat Waste Flowsheet $^{a}$

lst Cycle Waste (1AW)

2nd U Cycle Waste (10W)

Miscellaneous purex Hitw

Neutrallzed HaWC (Figure 13.1-1)

Miscellaneous HHW from Tank 15.4

Head End-Cake Wash

Total High-Heat Waste
Stream Description

Stream Composition, 1b$$
\left.\mathrm{HNO}_{3} \mathrm{Al}_{(\mathrm{NO}}\right)_{3} \mathrm{NaNO}_{3}
$$

$\mathrm{Fe}\left(\mathrm{SO}_{3} \mathrm{NH}_{2}\right)_{2}$

NaOH

Fe(OH) 3

$\mathrm{NaA10} 2$

$\mathrm{Na}_{2} \mathrm{SO}_{4}$

$\mathrm{H}_{2} \mathrm{O}$

Tota1

$1317 \quad 40$

21

522

15

$59 \quad 5$

5

5

6

107

19

0.5

126.5

14

10

17

20

$\begin{array}{rr}11,514 & 12,892 \\ 7,103 & 7,640 \\ 686 & 834 \\ 332 & 500 \\ 100 & 119 \\ 66 & 66.5 \\ 498 & 685.5\end{array}$

a. Bas Is: 1 MTU.

b. Includes: Frame Waste Recycle (6.6), Hot-Canyon Sumps 820 and 805 , ferrous sulfamate adjustment for plutonlum recovery column feed, 50\% Caustic. 
TABLE 13.1-2

Low-Heat Waste Flowsheet $^{\text {a }}$

Stream Description

2nd Pu Cycle Waste (2AW)

Miscellaneous Purex LHWb

Neutrallzed LAWC (Flgure 13.1-3)

B-Line Waste

Coating Uaste ${ }^{c}$

Decontaminat Ion Solution

Waste from Tank 5.2

Lab Waste Evaporator (18.6E)

General-Purpose Evaporator (710)

Total low-Heat Waste
Stream Composition, 16 $\mathrm{HNO}_{3} \mathrm{Na}_{2} \mathrm{SO}_{4} \mathrm{Fe}_{2}\left(\mathrm{SO}_{4}\right)_{3}$

$1566 \quad 43$

40

7

$\mathrm{NaAlO}_{2}$

$\mathrm{NaNO}_{2}$

A1 $\left(\mathrm{NO}_{3}\right)_{3}$

MAS, $\mathrm{H}_{2} \mathrm{O}$

Tota1

31

86

$\begin{array}{lll}78 & 8 & 32 \\ 75 & 33 & \\ 182 & 59 & \end{array}$

37

86
$307 \quad 68$

146

257

788
63

$\begin{array}{llllll} & & & 499 & 703 \\ 170 & 41 & 16 & & 310 & 434 \\ & & & & 756 & 1208 \\ 170 & 41 & 16 & 45 & 800 & 882 \\ & & & 1877 & 2524 \\ 170 & 41 & 16 & 458 & 474 \\ & & & & 3307 & 4561\end{array}$

a. Basis: 1 MTU.

b. Includes: B-Line Waste, AcId Solvent Washes, Alkallne Solvent Washes, $50 \%$ Caustic.

c. For Mark $31 \mathrm{~A}$ targets; Mark $31 \mathrm{~B}$ target coating waste contalns:

$$
\text { Ib/MTU }
$$

\begin{tabular}{lr}
$\mathrm{NaNO}_{3}$ & 388 \\
$\mathrm{NaOH}^{3}$ & 125 \\
$\mathrm{NaAlO}_{2}$ & 370 \\
$\mathrm{NaNO}_{2}$ & 87 \\
$\mathrm{H}_{2} \mathrm{O}^{\mathrm{O}}$ & $\underline{1614}$ \\
\multicolumn{1}{c}{ Total } & 2584
\end{tabular}


TABLE $13.1-3$

Purex Waste vs. Total Waste

High-Heat Waste

Purex Waste (HAWC)

$500 \mathrm{Ib} / \mathrm{MTU}$

Total High-Heat Waste (Table 13.1-1)

$685.51 \mathrm{~b} / \mathrm{MTU}$

Contribution of Purex Waste to

Total High-heat Waste

$72.9 \%$

Low-Heat Waste

Purex Waste (LAWC)

$703 \mathrm{lb} / \mathrm{MTU}$

Total Low-Heat Waste (Table 13.1-2)

$4561 \mathrm{Ib} / \mathrm{MTU}$

Contribution of Purex Waste to

Total Low-Heat Waste

$15.4 \%$

TABLE $13.1-4$

Waste Volumes

I/kg Alum:Lnum Plant

Flowsheet Experience

High-Heat Waste

HM Process

LAW

Head End

33.5

$\frac{0.1}{33.6}$

$\frac{-}{39.6^{2}}$

Low-Heat Waste

HM Process

Low-Activity Waste

Solvent Washes

Decontamination Waste

General-Purpose Evaporator

$\begin{array}{rr}22.2 & - \\ 4.3 & - \\ 1.1 & - \\ - & \frac{3.7 \mathrm{~b}}{27.6}\end{array}$

$\therefore \quad \begin{array}{ll}\text { L/kg Pu-238 } \\ \text { Flowsheet } & \text { Experience }\end{array}$

Frames

Frame Waste Recovery $\quad \therefore \quad 6150 \quad 7050$

Resin Digestion

$\frac{1870}{8020} \quad \frac{2250}{9300^{c}}$

a. See Reference 4 .

b. $11 / 77$ to $10 / 78$.

c. 1975 to $10 / 78$; volume adjusted to same salt content.

$-13.1 .7-$ 
TABLE 13.1-5

HM HIgh-Heat Haste ${ }^{a}$

Composition, kg

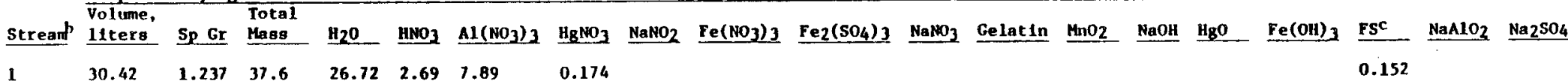

$\begin{array}{lllll}2 & 0.25 & 1.206 & 0.297 & 0.21\end{array}$

$\begin{array}{llllllllll}19.05 & 1.384 & 26.36 & 15.55 & 2.61 & 7.89 & 0.174 & 0.049 & 0.082 & 0.005\end{array}$

$\begin{array}{lllll}0.133 & 1.05 & 0.14 & 0.125 & 0.001\end{array}$

$\begin{array}{llll}12.26 & 1.52 & 18.642 & 9.32\end{array}$

$\begin{array}{llll}33.64 & 1.344 & 45.23 \quad 26.09\end{array}$

0.005

0.087

a. Basls: $1 \mathrm{~kg}$ Al fed to lot cycle. Streams are indicated here

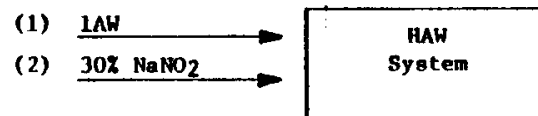

(2) $302 \mathrm{NaHO}_{2}$ System

b. Evolved gaseous products not shown.

c. FS is ferrous sulfamate, $\mathrm{Fe}\left(\mathrm{NH}_{2} \cdot \mathrm{SO}_{3}\right)_{2}$.
(3) HAW Conc

(4) Head End Cake $\longrightarrow$ Neutrallzer

(5) $50 \mathrm{Z} \mathrm{NaOH}$
Neutraliz.

HAWC 


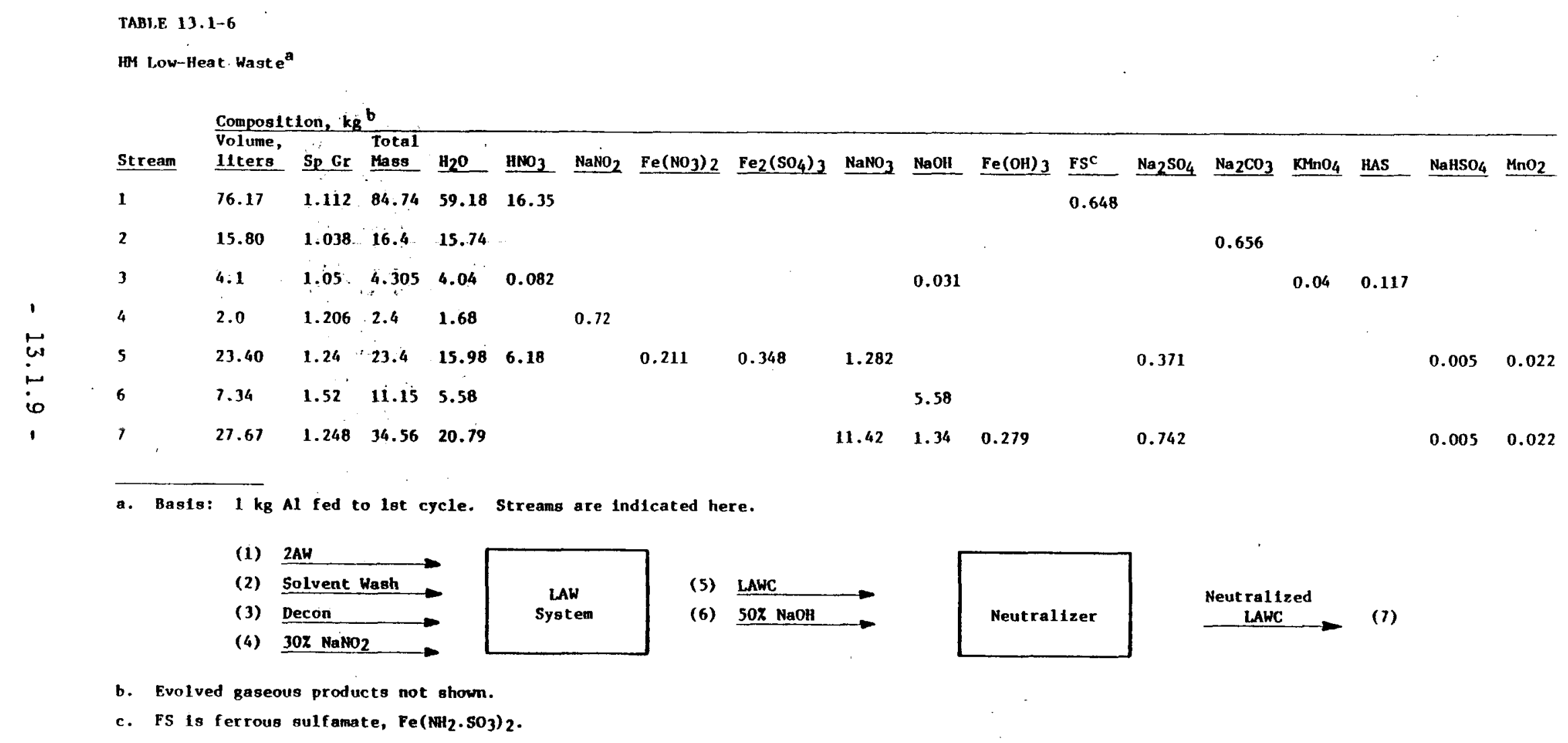


TABLE 13.1-7

Frame Waste Flowsheet ${ }^{a}$

Stream No.

and Description

Composition, $\mathrm{kB}_{\mathrm{B}}$

1 Waste

2 Waste

3 Waste

4 Waste

5 waste

6 cold Feed

7 Column Feed

8 Cold Feed

9 Product

10 Waste

11 Adjustment

12 Evaporator Feed

13 Overheads

14 Bottom

15 caust ic

16 Neutralfzed Waste

17 Resin

18 cold Feed

19 Digested Resin

20 Low-Heat Waste

\begin{tabular}{|c|c|c|c|c|c|c|c|c|c|c|c|c|c|}
\hline Actinide & Al & IN03 & $\mathrm{Hg}_{\mathrm{B}}\left(\mathrm{NO}_{3}\right)_{2}$ & $\underline{\mathbf{K F}}$ & $\mathrm{H}_{2} \mathrm{O}$ & $\mathbf{F S}$ & $\mathrm{N}_{2} \mathrm{ll}_{4} \mathrm{c}$ & $\begin{array}{l}\text { Ascorbic, } \\
\text { Oxalfc Acid }\end{array}$ & $\mathrm{NaNO}_{2}$ & NaOH & Resin & $\mathrm{KMnO}_{4}$ & Total \\
\hline 0.5 & 65 & 3254 & 1.9 & 5.7 & 4089 & 42 & 13 & - & - & - & $\because$ & - & 7471 \\
\hline 0.2 & - & 2171 & - & 1.9 & 3825 & 41 & 7 & - & - & - & - & - & 6046 \\
\hline - & - & 964 & - & - & 2764 & 31 & - & - & - & - & - & - & 3759 \\
\hline 0.04 & - & 11 & - & - & 243 & - & - & 1.6 & - & - & - & - & 256 \\
\hline- & - & 321 & - & - & 461 & - & - & - & - & - & - & - & 782 \\
\hline - & - & 3607 & - & - & 3675 & 115 & 63 & - & - & - & - & - & 7460 \\
\hline 0.94 & 65 & 10328 & 1.9 & 7.6 & 15057 & 229 & 83 & 1.6 & - & - & - & - & 25775 \\
\hline - & - & 604 & - & - & 1275 & - & - & - & - & - & - & - & 1879 \\
\hline 0.94 & - & 32 & - & - & 214 & - & - & - & - & - & - & - & 247 \\
\hline - & 65 & 10900 & 1.9 & 7.6 & 16118 & 229 & 83 & 1.6 & - & - & - & - & 27407 \\
\hline - & - & - & - & - & 938 & - & - & - & 404 & - & - & - & 1343 \\
\hline $\mathbf{0}$ & 65 & 10900 & 1.9 & 7.6 & 17057 & 229 & 83 & 1.6 & 404 & - & - & - & 28750 \\
\hline- & - & 8720 & - & - & 14535 & - & - & - & - & - & - & - & 23255 \\
\hline 0 & 65 & 2180 & 1.9 & 7.6 & 2522 & 229 & 83 & 1.6 & 404 & - & - & - & 5495 \\
\hline - & - & - & - & - & 1679 & - & - & - & - & 1679 & - & - & 3358 \\
\hline 0 & 65 & 2180 & 1.9 & 7.6 & 3788 & 229 & 83 & 1.6 & 404 & 1679 & - & - & $8440^{d, e}$ \\
\hline 0 & - & 349 & - & - & 509 & - & - & - & - & - & 59 & - & 917 \\
\hline - & - & - & - & - & 1009 & - & - & - & - & 335 & - & 43 & 1380 \\
\hline 0 & - & 349 & - & - & 1511 & - & - & - & - & 335 & 59 & 43 & $2297^{f}$ \\
\hline 0 & 65 & 2529 & 1.9 & 7.6 & 5299 & 229 & 83 & 1.6 & 404 & 2014 & 59 & 43 & $10737^{e}$ \\
\hline
\end{tabular}

a. Basls: 1 kg Pu-238 recovered; one column RC-1 gields 280 grams of Pu-238 and 965 grams of neptuntum.

b. FS la ferrous oulfamate.

c. $\mathrm{N}_{2} \mathrm{H}_{4}$ lo hydrazlne mononftrate.

d. Neutrallzed evaporator bottoms Sp Gr 21.35 .

e. Includes $137 \mathrm{~kg}$ of gaseous products.

f. Digested resin solution Sp Gr, 1.23 . 
TABLE $13.1-8$

Frame Waste Composition (Low-Heat Waste) ${ }^{a}$

\begin{tabular}{|c|c|c|c|}
\hline & Moles & $\underline{\mathrm{kg}}$ & Wt $\%$ \\
\hline $\mathrm{NO}_{3}^{-}$ & 40,158 & 2,490 & 23.5 \\
\hline $\mathrm{Na}^{+}$ & 56,205 & 1,293 & 12.2 \\
\hline $\mathrm{OH}^{-}$ & 20.759 & 353 & 3.3 \\
\hline $\mathrm{SO}_{4}^{2-}$ & 1,850 & 178 & 1.7 \\
\hline $\mathrm{Al}^{3+}$ & 2,401 & 65 & 0.6 \\
\hline $\mathrm{Fe}^{3+}$ & 925 & 52 & 0.5 \\
\hline $\mathrm{MnO}_{2}$ & 270 & 23.5 & 0.2 \\
\hline $\mathrm{k}^{+}$ & 403 & 15.8 & 0.2 \\
\hline $\mathrm{F}^{-}$ & 131 & 2.5 & 0.02 \\
\hline $\mathrm{Hg}^{2+}$ & 5.9 & 1.2 & 0.01 \\
\hline \multirow[t]{2}{*}{$\mathrm{H}_{2} \mathrm{O}^{\mathrm{C}}$} & 340,333 & 6,126 & 57.8 \\
\hline & & $\begin{array}{l}10,600 \\
\text { Volume, } \\
8020 \mathrm{~L})\end{array}$ & 100 \\
\hline
\end{tabular}

a. Basis: $1 \mathrm{~kg}$ Pu-238 recovered.

b. Moles required to balance ionic charges.

c. Weight by difference. 


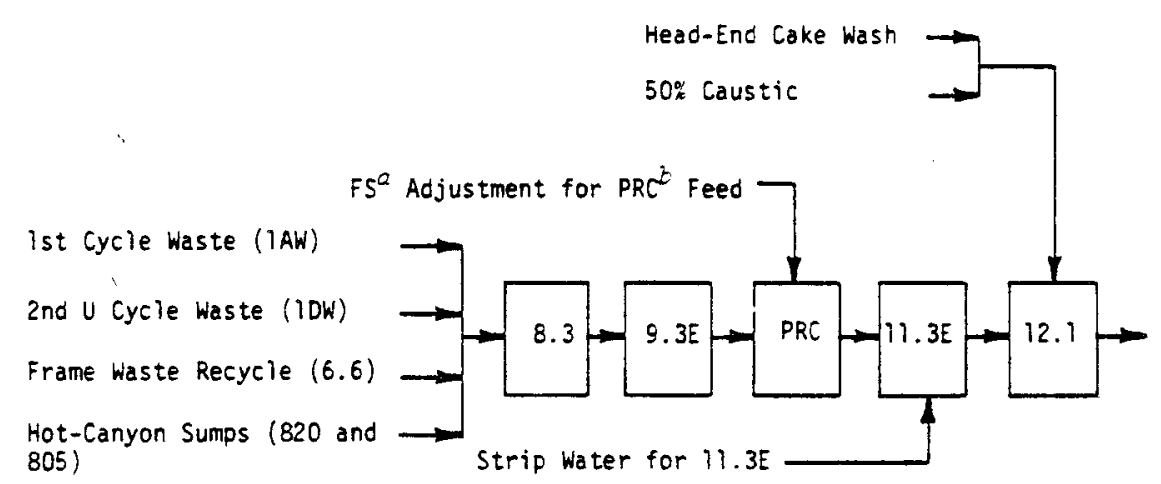

a. Ferrous Sulfamate

b. Plutonium Recovery Column

FIGURE 13.1-1. Purex High-Heat Waste

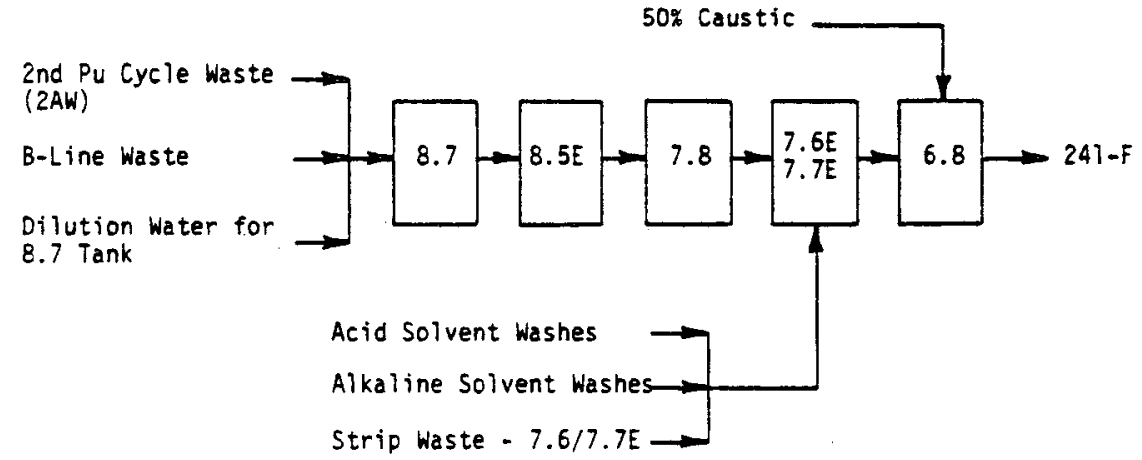

FIGURE 13.1-2. Miscellaneous High-Heat Waste

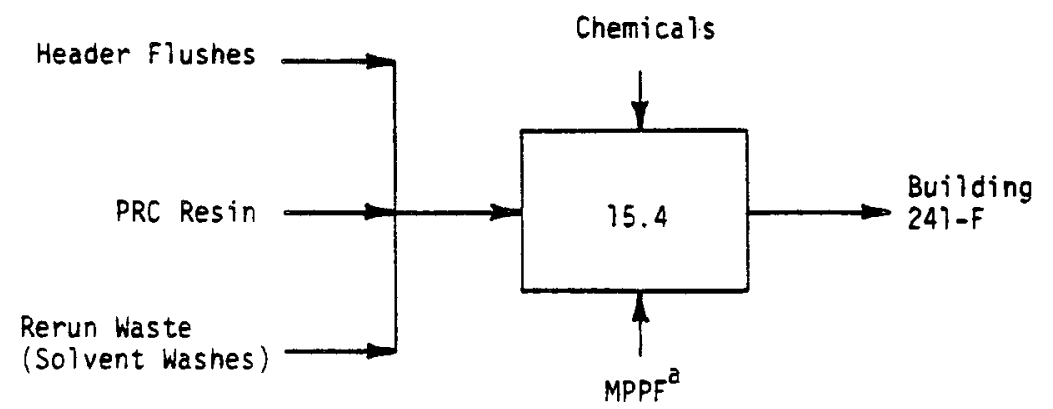

a. Multi-Purpose Processing Facility

FIGURE 13.1-3. Purex Low-Heat Waste 

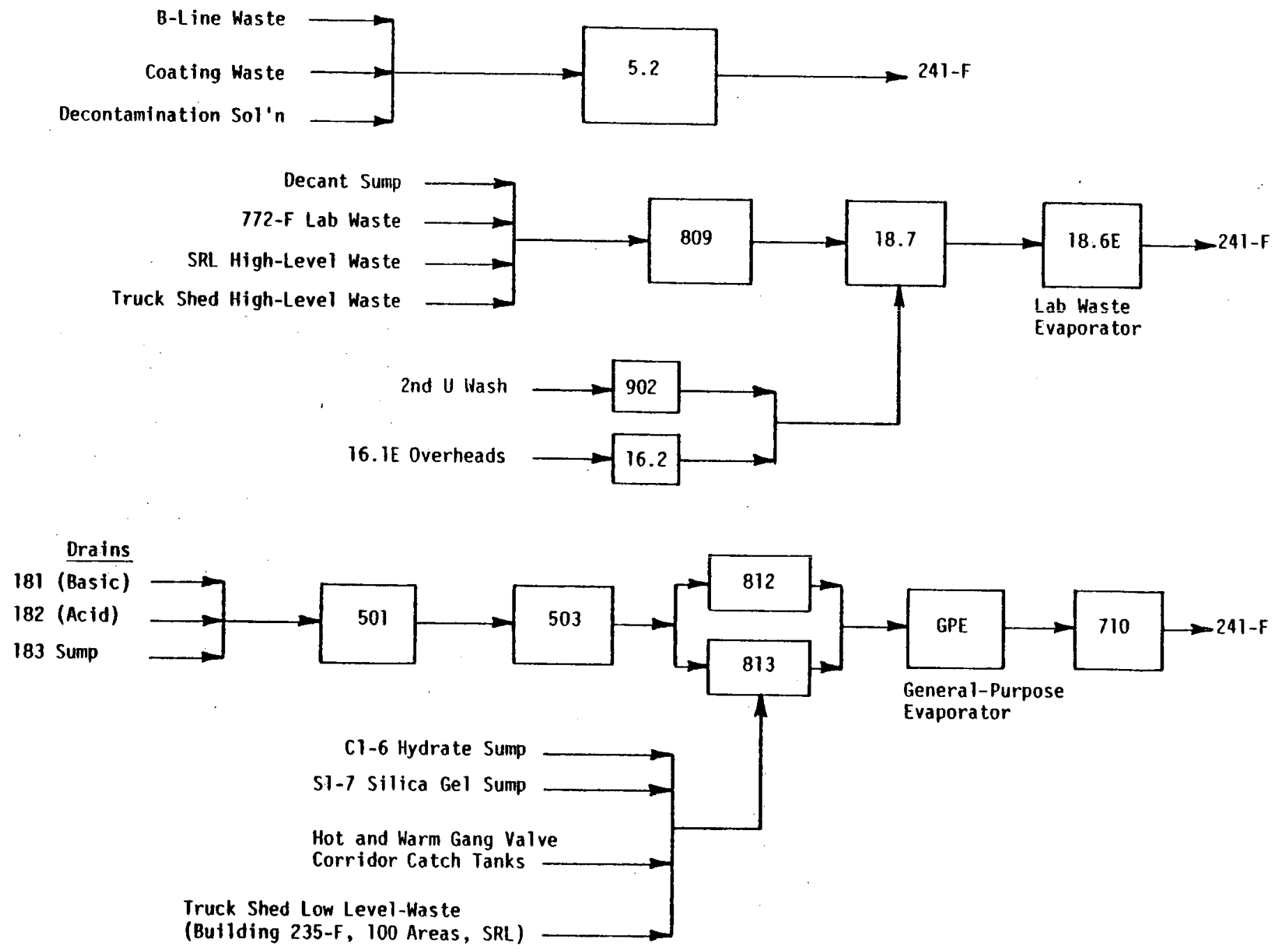

FIGURE 13.1-4. Miscellaneous Low-Heat Waste 


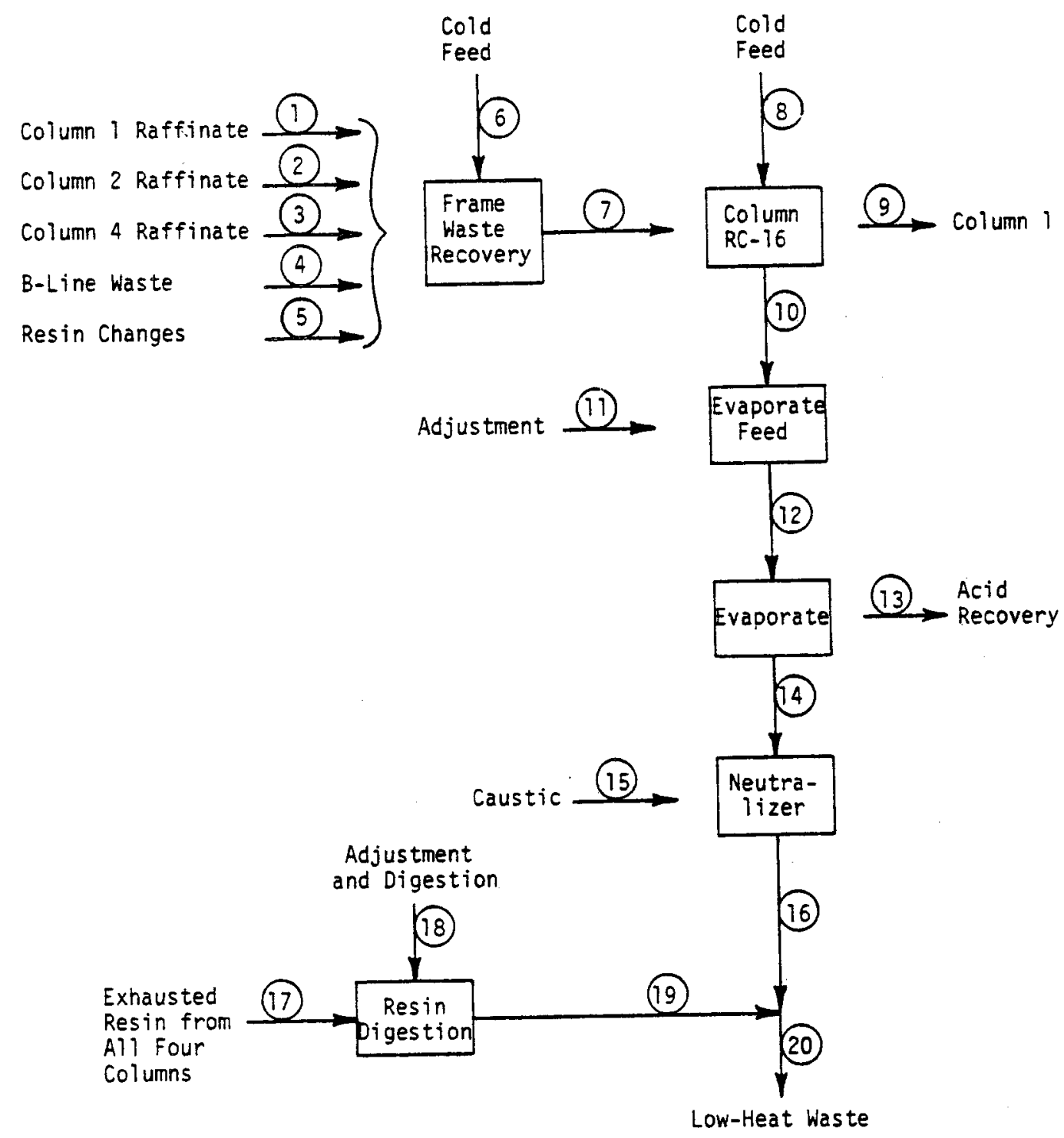

FIGURE 13.1-5. Frame Waste Flowsheet 


\subsection{BASES FOR DETERMINING DWPF FEED STREAM COMPOSITION}

\subsubsection{General}

This appendix sumnarizes the bases used to prepare the DWPF reference feed compositions.

\subsubsection{Tank Cleaning}

Tank cleaning was assumed to use $120 \mathrm{kgal}$ of 4 wt \% oxalic acid for dissolving/slurrying residual sludge left in tanks after hydraulic cleaning. Tank $16 \mathrm{H}$ oxalic acid was assumed to be neutralized with $10 \%$ excess $\mathrm{NaOH}$, clarified, evaporated, and stored with salt cake. Prior to DWPF startup, oxalic acid from 23 tanks was assumed to be digested (described below), neutralized, clarified, evaporated, and stored with salt cake. After startup, oxalic acid from 15 tanks was assumed to be digested, neutralized, clarified, and used to help dissolve salt cake for DWPF supernate feed preparation.

Digestion consists of adding 50 wt $\% \mathrm{HNO}_{3}$ with $\mathrm{Mn}\left(\mathrm{NO}_{3}\right)_{2}$ to make up a $I M$ HNO 3 and $0.01 M \mathrm{Mn}^{2+}$ solution. It was assumed $95 \%$ of the oxalic acid was digested by the reaction

$$
3 \mathrm{H}_{2} \mathrm{C}_{2} \mathrm{O}_{4}+2 \mathrm{HNO}_{3} \stackrel{x}{\rightarrow} 6 \mathrm{CO}_{2}(\mathrm{~g})+4 \mathrm{H}_{2} \mathrm{O}+2 \mathrm{NO} \quad x=95 \%
$$

Neutralization was assumed to be accomplished by adding 10 wt $\%$ excess $\mathrm{NaOH}$ in a 50 wt \% solution. The following reactions were assumed to occur

$$
\begin{aligned}
& \mathrm{H}_{2} \mathrm{C}_{2} \mathrm{O}_{4}+2 \mathrm{NaOH} \rightarrow \mathrm{Na}_{2} \mathrm{C}_{2} \mathrm{O}_{4} \rightarrow 2 \mathrm{H}_{2} \mathrm{O} \\
& \mathrm{HNO}_{3}+\mathrm{NaOH} \rightarrow \mathrm{NaNO}_{3}+\mathrm{H}_{2} \mathrm{O} \\
& 2 \mathrm{NaOH}+\mathrm{Mn}\left(\mathrm{NO}_{3}\right)_{2}+1 / 4 \mathrm{O}_{2}(\mathrm{~g})+\mathrm{MOO} \cdot \mathrm{OH}(\mathrm{s})+1 / 2 \mathrm{H}_{2} \mathrm{O}+2 \mathrm{NaNO}_{3}
\end{aligned}
$$

The following quantities were incorporated in the feed description of salt cake and salt cake diluent. 


$\begin{array}{ll}\text { Prior to DWPF, } & \text { During DWPF, } \\ \text { in Salt Cake, } & \text { as Diluent, } \\ \text { klb } & \text { klb }\end{array}$

\begin{tabular}{|c|c|c|}
\hline $\mathrm{NaNO}_{3}$ & 2,215 & 1,490 \\
\hline $\mathrm{Na}_{2} \mathrm{C}_{2} \mathrm{O}_{4}$ & 129 & 45 \\
\hline $\mathrm{NaOH}$ & 112 & 71 \\
\hline $\mathrm{H}_{2} \mathrm{O}$ & - & 16,821 \\
\hline Total & 2,456 & 18,427 \\
\hline
\end{tabular}

A total of $23.2 \mathrm{klb}$ of Mn from tank cleaning was accounted for in the composite sludge composition estimation.

\subsubsection{Forecast Quantities}

The following series of bases and assumptions were used to develop quantities used in preparing DWPF feed.

- 4.730 Mgal of reconstituted waste are to be processed each year.

- Forecast volumes for waste quantities on hand at startup are,

$$
\begin{array}{lr}
\text { Equivalent Sludge } & 4.314 \mathrm{Mgal} \\
\text { Equivalent Salt Cake } & 13.622 \mathrm{Mgal}
\end{array}
$$

The forecast production rate for fresh waste is $1.473 \mathrm{Mgal} / \mathrm{yr}$.

- Salt cake density is $1.8 \mathrm{~g} / \mathrm{cm}^{3}$ and contains 78 wt $\%$ salt on a dry basis. Four gallons of supernate makes one gallon of salt cake.

- Fresh waste and reconstituted waste contain $0.145 \mathrm{lb}$ of solids per gal. Supernate and redissolved salt cake contain $1000 \mathrm{ppm}$ of volume of sludge.

- The wt \% of salts in fresh waste supernate, reconstituted supernate, and in the interstitial supernate of settled sludge are all identical.

- The density of the solids is $3 \mathrm{~g} / \mathrm{cm}^{3}$ and the density of supernate is given by the following equations: 


\subsubsection{Compositions}

Salt compositions are based on liquid waste having the same relative compositions as reference supernate.

Reference Supernate Molarities

$\begin{array}{llll}\mathrm{NaNO}_{3} & 2.2 & \mathrm{Na}_{2} \mathrm{SO}_{4} & 0.3 \\ \mathrm{NaNO}_{2} & 1.1 & \mathrm{NaCl} & 0.022 \\ \mathrm{NaAlO}_{2} & 0.5 & \mathrm{NaF} & 0.002 \\ \mathrm{NaOH} & 0.75 & \mathrm{Na}[\mathrm{HgO}(\mathrm{OH})] & 0.001 \\ \mathrm{Na}_{2} \mathrm{CO}_{3} & 0.3 & & \end{array}$

Solids compositions were based upon the following elemental analysis which was derived from analyses of actual waste tank sludge samples.

$\begin{array}{lllll}\text { Element } & \text { Wt } \% & & \text { Element } & \text { Wt } \% \\ & 20.1 & \mathrm{Hg} & 0.994 \\ \mathrm{U}^{\mathrm{a}} & 2.28 & \mathrm{CI} & 0.900 \\ \mathrm{Ca} & 1.53 & \mathrm{~F} & 0.070^{\mathrm{d}} \\ \mathrm{Ni} & 2.80 & \mathrm{C} & 1.58^{\mathrm{d}} \\ \mathrm{Na} & 3.00^{\mathrm{b}} & \mathrm{Al} & 11.9 \\ \mathrm{NO}_{3}^{-} & 1.00^{\mathrm{b}} & \mathrm{Si} & 0.316 \\ \mathrm{SO}_{4}^{2-} & 0.50^{\mathrm{b}} & \mathrm{HgI} & 0.376^{\mathrm{e}} \\ \mathrm{Mn}^{\mathrm{F}} & 5.00^{\circ} & \text { Other } & \text { Balance }\end{array}$

a. Low-heat sludge assumed to contain no significant uranium.

b. Estimated average value, A. J. Hill, Jr., private communication, October 12, 1978.

c. Includes contribution forecast from waste tank decontamination.

d. E. J. Lukosius, private commication, March 6, 1978.

e. Based on 23,180 Ib of I-127 released to waste from B-Iine operations. 


$$
\begin{array}{ll}
\rho_{1}(x, t)=\rho_{w}(t) \div\left[1-\left(1-\rho_{w}(t) \div 2\right) x\right] & x<x^{*} \\
\rho_{2}(x, t)=0.9757+0.9813 x-0.0007 t & x>x^{*}
\end{array}
$$

Where $x=$ wt fraction of salt in supernate

$t=$ temperature, ${ }^{\circ} \mathrm{C}$

$$
\begin{aligned}
\rho_{w}(t) & =\text { water's density at temperature } t, g / \mathrm{cm}^{3} \\
x^{*} & =w t \text { fraction when } \rho_{1}\left(x^{*}, t\right)=\rho_{2}\left(x^{*}, t\right)
\end{aligned}
$$

On the basis of the assumptions listed above, the quantities of sludge, salt cake, and liquid waste on hand at startup are

$$
\begin{aligned}
& \text { Volume, Density, Salt, Solids, Water, Total } \\
& \text { Mgal } \mathrm{g} / \mathrm{cm}^{3} \mathrm{Mlb} \text { Mlb Mlb Mlb }
\end{aligned}
$$

$\begin{array}{lllllll}\text { Sludge } & 4.314 & 1.369 & 11.77 & 8.42 & 29.11 & 49.30\end{array}$

The time period required to process the waste inventory is $12.43 \mathrm{yr}$. The quantities of salt cake and sludge that will be consumed at the 12-gpm reconstituted basis and the 12.88-gpm DWPF feed basis instantaneous rates are given below assuming $75 \%$ attainment on all tank farm operations.

\begin{tabular}{ll} 
Instantaneous & Rates \\
\hline DWPF Feed & \\
Basis, & Reconstituted \\
gal/hr & Basis, gal/hr
\end{tabular}

$\begin{array}{lcc}\text { Sludge } & 52.8 & 52.8 \\ \text { Slurry } \mathrm{H}_{2} \mathrm{O} & 51.8 & \underline{52.8} \\ \quad & \underline{105.6} & 166.8 \\ \quad \text { Total } & 166.8 & 494.4 \\ \text { Salt Cake } & 494.4 & 26.1 \\ \text { Water } & 26.1 & \underline{667.2} \\ \text { Tank Cleaning Liquid } & \underline{667.2} & 720.0 \\ \quad \text { Total Supernate } & 772.8 & (12.00 \mathrm{gpm}) \\ \text { Total Feed } & (12.88 \mathrm{gpm}) & \end{array}$




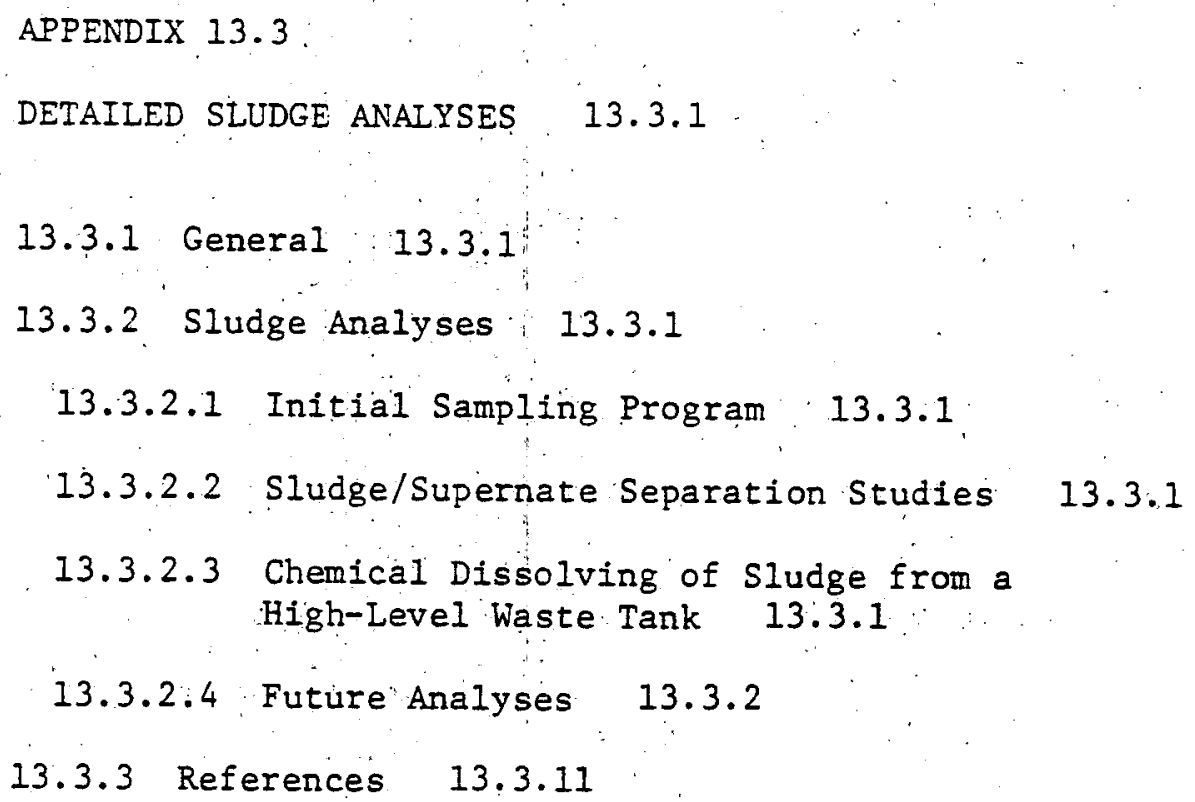




\subsection{DETAILED SLUDGE ANAIYSES}

\subsubsection{General}

Development of a process to convert Savannah River Plant waste to a high-integrity solid required chemical and radiometric characterization of the insoluble fraction of the waste. For the past several years, sludges have been sampled and analyzed at the Savannah River Laboratory. This appendix summarizes the chemical and radiometric analyses that have been performed to date.

\subsubsection{Sludge Analyses}

\subsubsection{Initial Sampling Program (J. A. Stone)}

In 1975, twelve 3-liter samples (essentially a surface-type of sample) were collected from four Savannah River Plant waste tanks with a hydraulically operated sampler. Each sludge sample was washed and dried to yield a powdered product that was subsequently characterized by chemical and radiometric analyses [1]. Tables 13.3-1 through 13.3-4 list the chemical composition of sludge from each waste tank sampled. Tables $13.3-5$ and $13.3-6$ list the residual leachable components and the concentration of radionuclides, respectively, for each sludge sample.

\subsubsection{Sludge/Supernate Separation Studies (J. A. Stone)}

Approximately one year following the initial sludge sampling program, additional sludge samples were obtained from the same four tanks plus four additional tanks. These samples were obtained to prepare a reference waste composition for demonstration of the initial conceptual process for separating the sludge fraction from the supernate fraction [2]. Table 13.3-7 lists the principal components in the washed, dried sludge. The principal radionuclides are tabulated in Table 13.3-8.

\subsubsection{Chemical Dissolving of Sludge from a High-Level Waste Tank \\ (A. J. Hill)}

A research and development effort has been under way at the Savannah River Laboratory to develop a method to chemically dissolve the sludge not anticipated to be removed during hydraulic 
slurrying and removal of Tank $16 \mathrm{H}$ sludge $[3,4]$. Tables $13 \cdot 3-9$ and 13.3-10 list, respectively, the principal chemical constituents and radionuclide constituents of washed, dried Tank 16H sludge.

\subsubsection{Future Analyses (J. R. Fowler)}

In January 1979, an extensive sludge sampling program was initiated to obtain large (25-1iter) subsurface sludge samples from Waste Tanks $4,7,8,18,11,12,13,15$, and 32 . These samples will be used in sludge washing and vitrification studies using bench-scale equipment in the SRL High-Level Caves [5]. As. of. this writing, Tank $15 \mathrm{H}$ has been sampled. Each sample will be thoroughly characterized both chemically and radiometrically $[6,7]$. As analytical results become available, this section will be updated and ultimately the reference feed composition to the DWPF will be altered as required. 
TABLE $13.3-1$

Chemical Composition of Washed, Dried Tank 5 Sludge

\begin{tabular}{|c|c|c|c|c|c|}
\hline Element & Wt \% & Mole $\%^{a}$ & Element & Wt \% & Mole \% \\
\hline $\mathrm{Fe}$ & 27.5 & 39.6 & $\mathrm{P}^{\mathrm{b}}$ & 0.07 & 0.2 \\
\hline U & 15.4 & 5.2 & $2 n^{b}$ & 0.07 & 0.09 \\
\hline Mn & 10.8 & 15.9 & Th & 0.07 & 0.02 \\
\hline $\mathrm{Na}$ & 6.1 & 21.6 & $\mathrm{Mg}$ & 0.06 & 0.21 \\
\hline $\mathrm{Ni}$ & 5.1 & 7.1 & $\mathrm{Cu}^{\mathrm{b}}$ & 0.06 & 0.07 \\
\hline Al & 1.5 & 4.6 & $\mathrm{Nb}$ & 0.05 & 0.05 \\
\hline $\mathrm{Ca}$ & 0.6 & 1.3 & $\mathrm{Y}^{\mathrm{b}}$ & 0.04 & 0.03 \\
\hline $\mathrm{Nd}^{\mathrm{b}}$ & 0.5 & 0.3 & $A g^{b}$ & 0.04 & 0.03 \\
\hline Si & $<0.4$ & $<1.2$ & $\mathrm{Pm}^{\mathrm{b}}$ & 0.04 & 0.02 \\
\hline $\mathrm{zr}^{\mathrm{b}}$ & 0.4 & 0.4 & $\mathrm{~Pb} b$ & 0.04 & 0.02 \\
\hline $\mathrm{Cr}{ }^{b}$ & 0.3 & 0.5 & $T i^{b}$ & 0.04 & 0.06 \\
\hline$R u^{b}$ & 0.3 & 0.2 & $\mathrm{Sm}^{\mathrm{b}}$ & $<0.04$ & $<0.02$ \\
\hline $\mathrm{Ba}$ & 0.25 & 0.15 & $E_{U^{b}}^{b}$ & 0.02 & 0.01 \\
\hline$C e^{b}$ & 0.2 & 0.1 & $\mathrm{v}^{\mathrm{b}}$ & 0.01 & 0.02 \\
\hline $\mathrm{K}$ & 0.14 & 0.3 & $R h^{b}$ & 0.01 & 0.01 \\
\hline $\mathrm{Cl}{ }^{\mathrm{b}}$ & 0.1 & 0.2 & $\mathrm{MO}^{\mathrm{b}}$ & $<0.01$ & $<0.01$ \\
\hline$S r^{b}$ & 0.1 & 0.09 & $\mathrm{Pu}$ & $<0.01$ & $<0.005$ \\
\hline $\mathrm{Hg}$ & 0.1 & 0.04 & $N p^{b}$ & $<0.008$ & $<0.002$ \\
\hline $\mathrm{La}^{\mathrm{b}}$ & 0.09 & 0.05 & $F^{b}$ & 0.007 & 0.03 \\
\hline $\operatorname{Pr}{ }^{b}$ & 0.09 & 0.05 & $B^{b}$ & $<0.003$ & $<0.02$ \\
\hline$s^{b}$ & 0.08 & 0.2 & & & \\
\hline
\end{tabular}

a. Calculated from sum of the elements shown, without $O$, $N$, or $\mathrm{C}$.

b. From spark-source mass spectrometry (factor of 2 uncertainty); all other values from elemental analyses. 
TABLE $13 \cdot 3-2$

Chemical Composition of Washed, Dried Tank 7 Sludge

\begin{tabular}{|c|c|c|c|c|c|}
\hline Element & Wt $\%$ & Mole $\%^{\mathrm{a}}$ & Element & Wt \% & Mole \% \\
\hline$C$ & 16.8 & 65.3 & $\mathrm{Cu}^{\mathrm{b}}$ & 0.15 & 0.11 \\
\hline $\mathrm{Fe}$ & 8.9 & 7.4 & $S r^{b}$ & 0.15 & 0.08 \\
\hline$U$ & 3.3 & 0.7 & $L a^{b}$ & 0.15 & 0.05 \\
\hline Si & 3.2 & 5.3 & $\mathrm{Pr}^{\mathrm{b}}$ & 0.15 & 0.05 \\
\hline $\mathrm{Na}$ & 2.8 & 5.7 & $\mathrm{Ba}$ & 0.13 & 0.04 \\
\hline Al & 2.5 & 4.3 & $\mathrm{NB}^{\mathrm{b}}$ & $<0.1$ & $<0.05$ \\
\hline Mn & 2.2 & 1.9 & $\mathrm{Mg}$ & 0.08 & 0.15 \\
\hline $\mathrm{Ni}$ & 2.1 & 1.6 & $\mathrm{Cs}^{\mathrm{b}}$ & 0.06 & 0.02 \\
\hline $\mathrm{Cl}{ }^{b}$ & 2.0 & 2.6 & $\mathrm{Hg} \mathrm{b}$ & 0.06 & 0.01 \\
\hline$N d^{b}$ & 1.0 & 0.3 & $Y^{b}$ & 0.05 & 0.03 \\
\hline $\mathrm{Ca}$ & 0.83 & 1.0 & $S m^{b}$ & 0.05 & 0.02 \\
\hline$s^{b}$ & 0.5 & 0.7 & $\mathrm{Rh}^{\mathrm{b}}$ & 0.05 & 0.02 \\
\hline $2 n^{b}$ & 0.5 & 0.4 & $B^{b}$ & $<0.05$ & $<0.21$ \\
\hline$z^{b}$ & 0.5 & 0.3 & $C d^{b}$ & $<0.05$ & $<0.02$ \\
\hline$R u^{b}$ & 0.5 & 0.2 & $\mathrm{P}^{\mathrm{b}}$ & 0.03 & 0.05 \\
\hline $\mathrm{Cr}^{\mathrm{b}}$ & 0.45 & 0.4 & $P d^{b}$ & 0.03 & 0.01 \\
\hline $\mathrm{k}^{\mathrm{b}}$ & 0.3 & 0.4 & $\mathrm{Mo}^{\mathrm{b}}$ & $<0.014$ & $<0.007$ \\
\hline$A g^{b}$ & 0.3 & 0.1 & $\mathrm{Eu}^{\mathrm{b}}$ & 0.013 & 0.004 \\
\hline$C e^{b}$ & 0.25 & 0.08 & $\mathrm{Co}^{\mathrm{b}}$ & $<0.013$ & $<0.010$ \\
\hline $\mathrm{Pb}^{\mathrm{b}}$ & 0.25 & 0.06 & Th & 0.007 & 0.001 \\
\hline$F^{b}$ & 0.15 & 0.37 & $\nabla^{b}$ & $<0.005$ & $<0.005$ \\
\hline
\end{tabular}

a. Calculated from sum of the elements shown, without O or N.

b. From spark-source mass spectrometry (factor of 2 uncertainty); all other values from elemental analyses. 
TABLE $13.3-3$

Chemical Composition of Washed, Dried Tank 13 Sludge

\begin{tabular}{|c|c|c|c|c|c|}
\hline Element & Wt $\%$ & Mole $\%^{\mathrm{a}}$ & Element & Wt \% & Mole $\%^{a}$ \\
\hline $\mathrm{Fe}$ & 27.9 & 39.9 & $2 \pi^{b}$ & $<0.2$ & $<0.3$ \\
\hline Mn & 8.8 & 12.8 & $\operatorname{Pr}^{b}$ & 0.2 & 0.1 \\
\hline Al & 7.1 & 21.0 & $\mathrm{Ba}$ & 0.15 & 0.09 \\
\hline$U$ & 4.0 & 1.3 & Th & 0.11 & 0.04 \\
\hline $\mathrm{Na}$ & 3.1 & 10.7 & $T i^{b}$ & $<0.1$ & $<0.2$ \\
\hline $\mathrm{Ca}$ & 2.3 & 4.7 & $\mathrm{Nb}^{\mathrm{b}}$ & $<0.1$ & $<0.09$ \\
\hline $\mathrm{Hg}$ & 2.1 & 0.8 & $\mathrm{Ag}^{\mathrm{b}}$ & $<0.1$ & $<0.07$ \\
\hline $\mathrm{Cl}{ }^{\mathrm{b}}$ & 1.0 & 2.3 & $\mathrm{Cr}$ & 0.09 & 0.13 \\
\hline$C e^{b}$ & 1.0 & 0.6 & $\mathrm{~K}^{\mathrm{b}}$ & 0.08 & 0.2 \\
\hline Nd & $<0.6$ & $<0.3$ & $\mathrm{Cs}^{\mathrm{b}}$ & $<0.06$ & $<0.04$ \\
\hline $\mathrm{Ni}$ & 0.5 & 0.7 & $\mathrm{Y}^{\mathrm{b}}$ & 0.05 & 0.05 \\
\hline $\mathrm{Pb}$ & 0.5 & 0.2 & $s^{b}$ & $<0.04$ & $<0.1$ \\
\hline Si & $<0.4$ & $<1.1$ & $\mathrm{Cub}$ & 0.03 & 0.04 \\
\hline $2 r^{b}$ & 0.4 & 0.4 & $v^{b}$ & $<0.007$ & $<0.01$ \\
\hline $\mathrm{Mgb}$ & 0.3 & 1.0 & $\mathrm{~B}^{\mathrm{b}}$ & 0.005 & 0.04 \\
\hline $\mathrm{Pb}^{\mathrm{b}}$ & 0.3 & 0.8 & $F^{b}$ & $<0.005$ & $<0.02$ \\
\hline $\mathrm{La}^{\mathrm{b}}$ & 0.3 & 0.2 & & & \\
\hline
\end{tabular}

a. Calculated from sum of elements shown, without 0 , N, or $\mathrm{C}$.

b. From spark-source mass spectrometry (factor of 3 uncertainty); all other values from elemental analyses. 
TABLE $13.3-4$

Chemical Composition of Washed, Dried Tank 15 Sludge

\begin{tabular}{|c|c|c|c|c|c|}
\hline Element & Wt \% & Mole $\%^{a}$ & Element & Wt \% & Mole $\%^{a}$ \\
\hline $\mathrm{Al}$ & 33.5 & 86.2 & $\operatorname{Pr}^{b}$ & 0.04 & 0.02 \\
\hline $\mathrm{Fe}$ & 3.1 & 3.9 & $L a^{b}$ & 0.04 & 0.02 \\
\hline Mn & 2.3 & 2.9 & $B^{b}$ & 0.03 & 0.20 \\
\hline $\mathrm{Nab}$ & 1.2 & 3.6 & $\mathrm{~Pb}^{\mathrm{b}}$ & .0 .03 & 0.07 \\
\hline $\mathrm{Hg}$ & 0.92 & 0.32 & $R u^{b}$ & 0.03 & 0.02 \\
\hline U & 0.91 & 0.26 & $T i^{b}$ & $<0.02$ & $<0.03$ \\
\hline $\mathrm{Ni}$ & 0.51 & 0.60 & $\mathrm{Nb}^{\mathrm{b}}$ & $<0.02$ & $<0.01$ \\
\hline $\mathrm{Nd}^{\mathrm{b}}$ & 0.30 & 0.15 & $s^{b}$ & $<0.02$ & $<0.05$ \\
\hline$S i b$ & 0.22 & 0.55 & $\mathrm{~K}$ & 0.015 & 0.03 \\
\hline $\mathrm{Ca}$ & 0.21 & 0.38 & $\mathrm{Cr}^{\mathrm{b}}$ & 0.01 & 0.02 \\
\hline Th & 0.18 & 0.06 & $\mathrm{Yb}$ & 0.01 & 0.01 \\
\hline Mg & 0.14 & 0.39 & $S m^{b}$ & 0.01 & 0.007 \\
\hline $2 r^{b}$ & 0.11 & 0.08 & $\mathrm{~Pb}^{\mathrm{b}}$ & 0.01 & 0.005 \\
\hline $\mathrm{Ba}$ & 0.10 & 0.05 & $\mathrm{Rh}^{\mathrm{b}}$ & 0.007 & 0.005 \\
\hline $\mathrm{Ce}^{\mathrm{b}}$ & 0.05 & 0.02 & $\mathrm{Pu}^{\mathrm{b}}$ & $<0.005$ & $<0.001$ \\
\hline$C u^{b}$ & 0.04 & 0.05 & $F^{b}$ & 0.002 & 0.009 \\
\hline$S r^{b}$ & 0.04 & 0.03 & $\mathrm{vb}^{\mathrm{b}}$ & $<0.0007$ & $<0.0007$ \\
\hline $2 n^{b}$ & $<0.04$ & $<0.04$ & & & \\
\hline
\end{tabular}

a. Calculated from sum of elements shown, without $0, \mathrm{~N}$, or $\mathrm{C}$.

b. From spark-source mass spectrometry (factor of 3 uncertainty); all other values from elemental analyses. 
TABLE 13.3-5

Residual Leachable Components

\begin{tabular}{|c|c|c|c|c|c|c|c|c|}
\hline \multirow[b]{2}{*}{ Component } & \multicolumn{2}{|l|}{ Tank 5} & \multicolumn{2}{|l|}{ Tank 7} & \multicolumn{2}{|c|}{ Tank 13} & \multicolumn{2}{|c|}{ Tank 15} \\
\hline & $\begin{array}{l}\text { Tetal, } \\
\text { wt } \%\end{array}$ & $\begin{array}{l}\text { Leachable, } \\
\text { wt } \%\end{array}$ & $\begin{array}{l}\text { TC }=31 \text {, } \\
\text { Wt } \%\end{array}$ & $\begin{array}{l}\text { Leachable, } \\
\text { we } \%\end{array}$ & $\begin{array}{l}\text { Total, } \\
\text { wt } \%\end{array}$ & $\begin{array}{l}\text { Leachable, } \\
\text { we } \%\end{array}$ & $\begin{array}{l}\text { Total, } \\
\text { wt } \%\end{array}$ & $\begin{array}{l}\text { Leachable, } \\
\text { we } \%\end{array}$ \\
\hline $\mathrm{Na}^{+}$ & 6.1 & 0.8 & 2.8 & 1.9 & 3.1 & 1.0 & 1.2 & 0.4 \\
\hline $\mathrm{NO}_{3}^{-}$ & 3.0 & 0.6 & 1.2 & 1.2 & 0.5 & 0.3 & 5.0 & 0.3 \\
\hline $\mathrm{NO}_{2}^{-}$ & 0.06 & 0.004 & 0.09 & 0.03 & 0.03 & 0.02 & 0.04 & 0.04 \\
\hline $\mathrm{SO}_{4}{ }^{2-}$ & $5.5^{a}$ & 0.8 & $19.5^{a}$ & 3.7 & $2.7^{a}$ & 0.8 & $5.7^{a}$ & 0.9 \\
\hline
\end{tabular}

a. Total sulfate values may be high by a factor of 5 to 10 ; results of analyses by three different methods gave poor agreement.

TABLE $13.3-6$

Specific Activity of Radionuclides

\begin{tabular}{lcccc} 
& \multicolumn{5}{l}{ Specific Activity, mCi/g } \\
Isotope & Tank 5 & Tank 7 & Tank 13 & Tank 15 \\
\cline { 4 - 5 } Co-60 & - & - & 0.01 & - \\
Sr-90 & 74.68 & 27.03 & 15.49 & 25.61 \\
Zr-95 & $<0.03$ & $<0.01$ & $<0.01$ & $<0.01$ \\
Nb-95 & $<0.03$ & $<0.01$ & 0.02 & $<0.02$ \\
Ru-103 & $<0.02$ & $<0.01$ & $<0.01$ & $<0.01$ \\
Ru-106 & 2.73 & 1.41 & 0.40 & 1.74 \\
Sb-125 & 0.43 & - & 0.12 & 1.27 \\
Cs-134 & $<0.02$ & 0.01 & $<0.01$ & 0.03 \\
Cs-137 & 1.29 & 1.30 & 0.30 & 0.07 \\
Ce-144 & 4.77 & 0.21 & 2.01 & 16.89 \\
Eu-154 & 0.47 & $<0.01$ & 0.30 & 1.18 \\
Gross $\alpha$ & 0.10 & 0.06 & 0.28 & 0.14
\end{tabular}


TABLE $13.3-7$

Principal Components of Washed, Dried Sludge

Tanks 4F,6F Tank 5F Tank 12H Tank 13H Tank $15 \mathrm{H}$ Tank 1.6H

Principal Metal

Cations, wt \%

$\begin{array}{lllllll}\mathrm{Fe} & 32.77 & 28.90 & 4.49 & 25.57 & 5.29 & 13.91 \\ \mathrm{Al} & 2.28 & 1.57 & 30.16 & 8.70 & 18.75 & 16.61 \\ \mathrm{Mn} & 1.99 & 5.83 & 1.69 & 7.85 & 2.45 & 2.59 \\ \mathrm{U} & 9.22 & 10.81 & \mathrm{a} & 4.18 & 3.77 & 4.49 \\ \mathrm{Na} & 2.95 & 5.66 & 1.03 & 2.58 & 2.45 & 2.19 \\ \mathrm{Sr} & 1.70^{\mathrm{b}} & 1.29^{\mathrm{b}} & \mathrm{c} & 3.50^{\mathrm{b}} & 1.80^{\mathrm{b}} & \mathrm{c} \\ \mathrm{Ca} & 2.28 & 0.90 & 2.13 & 1.76 & 0.52 & 2.87 \\ \mathrm{Hg} & 0.65 & 0.12 & 1.12 & 2.32 & 2.51 & 2.80 \\ \mathrm{Ni} & 6.29 & 6.34 & 0.46 & 0.45 & 0.73 & 0.30\end{array}$

Principal

Anions, wt \%

$\begin{array}{lcccccc}\mathrm{NO}_{3}^{-} & 0.12 & 1.16 & 0.42 & 0.31 & 0.19 & 0.32 \\ \mathrm{NO}_{2}^{-} & 0.02 & 0.12 & 0.17 & 0.01 & 0.16 & 0.15 \\ \mathrm{SO}_{4}^{2-} & <0.5 & <0.5 & <0.5 & <0.5 & <0.5 & <0.5 \\ \mathrm{PO}_{4}^{3-} & 0.69^{\mathrm{b}} & 0.32^{\mathrm{b}} & c & 2.15^{\mathrm{b}} & 2.87^{\mathrm{b}} & \mathrm{c}\end{array}$

a. Not detectable.

b. $\mathrm{Sr}_{3}\left(\mathrm{PO}_{4}\right)_{2}$ carrier added.

c. Not determined.

TABLE $13 \cdot 3-8$

Principal Radionuclides in Washed, Dried Sludge, mC1/g

\begin{tabular}{llllllll} 
Isotope & Tanks 4F,6F & Tank 5F & Tank 12H & Tank 13H & Tank 15H & Tank 16H \\
\cline { 2 - 3 } Sr-90 & 123.0 & 177.5 & 41.4 & 30.1 & 55.0 & 53.6 \\
Ce-144 & 30.5 & 1.5 & 17.4 & 0.3 & 5.4 & 0.6 \\
Ru-106 & 11.4 & 1.3 & 1.7 & 0.08 & 1.0 & 0.2 \\
Cs-137 & 0.7 & 0.9 & 0.05 & 0.3 & 0.1 & 0.2 \\
Eu-154 & 0.7 & 0.6 & 0.5 & 0.08 & 0.4 & 0.1 \\
Sb-125 & 1.4 & 0.9 & 0.3 & 0.06 & 0.3 & 0.04 \\
Co-60 & 1.1 & 1.1 & $<0.01$ & 0.01 & 0.06 & 0.02 \\
Gross $\alpha$ & 0.4 & 0.1 & 0.7 & 0.2 & 0.1 & 0.15
\end{tabular}


TABLE $13.3-9$

Calculated Principal Constituents of Washed and Dried Tank 16 Sludge

$\begin{array}{ll}\text { Constituent } & \text { Wt \% } \\ \mathrm{AlO}_{2}{ }^{-} & 16 \\ \mathrm{Fe}^{3+} & 40 \\ \mathrm{MnO}_{2} & 16 \\ \mathrm{Na}^{+} & 20 \\ \mathrm{SO}_{4}{ }^{2-} & 1.1 \\ \mathrm{Si}^{4+} & 2.0 \\ \mathrm{Ba}^{2+} & 1.0 \\ \mathrm{Ca}^{2+} & 1.0 \\ \mathrm{Ce}^{4+} & 1.0 \\ \mathrm{Hg}^{2+} & 2.5 \\ \mathrm{UO}_{2}^{2+} & 0.4\end{array}$

a. Calculated from data for washed and unwashed dried sludge. Estimated relative precision within \pm 30 to $40 \%$. 
TABLE $13 \cdot 3-10$

Major Radionuclides in Tank 16H Sludge

\begin{tabular}{lll} 
Nuclide & $\begin{array}{l}\text { Residual Activity in } \\
\text { Centrifuged, washed, } \\
\text { Dried Sludge, mCi/g }\end{array}$ & $\begin{array}{l}\text { Removed by } \\
\text { Two Washes, }\end{array}$ \\
\cline { 3 - 3 } Co-60 & 50.0 & Nil \\
Sr-90 & 8.6 & Nil \\
Y-90 & 8.6 & Nil \\
Nb-95 & 0.55 & Nil \\
Ru-106 & 13.6 & Nil \\
Rh-106 & 13.6 & Nil \\
Cs-134 & 0.40 & 94 \\
Cs-137 & 7.3 & 90 \\
Ba-137 & 7.3 & 90 \\
Ce-144 & 45.5 & Nil \\
Pr-144 & 45.5 & Nil \\
Pm-147 & $a$ & a \\
Eu-154 & 17.3 & Nil \\
Pub & 0.42 & Nil \\
& &
\end{tabular}

a. Not determined.

b. Total plutonium alpha activity. 


\subsubsection{References}

1. J. A. Stone, J. A. Kelley, and T. S. MoMillan. Sampling and Analyses of SRP High-Level Waste Sludges. USERDA Report DP-1399, E. I. du Pont de Nemours and Co., Savannah River Laboratory, Aiken, SC (1976).

2. J. A. Stone. Separation of SRP Waste Sludge and Supernate. USERDA Report DP-1441, E. I. du Pont de Nemours and Co., Savannah River Laboratory, Aiken, SC (1976).

3. R. F. Bradley and A. J. Hill, Jr. Chemical Dissolving of Sludge from a Eigh-Level Waste Tank at the Savannah River Plant. USDOE Report DP-1471, E. I. du Pont de Nemours and Co., Savannah River Laboratory, Aiken, SC (1977).

4. Memorandum, A. J. Hill, Jr. to M. L. Hyder. Chemical Dissolving of Tank 16H Sludge. DPST-78-208, E. I. du Pont de Nemours and Co., Savannah River Laboratory, Aiken, SC (January 9, 1978).

5. Memorandum, G. W. Wilds to W. J. Mottel. Sludge Sompling. DPST-78-619, E. I. du Pont de Nemours and Co., Savannah River Laboratory, Aiken, SC (December 4, 1978).

6. Memorandum, J. R. Fowler to D. L. McIntosh. Information Meeting - 4/27/79, Waste Processing and Analytical Needs. (May 8, 1979).

7. Memorandum, J. R. Wiley to J. A. Kelley (May 23, 1979). 
APPENDIX $13 \vdots 4$

DETAILED SUPERNATE ANALYSES

13.4 .1

13.4.1 General 13.4.1

13.4.2 Supernate Analyses 13.4.1

13.4.3 References 13.4.1 


\subsection{DETAILED SUPERNATE ANALYSES (R. S. Ondrejcin)}

\subsubsection{General}

Since 1972, a program has been conducted at SRI to characterize the soluble fraction (supernate) of the waste in storage in the 200-Area Waste Tank Farms. Supernate samples were analyzed for the major cations, anions, and radionuclides [1].

\subsubsection{Supernate Analyses}

Tables $13.4-1$ and $13.4-2$ sumarize the results from chemical and radiometric analyses of supernate samples from selected waste tanks in F Area. Similarly, the results on samples from H-Area tanks are summarized in Tables $13.4-3$ and 13.4-4.

\subsubsection{References}

1. R. S. Ondrejcin. Chemical Compositions of Supermate Stored in SRP High-Level Waste Tanks. USAEC Report DP-1347, E. I. du Pont de Nemours and Co., Savannah River Laboratory, Aiken, SC (August 1974). 
TABLE $23.4-1$

\section{F-Area Waste Tank Supernate Analyses}

\begin{tabular}{|c|c|c|c|c|c|c|c|c|c|c|}
\hline Tank & & Ion & zcentr & Eion, & & & & & & \\
\hline No. & Sampled & $\mathrm{Na}^{+}$ & $\mathrm{NO}_{3}^{-}$ & $\mathrm{NO}_{2}^{-}$ & $\mathrm{Al}(\mathrm{OH})_{4}^{-}$ & $\underline{\mathrm{OH}^{-}}$ & $\mathrm{CO}_{3}^{2-}$ & $\mathrm{SO}_{4}^{2-}$ & $\mathrm{PO}_{4}^{3-}$ & $\mathrm{CI}^{-}$ \\
\hline 1 & $2 / 21 / 73$ & 10.1 & 1.6 & 2.4 & 0.8 & 6.3 & $<0.1$ & 0.02 & 0.08 & 0.06 \\
\hline$I$ & $8 / 5 / 74$ & 11.7 & 1.9 & 3.4 & 0.8 & 7.6 & 0.13 & 0.007 & 0.06 & - \\
\hline 1 & $3 / 12 / 75$ & 13.7 & 1.5 & 2.7 & 0.6 & 9.1 & 0.11 & 0.007 & 0.08 & - \\
\hline 2 & $2 / 20 / 73$ & 9.3 & 2.4 & 2.9 & 0.7 & 4.5 & $<0.1$ & 0.02 & 0.04 & 0.06 \\
\hline 2 & $8 / 27 / 74$ & 13 & 1.5 & 2.6 & 0.9 & 9.4 & 0.09 & 0.008 & 0.07 & - \\
\hline 4 & $6 / 23 / 72$ & - & 2.4 & 3.1 & 0.5 & 2.8 & 0.2 & 0.03 & 0.04 & 0.03 \\
\hline 5 & $3 / 1 / 73$ & 9.4 & 2.4 & 3.1 & 0.7 & 4.4 & $<0.1$ & 0.02 & 0.04 & 0.06 \\
\hline 6 & $3 / 1 / 73$ & 5.0 & 1.6 & 1.1 & 0.4 & 1.7 & 0.1 & 0.14 & 0.02 & 0.04 \\
\hline 8 & $3 / 8 / 73$ & 4.0 & 1.7 & 0.5 & 0.4 & 1.1 & $<0.1$ & 0.18 & 0.02 & 0.03 \\
\hline 18 & $9 / 7 / 72$ & 12.5 & 2.5 & 2.6 & 0.7 & 3.4 & 0.3 & 0.02 & 0.03 & 0.11 \\
\hline 34 & $1 / 12 / 76$ & 11.4 & 2.4 & 2.6 & 0.4 & 5.9 & 20 & 0.008 & 0.04 & - \\
\hline
\end{tabular}

a. Dash indicates "not requested."

TABLE $13.4-2$

F-Area Waste Tank Supernate Radionuclide Analyses

\begin{tabular}{|c|c|c|c|c|c|c|}
\hline \multirow[b]{2}{*}{$\begin{array}{l}\text { Tank } \\
\text { No. } \\
\end{array}$} & \multirow[b]{2}{*}{$\begin{array}{l}\text { Date } \\
\text { Sampled }\end{array}$} & \multicolumn{5}{|c|}{ Activity, dis/min/mla } \\
\hline & & $\begin{array}{r}\mathrm{Cs}-137 \\
\times 10^{-9} \\
\end{array}$ & $\begin{array}{l}\text { Sr }-90 \\
\times 10^{-5} \\
\end{array}$ & $\begin{array}{r}R u-106 \\
\times 10^{-6} \\
\end{array}$ & $\begin{array}{l}\text { Total Pu } \\
\times 10^{-4} \\
\end{array}$ & $\begin{array}{l}\text { Gross } \alpha \\
\times 10^{-4} \\
\end{array}$ \\
\hline 1 & $2 / 21 / 73$ & 14 & 5 & 140 & 0.04 & $<0.05$ \\
\hline 1. & $8 / 5 / 74$ & 10 & 20 & 70 & - & 8.0 \\
\hline 1 & $3 / 12 / 75$ & 15 & 30 & - & 2 & 140 \\
\hline 2 & $2 / 20 / 73$ & 8 & 1 & 140 & $<0.01$ & $<0.05$ \\
\hline 2 & $8 / 24 / 74$ & 13 & 1.8 & 20 & - & 0.4 \\
\hline 4 & $6 / 23 / 72$ & 11 & - & - & 0.5 & - \\
\hline 5 & $3 / 1 / 73$ & 23 & 9 & 25 & 0.02 & 1 \\
\hline 6 & $3 / 1 / 73$ & 4 & 7 & 200 & 0.03 & 1 \\
\hline 8 & $3 / 8 / 73$ & 26 & 12 & 670 & 0.02 & 0.9 \\
\hline 18 & $9 / 7 / 72$ & 11 & - & 30 & 0.4 & - \\
\hline 34 & $1 / 12 / 76$ & 8 & 4.4 & 10 & 4.7 & 280 \\
\hline
\end{tabular}

a. Dash indicates "not requested." 
TABLE $13.4-3$

H-Area Waste Tank Supernate Analyses

\begin{tabular}{|c|c|c|c|c|c|c|c|c|c|c|}
\hline \multirow{2}{*}{$\begin{array}{l}\text { Tank } \\
\text { No. } \\
\end{array}$} & \multirow{2}{*}{$\begin{array}{l}\text { Date } \\
\text { Sampled }\end{array}$} & \multicolumn{9}{|c|}{ Ion Concentration, $\mathrm{M}^{\mathrm{a}}$} \\
\hline & & $\mathrm{Na}^{+}$ & $\mathrm{NO}_{3}^{-}$ & $\mathrm{NO}_{2}^{-}$ & $\mathrm{Al}(\mathrm{OH})_{4}^{-}$ & $\mathrm{OH}^{-}$ & $\mathrm{CO}_{3}^{2-}$ & $\mathrm{SO}_{4}{ }^{2-}$ & $\mathrm{PO}_{4}^{3-}$ & $\mathrm{Cl}^{-}$ \\
\hline 9 & $1 / 11 / 73$ & 12.5 & 1.9 & 3.2 & 2.6 & 3.8 & 0.1 & 0.02 & 0.05 & 0.029 \\
\hline 10 & $1 / 5 / 73$ & 9.1 & 4.5 & 1.8 & 1.0 & 1.9 & $<0.1$ & 0.08 & 0.02 & 0.020 \\
\hline 10 & $8 / 27 / 74$ & 8.9 & 3.1 & 2.1 & 1.2 & 3.6 & 0.18 & 0.02 & $<0.01$ & - \\
\hline 11 & $7 / 11 / 72$ & - & 3.7 & 0.6 & 0.9 & 0.8 & 0.1 & 0.03 & 0.009 & 0.005 \\
\hline 12 & $7 / 11 / 72$ & - & 3.3 & 1.1 & 0.7 & 1.0 & 0.2 & 0.03 & 0.009 & 0.005 \\
\hline 13 & $12 / 19 / 72$ & 5.7 & 3.6 & 0.5 & 0.4 & 1.1 & 0.1 & 0.08 & 0.02 & 0.018 \\
\hline 14 & $1 / 3 / 72$ & 8.9 & 2.8 & 2.0 & 1.1 & 2.5 & $<0.1$ & 0.04 & 0.01 & 0.019 \\
\hline 15 & $12 / 19 / 72$ & 6.2 & 3.6 & 1.1 & 1.0 & 1.0 & 0.1 & 0.05 & $<0.01$ & 0.016 \\
\hline 15 & $10 / 9 / 75$ & 7.1 & 3.4 & 1.2 & 0.53 & 1.4 & 0.1 & 0.04 & - & - \\
\hline 15 & $12 / 18 / 75$ & 7.1 & 3.3 & 1.2 & 0.54 & 1.6 & 0.04 & 0.04 & - & - \\
\hline 21 & $5 / 4 / 72$ & - & 6.4 & 0.2 & 1.2 & 2.6 & 0.3 & 0.06 & 0.009 & 0.015 \\
\hline 21 & $6 / 19 / 72$ & - & 5.3 & 1.5 & 1.0 & 2.6 & 0.1 & 0.05 & 0.009 & 0.020 \\
\hline 24 & $2 / 6 / 73$ & 9.4 & 2.6 & 1.7 & 0.9 & 4.3 & $<0.1$ & 0.02 & $<0.02$ & 0.040 \\
\hline 24 & $8 / 27 / 74$ & 4.1 & 1.5 & 0.5 & 0.2 & 2.6 & 0.13 & 0.01 & 0.02 & - \\
\hline
\end{tabular}

a. Dash indicates "not requested."

TABLE $\quad 13.4-4$

H-Area Waste Supernate Radionuclide Analyses

\begin{tabular}{|c|c|c|c|c|c|c|}
\hline \multirow[b]{2}{*}{$\begin{array}{l}\text { Tank } \\
\text { No. } \\
\end{array}$} & \multirow[b]{2}{*}{$\begin{array}{l}\text { Date } \\
\text { Sampled }\end{array}$} & \multicolumn{5}{|c|}{ Activity, dis $/ \mathrm{min} / \mathrm{ml}^{a}$} \\
\hline & & $\begin{array}{l}\mathrm{Cs}-137 \\
\times \quad 10^{-9} \\
\end{array}$ & $\begin{array}{l}\text { Sr-90 } \\
\times \quad 10^{-5} \\
\end{array}$ & $\begin{array}{r}\mathrm{Ru}-106 \\
\times \quad 10^{-6} \\
\end{array}$ & $\begin{array}{l}\text { Total Pu } \\
\times 10^{-4} \\
\end{array}$ & $\begin{array}{l}\text { Gross } \\
\times 10^{-1} \\
\end{array}$ \\
\hline 9 & $1 / 11 / 73$ & 4 & 3 & 4 & 3 & 40 \\
\hline 10 & $1 / 5 / 73$ & 8 & 0.4 & 4 & 14 & 25 \\
\hline 10 & $8 / 27 / 74$ & 4.5 & 0.9 & 10 & - & 20 \\
\hline 11 & $7 / 11 / 72$ & - & - & - & 0.2 & - \\
\hline 12 & $7 / 11 / 72$ & - & - & - & 0.001 & - \\
\hline 13 & $12 / 19 / 72$ & 1 & 0.2 & 3 & 0.8 & 3 \\
\hline 14 & $1 / 3 / 73$ & 2 & 18 & 0.9 & 6 & 8 \\
\hline 15 & $12 / 19 / 72$ & 5 & 21 & 2 & 0.2 & 0.5 \\
\hline 15 & $10 / 9 / 75$ & 2 & 30 & 0.3 & 0.6 & 0.8 \\
\hline 15 & $12 / 18 / 75$ & 2 & 26 & - & 1 & 65 \\
\hline 21 & $5 / 4 / 72$ & - & - & - & 0.5 & - \\
\hline 21 & $6 / 19 / 72$ & - & - & - & 0.5 & - \\
\hline 24 & $2 / 6 / 73$ & - & 23 & - & - & 1 \\
\hline 24 & $8 / 27 / 74$ & 0.7 & 0.6 & 0.1 & - & 5 \\
\hline
\end{tabular}

a. Dash indicates "not requested." 
APPENDIX 13.7

13.7 Isotopic Content of DWPF Process Streams 13.7.1

13.7.1 General 13.7.1

13.7.2 Radionuclide Composition of Spent Fuel Assemblies, Assembly Wastes, and Reference Waste Blend 13.7.1

13.7.3 Radionuclide Composition of Process Streams 13.7.2

13.7.4 Radionuclide Concentrations in Glass and Saltcrete 13.7 .4

13.7.5 Use of Microfiche 13.7.2

13.7.6 Cases on Microfiche, 13.7.3

13.7.7 References 


\subsubsection{General}

This appendix provides detailed technical information about the radionuclide composition of the DWPF reference feed, process streams, and waste products. Because the data from the radionuclide balance is quite lengthy, data are recorded on the microfiche cards found at the end of this appendix.

\subsubsection{Radionuclide Composition of Spent Fuel Assemblies,} Assembly Wastes and Reference Waste Blend

The calculational bases for computing the radionuclide composition of the reference waste feed to the DWPF is described in Chapter 7 of this document.

Radionuclide concentrations for irradiated assemblies are calculated in two steps. First, a GLASS computer calculation provides neutron fluxes and spectrum-averaged cross sections at various times during the irradiation. Second, the fluxes and cross sections from GLASS are used by the FPCALCG module of the SHIELD system to compute the isotopic inventory [1]. The first step is necessary since actinide isotopic inventories are sensitive to detailed neutron flux spectrum effects.

The GLASS-FPCALCG calculation computes most of the radionuclides within each assembly at the end of irradiation. The major exceptions are $\mathrm{H}-3, \mathrm{Eu}-154, \mathrm{Cr}-51$, and $\mathrm{Co}-60$.

Tritium is produced in ternary fission. The tritium content is computed from the equation

$$
3_{\mathrm{H} / \text { assembly }}=\frac{\text { Exposure/assembly }}{\text { Energy/fission }} \times{ }^{3} \mathrm{H} / \text { fission. }
$$

The following assumptions are made:

- One ${ }^{3} \mathrm{H}$ atom produced per $10^{4}$ fissions

- $195 \mathrm{MeV}$ per fission

- Assembly exposures listed in Table 7.1. 


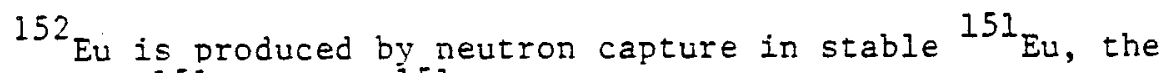
daughter of $151 \mathrm{Sm}$. The 151 Eu concentration in an irradiated assembly was determined using the equation

$$
\operatorname{Conc}\left({ }^{152} E u\right)=\sigma \int_{0}^{T} \phi(\bar{t}) \int_{0}^{\bar{t}} S_{m}(t) \lambda_{S m} d t d \bar{t}
$$

where $S_{m}(t)$ is the time-dependent concentration of ${ }^{15 l_{S m}}, \lambda_{S m}$ is

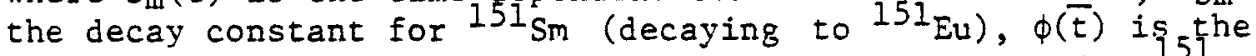
neutron flux, $\sigma$ is the neutron capture cross section for ${ }^{15 l}$, and $T$ is the period of irradiation.

${ }^{51} \mathrm{Cr}$ and ${ }^{60} \mathrm{Co}$ are produced from the activation of impurities in the fuel assemblies. The activation of a given isotope, J, after a period of irradiation and decay can be calculated by the formula

$$
\begin{aligned}
A_{B}= & \phi \sigma_{J \rightarrow B} N_{J}\left(1-e^{-\lambda_{B} t}\right) e^{-\lambda_{B} t_{D}} \\
\phi= & \text { neutron flux, neut/cm }{ }^{2}-s e c, \\
\sigma_{J \rightarrow B}= & \text { cross section (barns) for a neutron reaction with } \\
& \text { isotope } J \text { leading to an activated nucleus, } B, \\
N_{J}= & \text { atom density in atoms/b-cm of isotope } J, \\
\lambda_{b}= & \text { decay constant for the activated nucleus, } B, \\
& \left(\lambda_{B}=0.693 / T_{1 / 2}, \text { where } T_{\frac{1}{2}}\right. \text { is the half-life of the } \\
& \text { activated nucleus), } \\
t_{I}= & \text { irradiation period. } \\
t_{D}= & \text { decay time after the irradiation was ended, and } \\
A_{B}= & \text { number of disintegrations per second of isotope } B \\
& \text { per cubic centimeter. }
\end{aligned}
$$

This formula accounts for the buildup and decay of isotope $B$ from neutron capture in isotope $J$ and assumes that the loss of isotope $B$ to neutron reactions is negligible.

The $C_{r}$ impurity was assumed to be $0.2 \%$ of aluminum. The ${ }^{50} \mathrm{Cr}$ isotope is $4.35 \%$ of natural chromium and has a neutron capture cross section of 15.9 barns to produce the metastable isotope, $5 \mathrm{I}_{\mathrm{Cr}}$. 
The ${ }^{60}$ Co activity is due to neutron activation of ${ }^{59} \mathrm{Co}$ and ${ }^{60} \mathrm{Ni}$ impurities in the aluminum of the assemblies. The $\mathrm{Co}$ impurity was assumed to be $0.001 \%$ of aluminum. The ${ }^{59} \mathrm{Co}$ isotope is $100 \%$ of natural cobalt and has a neutron capture cross section of 37 barns to produce ${ }^{60} \mathrm{Co}$. The $\mathrm{Ni}$ impurity of aluminum was assumed to be $1 \% . \quad{ }^{60} \mathrm{Ni}$ is $26 \%$ of natural nickel and has an $(n, p)$ cross section of 9.25 barns to produce ${ }^{60}$.

Radionuclide concentrations for each assembly are listed at 0 and 180 days following reactor irradiation. Following the 180-day cooling period, separation factors (Table 7.2) are applied and concentrations are tabulated for ages up to 100 years. The reference waste blend is computed from the assembly concentrations and volume proportions of Table 7.3. The radionuclide concentrations in the reference blend are tabulated for ages 0.5 to 100 years.

\subsubsection{Radionuclide Composition of Process Streams}

A computer model of the DWPF reference flowsheet has been developed with the PROCESS module of the SHIELD system. The radionuclides are separated into soluble and insoluble radionuclides (Appendix 13.9). The components of each group are tabulated in Table 4.18. The steady state solutions from the soluble and insoluble cases are combined for final results. Results are listed for processing waste feed that is 5 years old and waste feed that is 15 years old.

\subsubsection{Radionuclide Concentrations in Glass and Saltcrete}

The radionuclide composition of glass and saltcrete has been computed for the solidification of wastes of ages 5, 10, $15,20,25,30,35,40,45$, and 50 years. For the 5 and 15 -year cases, the glass and saltcrete components are listed for decay periods up to 1000 years.

\subsubsection{Use of Microfiche}

The results of the radionuclide calculations are listed on the microfiche. Concentrations are listed in units of curies, grams, watts, and photons/second per volume. The table have headings with the form:

Shield. DWPF. ? ? $\quad$ Composit. ?

The first variable name refers to the flowsheet which contains this stream. The last name is the stream name. Reference 
flowsheet stream names have the form FS-i-j, where $i$ is the flowsheet number and $j$ is the stream number.

The times listed in each table are the times since reactor shutdown. Five and fifteen years are listed for the reference DWPF flowsheet.

\subsubsection{Cases on Microfiche}

Radionuclide concentrations in DWPF process streams have been calculated for three cases. The first case assumes sludge and supernate are 5 years old when vitrified. The second case assumes sludge and supernate are 15 years old when processed. In the third case, the sludge feed is 5 years old and the supernate is 15 years old.

\subsubsection{References}

1. D. R. Finch, J. R. Chandler and J. P. Church, The SHIELD System, Transactions of the American Nuclear Society, Volume 32, American Nuclear Society, Lagrange Park, IL (November 1979). 
APPENDIX 13.9

BASIS FOR DETERMINING RADIONUCLIDES IN SLUDGE AND SUPERNATE

FEEDS

\subsubsection{General}

13.9.2 Tank Farm Inventories

13.9.3 Feed Distribution

$-13.9 . i-$ 
13.9 BASIS FOR DETERMINING RADIONUCLIDES IN SLUDGE AND SUPERNATE EEEDS

\subsubsection{General}

This appendix summarizes the basis used to determine the proportionment of radionuclides between the sludge and supernate feeds.

\subsubsection{Tank Farm Inventories.} 13.2).

The quantities of solids and salt at startup are (see Appendix

$$
\text { Salt, MIb Solids, MIb }
$$

Sludge $\quad 11.77 \quad 8.42$

Salt Cake $\quad 159.49 \quad 0.1064$

Tank Cleaning $\quad 1.606$

The time required to process this waste inventory is 12.43 years.

\subsubsection{Feed Distribution}

Feed rates for the quantities in Section 13.9 .2 are

Sludge-Slurry $\quad 144.2 \quad 103.1$

Supernate $\quad 1975 \quad 1.302$

Totals $\quad 2119.2 \quad 104.4$

These feed rates assume $75 \%$ attainment on all tank farm operations. Radionuclides in the waste blend are assumed to have the following solubilities. 
Percent of Radionuclides that are Soluble in the Waste Blend

$\begin{array}{lll}\text { Group Ident. } & \text { Radionuclides } & \% \text { Soluble } \\ \text { I } & \text { Cs-Ba } & 100 \\ \text { II } & \text { Tc, Ru-Rh } & 50.0 \\ \text { III } & \text { Ag, Cd, I, Cr, } & 5.0 \\ & \text { Se, Pd, Te, TI } \\ \text { IV } & \text { La, Ce-Pr, Pm, } & 1.0 \\ \text { V } & \text { Nd, Sm, Tb, Sn-Sb } \\ \text { VI } & \text { Sr-Y, Rb, Mo } & 0.2 \\ & \text { Co, Zr-Nb, Eu, } & 0.1 \\ & \text { Np, U, Pu, Am, Cm }\end{array}$

The radionuclide distributions can be described by:

$\%$ of radionuclide in salt of supernate $=$

(lb/hr salt in supernate) (solubility fraction) (lb/hr salt in feed)

$\%$ of radionuclide in solids of supernate $=$

(lb/hr solids in supernate) (1-solubility fraction) (lb/hr solids in feed)

$\%$ of radionuclide in salt of sludge $=$

(lb/hr salt in sludge) (solubility fraction) (Ib/hr salt in feed)

$\%$ of radionuclide in solids of sludge $=$

(lb/hr solids in sludge) (1-solubility fraction) (lb/hr solids in feed) 


\begin{tabular}{|c|c|c|c|c|}
\hline \multirow[b]{2}{*}{ Group } & \multicolumn{4}{|c|}{ Percent Distribution } \\
\hline & Supernate & Insoluble & \multicolumn{2}{|c|}{ Sludge-Slurry } \\
\hline I & 93.20 & 0 & 6.80 & 0 \\
\hline II & 46.60 & 0.63 & 3.40 & 49.37 \\
\hline III & 4.66 & 1.19 & 0.34 & 93.81 \\
\hline IV & 0.93 & 1.24 & 0.07 & 97.76 \\
\hline $\mathrm{V}$ & 0.19 & 1.25 & 0.01 & 98.55 \\
\hline VI & 0.09 & 1.25 & 0.01 & 98.65 \\
\hline
\end{tabular}

